\title{
Development of an Innovative Hybrid Timber-Steel Moment-Resisting Frame for Seismic-Resistant Heavy Timber Structures
}

by

\author{
Ryan J. Gohlich
}

A thesis submitted to the Faculty of Graduate and Postdoctoral Affairs

in partial fulfillment of the requirements for the degree of

Master of Applied Science

in

Civil Engineering

Carleton University

Ottawa, Ontario

${ }^{\circ}$ Copyright by Ryan J. Gohlich, 2015 
Development of an Innovative Hybrid Timber-Steel Moment-Resisting Frame for Seismic-Resistant Heavy Timber Structures

\author{
Ryan J. Gohlich \\ Master of Applied Science \\ Civil and Environmental Engineering \\ Carleton University
}

2015

\title{
Abstract
}

This study presents the development and testing of a new hybrid timber-steel moment-resisting connection for application in mid-rise heavy timber structures. This system consists predominantly of timber members, but utilizes a steel yielding link at the beam-column joint that improves seismic performance by replacing brittle wood connections with ductile steel elements. The steel-to-timber connection was made using self-tapping screws, making it possible to transfer high bending moments while avoiding any inelastic behaviour. Four $2 / 3$ scale moment-resisting connection specimens were tested. The connections exhibited high ductility capacity. All significant plastic rotation was localized to the ductile steel link, and the steel-to-timber connections remained undamaged. Two-dimensional nonlinear dynamic time-history analysis of buildings incorporating this new connection were conducted. The seismic performance was compared to an equivalent steel-only moment frame. Model results showed that drifts and accelerations were similar between the two systems, but that the hybrid timber system had lower foundation forces. The findings suggest that the seismic performance of the new hybrid connections is similar to comparable steel-only frames, which may justify the use of a high seismic force reduction factor in their design. 


\section{Acknowledgments}

The author would firstly like to extend his sincere thanks to Dr. Jeffrey Erochko, who's support and mentorship made completion of this research possible, and who's assistance in procuring external funding made the graduate student life much easier.

The author would also like to acknowledge the technical expertise of Dr. Mohammad Mohammad and Dr. Marjan Popovski from FPInnovations, who co-investigated the project, and Max Closen who provided valuable insight into the design methods for self-tapping screws.

For all of the assistance in the Carleton Laboratory throughout the experimental program, the author would like to thank the lab staff, Colin Gilbert, Joshua Woods, Hailey Quiquero, and Sean Miller; without their assistance the research would surely still be underway.

For the countless hours spent in the dungeon of the Minto Centre, the author would like to sincerely thank his friends and colleagues, Colin Gilbert, Joshua Woods, Pedram Mortazavi, and Hussein Makke, who helped substantially with coursework. The author would also like to thank the Puchtingers for their assistance with the translation of some tedious German design guidelines.

The author would like to extend his heartfelt thanks to his family and friends, Colin, Makke, Talha, and his girlfriend Amy, who's moral support throughout the program was more helpful and motivating than they will ever know.

Finally, the author would like to acknowledge the financial contribution of the NewBuildS NSERC strategic research Network for Engineered Wood-based Building Systems and Carleton University through the development grant program. The author would like to thank Nordic En-

gineered Wood for donating a substantial amount of timber, Fastenal and MyTiCon for providing a significant discount on fasteners for the test frame. 


\section{Table of Contents}

$\begin{array}{ll}\text { Abstract } & \text { ii }\end{array}$

Acknowledgments $\quad$ iii

Table of Contents $\quad$ iv

List of Tables $\quad$ ix

List of Figures $\quad$ xi

$\begin{array}{ll}\text { Nomenclature } & \text { xviii }\end{array}$

1 Introduction 1

1.1 Seismic Design and Moment-Resisting Frames $\ldots \ldots \ldots \ldots$

1.2 Performance of Timber Frames $\ldots \ldots \ldots \ldots \ldots$

1.3 Timber Fastener Technology . . . . . . . . . . . . . . . . 5

1.4 Objective and Scope $\ldots \ldots \ldots \ldots \ldots \ldots \ldots$

2 Literature Review 9

2.1 Steel Moment-Resisting Frames _ . . . . . . . . . . . . . . . . . . 9

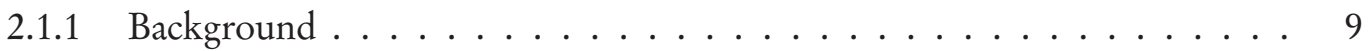

2.1.2 Plastic Hinging using Reduced Beam Sections . . . . . . . . . . . . . . 10

2.1.3 Bolted End-Plate Connections . . . . . . . . . . . . . . . . . 13

2.1.4 Nonlinear Replaceable Links (Shen, 2009 and Shen et al., 2011) . . . . . 16

2.2 Timber Moment-Resisting Frames . . . . . . . . . . . . . . . . 17 
2.3 Hybrid Moment-Resisting Connections . . . . . . . . . . . . . . . . . 21

2.4 Self-Tapping Screws . . . . . . . . . . . . . . . . . 23

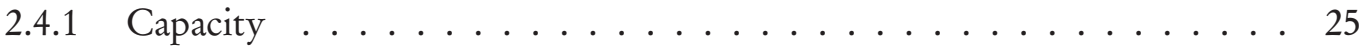

2.4.2 Connection Reinforcement . . . . . . . . . . . . . . . . . . 27

2.4.3 Moment-Resisting Connections using Self-Tapping Screws . . . . . . . . . 28

3 Hybrid Connection Design $\quad 32$

3.1 Preliminary Design . . . . . . . . . . . . . . . 33

3.2 Connection Design . . . . . . . . . . . . . . . . . . 35

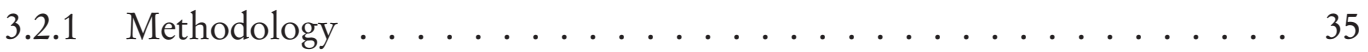

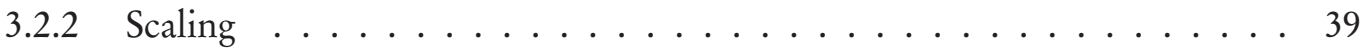

3.2.3 Material Properties . . . . . . . . . . . . . . . . . 42

3.2.4 Nonlinear Replaceable Link . . . . . . . . . . . . . . . . . . . . . . 44

3.2 .5 Panel Zone . . . . . . . . . . . . . . . . . . 52

3.2.6 Design of Timber Members . . . . . . . . . . . . . . . 55

3.2.7 Self-Tapping Screw Connection . . . . . . . . . . . . . . . 57

3.2 .8 Connection Summary . . . . . . . . . . . . . . . . . 71

3.3 Moisture and Shrinkage $\ldots \ldots \ldots \ldots \ldots \ldots$. . . . . . . . . . . . .

3.4 Consideration for Fire Performance $\ldots \ldots \ldots \ldots$

$\begin{array}{lll}4 & \text { Experimental Setup } & 74\end{array}$

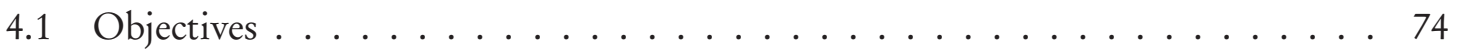

4.2 Test Assembly . . . . . . . . . . . . . . . . . . . 75

4.3 Test Specimens . . . . . . . . . . . . . . . . . . 77

4.3.1 Nonlinear Replaceable Links . . . . . . . . . . . . . . . . 77

4.3.2 Panel Zone and Beam Collar . . . . . . . . . . . . . . . . . . . . 79

4.3.3 Main Members . . . . . . . . . . . . . . . . . . . 79

4.3 .4 Self-Tapping Screws . . . . . . . . . . . . . . . . . . . . 81

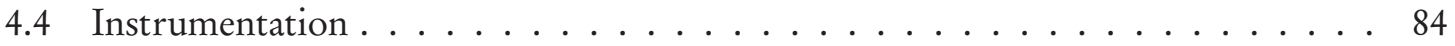

4.5 Loading Protocol . . . . . . . . . . . . . . . . . . . . 89 
4.6 Acceptance Criteria . . . . . . . . . . . . . . . . . . . . . . . 92

5 Experimental Results $\quad 95$

5.1 Summary of Test Setup . . . . . . . . . . . . . . . . . . 95

5.2 Data Analysis Methods . . . . . . . . . . . . . . . . . . . . . 97

5.2.1 Error in Data Analysis . . . . . . . . . . . . . . . . . . 101

5.3 Test Frame Performance . . . . . . . . . . . . . . . . . . . . . . . 102

5.3.1 Overview of Link Performance . . . . . . . . . . . . . . . . 102

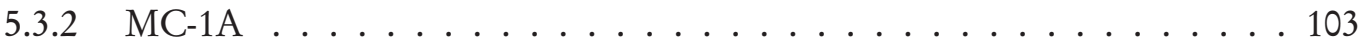

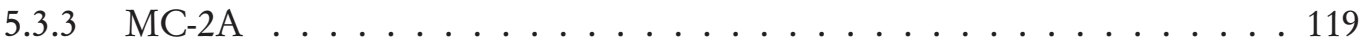

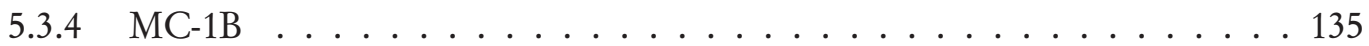

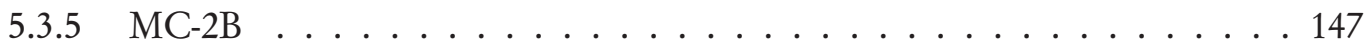

5.4 STS Connection Performance . . . . . . . . . . . . . . . . . . . . 161

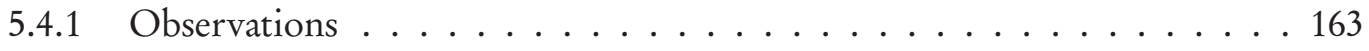

5.4 .2 Connection Slip . . . . . . . . . . . . . . . . . 165

5.5 Ductility and Energy Dissipation . . . . . . . . . . . . 168

5.6 Effect of Specimen Variation . . . . . . . . . . . . . . . . . . 171

$5.6 .1 \quad$ Link Type . . . . . . . . . . . . . . . . . . 171

5.6 .2 Beam Connection Type . . . . . . . . . . . . . . . . . . 174

5.7 Effect of Scaling . . . . . . . . . . . . . . . . . . . 176

$5.8 \quad$ Link Replaceability . . . . . . . . . . . . . . . . . . . . . . 177

5.9 Summary of Results . . . . . . . . . . . . . . . . . . . 180

6 Numerical Modelling $\quad 182$

6.1 Objectives . . . . . . . . . . . . . . . . . . . . 182

6.2 Prototype Structure . . . . . . . . . . . . . . . . . . 183

6.3 OpenSees Modelling . . . . . . . . . . . . . . . . . 186

6.3.1 Modelling of Test Specimen . . . . . . . . . . . . . . 186

6.3.2 Model Verification . . . . . . . . . . . . . . . . . . . 191

6.3.3 Full Moment-Resisting Frame Model . . . . . . . . . . . . . . . . 198 
6.4 Dynamic Time-History Analysis . . . . . . . . . . . . . . . . . . . . . . . 200

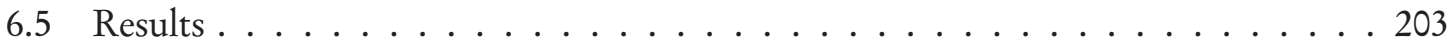

6.5.1 Member Performance . . . . . . . . . . . . . . . . . . . 204

6.5.2 Frame Performance . . . . . . . . . . . . . . . 205

6.5.3 Simplified Model . . . . . . . . . . . . . . . . . . . . 211

6.5.4 Effect of Link Size . . . . . . . . . . . . . . . . . . . . . . 213

6.6 Summary of Numerical Study Findings . . . . . . . . . . . . . . . . . . 214

7 Concluding Remarks 216

7.1 Summary of Findings . . . . . . . . . . . . . . . 216

7.1 .1 Design Process . . . . . . . . . . . . . . . . . 216

7.1.2 Experimental Findings . . . . . . . . . . . . . . . . . 217

7.1.3 Numerical Modelling . . . . . . . . . . . . . . . . . . . . . . 218

7.2 Future Research . . . . . . . . . . . . . . . . . . . . . . 218

$\begin{array}{ll}\text { List of References } & 227\end{array}$

$\begin{array}{lll}\text { Appendix A } & \text { Fabrication Drawings } & 228\end{array}$

Appendix B Seismic Design of Prototype Structures 252

B.1 Prototype Structure . . . . . . . . . . . . . . . . . . . 252

B.2 ETABS Modelling Assumptions . . . . . . . . . . . . . . . 253

B.3 Seismic Analysis . . . . . . . . . . . . . . . . 253

B.3.1 Gravity Loads . . . . . . . . . . . . . . . . . . . . 255

B.3.2 Equivalent Static Method . . . . . . . . . . . . . . 256

B.3.3 Response Spectrum Analysis . . . . . . . . . . . . . . . . . . 266

B.4 Seismic Design . . . . . . . . . . . . . . . . 268

B.4.1 Capacity-Design of MRFs . . . . . . . . . . . . . . . . . . . . 269

B.5 Design Results . . . . . . . . . . . . . . . . . . . 271

B.5.1 Dynamic Data . . . . . . . . . . . . . . . . . 271

B.5.2 Design Loads and Drift . . . . . . . . . . . . . . 271 
B.5.3 Final Member Selection . . . . . . . . . . . . . . . . . . . . 274 


\section{List of Tables}

3.1 Utilization of Beam Moment Capacity . . . . . . . . . . . . . . 34

3.2 Full Scale Capacity-Design Forces . . . . . . . . . . . . . . . . . 38

3.3 Scaling Factors for Connection Components . . . . . . . . . . . . . . . 40

3.4 Scaled Geometric Properties of Timber Elements . . . . . . . . . . . . . . 42

3.5 Scaled Geometric Properties of Nonlinear Replaceable Links . . . . . . . . . . 43

3.6 Scaled Capacity-Design Forces in Test Subassemblage . . . . . . . . . . . . . 43

3.7 Mechanical Properties of Timber Elements . . . . . . . . . . . . . . . . 44

3.8 Mechanical Properties of Self-Tapping Screws . . . . . . . . . . . . . . . 44

3.9 Link Design Details . . . . . . . . . . . . . . . . . . . . . 48

3.10 RBS Details . . . . . . . . . . . . . . . . . . . . 48

3.11 End-Plate Details . . . . . . . . . . . . . . . . . . 50

3.12 Capacity-Design of Timber . . . . . . . . . . . . . . 56

3.13 STS Connection Capacity $\ldots \ldots \ldots \ldots \ldots$. . . . . . . . . . . 61

3.14 STS Connection Spacing . . . . . . . . . . . . . . . . . 62

3.15 ZD-Plate Connection Capacity $\ldots \ldots \ldots \ldots$

4.1 Test Specimens . . . . . . . . . . . . . . . . . 78

4.2 Moisture Content . . . . . . . . . . . . . . . . . . . 82

4.3 Pre-drilling Recommendations . . . . . . . . . . . . . . 83

4.4 STS Pretension Force $\ldots \ldots \ldots \ldots \ldots \ldots$

4.5 Displacement Transducer Details . . . . . . . . . . . . . . . 87

4.6 Instrument Functions . . . . . . . . . . . . . . . . 91

4.7 Loading Protocol . . . . . . . . . . . . . . . . . . 93 
4.8 Error in Imposed Loading $\ldots \ldots \ldots$

5.1 Test Specimens . . . . . . . . . . . . . . . . . . . . 95

5.2 Maximum Screw Slip . . . . . . . . . . . . . . . . . . . 167

5.3 Global Connection Ductility . . . . . . . . . . . . . . . . . . 170

5.4 Elastic Stiffness of Test Frames . . . . . . . . . . . . . . . . . . . . 173

5.5 Summary of Test Results . . . . . . . . . . . . . . . . . . . . . 181

6.1 Parameters for Uniaxial Giuffre-Menegotto Pinto Material . . . . . . . . . . . . 195

6.2 Comparison of Drift Contribution Between Test and Model . . . . . . . . . . . 197

6.3 Earthquake Locations and PGAs (After FEMA P695, 2009) . . . . . . . . . 202

6.4 Earthquake Scaling Factors . . . . . . . . . . . . . . . . . . 202

6.5 Design and Model Building Periods . . . . . . . . . . . . . . . 203

6.6 Seismic Weight and Base Shear . . . . . . . . . . . . . . . . . 207

B.1 Modelling Assumptions for Steel Materials . . . . . . . . . . . . . . . 254

B.2 Gravity Loads on Prototype Buildings . . . . . . . . . . . . . . . . . 256

B.3 Design Spectrum for Victoria, British Columbia . . . . . . . . . . . . . . 258

B.4 Seismic Weight of Prototype Buildings . . . . . . . . . . . . . . . 261

B.5 Seismic Properties of Prototype Buildings . . . . . . . . . . . . . . . . 261

B.6 Initial Storey Shear for Hybrid Building . . . . . . . . . . . . . . . 262

B.7 Initial Storey Shear for Steel-only Building . . . . . . . . . . . . 263

B.8 Notional Loads for Hybrid Building . . . . . . . . . . . . . . . . . . 263

B.9 Notional Loads for Steel-only Building . . . . . . . . . . . . . . . . 264

B.10 P-delta Amplification Factor for Hybrid Building . . . . . . . . . . . . . 264

B.11 P-delta Amplification Factor for Steel-only Building . . . . . . . . . . . . 265

B.12 Final Equivalent Static Storey Forces for Hybrid MRF . . . . . . . . . . . . 266

B.13 Final Equivalent Static Storey Forces for Steel-only MRF . . . . . . . . . . . . 267

B.14 Dynamic Data for Linear Structural Model . . . . . . . . . . . . . . . 271

B.15 Link Design Forces . . . . . . . . . . . . . . . . . . . 272

B.16 Storey Drifts . . . . . . . . . . . . . . . . . . . . 273

B.17 Summary of Member and Link Sizes _ . . . . . . . . . . . . 276 


\section{List of Figures}

Figure 1.1 Typical Moment-Resisting Frame Deformation $\ldots \ldots \ldots$

Figure 1.2 Typical Hysteretic Response of Steel Moment Connection . . . . . . . . . 4

Figure 1.3 ZD Plate Components (from ETA-11/0470, 2012) . . . . . . . . . . 7

Figure 2.1 Post-Northridge Connections a) Strengthened b) Reduced Beam Section 11

Figure 2.2 Bolted End-Plate Connection a) Stiffened End-Plate b) Failure Modes . . . 15

Figure 2.3 Beam-Column Connection with Nonlinear Replaceable Link . . . . . . . 18

Figure 2.4 Traditional Timber Moment-Resisting Connections a) Circular Dowels b)

Nails or Rivets c) Glued-in Rods d) Bolts with Embedded Steel Plate . . . . . . . 19

Figure 2.5 Hybrid Connection with Steel Link and Glued-in Rods (from Andreolli

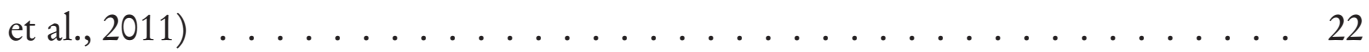

Figure 2.6 Hybrid Column Base Connection (from Humbert et al., 2014) . . . . . 24

Figure 2.7 Hybrid Connection with Slotted Steel Plate (from Komatsu et al., 2014) 24

Figure 2.8 STS Mmoment-Resisting Connection with Steel Beam Collar (from

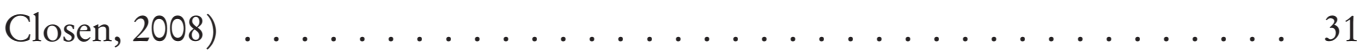

Figure 3.1 Connection Component Summary . . . . . . . . . . . . . . . . 37

Figure 3.2 Custom Steel Assemblies a) Steel Panel Zone b) NRL with Dogbone c)

Regular NRL d) Steel Beam Collar . . . . . . . . . . . . . . . . . . . 39

Figure 3.3 3D Connection Overview $\ldots \ldots \ldots \ldots$. . . . . . . . . 40

Figure 3.4 Reduced Beam Section Details . . . . . . . . . . . . . . . . . 47

Figure 3.5 Strength Demand at Column Face and Centre . . . . . . . . . . . . . 49

Figure 3.6 Bolted Unstiffened End-Plate Details . . . . . . . . . . . . . . . . 49

Figure 3.7 Timber End-Grain Bearing Plate . . . . . . . . . . . . . . 55 
Figure 3.8 Stain Compatibility Analysis . . . . . . . . . . . . . . . . . 58

Figure 3.9 Parallel to Grain Spacing of Inclined Screws . . . . . . . . . . . . . 63

Figure 3.10 Force Transfer Stages in ZD-Plate (after Closen, 2008) . . . . . . . . 63

Figure 3.11 Force Analysis of ZD-Plate Connection a) With End-Grain Bearing b)

Without End-Grain Bearing . . . . . . . . . . . . . . . . 64

Figure 3.12 Geometry of ZD-plate (ETA-11/0470, 2012) . . . . . . . . . . . 65

Figure 3.13 Additional Tension Perpendicular-to-grain Screws for ZD-plate Connections 65

Figure 3.14 Force Transfer Through 45 Degree STS Connection . . . . . . . . . . . 68

Figure 3.15 Force Transfer Through ZD-Plate Connection . . . . . . . . . . . . 69

Figure 3.16 Cut of Resultant Forces in 45 Degree STS Connection . . . . . . . . . . 70

Figure 3.17 Perpendicular-to-Grain Reinforcing Screws . . . . . . . . . . . . 71

Figure 3.18 Summary of Connection Details a) 45 Degree STS Connection b) ZD-

plate Connection . . . . . . . . . . . . . . . . . 72

Figure 4.1 Test Assembly Isotropic View $\ldots \ldots$. . . . . . . . . . . 76

Figure 4.2 Test Assembly Forces a) Member Deflections b) Moment Distribution c)

Shear Force Distribution . . . . . . . . . . . . . . . . . . 76

Figure 4.3 Test Assembly Plan View . . . . . . . . . . . . . . . . . . 78

Figure 4.4 Preparation of Timber Members . . . . . . . . . . . . . . . . . 80

Figure 4.5 Assembly of Timber and Steel Elements . . . . . . . . . . . . . . 81

Figure 4.6 VG plus Self-Tapping Screws . . . . . . . . . . . . . . . . . 82

Figure 4.7 STS Installation Accessories $\ldots \ldots \ldots \ldots$. . . . . . . . . 82

Figure 4.8 Installation of Reinforcing Screws $\ldots \ldots \ldots \ldots$

Figure 4.9 Installation of 45 Degree Screws $\ldots \ldots \ldots$. . . . . . . . 85

Figure 4.10 Installation of ZD-Plates $\ldots \ldots \ldots \ldots \ldots$

Figure 4.11 Beam and Column Assemblies . . . . . . . . . . . . . . 86

Figure 4.12 Photo of Full Test Assembly . . . . . . . . . . . . . . . . 86

Figure 4.13 Instrumentation Plan . . . . . . . . . . . . . . . 88

Figure 4.14 Photos of Displacement Transducers a) Panel Zone and Link Rotation b)

Screw Slip and Global Movement . . . . . . . . . . . . . . . . 88 
Figure 4.15 Strain Gauge Layout $\ldots \ldots$. . . . . . . . . . . . . . 90

Figure 4.16 Photos of Strain Gauge Locations . . . . . . . . . . . . . . 90

Figure 4.17 Cyclic Loading Protocol (AISC 341-10, 2010) . . . . . . . . . . . . 91

Figure 5.1 Photo of Complete Test Specimen . . . . . . . . . . . . . . 96

Figure 5.2 Idealized Deformation of Full Frame . . . . . . . . . . . . . 98

Figure 5.3 Deformation of Test Frame . . . . . . . . . . . . . . . . . 99

Figure 5.4 Failed Link Specimens a) MC-1A b) MC-2A c) MC-1B d) MC-2B . . . . 104

Figure 5.5 Summary of Observations for Test MC-1A . . . . . . . . . . . . 105

Figure 5.6 Yielding Propagation in Link for Test MC-1A a) Initial b) 1\% Drift c) 4\%

Drift d) Final . . . . . . . . . . . . . . . . . . . . 107

Figure 5.7 Frame Deformations Through Test MC-1A a) Initial b) 1\% Drift . . . . 108

Figure 5.8 Frame Deformations Through Test MC-1A a) 4\% Drift b) Final . . . . . . 109

Figure 5.9 Flange Yielding at $1 \%$ Drift for Test MC-1A . . . . . . . . . . . . 110

Figure 5.10 Yielding Near Flange Weld at 1\% Drift for Test MC-1A . . . . . . . . 110

Figure 5.11 Web Yielding at 3\% Drift for Test MC-1A . . . . . . . . . . . . 111

Figure 5.12 Local Buckling of Web at 4\% Drift for Test MC-1A . . . . . . . . . . . . 111

Figure 5.13 End-plate Gap Opening at 4\% Drift for Test MC-1A . . . . . . . . . . 112

Figure 5.14 Local Buckling of Flange at 5\% Drift for Test MC-1A . . . . . . . . . . . 112

Figure 5.15 Web Crack at $5 \%$ Drift for Test MC-1A . . . . . . . . . . . . 113

Figure 5.16 Force vs. Beam Tip Displacement Response for Test MC-1A . . . . . . . 115

Figure 5.17 Moment vs. Rotation Responses for Test MC-1A . . . . . . . . . . . 115

Figure 5.18 Total Storey Drift Decomposition for Test MC-1A . . . . . . . . . . . 117

Figure 5.19 Strain Profile Along Link Length for Test MC-1A Positive Bending at Midwidth of Flange . . . . . . . . . . . . . . . . . . . 117

Figure 5.20 Strain Profile Across Link Width for Test MC-1A Positive Bending at Middle of Link . . . . . . . . . . . . . . . . . . . . 118

Figure 5.21 Strain Profile Through Link Depth for Test MC-1A (Positive Bending) . 119

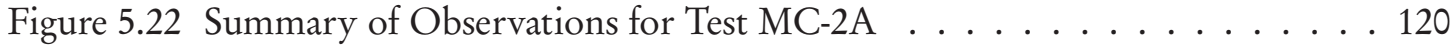


Figure 5.23 Yielding Propagation in Link for Test MC-2A a) Initial b) 1\% Drift c) 4\%

Drift d) Final . . . . . . . . . . . . . . . . . . . . . . 122

Figure 5.24 Frame Deformations Through Test MC-2A a) Initial b) 1\% Drift . . . . . 123

Figure 5.25 Frame Deformations Through Test MC-2A a) 4\% Drift b) Final . . . . . . 124

Figure 5.26 Flange Yielding at $1 \%$ Drift for Test MC-2A . . . . . . . . . . . . . 125

Figure 5.27 Yielding Around Weld Access Holes at 2\% Drift for Test MC-2A . . . . 125

Figure 5.28 Web Yielding at 4\% Drift for Test MC-2A . . . . . . . . . . . . 126

Figure 5.29 Local Flange Buckling at 5\% Drift for Test MC-2A . . . . . . . . . . 126

Figure 5.30 Initial Web crack at 5\% Drift for Test MC-2A . . . . . . . . . . . 127

Figure 5.31 Web Crack Propagation at 5\% Drift for Test MC-2A . . . . . . . . . . 127

Figure 5.32 Flange Fracture at 5\% Drift for Test MC-2A . . . . . . . . . . . . 128

Figure 5.33 Complete Link Cross-Section Fracture at 5\% Drift for Test MC-2A … 129

Figure 5.34 Force vs. Beam Tip Displacement Response for Test MC-2A . . . . . . . 131

Figure 5.35 Moment vs. Rotation Responses for Test MC-2A . . . . . . . . . . 131

Figure 5.36 Total Storey Drift Decomposition for Test MC-2A . . . . . . . . . 133

Figure 5.37 Strain Profile Along Link Length for Test MC-2A Positive Bending at Midwidth of Flange . . . . . . . . . . . . . . . . . . . 133

Figure 5.38 Strain Profile Across Link Width for Test MC-2A Positive Bending at Column Side of $\operatorname{Link} \ldots \ldots$. . . . . . . . . . . . . . . . . . 134

Figure 5.39 Strain Profile Through Link Depth for Test MC-2A (Positive Bending) . 134

Figure 5.40 Summary of Observations for Test MC-1B $\ldots \ldots$. . . . . . . 136

Figure 5.41 Yielding Propagation in Link for Test MC-1B a) Initial b) 1\% Drift c) 4\%

Drift d) Final . . . . . . . . . . . . . . . . . . . . . 137

Figure 5.42 Frame Deformations Through Test MC-1B a) Initial b) 1\% Drift . . . . . 138

Figure 5.43 Frame Deformations Through Test MC-1B a) 4\% Drift b) Final . . . . . 139

Figure 5.44 Flange Yielding for Test MC-1B a) 1\% Drift b) 1.5\% Drift . . . . . . . . 140

Figure 5.45 Yielding Near Flange Weld at 2\% Drift for Test MC-1B . . . . . . . . . . 140

Figure 5.46 Web Yielding at 3\% Drift for Test MC-1B . . . . . . . . . . . . 141

Figure 5.47 Local Buckling of Web at 4\% Drift for Test MC-1B . . . . . . . . . . 141 
Figure 5.48 Local Buckling of Flange at 4\% Drift for Test MC-1B . . . . . . . . . . . 142

Figure 5.49 Out of Plane Movement at 4\% Drift for Test MC-1B . . . . . . . . . . 142

Figure 5.50 Force vs. Beam Tip Displacement Response for Test MC-1B . . . . . . . 145

Figure 5.51 Moment vs. Rotation Responses for Test MC-1B . . . . . . . . . . . . 145

Figure 5.52 Total Storey Drift Decomposition for Test MC-1B . . . . . . . . . 146

Figure 5.53 Strain Profile Along Link Length for Test MC-1B Positive Bending at Midwidth of Flange . . . . . . . . . . . . . . . . . . . 146

Figure 5.54 Strain Profile Across Link Width for Test MC-1B Positive Bending at Middle of Link . . . . . . . . . . . . . . . . . . . . . . . 148

Figure 5.55 Strain Profile Through Link Depth for Test MC-1B (Positive Bending) . 148

Figure 5.56 Summary of Observations for Test MC-2B $\ldots \ldots$. . . . . . . . . . 149

Figure 5.57 Yielding Propagation in Link for Test MC-2B a) Initial b) 1\% Drift c) 4\%

Drift d) Final . . . . . . . . . . . . . . . . . . . . . . 151

Figure 5.58 From Deformations Through Test MC-2B a) Initial b) 1\% Drift . . . . . . 152

Figure 5.59 From Deformations Through Test MC-2B a) 4\% Drift b) Final . . . . . 153

Figure 5.60 Flange Yielding for Test MC-2B a) 1\% Drift b) 2\% Drift . . . . . . . . . . 154

Figure 5.61 Yielding Around Weld Access Hole at 2\% Drift for Test MC-2B . . . . . . 154

Figure 5.62 Web Yielding at 4\% Drift for Test MC-2B . . . . . . . . . . . . . 155

Figure 5.63 Initial Web Crack at 5\% Drift for Test MC-2B . . . . . . . . . . . . 155

Figure 5.64 Local Buckling of Flange for Test MC-2B a) 4\% Drift b) 5\% Drift . . . . 156

Figure 5.65 Propagation of Web Crack at 5\% Drift for Test MC-2B . . . . . . . . 156

Figure 5.66 Fracture of Top Flange at 5\% Drift for Test MC-2B . . . . . . . . . . 157

Figure 5.67 Complete Fracture of Link Cross-Section at 5\% Drift for Test MC-2B . . . 157

Figure 5.68 Force vs. Beam Tip Displacement Response for Test MC-2B . . . . . . . 159

Figure 5.69 Moment vs. Rotation Responses for Test MC-2B . . . . . . . . . . . . 159

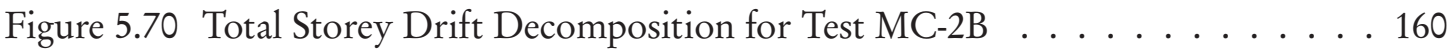

Figure 5.71 Strain Profile Along Link Length for Test MC-2B Positive Bending at Midwidth of Flange . . . . . . . . . . . . . . . . . . . . . . 161 
Figure 5.72 Strain Profile Across Link Width for Test MC-2B Positive Bending at Column Side of Link . . . . . . . . . . . . . . . . . . . . . . 162

Figure 5.73 Strain Profile Through Link Depth for Test MC-2B (Positive Bending) . 162

Figure 5.74 Beam STS Observations Following Tests MC-1A and MC-2A . . . . . . 164

Figure 5.75 Post-test Inspection of Beam STS Connections a) 45 Degree STS b) ZD-plate 164

Figure 5.76 Sample Wood Member Inspection . . . . . . . . . . . . . . 165

Figure 5.77 Sample Beam STS Hystereses . . . . . . . . . . . . . . . . . . 167

Figure 5.78 Sample Column STS Hystereses . . . . . . . . . . . . . . . 167

Figure 5.79 Cumulative Energy Dissipation . . . . . . . . . . . . . . . . . 169

Figure 5.80 Method of Ductility Calculation . . . . . . . . . . . . . . 170

Figure 5.81 Comparison of Hysteretic Behaviour for Specimens MC-1A and MC-2A . 172

Figure 5.82 Comparison of Hysteretic Behaviour for Specimens MC-1B and MC-2B . . 172

Figure 5.83 Comparison of Hysteretic Behaviour for STS Connectiona MC-1A and

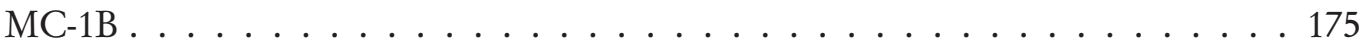

Figure 5.84 Comparison of Hysteretic Behaviour for STS Connectiona MC-2A and

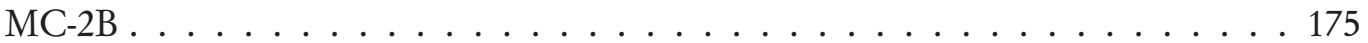

Figure 5.85 Link Replacement a) Bolt Removal b) Link Removal c) Link Installation

d) Bolt Tightening . . . . . . . . . . . . . . . . . . . 178

Figure 5.86 Misalignment of Replaced Link . . . . . . . . . . . . . . . . 179

Figure 5.87 Post-test Inspection of Panel Zone . . . . . . . . . . . . . . . . . 179

Figure 5.88 Post-test Inspection of Beam Collars a) 45 Degree STS b) ZD-plate . . . . . 180

Figure 6.1 Prototype Buildings a) Hybrid Timber-Steel b) Steel-Only . . . . . . . . . 184

Figure 6.2 Structural Layout of Prototype Buildings . . . . . . . . . . . . 185

Figure 6.3 Structural Layout of 2-D Frames . . . . . . . . . . . . . . . 187

Figure 6.4 Model Configuration for Test Specimen . . . . . . . . . . . . . . . 188

Figure 6.5 Model Element Types . . . . . . . . . . . . . . . . . . . . . 188

Figure 6.6 Trilinear Panel Zone Response (after Gupta and Krawinkler, 1999) . . 192

Figure 6.7 Force vs. Displacement Response of Model Frame . . . . . . . . . . . . . 192

Figure 6.8 Force vs. Displacement Response Comparison . . . . . . . . . . . . . . 194 
Figure 6.9 Moment vs. Rotation Response Comparison ～. . . . . . . . . . . . . . . 194

Figure 6.10 Force vs. Displacement Response with Design Link Strength . . . . . . . . 195

Figure 6.11 Link Response Comparison _ . . . . . . . . . . . . . . . 196

Figure 6.12 Drift Decomposition of Model ～. . . . . . . . . . . . . . . . . 197

Figure 6.13 Cumulative Energy Dissipation of Model . . . . . . . . . . . . . . 199

Figure 6.14 Full Building Model Components . . . . . . . . . . . . . . . . . 199

Figure 6.15 Link Behaviour Comparison for Fifth Storey Interior Joint Northridge

Record Beverly Hills Station . . . . . . . . . . . . . . . . . 206

Figure 6.16 Peak Foundation Forces for Hybrid and Steel-only Buildings . . . . . . . . 208

Figure 6.17 Peak Interstorey Drifts for Hybrid and Steel-only Buildings ～. . . . . . 210

Figure 6.18 Peak Residual Drifts for Hybrid and Steel-only Buildings . . . . . . . . . 211

Figure 6.19 Peak Storey Accelerations for Hybrid and Steel-only Buildings . . . . . . 212

Figure 6.20 Comparison of Link Response for Test MC-1A and Simplified Model . . 213

Figure 6.21 Response Plots of Simplified Model for Hybrid and Steel-only Buildings . . 214

Figure B.1 Structural Layout of Prototype Buildings . . . . . . . . . . . . . . 254

Figure B.2 Snow Load Profile for Victoria, British Columbia . . . . . . . . . . . . . 256

Figure B.3 Design Spectrum for Victoria, British Columbia . . . . . . . . . . 258

Figure B.4 Capacity-Design Force at Column Centre . . . . . . . . . . . . . . . 275

Figure B.5 Shear Force Upon Plastic Hinging . . . . . . . . . . . . . . . 276 


\title{
Nomenclature
}

\author{
a - distance between column face and RBS location \\ A - cross-sectional area of member \\ $A_{b} \quad$ - nominal area of bolt \\ $a_{L} \quad$ - loaded end-distance of self-tapping screw connection \\ b - member width \\ $b_{c} \quad$ - width of column flange \\ $b_{p} \quad$ - width of bolted end-plate \\ c - width of RBS cutout (single side) \\ $C_{f} \quad$ - applied axial load on column \\ $C_{p r} \quad$ - factor to account for strain hardening of steel \\ $C_{V} \quad$ - factor to account for load configuration of shear strength of timber \\ d - member depth \\ $d_{b} \quad$ - distance from one edge of end-plate to centre of opposite link flange \\ $d_{c} \quad$ - column depth \\ $d_{e} \quad$ - loaded edge distance of connection loaded in shear \\ $d_{S T S} \quad$ - diameter of self-tapping screw \\ $d_{1} \quad$ - distance between lower bolt holes and link bottom flange \\ $d_{2} \quad$ - distance between upper bolt holes and link bottom flange \\ E - elastic modulus \\ $e_{L} \quad-$ loaded edge-distance of self-tapping screw connection \\ F $\quad$ - force applied to beam tip during testing
}


$F_{a x, R k} \quad$ - withdrawal capacity of screw in ZD-plate connection

$f_{b+} \quad$ - bending strength of glulam in the positive direction

$f_{b-} \quad$ - bending strength of glulam in the negative direction

$f_{c} \quad$ - compression parallel to grain strength of glulam

$f_{c p} \quad$ - compression perpendicular to grain strength of glulam

$f_{t} \quad$ - tension parallel to grain strength of glulam

$F_{t} \quad$ - additional lateral load applied to top storey during seismic analysis

$F_{t, k} \quad$ - capacity of tension perpendicular to grain screws in ZD-plate connection

$F_{u} \quad$ - ultimate strength of steel

$f_{v} \quad$ - longitudinal shear strength of glulam

$F_{y} \quad$ - yield strength of steel

$F_{y p} \quad$ - yield strength of end-plate steel

$F_{Z D, R k}$ - capacity of ZD-plate connector

g - horizontal spacing of bolt holes for bolted end-plate connection

h - distance between linear potentiometers on link element

$h_{n} \quad$ - storey height

I - moment of inertia

$I_{E} \quad$ - importance factor for seismic analysis

$K_{D} \quad$ - factor associated with duration of load on timber member

$k_{\text {elastic }}$ - elastic stiffness of test specimen

$K_{L} \quad$ - factor associated with lateral stability of timber member

$K_{N} \quad$ - factor associated with notch in timber member

$K_{S F} \quad$ - factor associated with service conditions on timber member

$K_{T} \quad$ - factor associated with treatment applied to timber

$K_{x} \quad$ - factor associated with curvature of timber member

$K_{Z b g} \quad$ - factor associated with size of timber member

$k_{1} \quad$ - distance between centerline of web and edge of wed-to-flange fillet

$l_{a} \quad$ - embedment length of self-tapping screw above failure plane 
$l_{b} \quad$ - embedment length of self-tapping screw below failure plane

$L_{\text {beam }}$ - distance between linear potentiometers at beam ends

$l_{e f} \quad$ - effective embedment length of self-tapping screw

$L_{p} \quad$ - length of bolted-end-plate

$L_{P Z} \quad$ - distance between applied load and column centerline

$M_{c} \quad$ - moment at column centerline

$M_{c f} \quad$ - moment at column face

$M_{p c} \quad$ - nominal plastic moment calacity of column

$M_{p r} \quad$ - probable moment capacity of link

$M_{r} \quad$ - resistance of beam member to bending

$\mathrm{n}$ - number of self-tapping screws in a connection

$\mathrm{N} \quad$ - total number of storeys in building

$n_{e f} \quad$ - number of screws effective in transferring load

$n_{Z D} \quad$ - number of ZD-plates in connection

pf - distance between upper bolt holes and link top flange

$P_{r w, \alpha} \quad$ - withdrawal capacity of inclined self-tapping screw

$p_{t} \quad$ - distance between lower bolt holes and link top flange

$Q S_{r T} \quad$ - tension perpendicular to grain strength of timber member

$R_{d} \quad$ - seismic force reduction factor associated with ductility of frame

$R_{O} \quad$ - seismic force reduction factor associated with overstrength of frame

$R_{y} \quad$ - factor to estimate probable yield stress of steel (1.1)

s $\quad$ - length of RBS cutout

$\mathrm{S} \quad$ - elastic modulus of gross cross-section

$S_{a} \quad$ - spectral acceleration

$S_{A} \quad$ - scaling factor for area

$S_{e} \quad$ - effective elastic modulus of reduced cross-section of dogbone link

$S_{E} \quad$ - scaling factor for elastic modulus

$S_{F} \quad$ - scaling factor for force 


\begin{tabular}{|c|c|}
\hline$S_{I}$ & - scaling factor for moment of inertia \\
\hline$S_{L}$ & - scaling factor for length dimensions \\
\hline$S_{M}$ & - scaling factor for moment \\
\hline$S_{P}$ & - spacing of self-tapping screws parallel to grain \\
\hline$S_{Q}$ & - spacing of self-tapping screws perpendicular to grain \\
\hline$S_{Z}$ & - scaling factor for section modulus \\
\hline$T_{a}$ & - first mode fundamental period of vibration of building \\
\hline$t_{b p}$ & - thickness of bearing plate \\
\hline$t_{c}$ & - column section flange thickness \\
\hline$T_{f}$ & - applied tensile force \\
\hline$t_{f}$ & - flange thickness of steel w-section \\
\hline$t_{p}$ & - end-plate thickness \\
\hline $\mathrm{V}$ & - seismic base shear \\
\hline$V_{c f}$ & - shear at column face \\
\hline$V_{e}$ & - elastic base shear \\
\hline$V_{e d}$ & - design elastic base shear \\
\hline$V_{h}$ & - shear in link upon plastic hinging \\
\hline$V_{p z}$ & - shear force applied to panel zone \\
\hline$V_{r}$ & - shear resistance of member \\
\hline W & - seismic weight of building \\
\hline$W_{f}$ & - total applied load on timber member \\
\hline$Z_{e}$ & - effective plastic modulus of reduced cross-section of dogbone link \\
\hline$Z_{x}$ & - plastic modulus of gross cross-section \\
\hline$\alpha$ & - inclination angle of self-tapping screw \\
\hline$\delta$ & beam tip displacement during testing \\
\hline$\theta$ & - total storey drift angle \\
\hline$\theta_{\text {beam }}$ & - total beam rotation \\
\hline$\theta_{\text {link }}$ & - total link rotation \\
\hline
\end{tabular}




$\begin{array}{ll}\theta_{p} & \text { - total plastic storey drift angle } \\ \theta_{P Z} & \text { - total panel zone rotation } \\ \mu & \quad \text { - coefficient of friction in self-tapping screw connection } \\ \rho & \text { - density of wood } \\ \sigma_{w} & \text { - compressive stress in timber } \\ \phi & \text { - material-based resistance factor } \\ \phi_{b} & \text { - resistance factor for bolt shear strength }\end{array}$




\section{Chapter 1: Introduction}

Buildings require well designed lateral load resisting systems (LLRS) to transfer forces induced by wind and earthquakes to the foundation of the structure. Such systems include shear walls (panel-type elements with high in-plane stiffness), braced frames (which use pinned beamcolumn joints with additional inclined members to transfer lateral loads through axial forces), and moment-resisting frames (MRFs) (which transfer loads as applied moments through rigid beam-column connections.

In modern construction, lateral load resisting systems are typically comprised of steel or concrete, since their seismic behaviour is well understood; these materials are capable of providing high strength, ductility, and stiffness. The high strength-to-weight ratio of wood gives it inherent benefits for seismic design, however the risk of brittle failure due to limited tension perpendicular-to-grain strength inherent in some moment-resisting connections cause it to fall short with regards to seismic performance when applied to moment-resisting joints.

This research aims to overcome the seismic deficiency inherent in wood moment-resisting frames and limit brittle failure by incorporating well-detailed steel yielding components that localize all seismic damage to a single ductile element. This thesis will present the development, design, and testing of a new hybrid timber-steel moment-resisting connection. The numerical modelling of a full frame utilizing the developed connection will be discussed. The goal of this research is to determine if high seismic force reduction factors are justifiable provided that plastic behaviour is localized to ductile connection components, and damage and excessive deformations can be avoided in the steel-to-timber connections. 


\subsection{Seismic Design and Moment-Resisting Frames}

This chapter introduces design aspects for moment-resisting frames made of steel and timber, and provides an overview of currently available beam-column connection methods, as well as the mechanical properties of timber. The objectives and scope of research are also presented.

To improve the cost efficiency of building construction in high seismic regions, it is common practice to design an LLRS to promote ductile failure modes, which reduces seismic forces imparted on the structure by allowing plastic deformation of structural elements. In steel construction, moment-resisting frames (MRFs) are a favourable choice among designers as they are the most architecturally versatile, and are generally assigned high ductility and overstrength factors by building codes. MRFs accommodate lateral loads through a rigid connection at the beamcolumn interface, made using welds and/or high-strength bolts. This type of connection allows for the development of moments and shear forces which can then be carried to the foundations of the structure. Due to this rigid action, the beams or columns themselves must deform to achieve lateral displacement, and so these members are responsible for the lateral strength and stiffness required to resist seismic loads (Bruneau, 1998). An MRF achieves ductile failure through either flexural yielding of the beams or columns near the beam-column interface, or shear yielding of the panel zone. The deformation undergone by a typical MRF is shown in Figure 1.1 below. By detailing these regions to accommodate large plastic deformations without significant reduction in strength, it is possible to increase both the cost efficiency and life safety to occupants beyond that of frames exhibiting limited ductility that can be susceptible to brittle failure. Highly ductile structures will visibly deform without complete failure, allowing occupants to safely evacuate the building before collapse in the event of an earthquake.

The high ductility and energy dissipating capabilities of steel make it an ideal material for use in seismic force resisting systems. Well detailed steel components may undergo large plastic deformations without significant loss in strength, and maintain elastic stiffness throughout many loading cycles. If a connection is detailed properly, this can allow for a greater dissipation of hysteretic energy than is possible from wood or concrete. The energy input to a structure 


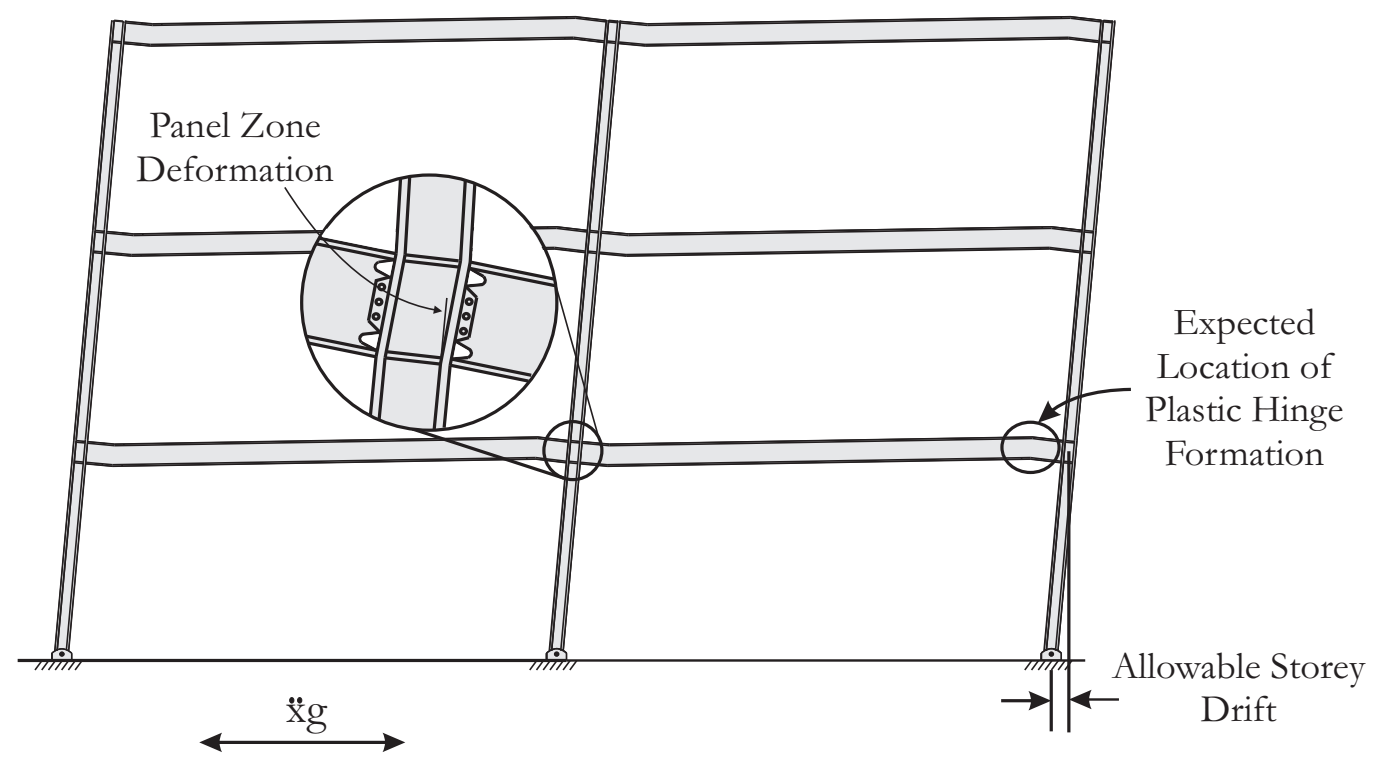

Figure 1.1: Typical Moment-Resisting Frame Deformation

during severe ground motions will be dissipated through yielding of specially detailed steel components; sometimes incorporating reduced beam section connections. Figure 1.2 below shows the hysteretic behaviour of a typical steel moment-resisting connection exhibiting high ductility and energy dissipation.

Designers use the capacity-design principle to ensure that an LLRS undergoes ductile and predictable failure modes. This approach was developed in New Zealand in the 1960s as a means to accommodate severe ground motions (Bruneau, 1998). It is recognized that the most efficient way to design a structure is to accommodate a moderate amount of damage. In capacity-design, the designer selects a location within the structural system where a majority of the inelastic behavior will take place without significant strength degradation; this component is detailed to accommodate the design forces when subjected to large deformations, while the remaining structural components that cannot efficiently dissipate energy are capacity-designed to remain elastic under the loads associated with yielding of the plastic zone (Bruneau, 1998). Assigning proper overstrength factors to the less ductile elements along the load path prevents undesirable brittle failure modes from occurring, ensuring that high ductility is achieved while a majority of the structure remains undamaged and specified drift requirements are still met. This has become 


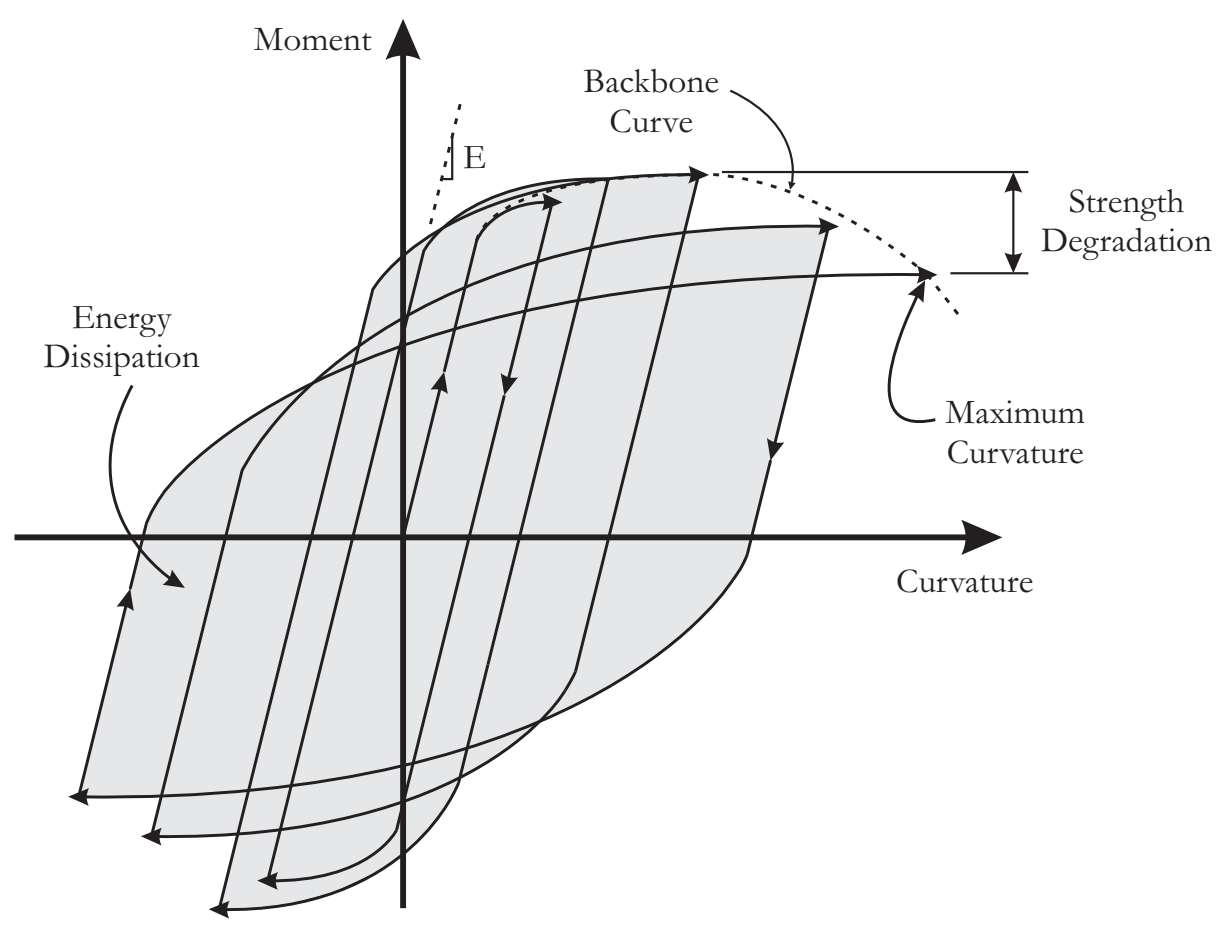

Figure 1.2: Typical Hysteretic Response of Steel Moment Connection

a common practice in modern seismic design (Filiatrault et al. 2013).

\subsection{Performance of Timber Frames}

Tall wood buildings are uncommon in Ontario since the Ontario Building Code prohibited the construction of structures above four storeys built from combustible material in the past; a restriction that has since been increased to six storeys (2012 Ontario Building Code Compendium, 2015). Due to susceptibility of timber moment-resisting connections to brittle failure modes, some recent research has focused on the development of hybrid wood-steel, instead of relying on an all-timber structure (Andreolli et al. 2011, Closen 2008, Humbert et al. 2014, Komatsu et al. 2014, Nakatani et al. 2012). Timber connections are generally designed to rely on bending of steel dowel-type fasteners and crushing of the wood fibres to achieve ductility, making it difficult to achieve levels of seismic performance comparable to steel yielding components or a robust concrete system. Nevertheless, timber has enormous potential for seismic design. Not only is timber the most abundant and sustainable building material produced in Canada, but it 
also has a much higher strength-to-weight ratio than steel or concrete. The reduced weight of timber results in lower imposed seismic forces on the structure, making it an ideal material for seismic-resistant structures (Tall Wood Building Report, 2013).

Modern technology has allowed for the development of engineered wood products and fastener components tailored to the design of mid-rise or even high-rise wood buildings using heavy timber elements. Wood is an orthotropic material, and thus more complex than steel or concrete. In general, wood is stronger and stiffer when loaded parallel to grain than perpendicular-to-grain. The low strength of wood when loaded in tension perpendicular-to-grain is the most significant drawback in timber design. This is especially true in timber moment frames, where the configuration of dowels commonly causes high tension perpendicular-to-grain stresses that result in brittle failure (Jorissen and Fragiacomo, 2011). The same failure mode can also be induced by moisture-related shrinkage, and must be accounted for in design.

\subsection{Timber Fastener Technology}

Traditional timber connections use bolts/dowels, timber rivets, lag screws or nails to transfer loads through a joint. The configuration of these traditional fasteners in timber MRFs often leads to high tension perpendicular-to-grain stresses or cause issues with moisture and shrinkage at the connection interface. Furthermore, the capacity of a laterally loaded dowel-type fastener connection is limited by the embedment strength of the timber and the bending strength of the dowel, which are typically quite low (Krenn and Schickhofer, 2009). There have been many advancements in timber connection technology that can allow designers to achieve high capacity and ductility and avoid shrinkage related connection failure. For the implementation of beam and column type construction, high-strength connections are necessary. Recent research has shown that self-tapping screws have enormous potential for use in MRFs subjected to severe seismic loading (Closen, 2008, Krenn and Schickhofer, 2009).

Self-tapping screws (STS) are large wood screws that provide a high-strength mechanical connection between the screw threads and the timber material. This bond creates a high stiffness load transfer mechanism that can efficiently transfer tensile and compressive forces along the 
screw axis (Gehloff, 2011). STS are made of hardened steel with a self-drilling tip that allows the screw to drill its own pilot hole to reduce wood splitting during installation. Both fully threaded and partially threaded screws are available, although research shows that fully threaded screws achieve higher capacity and a more uniform stress distribution along the screw length while avoiding the head pullthrough failure mode (Dietsch and Brandner, 2015). STS are now available in lengths up to $1400 \mathrm{~mm}$ and diameters up to $14 \mathrm{~mm}$ making it possible to transfer design loads that far exceed the capabilities of standard wood screws and many other dowel-type fasteners (Closen, 2008). This makes it possible to not only use STS as connection reinforcement, but as the primary load transferring mechanism as well. Extensive research on the mechanical behaviour of STS in Canadian wood species has led to the release of the Evaluation Report for SWG ASSY VG Plus and SWG ASSY 3.0 Self-Tapping Wood Screws (National Research Council of Canada, 2013).

Wood-to-wood connections using STS have been used for nearly a decade, but recent adaptations now use inclined STS to create moment connections with steel top and bottom plates, rigid column base connections, as well as hybrid timber-steel truss systems (Krenn and Schickhofer, 2009). With steel top and bottom plate connections, the capacity is governed by the tensile and withdrawal strength of the STS in combination with friction forces induced between the steel and timber components; this is typically much higher than laterally loaded dowel-type connections (Krenn and Schickhofer, 2009).

In order to further advance the potential for fully-threaded STS, they may be used in combination with tension-compression plates (ZD-plates) to better utilize the available connection space. A ZD-plate is a two piece assembly (as seen in Figure 1.3) manufactured by Schraubenwerk Gaisbach Gmbh (SWG) in Germany (Closen, 2008). The screw holder is fastened to the timber member using four ten millimeter fully threaded STS; two screws are oriented in each direction and the cover plate is installed to bear on the screw heads. When a lateral load is applied, this setup allows for two screws to transfer forces in tension, and two screws to transfer forces in compression. Generally STS connections without ZD-plates can only rely on load transfer through tension in the STS, so compressive forces must be taken in bearing on the wood member. After the ZD-plate is fastened to the timber element, it can then be bolted to the steel plate, 
thus the STS can be pre-installed in more favourable working conditions before arriving to the construction site.

\subsection{Objective and Scope}

The purpose of this research is to develop a new hybrid timber-steel moment-resisting connection for use in mid-rise heavy timber buildings. In order for the MRF to achieve a level of ductility and energy dissipation necessary to perform efficiently under seismic loading, the connection was detailed such that all plastic deformations were localized to a single ductile steel component, thereby justifying the use of high ductility factors for seismic design. All timber members and STS connections were assigned an overstrength factor necessary to avoid failure or excessive deformation of these components. The purpose of this design methodology was to show that it is possible for timber members and steel-to-timber connections to remain entirely elastic upon yielding of steel components, which is a quality not yet found in existing large-scale connections.

The design philosophy for the newly developed hybrid connection was validated through an experimental program involving four two-thirds scale frame tests. The experimental tests were conducted to determine if all plastic rotations could be localized to a single ductile steel component while timber members remain entirely elastic, assess the ability of inclined STS and ZD-plate connections to transmit capacity-design forces without sustaining large deformations, and determine if the the use of existing design guidelines leads to an adequate connection design.

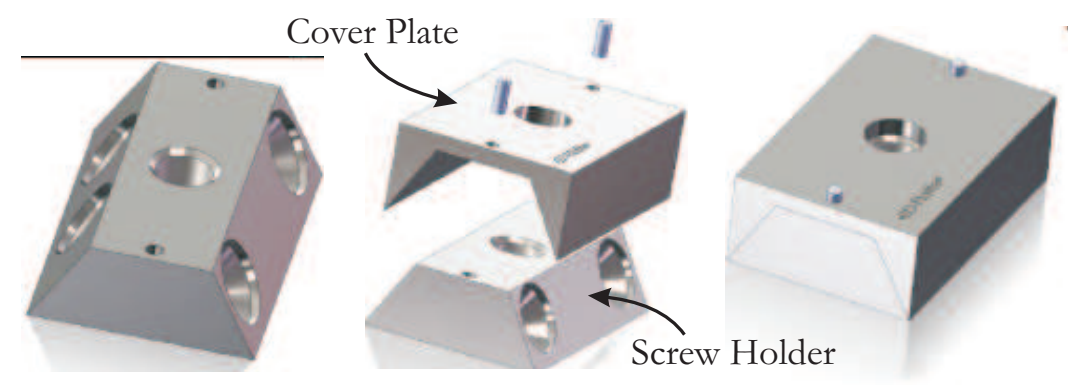

Figure 1.3: ZD Plate Components (from ETA-11/0470, 2012) 
The results of the experimental study was also used to assess the accuracy of numerical models of the proposed connection. The objectives of the numerical study were to compare the seismic performance of a hybrid frame using the proposed connection and an equivalent steel-only frame, verify that high ductility factors may be used for the design of the hybrid system, and verify the capacity design methods used in the design of the hybrid frame.

Each chapter of this thesis will introduce a major component of the research. Chapter 2 will summarize existing literature on topics relevant to this research and essential to proper design and assembly of the test specimens. Chapter 3 will outline the design process for the hybrid timber-steel connection, including preliminary design alternatives and details on the design of different connection components. The experimental program will be presented in Chapter 4, followed by a summary of the test results in Chapter 5 . The methods used to model the prototype structure and results of the numerical study will be discussed in Chapter 6. Lastly, conclusions and recommendations will be given in Chapter 7 .

Ryan Gohlich, Department of Civil and Environmental Engineering, Carleton University 


\section{Chapter 2: Literature Review}

This chapter provides a brief background on traditional and modern moment-resisting frames used in both steel and heavy timber construction. Connection details used in the design of modern steel moment-resisting frames (MRFs) are discussed, including reduced beam sections, steel end-plate connections and replaceable links. Typical heavy timber and existing hybrid MRFs are briefly introduced and recent developments in self-tapping screw technology are discussed in detail.

\subsection{Steel Moment-Resisting Frames}

\subsubsection{Background}

A steel moment-resisting frame (MRF) is a lateral load resisting system (LLRS) comprised only of beam and column elements, that transfer lateral loads imposed by wind and earthquakes to the building foundation by developing moments at rigid beam-to-column joints. Such frames have had an excellent reputation as seismic force resisting systems since the beginning of the 1900s (Bruneau, 1998). Extensive research in the 1970s on the cyclic performance of bolted beam-tocolumn joints led to the rapid adoption of these frames in commercial buildings due to their ease of construction and absence of intrusive bracing members and wall panels (Bruneau, 1998).

On January 17, 1994, the Northridge earthquake, magnitude 6.7 struck Los Angeles causing 20 billion dollars in damage to steel MRFs (Bruneau, 1998). More than 100 buildings were found to have suffered substantial structural damage at the beam-column interface of steel frames constructed using welded flange-bolted web connections (usually fractures of the beam bottom flange propagating from the weld) (Bruneau, 1998). 
As a result of the Northridge earthquake, the SAC Joint Venture, American Institute of Steel Construction (AISC), Federal Emergency Management Agency (FEMA), and other organizations collaborated in an intensive research program to develop improved beam-column connections. Phase one of this program included literature reviews and analytical studies of damaged and undamaged buildings (FEMA-350, 2000). Phase two continued with a series of full-scale beam-column connection tests (120 in total) of various configurations to determine the cause of the brittle failure of the pre-Northridge designs, and to determine ways to increase the plastic rotation capacity of these frames (FEMA-350, 2000).

\subsubsection{Plastic Hinging using Reduced Beam Sections}

The 1994 Northridge earthquake sparked a need for better detailed beam-column connections in steel MRFs. Two popular methods were developed to increase the plastic rotation capacity of the connection: strengthening the beam-column interface at the weld locations, and weakening of the beam at a specified distance away from the column face (known as a reduced beam section or RBS). Each of these connection types is shown in Figure 2.1. The goal of these connection details was to move the location of plastic hinging away from the welded connections, since pre-Northridge connections were susceptible to brittle weld failure, which reduces overall ductility of the MRF (Bruneau, 1998). Plastic hinging is a desirable behaviour common in steel and concrete frames that localizes plastic deformations to specially detailed regions of the frame that are capable of providing significant plastic rotation capacity. In steel MRFs, it is possible to force plastic hinging in either the beam or column, but in multi-storey structures plastic hinging of the beam far away from the brittle weld metal is most desirable (Filiatrault et al. 2013).

Strengthening of the connection is typically done using cover plates, side plates, ribs, or haunches (Bruneau, 1998). Each of these methods has the desired outcome, however it also results in an increased moment at the column face and shear force in the panel zone because the design moment is taken as the moment at the location of plastic hinging (Bruneau, 1998). Weakening of the beam away from the column face became a widely accepted alternative and achieves plastic hinging by reducing the cross-sectional area of the beam flanges at specified locations (Bruneau,

Ryan Gohlich, Department of Civil and Environmental Engineering, Carleton University 

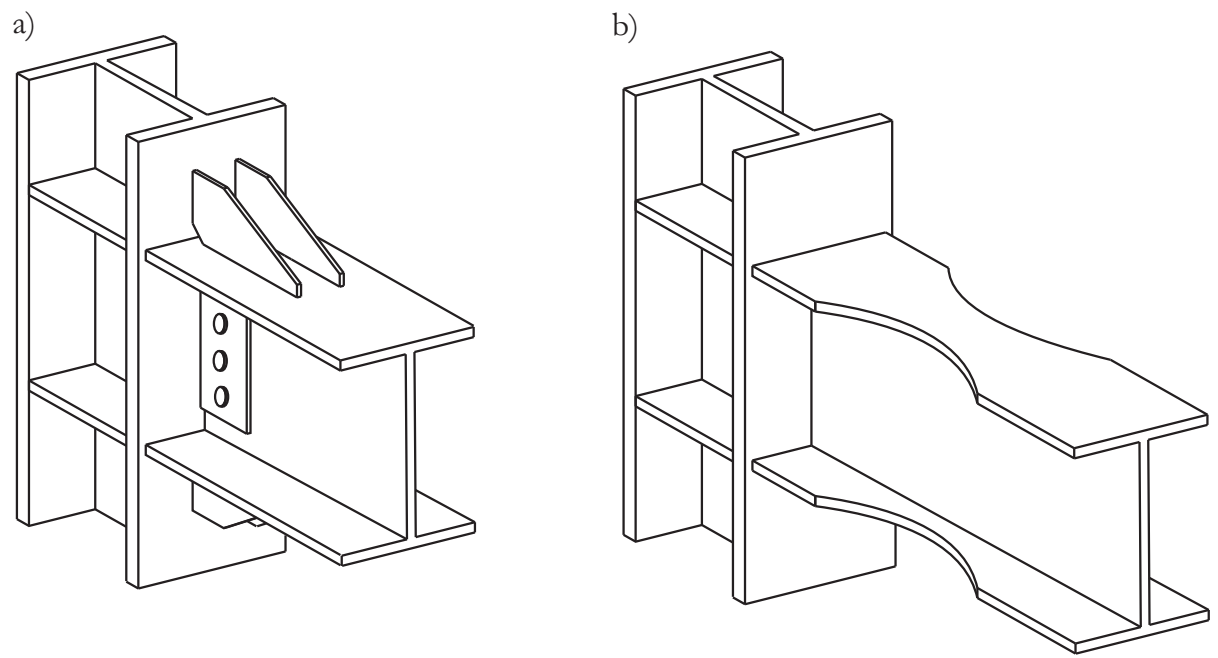

Figure 2.1: Post-Northridge Connections

a) Strengthened b) Reduced Beam Section

1998). The connection to the column face is made using complete joint penetration groove welds for the beam flanges (usually using weld access holes) and welded or bolted connections for the beam web; this detail is known as a dogbone section (Bruneau, 1998).

Two dogbone shapes are typically considered for design. The first is tapered linearly to approximate the moment diagram of the beam, and the second uses radial flange cuts as seen in Figure 2.1 (Pachoumis, 2009). This avoids abrupt changes in the cross-section and associated stress concentrations (Pachoumis, 2009). These connections achieve ductility through local buckling of the beam web and flanges, as well as lateral torsional buckling (LTB) (Pachoumis, 2009). Preliminary testing showed both strengthening of the connection and weakening of the beam successfully increased plastic rotation levels (Bruneau, 1998).

Popov et al. (1998) tested a series of connections designed using both pre-Northridge and post-Northridge methods to show the potential of the dogbone connection. Three beam-column assemblies were tested using the traditional welded flange-bolted web configuration. All three connections showed cracks rapidly propagating form the centre of the bottom beam flange into the column flange and web, as well as through the entire beam flange. Popov et al. also tested dogbone connections, the first with radial cuts made in the top and bottom flanges, and the second with radial cuts made in only the bottom flange (a typical detail for seismic retrofit of 
existing steel MRFs). Both specimens sustained many cycles at high plastic deformation, achieving plastic rotations that far exceeded the required 3 percent (requirement at the time of testing, which has since increased to 4 percent (AISC 341-10, 2010)). After comparing the hysteretic behaviour of pre and post-Northridge connections, it was clear that much more ductility and energy dissipation could be achieved using the new dogbone section.

Uang and Fan (2001) performed numerical studies on the performance of RBS connections based on the the results of previously tested specimens, using nonlinear models to establish a relationship between plastic rotation capacity and strength degradation rate. These models were used to examine the effects of web and flange slenderness and the presence of concrete floor slabs on the strength-rotation relationship. Analysis results showed lateral torsional buckling had little effect on performance, however for high levels of plastic rotation, the slenderness ratio for web local buckling should be reduced from that specified in the Seismic Provisions for Structural Steel Buildings (AISC 341-10, 2010) when designing RBS connections. Uang and Fan also suggest that the increased stability due to the presence of a concrete floor slab can benefit the connection in terms of both strength and rotation capacity under positive bending, but only negligibly increase rotation capacity under negative bending, and should hence be ignored in the design of the connection (Uang and Fan, 2001).

Jones et al. (2002) examined the performance of moment connections with RBS experimentally, investigating the effect of panel zone strength, the beam web connection type, and the presence of a composite floor slab. "Weak" panel zones designed so that the panel zone accommodated a majority of the plastic behaviour resulted in the most stable hysteretic response, however they often led to fracture of the flange weld at the column face at large storey drift angles. "Balanced" panel zones were designed to promote yielding in both the beam and panel zone, and usually failed due to excessive strength degradation. "Strong" panel zones dissipated less energy than the alternatives. Specimens were designed using either welded or bolted beam web connections. Results showed that use of a welded web connection tends to decrease the likelihood of flange weld fracture at the column face, although both welded and bolted web specimens performed adequately. The presence of a composite slab was shown to benefit the energy dissipation and global stability of the connection without any signs of local strain increase in the 
flanges. All but one test found the RBS connection to achieve acceptable levels of ductility and reached a total storey drift of $0.04 \mathrm{rad}$ as required by AISC Seismic Provisions (Jones et al., 2002). Similar findings with regards to panel zone strength were presented by Deylami and Tabar (2004) and Lee et al. (2004).

Chi and Uang (2002) studied the effects of using RBS connections with deep columns. Significant column twisting was witnessed during all experimental tests at approximately 0.03 rad storey drift. In one test, a large crack formed where the column flange met the column web, and propagated through the continuity plates. Chi and Uang suggested a design method for estimating the torsional force applied on the column due to lateral torsional buckling of the RBS.

Similar findings were presented by Ricles et al. (2004). In most specimens, local buckling of the beam caused fracture in the flange at 6 percent drift. Tests showed that lateral displacement of the bottom flange in compression caused column twist. The use of smaller beam sizes was also shown to limit torsion in the column. All tests showed that the presence of a floor slab can reduce column twist and strength degradation. Specimens designed with weaker panel zones experienced less strength degradation and column twist than those whose panel zones remained elastic (Ricles et al. 2004).

Prequalified connections must undergo sufficient testing, analysis and evaluation to be deemed reliable in meeting the specified performance criteria outlined in the Seismic Provisions for Structural Steel Buildings (AISC 341-10, 2010). Attainment of prequalification is based on strength degradation of the connection over specified levels of plastic rotation, depending on the class of moment frame desired for design. To date, thanks to the SAC Joint Venture, FEMA and other research programs providing experimental data, many connection configurations have become prequalified for use in steel MRFs, including reduced beam sections and various bolted end plate connections (AISC 341-10, 2010).

\subsubsection{Bolted End-Plate Connections}

Bolted end-plate connections rely on a thick steel plate welded to the end of a beam member, which can be bolted on-site to the face of a column. This improve the quality of welds (performed in-shop) and reduces construction time. These connections have been shown to perform 
well under monotonic loading, but as RBS connections with fully welded joints became popular, little research had initially been done on the seismic performance of bolted end-plate connections and their ability to withstand cyclic loading (Bruneau, 1998). Research into the cyclic performance of bolted end-plate connections showed that added stiffeners, thicker end-plates, or weaker panel zones could improve the nonlinear behaviour of these connections (Bruneau, 1998).

Typical bolted end-plate connections use a fully welded connection between the beam and the end-plate, which can then be fastened to the column flange using multiple high strength pretensioned bolts (Bruneau, 1998). Many prequalified configurations of this type of connection have been developed, both stiffened and unstiffened, using a varying number of bolt rows. A common bolted stiffened end plate connection is shown in Figure $2.2 \mathrm{a}$ ).

Tsai and Popov (1990) experimented on bolted end-plate connections with an four-bolt configuration. All specimens showed progressive increase in gap size between the deformed endplate and the column face, and fracture of the inner bolts in one specimen with small bolts resulted in pinching of the hysteretic response and limited the nonlinear behaviour of the beam. Connection performance was significantly increased by using larger bolts, which promoted local buckling of the beam web and flanges. The authors suggest that design specifications with regards to bolt size in the AISC Seismic Provisions should be modified to reduce the probability of bolt fracture. Furthermore, they found that to achieve a balanced force distribution among all bolts, stiffeners can be added to the extended portion of the end-plate.

Although some failure within the end-plate and tension bolts is acceptable, designers must have an adequate understanding of the potential failure modes in end-plate connections when using capacity-design to allow for proper plastic behaviour of the beam elements. Research done by Chasten et al. (1992) as well as Shi et al. (2007) showed that the main failure modes in these connections include end-plate yielding, bolt fracture, and shear failure of the end-plate. Chasten et al. (1992) showed that end-plate yielding can occur from prying forces that were unforeseen in early design guidelines. These forces can be predicted using the equivalent tee-stub method, yield line theory, or finite element analysis (the latter two are used in most modern guidelines)

Ryan Gohlich, Department of Civil and Environmental Engineering, Carleton University 


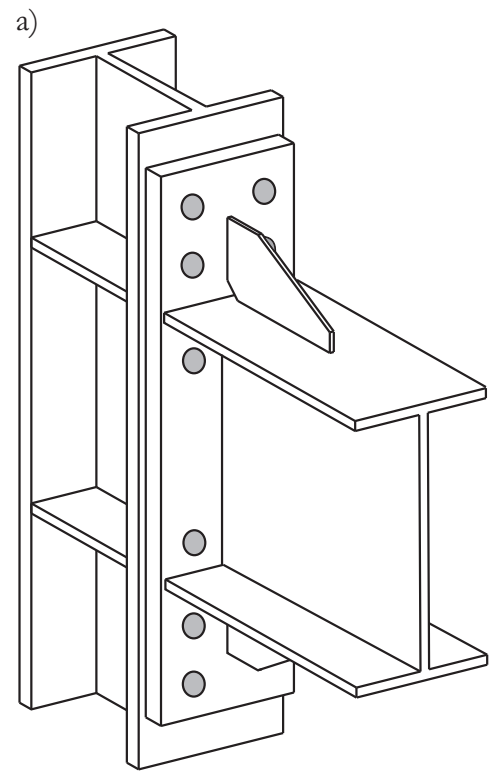

b)

Figure 2.2: Bolted End-Plate Connection

a) Stiffened End-Plate b) Failure Modes

(Chasten et al., 1992). Chasten et al. (1992) also showed that prying forces in unstiffened endplates can increase bolt tension forces, and it was recommended that design bolt force be increased by 30-40 percent to account for the extra prying force. Furthermore, tests showed that slight variations in bolt layout can lead to high shear stresses in the end-plate, so particular attention should be paid to this detail (Chasten et al., 1992). Shi et al. (2007) showed that undersized bolts can not only fracture, but also lead to significant gap formation between the end-plate and column face, resulting in pinching behaviour and limiting energy dissipation. It was recommended that thick end-plates and large bolts be used for best performance (Shi et al., 2007). To maximize ductility, the connection should be detailed such that failure occurs first in the end-plate, followed by the panel zone, and lastly by bolt elongation (Shi et al. 2007). The typical deformed shape of a loaded unstiffened end-plate connection can be seen in Figure $2.2 \mathrm{~b}$ ).

Sumner and Murray (2002) compared the the performance of end-plate connections of various thickness. It was found that use of a thick end-plate generally led to beam yielding, providing high ductility and rotation capacity, while that of thin end-plates is adequate, but is usually followed by brittle bolt rupture failure. This research was part of an extensive experimental program completed by Sumner to develop a design procedure for extended bolted end-plate connections. 
Results of this research were used in the development of guidelines for the design of end-plates, connecting bolts, and column flanges for a range of connection configurations (stiffened and unstiffened with 4, 6, and 8-bolt patterns), as well as connection detailing and fabrication practices (Sumner, 2003).

\subsubsection{Nonlinear Replaceable Links (Shen, 2009 and Shen et al., 2011)}

The prequalification of the RBS and extended bolted end-plate connections provided modern seismic design alternatives that are both high performance and easy to install. This overcame the many drawbacks of the pre-Northridge steel moment connections, however there are still drawbacks associated with these and other types of prequalified connections. In standard beamcolumn connections, strength and drift designs are interlinked (Shen et al., 2011). Since MRFs are quite flexible, excessive drifts (commonly governing the frame design) are accommodated by increasing beam and/or column size, which subsequently increases the resistance of the ductile fuse since the RBS size is not independent of the beam size. This results in increased capacity-design forces on the connections, columns, and foundations, which in turn requires larger sections sizes. Furthermore, assessment and post-earthquake repair of these connections can be quite difficult, costly and disruptive (Shen et al., 2011).

To mitigate the drawbacks inherent in typical post-Northridge solutions and increase design efficiency, the nonlinear replaceable link (NRL) concept was developed (Shen et al. 2011). Like the RBS connections, NRLs reduce the moment capacity of the beam at a distance away from the column face, protecting the brittle connection components. However, rather than reducing the flange size of the beam member, only a portion of the beam is replaced by a steel section with a lower moment capacity. This section is then connected to the beam and column face using bolted end-plate connections on each side. Like the RBS, capacity-design is used to limit force transfer to the connections, columns, and foundation. The components of a NRL can be seen in Figure 2.3. Because the size of the NRL is independent of the beam size, beam and column sizes can be increased to accommodate drift requirements without increasing the size and resistance of the ductile fuse. This effectively uncouples strength and drift design and eliminates the associated drawback of RBS connections. Furthermore, since NRLs accommodate all seismic 
damage, connections can be easily inspected and repaired at low cost following an earthquake, with minimal disruption to building occupants.

Since the NRL is a fairly new concept, limited research exists on the performance of such a connection; however, Shen (2009) undertook an extensive research program to evaluate the seismic performance of NRLs with different connection configurations to determine if behaviour comparable to RBS connections could be achieved. Four full scale connections were tested under reverse-cyclic loading; two connections used steel w-sections with unstiffened extended bolted end-plate connections, and two used back-to-back c-channels bolted to the beam web. These connections were designed using the Moment Connections for Seismic Applications guidelines (CISC, 2008). The goals of this research were to discover if these connections could achieve adequate plastic rotation capacity without significant loss in strength, and to test the replaceability of the link and performance of damaged links under subsequent seismic loading. Tests on the end-plate links showed that tension flange strains could be concentrated in the centre of the flange (longitudinally), thus protecting the flange welds; while some fracturing of these welds was present, it was not prior to reaching acceptance criteria. Each connection sustained at least 0.04 rad storey drift without significant strength degradation. Limited yielding occurred in the panel zone and beam member, but propagation ceased before high rotation cycles were reached. In general, it was found that when designed using existing provisions, the links were able to maintain stable hysteretic behaviour with high strength, ductility, and rotation capacity. Furthermore, links could be easily replaced with no consequential performance degradation. The author recommends performing nonlinear time-history analysis on buildings incorporating NRLs (Shen, 2009).

\subsection{Timber Moment-Resisting Frames}

Although timber has many inherent benefits with regards to seismic design, use of heavy timber MRFs is still primarily limited to low rise structures. Timber is quite effective in single storey portal frames, and bays can span up to 40 metres in length (Buchanan and Fairweather, 1993). For this reason, timber structures with MRFs are typically used in commercial buildings 


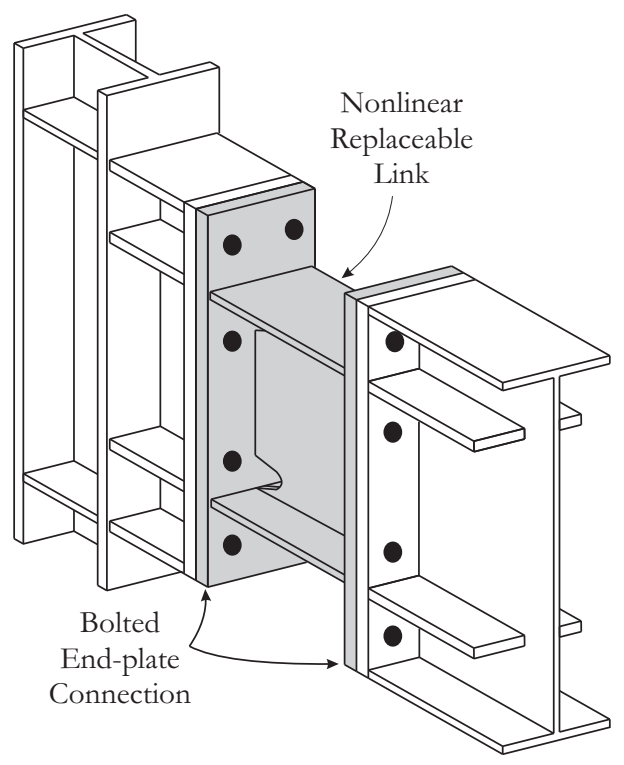

Figure 2.3: Beam-Column Connection with Nonlinear Replaceable Link

that require large open spaces (Buchanan and Fairweather, 1993).

Due to the orthotropic nature of wood and the presence of defects, wood tends to fail in a brittle manner, even in bending (unlike concrete or steel). Consequently, designers rely upon the connections between timber elements to provide the necessary ductility and energy dissipation required to withstand severe ground motions (Andreolli et al. 2011). The difficulty designers face regarding timber MRFs is detailing connections to achieve both high strength, as well as high ductility.

Designers may overcome the aforementioned design issues using either traditional doweltype connections or modern connections using adhesives, CFRP, and advanced fasteners. If the connection is properly detailed, incorporating steel components to provide the necessary ductility for seismic design and capacity-design procedures to protect brittle components, high strength and ductility may be achieved. To date, only a moderate amount of ductility has been achieved for timber moment-resisting connections. Most traditional moment connections utilize doweltype fasteners, such as bolts, steel dowels, or nails. Design of these fasteners in both Europe and North America are based on the works of Johansen (1949) and is dependent on both the embedment strength of timber and the resistance of dowels in bending. Other connection types include timber rivets and glued-in rods. Examples of moment connections using the aforementioned 
fasteners can be see in Figure 2.4.

a)

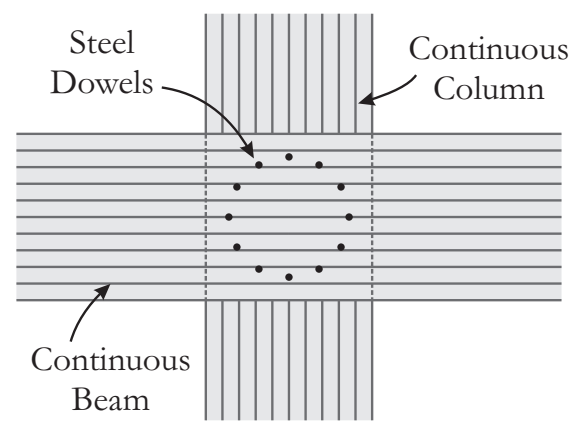

c)

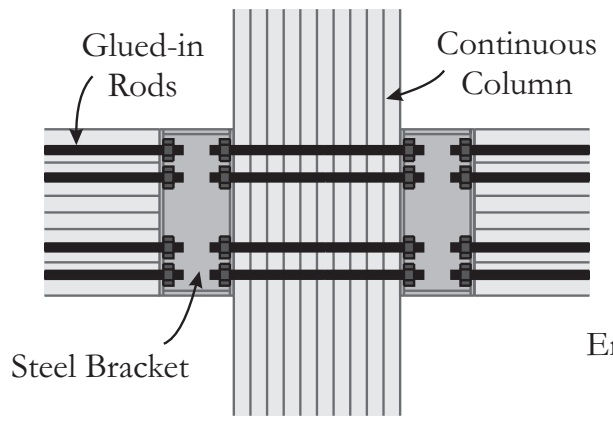

b)

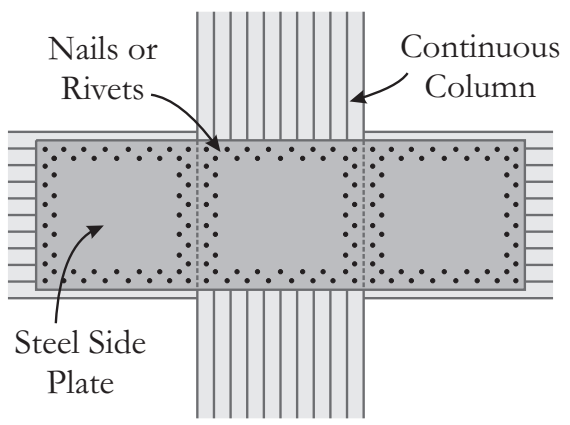

d)

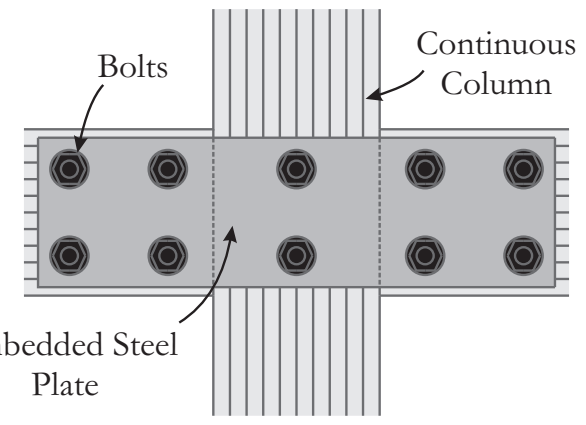

Figure 2.4: Traditional Timber Moment-Resisting Connections

a) Circular Dowels b) Nails or Rivets

c) Glued-in Rods d) Bolts with Embedded Steel Plate

Buchanan and Fairweather (1993) have provided a detailed summary of traditional timber moment-resisting connections that are available to designers. One of the most popular connections for portal frames consists of steel dowels driven through timber beams and columns in a circular configuration as seen in 2.4 a). High aesthetic quality and ease of construction make this an attractive option, however these connections generally cannot develop the full strength of the connecting members, and can often lead to splitting failure. Bouchair et al. (2007) experimented on reinforced and unreinforced connections with this configuration. The unreinforced connection exhibited brittle failure while the connection reinforced with glued-on wood side panels accommodated large plastic rotations with a capacity nearly twice that of the unreinforced alternative. The connections were designed according to European standards and Bouchair et al. (2007) presented design methods. 
Nailed moment connections generally connect beams to columns using steel or plywood side plates as shown in Figure $2.4 \mathrm{~b}$ ). Application is usually limited to deep slender sections, but tests show potential for good hysteretic behaviour (Buchanan and Fairweather, 1993). Riveted connections are very similar to nailed connections; often using steel side plates. Timber rivets tend to be stiffer than nails, and the oblong shape prevents damage to the wood fibres during installation. Popovski and Karacabeyli (2004) have shown that well-detailed riveted moment connections can fail in a ductile manner by means of rivet yielding, and can sustain large plastic deformations without abrupt failure.

Glued-in threaded steel rods have been gaining popularity since the early 1990's (Tlustochowicz et al., 2011). As the name implies, threaded rods are inserted into a hole in the timber section and held in place using high-strength epoxy. Figure $2.4 \mathrm{c}$ ) shows one of many possible configurations for glued-in rod moment connections. Use of this connection type requires high quality control and assembly is usually completed in a shop, prior to delivery on site. Benefits include good fire performance, high aesthetic quality, and limited induced splitting stresses. Tlustochowicz et al. (2011) presents design recommendations for glued-in rods.

Bolted connections with embedded steel plates similar to that shown in Figure $2.4 \mathrm{~d}$ ) are among the most common used in timber frames. They are typically designed to transfer shear forces due to gravity loading. Since the moment capacity is commonly overlooked by designers, in the event of a severe ground motion, unforeseen applied moments usually lead to abrupt splitting failure of the timber elements (Lam et al. 2010). Lam et al. (2010) showed that while standard bolted connections exhibit poor hysteretic behaviour, using self-tapping screws as reinforcement can increase capacity by over 70 percent, and delay brittle failure modes.

In order to develop enough moment capacity for use in multistorey structures, connections with many fasteners are necessary since there is often an inherent group effect associated with large connections. Jorissen (1999) studied the effects of the number of fasteners in a group using bolted wood-wood tension connections. It was determined that fastener spacing within a row had the most considerable effect; the most balanced distribution came when fastener spacing is at a maximum. Furthermore, Jorissen found that load distribution among fasteners was nearly uniform at the time of failure because deformations in the bolts carrying higher loads allowed 
for stress redistribution within the group. A design method was developed for determining the effect of the number of fasteners within a group (Jorissen, 1999). Zarnani and Quenneville (2014) experimented with timber rivets to develop a design approach for the group effect of fasteners based on the relative stiffness of each plane of resistance in the connection.

In order to overcome the limited ductility and rotation capacity exhibited by traditional timber moment-resisting connections, it is necessary to improve upon or develop new methods of forming rigid beam-column joints in timber frames. The traditional bolted moment-resisting timber connection tested by Lam et al. (2010) achieved a ductility of only 2.76 , significantly lower than that achievable by steel moment-resisting connections. Tests by Bouchair et al. (2007) on a typical dowel-type moment-resisting connections exhibited a ductility of only 2.1. Furthermore, both systems achieve little energy dissipation due to the early onset of brittle failure modes. In order to take advantage of the high strength to weight ratio of wood in lowering seismic design forces (relative to steel and concrete), steps must be taken to overcome the seismic deficiencies inherent of wood that limit the ductility and plastic rotation capacity. By integrating modern timber connection technology into hybrid timber-steel system, brittle wood failure modes can be avoided and overall seismic performance can be improved.

\subsection{Hybrid Moment-Resisting Connections}

To negate the inherent brittle nature of timber that hinders the seismic performance of moment-resisting connections, designers may choose to rely on specially detailed steel components to accommodate a majority of the plastic behaviour induced during severe ground motions. The National Building Code of Canada (NBCC, 2010) limits the ductility factor $\left(R_{d}\right)$ to 2.0 for timber moment frames due to the brittle nature of wood under some loading conditions, but steel MRFs classed as "Ductile Moment-Resisting Frames" are assigned a ductility factor of 5.0, greatly reducing seismic design forces imparted on the frame. By developing systems which are primarily wood-based with steel yielding components, designers can take advantage of the low weight of wood as well as the high ductility factor associated with steel MRFs to greatly lower the design base shear on the frame. This results in smaller structural elements and lower foundation

Ryan Gohlich, Department of Civil and Environmental Engineering, Carleton University 
forces and allows for cost savings that can potentially offset the higher cost of wood as compared to steel or concrete.

Research into hybrid timber-steel connections beyond that of typical dowel fasteners with steel plates is fairly limited; there is a need to develop a method of providing both high strength and high ductility by using steel yielding elements. Although most experimental research on hybrid timber-steel connections are done on small-scale specimens, findings of previous studies show good potential for improving the hysteretic behaviour of timber systems.

Andreolli et al. (2011) developed a hybrid connection using a steel section with welded on end-plates which were connected to timber elements by means of glued-in rods (shown in Figure 2.5). A model that can suitably predict the moment and rotation capacity, stiffness, and failure mode of the connection was also proposed. Unlike the nonlinear replaceable link, this connection was detailed such that ductility is achieved through yielding of the steel end-plate. Three possible failure modes were seen during experimental tests: end-plate yielding (ductile), failure of the glued-in rod (potentially brittle), and a combination of the two. Cyclic tests showed high rotation capacity (up to $0.1 \mathrm{rad}$ ) with moderate pinching behaviour. Although the strength of the joint was relatively low, it can be expected that tests at a larger scale can increase capacity without hindering the high ductility achieved by the connection (Andreolli et al. 2011).

Humbert et al. (2014) experimented on various configurations of timber column base connections using embedded steel knife plates that were bolted to the foundation and connected to the timber using steel dowels. This connection can be seen in Figure 2.6. Connections using

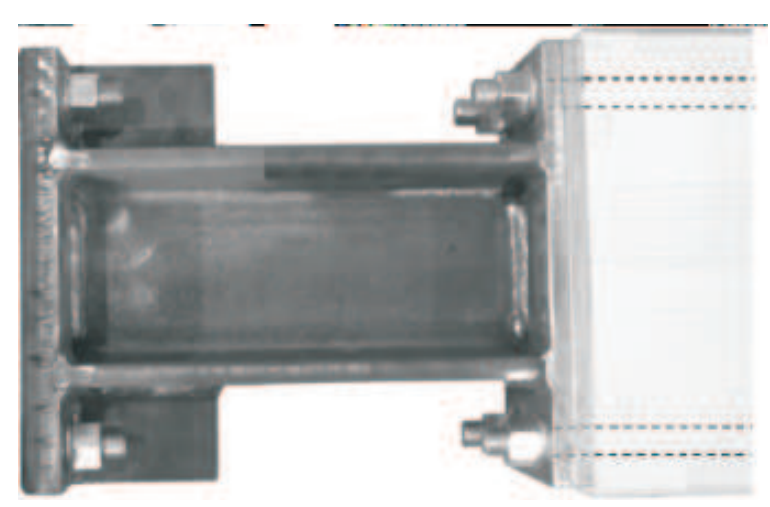

Figure 2.5: Hybrid Connection with Steel Link and Glued-in Rods (from Andreolli et al., 2011) 
tee-shaped knife plates showed high rotation capacity, but ductility was fairly low and energy dissipation was limited by pinching of the hysteresis cause by oversized gaps accommodating the knife plates. Increasing the thickness of the steel plate resulted in higher stiffness and moment capacity, but resulted in weld fracture and crack propagation in the wood from the knife plate gap. Use of a single I-shaped knife plate led to splitting at the dowel location and low capacity and stiffness (Humbert et al. 2014).

Komatsu et al. (2014) used shake table tests to determine the seismic performance of a newly developed moment connection (shown in Figure 2.7) under dynamic loading. The joint was formed using U-shaped brackets that were attached to the beam and column and bolted together using slotted steel plates. The brackets were attached to the timber elements using lagscrewbolts to transfer moment forces and typical lag screws to transfer shear forces. A lagscrewbolt is a threaded rod with a tapped hole in the end that is screwed into the timber, and connected to the steel bracket using high-strength bolts. Analysis of the nonlinear behaviour showed appreciable moment capacity with plastic rotations reaching up to 0.09 rad. Full hysteresis loops indicated potential for high energy dissipation, however since the energy dissipation capacity relied on friction developed at the slotted bolt holes, prolonged exposure to cyclic loading may hinder the overall energy dissipation. Furthermore, failure of the panel zone in longitudinal shear slightly degraded performance, and it is suggested that more research be conducted in this area (Komatsu et al. 2014). Similar research was presented using inclined lagscrewbolts in (Nakatani et al. 2012).

\subsection{Self-Tapping Screws}

Self-tapping screws (STS) are most commonly used as reinforcement to resist excessive tension perpendicular-to-grain stresses induced by dowel-type connections loaded in shear. In recent years, their potential for use as a primary load transferring mechanism has become apparent. Until recently, STS were mostly used in Europe, so limited research exists on STS in Canadian 


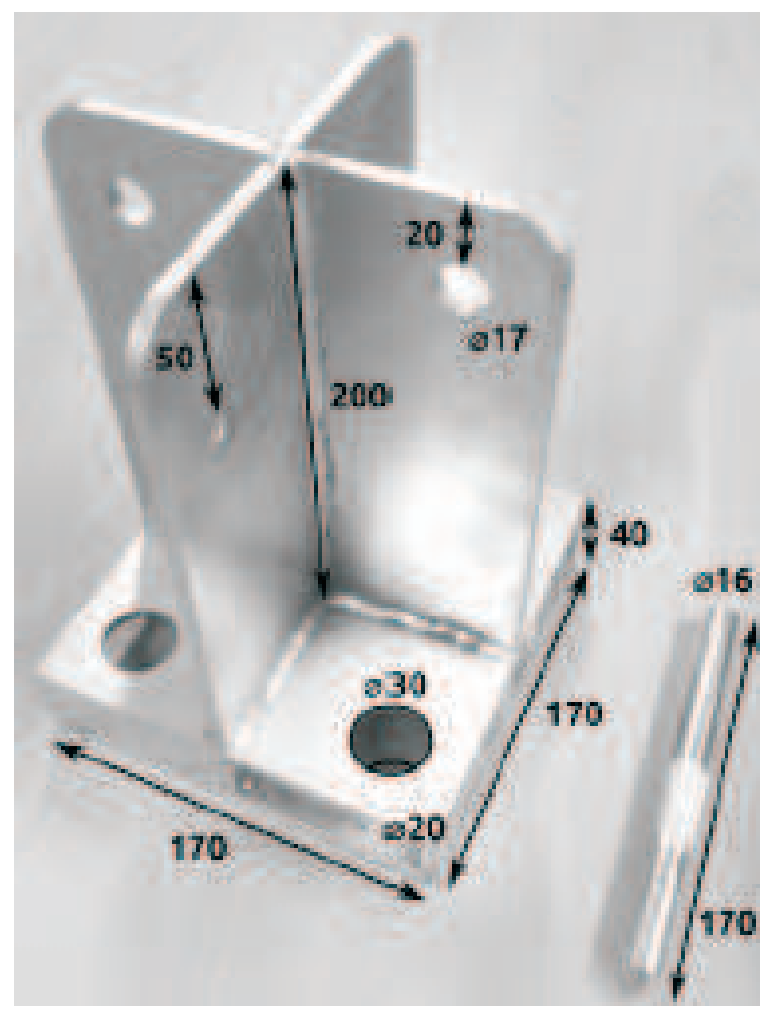

Figure 2.6: Hybrid Column Base Connection (from Humbert et al., 2014)

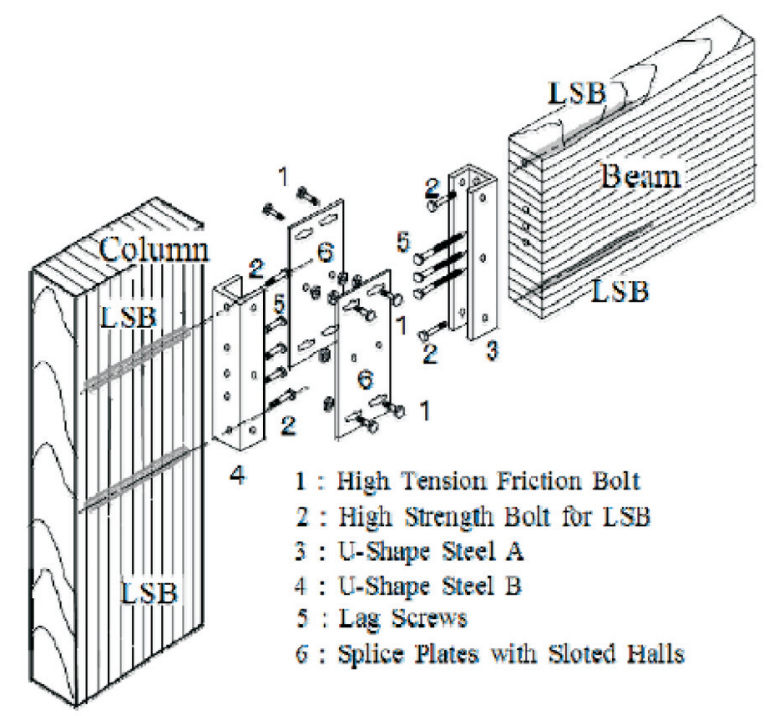

Figure 2.7: Hybrid Connection with Slotted Steel Plate (from Komatsu et al., 2014) 
timber species. Although a Canadian approved design method has recently been released $(\mathrm{Na}-$ tional Research Council of Canada, 2013), a full review of the literature for STS capacity and use will be presented in this section.

\subsubsection{Capacity}

Influential parameters on the capacity of screws loaded in withdrawal include penetration length, screw diameter, angle relative to the grain direction, wood density, and the characteristic withdrawal capacity (Gehloff, 2011). Characteristic withdrawal capacity refers to the capacity of a single screw based on test results. The most popular standards used in the design of STS are Eurocode5 (Ellingsbo and Malo, 2012) and the German wood building code (DIN 1052:2004-08). Eurocode5 gives the following design equation for a group of STS (Ellingsbo and Malo, 2012):

$$
F_{a x, \alpha, R k}=\frac{n_{e f} \cdot f_{a x, k} \cdot d \cdot l_{e f} \cdot k_{d}}{1.2 \cos (\alpha)^{2}+\sin (\alpha)^{2}}
$$

where the characteristic withdrawal capacity is:

$$
f_{a x, k}=0.52 d^{-0.5} \cdot l_{e f}^{-0.1} \cdot \rho_{k}^{0.8}
$$

and

$$
k_{d}=\min \left\{\frac{d}{8} ; 1.00\right\}
$$

where:

$n_{e f}$ is the effective number of fasteners in the connection

$d$ is the screw diameter

$l_{e f}$ is the effective embedment length of the STS

$\alpha$ is the angle of inclination of the STS

$\rho_{k}$ is the density of wood

Equation (2.4) shows the withdrawal capacity for STS groups as presented by the German standards (Gehloff, 2011): 


$$
R_{a x, K}=\min \left\{\frac{f_{1, K} \cdot d \cdot l_{e f}}{\sin ^{2} \alpha+\frac{4}{3} \cdot \operatorname{cose}^{2} \alpha} ; f_{2, K} \cdot d_{k}^{2}\right\}
$$

where the characteristic withdrawal capacity is:

$$
f_{1, K}=\phi \cdot 10^{-6} \rho_{k}^{2}
$$

and

$f_{2, K}$ is the characteristic strength for head pull-through

$d_{k}$ is the outer diameter of the screw head

Note that the definition of other variables in equation (2.4) and equation (2.5) are the same as defined for equations (2.1) through (2.3).

A recently released Canadian approval for the design of STS using SWG ASSY VG Plus and SWG ASSY 3.0 Self-Tapping Wood Screws (National Research Council of Canada, 2013) now allows designers to more accurately predict the capacity of connections made in Canadian wood species (SWG ASSY refers to the type of screw). The withdrawal capacity (per screw) of SWG ASSY screws installed at an angle to grain of $\alpha$ can be calculated as:

$$
P_{r w, \alpha}=\phi \frac{0.8 \cdot \delta(b \cdot 0.84 \cdot \rho)^{2} \cdot d \cdot l_{e f} \cdot 10^{-6}}{\sin ^{2} \alpha+\frac{4}{3} \cdot \cos ^{2} \alpha} \cdot K_{D} \cdot K_{S F}
$$

Where:

$\delta=82$ for a density greater than $440 \mathrm{~kg} / \mathrm{m}^{3}$ and 85 otherwise

$b=1$ for D-Fir-L., SPF, SYP, WRC, and Hem-Fir

$K_{D}$ is a factor associated with the duration of loading on a wood member

$K_{S F}$ is a factor associated with the serviceability conditions of a wood member

This capacity is limited by the tensile strength of the hardened steel screw; factored design values are presented in the evaluation report (National Research Council of Canada, 2013).

STS connections are typically configured such that fasteners are installed at an angle to the grain of usually 30 or 45 degrees. In most cases it has been found that installation angle has little effect on the characteristic withdrawal capacity of the fastener (Ringhofer and Schickhofer, 2014). 
Due to the high stiffness of STS loaded in withdrawal, it is assumed that inclined screws transfer all load in their longitudinal direction, allowing designers to ignore the weak shear capacity of the screws. Work done by Krenn and Schickhofer (2009) on inclined STS connections with steel connecting plates suggest that dowel behaviour (shear yielding of the screw and embedment failure of wood) may be neglected in the design since the shear plane of the connection experiences little deformation. Furthermore, in Kevarinmaki (2002) developed design equations for the application of inclined screws and established a method of determining the slip modulus of screwed connections. It was found that maximum connection capacity could be achieved with little slip at the shear interface, so connection strength does not have to account for dowel behaviour.

Bejtka and Blaß (2002) and Tomasi et al. (2010) also conducted experimental programs to investigate the behaviour of inclined STS loaded in combined axial and shear. Bejtka and Blaß extended Johansen's yield theory to account for withdrawal and bending of the dowel, embedment strength of the wood, and friction at the shear plane. It was found that the inclination of the STS could increase capacity by more than 50 percent relative to screws installed in the perpendicular-to-grain direction. Tomasi et al. (2010) found that both strength and stiffness of the connection increased as the angle of inclination decreased and no group effect was evident for inclined STS connections when fasteners were placed in a single row. The group effect for inclined STS connections is not accounted for in most design guidelines. The number of fasteners in a group effective at transferring load is commonly assumed to be $n^{0.9}$, but more research is required in this area (Mahlknecht et al. 2014).

\subsubsection{Connection Reinforcement}

As previously discussed, a significant challenge in timber connection design is high tension perpendicular-to-grain stresses induced by traditional dowel-type fasteners when loaded in shear. There are various connection reinforcement options available to solve this problem, which include glued-on wood-based side panels (Bouchair et al. 2007), punched steel side-plates (Blaß et al., n.d.), glued-in rods, or STS (Lam et al., 2010). Due to their ease of installation, STS have become a popular choice as connection reinforcement and can be used to transfer these stresses as an axial load in the screw to prevent brittle tension perpendicular-to-grain and longitudinal shear 
failure of the timber member.

$\mathrm{Blaß}$ and Bejtka (2004) suggest ignoring the tension perpendicular-to-grain strength of the wood material when designing reinforcing screws, and also found that if adequate reinforcement is provided, the load applied to the connection may be distributed evenly among all fasteners. Similar findings were presented by Blaß and Schadle (2011) when studying the ductility of reinforced dowel-type connections. Their tests showed that if the connection reinforcement is overdesigned, the connection may achieve a capacity higher than the design strength of the dowel-type connection. Lam et al. (2010) conducted tests on unreinforced, reinforced, and retrofitted bolted moment connections. It was found that unreinforced moment connections were susceptible to brittle failure at low strength demands. Damaged connections that were repaired using STS were able to achieve strength up to 85 percent greater than the original connection strength, and connections with reinforcement placed prior to failure achieve more than twice the capacity of the unreinforced connection.

Dietsch and Brandner (2015) performed a review of state-of-the-art timber fasteners and developed the following design recommendations for connections reinforced with STS:

- Distance between reinforcement and stress concentration should be kept to a minimum

- A net reduction in cross-section should be accounted for in strength calculations

- Resistance of timber to splitting should be ignored

- The thread of the reinforcing screw should cover at least 75 percent of member depth

It is suggested that following such recommendations will provide maximum connection strength and limit splitting of the timber element which will allow all fasteners to provide equal resistance to applied loads.

\subsubsection{Moment-Resisting Connections using Self-Tapping Screws}

Limited research exists on the application of STS as the primary load transfer mechanism. Through the application of inclined STS connections with steel outer plates, it becomes possible to negate the inherent qualities of timber that hinder the performance of dowel-type momentresisting connections, and develop high strength and even highly ductile connections. 
Krenn and Schickhofer (2009) studied the performance of STS connections using inclined screws and steel outer members (top and bottom plates). The research focused on the group effect of connections with multiple fasteners. Suggestions for fastener layout and connection detailing were presented. It was shown that the parameters most effecting group behaviour are withdrawal capacity, screw tensile capacity, and splitting capacity of the timber. They showed that the total number of screws has little impact on individual screw capacity, and the high stiffness of steel-timber connections with inclined screws negates any group effect on stiffness. Methods of accounting for the frictional resistance between the steel and timber face were also presented. To minimize the group effect, it was suggested that all screws be identical with the same installation angle, the threaded length of the screw should exceed sixteen screw diameters, and screw tips crossing in the middle of the timber member should overlap by four screw diameters to avoid premature splitting failure. When designing these connections, it is common practice to limit the number of screws per row to 15 and assume that $85-90 \%$ of fasteners are effective in transferring load (Krenn and Schickhofer, 2009). Results from this research show that connections can be conservatively designed by assuming that the effective number of fasteners is equal to $90 \%$ of the total number of fasteners.

Closen (2008) developed a moment connection that fastened a steel collar to a wood beam and column using STS and ZD-plates (see Figure 2.8). The seismic performance of multiple specimens was evaluated using reverse cyclic loading tests. Ringhofer and Schickhofer (2014) showed that withdrawal capacity is independent of the rate of loading on the fastener, so it can be expected that cyclic loading can accurately represent seismic behaviour without need of dynamic tests. The connection developed by Closen was designed to promote failure of the screw connection in order to allow designers to better predict the capacity of such connections, and design the steel yielding elements accordingly to increase ductility. The failure mode varied between connections, and included fracture of the tension screws followed by yielding of compression screws, bending and thread failure of the bolts connecting the steel to the ZD-plates, yielding of the steel collar plate, brittle tension perpendicular-to-grain and longitudinal shear failure of the timber panel zone. Overall, high capacity and stiffness was reached with high plastic rotations, however ductility was limited by brittle failure modes. The author recommends detailing the 
connection such that the steel collar plate forms a yielding mechanism to increase ductility and energy dissipation. 


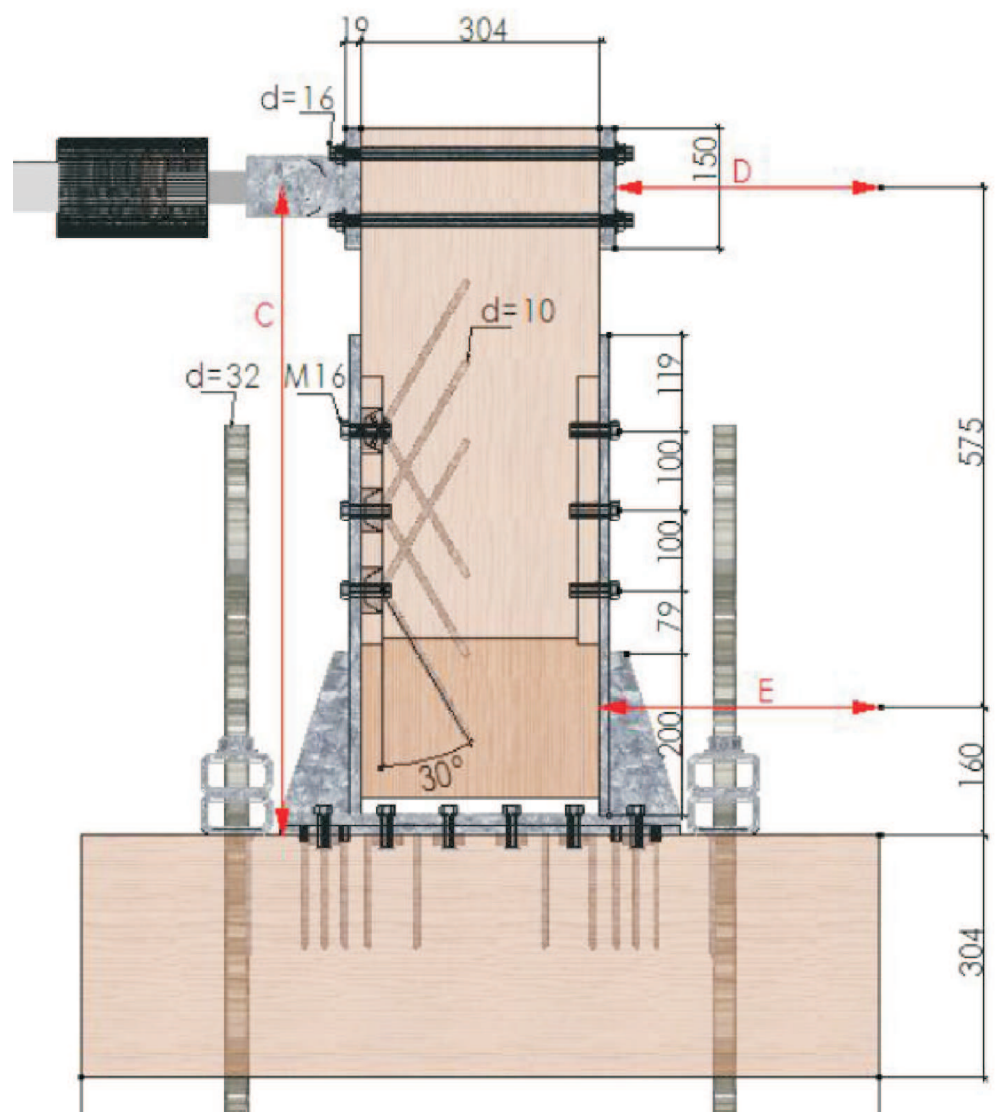

Figure 2.8: STS Mmoment-Resisting Connection with Steel Beam Collar (from Closen, 2008) 


\section{Chapter 3: Hybrid Connection Design}

As discussed in the previous chapter, current timber moment-resisting frames (MRFs) typically use dowel-type fasteners to form beam-column connections. Due to the inherent brittle nature of wood in the perpendicular-to-grain direction, these connections often have limited ductility and energy dissipation capacity. They may experience brittle failure in an earthquake which threatens life safety, and leads to difficult and costly repair of damaged members. Since the high ductility of well-designed steel MRFs result in high seismic performance, the shortcomings associated with timber may be overcome by incorporating steel yielding mechanisms into a predominantly timber frame. Previous research shows that self-tapping screws (STS) can perform well as the primary load transfer mechanism in steel-to-timber connections.

For this research, a hybrid timber-steel moment-resisting connection was developed that incorporated a ductile moment-yielding element to achieve the goals necessary for fulfillment of the research project. The primary goal was for all timber elements to remain elastic under severe seismic loading in order to avoid damage to brittle timber elements, which would jeopardize the seismic performance of the building. This also negated the need for complex modelling of orthotropic wood materials. The secondary task was to detail the connection such that the seismic fuse would be removable and replaceable; a detail not yet seen in a heavy timber context. An added benefit of the connection detailing is that it uses design procedures that are already familiar to engineers which increases the likelihood of adoption into the timber engineering market. Since the seismic behaviour of steel is well understood, the most significant research challenge was the development of a steel-to-timber connections that could withstand the applied seismic loading without undergoing plastic deformation that would hinder seismic performance. 


\subsection{Preliminary Design}

Many different connection configurations were considered to transfer the high bending moments from the steel yielding hinge to the timber elements. The primary considerations for selecting an appropriate connection type were the ability to adequately transfer the capacity-design forces, overall connection size (for aesthetic purposes), and ease of fabrication. The connection types that were considered included bolts, steel dowels, lag screws, nails, rivets, self-tapping screws, and glued in rods (GI rods).

The design using a bolted connection would rely on multiple rows of large bolts attached to the steel collar using side plates. This connection would require a large reduction in cross section to accommodate the high number of bolts necessary to transfer the capacity-design forces, and consequently, larger timber sections would be necessary. The second design consisted of steel knife plates fastened to the timber members using a circular configuration of steel dowels. The details of this connection would make fabrication difficult. Furthermore, large wood members would be necessary to accommodate the circular dowel configuration, and a triple knife plate would be required to transfer the high bending moments applied to the dowels. The connection using lag screws with top and bottom plates would require many large fasteners to transfer the necessary design forces, resulting in a comparatively long connection and high reduction in net cross-section. The nailed connection type had inadequate strength to transfer the necessary design forces efficiently. Glulam rivets could potentially develop the required capacity when using a combination of top/bottom and side plates, however many fasteners would be necessary, and the fastener groups would be difficult to assemble. The STS connection would use top and bottom plates with inclined screws to fasten the steel collar to the timber member. This connection would require many fasteners, however installation would be fairly simple, and connection size could be kept small compared to other alternatives. Finally, the alternative using GI rods would require deep wood members to accommodate enough rods to transfer the design moments.

Table 3.1 shows a comparison of the total percentage of beam moment capacity that is utilized by each connection type. Since it is necessary to increase the size of the wood beam to 
accommodate spacing requirements for some fastener types (dowels and GI rods), such connections are less efficient due to the high overcapacity of the beam member. The moment resistance of the connections given in Table 3.1 is based on the preliminary seismic analysis of a six-storey wood building, and was required to exceed the target applied moment of $350 \mathrm{kN} \cdot \mathrm{m}$ (capacitydesign force on the steel-timber connection). The total beam moment resistance utilized by connection types that could develop the necessary design moment without increase in beam size were similar. The doweled and GI rod connections required significant increase in beam size to accommodate design moments. It should be noted that connection efficiency of the bolted, lag screw, riveted, and STS connections could have been increased by using longer connections. The size of these connection types does not influence the required beam member size. The nailed connection was excluded from this comparison since the connection size required to develop the design moment was significantly greater than all other alternatives.

Table 3.1 also summarizes the total connection length for each alternative. The STS connection required the shortest connection of all efficient alternatives (bolt, lag screw, rivet, and STS). The STS connection was chosen as the superior alternative based on strength, efficiency, connection length, aesthetic quality, and ease of fabrication.

Table 3.1: Utilization of Beam Moment Capacity

\begin{tabular}{c|cccc}
\hline Connection Type & $M_{r, \text { beam }}(\mathrm{kN} \cdot \mathrm{m})$ & $M_{r, \text { conn }}(\mathrm{kN} \cdot \mathrm{m})$ & Utilization & Length $(\mathrm{mm})$ \\
\hline Bolt & 450 & 380 & $85 \%$ & 610 \\
Dowel & 569 & 371 & $65 \%$ & 570 \\
Lag Screw & 450 & 366 & $81 \%$ & 810 \\
Rivet & 450 & 353 & $78 \%$ & 830 \\
STS & 450 & 364 & $81 \%$ & 525 \\
GI Rod & 775 & 420 & $54 \%$ & 450 \\
\hline
\end{tabular}




\subsection{Connection Design}

\subsubsection{Methodology}

A conceptual beam-column connection was developed and designed using existing applicable Canadian design standards. A preliminary structural design and analysis of a full-scale three-dimensional six-storey building was completed to estimate the maximum force applied at a beam-column interface of the moment-resisting frame (MRF) and adequately design and build prototype test specimens. The building was designed to be located in Victoria, B.C., with a fourbay braced frame in the North-South direction (total length of $26 \mathrm{~m}$, and a seven-bay MRF in the East-West direction (total length of $45.5 \mathrm{~m}$ ). The development and design of the prototype structure was completed in collaboration with another graduate student, and the details on the seismic design can be found in Appendix B. The applicable standards used in the design and analysis of the prototype building and connection include:

- National Building Code of Canada (NBCC, 2010)

- Limit States Design of Steel Structures (CSA S16-09, 2010)

- Engineering Design in Wood (CSA O86, 2010)

- Moment Connections for Seismic Applications (CISC, 2008)

- Canadian approval for the design of STS using SWG ASSY VG Plus and SWG ASSY 3.0 Self-Tapping Wood Screws (National Research Council of Canada, 2013)

- European Technical Approval for ZD-plates (ETA-11/0470, 2012)

A layout of the MRF was developed and an equivalent static seismic analysis was carried out to determine the initial member sizes for the MRF. Gravity analysis was completed to design the gravity frame and adequately estimate the seismic weight of the building. Details of the resulting prototype structure can be found in Chapter 6 and Appendix B. Once preliminary member sizes were determined, response spectrum analysis of the complete three-dimensional structure was performed and the design was iteratively updated based on strength and drift criteria (NBCC, 2010) until appropriate design forces at the beam-column interface were obtained. It should be noted that for the preliminary design, each beam-column joint was considered to be entirely 
made of timber. The nonlinear replaceable links were included in the final prototype building design and in a more comprehensive nonlinear time-history analysis model that will be discussed in Chapter 6.

The analysis of the prototype building design yielded a target moment capacity of 234 $\mathrm{kN} \cdot \mathrm{m}$ at the lower storey exterior beam-column connection. Since the steel-to-timber connection was designed based on capacity-design forces (according to the probable moment capacity of the link), the design moment for the connection was taken as $350 \mathrm{kN} \cdot \mathrm{m}$. Using this value, analysis and design of the prototype test setup was completed. To ensure that the developed connection could be adopted into buildings of at least six storeys, the connection was designed to withstand the moment applied to an exterior beam-column connection at the first floor level.

The test configuration was designed to represent the boundary conditions of a second storey joint (with two columns of equal length); this reduced the length of the lower column in the experimental assembly, subsequently reducing cost and space requirements without negatively impacting test results. It was assumed that points of inflection were located at the midspan of the beam and the centre of the upper and lower columns, which allowed for only half of the column to be tested. The point of inflection at the centre-height of each column was simulated using a pinned connection.

The developed hybrid moment-resisting connection consists of the following components, as shown in Figure 3.1:

- Nonlinear Replaceable Link

- Bolted End-Plate Connection

- Steel Collar

- Steel Panel Zone

- Glulam Beam

- Glulam Columns

- Primary STS Connection

- ZD-Plate Connection

- Reinforcing Screws

Ryan Gohlich, Department of Civil and Environmental Engineering, Carleton University 


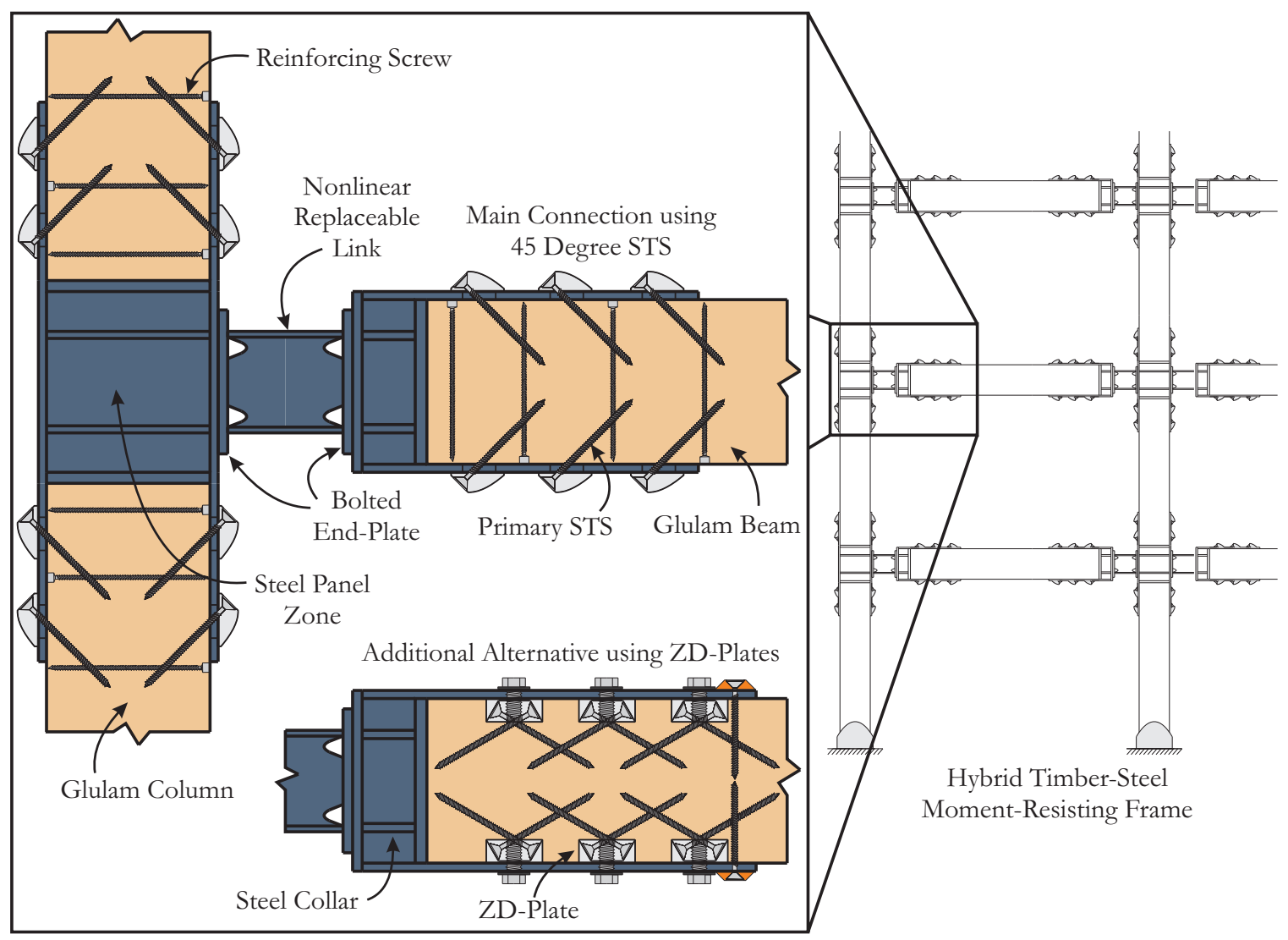

Figure 3.1: Connection Component Summary 
Table 3.2 shows the design force for each connection component. It should be noted that the yielding hinge forces presented in this table are the actual forces determined based on the design forces from the prototype building model (based on a response spectrum analysis and loads from the NBCC (2010)). The forces applied to all other components in Table 3.2 were calculated using the capacity-design principle based on the probable moment capacity of the yielding hinge $(350 \mathrm{kN} \cdot \mathrm{m})$, which corresponds to a factored moment capacity of $251 \mathrm{kN} \cdot \mathrm{m}$. The probable moment capacity was calculated based on the nominal moment capacity, amplified to account for the strain hardening of steel and the estimated overcapacity (see equation (3.2)). The capacity design force of the timber beam was conservatively taken as the probable moment capacity of the link, and the capacity design force of the timber columns was taken as half of the moment at the column centreline upon yielding of the plastic hinge. The capacity design forces assigned to the STS connections was the same as that of the adjacent timber members. The panel zone shear force presented in Table 3.2 was taken as the moment at the column face divided by effective moment-arm for bolted end-plate connections. This will be further explained in future sections of this chapter.

Four steel assemblies were designed and fabricated to form the high-strength, ductile beam column interface. These included the steel panel zone, two variations of nonlinear replaceable link (one incorporating a dogbone detail, regarded as the RBS link, and the other regarded as the regular link, with no dogbone detail), and a steel beam collar. These assemblies are depicted in Figure 3.2. The steel assemblies were detailed to be connected to timber elements using STS. A

Table 3.2: Full Scale Capacity-Design Forces

\begin{tabular}{c|ccc}
\hline Component & Moment $(\mathrm{kN} \cdot \mathrm{m})$ & Shear $(\mathrm{kN})$ & Axial $(\mathrm{kN})$ \\
\hline Yielding Hinge & 234 & 135 & 0 \\
Panel Zone & 437 & 1113 & 69 \\
Steel Beam Collar & 288 & 135 & 0 \\
Timber Beam/STS Connection & 270 & 135 & 0 \\
Timber Columns/STS Connection & 219 & 127 & 69 \\
\hline
\end{tabular}

Ryan Gohlich, Department of Civil and Environmental Engineering, Carleton University 
a)

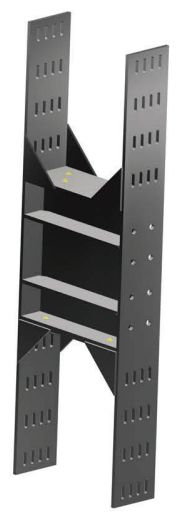

b)

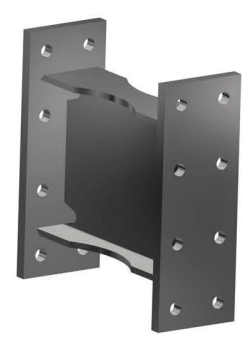

c)

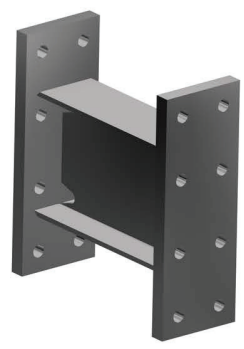

d)

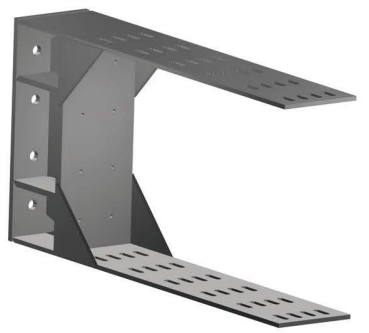

Figure 3.2: Custom Steel Assemblies a) Steel Panel Zone

b) NRL with Dogbone c) Regular NRL

d) Steel Beam Collar

three-dimensional graphical representation of the full connection is shown in Figure 3.3.

Independent design of each connection component was completed following the capacitydesign procedure, detailed such that all plastic behaviour was concentrated in the nonlinear replaceable link. All other components were capacity-designed to remain elastic under the loads associated with yielding of the link. The bolted end-plate connection fastening the link to the beam collar and column face was designed to remain elastic, but some damage is allowable since these components will be replaced along with the link. The primary STS connections and the ZD-plate connections were also designed such that no damage or significant deformations would occur at the steel-to-timber interface.

\subsubsection{Scaling}

In order to limit space requirements for testing and reduce the cost of specimen fabrication, laboratory tests were performed on specimens that were two-thirds the size of the full-scale connection design. All length measurements were scaled by a factor of $2 / 3$. The corresponding scaling factors for all other quantities can be seen in Table 3.3. The scaling factor for the elastic modulus was taken as unity since this property is independant of the member dimensions.

Due to the high cost of custom timber element fabrication and the limited availability of standard sizes, not all target scaled dimensions could be obtained. Table 3.4 presents the full-scale, 


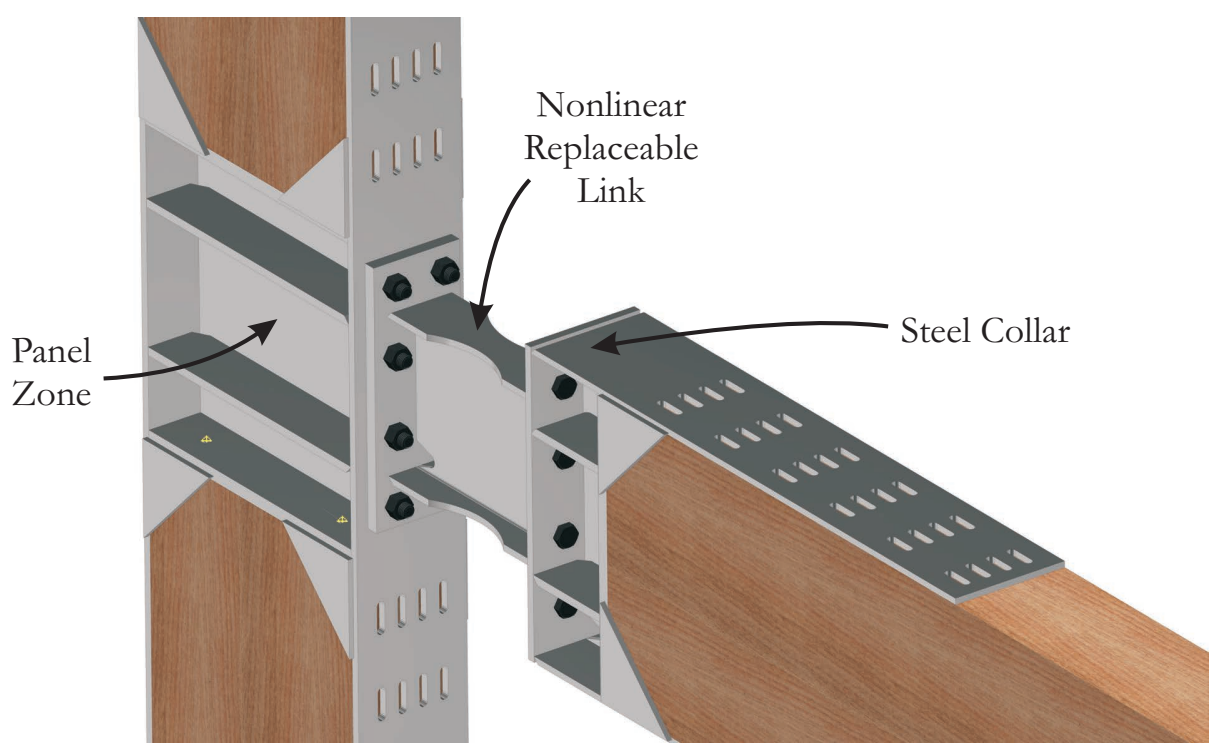

Figure 3.3: 3D Connection Overview

Table 3.3: Scaling Factors for Connection Components

\begin{tabular}{c|cc}
\hline Quantity & Description & Scaling Factor \\
\hline Length & $S_{L}$ & 0.6667 \\
Elastic Modulus & $S_{E}$ & 1.0000 \\
Force & $S_{F}=S_{E} S_{L}^{2}$ & 0.4444 \\
Moment & $S_{M}=S_{F} S_{L}$ & 0.2963 \\
Area & $S_{A}=S_{L}^{2}$ & 0.4444 \\
Section Modulus & $S_{Z}=S_{L}^{3}$ & 0.2963 \\
Moment of Inertia & $S_{I}=S_{L}^{4}$ & 0.1975 \\
\hline
\end{tabular}


target, and final scaled dimensions for the MRF and the timber elements. The error between the target and actual properties (based on available member size) in also shown in Table 3.4. Sizes were chosen such that the error was reduced. The primary exception to this is the upper column, which had a significantly higher moment of inertia than suggested by the target value. Since the size of the beams and columns were similar in the prototype building design, all timber elements were chosen to be identically sized for ease of fabrication.

Similarly, Table 3.5 shows the properties of the full and two-thirds scale nonlinear replaceable link elements, and the error between target and actual properties. It was decided to also examine the behaviour of links without radial flange cuts. Due to the limited availability of small-sized steel w-sections, it was difficult to obtain a section that adequately met all scaling goals. A W200 x 22 was selected for the link that did not have radial flange cuts. This section has a moment of inertia approximately $17 \%$ below that of the target value. Stiffness of this section is lower than desired, but this problem would likely be solved when using full-scale connections with more available size options. The most significant implication of the lower elastic stiffness for the regular link is the effect of connection ductility. The lower stiffness increased the yield rotation which reduced the ductility achieved by the regular link specimens. When selecting an appropriate scaled w-section, focus was placed on the plastic modulus in order to ensure that the scaled design moment could be reached but not significantly exceeded.

Table 3.6 shows the design forces used for the final two-thirds scale test subassemblage. The design forces for the nonlinear replaceable link are the forces required to yield the link. In order to capture the plastic behaviour of the link, a moment of $101 \mathrm{kN} \cdot \mathrm{m}$ was applied during testing to reach the probable moment capacity of the link; the forces applied to the remaining components shown in Table 3.6 are the capacity-design forces present upon yielding of the nonlinear replaceable link. It should also be noted that the panel zone forces presented in Table 3.6 are based on the regular link with no radial flange cuts since the reduced depth of this link section resulted in higher panel zone shear forces than the link with the dogbone detail.

Ryan Gohlich, Department of Civil and Environmental Engineering, Carleton University 
Table 3.4: Scaled Geometric Properties of Timber Elements

\begin{tabular}{c|cccc}
\hline Property & Full Scale & Goal & Scaled & Error \\
\hline Bay Span $(\mathrm{mm})$ & 6500 & 4333 & 4333 & N/A \\
Storey Height $(\mathrm{mm})$ & 3700 & 2467 & 2467 & N/A \\
\hline$b_{\text {beam }}(\mathrm{mm})$ & 265 & 177 & 184 & $4.0 \%$ \\
$d_{\text {beam }}(\mathrm{mm})$ & 608 & 405 & 457 & $12.8 \%$ \\
$I_{\text {beam }}\left(\mathrm{mm}^{4}\right)$ & $4.96 \times 10^{9}$ & $0.98 \times 10^{9}$ & $1.46 \times 10^{9}$ & $49.0 \%$ \\
\hline$b_{\text {uppercolumn }}(\mathrm{mm})$ & 265 & 177 & 184 & $4.0 \%$ \\
$d_{\text {uppercolumn }}(\mathrm{mm})$ & 532 & 355 & 457 & $28.7 \%$ \\
$I_{\text {uppercolumn }}(\mathrm{mm})$ & $3.32 \times 10^{9}$ & $0.66 \times 10^{9}$ & $1.46 \times 10^{9}$ & $121.2 \%$ \\
\hline$b_{\text {lowercolumn }}(\mathrm{mm})$ & 265 & 177 & 184 & $4.0 \%$ \\
$d_{\text {lowercolumn }}\left(\mathrm{mm}^{4}\right)$ & 646 & 431 & 457 & $6.0 \%$ \\
$I_{\text {lowercolumn }}\left(\mathrm{mm}^{4}\right)$ & $5.95 \times 10^{9}$ & $1.18 \times 10^{9}$ & $1.46 \times 10^{9}$ & $23.7 \%$ \\
\hline
\end{tabular}

\subsubsection{Material Properties}

All steel and timber used for the test specimens were fabricated from standard Canadian material grades or equivalent. The STS screws and components were imported from Germany due to the absence of Canadian fabricators. All nonlinear replaceable links used steel rolled wsections of grade CSA G40.21 - 350W with a nominal yield strength of $F_{y}=350 \mathrm{MPa}$ and an ultimate strength of $F_{u}=450 \mathrm{MPa}$. All other steel components including the end-plates, panel zone, steel collar, stiffeners, and top/bottom plates for the STS connection used steel of grade CSA G40.21 - 300W or equivalent with a yield strength of $F_{y}=300 \mathrm{MPa}$ and an ultimate strength of $F_{u}=450 \mathrm{MPa}$. Coupon tests were not performed on the steel connection components.

The glulam sections used for the beams and columns in the experimental program were provided by Nordic Engineered Wood and used 24F-ES/NPG grade lumber specific to Nordic wood products, so mechanical properties differed slightly from what is found in CSA-086-09. The mechanical properties of this grade (provided by the manufacturer) can be seen in Table 3.7 (Nordic Engineered Wood, 2013).

The self-tapping screws were fabricated in Germany, but the design was completed using 
Table 3.5: Scaled Geometric Properties of Nonlinear Replaceable Links

\begin{tabular}{c|cccc}
\hline Property & Full Scale & Goal & Scaled & Error \\
\hline WITH DOGBONE DETAIL & & \\
Section & W $360 \times 72$ & N/A & W $250 \times 28$ & N/A \\
$d(\mathrm{~mm})$ & 350 & 233 & 260 & $11.6 \%$ \\
$b(\mathrm{~mm})$ & 204 & 136 & 102 & $25.0 \%$ \\
$t_{f}(\mathrm{~mm})$ & 15.1 & 10.1 & 10.0 & $1.0 \%$ \\
$w(\mathrm{~mm})$ & 8.6 & 5.7 & 6.4 & $12.3 \%$ \\
$A\left(\mathrm{~mm}^{2}\right)$ & 9100 & 4044 & 3630 & $10.2 \%$ \\
$Z_{e}\left(\mathrm{~mm}^{3}\right)$ & $1.28 \times 10^{6}$ & $0.379 \times 10^{6}$ & $0.353 \times 10^{6}$ & $6.9 \%$ \\
$I\left(\mathrm{~mm}^{4}\right)$ & $201 \times 10^{6}$ & $39.7 \times 10^{6}$ & $40.0 \times 10^{6}$ & $0.8 \%$ \\
\hline \hline
\end{tabular}

\begin{tabular}{c|cccc}
\multicolumn{5}{l}{ WITHOUT DOGBONE DETAIL } \\
Section & W $360 \times 45$ & N/A & W200 $\times 22$ & N/A \\
$d(\mathrm{~mm})$ & 352 & 235 & 206 & $12.3 \%$ \\
$b(\mathrm{~mm})$ & 171 & 114 & 102 & $10.5 \%$ \\
$t_{f}(\mathrm{~mm})$ & 9.8 & 6.5 & 8.0 & $23.1 \%$ \\
$w(\mathrm{~mm})$ & 6.9 & 4.6 & 6.2 & $34.8 \%$ \\
$A\left(\mathrm{~mm}^{2}\right)$ & 5730 & 2547 & 2860 & $12.3 \%$ \\
$Z_{e}\left(\mathrm{~mm}^{3}\right)$ & $0.779 \times 10^{6}$ & $0.231 \times 10^{6}$ & $0.222 \times 10^{6}$ & $3.9 \%$ \\
$I\left(\mathrm{~mm}^{4}\right)$ & $122 \times 10^{6}$ & $24.1 \times 10^{6}$ & $20.0 \times 10^{6}$ & $17.0 \%$ \\
\hline
\end{tabular}

Table 3.6: Scaled Capacity-Design Forces in Test Subassemblage

\begin{tabular}{c|ccc}
\hline Component & Moment $(\mathrm{kN} \cdot \mathrm{m})$ & Shear $(\mathrm{kN})$ & Axial $(\mathrm{kN})$ \\
\hline Nonlinear Replaceable Link & 70 & 55 & 0 \\
Steel Panel Zone & 120 & 455 & 28 \\
Steel Beam Collar & 101 & 55 & 0 \\
Timber Beam/STS Connection & 101 & 55 & 0 \\
Timber Columns/STS Connection & 60 & 52 & 29 \\
\hline
\end{tabular}


Table 3.7: Mechanical Properties of Timber Elements

\begin{tabular}{c|c}
\hline Specified Strength & 24F-ES/NPG $(\mathrm{MPa})$ \\
\hline$f_{b+}$ & 30.7 \\
$f_{b-}$ & 30.7 \\
$f_{v}$ & 2.2 \\
$f_{c p}$ & 7.5 \\
$f_{c}$ & 33.0 \\
$f_{t}$ & 20.4 \\
$E$ & 12400 \\
\hline Mean Relative Density & 0.47 \\
Density & $560 \mathrm{~kg} / \mathrm{m}^{3}$ \\
\hline
\end{tabular}

mechanical properties specified in the Canadian Approval for SWG ASSY VG Plus and SWG ASSY 3.0 Self Tapping Wood Screws (National Research Council of Canada, 2013). The mechanical properties of the fully threaded STS are presented in Table 3.8. The nominal screw strength per millimeter of embedment can be found in the STS selection tables specified in the document (National Research Council of Canada, 2013).

\subsubsection{Nonlinear Replaceable Link}

\subsubsection{W-section}

As stated previously, each steel w-section acting as the nonlinear replaceable link was designed to withstand the scaled moment demand at the beam-column interface of the selected joint location on the prototype structure (see Table 3.6). This section presents the general procedure

Table 3.8: Mechanical Properties of Self-Tapping Screws

\begin{tabular}{c|ccc}
\hline Screw Diameter & $\begin{array}{c}\text { Bending } \\
\text { Strength }(\mathrm{MPa})\end{array}$ & $\begin{array}{c}\text { Tensile Strength } \\
(\mathrm{MPa})\end{array}$ & $\begin{array}{c}\text { Shear Strength } \\
(\mathrm{MPa})\end{array}$ \\
\hline 8 & 1015 & 18.9 & 641 \\
10 & 942 & 24 & 691 \\
12 & 1147 & 30 & 536 \\
\hline
\end{tabular}

Ryan Gohlich, Department of Civil and Environmental Engineering, Carleton University 
used to design a regular nonlinear replaceable link, as well as a nonlinear replaceable link with a reduced beam section (RBS) detail. These specimens were designed in accordance with the Moment Connection for Seismic Applications guideline (CISC, 2008).

The regular nonlinear replaceable link used an unaltered w-section sized to withstand a moment at its centre of $M f$, hinge $=70 \mathrm{kN} \cdot \mathrm{m}$. The link was sized using clause 13.5 from Limit States Design of Steel Structures (CSA S16-09, 2010) where the full plastic factored moment capacity is:

$$
M_{r}=\phi \cdot F_{y} \cdot Z_{x}
$$

To ensure that all other components remained elastic, they were designed to withstand forces exceeding the probable peak plastic moment capacity at the location of the plastic hinge (centre of the link). This value was estimated using equation (3.2) from the Moment Connections for Seismic Applications guideline (CISC, 2008), and accounts for strain hardening, local restraint, and additional reinforcements.

$$
M_{p r}=C_{p r} \cdot R_{y} \cdot F_{y} \cdot Z_{e}
$$

where:

$$
C_{p r}=\frac{F_{y}+F_{u}}{2 F_{y}}=1.15
$$

and

$R_{y}=1.1$

$R_{y} \cdot F_{y}$ is the expected yield stress of the section

$Z_{e}$ is the effective plastic modulus at the reduced section of the dogbone detail

It should be noted that for the link with no dogbone detail, $Z_{e}$ should be taken as $Z_{x}$ (the plastic modulus of the gross cross-section).

The link geometry was determined using suggestions presented in section 6 of the Moment Connections for Seismic Applications guidelines (CISC, 2008). This section recommends a range 
for both the location and length of the plastic hinge, shown in equation (3.4) and (3.5).

$$
\begin{aligned}
& 0.5 b \leq a \leq 0.75 b \\
& 0.65 d \leq s \leq 0.85 d
\end{aligned}
$$

where $a$ is the distance from the column face to the beginning of the dogbone detail, and $s$ is the length of the dogbone cutout. For this connection, $b$ was taken as the width of the timber beam, and $d$ was taken as the depth of the steel link. The total length of the w-section was then designed to be $2 a+s$. It should be noted that the length of the link with no dogbone detail can be taken as $s$ (excluding the length $a$ on each end), however to make the connections more interchangeable for testing, then same method was used to determine the length of both links. The lower limit for the hinge location (a) is to ensure that tensile stresses in the link flange are uniform at the column face, and the upper limit restricts the increase in moment between the plastic hinge location and the column face. The lower limit for the length of the reduced portion of the link $(s)$ is to reduce inelastic strain in the link while the upper limit minimizes loss in stiffness due to the presence of the link (Shen, 2009).

Sofias et al. (2004) showed that RBS connections can be used in combination with bolted end-plate connections to protect the end-plates, bolts, welds, and column flanges, by promoting failure at the RBS location. To examine this, links were also designed using heavier w-sections with RBS details to keep the effective plastic modulus of the link equal to that of the regular link. The procedure for selecting an appropriate section is the same as that stated above, with the addition of radial flange cuts. The amount of material removed from the flange is estimated using equation (3.6) (CISC, 2008).

$$
0.2 b \leq c \leq 0.25 b
$$

where $c$ is the depth of radial flange cut, and $b$ is the with of the flange. Not more than $50 \%$ of the beam flange may be removed. Figure 3.4 shows the details of a nonlinear replaceable link 
with radial flange cuts.

The effective plastic modulus of the net cross section of the link can then be calculated according to equation (3.7) (CISC, 2008). Tables 3.9 and 3.10 summarize the design details for each of the two links used.

$$
Z_{e, R B S}=Z_{\text {gross }}-\left(2 c \cdot t_{\text {flange }} \cdot\left(d_{\text {link }}-t_{\text {flange }}\right)\right)
$$

The designer must also ensure that the shear strength demand at the column face during plastic hinging of the link does not exceed the factored shear resistance of the link. Since it is assumed that the web accommodates all shear force, the RBS detail has no effect on shear strength. The shear force applied to the section during plastic hinging must account for the probable moment capacity of the link plus the contribution from any loads applied to the beam, including self-weight. For this connection, only the point load at the end of the cantilevered beam contributed to shear stresses. When the connection was applied to the prototype building subjected to lateral loading, the shear force applied at the connection was lower than that applied during testing. Further details of the loads applied during testing can be found in Chapter 4.

\subsubsection{Bolted End-plate}

In order to transfer the load from the beam to the link and the link to the column face, extended bolted end-plate connections were used at each end of the w-section. Although the depth of w-section varied between the two link types, identical end-plate bolt patterns were used to make the links easily interchangeable with the column panel zone. The end-plate at either end

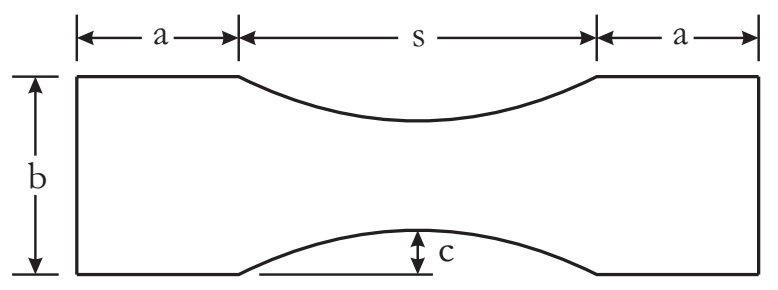

Figure 3.4: Reduced Beam Section Details

Ryan Gohlich, Department of Civil and Environmental Engineering, Carleton University 
Table 3.9: Link Design Details

\begin{tabular}{c|cccccccc}
\hline $\begin{array}{c}\text { Link } \\
\text { Type }\end{array}$ & Section & $\begin{array}{c}d \\
(\mathrm{~mm})\end{array}$ & $\begin{array}{c}b \\
(\mathrm{~mm})\end{array}$ & $\begin{array}{c}t_{f} \\
(\mathrm{~mm})\end{array}$ & $\begin{array}{c}w \\
(\mathrm{~mm})\end{array}$ & $\begin{array}{c}Z_{e} \\
\left(\mathrm{~mm}^{3}\right)\end{array}$ & $\begin{array}{c}M_{f} \\
(\mathrm{kN} \cdot \mathrm{m})\end{array}$ & $\begin{array}{c}M_{p r} \\
(\mathrm{kN} \cdot \mathrm{m})\end{array}$ \\
\hline $\begin{array}{c}\text { Regular } \\
\text { Link }\end{array}$ & W200 $\times 22$ & 206 & 102 & 8.0 & 6.2 & $222 \times 10^{3}$ & 70.0 & 98.3 \\
$\begin{array}{c}\text { Link } \\
\text { with RBS }\end{array}$ & W250 28 & 260 & 102 & 10.0 & 6.4 & $228 \times 10^{3}$ & 70.0 & 101 \\
\hline
\end{tabular}

Table 3.10: RBS Details

\begin{tabular}{c|ccc}
\hline Link Type & $a(\mathrm{~mm})$ & $s(\mathrm{~mm})$ & $c(\mathrm{~mm})$ \\
\hline Regular Link & 90 & 140 & N/A \\
Link with RBS & 90 & 170 & 25 \\
\hline
\end{tabular}

of the link was also identical and designed to accommodate the shear and moment demands at the column face, as seen in Figure 3.5. The moment demand at the column face was taken as follows:

$$
M_{c f}=M_{p r}+V_{h}(a+s / 2)
$$

where $V_{h}$ is the shear force in the link upon plastic hinging.

The extended bolted end-plate connections were designed according to the Moment Connections for Seismic Applications guidelines (CISC, 2008). Of the available prequalified connections, it was decided to use an unstiffened end-plate with a four-bolt configuration as shown in Figure 3.6. Determining the bolt configuration is an iterative process; design details for each end-plate are presented in Table 3.11.

Once the bolt configuration was determined, the size of bolt and end-plate thickness could be calculated. The bolt size was selected based on bolt tension and shear criteria, as specified in the Moment Connections for Seismic Applications guidelines (CISC, 2008). The design criteria for bolt tension and shear are shown in equation (3.9) and (3.10) respectively (both equations were taken from the Moment Connections for Seismic Applications guidelines (CISC, 2008). 


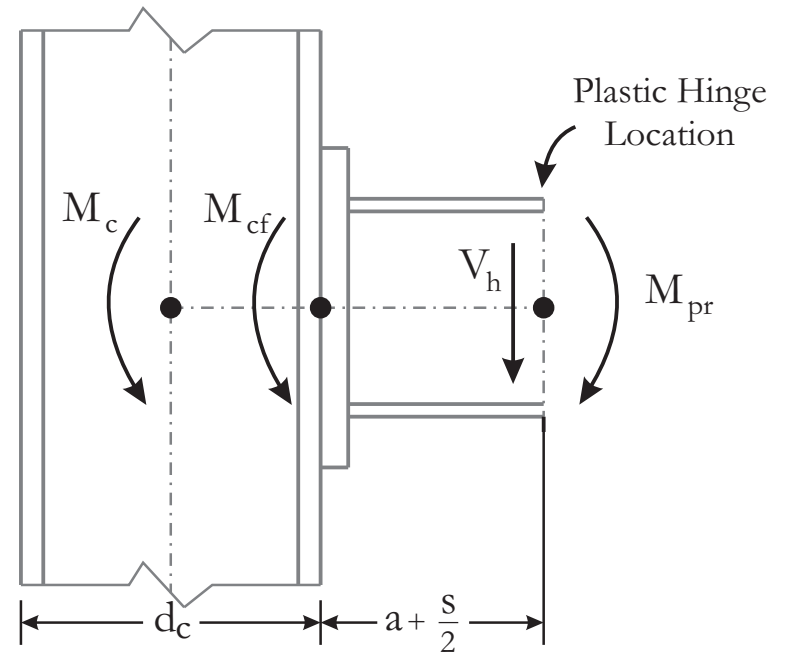

Figure 3.5: Strength Demand at Column Face and Centre

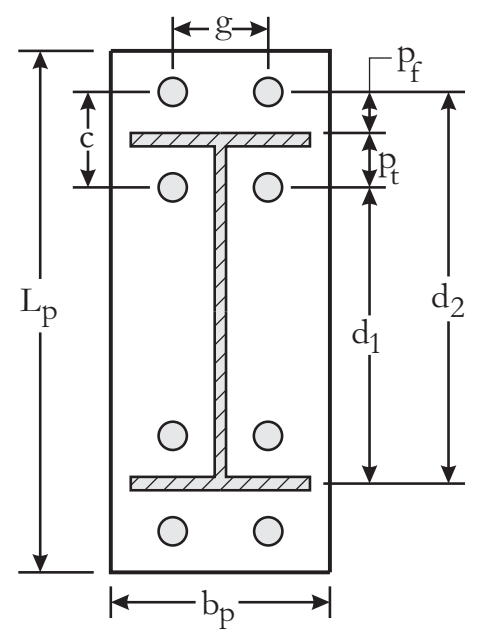

Figure 3.6: Bolted Unstiffened End-Plate Details 
Table 3.11: End-Plate Details

\begin{tabular}{|c|c|c|}
\hline Design Property & Regular Link & Link with RBS \\
\hline$M_{c f}(\mathrm{kN} \cdot \mathrm{m})$ & 108 & 111 \\
\hline$p_{f}(\mathrm{~mm})$ & 62 & 35 \\
\hline$p_{t}(\mathrm{~mm})$ & 43 & 70 \\
\hline$L_{p}(\mathrm{~mm})$ & 400 & 400 \\
\hline$b_{p}(\mathrm{~mm})$ & 145 & 145 \\
\hline$g(\mathrm{~mm})$ & 81 & 81 \\
\hline$d_{1}(\mathrm{~mm})$ & 159 & 185 \\
\hline$d_{2}(\mathrm{~mm})$ & 264 & 290 \\
\hline \multicolumn{3}{|c|}{$0.75 \cdot A_{b} \cdot F_{u} \geq \frac{M_{c f}}{2\left(d_{1}+d_{2}\right)}$} \\
\hline \multicolumn{3}{|c|}{$3 \cdot A_{b}\left(0.5 \cdot F_{u}\right) \geq V_{c f}$} \\
\hline
\end{tabular}

where $V_{c f}$ is the shear at the column face due to plastic hinging of the link plus any additional applied shear forces. Studies performed by Chasten et al. (1992) and Sumner and Murray (2002) on bolted end-plate connections showed that bolt tension forces can be significantly affected by prying action of the end-plate, but prying forces can be limited by using thick end-plates. For this design, bolts were overdesigned, and thick end-plates were used which reduced the likelihood of bolt tension failure due to prying forces.

The bolt was sized such that the applied tension did not exceed 70 percent of the bolt tensile capacity. Bolt shear failure was also precluded using clause 13.12.1.2 (c) of Limit States Design of Steel Structures (CSA S16-09, 2010) as follows:

$$
V_{c f} \leq 0.6 \phi_{b} n m A_{b} F_{u}
$$

where $n$ is the number of bolts and $m$ is the number of shear planes. Based on this criteria, 
$19.05 \mathrm{~mm}$ (3/4 inch) bolts were selected. In adherence with Limit States Design of Steel Structures (CSA S16-09, 2010), the bolts were pretensioned to 70\% of their tensile capacity.

The thickness of the end-plates was selected based on bending and shear capacity as outlined in the Moment Connections for Seismic Applications guidelines (CISC, 2008). This states that end-plate thickness should satisfy equation (3.12) for flexure and equation (3.13) for shear.

$$
t_{p} \geq \sqrt{\frac{M_{c f}}{0.8 F_{y p}\left\{\left(d_{p}-p_{t}\right)\left[\frac{b_{p}}{2}\left(\frac{1}{p_{f}}+\frac{1}{s}\right)+\left(p_{f}+s\right) \frac{2}{g}\right]+\frac{b_{p}}{2}\left(\frac{d_{b}}{p_{f}}+\frac{1}{2}\right)\right\}}}
$$

where:

$s=\sqrt{b_{p} \cdot g}$

$F_{y p}$ is the yield strength of the steel end-plate (conservatively taken as $250 \mathrm{MPa}$ )

$d_{p}$ is the distance from one edge of end-plate to centre of opposite link flange

$p_{t}, p_{f}, b_{p}$, and $g$ are defined in Figure 3.6

$$
t_{p} \geq \frac{M_{c f}}{1.1 F_{y p} b_{p}\left(d_{b}-t_{b}\right)}
$$

The end plate thickness for the regular link and link with the RBS detail were $19.05 \mathrm{~mm}$ (3/4 inch) and $25.4 \mathrm{~mm}$ (1 inch) respectively. The connection between the end-plate and the link section was made using a complete joint penetration groove (CJPG) weld with weld-access holes. The geometry of the weld access holes is specified in the Moment Connections for Seismic Applications guideline (CISC, 2008), and must be included in order to avoid stress concentrations and brittle failure of the flange-to-end-plate welds. The web connection can be made using either a double fillet weld or a CJPG weld. For this project, CJPG welds were used for the web connections. Further weld details can be found in Appendix A. If end-plate configurations are required that are not present in the Moment Connections for Seismic Applications guidelines (CISC, 2008), additional design information may be found in Sumner (2003). 


\subsubsection{Panel Zone}

During the preliminary design phase it was determined that the high panel zone shear forces would likely lead to excessive longitudinal shear and tension perpendicular-to-grain stresses if the panel zone was made of timber. During a severe seismic event, this would likely result in the brittle failure of the panel zone and hinder the effectiveness of the plastic hinge. To avoid this problem, the timber panel zone was removed from the column and replaced with a custom steel section comprised of welded steel plates as seen in Figure 3.1.

The steel panel zone was designed and detailed according to Limit States Design of Steel Structures (CSA S16-09, 2010) and the Moment Connections for Seismic Applications Guidelines (CISC, 2008). The flanges of the steel panel zone were designed according to Limit States Design of Steel Structures based on bending capacity, where the applied moment was taken as the moment at the centre of the column, and calculated according to equation (3.14).

$$
M_{c}=M_{p r}+V_{h}\left(a+s / 2+d_{c} / 2\right)
$$

The designer must verify that the selected column (panel zone) flange thickness meets the requirements specified in the Moment Connections for Seismic Applications guidelines (CISC, 2008). Since continuity plates were provided in the panel zone, the flange thickness was required to satisfy equation (3.15).

$$
t_{c} \geq \sqrt{\frac{M_{c f}}{\frac{2\left(d_{b}-t_{b}\right)}{0.8 F_{y c} Y_{c}}}}
$$

where:

$$
\begin{gathered}
Y_{c}=\left(\frac{c}{2}+s\right)\left(\frac{1}{C_{2}}+\frac{2}{C_{1}}\right)+\left(C_{2}+C_{1}\right)\left(\frac{4}{c}+\frac{2}{s}\right) \\
C_{1}=\frac{g}{2}-k_{1}
\end{gathered}
$$

Ryan Gohlich, Department of Civil and Environmental Engineering, Carleton University 


$$
\begin{gathered}
C_{2}=\frac{b_{c}-g}{2} \\
s=\sqrt{\frac{C_{1} C_{2}}{C_{2}+2 C_{1}}\left(2 b_{c}-4 k_{1}\right)}
\end{gathered}
$$

where $k_{1}$ is the distance between the centerline of the web and edge of wed-to-flange fillet of the steel w-section. A column (panel zone) flange thickness of $12.7 \mathrm{~mm}(1 / 2 \mathrm{inch})$ was used for this connection.

Since the section was fabricated from individual plates, the thickness of the column web plate was chosen such that doubler plates would not be required, which reduced fabrication costs. The required thickness was calculated using equation (3.16) from clause 27.2.4.2.2 of Limit States Design of Steel Structures (CSA S16-09, 2010) to ensure that the panel zone would remain elastic under severe ground motions.

$$
V_{p z} \leq 0.55 \phi d_{c} w^{\prime} F_{y c}
$$

where:

$V_{p z}=\frac{M_{c f}}{d_{2}}$

$d_{2}$ is the distance between the upper bolt holes of the end-plate and link bottom flange

$d_{c}$ is the depth of the steel column panel zone section

$w^{\prime}$ is the panel zone web thickness including the thickness of any doubler plates

The adequacy of the panel zone strength must then be confirmed according to section 3.4 of the Moment Connections for Seismic Applications guidelines (CISC, 2008), proportioning the web such that thickness satisfies equation (3.17). Axial capacity and combined axial and bending must also be considered in design according to Limit States Design of Steel Structures (CSA S16-09, 2010).

$$
w^{\prime} \geq \frac{C_{y} M_{c}\left(\frac{h-d_{b}}{h}\right)}{0.9\left(0.6 R_{y c} F_{y c} d_{c}\right)\left(d_{b}-t_{b}\right)}
$$


where $h$ is the average storey height of storeys above and below the joint

$$
C_{y}=\frac{S_{e}}{C_{p r} Z_{e}}
$$

$S_{e}$ is the effective elastic modulus of the beam at the centre of the link

A $9.53 \mathrm{~mm}$ (3/8 inch) thick column web was found to be adequate for this connection. To ensure that the strong column - weak beam design principle was followed as specified by CSA S16-09, the following requirement was also checked:

$$
\sum M_{r c}^{\prime} \geq M_{c}
$$

where:

$$
M_{r c}^{\prime}=1.18 \phi M_{p c}\left(1-\frac{C_{f}}{\phi C_{y}}\right) \leq \phi M_{p c}
$$

$M_{p c}$ is the nominal moment capacity of the column

Since the test does not account for gravity loads in the column sections, $C_{f}$ was taken as zero. In a study on RBS connections with deep columns, Zhang and Ricles (2006) concluded that the presence of the column axial load has little effect on the local and global connection performance, hence omitting it from the experimental program should not effect the validity of the results.

Continuity plates were provided to ensure that the panel zone did not fail by means of web crippling and yielding or flange tension failure. The thickness of the continuity plates should be equal-to or greater-than the thickness of the link flanges according to the Moment Connections for Seismic Applications guidelines (CISC, 2008). Since the two link types were of different depth, the continuity plate was placed in between the two positions resulting in a slight offset from the desired location. Thicker continuity plates $(12.7 \mathrm{~mm}$, or $1 / 2 \mathrm{inch})$ were adopted to minimize any negative effect caused by this offset. The welds were designed according to the Moment Connections for Seismic Applications guidelines (CISC, 2008). CJPG welds were used to connect the continuity plate to the link-side column flange. The other two sides were connected using fillet welds. Procedures identical to that of the steel panel zone described above were also used for the design of the steel collar web, continuity plates, and flanges.

Ryan Gohlich, Department of Civil and Environmental Engineering, Carleton University 
Thick steel base plates were used to transfer loads due to axial and bending stresses from the panel zone to the end-grain of the timber columns. Equation (3.20) shows the method of determining bearing-plate thickness according to Limit States Design of Steel Structures (CSA S16-09, 2010).

$$
t_{b p} \geq \sqrt{\frac{2 C_{f} n^{2}}{B C \phi F_{y}}}
$$

where $C_{f}$ force applied and $n, B$, and $C$ are shown in Figure 3.7.

\subsubsection{Design of Timber Members}

Since the timber members have the potential to be a brittle component of the connection, the timber beams were designed to withstand the full probable moment capacity of the link, and each timber column was designed to withstand half of the moment applied to the column centre (due to plastic hinging in the link). The moment at the panel zone was split between upper and lower columns based on relative stiffness. Due to the configuration of the test setup (see Figure 4.2), the shear forces in the test specimens were higher than would be present in the actual structure, however this had little effect since design of these members was governed by moment capacity.

The moment capacity of the timber beams and columns was determined according to clause 6.5.6.5.1 of Engineering Design in Wood (CSA O86-09, 2010), which is taken as the maximum of equation (3.21) and equation (3.22).

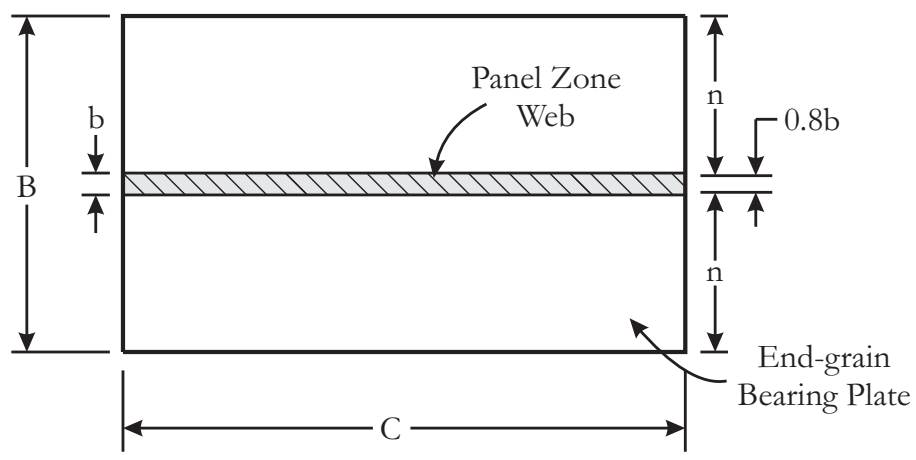

Figure 3.7: Timber End-Grain Bearing Plate 


$$
\begin{gathered}
M_{r 1}=\phi F_{b} S K_{x} K_{Z b g} \\
M_{r 2}=\phi F_{b} S K_{x} K_{L}
\end{gathered}
$$

where:

$F_{b}$ is the factored bending strength of timber

$S$ is the elastic modulus of a timber member

$K_{x}$ is a factor associated with curvature of a timber member

$K_{Z b g}$ is a factor associated with size of a timber member

$K_{L}$ is a factor associated with lateral stability of a timber member

Dietsch and Brandner (2015) state that for screws with a diameter greater than $6 \mathrm{~mm}$, member stiffness will not be affected, but the capacity of the timber member should account for the net reduction in cross-section after installation of the STS. Table 3.12 presents the capacitydesign moment, gross, and net resistance of timber cross-section using both 45degree, $12 \mathrm{~mm}$ diameter STS, and ZD-plates with $10 \mathrm{~mm}$ diameter STS. Although the STS of the ZD-plate connection removed less material than the 45 degree STS connection, the overall net cross-section was lower since the ZD-plates were recessed into the timber beam, as seen through the reduction of the gross moment capacity. The gross cross-section does not account for loss in cross-section area from the installation of the STS, and does not account for the recessed area for the ZD-plate connection, while the net cross-section refers to the area of wood remaining after installation of the STS.

The adequacy of the shear capacity of the beams and columns was confirmed according to

Table 3.12: Capacity-Design of Timber

\begin{tabular}{c|ccc}
\hline $\begin{array}{c}\text { STS Connection } \\
\text { Type }\end{array}$ & $\begin{array}{c}M_{f, \text { capacity }} \\
(\mathrm{kN} \cdot \mathrm{m})\end{array}$ & $\begin{array}{c}M_{r, \text { gross }} \\
(\mathrm{kN} \cdot \mathrm{m})\end{array}$ & $\begin{array}{c}M_{r, \text { net }} \\
(\mathrm{kN} \cdot \mathrm{m})\end{array}$ \\
\hline $45^{\circ}$ & 101 & 177 & 131 \\
ZD-plate & 101 & 138 & 108 \\
\hline
\end{tabular}

Ryan Gohlich, Department of Civil and Environmental Engineering, Carleton University 
clause 6.5.7.2 of Engineering Design in Wood (CSA O86-09, 2010). Preliminary shear design was completed using equation (3.23) and was later checked using equation (3.24) (a less conservative method). The timber elements were found to be approximately three times over-designed with regards to shear strength.

$$
\begin{gathered}
V_{r}=\phi F_{v} \frac{2 A_{g}}{3} K_{N} \\
V_{r}=\phi F_{v} 0.48 A_{g} K_{N} C_{V} Z^{-0.18} \geq W_{f}
\end{gathered}
$$

Since the test setup did not account for gravity loads, axial capacity for overall member strength was not considered, however in the design of the prototype structure presented in Appendix $\mathrm{B}$, the adequacy of the axial capacity of each timber member was checked using clause 6.5.8.4 and 6.5.12 of Engineering Design in Wood (CSA O86-09, 2010). The design method to account for the axial stresses transferred to the end-grain of the timber from the STS connection can be found in the following section. To transfer shear forces from the timber members to the steel sections, triangular shear tabs were used to create a shear shelf and minimize bending of the steel top and bottom plates due to shear forces. The bearing capacity required to resist the force applied to the timber elements from the shear shelf was determined using clause 6.5.9.3 of Engineering Design in Wood (CSA O86-09, 2010).

\subsubsection{Self-Tapping Screw Connection}

The design for the self-tapping screw connections shown in Figure 3.1 consisted of the STS design ( $45^{\circ}$ or ZD-plate), STS reinforcing screws, steel top and bottom plates, and verification of the axial capacity of the end-grain of the timber. The capacity design force assigned to the self-tapping screw connections was the same as the capacity design force assigned to the adjacent timber members (refer to Table 3.6)

Ryan Gohlich, Department of Civil and Environmental Engineering, Carleton University 


\subsubsection{Strain Compatibility Analysis}

Strain compatibility analysis was completed in order to estimate the magnitude of force that was taken by the steel top/bottom plate and the end-grain of the timber element; these two forces make up the force couple that is necessary to form the moment connection between the steel collar and timber element. The configuration of screws in the 45 degree connections used for both columns and one beam alternative only allows the STS to transfer forces while the steel plate is in tension. The special 45 degree washers bear on the screw heads when the steel plate is pulled. Since the screws only run in one direction, the STS are unable to resist compressive forces. Consequently, the compressive stresses caused by the bending force must be transferred in bearing at the end-grain of the timber elements.

Batchelar (2007) suggests that the designer can apply the same principles for strain compatibility in timber design as are used in reinforced concrete with the "transformed area method" by assuming that any deformations at the connection interface are minimal and there is a linear triangular stress distribution in the timber compression zone. Figure 3.8 shows the expected stress and force distribution through the connection using strain compatibility. This method assumes that the STS connection between the steel STS side-plate and the timber member is completely rigid. Zarnani and Quenneville (2014) developed a stiffness-based approach for determining the force distribution among components of spliced moment-resisting connections that would account for the behaviour of the fasteners making up the connection.

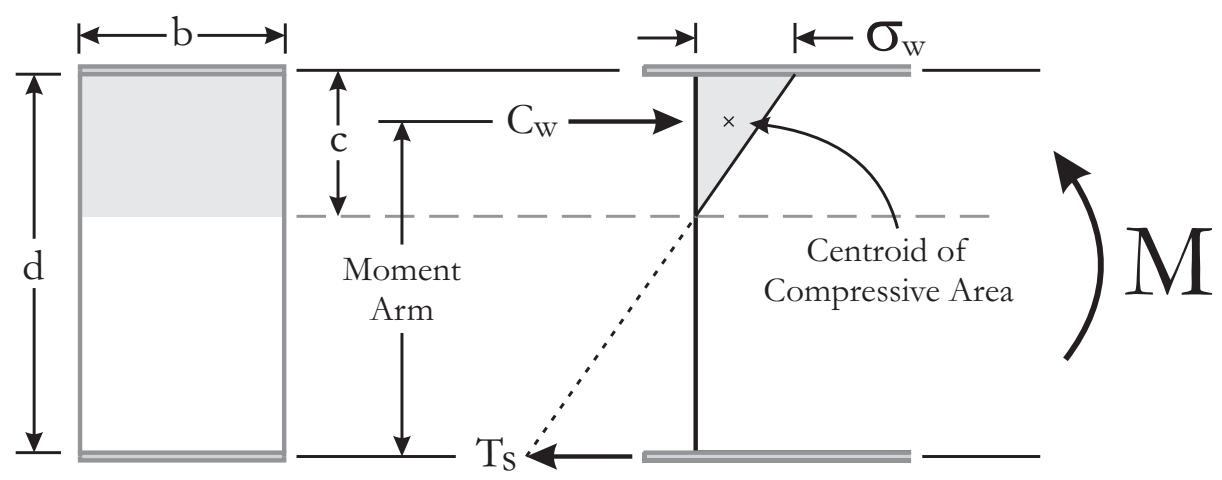

Figure 3.8: Stain Compatibility Analysis 
Since the analysis location was at the end-grain of the timber member (where the applied moment is at a maximum), none of the wood fibres experience tension stresses (as there would be at the midspan of a beam). This simplifies the analysis to a two-force couple as shown in Figure 3.8. By evaluating these forces, the moment capacity of the connection can be calculated. Strain compatibility analysis is an iterative process performed using the following steps:

1. Determine capacity-design force applied to connection

2. Estimate STS layout (in order to design steel STS side-plate)

3. Estimate required steel STS side-plate thickness

4. Calculate maximum allowable compressive stress for timber

5. Guess depth of timber compression zone

6. Guess maximum stress in timber compression zone

7. Calculate strain and stress in steel and timber

8. Calculate force in steel and timber $\left(C_{w}\right.$ and $\left.T_{s}\right)$

9. Iteratively guess timber stress until $C_{w}$ is equal to $T_{s}$

10. Use force equilibrium to calculate moment capacity

11. Return to step 5 until adequate connection strength has been achieved

Since it is assumed that the stress profile in the timber compression zone follows a linear triangular distribution, the depth of the compression zone will not change regardless of the compressive stress at the extreme fibre (for a given steel plate thickness). Consequently, the analysis may be performed by iterating values of maximum timber stress as opposed to compression zone depth (as is the case in reinforced concrete design). By knowing these two values, the stress profile of the cross-section can be estimated, and the force in the timber and steel may be calculated for any given stress profile. It should be noted that the aforementioned procedure is only valid if the timber member remains elastic. The force resisted by timber in compression may be estimated using $C_{w}=\frac{1}{2} \cdot c \cdot b \cdot \sigma_{w}$. The process is iteratively updated until horizontal equilibrium of these two forces is satisfied, and the moment capacity can be calculated. The STS layout and steel design should be adjusted until the moment capacity is adequate. The target moment capacity 
for the STS connections was the same as that of the corresponding timber elements. The maximum allowable axial stress in the end grain of the timber was determined using clause 6.5.8.4.2 of Engineering Design in Wood (CSA O86-09, 2010) as follows:

$$
\sigma_{w, \text { allow }}=\phi F_{c} K_{Z c g} K_{C}
$$

where:

$F_{c}$ is the factored compressive strength parallel-to-grain of timber

$K_{Z c g}$ is a factor associated with size of a timber member

$K_{C}$ is a factor associated with slenderness of a timber member

\subsubsection{Self-Tapping Screw Design}

The design of all self-tapping screws was completed in accordance with the recently released Canadian Code Approval for SWG ASSY VG Plus and SWG ASSY 3.0 Self-Tapping Wood Screws (National Research Council of Canada, 2013). All equations presented in this section are taken from this document. All STS used as primary load transfer mechanisms were installed at a 45 degree angle to the grain so that they were loaded primarily in withdrawal instead of shear (with the exception of the ZD-plate screws, which used an installation angle of 30 degrees). The high stiffness of STS loaded in withdrawal allows the force to be transferred along the screw axis, and avoid weak dowel-type behaviour when loaded in combined axial and shear.

The STS connection was designed by first selecting a screw type and size $(12 \times 300 \mathrm{~mm}$ VG plus CSK for 45 degree connection and 10 x 260 mm VG plus CSK for ZD-plate connection (VG Plus CSK refers to the STS head type)), selecting appropriate fastener spacing, calculating the capacity per screw, and determining the number of required fasteners with consideration for group effect. The screw length was selected to achieve a withdrawal capacity near that of the tensile capacity of the screw. The withdrawal capacity of an individual screw can be calculated using equation (3.26). The number of screws required for the connection was determined using equation (3.27), assuming that only $n^{0.9}$ fasteners are effective in transferring load. The final capacity of an individual inclined screw is calculated by taking the horizontal component of the 
capacity longitudinal to the screw.

$$
P_{r w, \alpha}=\phi \frac{0.8 \cdot \delta(b \cdot 0.84 \cdot \rho)^{2} \cdot d \cdot l_{e f} \cdot 10^{-6}}{\sin ^{2} \alpha+\frac{4}{3} \cdot \cos ^{2} \alpha} \cdot K_{D} \cdot K_{S F}
$$

where:

$$
\begin{aligned}
& \phi=0.9 \\
& \delta=82 \text { for a density greater than } 440 \mathrm{~kg} / \mathrm{m}^{3} \text { and } 85 \text { otherwise } \\
& b=1 \text { for D-Fir-L., SPF, SYP, WRC, and Hem-Fir or } 0.75 \text { for Parallam } \\
& \rho=\text { mean oven-dry relative density }\left(\mathrm{kg} / \mathrm{m}^{3}\right) \\
& d=\text { the outer screw diameter }(\mathrm{mm}) \\
& l_{e f}=\text { embedment depth (excluding tip length) } \\
& \alpha=\text { screw installation angle }
\end{aligned}
$$

$$
n_{r e q}=\left(\frac{T_{f}}{P_{r w, \alpha}}\right)^{1 / 0.9}
$$

where $T_{f}$ is the total applied force, and $P_{r w, \alpha}$ is the maximum of the horizontal component of the withdrawal capacity and factored tensile capacity of an individual screw. For the $12 \times 300 \mathrm{~mm}$ STS, the withdrawal and tensile capacities were $27.1 \mathrm{kN}$ and $24.0 \mathrm{kN}$ respectively. Table 3.13 shows the design details of the 45 degree STS connections for the beam and columns.

The spacing of the STS was selected according to Table 4.1.3.1 of the Canadian Code Approval for STS based on minimum requirements for douglas-fir larch. Although an alternative wood species was used for the test specimens, this results in more conservative (larger) spacing requirements. The minimum spacing requirements are specified to avoid splitting of the timber,

Table 3.13: STS Connection Capacity

\begin{tabular}{c|ccccc}
\hline Location & $T_{f}(\mathrm{kN})$ & $T_{r}(\mathrm{kN})$ & $M_{f}(\mathrm{kN} \cdot \mathrm{m})$ & $M_{r}(\mathrm{kN} \cdot \mathrm{m})$ & $n_{S T S}$ \\
\hline Beam & 285 & 296 & 110 & 114 & 24 \\
Column & 188 & 206 & 60 & 78 & 16 \\
\hline
\end{tabular}


although some European technical approvals permit reduced spacing if predrilling is used. Table 3.14 presents the minimum allowable spacing along with the actual spacing used for the STS, where $S_{P}$ is the spacing parallel to grain, $S_{Q}$ is the spacing perpendicular-to-grain, $a_{L}$ is the loaded end distance, and $e_{L}$ is the loaded edge distance.

For inclined screws, the spacing parallel to grain is taken as the perpendicular distance between screws, as shown in Figure 3.9. For this connection, a horizontal spacing of $130 \mathrm{~mm}$ was used, which corresponds to a perpendicular spacing of $92 \mathrm{~mm}$.

\subsubsection{Tension-Compression Plate Design}

An alternative STS connection using groups of tension-compression (ZD) plates was used for one beam specimen, as shown in Figure 3.1. Unlike the connection using 45 degree STS installed in one direction, the ZD-plate consists of screws that are installed in both directions with a cover plate bearing on each screw head. This allows the connection to transfer force in both tension and compression, where the former connection type transferred forces strictly in tension. Furthermore, since screws are installed at a 30 degree angle, more force is transferred parallel to the timber member compared to screws with a 45 degree installation angle, so higher capacity is achieved per screw.

Figure 3.10 shows the principle forces acting on the ZD-plate through different loading stages (Closen, 2008). Part a) shows the forces just as the load is applied. Only the tension-screw is engaged, and the vertical component of the inclined force creates a bearing load on the timber. Part b) shows the forces just after the cover plate begins to bear on the compression-screw heads.

Table 3.14: STS Connection Spacing

\begin{tabular}{c|cc}
\hline & Minimum Spacing $(\mathrm{mm})$ & Actual Spacing $(\mathrm{mm})$ \\
\hline$S_{P}$ & $7.5 d=90$ & 92 \\
$S_{Q}$ & $2.5 d=30$ & 35 \\
$a_{L}$ & $7.5 d=90$ & 92 \\
$e_{L}$ & $3 d=36$ & 39.5 \\
\hline
\end{tabular}

Ryan Gohlich, Department of Civil and Environmental Engineering, Carleton University 


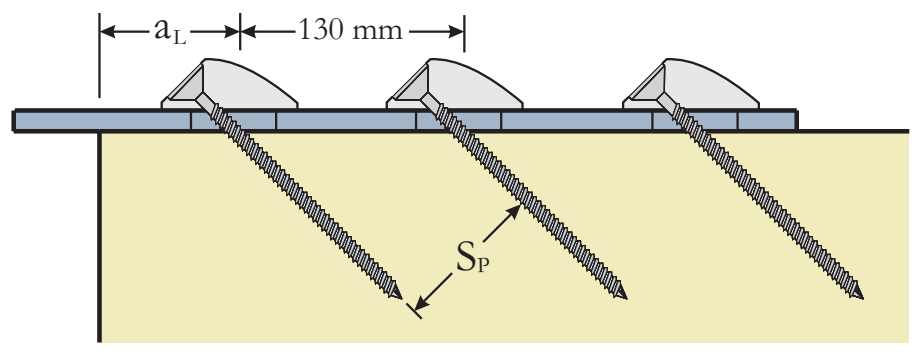

Figure 3.9: Parallel to Grain Spacing of Inclined Screws

This occurs after slight deformations of the plate. Lastly, part c) shows the forces when full load is applied. Both tension and compression-screws are activated, and there is an additional force present perpendicular to the shear plane as a result of the eccentricity between the location of the applied load (top of cover plate through bolt shear) and the resulting screw force (Closen, 2008).

Strain compatibility was used to evaluate the force applied to each ZD-plate connection following the same methods as previously stated, however the designer may choose to ignore the beneficial contribution of the timber end-grain bearing resistance and design the connection using only a single force couple provided by the steel top and bottom plates. If this method is used, the tensile force applied to each set of ZD-plates is simply $M_{f} / d$ where $M_{f}$ is the capacity-design force acting on the connection and $d$ is the depth of the timber section. Both types of analysis are depicted in Figure 3.11.

The ZD-plate connections were designed according to the European Technical Approval for ZD-Plates (ETA-11/0470, 2012) held by SWG Schraubenwerk Gaisbach GmbH. The $55 \times 86 \mathrm{~mm}$ ZD-plate is fastened to the timber section using $10 \mathrm{~mm}$ VG plus CSK screws (larger ZD-plates are available). The geometry of the ZD-plates used for this study is shown in Figure

a)

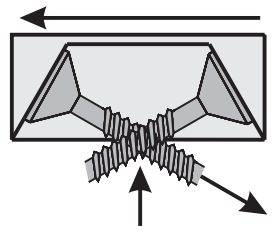

b)

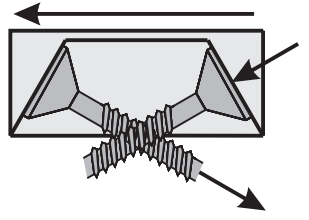

c)

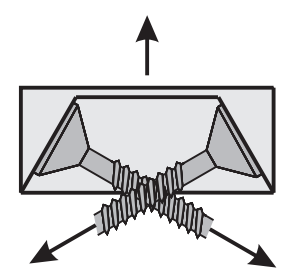

Figure 3.10: Force Transfer Stages in ZD-Plate (after Closen, 2008) 
a)

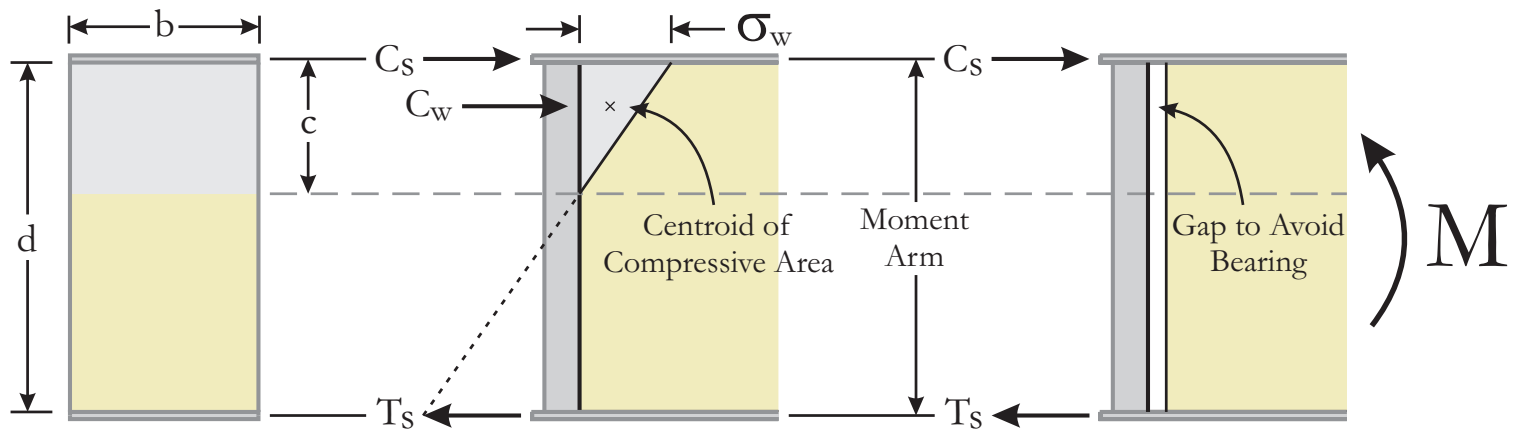

Figure 3.11: Force Analysis of ZD-Plate Connection

a) With End-Grain Bearing

b) Without End-Grain Bearing

3.12. The connection is designed by first selecting the length of screw and determining its characteristic capacity as per the previous section. Next the designer must decide if additional screws perpendicular to the shear plane (as shown in Figure 3.13) will be installed at the end of the connection to account for the eccentricity of the load; the force caused by the eccentricity between the steel top plate and ZD plate-timber interface is assumed to be transferred perpendicular to shear plane (Closen, 2008). The capacity of each ZD-plate can then be determined, and the number of necessary ZD-plates can be calculated. Lastly, the designer must verify the adequacy of the bolts that transfer the load between the steel top plate and the ZD-plate, and verify the design of the steel top plate according to Limit States Design of Steel Structures (CSA S16-09, 2010), accounting for gross and net tension capacity, row shear, and any applicable combinations or shear and tension failure in the steel plate.

The capacity of a single ZD-plate when no additional screws perpendicular to the shear plane are provided can be calculated according to equation (3.28) (ETA-11/0470, 2012). When additional STS are provided, that capacity is as shown in equation (3.29), where the additional screws are designed to accommodate a tensile force shown in equation (3.30).

$$
F_{Z D, R k}=F_{a x, R k} \cdot \frac{3 \cdot n_{Z D}-1.3}{1+\frac{16+0.3 \cdot t}{a_{1} \cdot\left(n_{Z D}-1\right)}}
$$



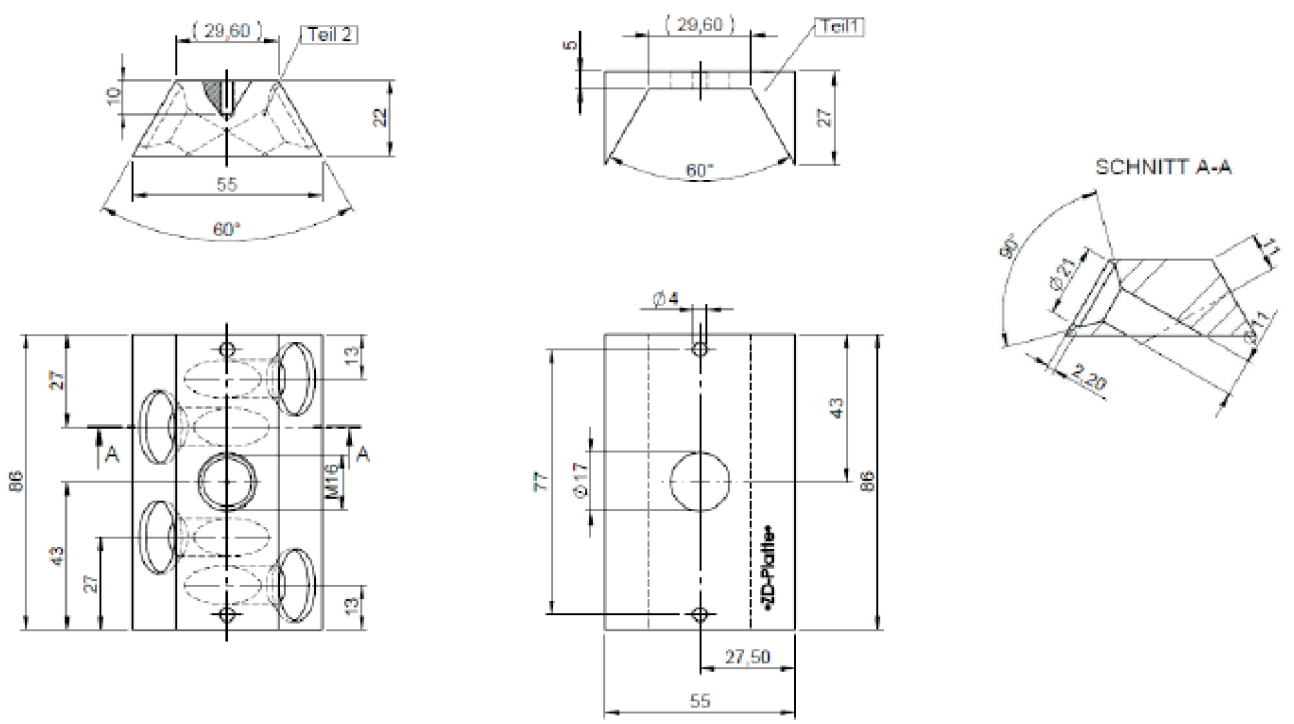

Figure 3.12: Geometry of ZD-plate (ETA-11/0470, 2012)

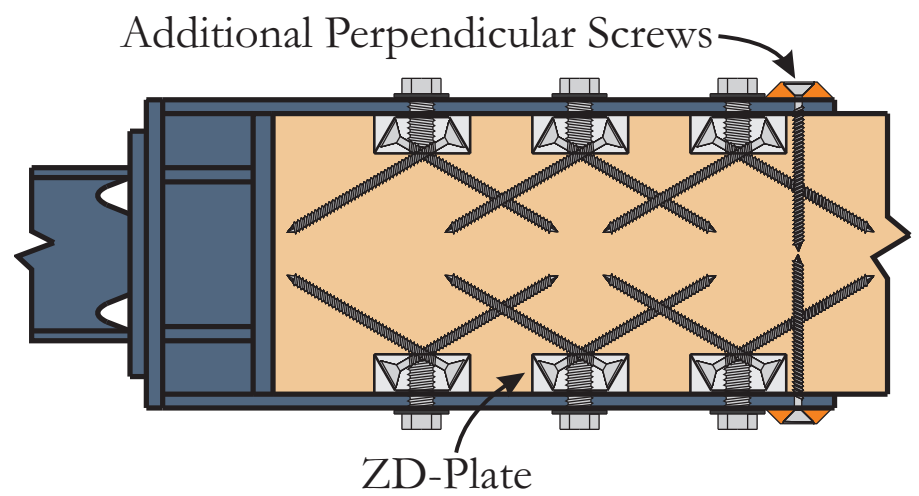

Figure 3.13: Additional Tension Perpendicular-to-grain Screws for ZD-plate Connections 


$$
\begin{gathered}
F_{Z D, R k}=F_{a x, R k} \cdot 3 \cdot n_{Z D} \\
F_{t, k}=F_{a x, R k} \cdot \frac{3 \cdot n_{Z D}}{\frac{a_{1} \cdot\left(n_{Z D}-1\right)}{27+t / 2}-\frac{1}{4}}
\end{gathered}
$$

where:

$F_{a x, R k}$ is the withdrawal or tensile capacity of a single screw

$n_{Z D}$ is the number of ZD-plates in the connection

$t$ is the steel top plate thickness

$a_{1}$ is the spacing of the ZD-plate connectors

It should be noted that the compressive capacity of an STS is approximately $30 \%$ of the tensile capacity; this is reflected in the capacity equations for ZD-plates. The withdrawal and tensile capacity of the screw should be determined in accordance with the applicable technical approval. For this size of ZD-plate, the STS should have a diameter of $10 \mathrm{~mm}$, and a length between $240 \mathrm{~mm}$ and $600 \mathrm{~mm}$. The bolts connecting the ZD-plates to the steel top plate should have a diameter of $16 \mathrm{~mm}$, and a length between $30 \mathrm{~mm}$ and $60 \mathrm{~mm}$. M16 bolts of grade 10.9 are standard for this type of connection, and were used for this project. Table 3.15 shows the design details for the ZD-plate connection used in this project. Two additional $10 \mathrm{x} 200 \mathrm{~mm}$ perpendicular screws were provided to satisfy equation (3.30).

The minimum spacing requirements for the screws in the ZD-plate connections are the same as those shown in Table 3.14, although for the parallel to grain spacing, $5 d$ was used which is allowable for wood species other than douglas-fir larch. The minimum spacing parallel to the grain of consecutive ZD-plates is $100 \mathrm{~mm}$, which corresponds to a perpendicular screw spacing

Table 3.15: ZD-Plate Connection Capacity

\begin{tabular}{c|ccccc}
\hline Property & $T_{f}(\mathrm{kN})$ & $T_{r}(\mathrm{kN})$ & $M_{f}(\mathrm{kN} \cdot \mathrm{m})$ & $M_{r}(\mathrm{kN} \cdot \mathrm{m})$ & $n_{\mathrm{ZD}}$ \\
\hline Additional STS & 271 & 301 & 110 & 122 & 6 \\
No Additional STS & 271 & 269 & 110 & 109 & 6 \\
\hline
\end{tabular}


of $50 \mathrm{~mm}$ (for $10 \mathrm{~mm}$ diameter screws, $S_{P}=5 d$ and $\frac{5 \cdot 10}{\sin 30}=100 \mathrm{~mm}$ ).

\subsubsection{Connection Reinforcement}

Due to the configuration of STS in the connection, it is possible for failure of the timber members to occur as a result of excessive tension perpendicular-to-grain and longitudinal shear stresses. Such a failure could result in crack formations around the mid-depth of the beams or columns, which would hinder the moment and shear capacity and potentially lead to collapse of a frame incorporating this connection. It is possible to reinforce the timber elements to avoid such failures. For this project, it was determined that reinforcement was required to accommodate excessive tension perpendicular-to-grain stresses in the connection using 45 degree STS. Alternative reinforcing methods considered included glued-on wood side panels, exterior tension strapping, self-tapping screws, or threaded rods inserted along the member depth to clamp the steel top and bottom plates together. It was decided to used STS reinforcing screws due to their availability, ease of design and installation, and relatively low cost.

Figure 3.14 shows the force transfer through each component of the 45 degree STS connection due to an applied moment on the nonlinear replaceable link. When the moment is applied, a force couple is created that exerts compressive stresses on the bottom of the timber member and tensile stresses on the steel plate at the top of the member. This tensile force is transferred into the top of the timber member through the STS. Due to the high axial stiffness of the STS, all force is considered to be transferred parallel to the screw. Due to the inclined installation angle, this results in both parallel and perpendicular forces being transferred into the timber element, as seen at the top of Figure 3.14. When examining all resultant forces throughout the connection, it becomes obvious that the only forces present that can counteract the parallel and perpendicularto-grain loads is the direct resistance of the timber. Consequently, the designer must verify that the stresses induced in the timber can be accommodated by the tension perpendicular-to-grain and longitudinal shear strength of the member. If this is not the case, then one of the aforementioned reinforcing methods must be applied.

Similarly, Figure 3.15 shows the force transfer through each component of the ZD-plate

Ryan Gohlich, Department of Civil and Environmental Engineering, Carleton University 


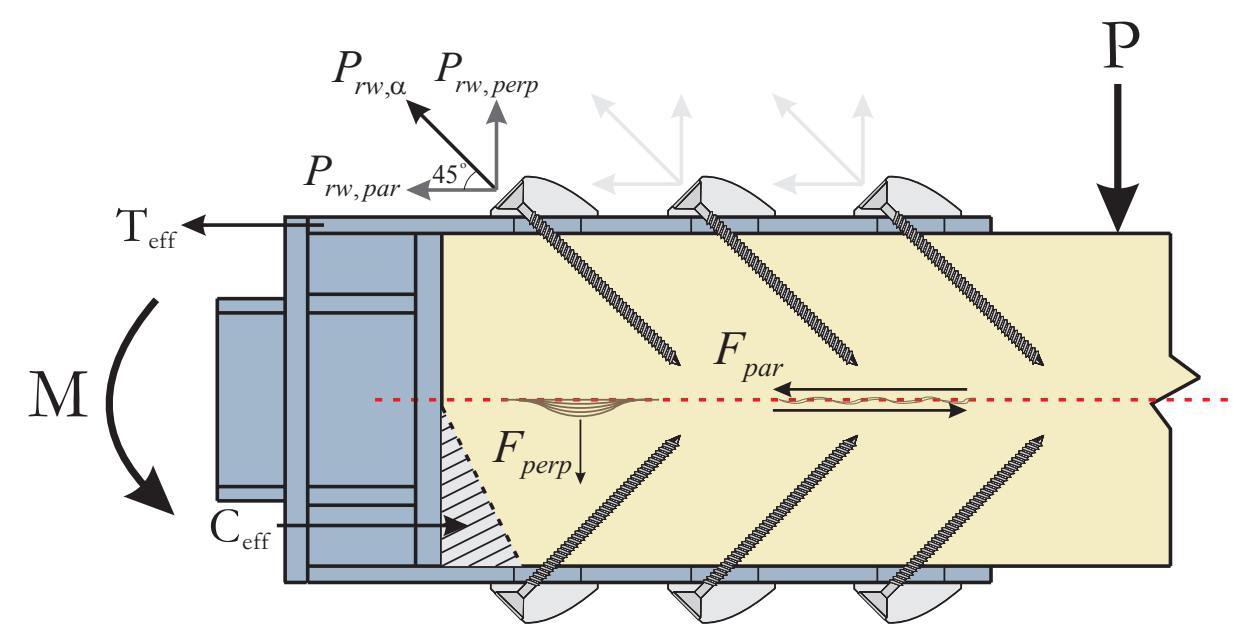

Figure 3.14: Force Transfer Through 45 Degree STS Connection

connection. The moment applies a force couple to the top and bottom of the timber beam as before, however because the screws in this connection are installed in both directions, the resultant tension perpendicular-to-grain force applied by a tension screw is counteracted by an opposing force applied by a compression screw. These resultant forces are shown at the top of Figure 3.15. Consequently, the only tension perpendicular-to-grain stress that is applied directly to the timber is that resulting from the eccentricity between the location of the shear plane and the bottom of the ZD-plate (where the screws actually fasten to the timber). This force is accommodated by additional self-tapping screws placed at the end of the connection (see Figure 3.13). Additional tension perpendicular-to-grain reinforcement was not required. Conversely, the parallel to grain forces on the top and bottom of the member are in opposing directions with no other force present to counteract it. This develops longitudinal shear stresses directly in the timber member. The designer must take care to ensure these stresses do not exceed the shear capacity of the member. If required, longitudinal to grain reinforcement should be installed. One simple method would be to use inclined screws installed across the entire depth of the member to ensure it crosses the assumed location of the shear plane (near the mid-depth of the member). For this project, the shear capacity of the member was adequate, so no such reinforcement was necessary.

Krenn and Schickhofer (2009) recommend overlapping the screw tips at the centre of the 


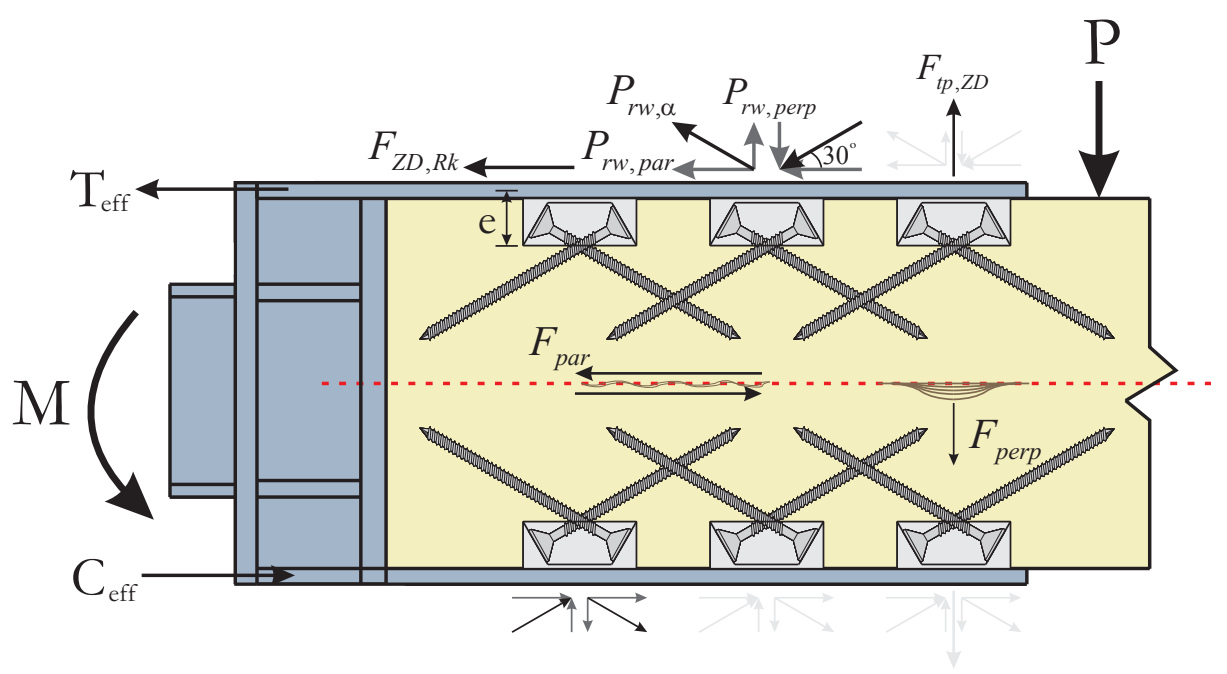

Figure 3.15: Force Transfer Through ZD-Plate Connection

member by a minimum of four screw diameters to avoid splitting of the otherwise unreinforced portion of the timber. This suggestion was not followed for this project due to difficulties this would impose on the alignment of the screws, since they would interfere with each other at the centreline of the member (it is also suggested that the crossing screws do no touch). Instead, independent reinforcement was provided to allow for use of shorter screws that could be installed more quickly and easily without the use of expensive, heavy-duty equipment.

Figure 3.16 shows the resultant forces of a cut section used to estimate the tension perpendicular-to-grain stresses that must be accommodated by reinforcing screws. Although these stresses are applied at the STS location, it can be assumed that the forces are evenly distributed across an imaginary failure plane (likewise for the longitudinal shear forces). Since the fasteners are installed at a 45 degree angle, resultant forces from horizontal and vertical contributions are approximately equal, therefore, by knowing the amount of force applied to the shear plane, the vertical force (tension perpendicular-to-grain) force can be estimated. Figure 3.16 shows that the horizontal force applied to the STS are also resisted by embedment of the fastener in the timber (ignored during design), as well as frictional forces developed between the steel top plate and the surface of the wood. This figure also shows a method presented by Krenn and Schickhofer (2009) used to approximate the contribution of friction to the overall resistance of the connection by assuming the coefficient of friction to be $\mu=0.25$. By considering the portion 
of load resisted by friction, as well as the tension perpendicular-to-grain capacity of the timber itself, the portion of tension perpendicular-to-grain load that must be accommodated by additional reinforcement can be estimated. This is likely a conservative design since the force reduction due to embedment strength is ignored. For this connection, $8 \times 430 \mathrm{~mm}$ VG plus CSK STS were used as reinforcement, with 16 screws installed in the timber beam and 10 screws installed in each timber column. The splitting resistance of timber can be calculated using equation (3.31) from clause 10.4.4.7 of Engineering Design in Wood (CSA O86-09, 2010).

$$
Q S_{r T}=\phi \cdot 14 \cdot t \sqrt{\frac{d_{e}}{1-\frac{d_{e}}{d}}}\left(K_{D} K_{s F} K_{T}\right)
$$

where $t$ is the member width, and $d_{e}$ is the loaded edge distance, assumed to be the vertical distance between the timber face and the tip of the screw, as seen in Figure 3.17.

Figure 3.17 shows the location and design methodology used for the reinforcing STS. After the applied tension perpendicular-to-grain force is estimated, the designer simply selects a screw size and type and determines the number of screws required. The latter is done by calculating the withdrawal resistance of each screw as per equation (3.26), where $l_{e f}$ is taken as the minimum of $l_{a}$ and $l_{b}$ from Figure 3.17. The layout of the reinforcing screws can be seen in Figure 3.18. A similar layout was used for the column sections but only 10 screws were necessary.

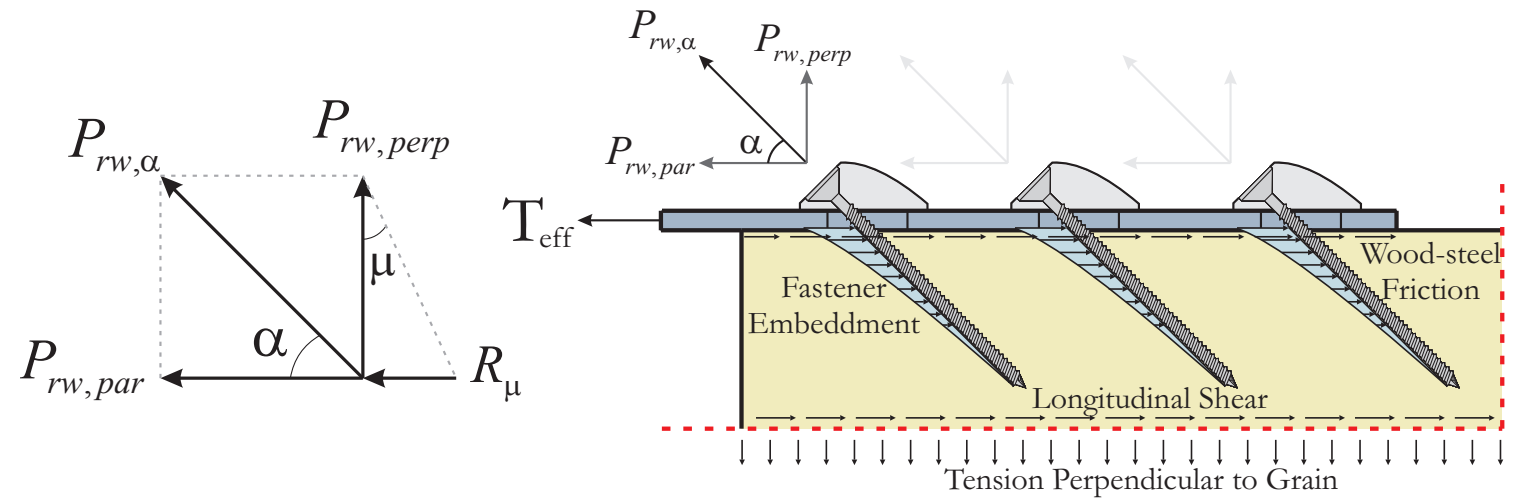

Figure 3.16: Cut of Resultant Forces in 45 Degree STS Connection 


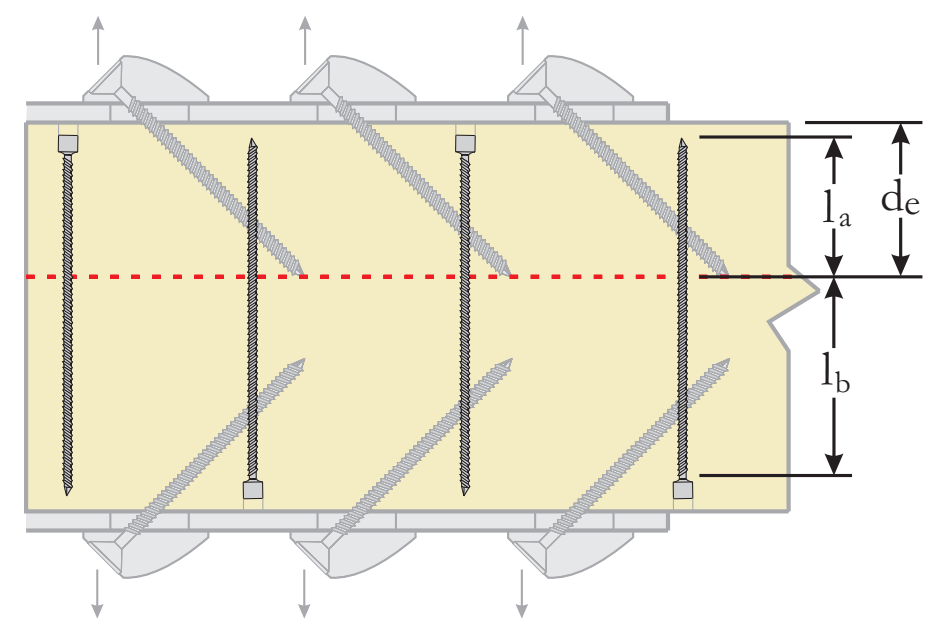

Figure 3.17: Perpendicular-to-Grain Reinforcing Screws

\subsubsection{Connection Summary}

Figure 3.18 shows a scaled summary of the STS connections used to transfer moments between the steel collar and the beam. Layouts of both the 45 degree STS connection and the ZD-plate connection are presented. The 45 degree STS connection was also used to transfer moments between the steel panel zone and the timber columns; details of this connection are not depicted, but are identical to that of the beam connection, except that the number of fasteners per row was four instead of six. The spacing of the tension perpendicular-to-grain reinforcing screws in the 45 degree STS connection for the beam was the same as the spacing of the primary STS (130 mm). Full connection detail drawings can be found in Appendix A.

\subsection{Moisture and Shrinkage}

Shrinkage due to change in moisture content was not considered in the design for this project because the specimen was only assembled over a short period of time and was unaffected by moisture-related shrinkage. Moreover, since this is an interior connection detail, it is likely that it will be dry prior to assembly (assuming that seasoned heavy timber is used), which reduces the chance of shrinkage related crack formation. Although cracking would likely only occur in locations away from the primary load transfer mechanisms (ie. at mid-depth of the timber 
a)
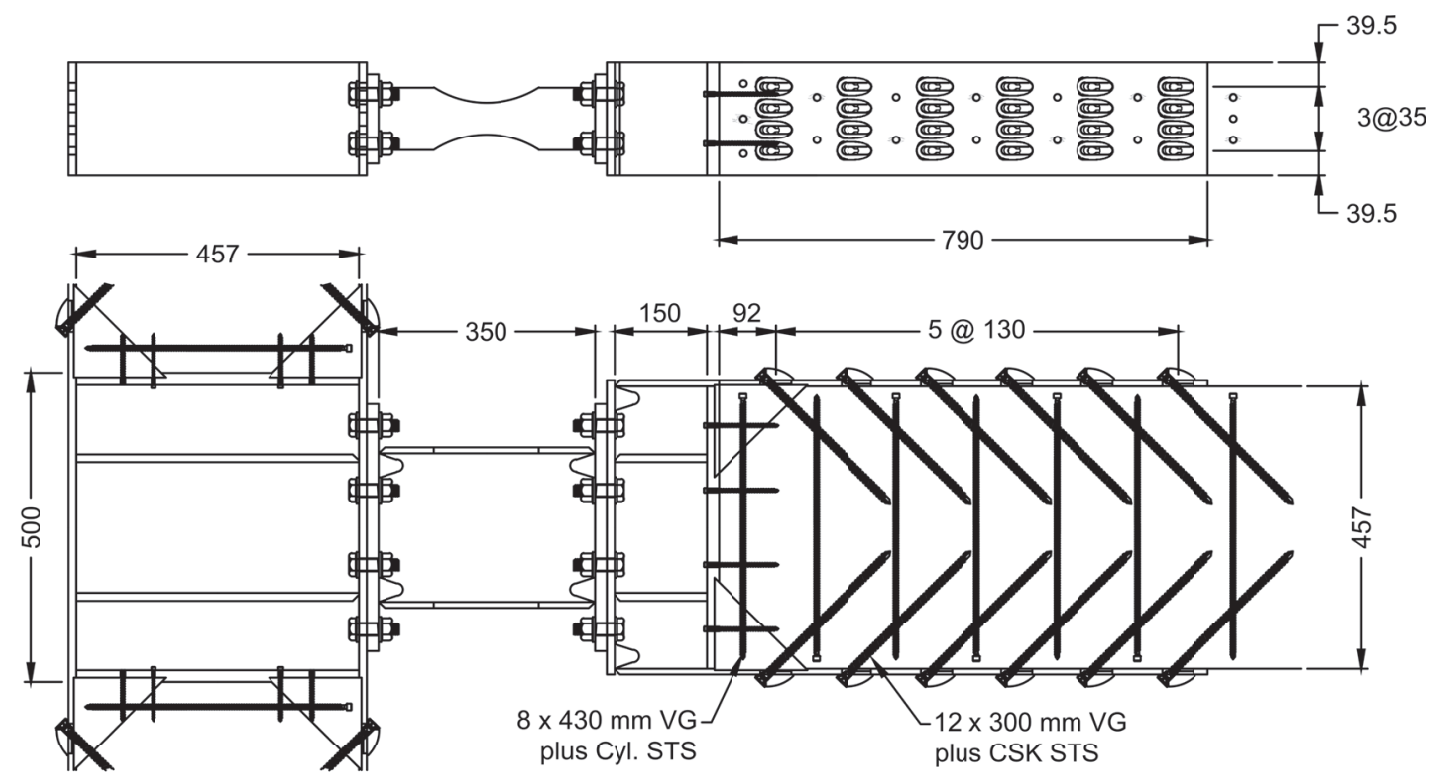

b)
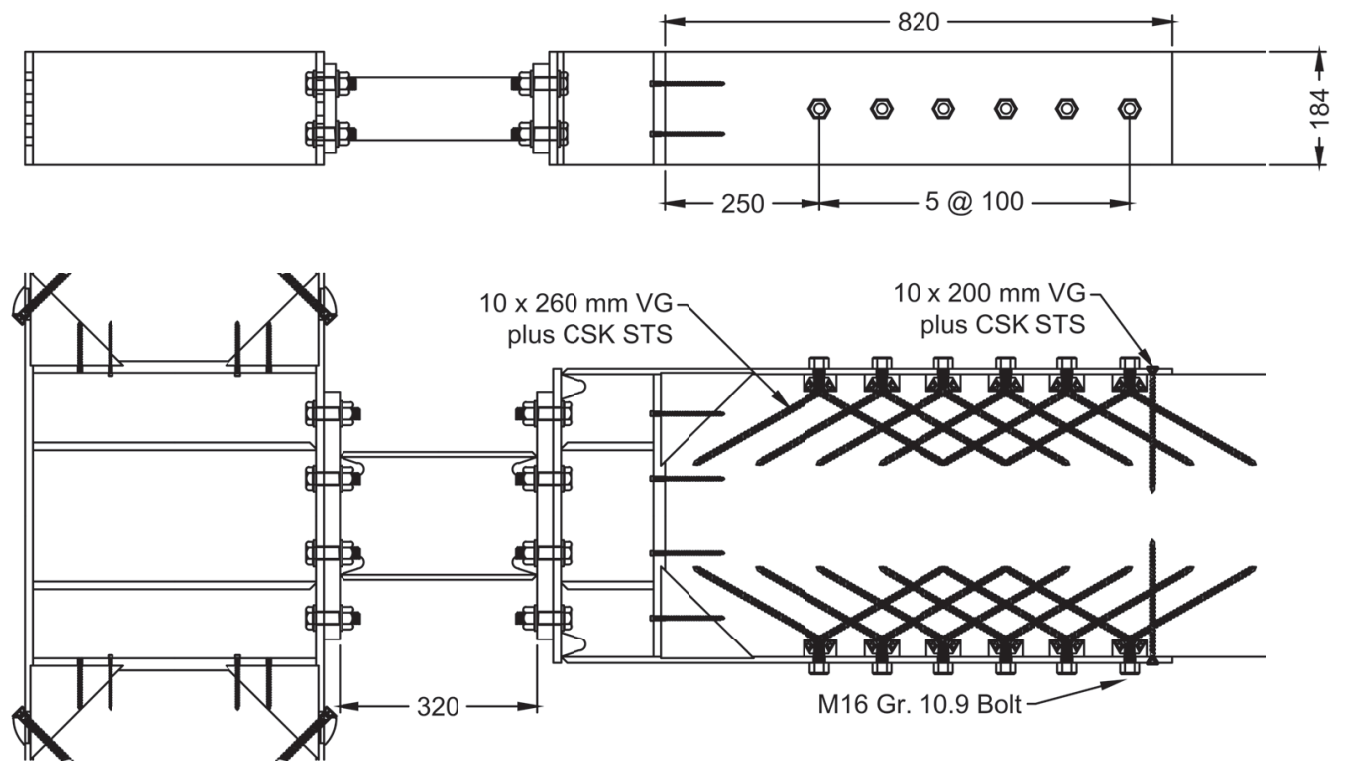

Figure 3.18: Summary of Connection Details a) 45 Degree STS Connection

b) ZD-plate Connection 
members), care should be taken in detailing the connection to avoid this issue as it can have detrimental effects on the strength and stiffness of the timber.

The shrinkage stresses induced in the timber elements can be determined by approximating the strain due to a change in relative humidity throughout the year. This stress must be accommodated using one of the aforementioned methods of tension perpendicular-to-grain reinforcement. For this type of connection, shrinkage stresses could simply be added to the existing tension perpendicular-to-grain stresses described earlier; the summation of which would be accommodated by the STS reinforcing screws. Angst and Malo (2012) showed that STS reinforcement for can reduce shrinkage stresses in the timber by up to $70 \%$.

\subsection{Consideration for Fire Performance}

The fire performance of buildings is heavily influenced by the connection detailing. This is of particular concern in hybrid structures incorporating thin steel components since steel yields at very low temperatures. Although timber is a combustible material, the formation of a char layer helps to improve the overall fire rating and protect internal connection components. However, exposed steel components must be protected to ensure that the fire rating meets applicable code standards. A study of the fire performance of this connection was out of the scope of the project, but since most steel details in the connection are identical to those found in existing steel-only MRFs, standard fire protection methods could be used to improve the fire performance. Such methods include intumescent paint, or enclosing the steel components in gypsum or wood panels.

Because the structural members and connection components were designed to withstand severe ground motions, seismic forces imparted on the frame were significantly higher than the gravity loads applied under regular service conditions, therefore all connection components have a high factor of safety when subjected to gravity loading itself. The overcapacity of the structural members increases the fire rating of the frame. Based on this overcapacity, when the frame is not subjected to seismic loading, adequate fire performance can likely be achieved. Future studies should be conducted on the fire performance of hybrid connections utilizing exterior steel plates.

Ryan Gohlich, Department of Civil and Environmental Engineering, Carleton University 


\section{Chapter 4: Experimental Setup}

\subsection{Objectives}

Four $2 / 3$ scale beam-column assemblies with nonlinear replaceable links (NRL) were tested under reverse cyclic loading at the Carleton University civil engineering structures laboratory. The objective of each test was to evaluate the overall ductility and energy dissipated by the connection, as well as to verify that expected strength and deformation levels could be reached without excessive strength degradation in the link or brittle failure of the timber members or selftapping screw (STS) connections when designed according to existing Canadian steel and timber design standards and approvals. Since the links in the proposed connection are smaller than links in a typical steel-only frame (due to scaling and reduced seismic loads), the experimental program will also provide insight into the performance of smaller links designed using the same guidelines as typical connections.

Two test specimens used nonlinear replaceable links with reduced beam section (RBS) details and two specimens used standard w-section links with no RBS detail. The former will henceforth be regarded as the RBS link, and the latter as the regular link. A single column/steel panel zone assembly was used for all four tests, and the link was changed for each test. Furthermore, two different methods were used to connect the beam element to the link; one used 45 degree STS and the other used ZD-plates. The results of the four possible combinations were compared to examine the effects that each detail had on overall seismic performance. Results of the experimental study were used to perform nonlinear dynamic time-history analysis on a frame incorporating the moment-resisting connection. Modelling methods are presented in Chapter 6. 


\subsection{Test Assembly}

The hybrid moment-resisting connection was designed for application in a six-storey structure located in Victoria, B.C. The test specimen, shown in Figure 4.1, was made to represent a scaled down version of a second-floor exterior beam-column connection. This reduced the space required for testing compared to a first-floor connection since points of inflection were assumed to be located at mid-height of the upper and lower columns, so column lengths for use in the test could be taken as half of the storey height with a true pin at the end. The moment was applied to the nonlinear replaceable link by means of a point load at the tip of the cantilevered beam. The deflected shape and force distribution on structural elements at this connection location of the prototype building can be seen in Figure 4.2.

The method of applying the external load to the test specimen to achieve the desired moment at the plastic hinge location varied slightly from the true load distribution experienced by a full frame subjected to lateral ground motion, resulting in a higher shear force applied to the beam member. This has few implications since the design of all components (except for the shear tabs) was governed by moment, and not by shear. It should also be noted that the axial load normally present in the column members of a frame subjected to lateral loading was excluded from this experimental test. Addition of axial load in the column members would impose many difficulties related to lab equipment setup. Zhang and Ricles (2006) have shown that such an addition would have little effect on overall beam-column connection performance. Furthermore, the effect of floor slab on the lateral stability of the test setup was excluded (no slab was used in the test). This is a conservative approach, since Uang and Fan (2001) suggest that the increased stability due to the presence of a floor slab can benefit both the strength and rotation capacity of the connection.

A plan view of the test assembly can be seen in Figure 4.3. The test assembly was set up such that the specimen could be mounted in the horizontal position. This was done to make test setup and observations easier. The test specimen was supported at the column ends by two true pins that allowed free rotation (zero moment) to simulate the points of inflection at mid-height of 


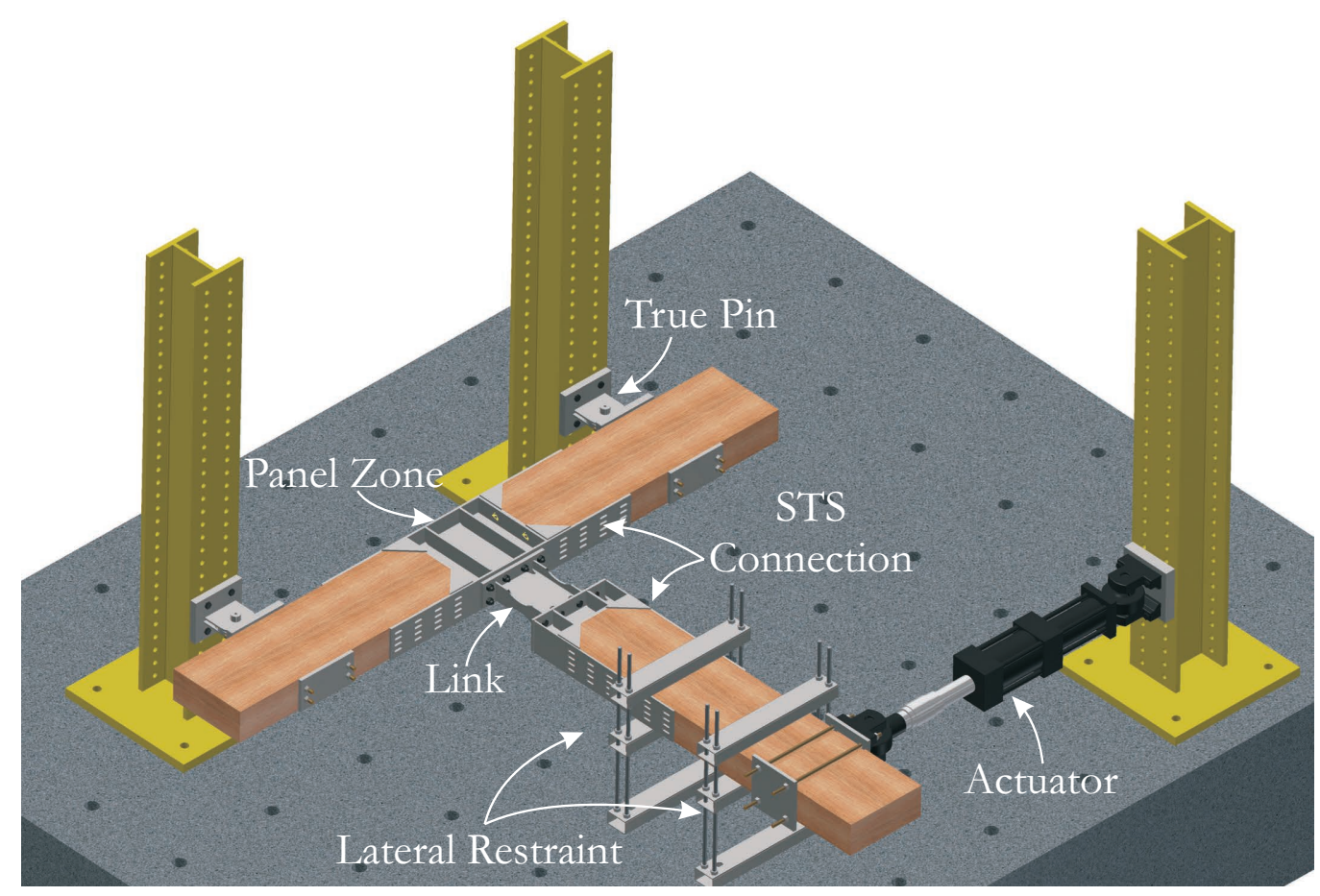

Figure 4.1: Test Assembly Isotropic View

a)

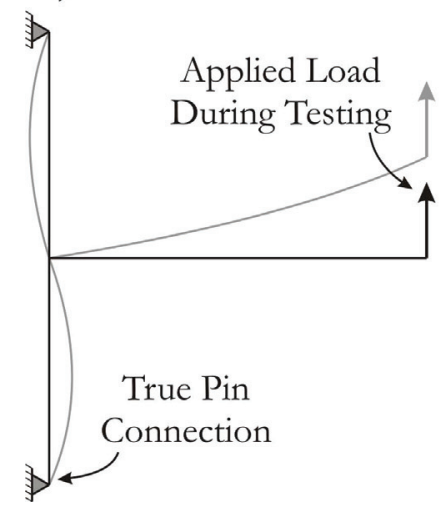

b)

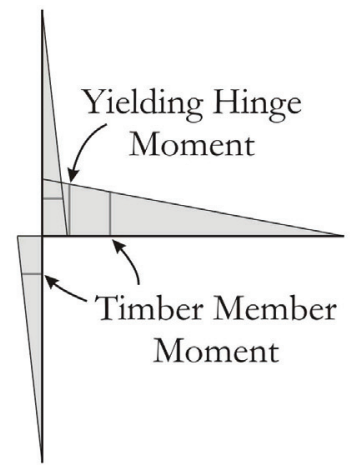

c)

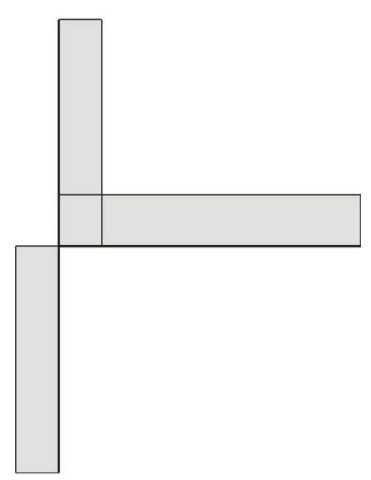

Figure 4.2: Test Assembly Forces a) Member Deflections

b) Moment Distribution c) Shear Force Distribution 
the columns. The beam free end was supported by two lateral restraint systems. This minimized out of plane movement, supported the self-weight of the specimen, and reduced potential for lateral torsional buckling that would not be present in the full frame (because the floor system that would laterally support the frame in the building is not included in the test setup). The actuator and true pins were supported by three large steel columns that were prestressed to the laboratory strong-floor using $32 \mathrm{~mm}$ dywidag bars. The lateral restraint system was pretensioned to the strong floor using $27 \mathrm{~mm}$ dywidag bars. Hydrostone was used underneath the columns to increase the coefficient of friction between the floor and the steel column base-plate. All bolts and rods connecting the test specimen to the support columns were pretensioned in accordance with section 23 of Limit States Design of Steel Structures (CSA S16-09, 2010) using the turn-of-nut method. An MTS systems series 244.31 actuator with $245 \mathrm{kN}$ (55 kip) capacity and a $254 \mathrm{~mm}$ (10 inch) stroke was used for the displacement-based cyclic loading of the beam tip.

\subsection{Test Specimens}

All steel fabrication for the links, panel zone, and beam collar assemblies was done by a local steel fabrication shop in Ottawa, Ontario, using G40.21 300W steel or equivalent, with the exception of the links, which were G40.21 350W steel. Since all cutting was done by water jet, the precision of the cuts was good, requiring little adjustment of the fabricated pieces during assembly. Timber members were generously donated by Nordic Engineered Wood, and all STS and accessories were provided at a discount by MyTiCon. Procedures and details for the design of all components can be found in Chapter 3, and detailed fabrication drawings can be found in Appendix A. Table 4.1 shows the components of each test assembly. Four combinations of beam and link assembly were tested, as shown in Table 4.1.

\subsubsection{Nonlinear Replaceable Links}

Two identical RBS links and two identical regular links were fabricated, each type using the same geometric and material properties to verify the performance of the replaced link. The 


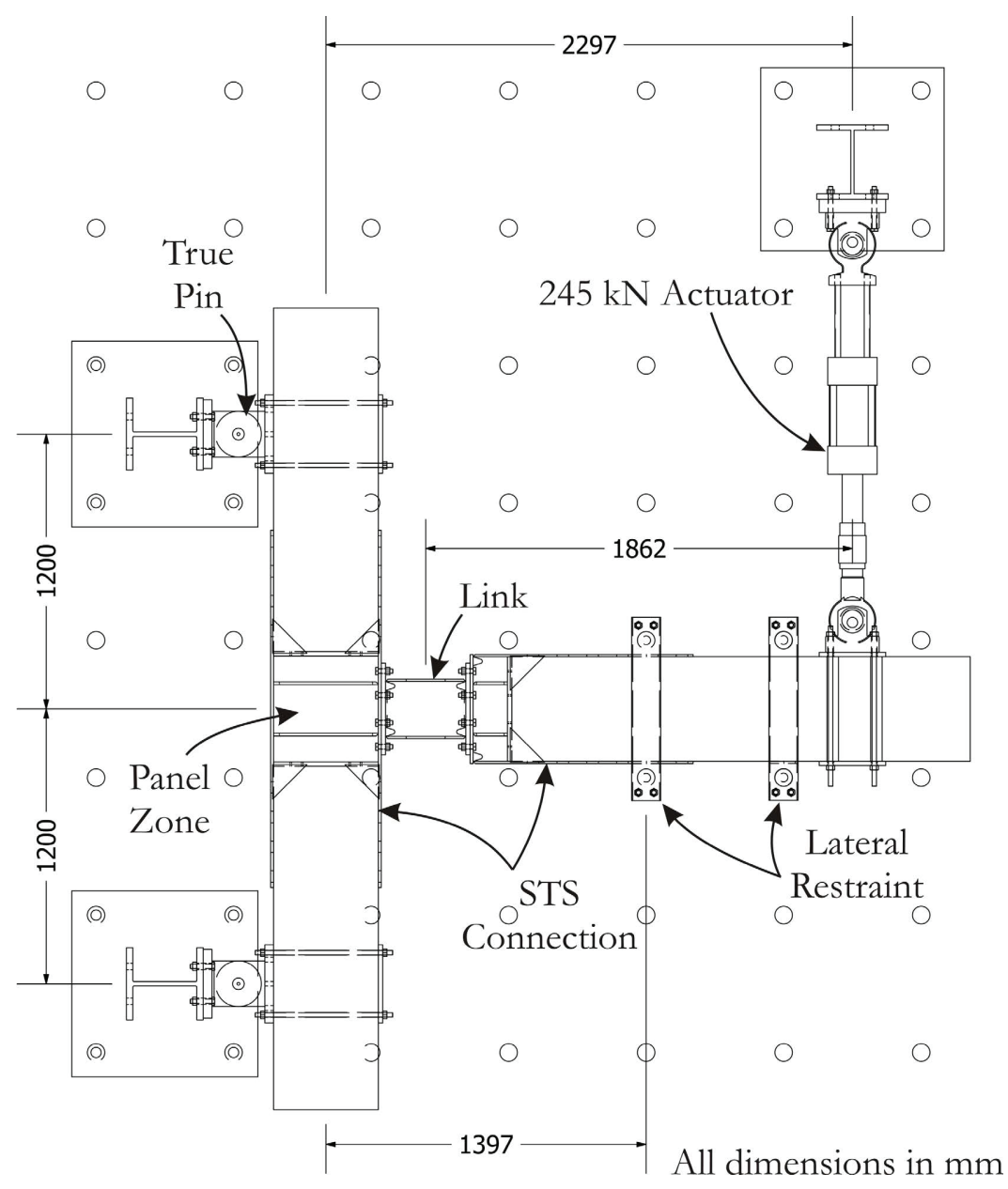

Figure 4.3: Test Assembly Plan View

Table 4.1: Test Specimens

\begin{tabular}{c|cc}
\hline Specimen & Link Type & Beam Connection \\
\hline MC-1A & RBS & $45^{\circ}$ STS \\
MC-2A & Regular & $45^{\circ}$ STS \\
MC-1B & RBS & ZD-Plate \\
MC-2B & Regular & ZD-Plate \\
\hline
\end{tabular}


use of duplicate specimens also helped to assess the replaceability of the link and determine if replacement had any detrimental effects on surrounding connection components.

The RBS links and regular links used W250 x 28 and W200 x 22 sections respectively. Class 1 sections were chosen to ensure flexural yielding of the flanges, maximizing ductility. Little laboratory preparation was required for the links since fabrication was completed outside of the university. Weld access holes were provided to ensure that the quality of weld met CISC standards. Complete joint penetration groove welds were used to connect the link to the endplates. End-plates were connected to the beam and column using $19.05 \mathrm{~mm}$ (3/4 inch) ASTM A325 bolts pretensioned to $70 \%$ of their tensile capacity using the turn-of-nut method as specified in Limit States Design of Steel Structures (CSA S16-09, 2010). This corresponded to a $1 / 3$ total turn-of-nut. Bolts were pretensioned using a large torque wrench. Due to the presence of heavy mill-scale on the specimens, locations where instruments would be installed were carefully filed down to bare steel using a Dynabrade Dynafile II. The filed area was kept as small as possible since flaking of the mill-scale is the primary indication of steel yielding, however many instruments were installed on each link as they are the source of most inelastic behaviour in the connection. Each link was white-washed to more easily detect flaking of the mill-scale.

\subsubsection{Panel Zone and Beam Collar}

A single steel panel zone was fabricated from steel plates and used for all four tests. Flanges of the section were extended beyond the boundaries of the panel zone to double as the STS sideplate for the STS connection to the timber columns. Weld access holes were provided in the collar web to improve the quality of welds connecting the collar to the STS side-plates. Nearly identical collars were used for the 45 degree STS beam and the ZD-plate beam, except that slotted holes were used in the former to accommodate the inclined screws, whereas regular holes were used in the latter to accommodate the bolts connecting the STS side-plate to the ZD-plate.

\subsubsection{Main Members}

Timber members were generously donated by Nordic Engineered Wood. The grade used was 24F-ES/NPG, all sections had a $184 \times 457 \mathrm{~mm}$ cross-section, and beam and column lengths 
were $2.0 \mathrm{~m}$ and $1.5 \mathrm{~m}$ respectively. Gross dimensions were quite close to those specified, however slight modifications of the wood sections were necessary to ensure that they would be an exact fit for the beam collars and panel zone. The edges of one end of each wood member required chamfers to avoid interference with the fillet welds on the collars. This was done using a hand plane and Dynafile. The column sections were slightly wider than the steel of the panel zone, so corners were routed down to allow for an easier fit between the steel shear tabs. The top and bottom of one beam required an $86 \mathrm{~mm}$ wide, $620 \mathrm{~mm}$ long, and $27 \mathrm{~mm}$ deep channel to accommodate the embedment of the ZD-plates. Both sides of each beam required two $12.7 \mathrm{~mm} \mathrm{(1/2}$ inch) deep channels to accommodate the actuator mounting system. All channels were installed using a Rockwell model 6301 household router. Each wood column required four $22.2 \mathrm{~mm}$ (7/8 inch) holes through the entire depth to accommodate the support mounting system for the true pins. Holes were drilled with a $457 \mathrm{~mm}$ (18 inch) long auger bit on a KAO MING KMR-980S radial arm drill press. Pictures of the preparation for all timber sections can be seen in Figure 4.4.

Several methods were used in an attempt to fit the timber members into the steel collars for the beam and column assemblies. The most effective method was that shown in Figure 4.5, which used bar clamps to slide the timber members into the steel collars. Once the end grain of the timber was as close as possible to the bearing plates, small STS were inserted into the end grain to hold the timber member in place while the primary STS were installed. The closure of the gap between end grain and bearing plate was imperative to ensure full contact between the
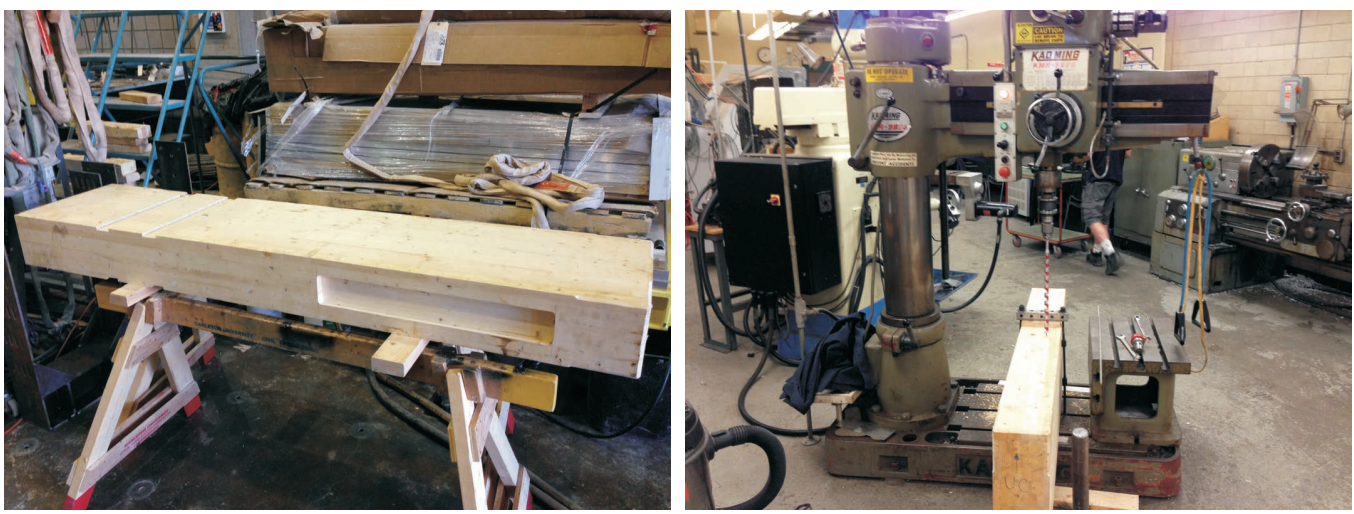

Figure 4.4: Preparation of Timber Members 
timber end-grain and the collar so that the end-grain could be properly engaged in compression when the link is bending. If any gaps were present, the screws would likely undergo excessive deformation prior to bearing of the end-grain.

Moisture content of all timber sections was recorded prior to each test using a Delmhorst Model RC-IC Solid State Moisture Detector. These readings are shown in Table 4.2 below. Since each timber member was stored in the lab close to the test location for a 7 month period prior to testing, moisture content of all timber sections were roughly the same. Moisture content of the timber did not vary between tests since all tests were completed within a 5 day period.

\subsubsection{Self-Tapping Screws}

All STS and accessories were ordered from MyTiCon in Vancouver, B.C. All screws were installed using a Dewalt DW130V mud mixing drill; a larger drill is recommended for easier installation. A drill with high torque should be selected for best results (ie. high amperage motor and low RPM). Figure 4.6 shows a photo of all STS used in the assembly, and Figure 4.7 shows the accessories necessary for installation.

Holes were pre-drilled prior to the installation of each STS in the assembly. This allowed for easier installation, and ensured that all screws were installed at the correct angle. The predrilling jig shown in Figure 4.7 was used for the installation of the 45 degree STS. A similar
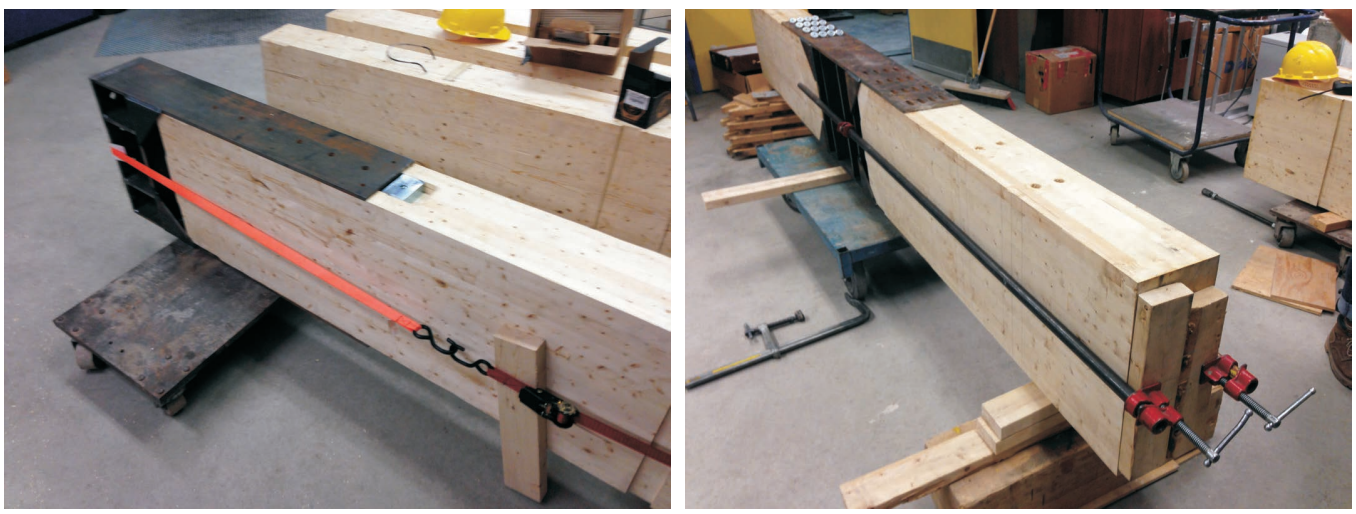

Figure 4.5: Assembly of Timber and Steel Elements

Ryan Gohlich, Department of Civil and Environmental Engineering, Carleton University 
Table 4.2: Moisture Content

\begin{tabular}{c|c}
\hline Timber Member & Moisture Content (\%) \\
\hline Beam & 8.25 \\
Upper Column & 8.5 \\
Lower Column & 8.5 \\
\hline
\end{tabular}

$45^{\circ}$ Washer

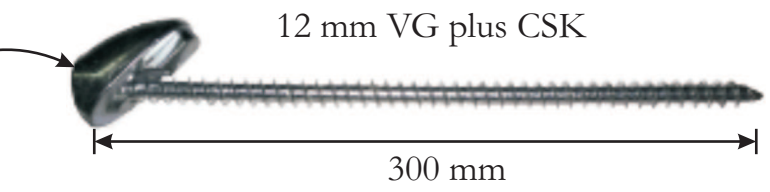

$10 \mathrm{~mm}$ VG plus CSK

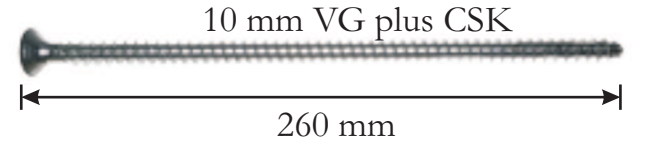

$10 \mathrm{~mm}$ VG plus CSK

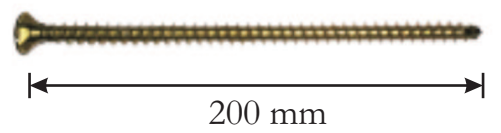

$6 \mathrm{~mm}$ VG plus Cyl.

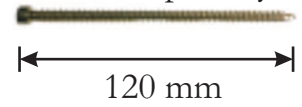

Figure 4.6: VG plus Self-Tapping Screws

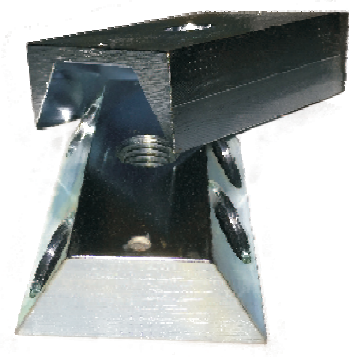

ZD-Plate

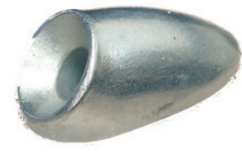

$45^{\circ}$ Washer

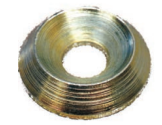

Cup Washer

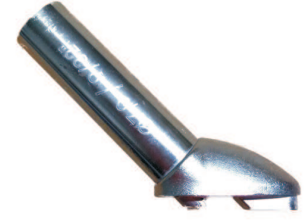

Predrilling Jig

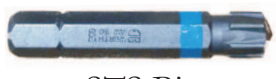

STS Bit

Figure 4.7: STS Installation Accessories 
jig was used for the 30 degree holes required for installation of the ZD-plates (a steel tube was fabricated that could be inserted into the ZD-plate). A 90 degree drill jig was fabricated in the lab pre-drill holes for the perpendicular-to-grain reinforcing screws. Pre-drilling for the STS followed the recommendations set forth by MyTiCon (Pre-drilling Instructions for SWG ASSY Screws, Max Closen). The diameter and depth of pre-drilling hole for each screw size can be found in Table 4.3.

The recommended pre-drilling depth for the $430 \mathrm{~mm}$ long perpendicular-to-grain reinforcing screws was purposefully exceeded to increase ease of installation. Without exceeding the recommended pre-drilling depth of the screws, when they were embedded a significant amount (around $350 \mathrm{~mm}$ ) into the timber member, the high friction forces developed between the screw threads and wood fibres resulted in an applied torsion force that exceeded the capacity of the screw causing the screw heads to snap off during installation. This was not an issue for the larger screws since the increased diameter resulted in a higher torsional capacity. To reduce the torque applied to the perpendicular-to-grain screws, holes were pre-drilled along the entire depth of the member. Ringhofer and Schickhofer (2014) showed that pre-drilling has little effect on capacity when screws are installed perpendicular-to-grain, and the capacity can even increase slightly when pre-drilling is utilized for end-grain applications.

Once pre-drilling was completed, the connection area was cleaned and screws were installed using a high-powered drill. The 45 degree connection required special washers (shown in Figure 4.7) which were inserted in slotted holes in the steel STS side-plate prior to screw installation. Methods for installing the tension perpendicular-to-grain reinforcing screws and the 45 degree

Table 4.3: Pre-drilling Recommendations

\begin{tabular}{c|cccc}
\hline$d_{\text {STS }}(\mathrm{mm})$ & $d_{\text {hole }}$ (inch) & $d_{\text {hole }}(\mathrm{mm})$ & Depth (inch) & Depth $(\mathrm{mm})$ \\
\hline 6 & $5 / 32$ & 4 & 2 & 50.8 \\
8 & $3 / 16$ & 5 & 4 & 101.6 \\
10 & $7 / 32$ or $15 / 64$ & 6 & 6 & 152.4 \\
12 & $17 / 64$ or $9 / 32$ & 7 & 8 & 203.2 \\
\hline
\end{tabular}

Ryan Gohlich, Department of Civil and Environmental Engineering, Carleton University 
STS can be seen in Figures 4.8 and 4.9 respectively. Care must be taken to ensure that the washer is sitting flat on the plate and fully inserted in the slotted hole to avoid localized stresses around the screw head when loaded. For the installation of the ZD-plates, the lower screw holder plate must by secured in place prior to pre-drilling. Once pre-drilling is complete, all four STS should be installed before removing the securing system for the ZD-plate. Fine-tuning of ZD-plate location can be done by sequentially tightening each screw. The method used to secure the ZD-plates for this setup is shown in Figure 4.10. Once all STS are nearly tight against the washer, they should be tightened with a torque wrench to the amount specified in Table 4.4. Regarding the ZD-plate, once the installation of the lower screw holder plate is complete, the lid can be installed with the provided steel dowels, lightly tapped in place with a hammer. Lastly, the steel collar can be placed around the ZD-plates, and secured using M16 grade 10.9 bolts, pretensioned to a force of $230 \mathrm{~N} \cdot \mathrm{m}(170 \mathrm{ft} \cdot \mathrm{lb})$ using a torque wrench.

A photo of each completed assembly can be seen in Figure 4.11 and the full assembly is shown in Figure 4.12.

\subsection{Instrumentation}

Global displacements of the entire test assembly and local rotations of individual connection components were measured using a series of linear variable differential transformers

Table 4.4: STS Pretension Force

\begin{tabular}{c|cc}
\hline$d_{\text {STS }}(\mathrm{mm})$ & Pretension Torque $(\mathrm{N} \cdot \mathrm{m})$ & Pretension Torque $(\mathrm{ft} \cdot \mathrm{lb})$ \\
\hline 8 & 23 & 17 \\
10 & 45 & 33 \\
12 & 75 & 55 \\
\hline
\end{tabular}

Ryan Gohlich, Department of Civil and Environmental Engineering, Carleton University 

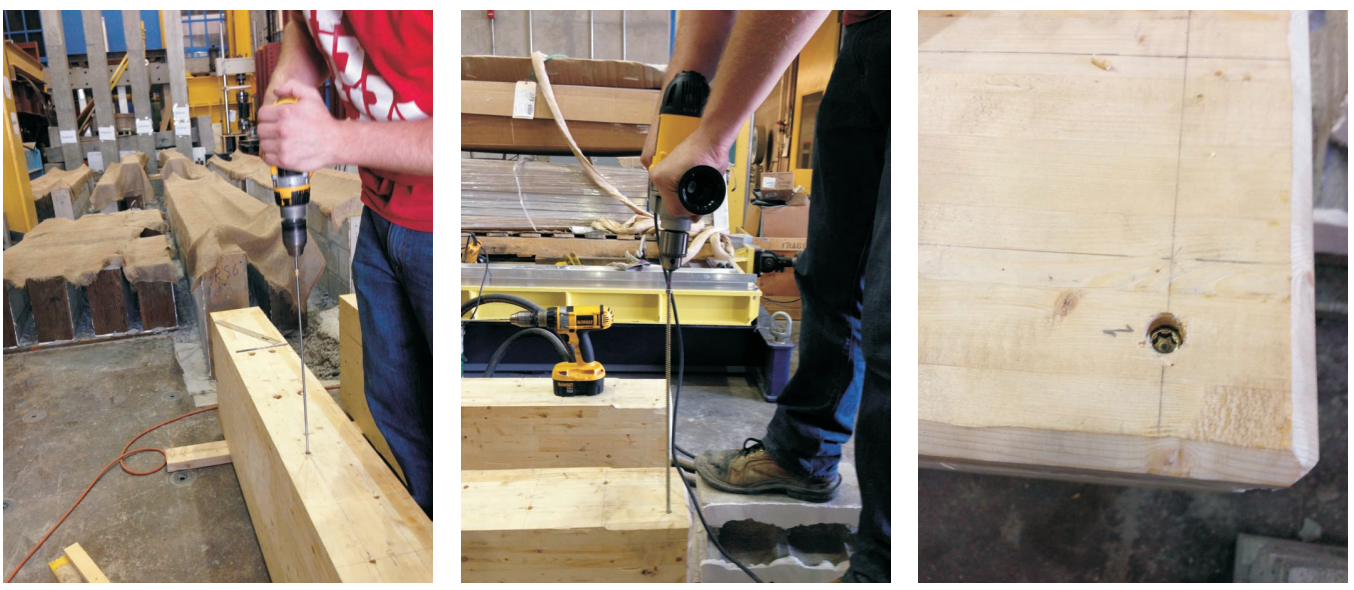

Figure 4.8: Installation of Reinforcing Screws
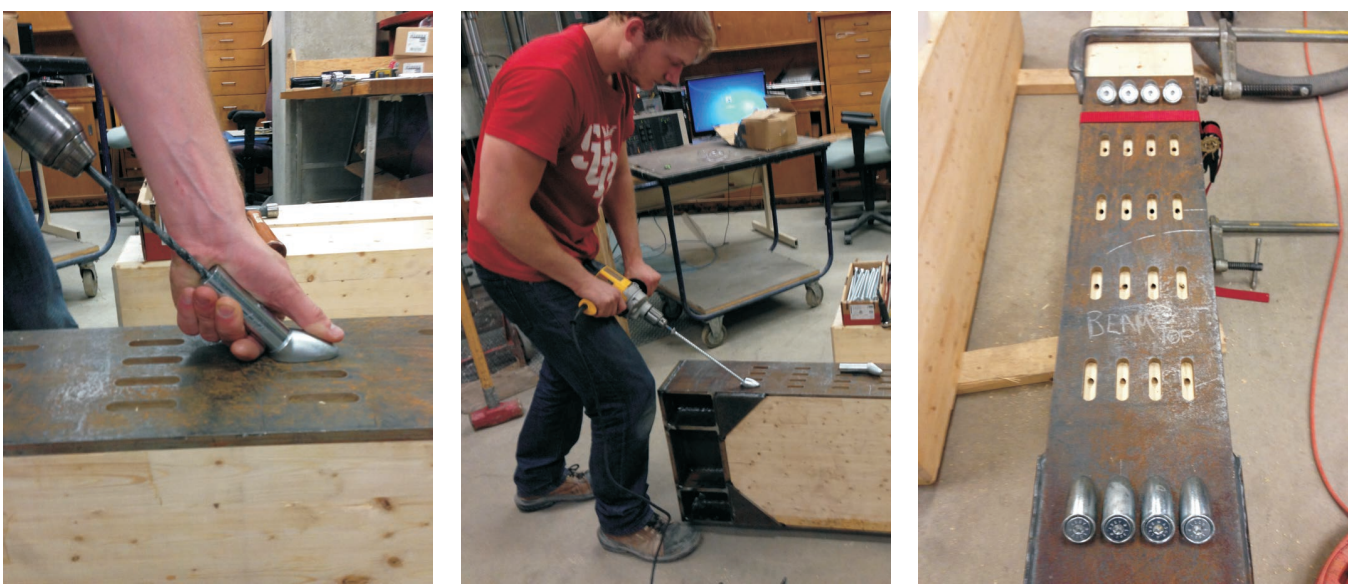

Figure 4.9: Installation of 45 Degree Screws
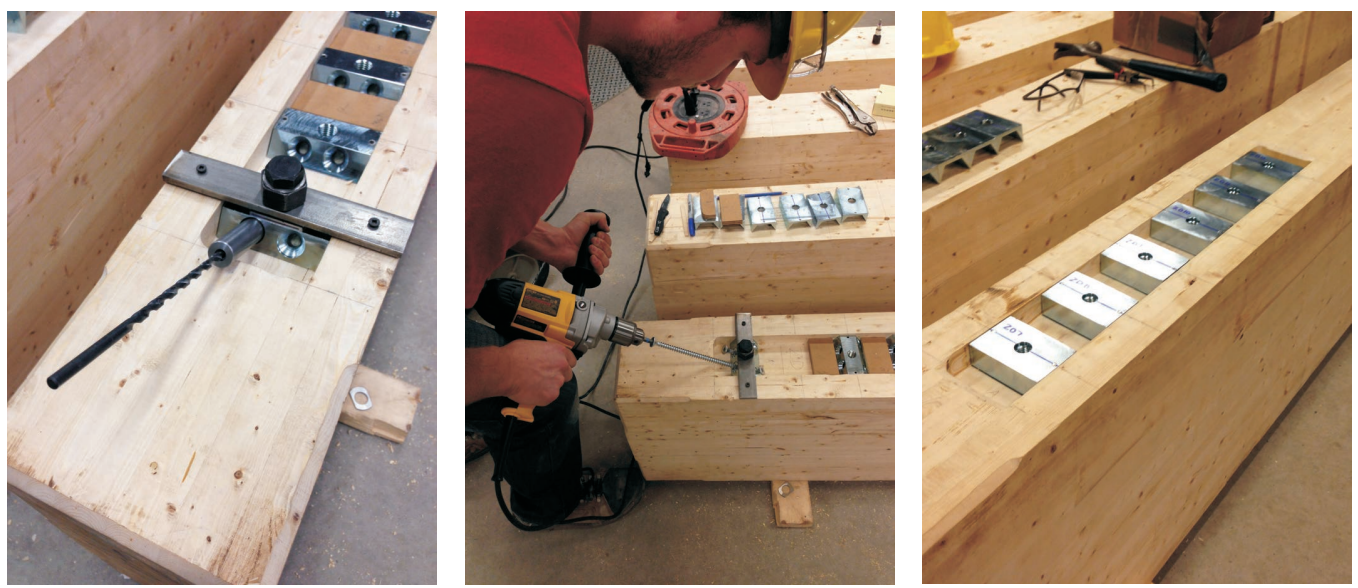

Figure 4.10: Installation of ZD-Plates 

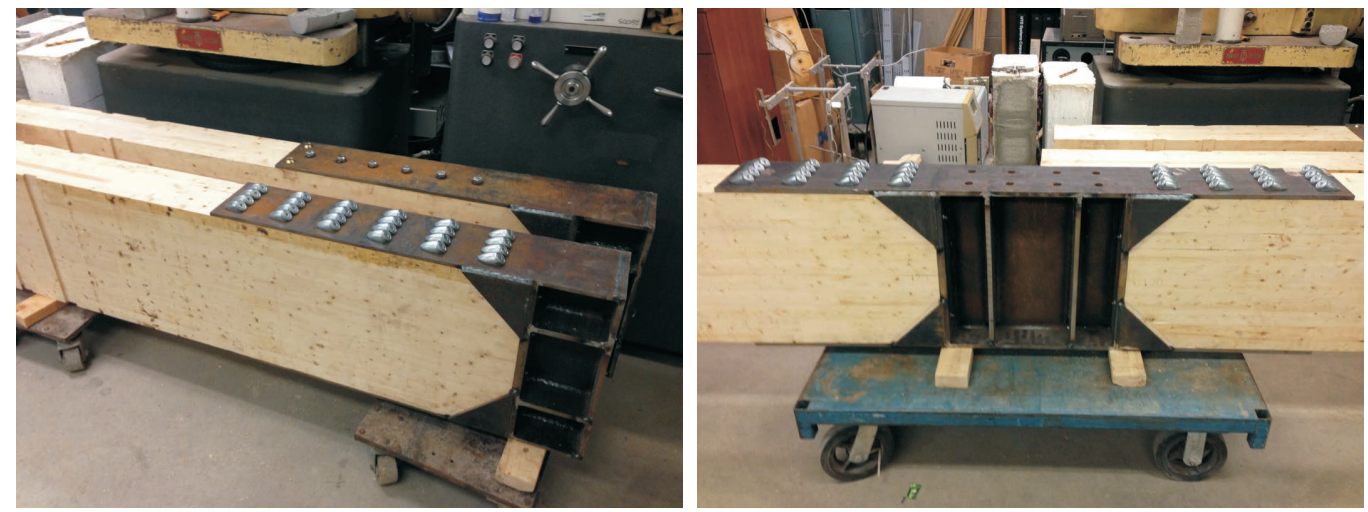

Figure 4.11: Beam and Column Assemblies

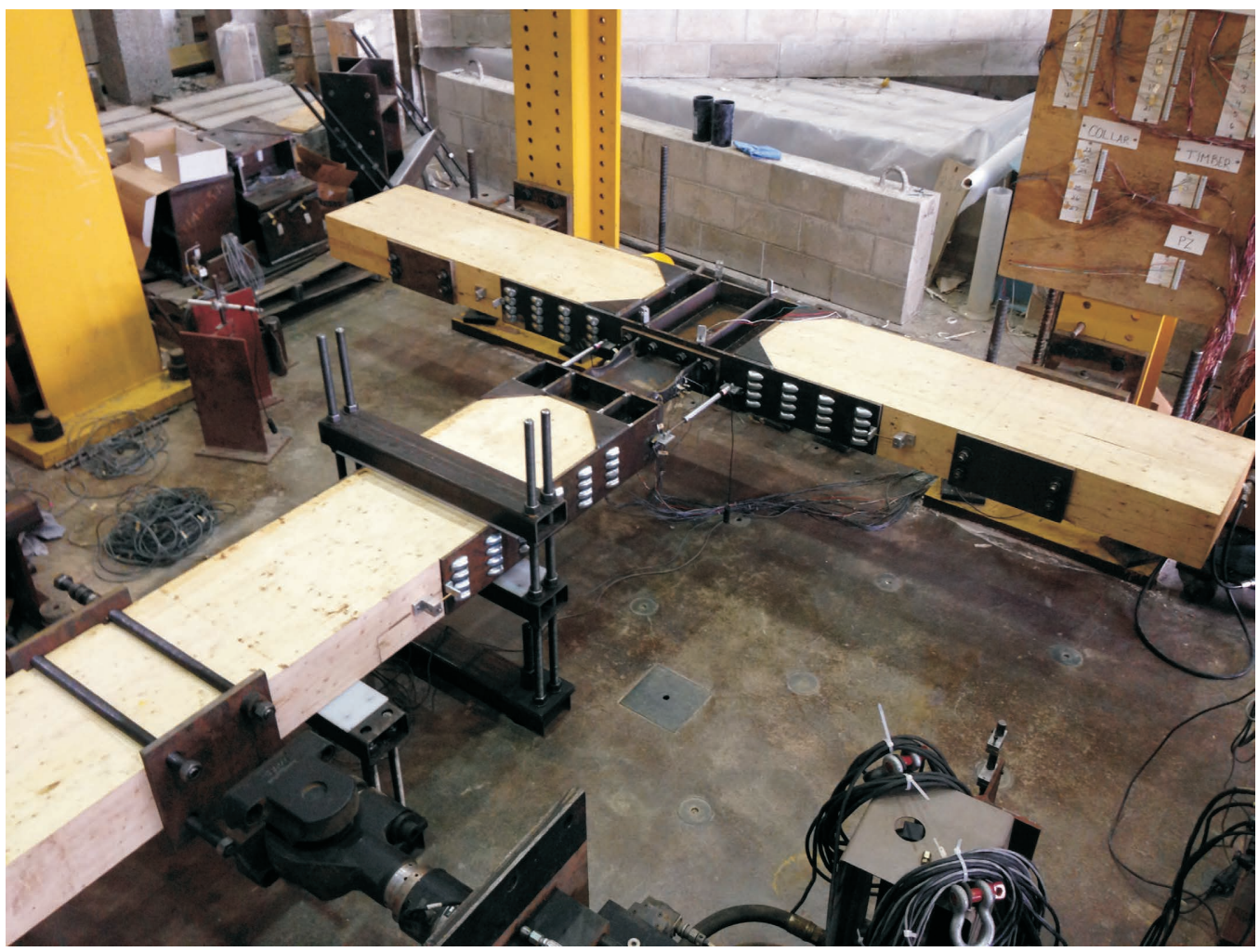

Figure 4.12: Photo of Full Test Assembly 
(LVDTs), linear potentiometers, and string potentiometers. Based on design equations, the approximate imposed displacements during testing were estimated to determine the range requirements of each instrument. Displacement transducers were mounted to steel and timber components using aluminum brackets held on by set screws. Figure 4.13 depicts the location of the displacement transducers. LVDTs were used to measure the total movement of the supports relative to the strong floor, as well as the rotation of the panel zone. Linear potentiometers were used to measure the total rotation of the links and the rigid-body rotation of the beams. Total movement of the actuator was measured using a string potentiometer. LVDTs were also used to observe the deformation of the STS connection by measuring the relative movement between the steel STS side-plates and the timber members. This was further observed by adding a line of paint across this joint. Details on the type and range of each instrument are presented in Table 4.5. Figure 4.14 shows photos of the displacement transducers used in the test.

Displacement transducers were calibrated to convert voltage readings into direct displacement readings assuming a linear relationship between voltage and displacement. This is a valid assumption provided that the location of the core of the device is kept within the valid range relative to the location of the body. The change in voltage was recorded over a known displacement to determine the voltage-displacement relationship. The linear potentiometers were calibrated over a range of $152.4 \mathrm{~mm}$, moving the device $25.4 \mathrm{~mm}$ at a time. The string potentiometer was calibrated over a range of $250 \mathrm{~mm}$, moving the device $50 \mathrm{~mm}$ at a time. The LVDTs were calibrated using a large micrometer over a range of $\pm 6 \mathrm{~mm}$. The core of the device was set as close as possible to the zero locations, and then moved $1 \mathrm{~mm}$ at a time over the aforementioned range.

Table 4.5: Displacement Transducer Details

\begin{tabular}{c|ccc}
\hline Instrument No. & Type & Range $(\mathrm{mm})$ & Range (in.) \\
\hline D1 & String Pot. & \pm 152.4 & \pm 6 \\
D2-D4 & Linear Pot. & \pm 76.2 & \pm 3 \\
D5-D15 & LVDT & \pm 6.35 & $\pm 1 / 4$ \\
\hline
\end{tabular}

Ryan Gohlich, Department of Civil and Environmental Engineering, Carleton University 


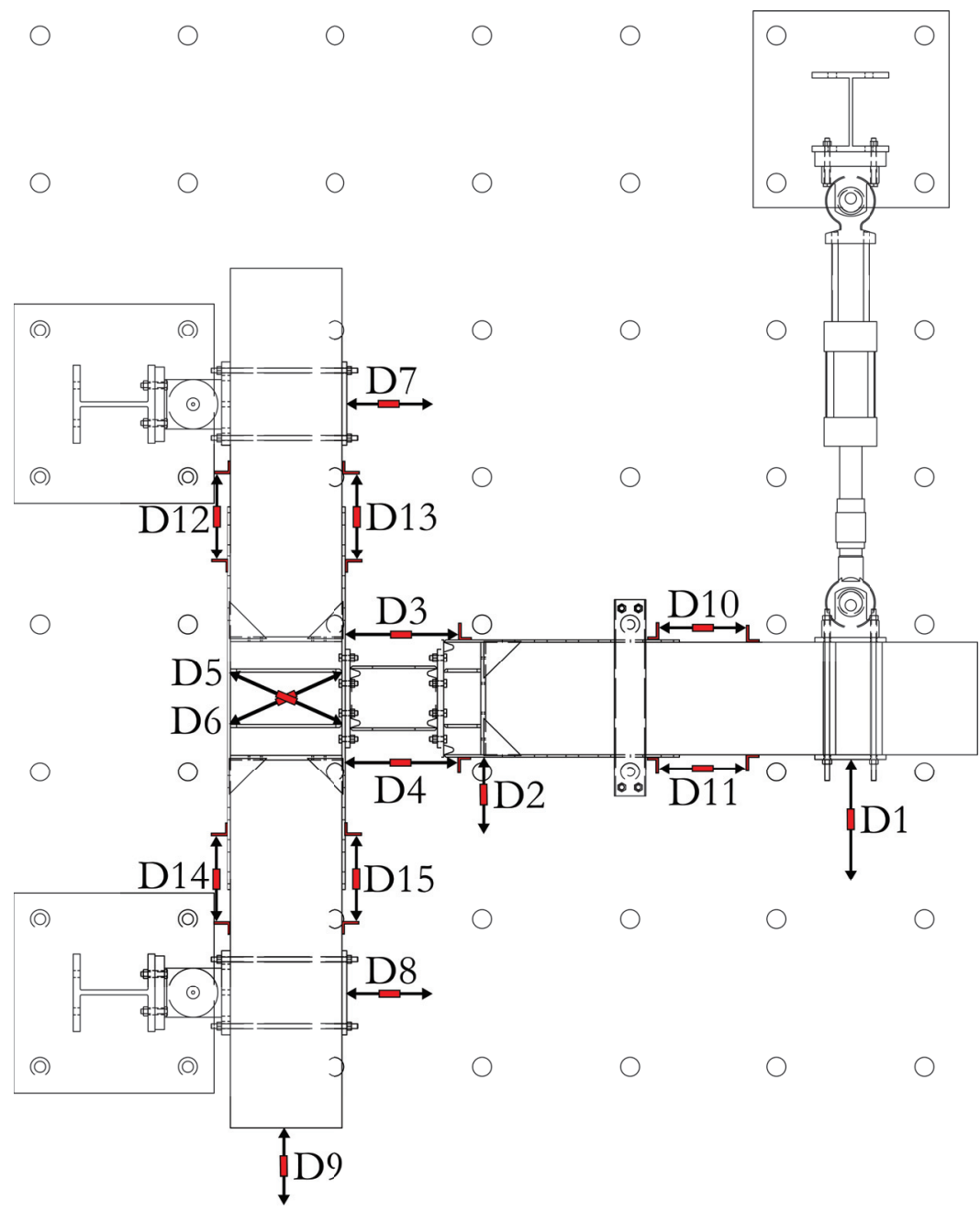

Figure 4.13: Instrumentation Plan
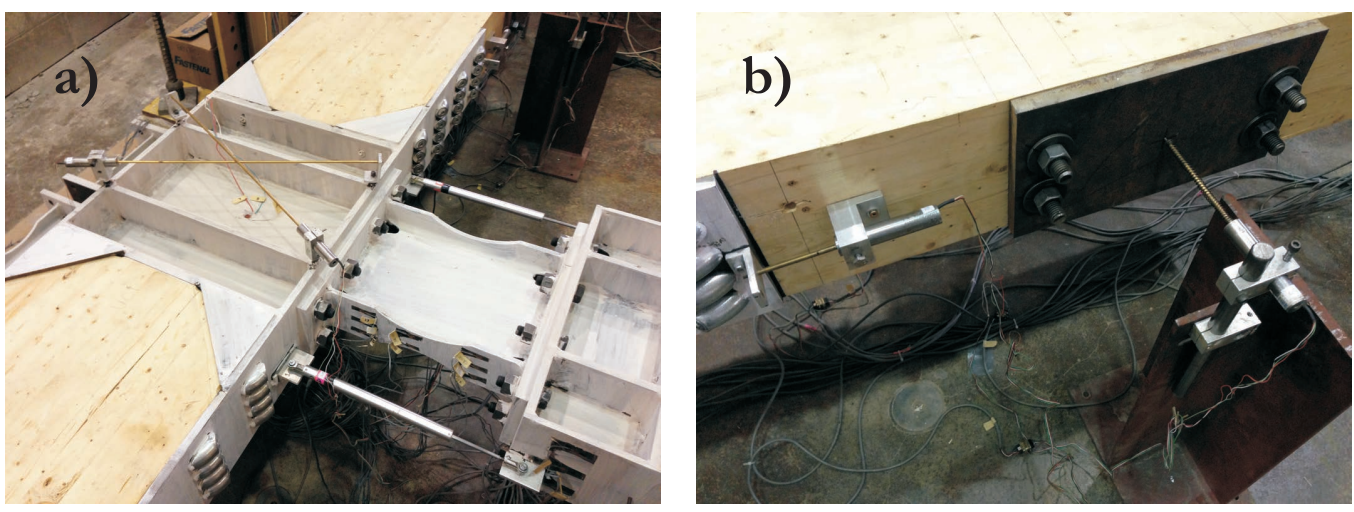

Figure 4.14: Photos of Displacement Transducers

a) Panel Zone and Link Rotation b) Screw Slip and Global Movement 
The string potentiometer and three linear potentiometers were powered using a single hp E36 10 amp DC power supply. The LVDTs required 2 Cybernex power supplies, each with a range of \pm 15 volts.

Uni-axial strain gauges were used to measure localized strain profiles in the link flanges and webs, and steel beam collars. $5 \mathrm{~mm}$ long gauges were used for steel applications. Rosette style strain gauges were used on all link webs and the steel panel zone web in order to measure the shear stresses. Figure 4.15 shows the layout of all strain gauges, and Figure 4.16 shows photos of installed gauges.

Table 4.6 summarizes the function of each instrument (Pot., LVDT, RS, and SG refer to potentiometer, linear variable differential transformer, rosette, and strain gauge respectively).

The actuator system was controlled using an MTS 458.10 MicroConsole. Data was collected during the tests using a National Instruments CompactDAQ system. Data was read and recorded at a rate of one data point per second $(1 \mathrm{~Hz})$.

\subsection{Loading Protocol}

The loading protocol used for the cyclic testing of the connection was taken from Chapter K of AISC 341-10 Seismic Provisions for Structural Steel Buildings (2010), which deals with the testing provisions for prequalified steel connections. The specified loading protocol is a cyclic displacement-based loading history with target displacement amplitudes that are based on the total storey drift of the frame. The loading protocol is shown in Figure 4.17.

These provisions also provide test assembly requirements to ensure realistic representation of seismically loaded frames, as follows (AISC 341-10, 2010):

- The assembly must consist of a single column with beams attached to one or both sides.

- Points of inflection must coincide with anticipated points of inflection of the prototype building.

- Lateral restraints are permitted near points of applied load.

Ryan Gohlich, Department of Civil and Environmental Engineering, Carleton University 

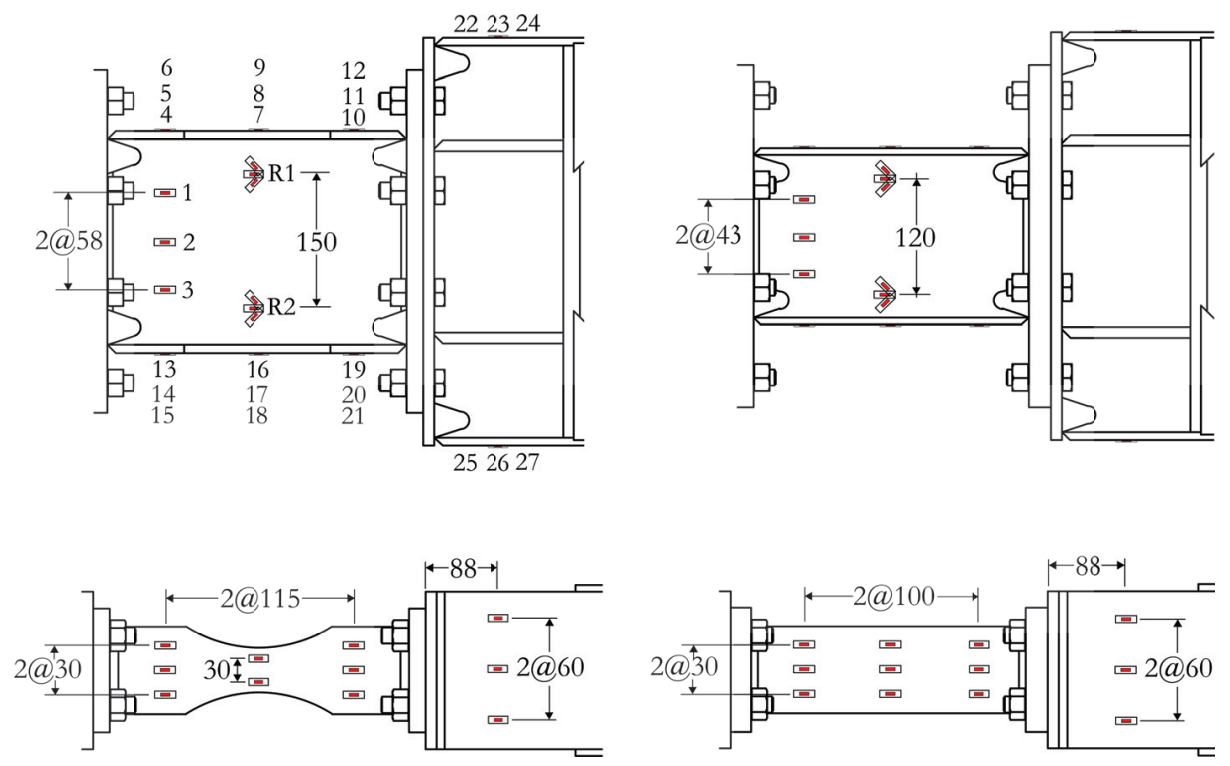

Figure 4.15: Strain Gauge Layout
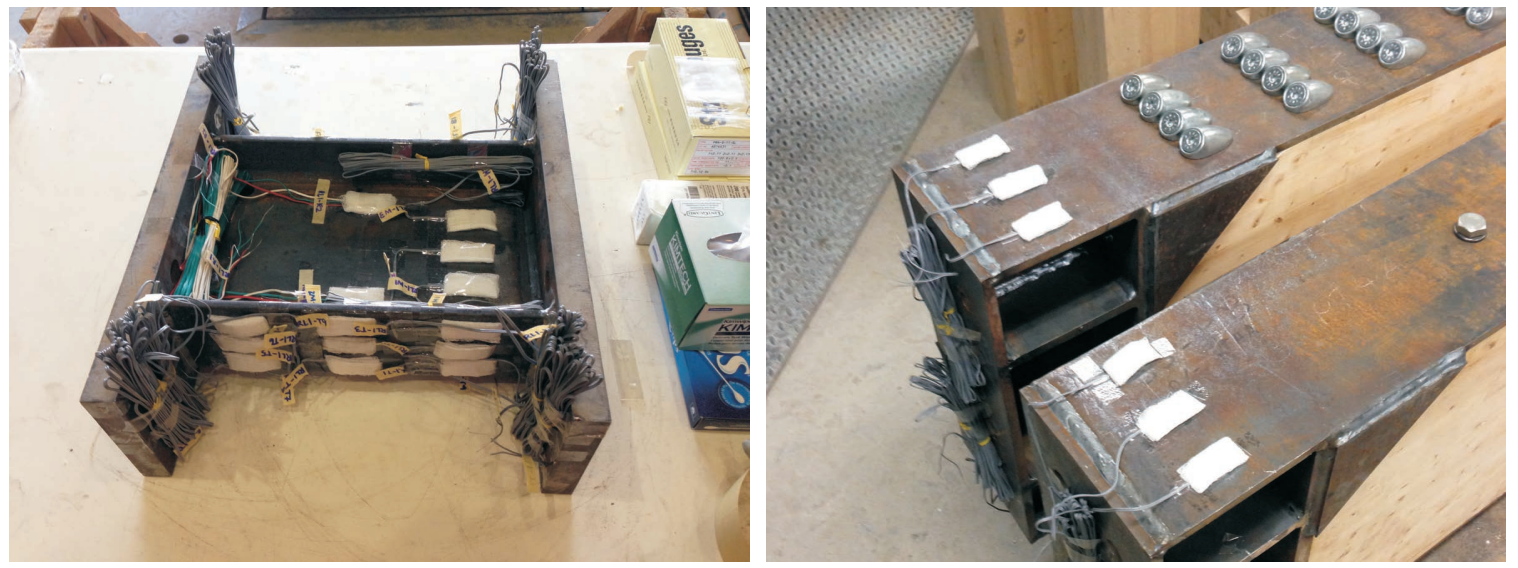

Figure 4.16: Photos of Strain Gauge Locations 
Table 4.6: Instrument Functions

\begin{tabular}{c|cc}
\hline Type & Instrument No. & Function \\
\hline Pot. & D1-D2 & Beam rotation \\
Pot. & D3-D4 & Link rotation \\
LVDT & D5-D6 & Panel Zone Rotation \\
LVDT & D7-D9 & Support movement \\
LVDT & D10-D15 & STS deformation \\
RS & R1-R2 & Link web shear \\
SG & 1-3 & Link web bending \\
SG & $4-21$ & Link flange stress profile \\
SG & $22-27$ & Force in STS connection \\
\hline
\end{tabular}

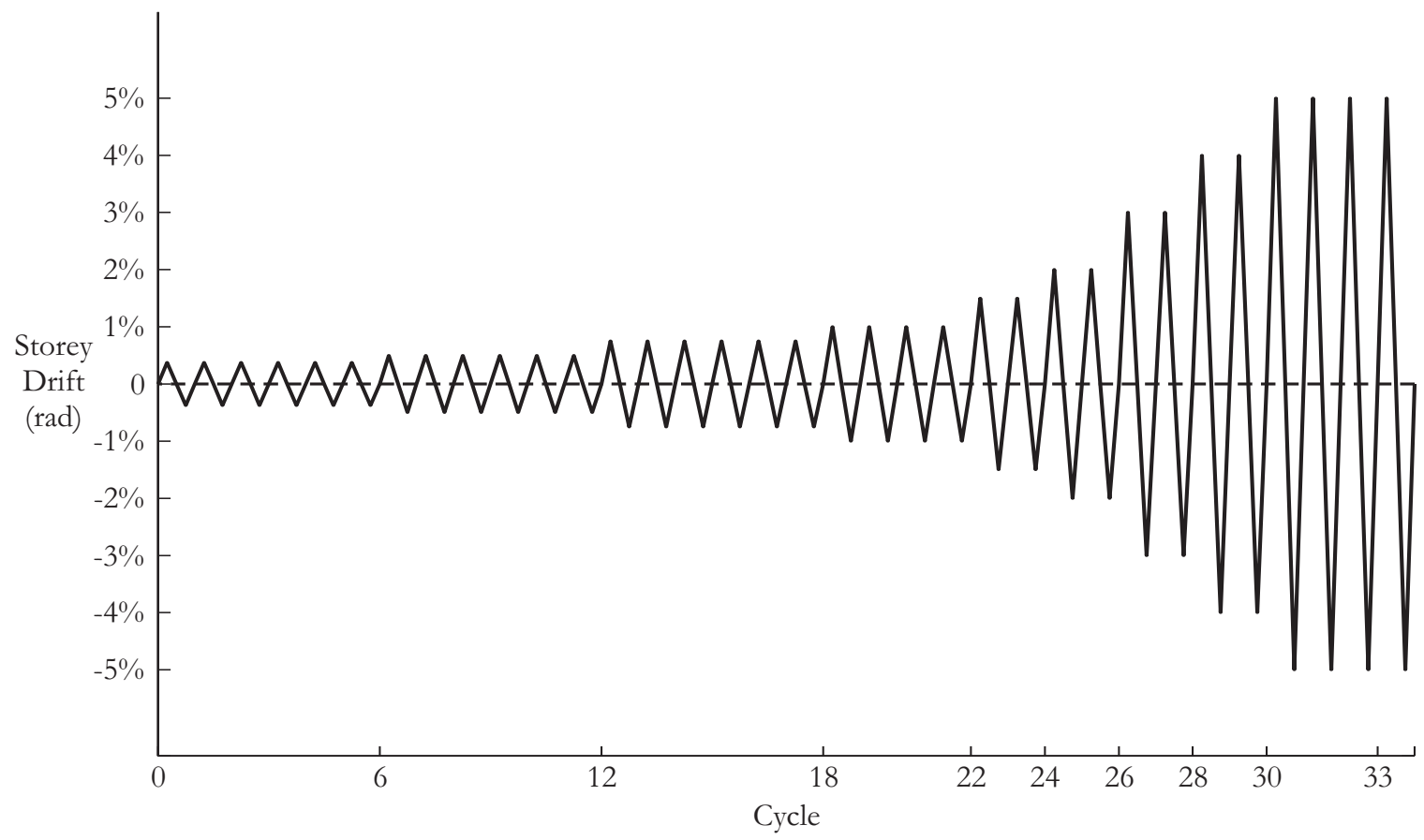

Figure 4.17: Cyclic Loading Protocol (AISC 341-10, 2010) 
Each of these requirements was satisfied for the test setup described in this study. The recommended loading sequence from Chapter K (AISC 341-10, 2010), shown in Table 4.7, was implemented by controlling the storey drift angle, $\theta$, of the test frame. This was done by imposing a cyclic push-pull displacement history to the beam-tip for a specified number of cycles using a $245 \mathrm{kN}$ actuator located approximately $1.87 \mathrm{~m}$ from the expected location of plastic hinging (middle of the link). The required beam-tip displacement (shown in Table 4.7) was calculated as the product of the required storey drift angle and the distance from the point of load to the centerline of the column $(2.3 \mathrm{~m})$.

Displacements were applied at a loading rate of $1 \mathrm{~mm} / \mathrm{sec}$. Following completion of the specified sequence, loading should be continued at increments of $\theta=0.01 \mathrm{rad}$ with two cycles per step until acceptance criteria is exceeded or severe brittle failure of any component was observed (AISC 341-10, 2010). A limitation of 0.05 rad rotation was placed on the magnitude of beam tip displacement due to the configuration of the lateral restraint system. This level of rotation was applied cyclically until failure of the specimen occurred. It should also be noted that displacements specified in the loading protocol were approximate during testing. Slight errors in the control system resulted in small deviations from the displacements given in Table 4.7, so imposed storey drift levels were less than those specified in Chapter K of the Seismic Provisions for Structural Steel Buildings (AISC 341-10, 2010). The difference in imposed versus specified displacement is quantified in Table 4.8 for both the positive and negative loading cycles. Actual displacements imposed during testing were recorded and used for all data analysis.

\subsection{Acceptance Criteria}

AISC 341-10 Seismic Provisions for Structural Steel Buildings (2010) states that the test specimen must sustain at least one full cycle at a storey drift angle of $0.04 \mathrm{rad}$ without showing signs of significant strength degradation. These provisions specify that the reduced section must sustain an applied moment at the column face of at least $80 \%$ of the nominal moment capacity of the beam for the duration of the test. Due to the presence of the nonlinear replaceable link, 
Table 4.7: Loading Protocol

\begin{tabular}{c|cc}
\hline No. of Cycles & $\theta(\mathrm{rad})$ & Beam Tip Disp. (mm) \\
\hline 6 & 0.00375 & 8.65 \\
6 & 0.005 & 11.53 \\
6 & 0.0075 & 17.30 \\
4 & 0.01 & 23.06 \\
2 & 0.015 & 34.59 \\
2 & 0.02 & 46.13 \\
2 & 0.03 & 69.19 \\
2 & 0.04 & 92.25 \\
$\mathrm{n}$ & 0.05 & 115.32 \\
\hline
\end{tabular}

Table 4.8: Error in Imposed Loading

\begin{tabular}{c|cc}
\hline Drift & Difference $_{\text {positive }}(\%)$ & Difference $_{\text {negative }}(\%)$ \\
\hline 0.00375 & 3.2 & 4.2 \\
0.005 & 2.2 & 1.2 \\
0.0075 & 1.7 & 1.3 \\
0.01 & 1.5 & 1.5 \\
0.015 & 1.9 & 1.9 \\
0.02 & 1.9 & 2.0 \\
0.03 & 1.8 & 0.7 \\
0.04 & 2.3 & 0.02 \\
0.05 & 2.7 & 0.3 \\
\hline
\end{tabular}


the failure criteria has been defined as any strength degradation below $80 \%$ of the peak capacity of the nonlinear replaceable link. 


\section{Chapter 5: Experimental Results}

This chapter presents and discusses the experimental findings of the study described in the previous chapter. Performance of the hybrid connection is analyzed by means of experimental observations, hysteretic behaviour, and strain profiles throughout various components of the test specimen.

\subsection{Summary of Test Setup}

Figure 5.1 shows an overview of the complete test assembly. Four tests were completed to evaluate the seismic performance of the proposed connection in accordance with the Seismic Provisions for Structural Steel Buildings (AISC 341-10, 2010). Two tests were completed using nonlinear replaceable links (NRLs) with a dogbone detail (regarded as the RBS link) and two tests were complete with NRLs that did not incorporate a dogbone detail (regarded as the regular link). Two tests used a 45 degree self-tapping screw (STS) connection at the beam-to-collar interface, and two tests used a ZD-plate connection at the beam-to-collar interface. Table 5.1 shows the

Table 5.1: Test Specimens

\begin{tabular}{c|cc}
\hline Specimen & Link Type & Beam Connection \\
\hline MC-1A & RBS & $45^{\circ}$ STS \\
MC-2A & Regular & $45^{\circ}$ STS \\
MC-1B & RBS & ZD-Plate \\
MC-2B & Regular & ZD-Plate \\
\hline
\end{tabular}




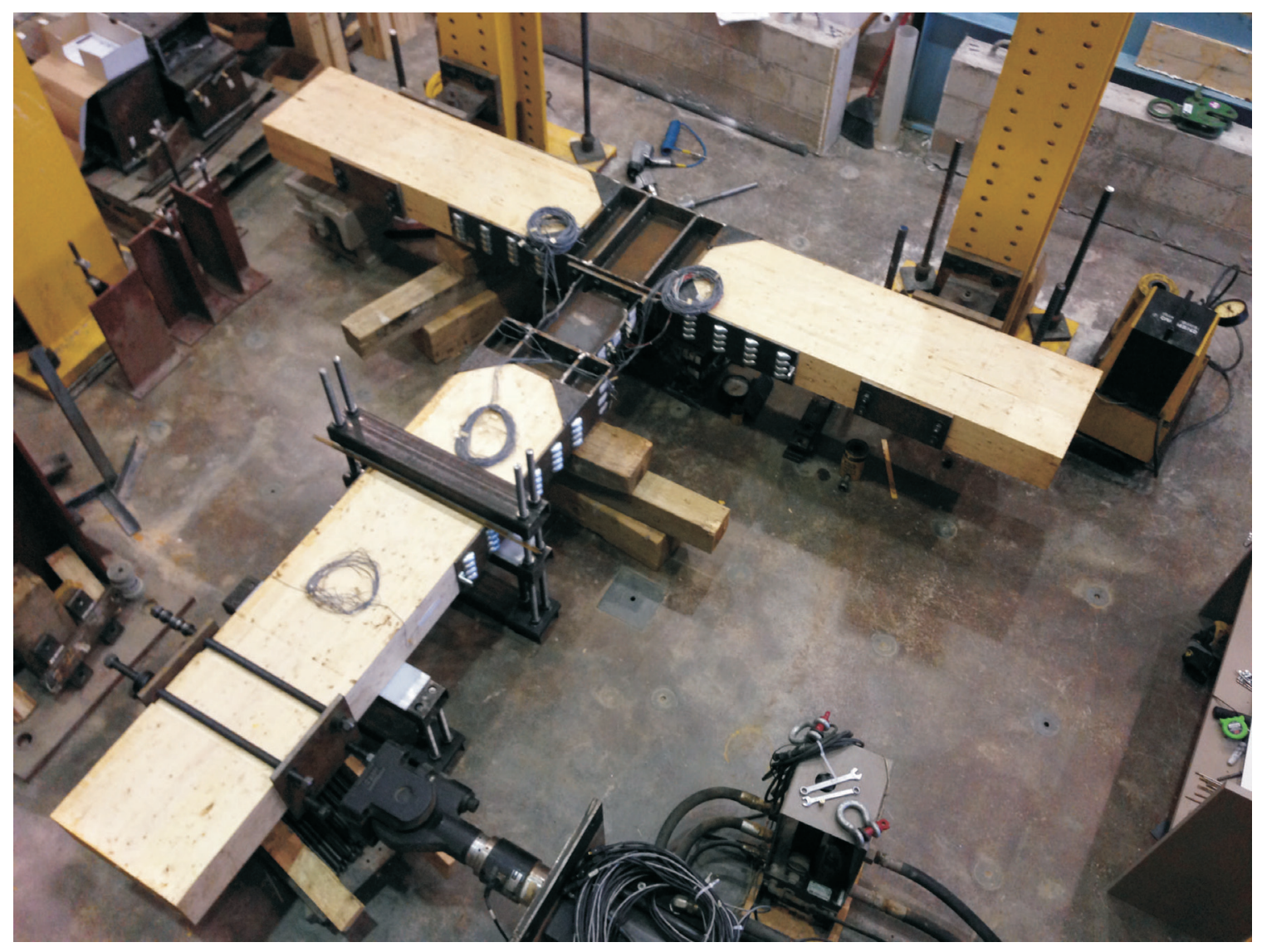

Figure 5.1: Photo of Complete Test Specimen 
combinations of link type and beam type for each of the four connections.

\subsection{Data Analysis Methods}

Figure 5.2 shows an idealized deformation of the proposed connection in a full portal frame. Because the total interstorey drift on the frame is equal to the rotation of the line extending from the column centerline to the middle of the beam, the total storey drift can be represented as the simplified frame shown in Figure 5.3. In this frame, the total interstorey drift is effectively equal to the rotation of the line extending from the column centerline to the beam tip.

Performance of the proposed connection was evaluated based on global hysteretic response, local rotations of each individual STS connection, and strain profiles of various connection components. Global hysteretic response is presented for each test using beam tip force $(\mathrm{F})$ versus beam tip displacement $\left(\delta_{\text {act }}\right)$, moment at the column face $\left(M_{c f}\right)$ versus total storey drift angle $(\theta)$, and moment at the column face versus plastic storey drift angle $\left(\theta_{P}\right)$. The beam tip force was directly measured by a load cell attached to the actuator, and the beam tip displacement was directly measured using displacement transducer D1. The moment at the column face and the total storey drift angle were calculated using equations (5.1) and (5.2) respectively.

$$
M_{c f}=F\left(L_{P Z}-\frac{d_{c}}{2}\right)
$$

where $L_{P Z}$ is the distance from the point of load to the centerline of the column $(2.3 \mathrm{~m})$ (see Figure 5.3) and $d_{c}$ is the depth of the column.

$$
\theta=\frac{\delta_{a c t}}{L_{P Z}}
$$

The plastic storey drift angle was caluclated by subtracting the total elastic drift portion of the response from the global hysteretic response, as shown in equation (5.3).

$$
\theta_{P}=\theta-\frac{F}{k_{\text {elastic }} \cdot L_{P Z}}
$$




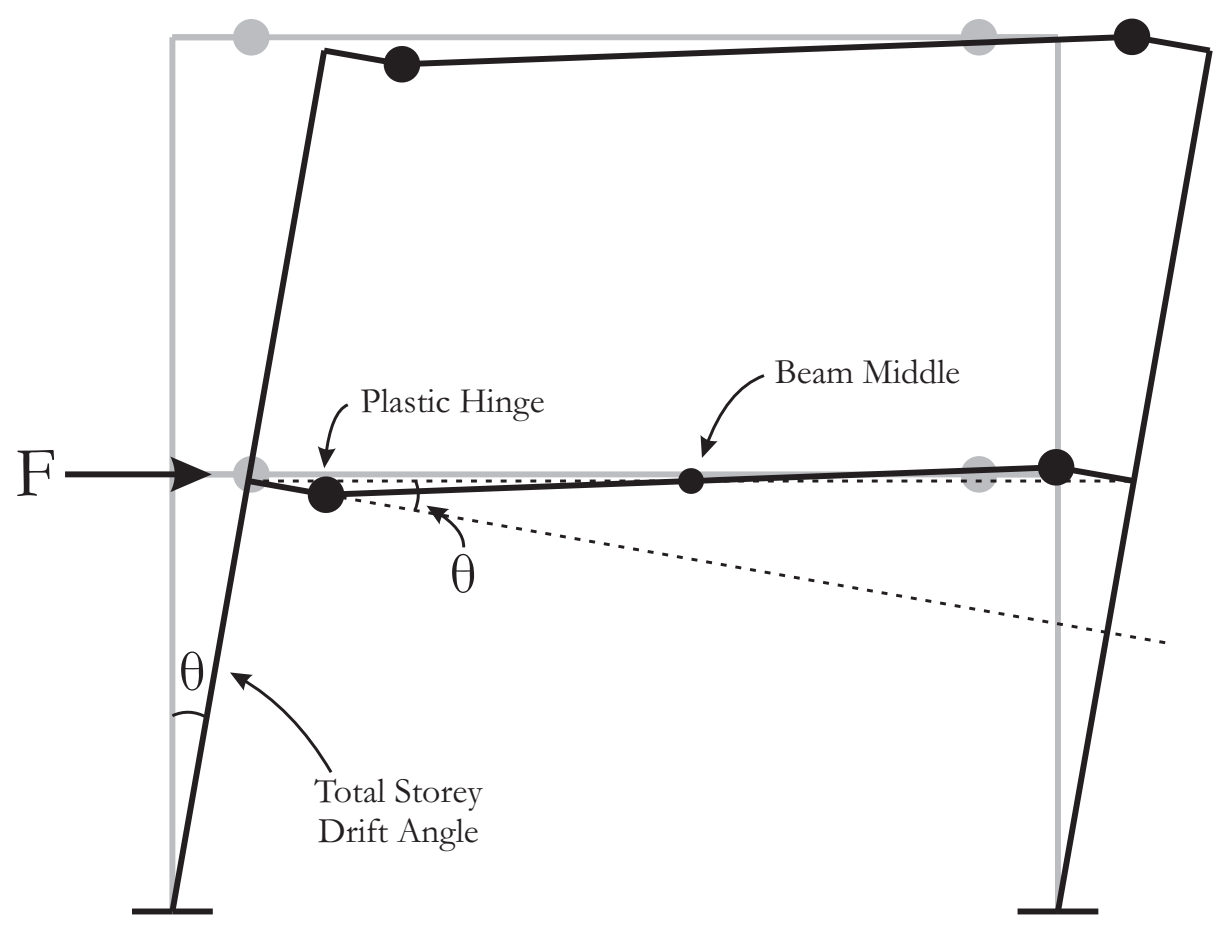

Figure 5.2: Idealized Deformation of Full Frame

The elastic rotational stiffness $\left(k_{\text {elastic }}\right)$ was was taken from the global force versus beam tip displacement hysteresis plot by calculating the slope of the elastic portion of the response between the origin to the point at the first onset of yielding.

The hysteretic response of the STS connections is presented as the moment at mid-length of the STS connection (see Figure 5.3) ( $M_{S T S}$ ) versus the effective rotation caused by the slip of the STS connection on the top and bottom of the wood member $\left(\theta_{S T S \text {, eff }}\right.$, relative to the column centerline). This was done for each of the three STS connections per test (beam, upper column, and lower column). The moment at mid-length of the beam STS connection was calculated as the product of the actuator force and the distance between the actuator and mid-length of the STS connection $(1.06 \mathrm{~m})$. The moment at mid-length of the column STS connection was determined in a similar manner, assuming that the moment at the centerline of the column was evenly distributed between the upper and lower columns. The total rotation of each connection was calculated according to equation (5.4) below.

$$
\theta_{S T S, \text { total }}=\frac{\delta_{11}-\delta_{10}}{s}
$$




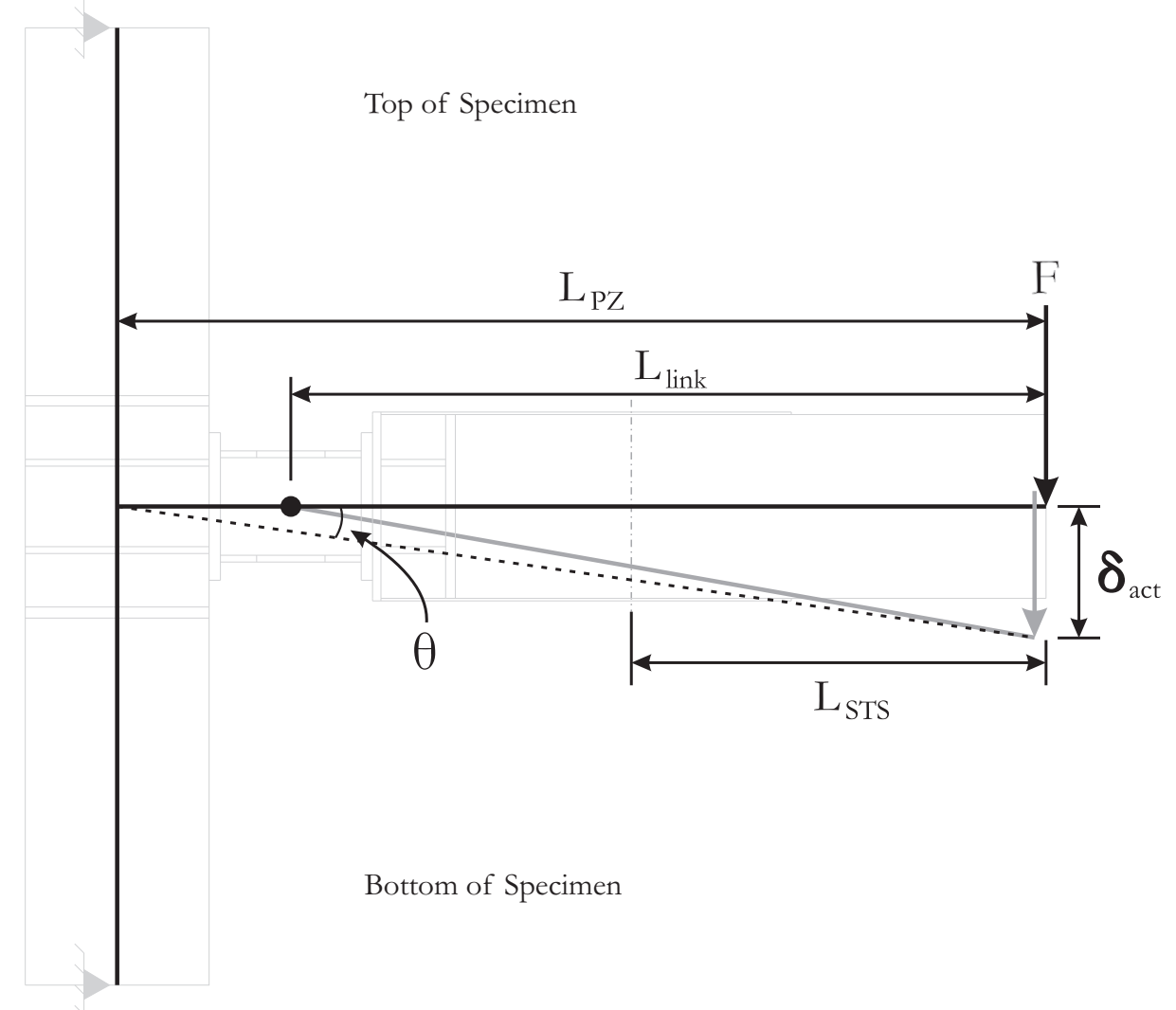

Figure 5.3: Deformation of Test Frame 
where $s$ is the distance between LVDTs D11 and D10 (shown in Figure 4.13), $\delta_{11}$ and $\delta_{10}$ are the displacements measured by LVDTs D11 and D10 respectively. It should be noted that D11 and D10 are for the beam STS connection. To find the effective rotation of the column STS connections, the same equation is used, but readings from D13 and D12 should be used for the upper column and readings from D15 and D14 should be used for the lower column.

The contribution of each connection component $\left(\theta_{\text {link }}, \theta_{P Z}, \theta_{S T S}\right.$, and $\left.\theta_{\text {elastic }}\right)$ to total storey drift is presented as percent contribution to total storey drift angle (out of $100 \%$ ). The overall STS connection contribution to total storey drift angle $\left(\theta_{S T S}\right)$ was taken as the sum of the rotation due to each of the three individual connections, factored to give a total effective rotation relative to the centerline of the column. The effective rotation of the beam STS connection was calculated using equation (5.5). The effective rotation of the column STS connections were calculated in a similar manner.

$$
\theta_{S T S, e f f}=\theta_{S T S}\left(\frac{L_{S T S}}{L_{P Z}}\right)
$$

Equation (5.6) presents the method of calculating the total rotation of the link relative to the link centre, where $\delta_{4}$ and $\delta_{3}$ are the displacements measured by LVDTs D4 and D3 respectively, and $\mathrm{h}$ is the distance between LVDTs D4 and D3 (527 mm).

$$
\theta_{\text {link }}=\frac{\delta_{4}-\delta_{3}}{h}
$$

The effective link rotation relative to the column centerline can then be calculated using equation (5.7), where $L_{\text {link }}$ is the distance between the actuator and the link centre (see Figure $5.3)$.

$$
\theta_{\text {link }, \text { eff }}=\theta_{\text {link }}\left(\frac{L_{\text {link }}}{L_{P Z}}\right)
$$

The total panel zone rotation is calculated using equation (5.8), where $a$ is equal to the distance between panel zone stiffeners $(233 \mathrm{~mm})$ and $b$ is equal to the column depth from the centre of the inner flange to the centre of the outer flange $(450 \mathrm{~mm})$. It should be noted that the 
panel zone rotation does not need to be converted to an effective rotation since the panel zone rotation is inherently relative to the column centerline.

$$
\theta_{P Z}=\frac{\sqrt{a^{2}+b^{2}}\left(\delta_{6}-\delta 5\right)}{2 a b}
$$

where $\delta_{6}$ and $\delta_{5}$ are the displacement readings from LVDTs D6 and D5 respectively.

The contribution to total storey drift from all other elastic components can be calculated by subtracting the contribution of the link, STS connections, and panel zone from the total rotation achieved during testing, as shown in equation (5.9). This quantity represents the rotation due to bending of both timber columns and the timber beam, as well as any additional movements in unmeasured connection components.

$$
\theta_{\text {elastic }}=\theta-\theta_{\text {link,eff }}-\theta_{S T S, e f f}-\theta_{P Z}
$$

Local behaviour of individual connection components such as link flanges and web, steel beam collar, and timber beam were monitored directly using raw strain readings. Critical data was plotted (as strain profiles) and is presented in the following sections.

\subsubsection{Error in Data Analysis}

Some error was introduced into the test readings due to instrument calibration and support movement. Error in the calibration of the instruments was quantified prior to testing (during calibration) by accurately measuring the movement of the instrument and observing the reading output by the data acquisition system. Since the LVDTs were measuring small displacements ( \pm $6.35 \mathrm{~mm}$ ), the error was on the order of one one hundredth of a millimeter. The calibration of the potentiometers introduced a maximum error on the order of one tenth of a millimeter. Such small error did not significantly impact the accuracy of the readings.

Error was introduced to the global movement readings due to small deformations in the support pins and connections to the supports. These errors were measured by LVDTs D7, D8, and D9 (see Figure 4.13). Rotations in the timber members contributed somewhat to the total displacement measurement output by these LVDTs. This led to uncertainty about what portion 
of the readings was due to global translation of the setup, and what portion was due to local rotation of the columns (around the pinned connection) caused by bending. For this reason, these readings were not included in the calculations for global connection rotation; however, by conservatively assuming that all movement was due to global translation (and subtracting it from the global connection movement), the overall response was only changed by approximately $1 \%$ of the total drift at the maximum drift limit (ie. $0.0005 \mathrm{rad}$ difference at $0.05 \mathrm{rad}$ rotation). This potential error varied in linear proportion to the applied total drift. No sudden changes in displacement were observed, indicating that there was no abrupt slip of connections, and movements varied based on force for the duration of the test. Since the error was found to be very small and the actual magnitude of the pin movement was not easily quantified, this effect was not accounted for in the calculations of the drifts.

\subsection{Test Frame Performance}

The following section presents the findings of the experimental program. First, the test observations will be shown, followed by a discussion of the performance of each specimen, the behaviour of the steel-timber connection, and a comparison of different test specimens. Experimental observations will be presented using a summary plot of major events, followed by photographs of such events. For components that show no obvious change in behaviour (remain elastic), photos are not presented, but the behaviour of such components is addressed in the discussion. The beam side (BS) refers to the end of the link closest to the beam member, the column side (CS) refers to the end of the link closest to the panel zone, and the middle refers to the centerline of the link length. The top of the specimen refers to the side of load application. A positive movement refers to the actuator pushing outward, hence clock-wise rotations are considered positive. Figure 5.3 shows the direction of positive beam rotation.

\subsubsection{Overview of Link Performance}

Figure 5.4 shows a photo of each link specimen (subsequent to testing) where a majority of the inelastic behaviour has taken place. Links with the dogbone detail shown in a) and c)

Ryan Gohlich, Department of Civil and Environmental Engineering, Carleton University 
exhibited ductile behaviour at multiple cycles of $0.05 \mathrm{rad}$ storey drift, and testing ceased due to excessive out of plane movements. Additional cycles would risk damaging the beam and column components of the connection, which were to be reused in subsequent tests. Links shown in b) and d) exhibited ductile behaviour at all cycles of 0.04 rad storey drift, however sudden failure by means of flange fracture occurred when displaced to 0.05 rad storey drift. Further cycling resulted in complete fracture of the entire link cross-section.

\subsubsection{MC-1A}

\subsubsection{Failure Sequence}

The first test used a steel link with a dogbone detail, and the beam connection type used 45 degree STS (the same as the column connections). A summary of the test observations can be seen in Figure 5.5.

Figures 5.6, 5.7, and 5.8 show a summary of the yield propogation through the link at critical points in the test (initial conditions, first onset of yielding ( $0.01 \mathrm{rad})$, acceptance criteria limit $(0.04 \mathrm{rad})$, and link failure $(0.05 \mathrm{rad})$. All components of the connection remained elastic until the third cycle at $0.005 \mathrm{rad}$ storey drift angle. At this point, slight signs of yielding at the link middle (dogbone) location and flange-to-end-plate weld location were observed. Yielding in these locations became more pronounced as the frame approached $0.01 \mathrm{rad}$ storey drift angle (Figures 5.9 and 5.10), and yielding began around the weld access holes. Yielding propagated into the link web at $0.01 \mathrm{rad}$ drift. Due to the low out-of-plane stiffness of the link with the dogbone detail, out-of-plane local buckling of the web began at $0.02 \mathrm{rad}$ storey drift and was greater than expected. Web yielding became excessive (Figure 5.11) and local buckling of the web began at $0.03 \mathrm{rad}$ drift. At this point, out-of-plane movement became excessive (Figure 5.12), so an additional lateral restraint was provided closer to the actuator to limit lateral torsional buckling. At 0.04 rad drift, slight gap openings were observed between the column side end-plate and the column face (Figure 5.13), and local buckling began in the link flanges (Figure 5.14). As

cycles continued at $0.05 \mathrm{rad}$ drift, yielding continued to propagate to the ends of the flanges and

Ryan Gohlich, Department of Civil and Environmental Engineering, Carleton University 

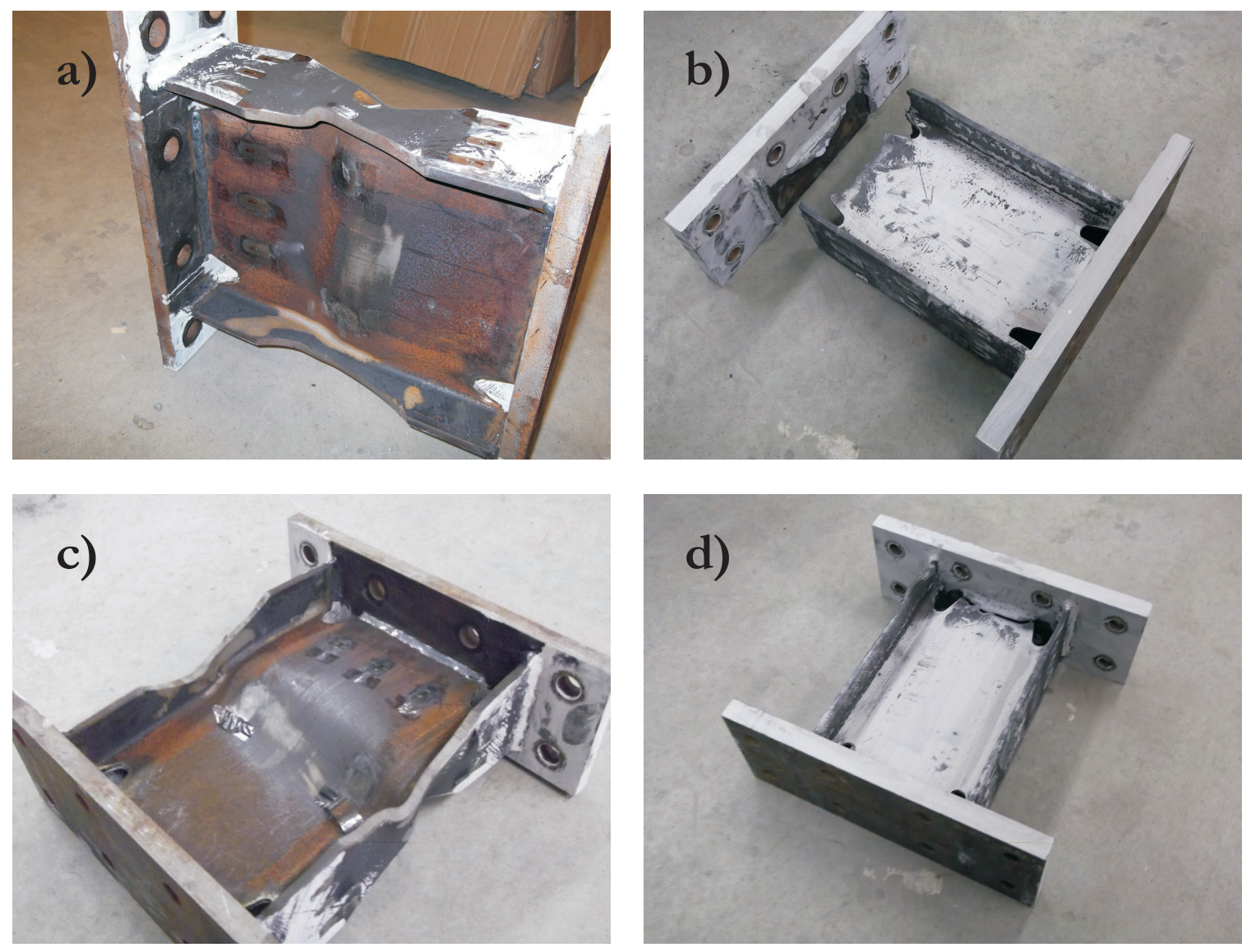

Figure 5.4: Failed Link Specimens

a) $\mathrm{MC}-1 \mathrm{~A} \mathrm{~b}$ ) $\mathrm{MC}-2 \mathrm{~A}$ c) $\mathrm{MC}-1 \mathrm{~B}$ d) $\mathrm{MC}-2 \mathrm{~B}$ 


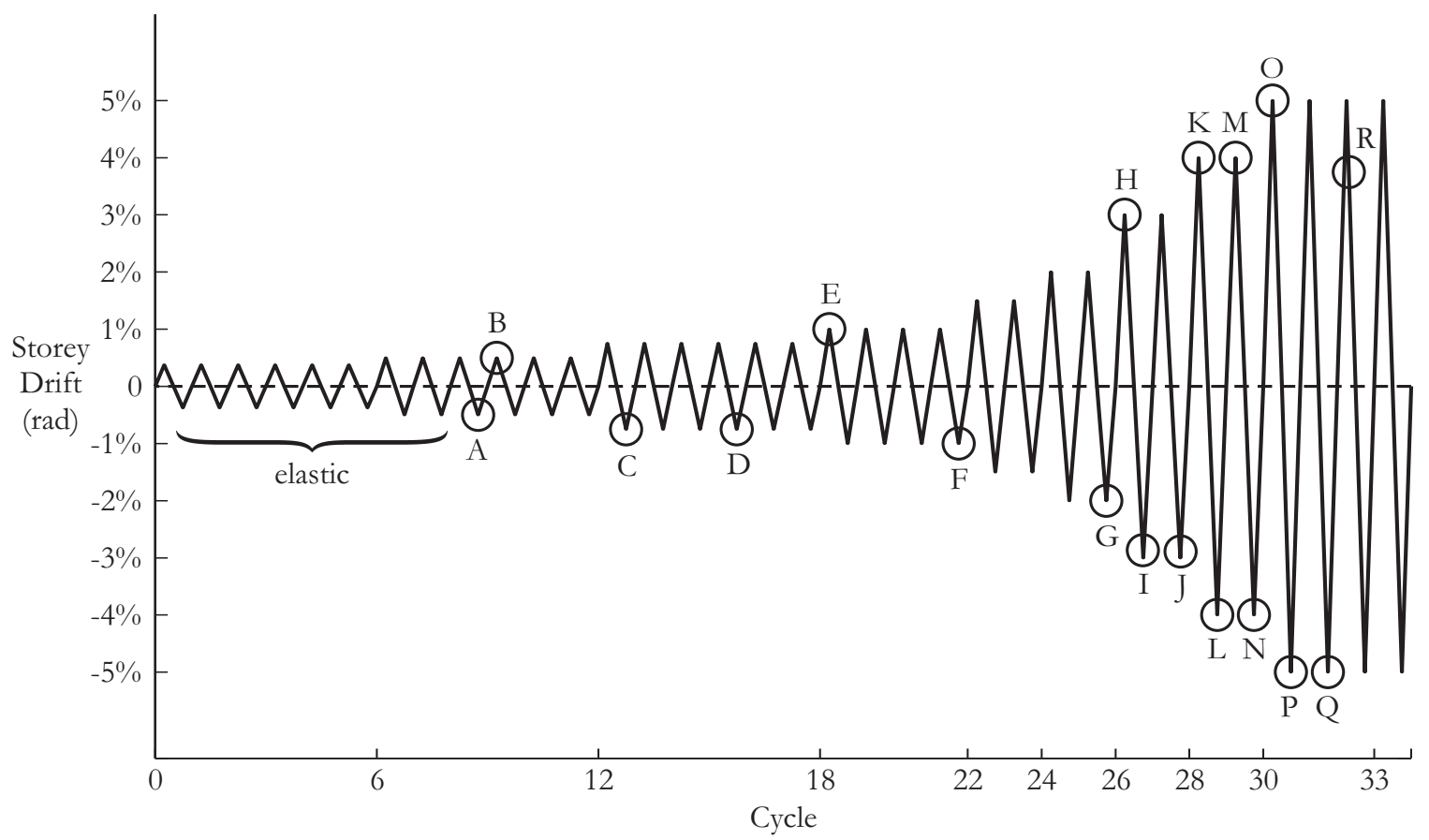

A - Yielding of link top flange at dogbone location, slight flaking of white-wash at end-plate weld (CS)

B - Slight flaking of white-wash at end-plate weld of bottom flange

C- Yielding of link at dogbone location becomes more excessive

$\mathrm{D}^{-}$Yielding begins at top beam-side weld access hole

E- Yielding propagates into link web

F - Excessive flaking of white-wash at bottom flange end-plate weld (CS)

$\mathrm{G}^{-}$Signs of lateral torsional buckling of timber beam

$\mathrm{H}^{-}$Uniform yielding across entire link flange

I - Strain gauges fall off of link flanges, excessive lateral torsion buckling of timber beam

$\mathrm{J}$ - Local buckling of link web begins

K- Strength drop due to excessive out-of-plane deformations, tightened lateral restraints

L - Local buckling of top flange, signs of end-plate deformation (CS)

$\mathrm{M}^{-}$Slight gap opening of end-plate, local buckling in bottom flange

$\mathrm{N}^{-}$Installed additional lateral restraint closer to point of load

$\mathrm{O}^{-}$Excessive web local buckling, yielding on beam-side of link flanges

$\mathrm{P}$ - Excessive flange local buckling, web yielding at end-plate (CS)

Q- Small crack on web-to-end-plate weld at top of link (CS)

$\mathrm{R}$ - Test ended due to excessive out of plate deformations

Figure 5.5: Summary of Observations for Test MC-1A 
to the beam side of the link web. Just before termination of the test, a small crack developed near the web-to-end-plate weld (Figure 5.15). Areas where the white-wash flaked off in Figures 5.6 through 5.15 are indications of steel yielding.

Examination of these above photos show that the dogbone section was successful in localizing plastic deformations to the centre of the link. Significant propagation of yielding towards the link ends and brittle weld components did not occur until the later cycles, and even then was not substantial. The small gap openings that were seen indicate that the end-plates may be slightly overdesigned, since more end-plate bending was expected based on design equations. After the tests, all end-plate bolts remained tight, so it is unlikely that any inelastic bolt elongation occurred. The crack that developed in the column side of the link showed no indication that it affected the connection performance, although crack propagation could be possible if the frame was pushed to drift levels exceeding $0.05 \mathrm{rad}$. The aspect ratios of the selected link resulted in the onset of web local buckling prior to flange local buckling, which was not anticipated. Such connections usually rely on flange local buckling as the primary failure mechanism; however, this did not negatively impact the results, and is likely an effect of scaling since larger w-sections are usually used for these connections. The connections appeared to exhibit quite ductile behaviour up to $0.05 \mathrm{rad}$ storey drift. At this level, the test was stopped after 2.5 cycles due to excessive outof-plane local buckling of the link web, which was beginning to cause out-of-plane movements of the support pins and the beam and column sections (which needed to be used for subsequent tests). No observable plastic deformations or brittle failures occurred in the timber elements, steel-to-timber connections, or the steel panel zone.

Ryan Gohlich, Department of Civil and Environmental Engineering, Carleton University 

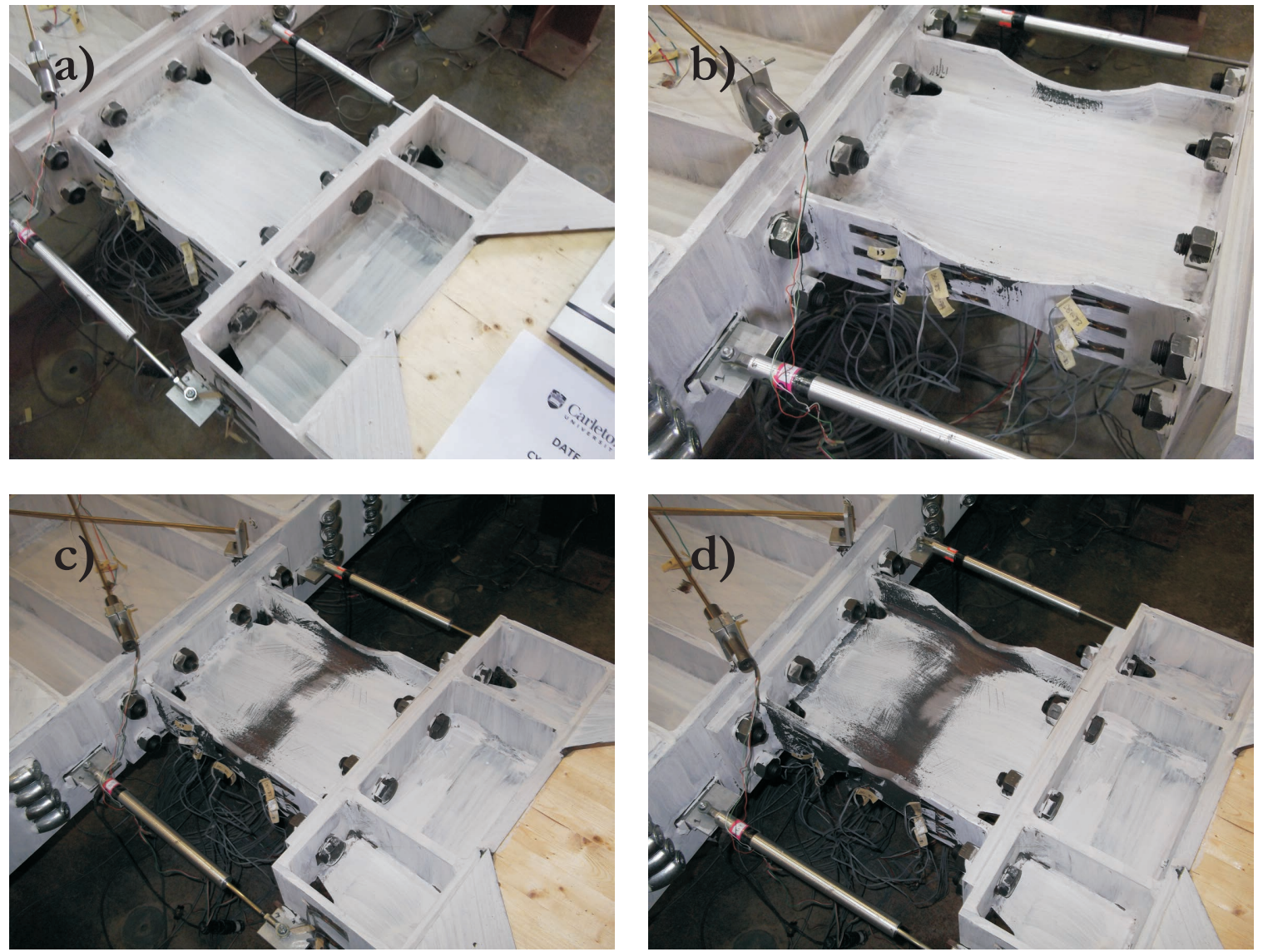

Figure 5.6: Yielding Propagation in Link for Test MC-1A a) Initial b) $1 \%$ Drift c) $4 \%$ Drift d) Final 

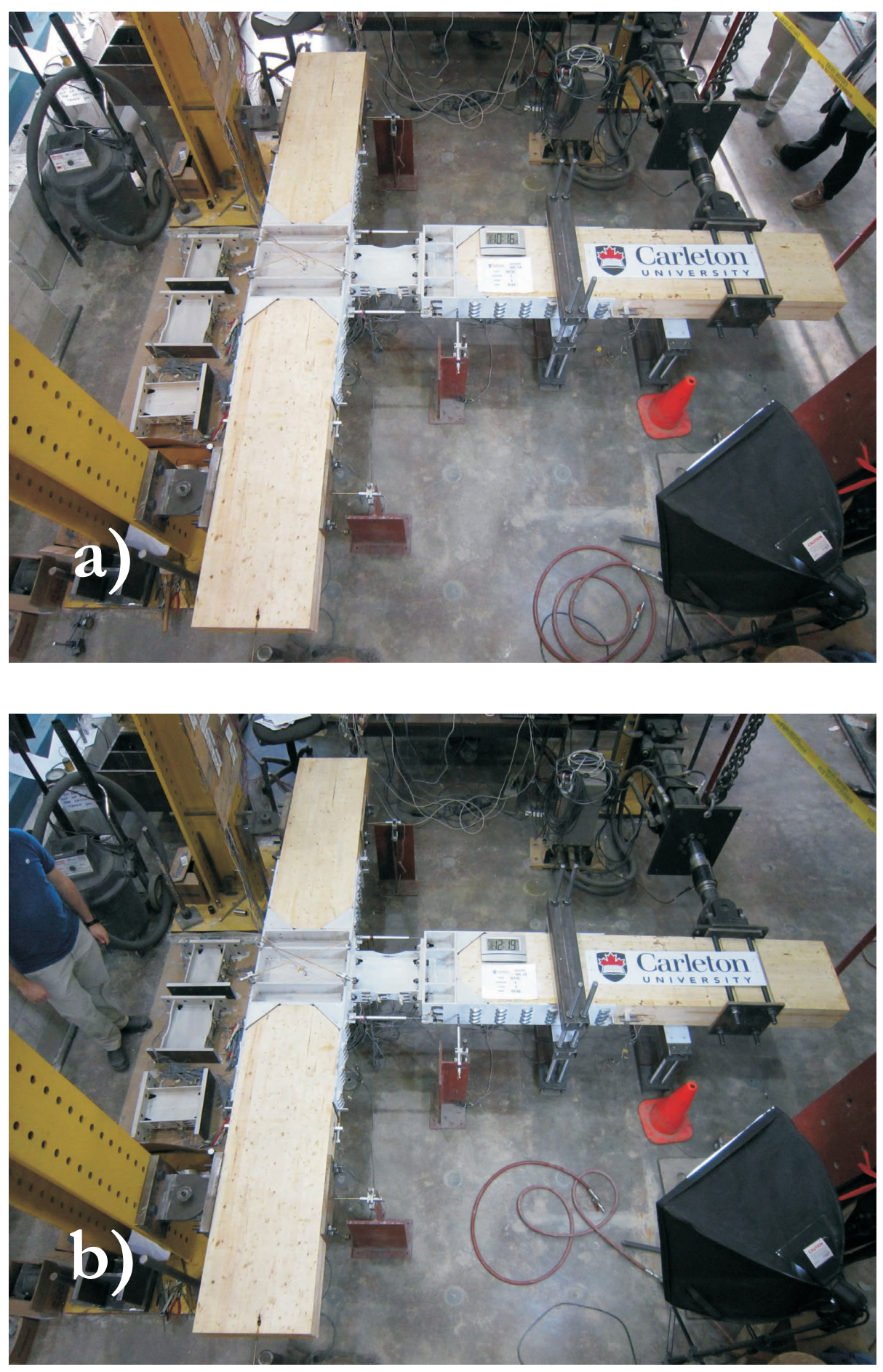

Figure 5.7: Frame Deformations Through Test MC-1A a) Initial b) $1 \%$ Drift 

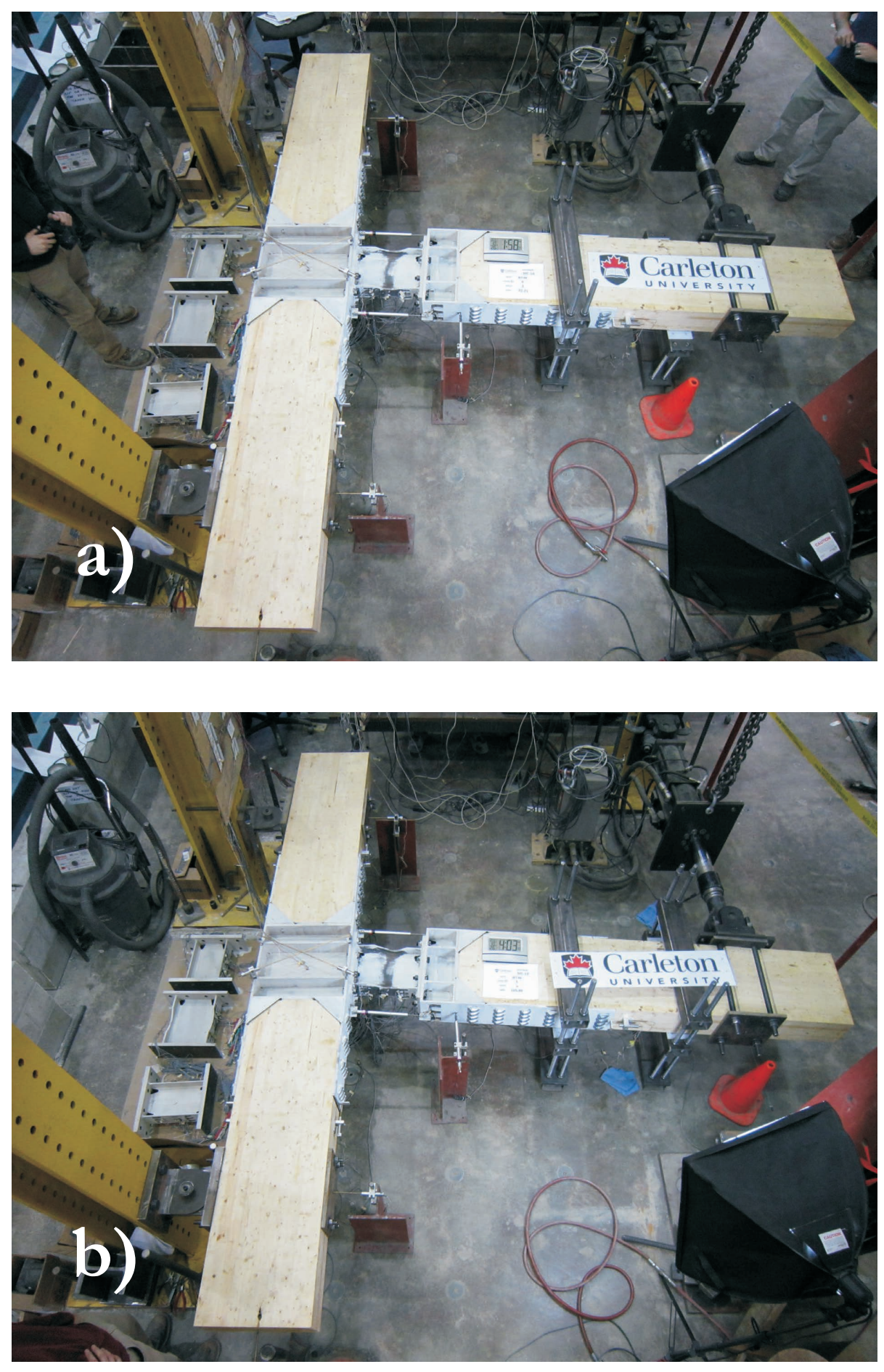

Figure 5.8: Frame Deformations Through Test MC-1A a) $4 \%$ Drift b) Final 


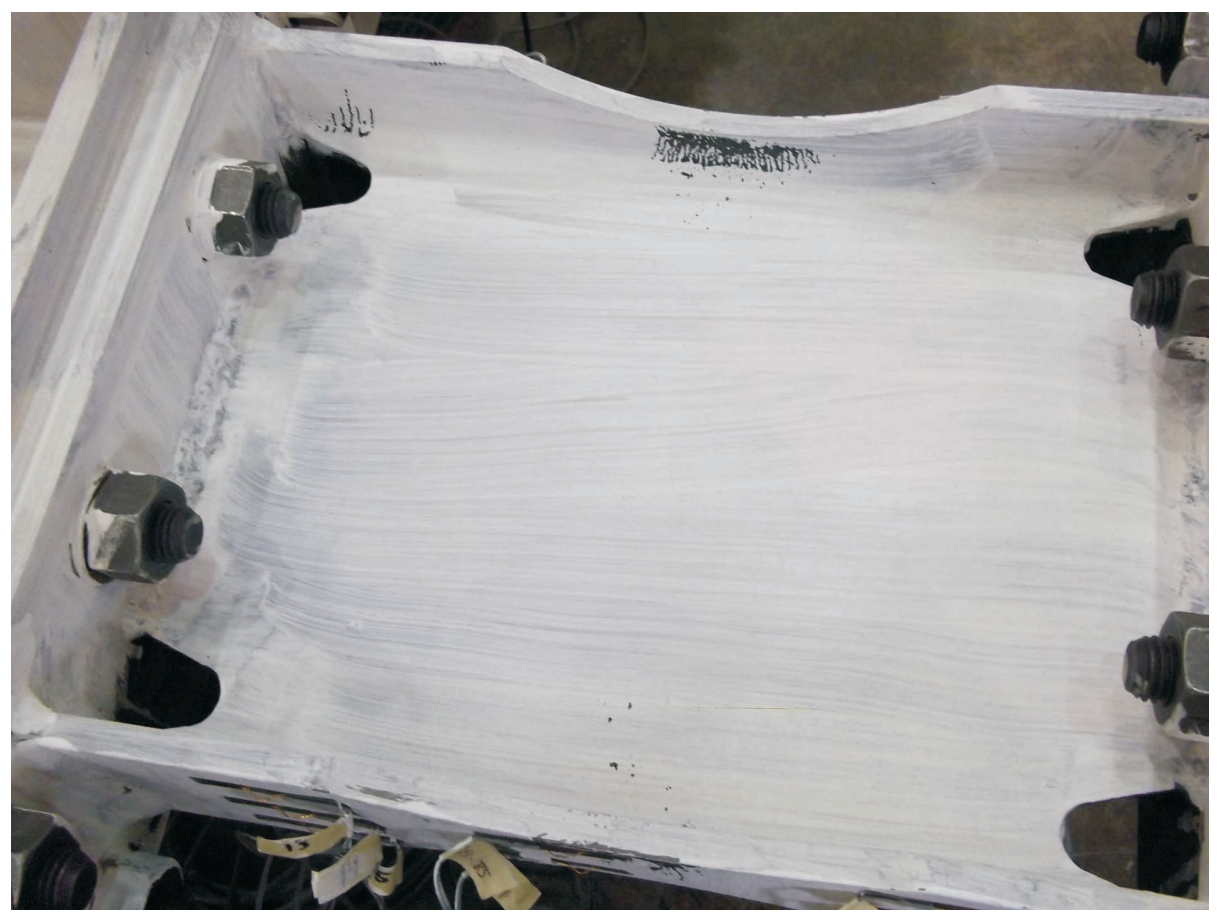

Figure 5.9: Flange Yielding at 1\% Drift for Test MC-1A

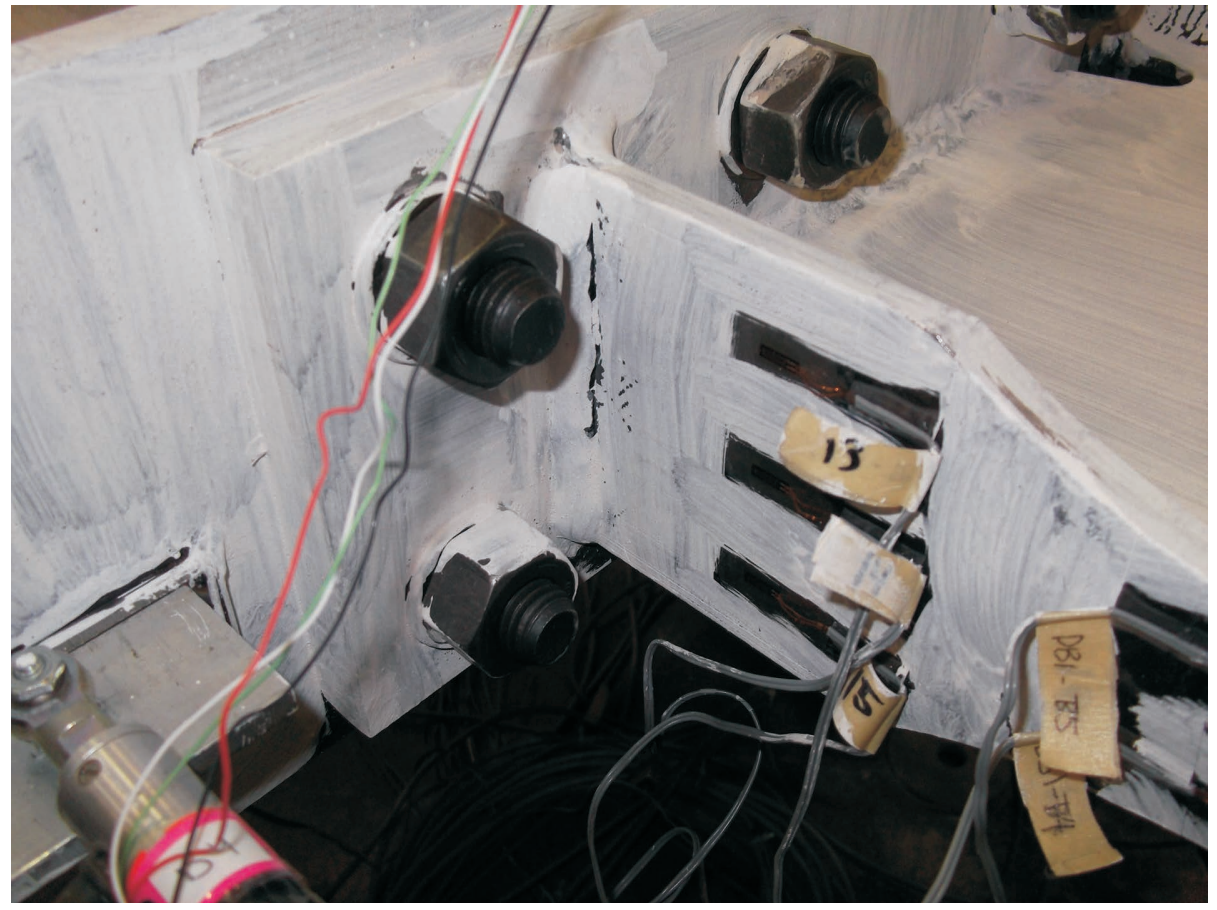

Figure 5.10: Yielding Near Flange Weld at 1\% Drift for Test MC-1A 


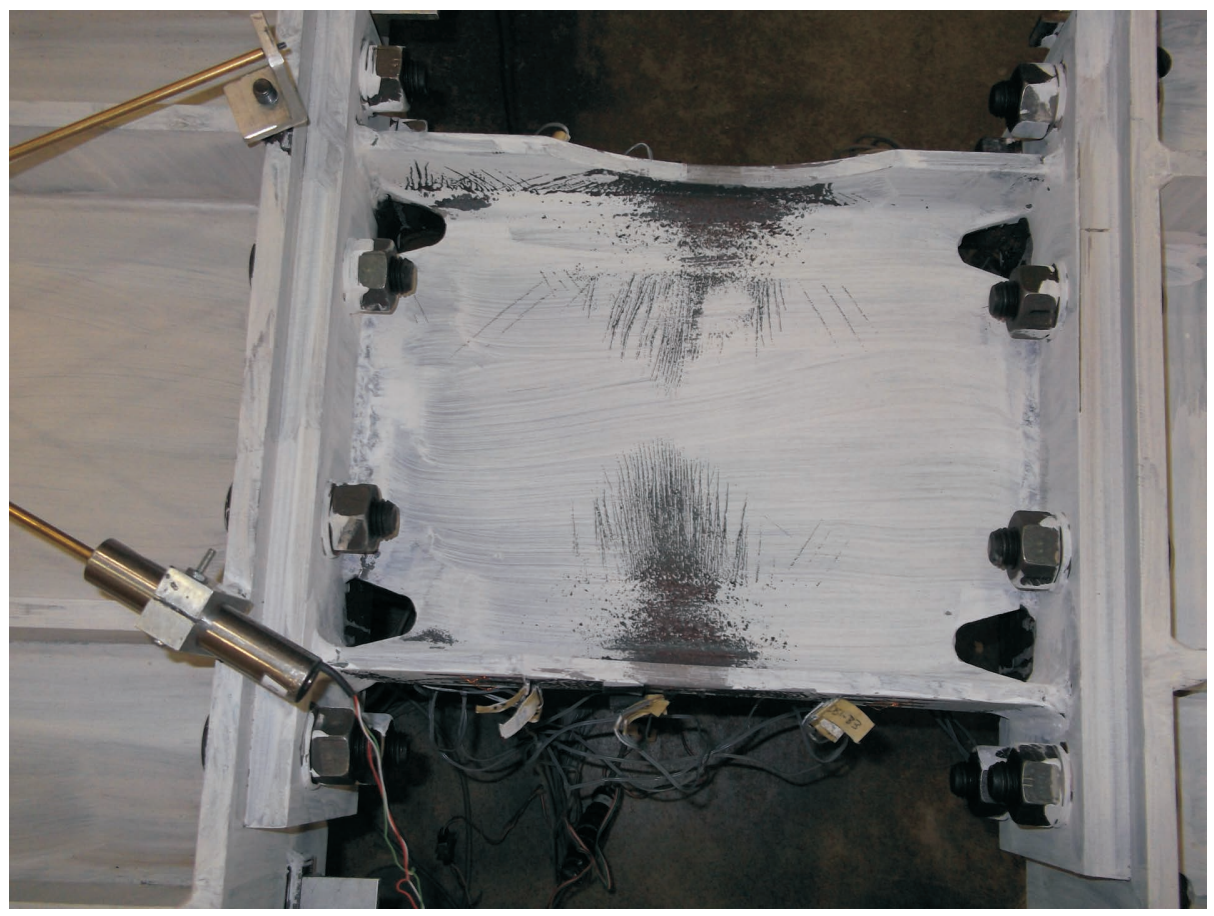

Figure 5.11: Web Yielding at 3\% Drift for Test MC-1A

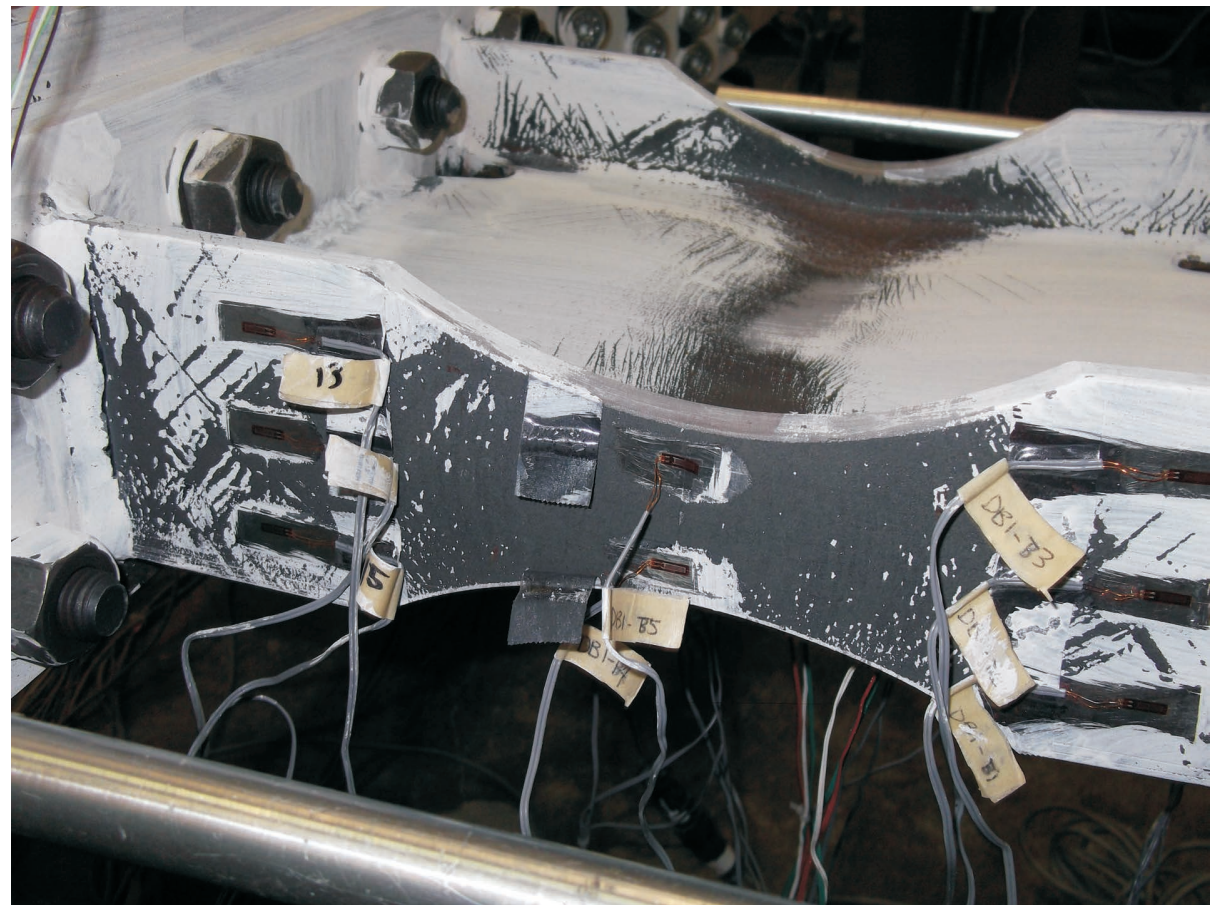

Figure 5.12: Local Buckling of Web at 4\% Drift for Test MC-1A 


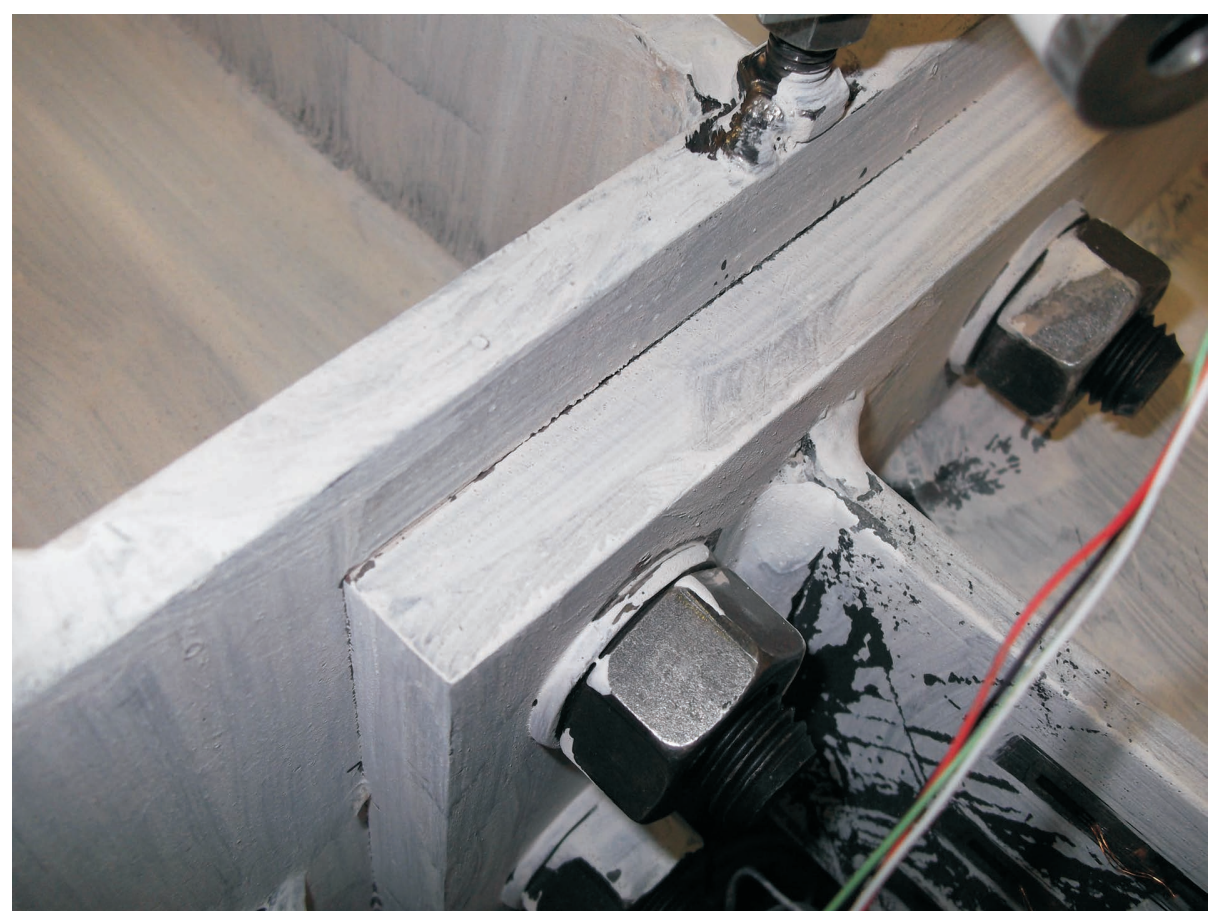

Figure 5.13: End-plate Gap Opening at 4\% Drift for Test MC-1A

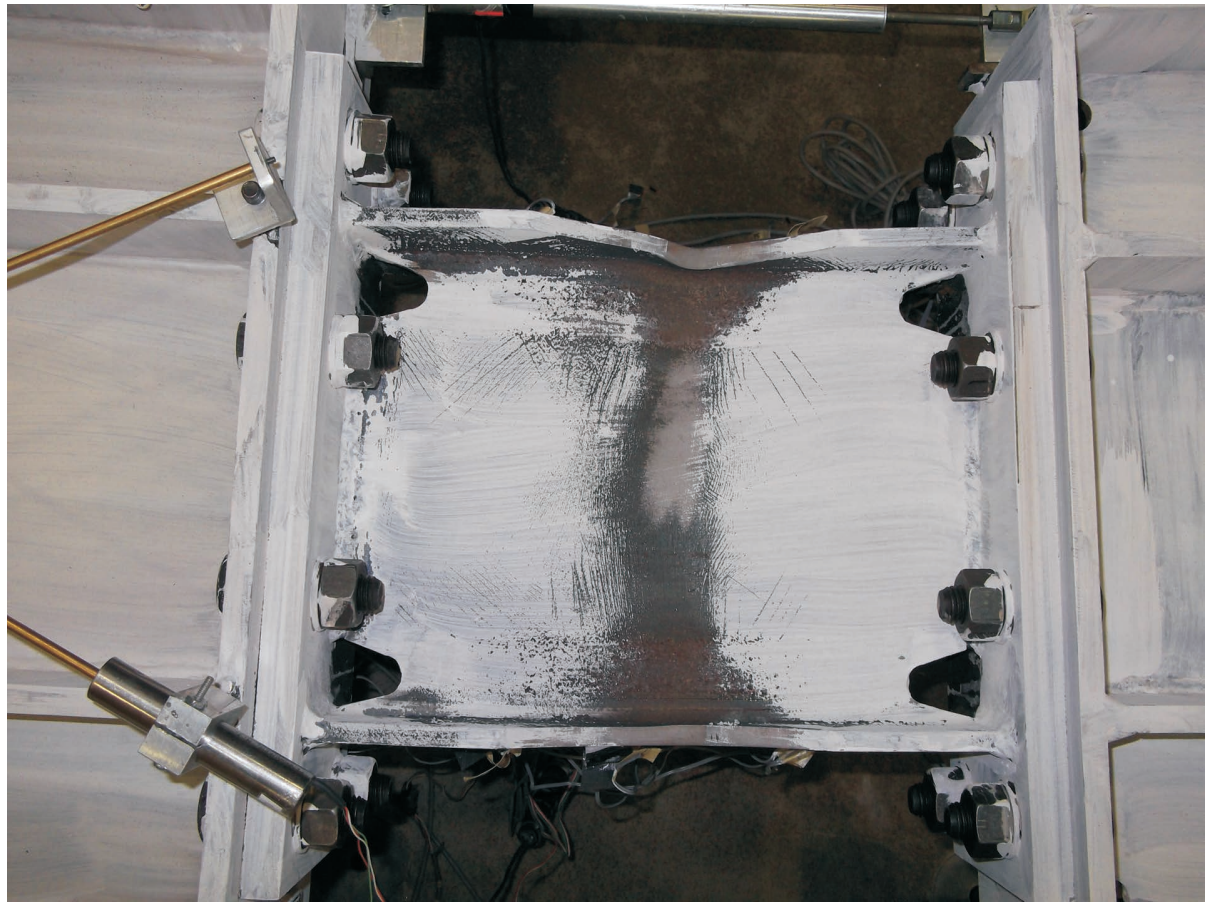

Figure 5.14: Local Buckling of Flange at 5\% Drift for Test MC-1A 


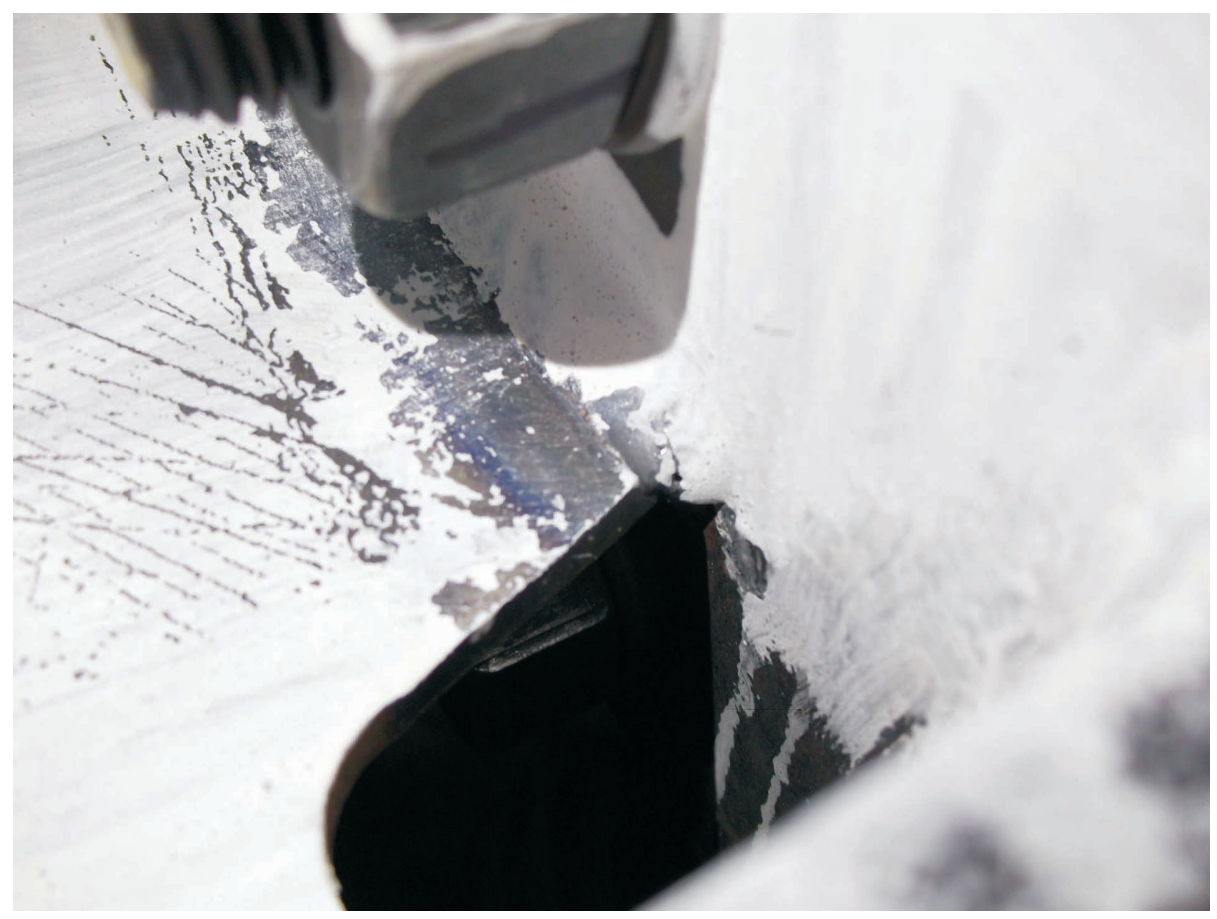

Figure 5.15: Web Crack at 5\% Drift for Test MC-1A

\subsubsection{Hysteretic Behaviour and Drift Analysis}

The first test specimen was able to sustain a peak load $\left(F_{\text {peak }}\right)$ of $69 \mathrm{kN}$ at $0.05 \mathrm{rad}$ storey drift. Figure 5.16 shows the global beam tip force versus beam tip displacement hysteretic response of the frame, and indicates the peak load, the estimated peak load $\left(F_{p r}\right)$, the design level load $\left(F_{\text {design }}\right)$, and the value corresponding to $80 \%$ of the peak load $\left(0.8 F_{\text {peak }}\right)$. The estimated peak load was calculated as $F_{r} \cdot R_{y} \cdot C_{p r}$, where $F_{r}$ is the beam tip force required to cause a moment in the link equal to the nominal moment capacity. The design level load is the beam tip force required to cause a moment in the link equal to the factored moment capacity. The connection reached a load of approximately $62 \mathrm{kN}$ during the $0.04 \mathrm{rad}$ cycle, with no signs of strength degradation. To meet the failure criteria, the connection was required to sustain a complete cycle at $0.04 \mathrm{rad}$ drift ( $92.25 \mathrm{~mm}$ beam tip displacement) without strength deteriorating below $80 \%$ of the peak load achieved during the test $(55 \mathrm{kN})$. It appears that slight strength degradation reduced connection resistance to approximately $60 \mathrm{kN}$ during the second cycle at $0.04 \mathrm{rad}$, meaning that this connection met the failure criteria specified by the AISC Seismic Provisions for Structural 
Steel Buildings (2010). More significant strength degradation was present during the 0.05 rad cycles after local flange buckling became more excessive. Further strength degradation would likely occur if the test continued due to fatigue of the link flanges. The hysteretic response was found to be quite stable, with no signs of pinching or sudden strength drop. This indicates that there was little deformation in the STS connections and no bolt elongation in the bolted end-plate connection. Furthermore, the connection stayed within the elastic range under design level forces. The maximum resistance of the link was greater than anticipated, but there was no evidence that this impacted the performance of the members designed to remain elastic under capacity-design forces.

Figure 5.17 shows the column face moment versus total storey drift angle as well as the column face moment versus plastic storey drift angle. The same trends were followed in the moment-rotation response as were discussed in the load-displacement response. The connection sustained a peak moment $\left(M_{c f, p e a k}\right)$ of $142 \mathrm{kN} \cdot \mathrm{m}, 14 \%$ higher than the expected moment capacity $\left(M_{p r}\right)$ of the connection under full plastic behaviour. By comparing the total storey drift response to the plastic storey drift response, it was shown that approximately $76 \%$ (0.037 rad) of the total storey drift was accommodated by plastic deformations, indicating high levels of ductility and energy dissipation.

Figure 5.18 shows the contribution of each connection component (link, panel zone, STS connection, and remaining elastic components) to the total storey drift angle at selected drift levels. Drift decomposition at $0.05 \mathrm{rad}$ was not presented due to movement of displacement transducer D2 during the final cycles of the test. Throughout all cycles, it is evident that the link had the greatest contribution to storey drift angle. This was expected since it was the primary yielding mechanism, and it was less stiff than other components. Link contribution increased under larger storey drift angles due to propagation of yielding into other portions of the link. Relative increase in link contribution progressively lessened between cycles under higher drift levels, indicating that the link had fully yielded, however total link contribution would continue to increase as drift angle increased. This also indicates the the design ideology was correct, and most of the inelastic behaviour was successfully localized into the ductile fuse. The panel zone 


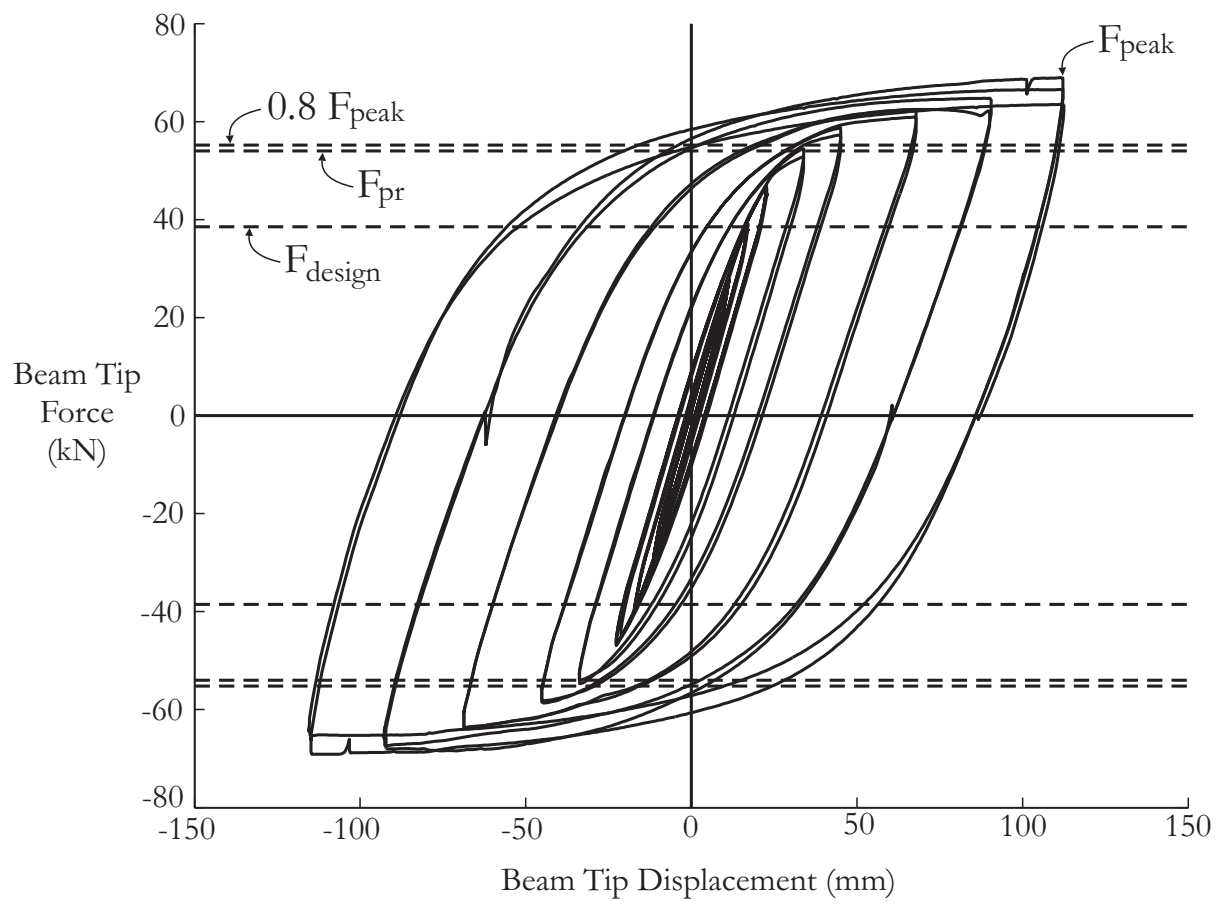

Figure 5.16: Force vs. Beam Tip Displacement Response for Test MC-1A

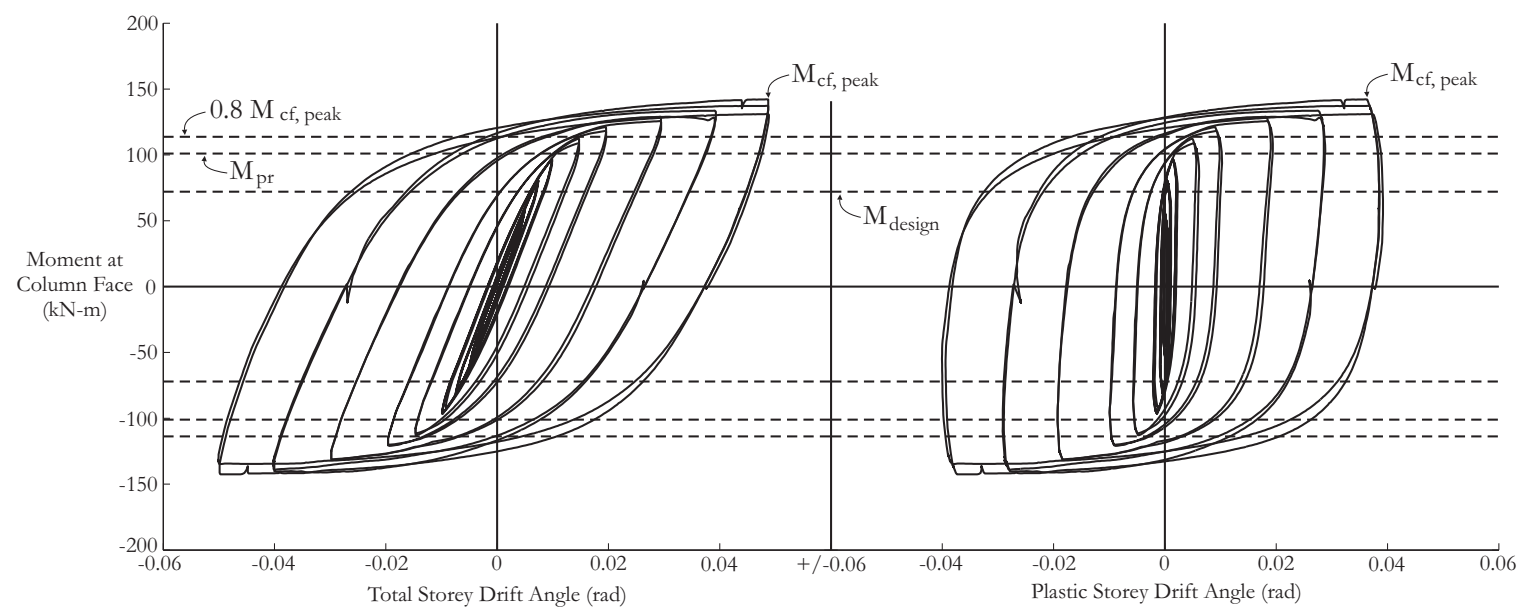

Figure 5.17: Moment vs. Rotation Responses for Test MC-1A 
contribution was quite low at all drift levels since it was designed to remain fully elastic. Since the wood beam did not undergo plastic deformations, initial contribution was high during elastic cycles, but the contribution lessened as the link began to deform plastically. The increase in STS connection contribution between cycles at $0.005 \mathrm{rad}$ and $0.01 \mathrm{rad}$ is likely due to friction slip at the steel-to-timber interface. It is likely that the force applied at $0.005 \mathrm{rad}$ drift angle was not enough to cause significant initial slip, but the increased force applied for the 0.01 rad cycles overcame the required friction force to initiate slip. The reduction in STS connection contribution as storey drift angle increased indicates that there was some initial slip in the connection which stabilized as drift level increased. This could be due to the small gap present between the end-grain of the timber and the bearing plate, or further setting of the STS into the 45 degree washer.

\subsubsection{Strain Analysis}

Figures 5.19 through 5.21 show the strain profiles across various parts of the link, where a majority of the plastic behaviour was located. Data is only presented up to $0.04 \mathrm{rad}$ drift, at which point many of the strain guages began to fall off. Examining the strain across the link length at centre width (shown in Figure 5.19) shows that tensile strain is at a maximum at the link centre. This is a result of the dogbone detail, since a large portion of the flange was removed at this location. This plot shows that prior to the onset of yielding (at and below $0.01 \mathrm{rad}$ drift) the strain profile was approximately linear, and became more nonlinear as strains exceed the yield strain of the steel $(0.00175 \mathrm{~mm} / \mathrm{mm})$.

Figure 5.20 shows the strain profile across the flange width at the middle of the link (dogbone location) where strains were highest. Due to space restrictions, only two strain gauges were installed on each flange at the middle of the link for links with a dogbone detail. The strain on each side of the web was found to be relatively constant at low drift levels, but became unbalanced as yielding in the flanges became excessive. This shift in behaviour tended to coincide with the onset of local flange buckling, which developed higher tensile forces on one side of the flange than on the other.

Ryan Gohlich, Department of Civil and Environmental Engineering, Carleton University 


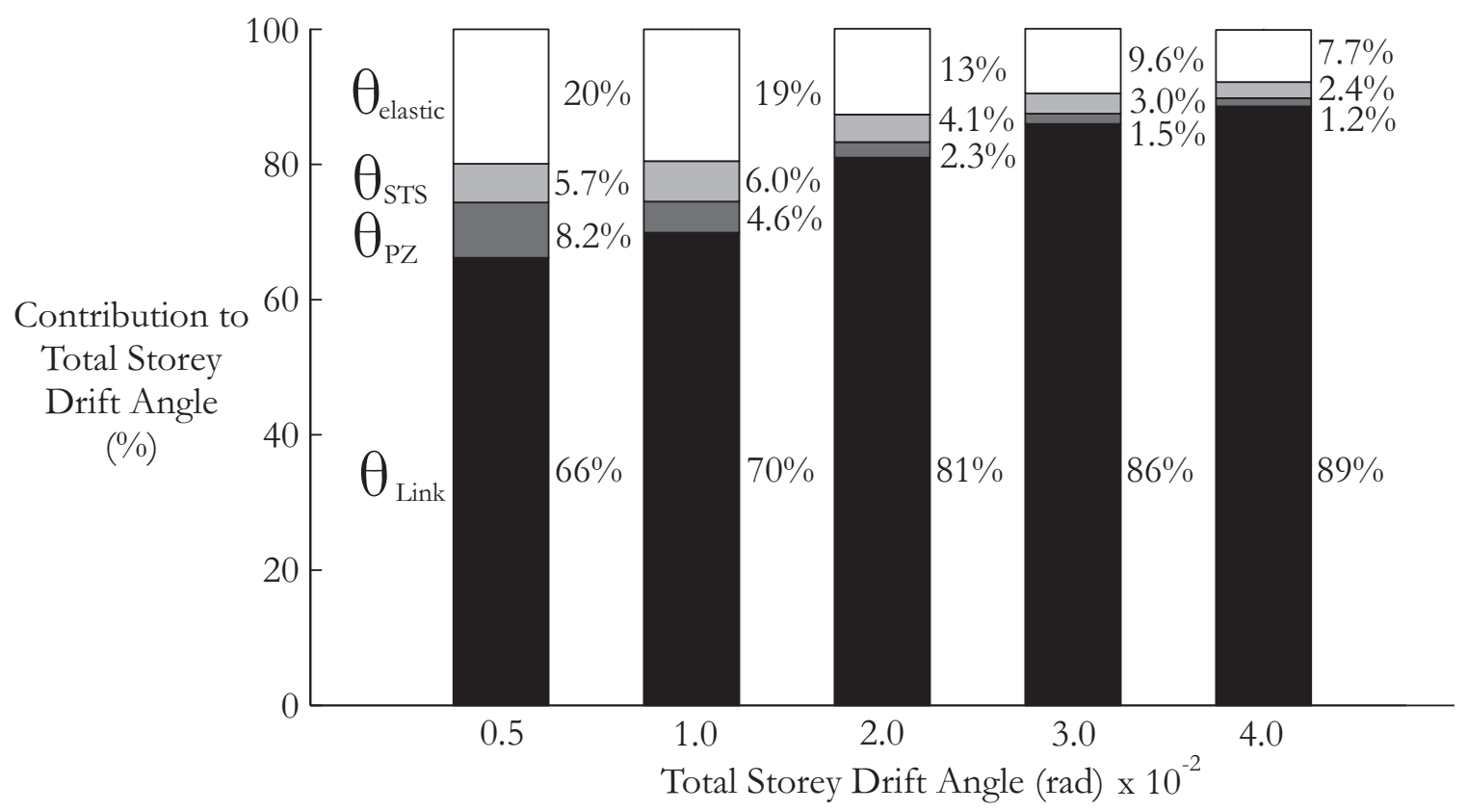

Figure 5.18: Total Storey Drift Decomposition for Test MC-1A

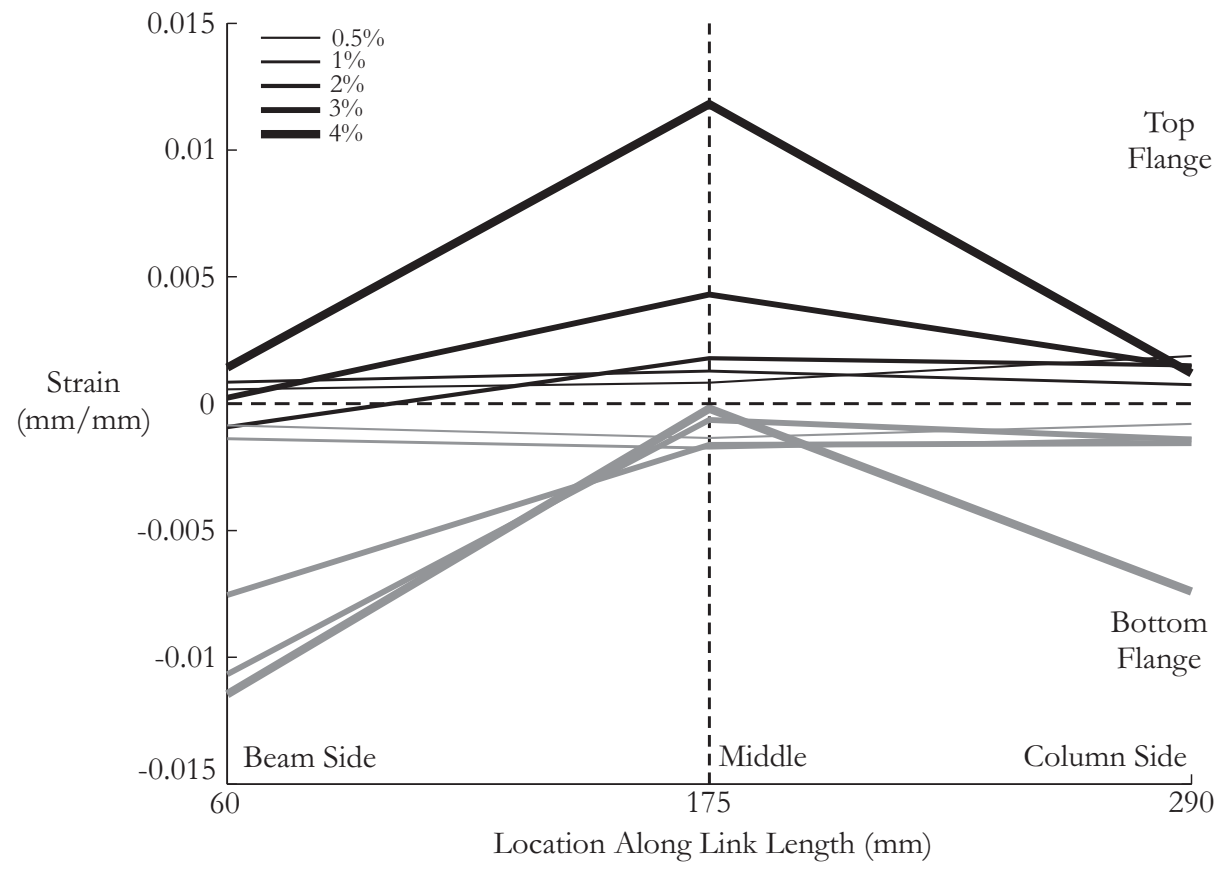

Figure 5.19: Strain Profile Along Link Length for Test MC-1A

Positive Bending at Mid-width of Flange 


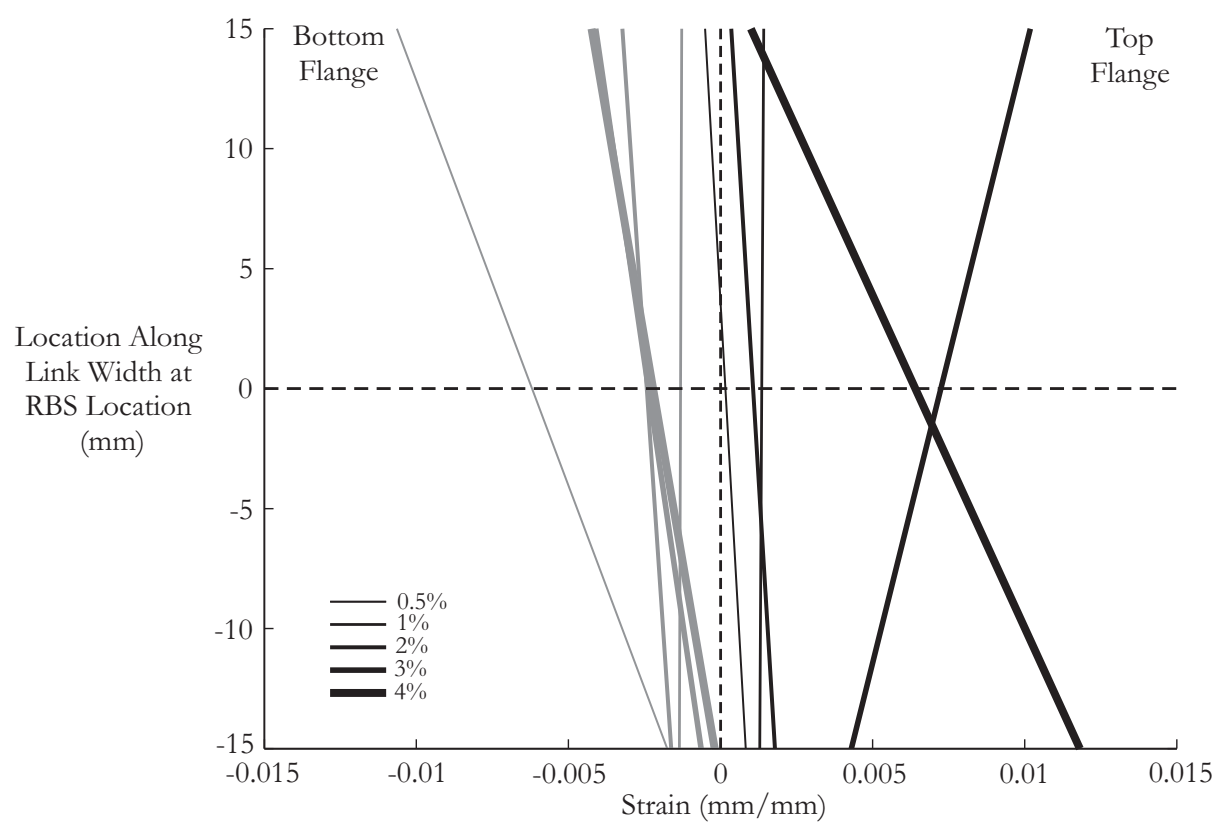

Figure 5.20: Strain Profile Across Link Width for Test MC-1A Positive Bending at Middle of Link

Figure 5.21 presents the strain profile through the depth of the link web at the column side. As expected, the strain profile was linear, and stains remained close to zero at the centerline of the link web prior to yielding. The strain profile indicates that yielding propagated from the bottom of the link upward, with high beam-side strains peaking near the bottom flange weld access hole. It is possible to minimize this strain by removing the weld access holes, but further studies must be done on how this would effect the quality of the flange-to-end-plate welds.

The strain gauges were installed on the beam collar in an attempt to estimate the force going into the STS connection steel top and bottom plates using strain compatibility analysis. The calculated applied moments using these strain readings appear to be underestimated when compared to the applied moment calculated using the product of the applied force with the moment arm, indicating that some force may be transferred through other connection components. The strain profile was not linear, and strains on the outer edges of the collar were significantly higher. Strain readings may have been effected by the triangular shear tabs welded to the edges of the collar. 


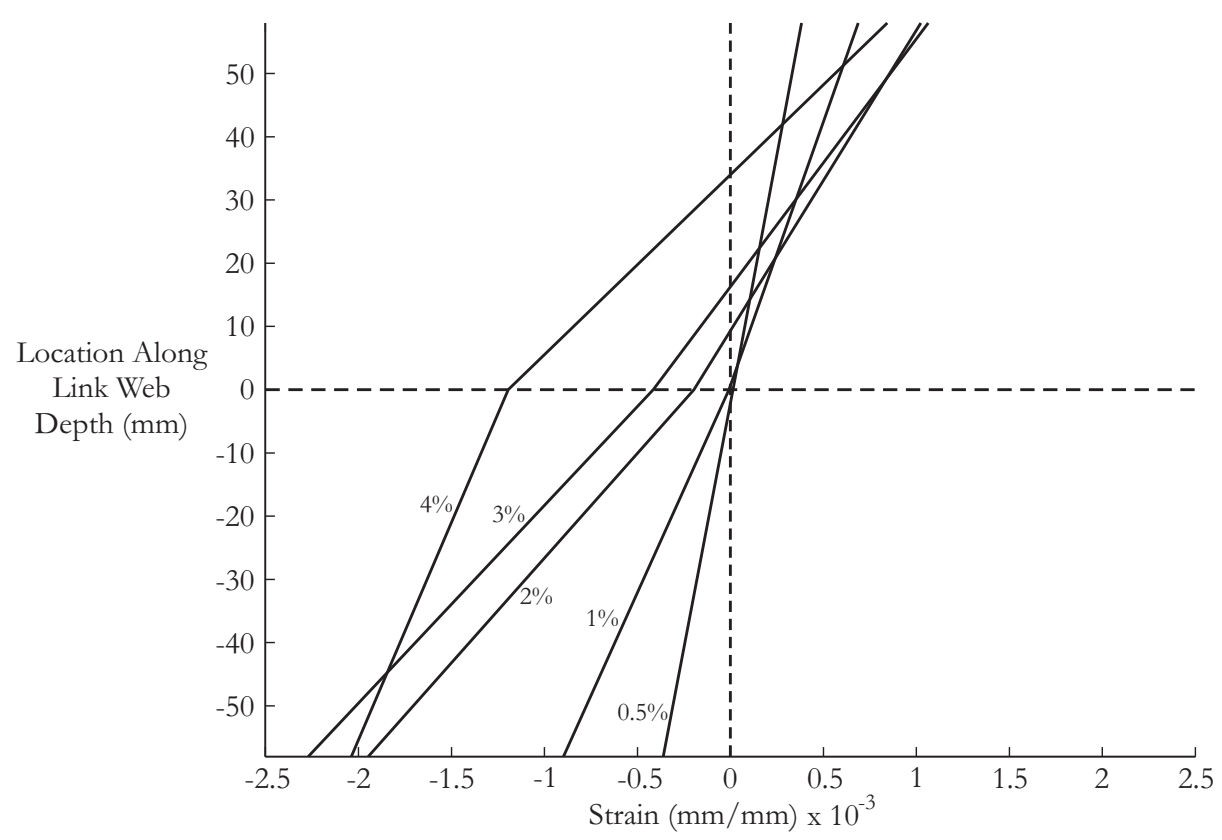

Figure 5.21: Strain Profile Through Link Depth for Test MC-1A (Positive Bending)

\subsubsection{MC-2A}

\subsubsection{Failure Sequence}

The second test used a steel link made of a lighter section with no dogbone detail, and the beam connection type used 45 degree STS (the same as the column connections). The link was designed to have the same capacity as the previous test, however failure sequence and failure mode were effected by the absence of the dogbone detail. A summary of the test observations can be seen in Figure 5.22.

Figures 5.23, 5.24, and 5.25 show a summary of the yield propagation through the link at critical points in the test. Due to the reduced stiffness of this link (relative to the previous test), the connection remained entirely elastic until the end of the first cycle at $0.01 \mathrm{rad}$ storey drift. Initial onset of yielding was located near the flange-to-end-plate welds (Figure 5.26). Yielding was present at both the column side and beam side of the link, however it was much more severe at the column side. This is to be expected since the moment gradient results in peak moments at the column side, and since the flange is of uniform width, there is no mechanism by which yielding 


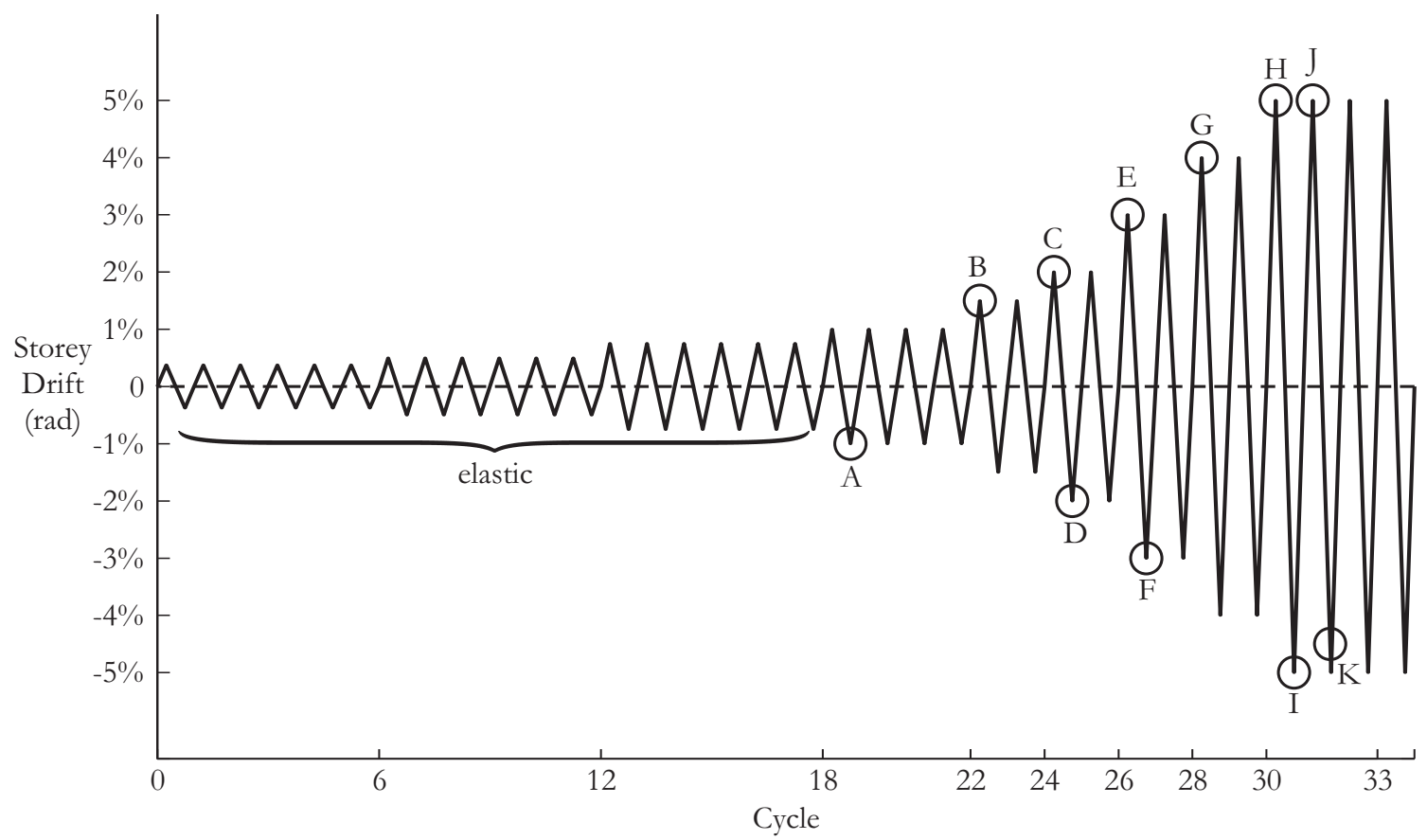

A - Yielding at flange-to-end-plate welds on BS and CS

B - Significant propagation of flange yielding from BS and CS towards link centre

$\mathrm{C}^{-}$Yielding around weld access holes and centre of link flanges

$\mathrm{D}^{-}$Slight flaking on middle of BS end-plate (not likely due to yielding)

E - Yielding propagates uniformly along flange length

F - Yielding of upper and lower portion of link web at mid-length of link, web yielding propagating from weld access holes on CS

$\mathrm{G}^{-}$Yielding of link web propagates along link length

$\mathrm{H}^{-}$Local buckling of bottom flange at CS near weld

I - Large fracture at bottom of web-to-end-plate weld (CS) near weld access hole, propagating into web, loud crack, slight gap opening between end-plate and column face

$\mathrm{J}$ - Fracture of entire width of top flange, fracture of top-side of web at weld access hole

$\mathrm{K}$ - Complete fracture of entire link cross-section at CS near end-plate weld

Figure 5.22: Summary of Observations for Test MC-2A 
can be localized away from the flange weld. Throughout the 0.015 rad cycle, yielding propagated towards the centre of the link, and around the weld access holes at $0.02 \mathrm{rad}$ drift (Figure 5.27). During the 0.03 rad cycles, yielding propagated from the column side weld access holes into the link web. Figure 5.28 shows more pronounced web yielding at $0.04 \mathrm{rad}$ storey drift. Local buckling of the flange occurred immediately after 0.05 rad storey drift was reached (Figure 5.29). This was soon followed by a large crack at the web-to-end-plate weld, starting at the weld access hole and propagating into the link web as shown in Figures 5.30 and 5.31. Complete fracture of the opposite link flange occurred during the following cycle near the column side flange weld (Figure 5.32), followed by complete fracture of the entire link cross-section near the column side end-plate welds, shown in Figure 5.33.

The photos of the link observations during testing clearly show the yielding and failure progression of the specimen. As expected, a majority of the yielding and failure occurred near the column side end-plate. Yielding only propagated into the middle of the link after the end had been fully yielded and strain hardened. Failure close to the brittle weld metal is not ideal, however brittle fractures in the link did not appear until $0.05 \mathrm{rad}$ storey drift angle, after the acceptance criteria was met. Brittle fracture was preceded by local buckling of the flanges, which was easily identifiable. Since the sizing of the weld access hole is independent of the link size, it is likely that on a full scale link with a greater flange thickness, local buckling would not occur in the location shown in Figure 5.29, but would likely buckle in a similar manner to that presented by Shen (2009). Initial signs of brittle failure by means of web cracking were quickly followed by flange fracture, and complete fracture of the entire link cross-section. This is not an ideal failure mode, and closely resembles that of pre-Northridge steel moment-resisting connections. However, it is clear that the capacity-design method was successful in postponing this brittle 

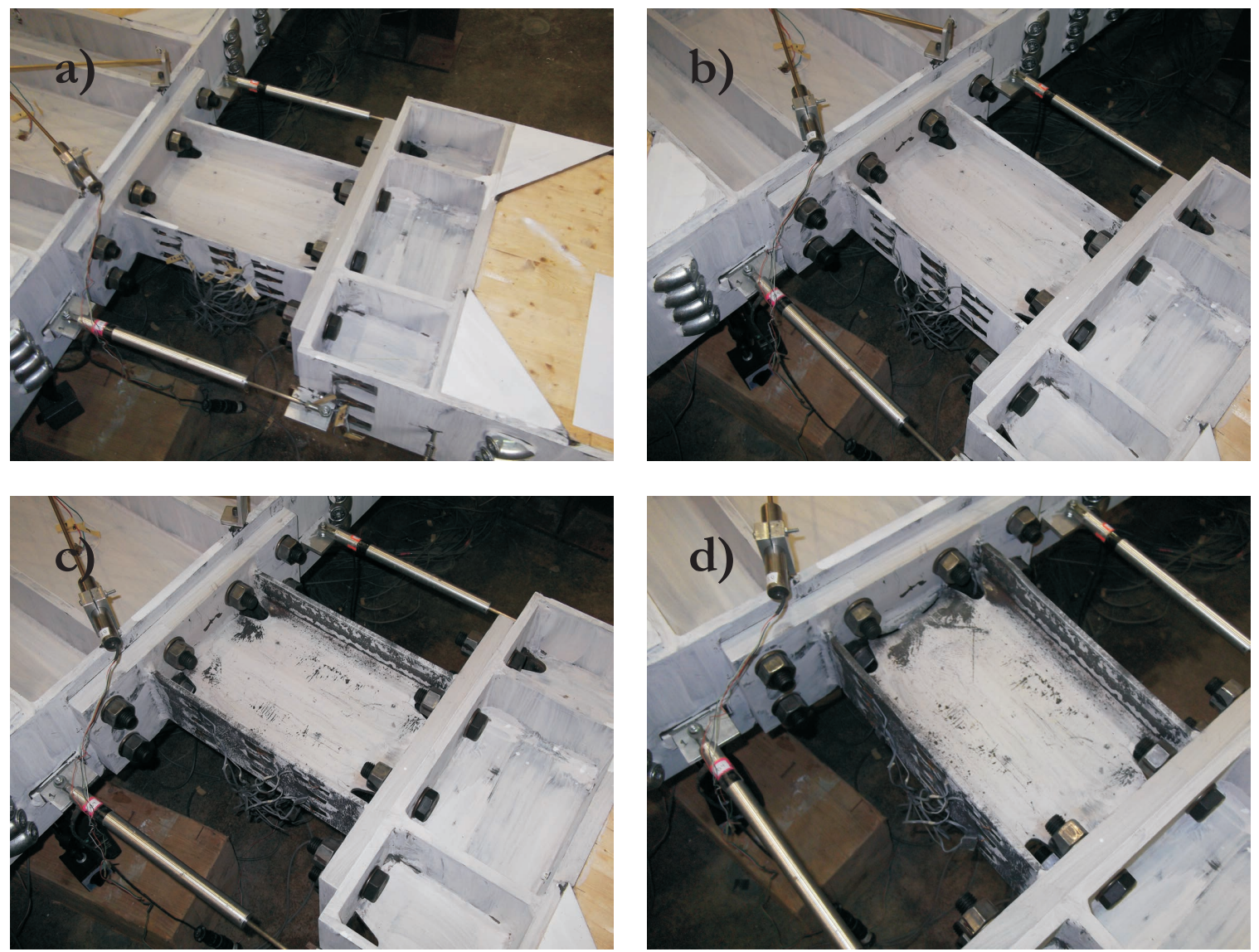

Figure 5.23: Yielding Propagation in Link for Test MC-2A a) Initial b) $1 \%$ Drift c) $4 \%$ Drift d) Final 

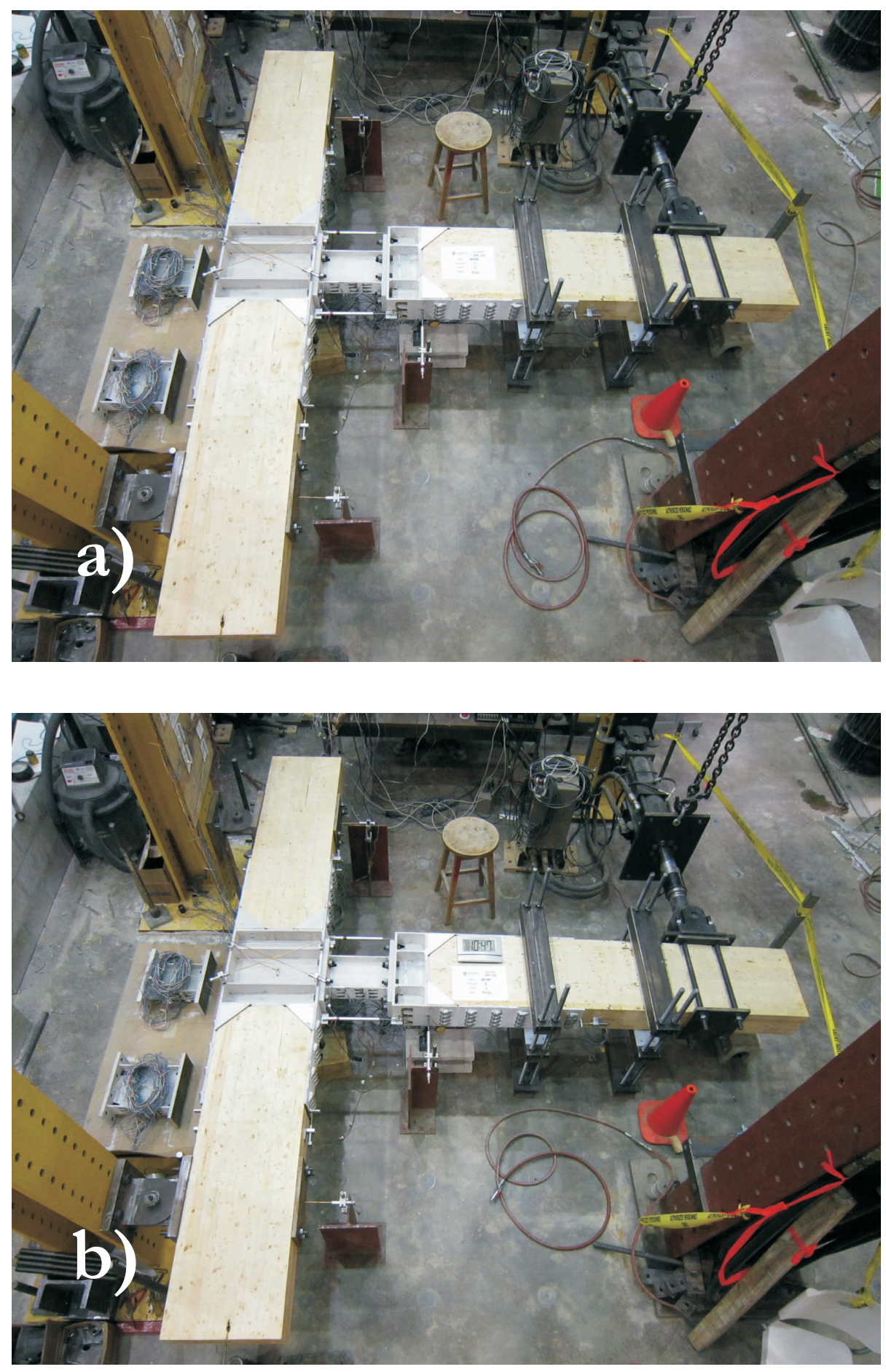

Figure 5.24: Frame Deformations Through Test MC-2A

a) Initial b) $1 \%$ Drift 

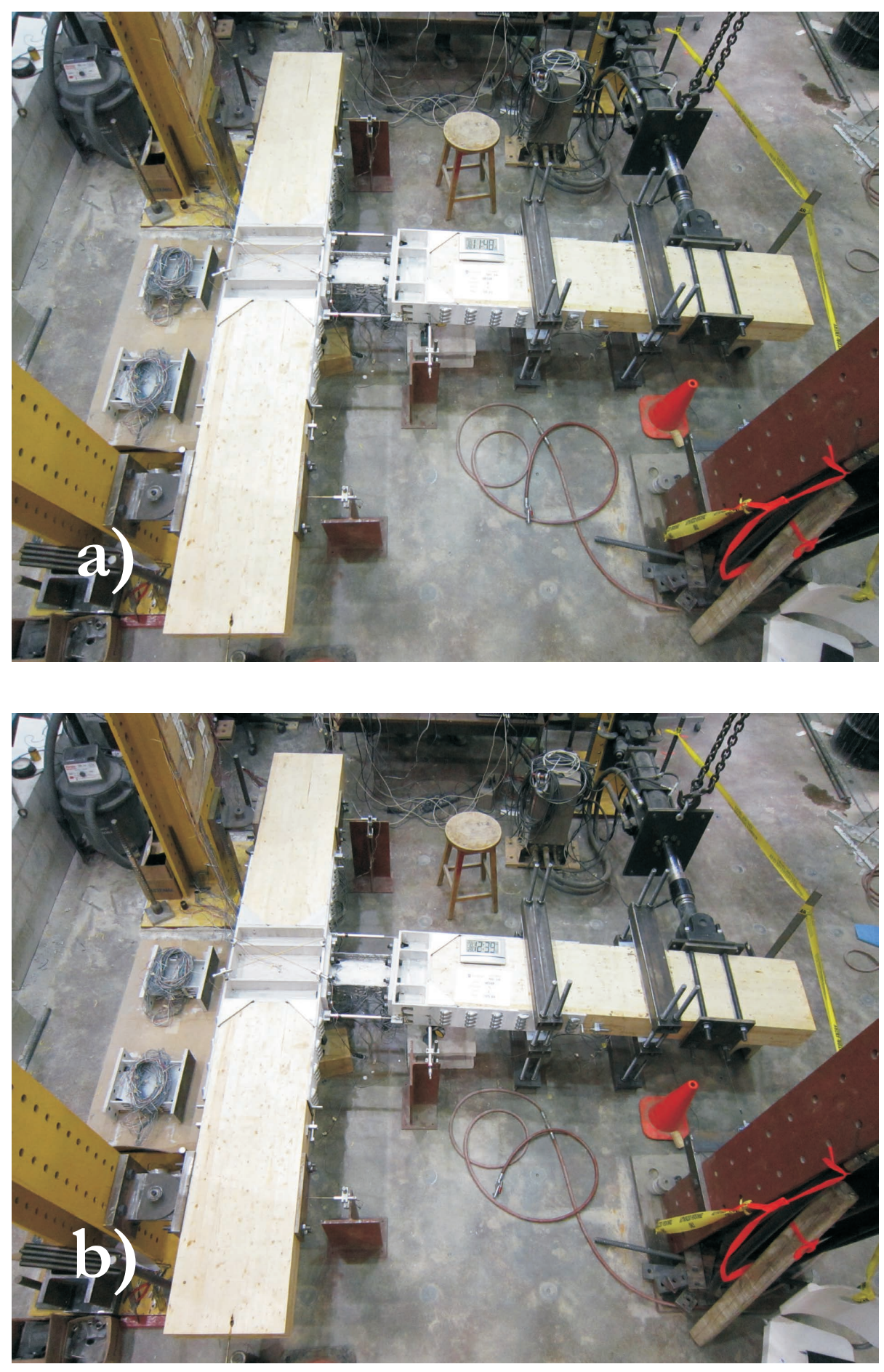

Figure 5.25: Frame Deformations Through Test MC-2A

a) $4 \%$ Drift b) Final 


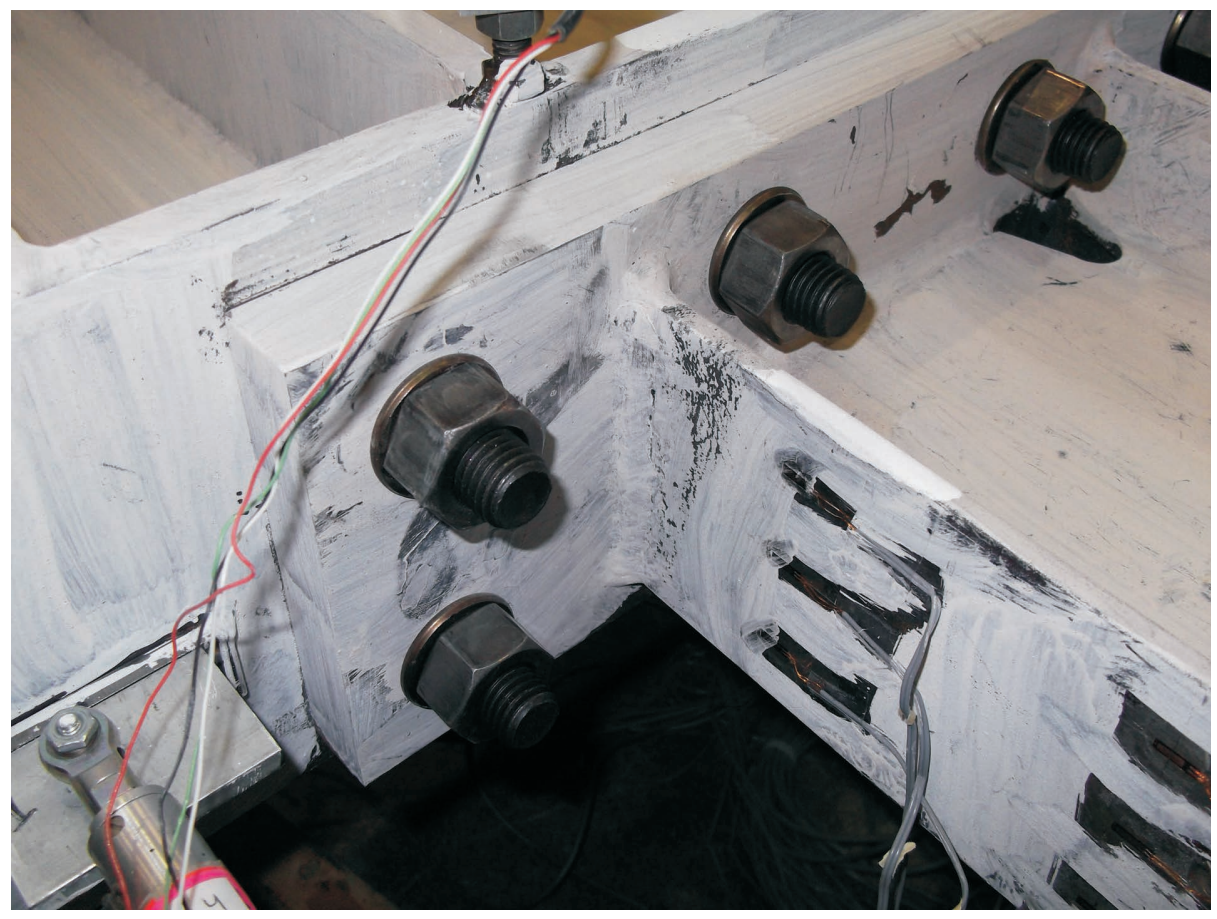

Figure 5.26: Flange Yielding at 1\% Drift for Test MC-2A

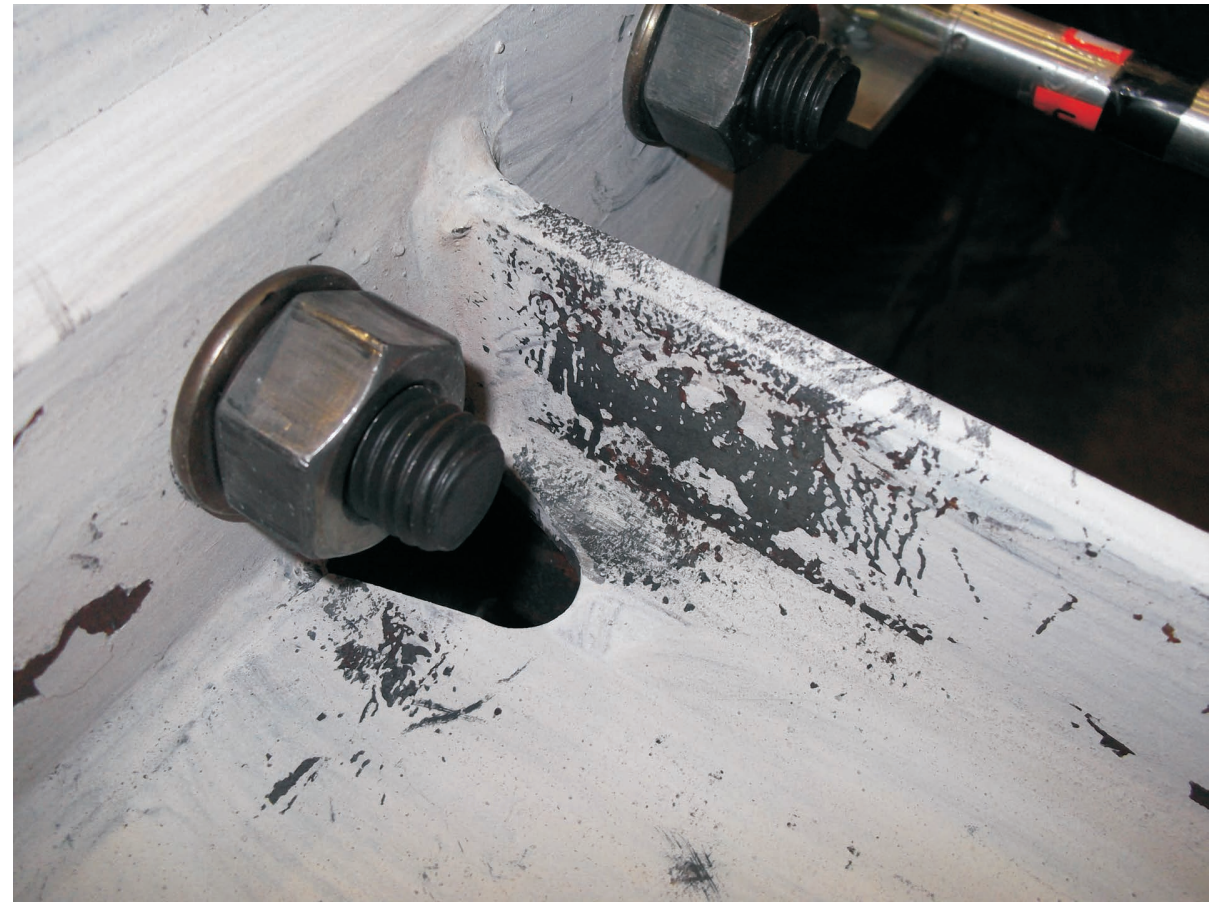

Figure 5.27: Yielding Around Weld Access Holes at 2\% Drift for Test MC-2A 


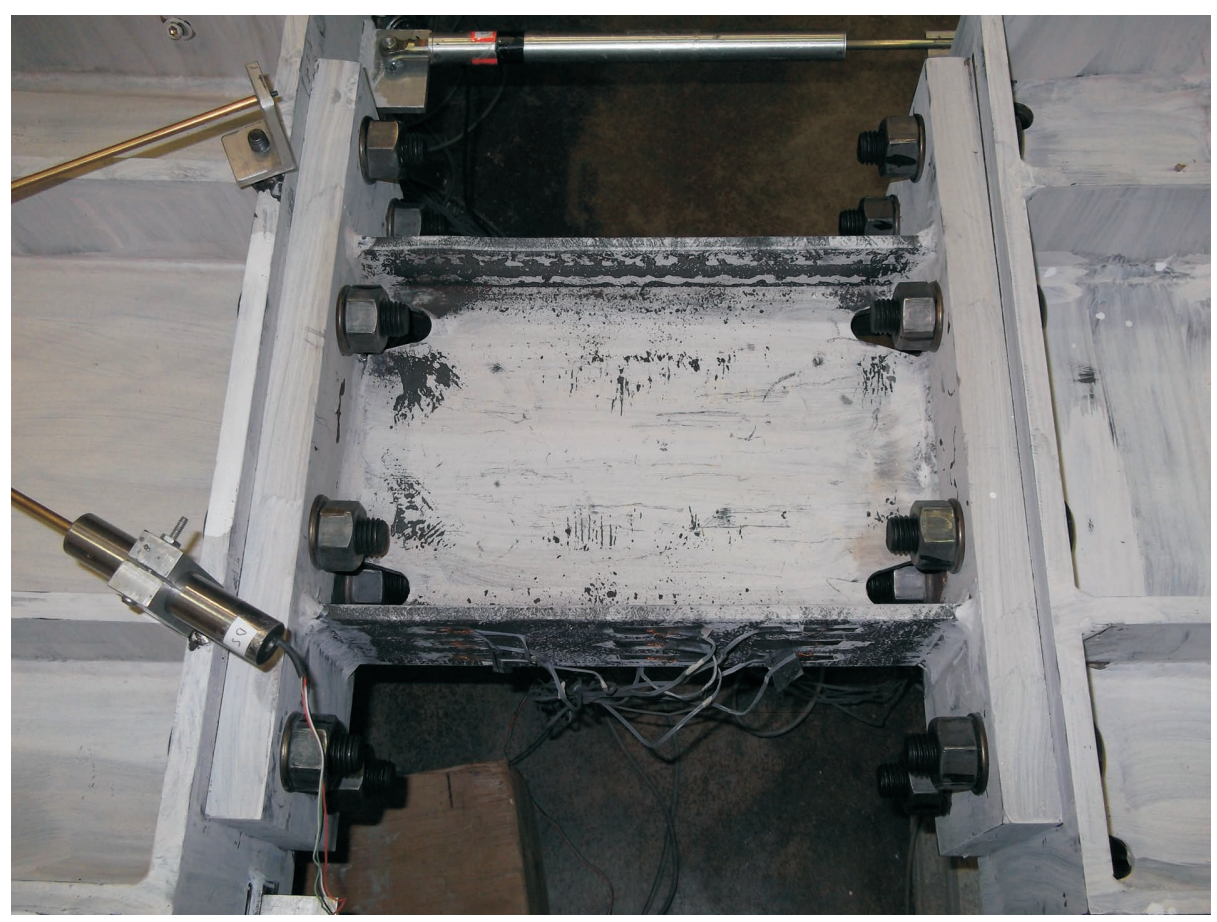

Figure 5.28: Web Yielding at 4\% Drift for Test MC-2A

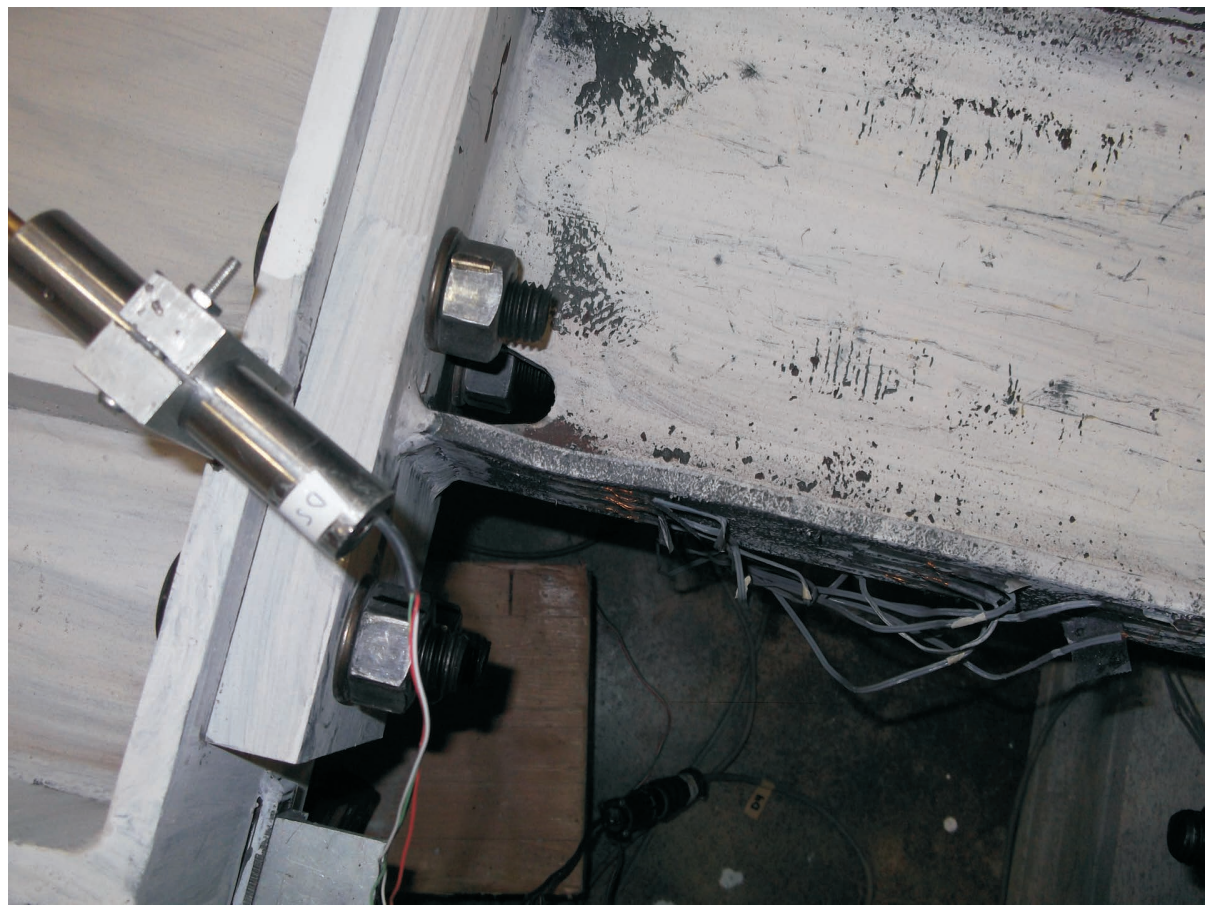

Figure 5.29: Local Flange Buckling at 5\% Drift for Test MC-2A 


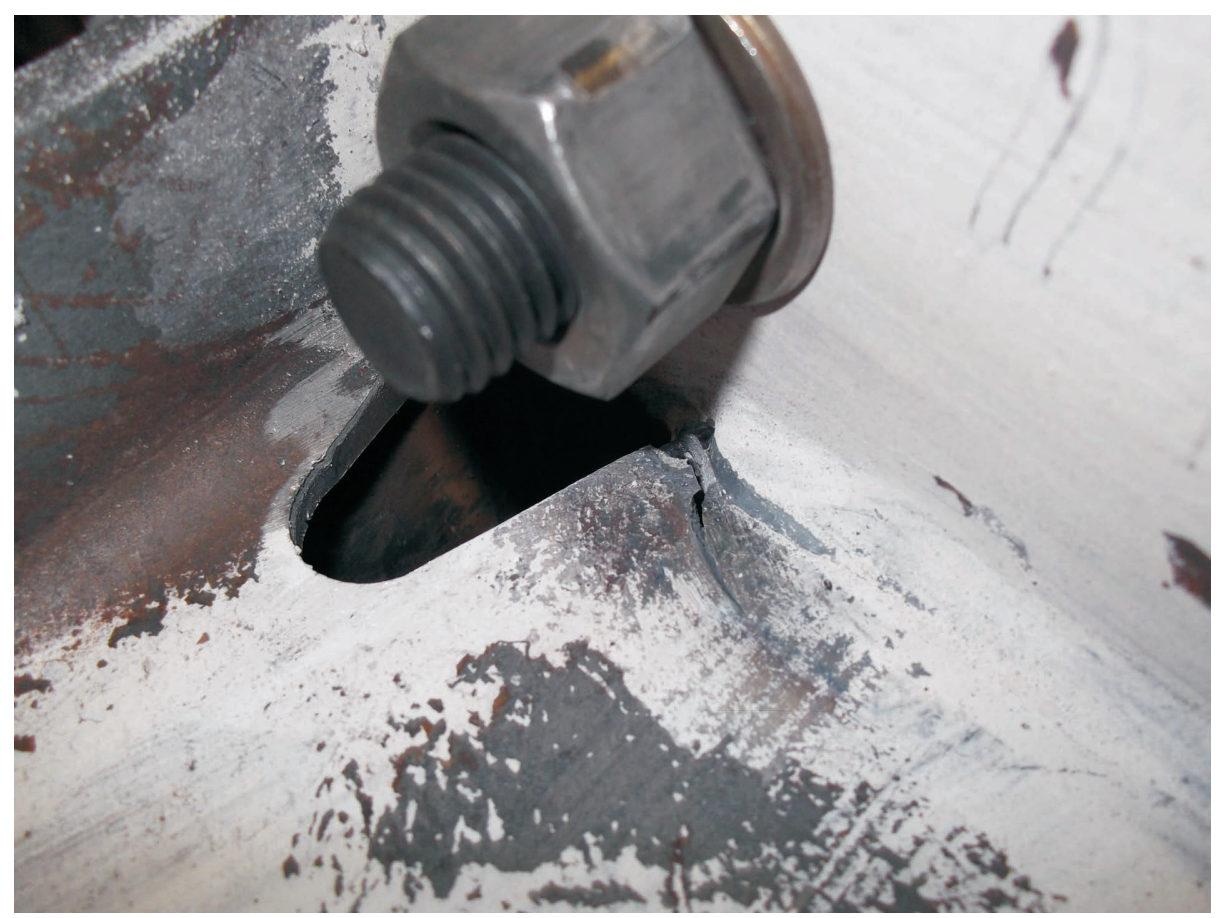

Figure 5.30: Initial Web crack at 5\% Drift for Test MC-2A

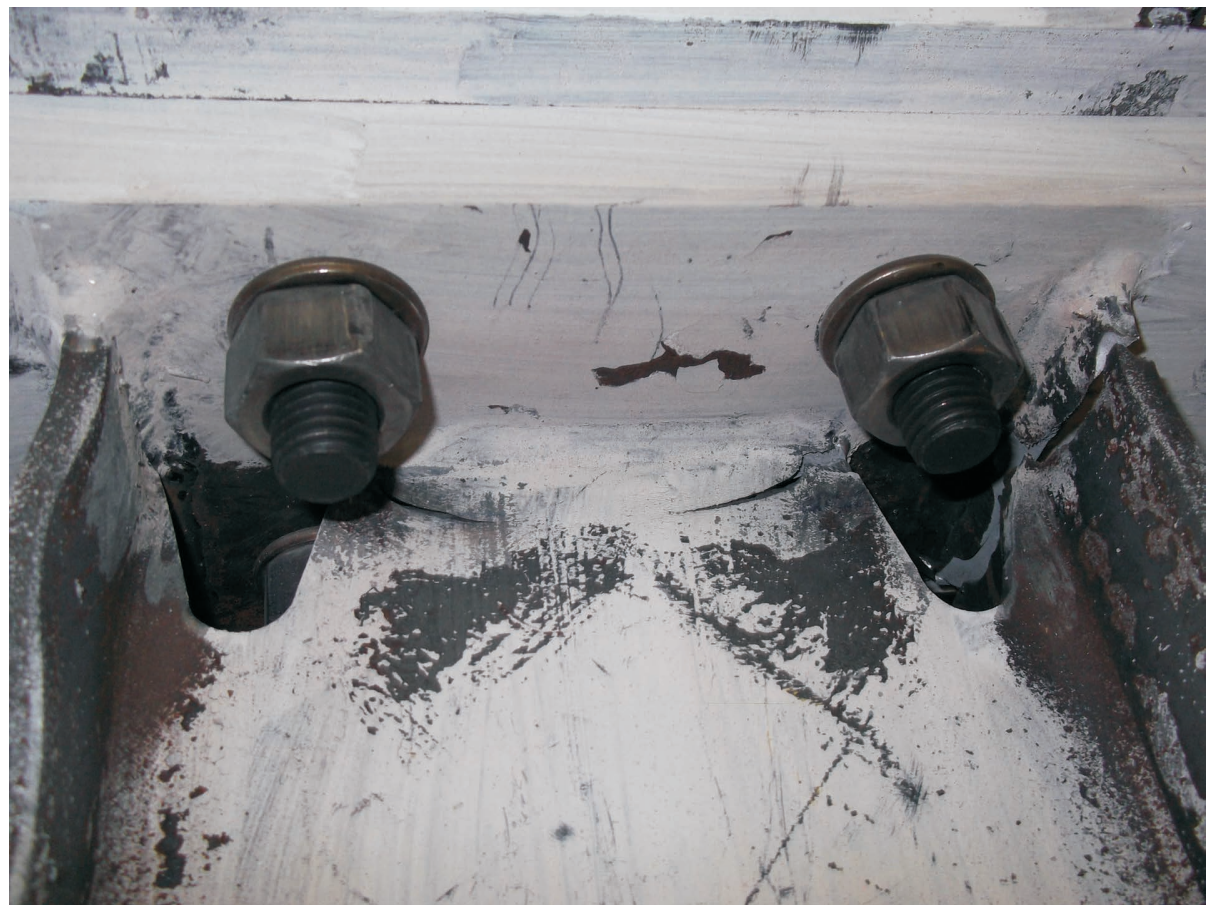

Figure 5.31: Web Crack Propagation at 5\% Drift for Test MC-2A 


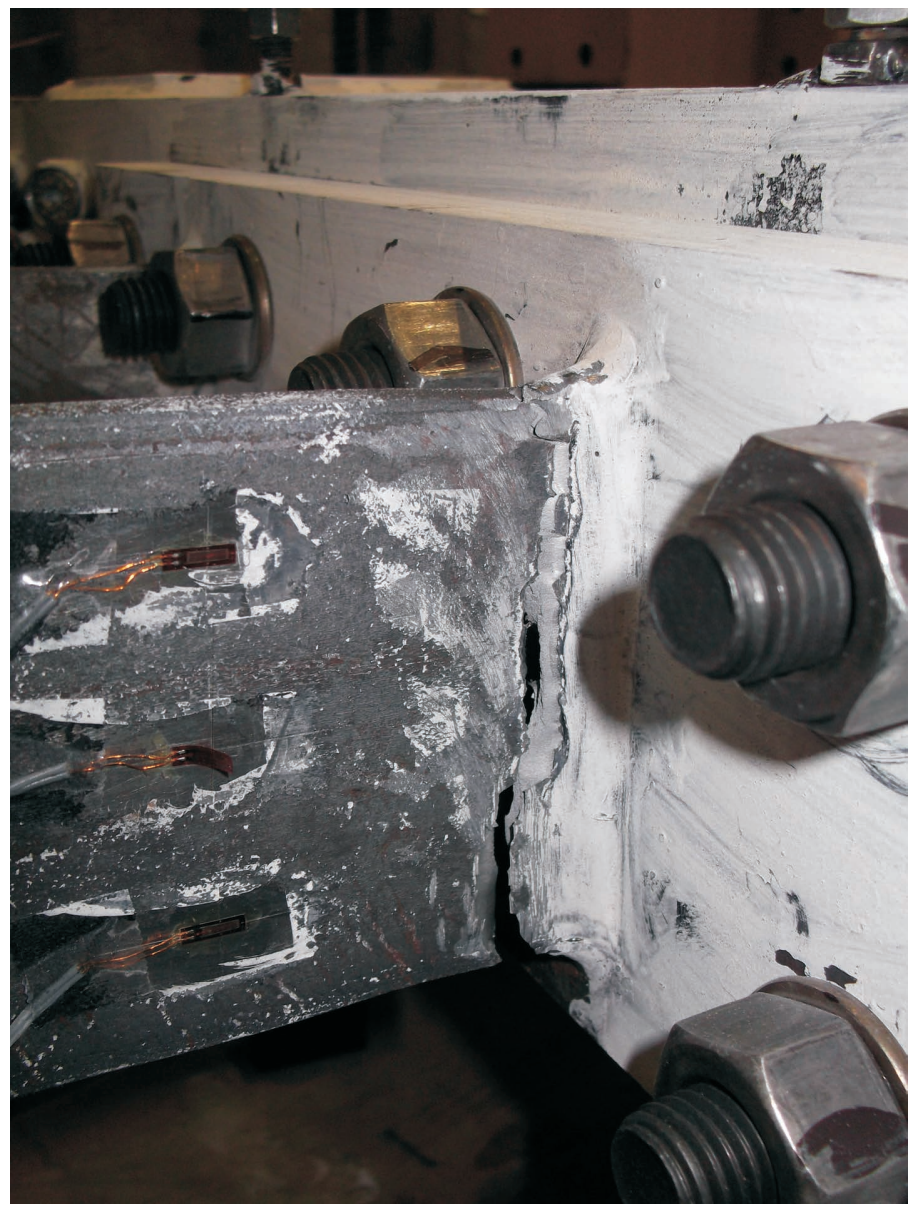

Figure 5.32: Flange Fracture at 5\% Drift for Test MC-2A 


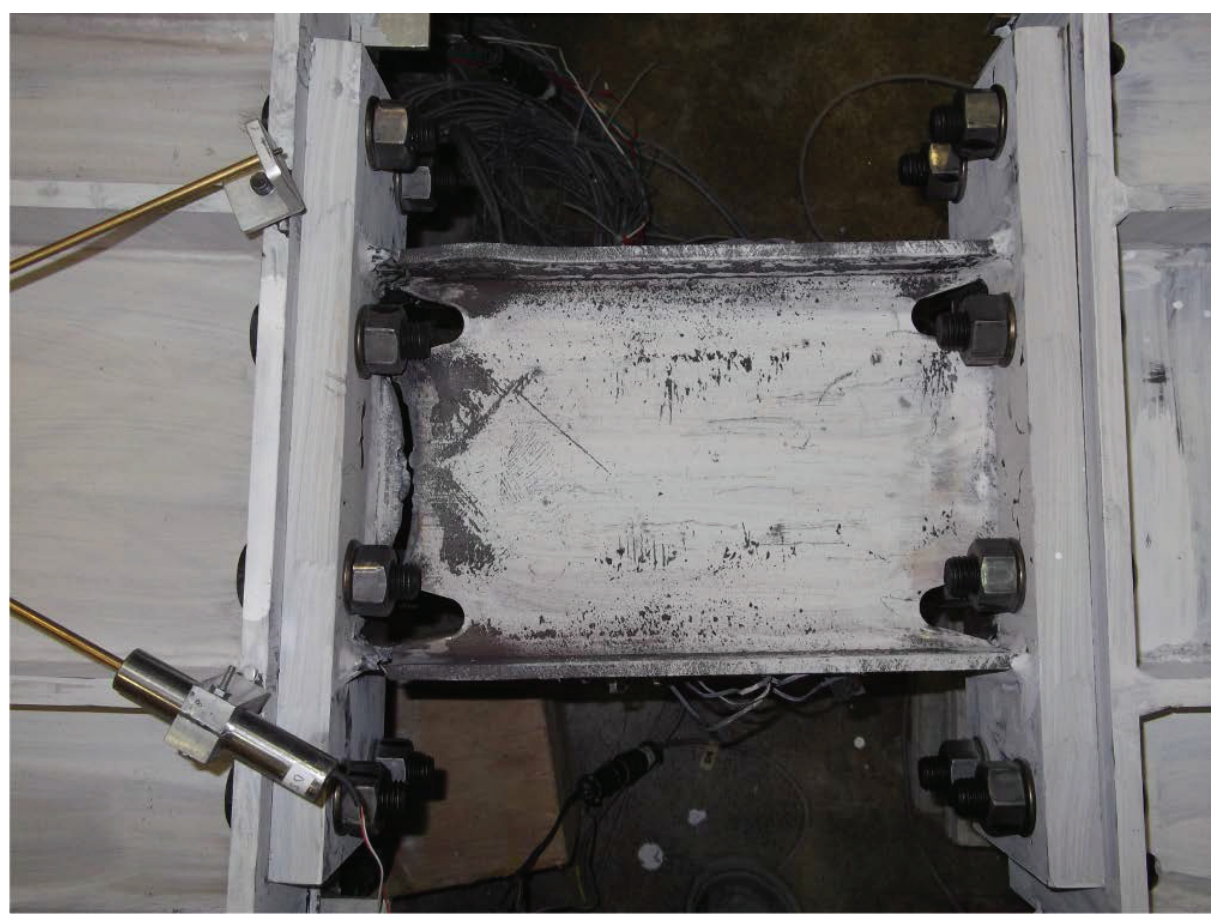

Figure 5.33: Complete Link Cross-Section Fracture at 5\% Drift for Test MC-2A

failure until high drift levels were reached. Further studies should be done to determine the failure mode with larger connections, where links with more appropriate aspect ratios can be used. For small scale connections, appropriate link sizes are limited. End-plate bolts remained tight following specimen failure, indicating that no bolt elongation took place. No observable plastic deformations or brittle failures occurred in and timber elements, steel-to-timber connections, or the steel panel zone.

\subsubsection{Hysteretic Behaviour and Drift Analysis}

The global hysteretic response (load vs. displacement) of the second test specimen is shown in Figure 5.34. This connection sustained a peak applied load at the beam tip $\left(F_{\text {peak }}\right)$ of $54.9 \mathrm{kN}$ at $0.05 \mathrm{rad}$ storey drift, which is close to the estimated full plastic capacity $\left(F_{p r}\right)$ of the connection $(52.2 \mathrm{kN})$. This connection reached a load of approximately $52 \mathrm{kN}$ during both cycles at $0.04 \mathrm{rad}$ storey drift. As indicated on the plot, this is higher than $80 \%$ of the peak load $(43.9 \mathrm{kN})$, meaning that the failure criteria for this connection was satisfied. There were no signs of strength degradation in the connection up to the peak drift of $0.05 \mathrm{rad}$. No drop in force was observed 
until fracture occurred during the second cycle at $0.05 \mathrm{rad}$ storey drift. No drop in force was seen due to initiation of cracking in the web. The initial force drop during the positive portion of the second cycle coincided with fracture of the link flange. Loading continued with little resistance until the drift limit was reached. During the unloading portion of the cycle, the gap due to the flange fracture closed and the specimen retained some stiffness due to bearing of the fractured flange on the end-plate. Strength then increased until complete fracture of the entire link cross-section occurred near the negative drift limit. Again, the global hysteretic response was very stable and resembled that of a typical steel-only moment-resisting connection. No sign of pinching was present, indicating that there was likely little bolt elongation at the end-plates, and little slip in the STS connections. Furthermore, the connection remained elastic under design loads $\left(F_{\text {design }}\right)$.

Figure 5.35 shows the moment versus rotation response of the connection for both the total storey drift angle and the plastic storey drift angle. The connection sustained a peak moment at the column face $\left(M_{c f, p e a k}\right)$ of $113 \mathrm{kN} \cdot \mathrm{m}$. This is approximately $11 \%$ higher than the expected moment capacity of the link under full plastic behaviour, which is adequate for design. The ability to predict the connection strength this closely is beneficial for connection design using the capacity-design principle. Since plastic hinging occurred at the column-side of the link, the designer should take care to choose the initial link section based on the moment at the column face and not at the middle of the link. The peak plastic storey drift angle was found to be $0.037 \mathrm{rad}$, meaning that $74 \%$ of the total storey drift angle was accommodated by plastic rotation. This indicates that high levels of ductility and energy dissipation were achieved.

Figure 5.36 shows the decomposition of total storey drift into the contribution from individual connection components. It is evident that a majority of the rotation was localized into the link, indicating that the capacity-design method was successful. Initial link rotations in the elastic range were quite high since the link was the most flexible part of the connection. It is evident that most plastic behaviour took place in the link, since the total percent contribution to storey drift angle changed very little between drift levels. Following plastic hinging of the link, drift contribution from the panel zone, STS connection, and elastic components lessened. Since there 


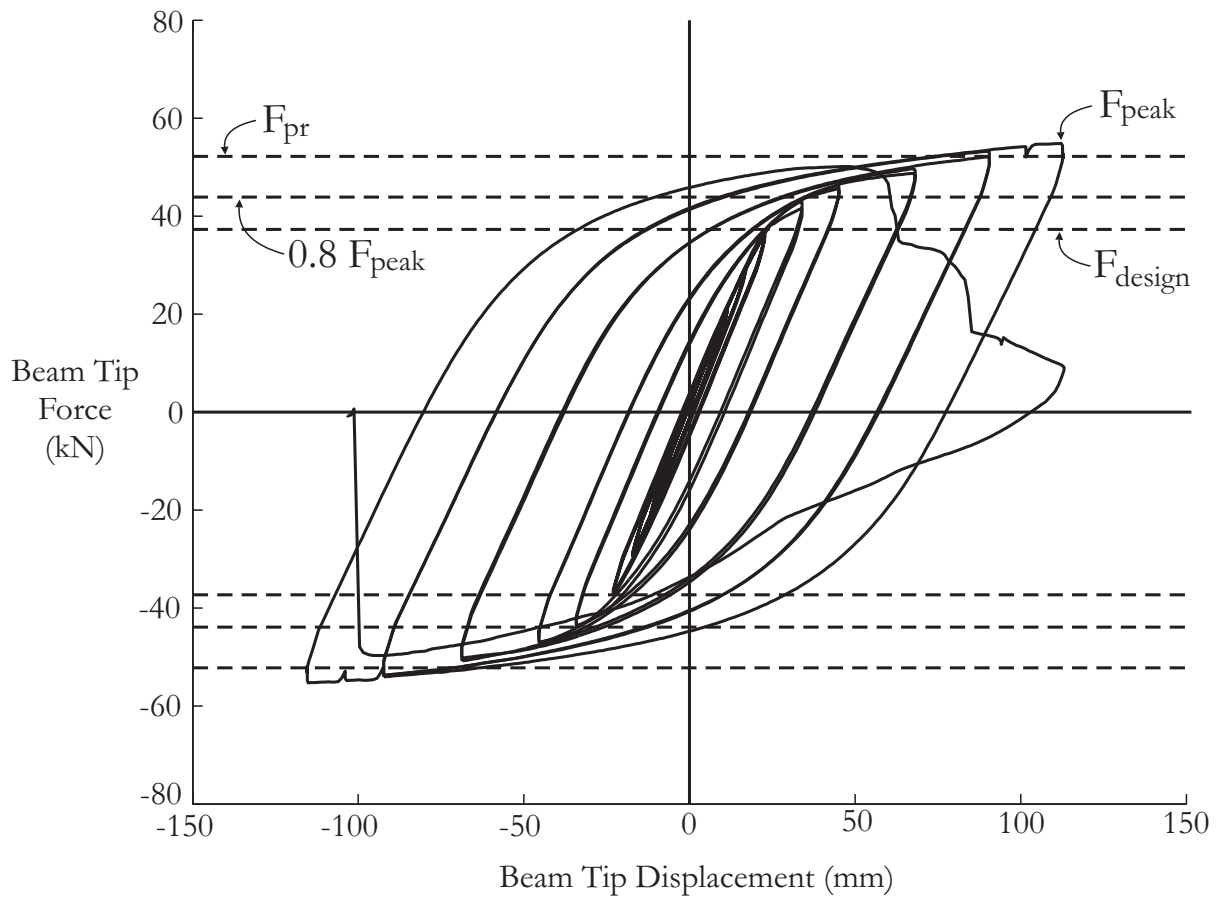

Figure 5.34: Force vs. Beam Tip Displacement Response for Test MC-2A

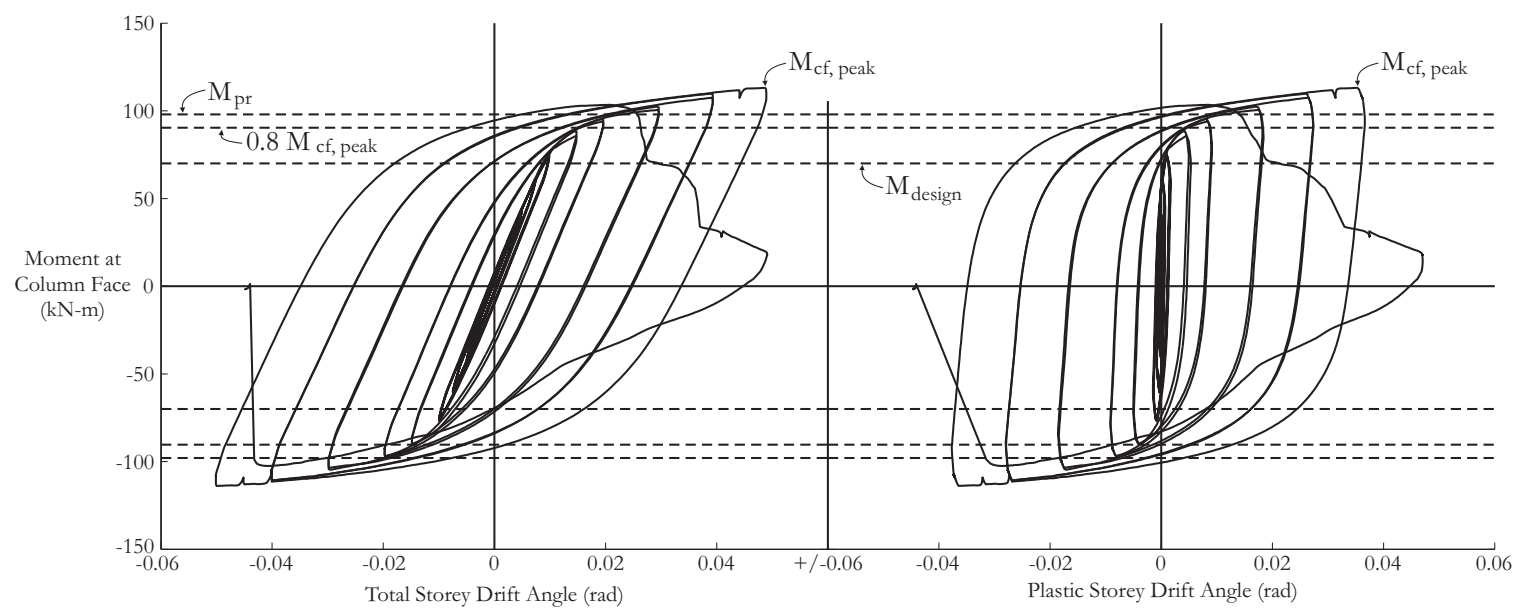

Figure 5.35: Moment vs. Rotation Responses for Test MC-2A 
was no plastic behaviour present in the timber members or steel panel zone, contributions from these components during the later test cycles were minimal.

\subsubsection{Strain Analysis}

The local behaviour of individual parts of the connection was monitored using strain gauges, and analyzed by means of strain profile. Figure 5.37 shows the strain profile in the link flanges along the length of the link (at mid width). As expected, maximum strain was located at the column side of the link, which coincides with the location of initial yield onset observed during the test. Since the flanges had a constant cross-section, the strain profile tended to be less concentrated in the middle of the link than in the previous test. Prior to yielding, the strain profile remained linear. The strain between the middle of the link and the beam side appeared to remain approximately constant up to $0.01 \mathrm{rad}$ drift, at which point the beam side of the link began to yield. The strain profile of the top and bottom flanges tended to be nearly symmetrical. Overall, this connection behaved in a more predictable manner than the previous test.

Figure 5.38 shows the strain profile across the link flange width at the column side of the link where strains were highest. The strain was fairly uniform across the width compared to the RBS link test; it was completely linear before the onset of yielding, but became less linear afterwards. Since local buckling of the flange was symmetrical on each side of the web, the strain profiles were more linear than in the previous test. Behaviour of the top and bottom flanges were similar.

Figure 5.39 shows the strain profile through the depth of the link at the column side. Profiles remained linear under all drift levels, however it appears that yielding initiated in the top of the web (refer to Figure 5.3 for definition), and propagated downward. At large drift levels, this resulted in significantly higher strains in the top of the link web.

Ryan Gohlich, Department of Civil and Environmental Engineering, Carleton University 


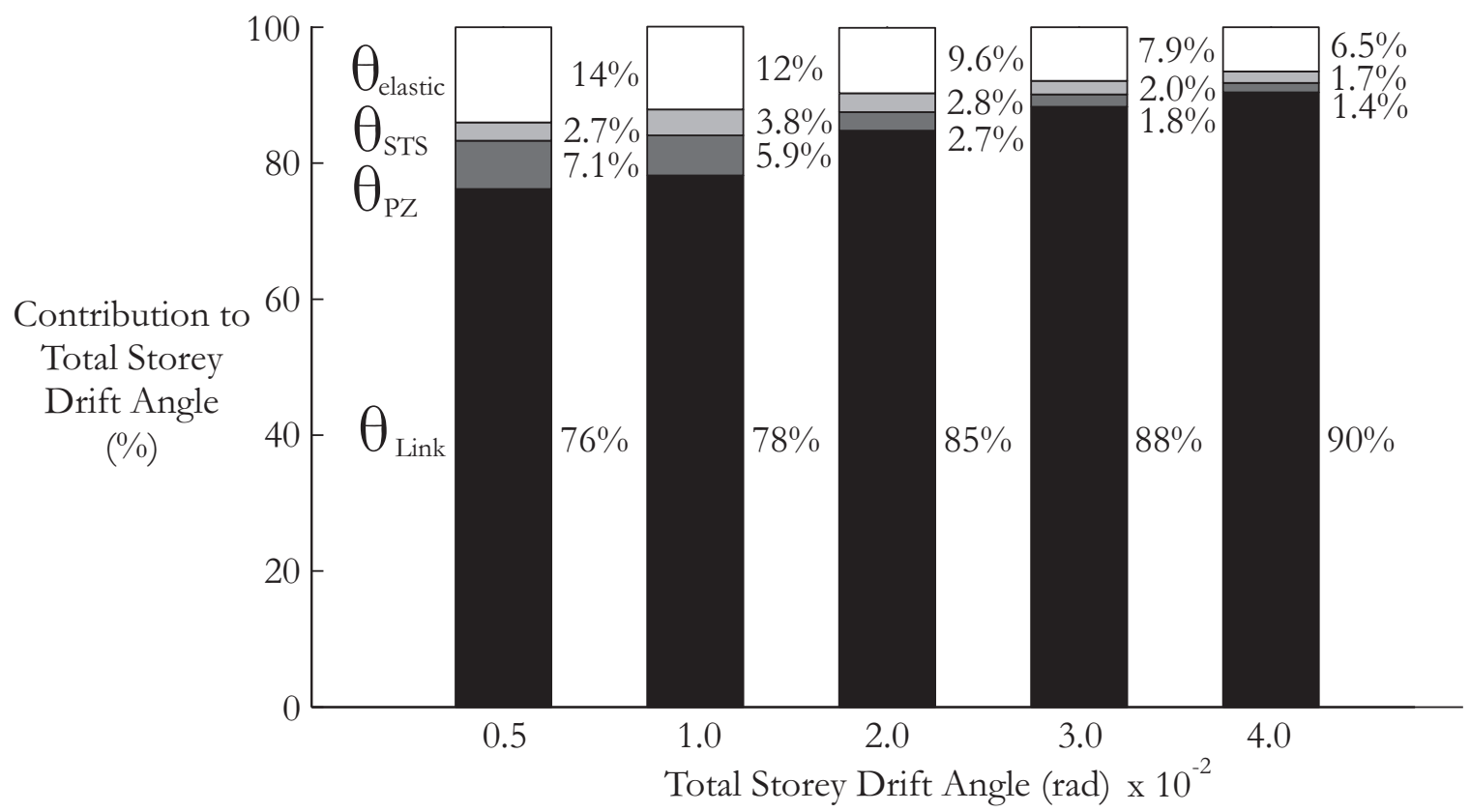

Figure 5.36: Total Storey Drift Decomposition for Test MC-2A

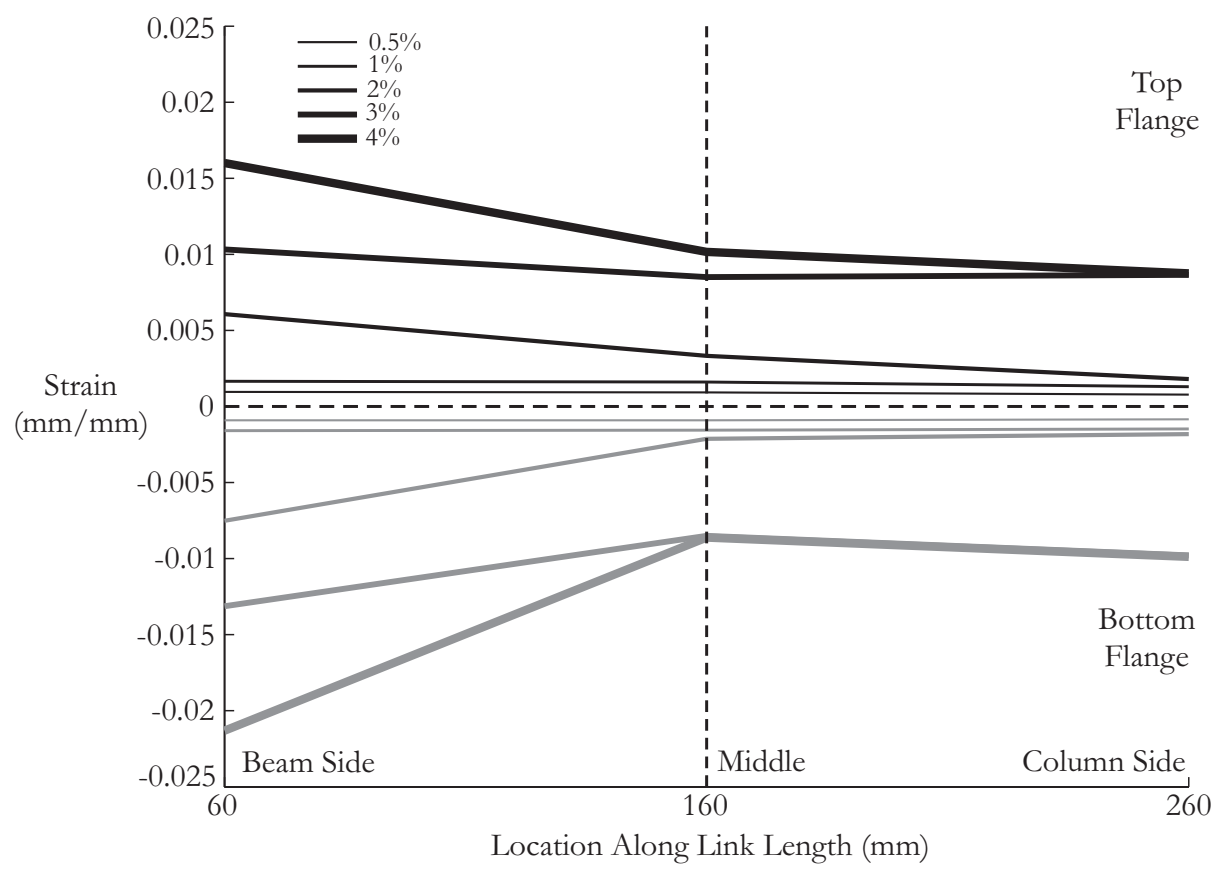

Figure 5.37: Strain Profile Along Link Length for Test MC-2A

Positive Bending at Mid-width of Flange 


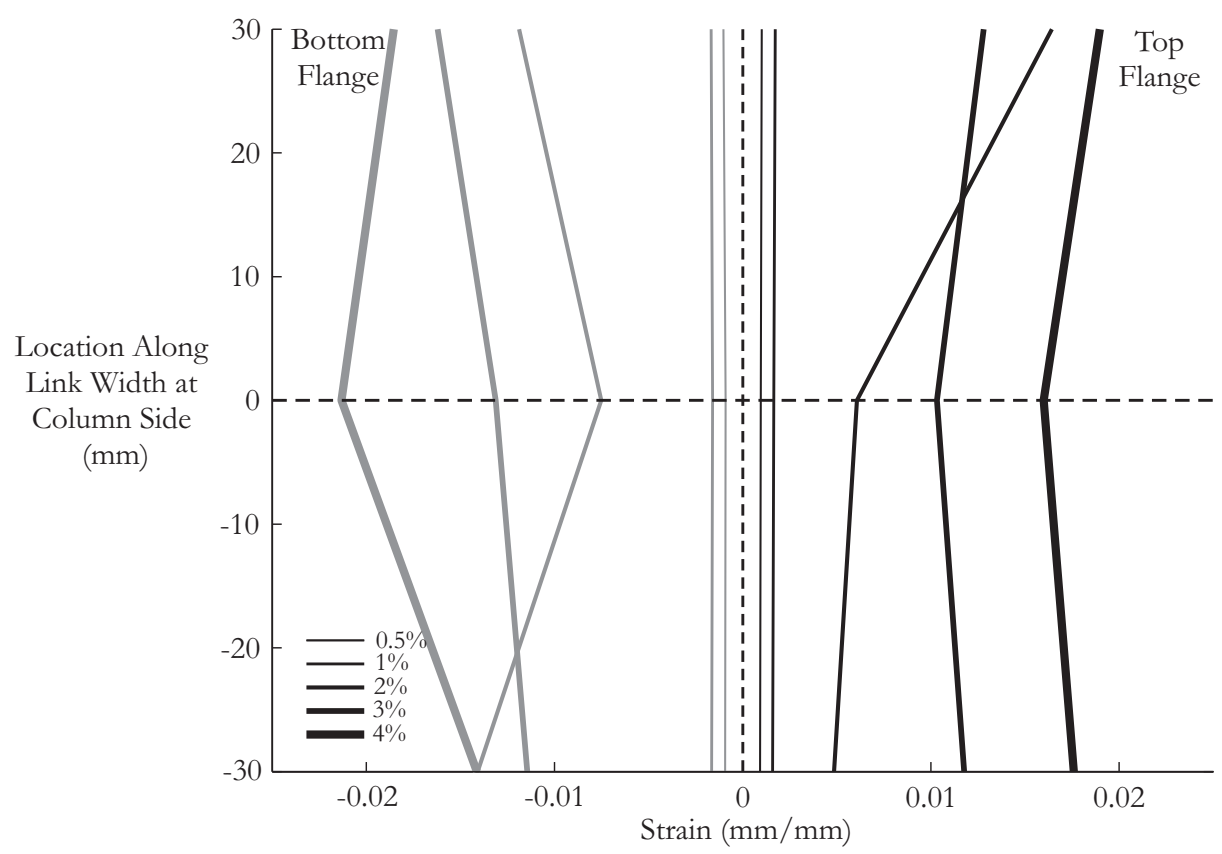

Figure 5.38: Strain Profile Across Link Width for Test MC-2A Positive Bending at Column Side of Link

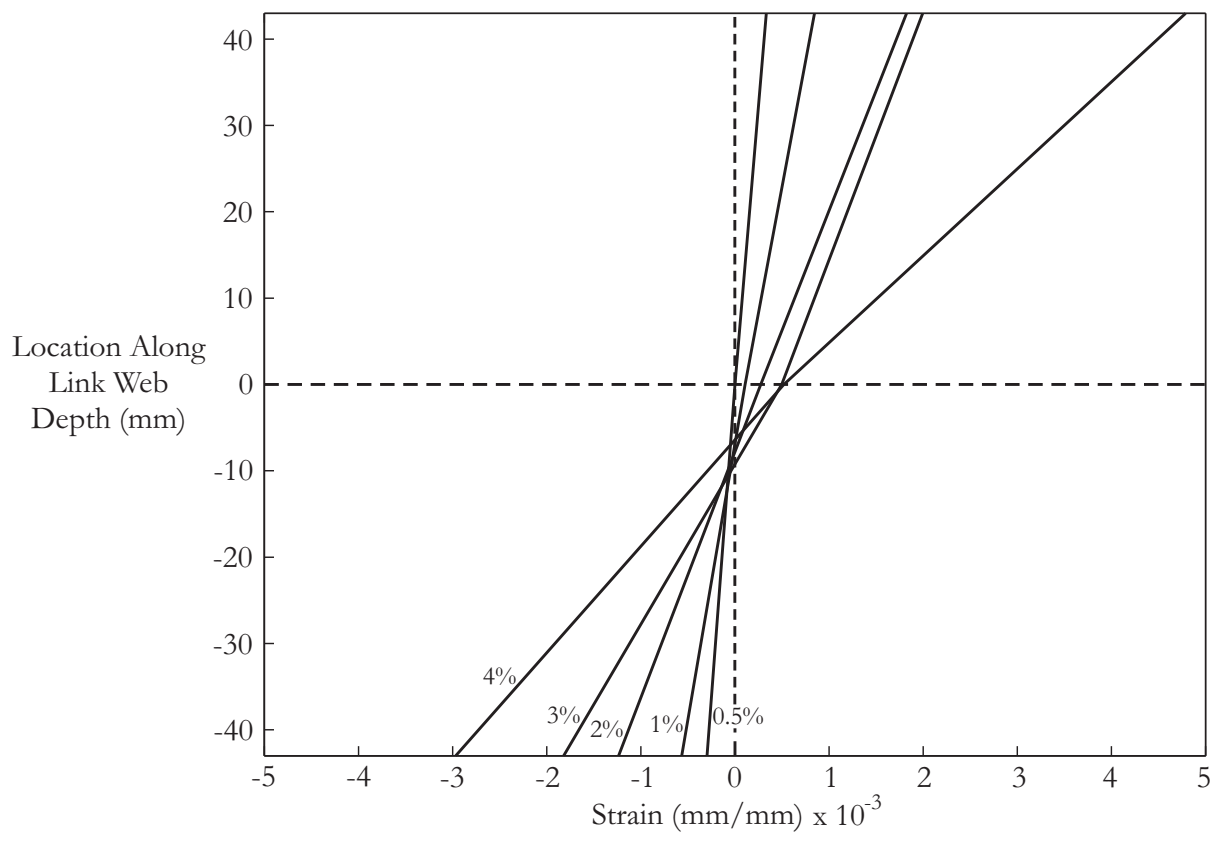

Figure 5.39: Strain Profile Through Link Depth for Test MC-2A (Positive Bending) 


\subsubsection{MC-1B}

\subsubsection{Failure Sequence}

The third test used a steel link with a dogbone detail, and the beam connection type used STS with ZD-plates, while the column STS connections remained the same as in the previous two tests. A summary of the test observations can be seen in Figure 5.40. They are quite similar to the observations of the first test since identical links were used, however there were some slight differences as a result of the change in beam STS connection type.

Figures 5.41, 5.42, and 5.43 show a summary of the yield propagation through the link at critical points in the test. The connection showed initial signs of yielding during the third cycle at $0.005 \mathrm{rad}$ storey drift. Initial yielding was located near the flange-to-end-plate welds on both the beam side and column side of the link. At 0.0075 rad storey drift, yielding began at the middle of the link flanges, which became the primary location for yield propagation (Figure 5.44). At the second cycle of $0.01 \mathrm{rad}$ storey drift, yielding propagated into the link web and around the weld access holes. Upon reaching 0.015 rad drift, uniform yielding across the entire flange width a the dogbone location was observed, and more significant yielding near the flange-to-end-plate weld occurred at $0.02 \mathrm{rad}$ drift (Figure 5.45). A slight gap opening was observed between the end-plate and the column face at $0.03 \mathrm{rad}$ drift, along with more excessive web yielding (Figure 5.46). During the final cycle at 0.03 rad storey drift, local buckling of the web began (Figure 5.47), followed by local flange buckling at $0.04 \mathrm{rad}$ drift (Figure 5.48). Excessive out-of-plane web buckling began during the last cycle at 0.04 rad drift, as seen in Figure 5.49, and continued until it caused bending in the pinned connection supports (out-of-plane). The additional lateral restraint provided after the first test was successful in postponing out-of-plane local web buckling, allowing the third test to run for an additional cycle. 


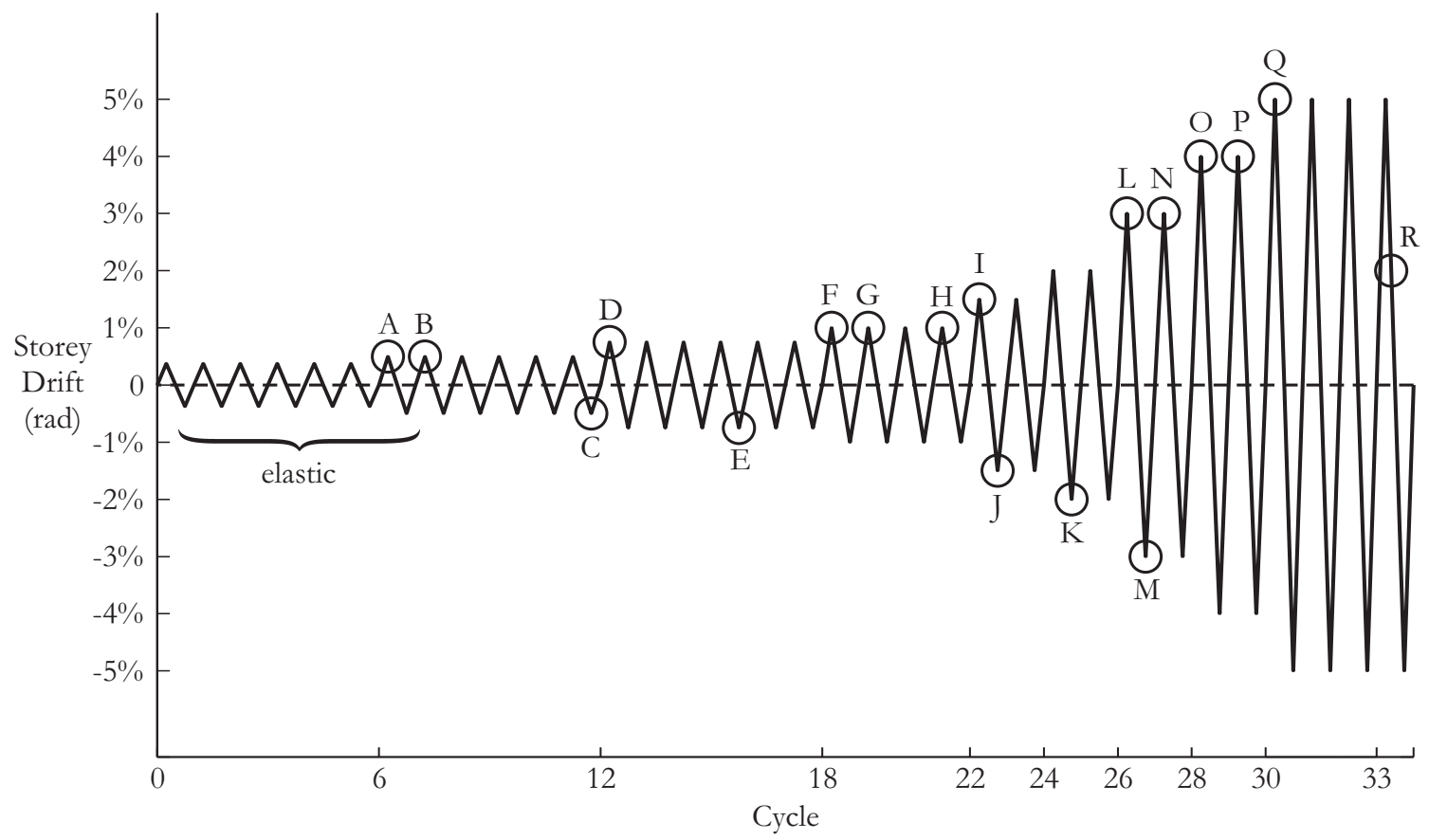

A - Creaking noise at steel-timber interfaces (ZD-plate connection, bearing plate) at max cycle amplitude

B - Slight flaking of white-wash at flange-to-end-plate welds (BS and CS)

C- Increased yielding near flange-to-end-plate welds

$\mathrm{D}^{-}$Creaking noise gets louder, yielding begins in link flange at dogbone location

E- Continued yield propagation at dogbone location

$\mathrm{F}$ - Excessive yielding at dogbone location

$\mathrm{G}^{-}$Yield propagation into link web near dogbone location, yielding starts at weld access holes (CS)

$\mathrm{H}^{-}$Loud creaking noises when cycling through zero dispalcement

I - Yield propagation further across depth of link web (at dogbone location)

$\mathrm{J}$ - Uniform Yielding across flange width

K- Yield propagation across link web depth and around weld access holes

L - Slight gap opening between CS end-plate and column-face

$\mathrm{M}^{-}$Yield propagation in flange and web-to-end-plate welds

$\mathrm{N}^{-}$Local buckling of web begins

$\mathrm{O}^{-}$Local bucking of link web continues and local buckling of link flanges begins

P - Web local buckling causes lateral torsional buckling

Q- Significant out of plane movement of column assembly due to lateral torsional buckling of link

$\mathrm{R}$ - Test ended due to excessive out of plane deformations

Figure 5.40: Summary of Observations for Test MC-1B 

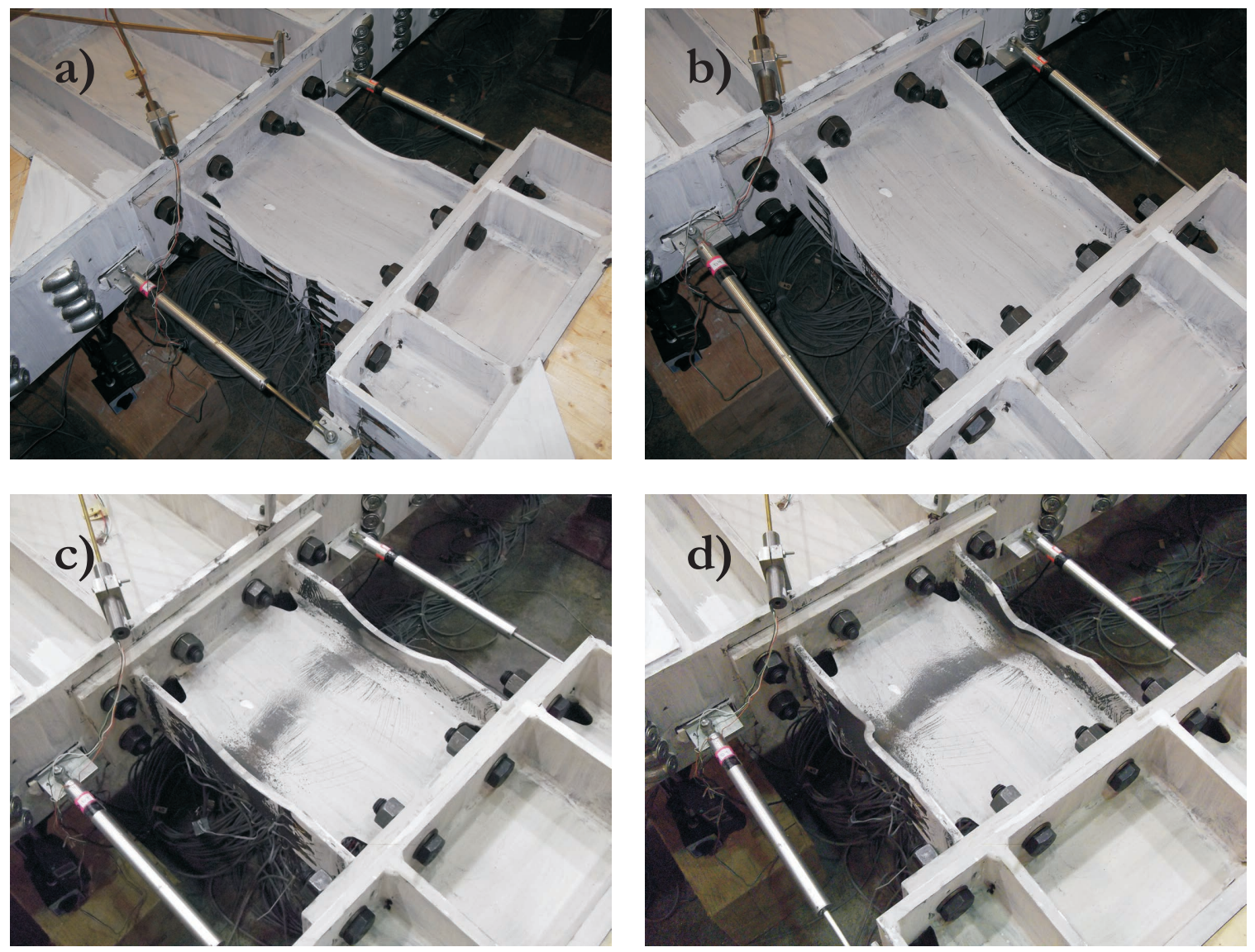

Figure 5.41: Yielding Propagation in Link for Test MC-1B

a) Initial b) $1 \%$ Drift c) $4 \%$ Drift d) Final 

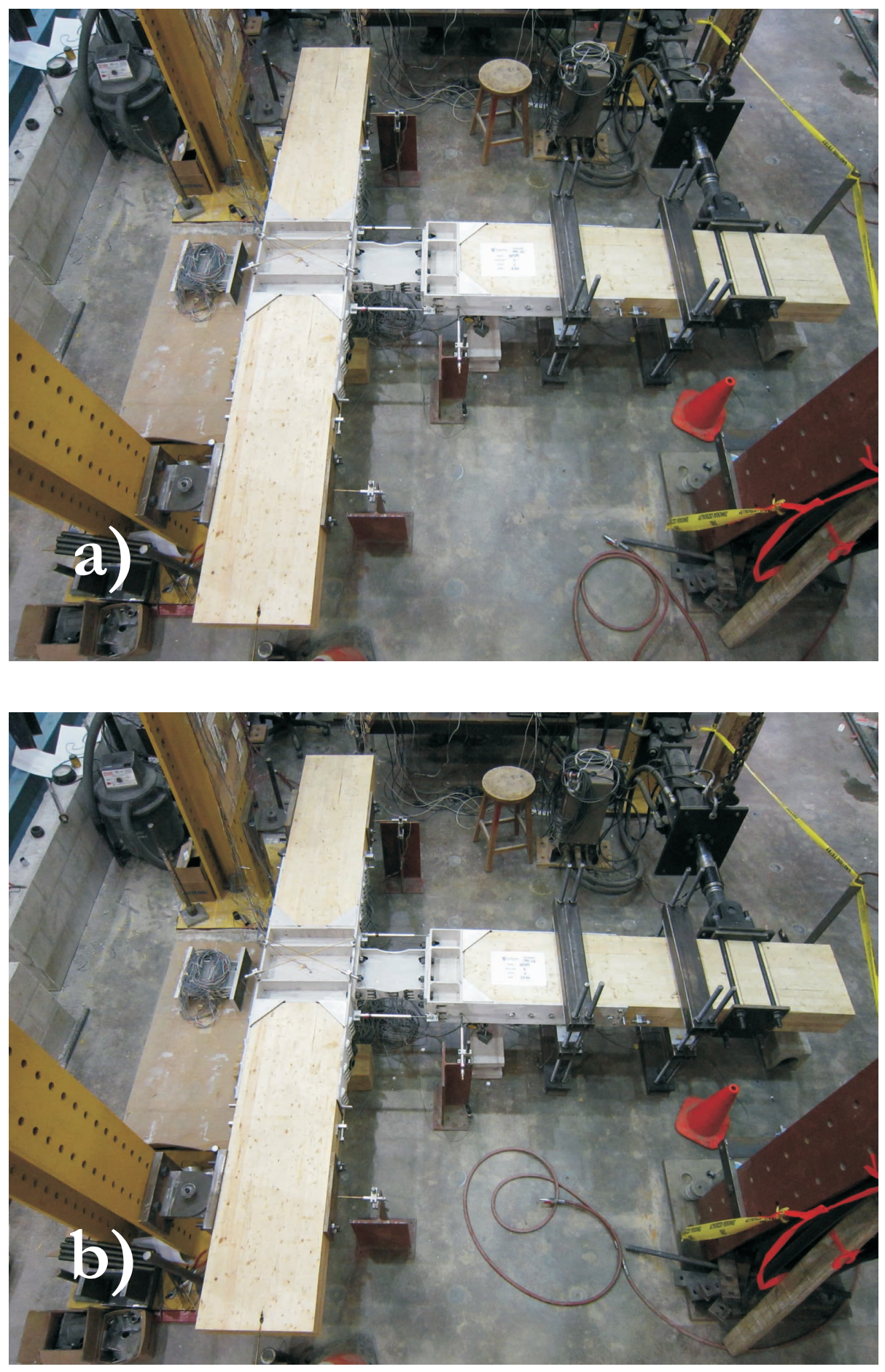

Figure 5.42: Frame Deformations Through Test MC-1B a) Initial b) $1 \%$ Drift 

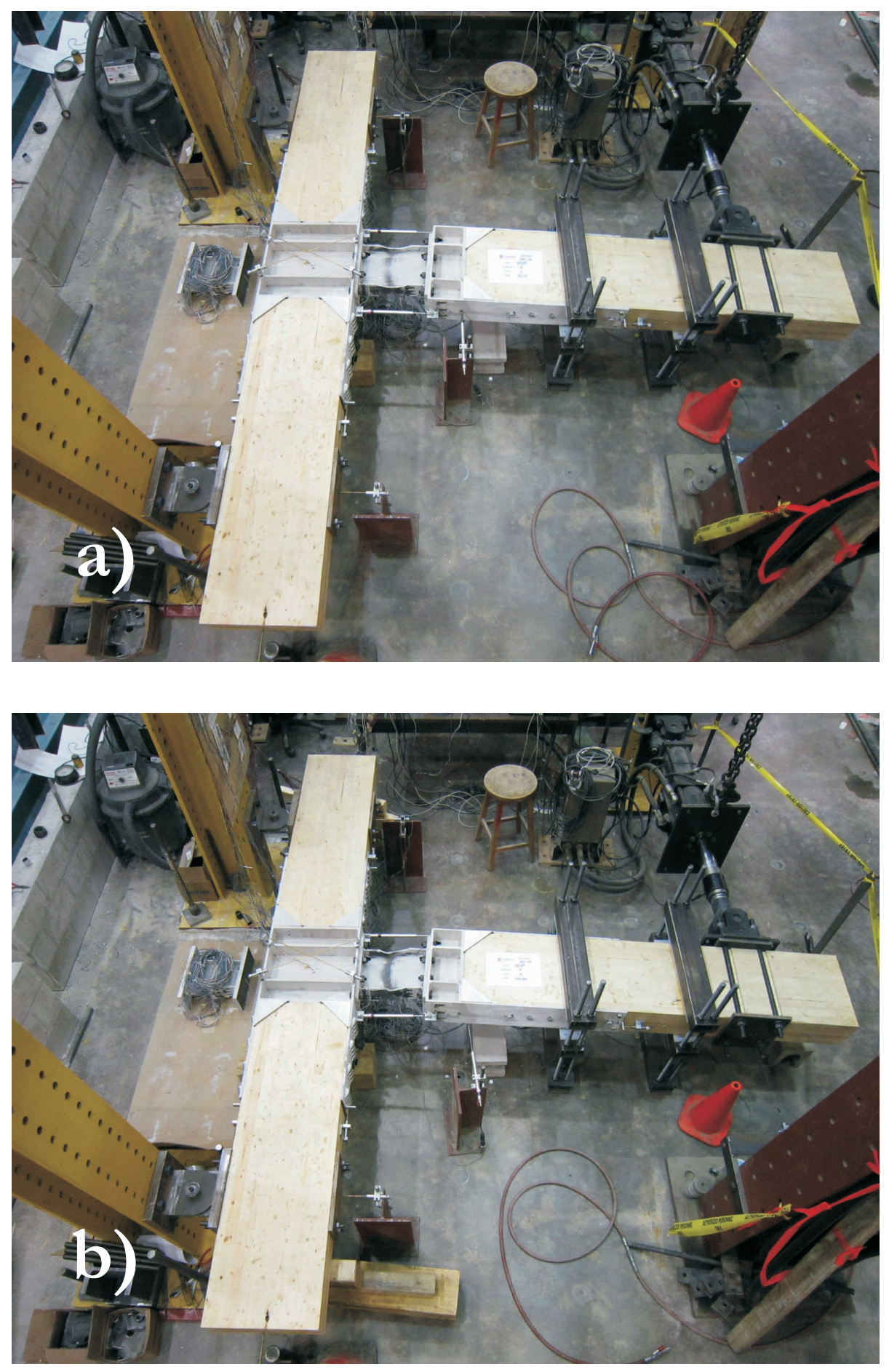

Figure 5.43: Frame Deformations Through Test MC-1B a) $4 \%$ Drift b) Final 

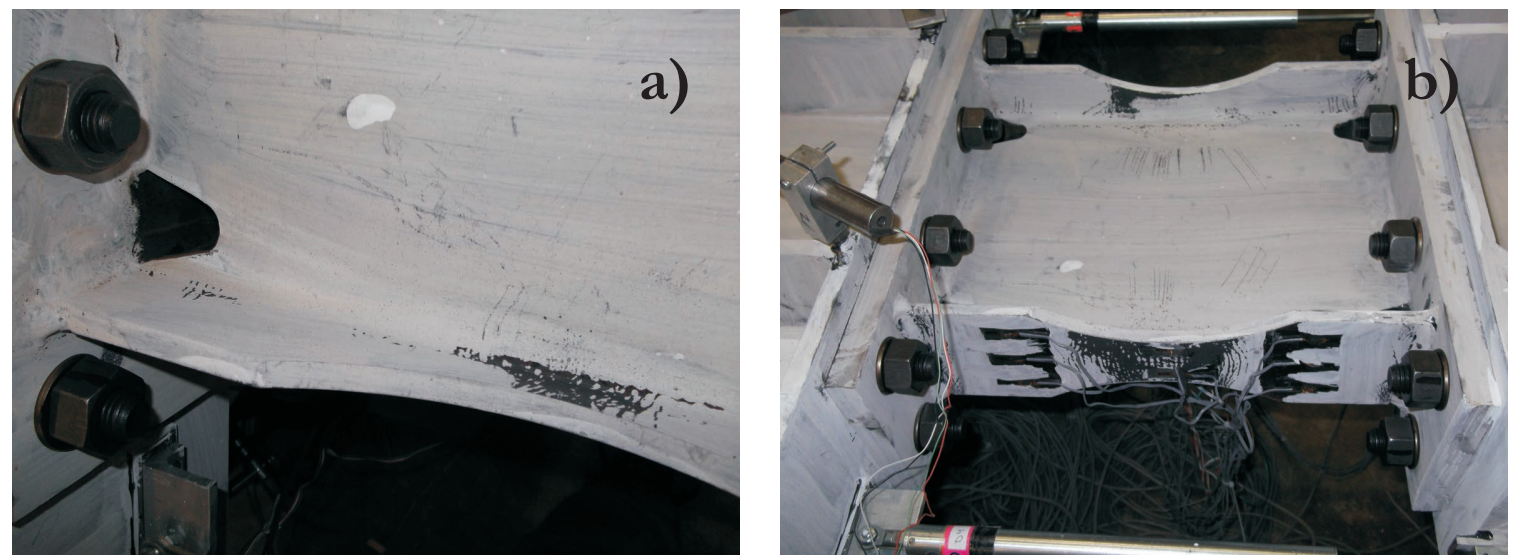

Figure 5.44: Flange Yielding for Test MC-1B

a) $1 \%$ Drift b) $1.5 \%$ Drift

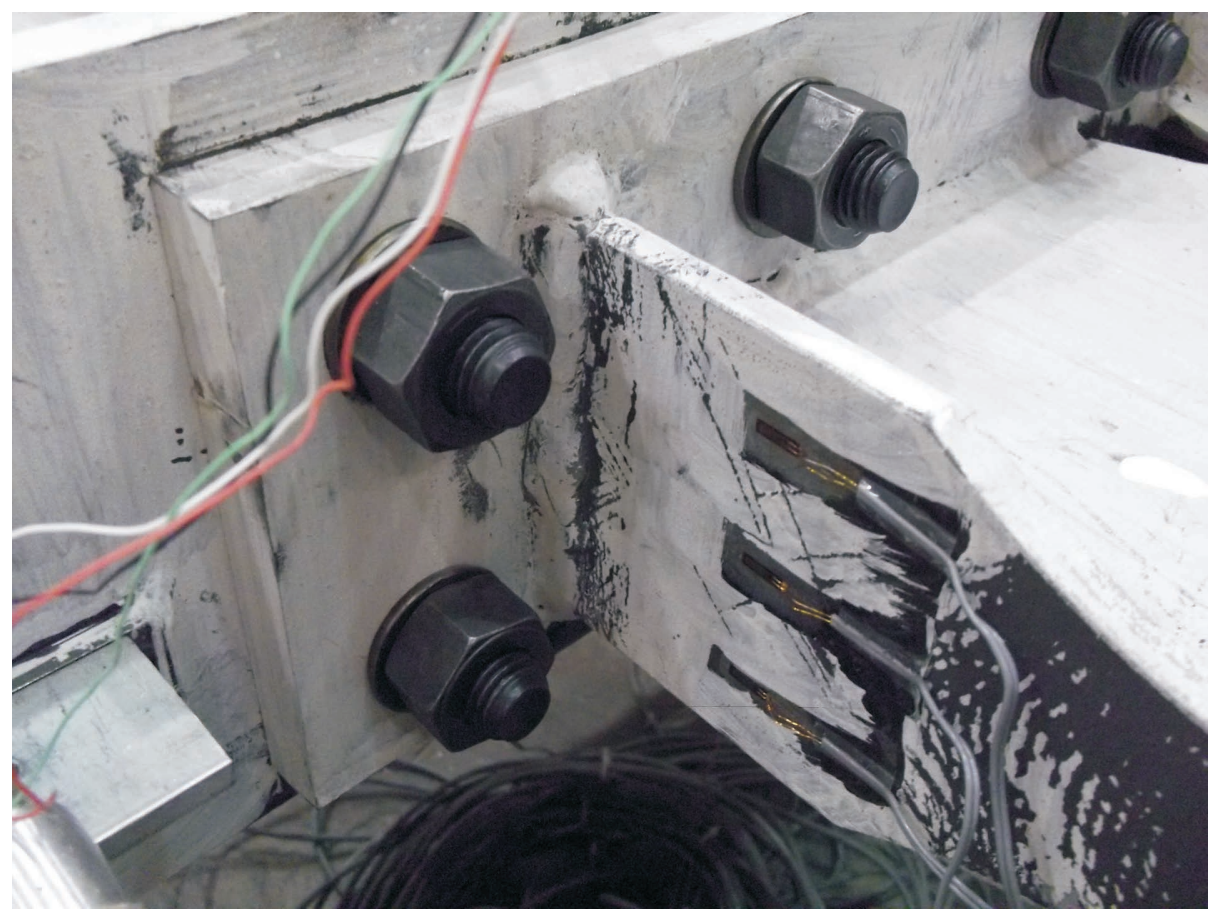

Figure 5.45: Yielding Near Flange Weld at 2\% Drift for Test MC-1B 


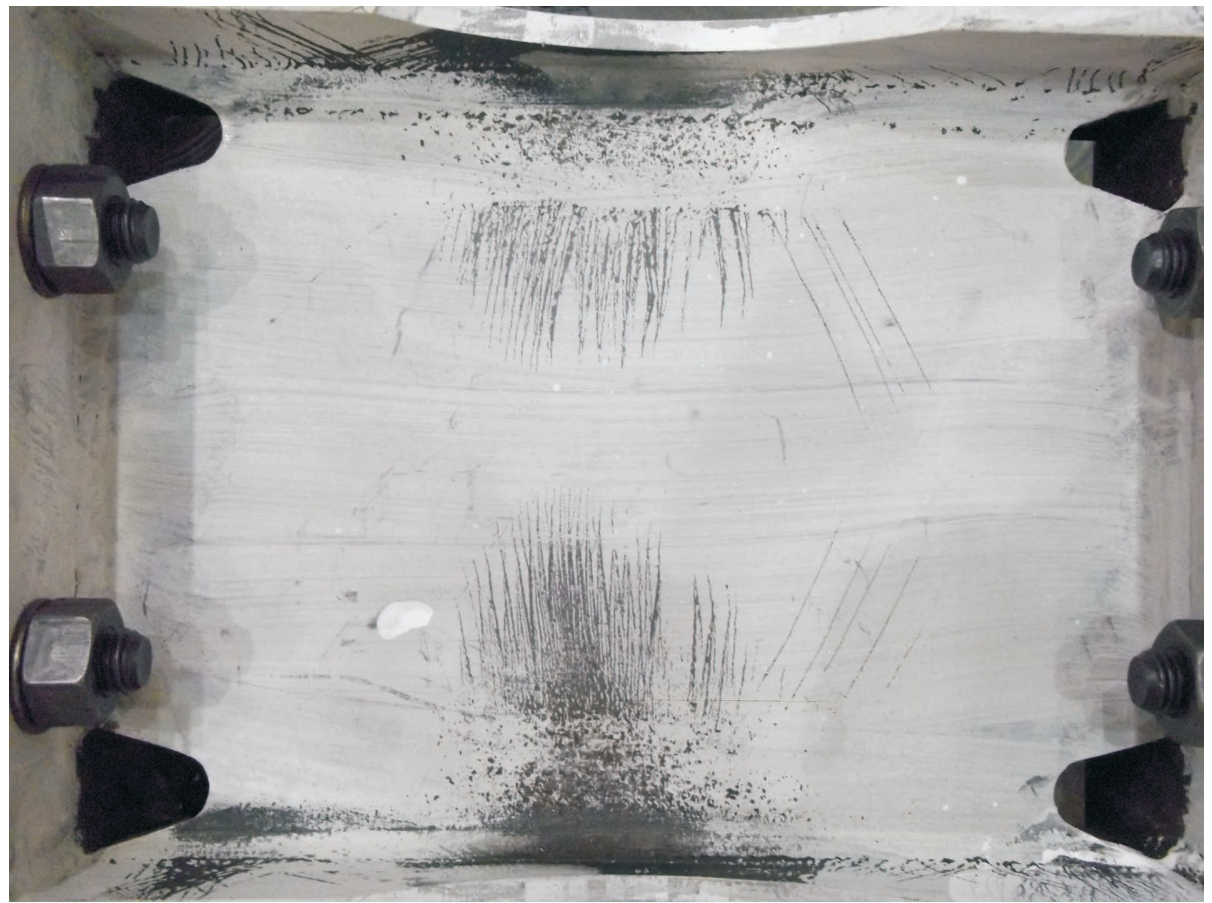

Figure 5.46: Web Yielding at 3\% Drift for Test MC-1B

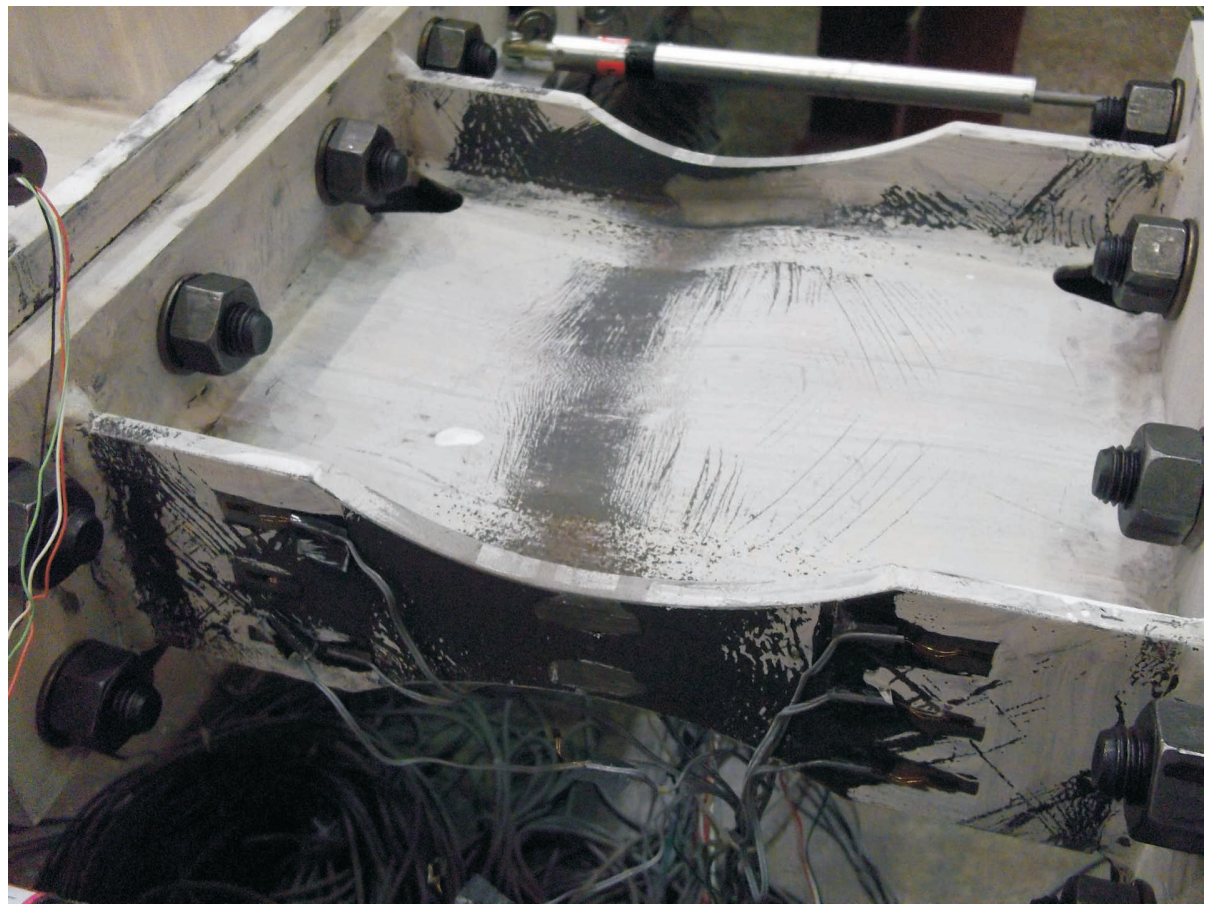

Figure 5.47: Local Buckling of Web at 4\% Drift for Test MC-1B 


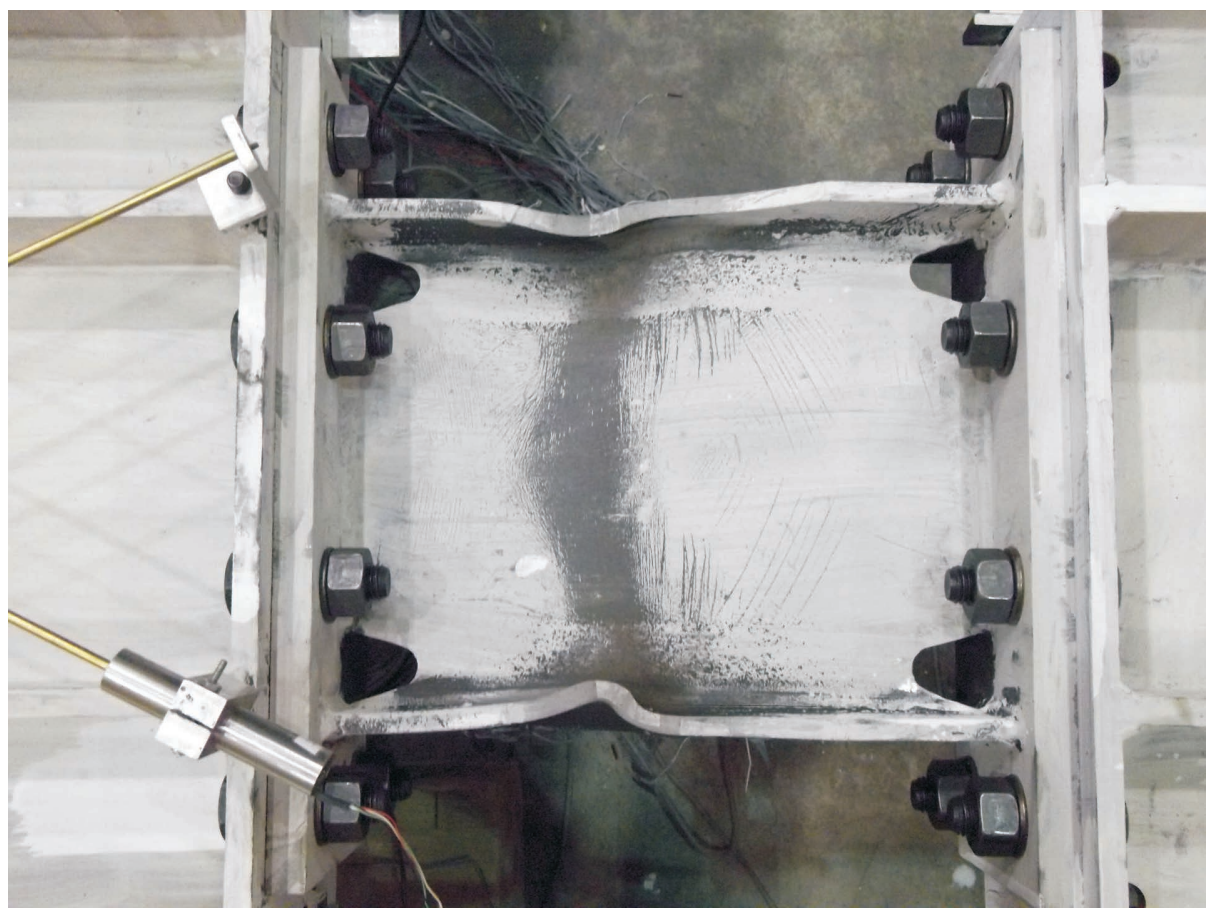

Figure 5.48: Local Buckling of Flange at 4\% Drift for Test MC-1B

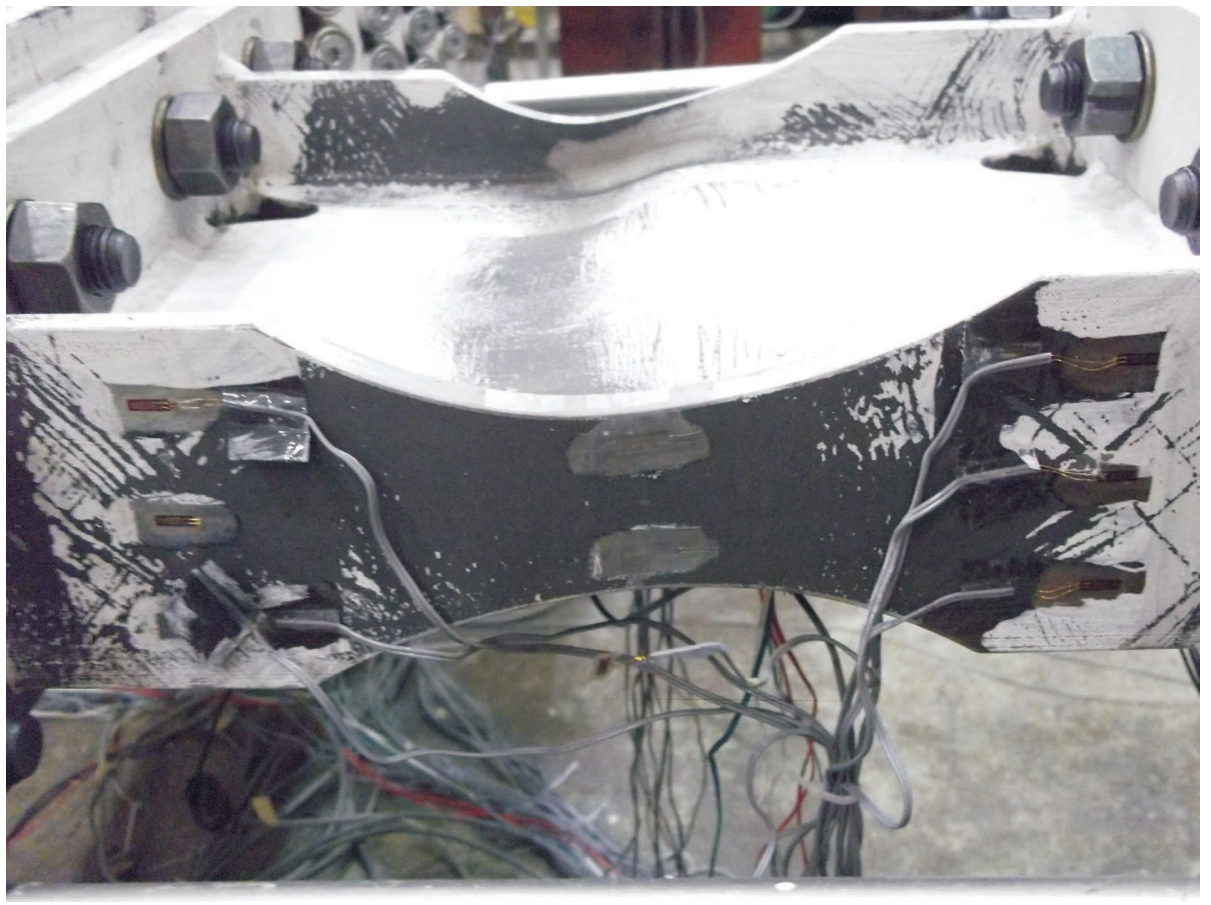

Figure 5.49: Out of Plane Movement at 4\% Drift for Test MC-1B 
Loud creaking noises were heard throughout the test, beginning at the $0.005 \mathrm{rad}$ cycle set. At low drift levels, creaking was loudest at maximum cycle amplitudes, while during later cycles, creaking was loudest when the beam passed through the zero displacement location. These noises appeared to be coming from the steel-timber interfaces of the beam STS connection (STS location as well as end-grain bearing plate). This indicates that there was likely more slip in the ZD-plate connection than in the 45 degree STS connection in the previous tests. It is unlikely that the ZDplate itself was slipping, but rather the over-sized holes accommodating the steel plate to ZD-plate bolts allowed for some slippage between the steel plate and the timber beam surface.

Similar to test MC-1A, the dogbone detail was successful in forming a plastic hinge at the centre of the link, away from brittle connection components. Again, the low out-of-plane stiffness of the RBS link resulted in excessive out-of-plane local buckling of the web, which would likely be avoided in a full-scale test. There were no signs of weld cracking in the web, and endplate gap opening was minimal. End-plate bolts remained tight after the test was completed, so again, it is unlikely that any bolt elongation took place that could limit the energy dissipation of the connection. Based on the test observations, it appears that the beam connection type had little effect on the overall performance of the link in terms of failure sequence and failure mode. There were no signs of plastic deformations in the panel zone, column and beam sections, or the STS connections.

\subsubsection{Hysteretic Behaviour and Drift Analysis}

The global force versus displacement hysteresis is presented in Figure 5.50. Findings were similar to that of test MC-1A. The peak load resisted by the connection was $63.4 \mathrm{kN}$ at $0.05 \mathrm{rad}$ storey drift angle, slightly less than the first test specimen. Since the connection was able to withstand $80 \%$ of this value $(50.8 \mathrm{kN})$ at $0.04 \mathrm{rad}$ drift angle, this test specimen met the acceptance criteria. This connection did not show signs of strength degradation until the $0.05 \mathrm{rad}$ drift cycles, where it sustained 3.5 cycles without strength decreasing below $80 \%$ of the peak load. Based on the response shown, it is likely that continued cycles would have led to a strength degradation below $80 \%$ of the peak load. The connection remained in the elastic range under design level loads $\left(F_{\text {design }}\right)$. No pinching behaviour was seen in the hysteretic response, indicating that bolt 
elongation was likely not present, and the STS connection slip was likely not significant enough to effect the global connection behaviour.

The global moment versus storey drift angle (total and plastic) is shown in Figure 5.51. The peak moment sustained by the connection was $131 \mathrm{kN} \cdot \mathrm{m}$, which is $5.3 \%$ higher than the probable moment capacity of the link $\left(M_{p r}\right)$. The plastic storey drift was $0.035 \mathrm{rad}$, meaning that $70 \%$ of the total storey drift was accommodated by plastic deformations. Overall, the global hysteretic behaviour was as expected, and similar to that of a steel-only moment-resisting connection. The agreement between the design resistance and that determined from the test supports the use of the capacity-design procedure.

Figure 5.52 shows the contribution of each connection component to total storey drift angle. The contribution from each component is nearly identical to that of test MC-1A. This indicates that the change in beam connection type had little effect on overall drift performance. Although the link was slightly weaker, it accommodated the same level of drift throughout the test.

\subsubsection{Strain Analysis}

The strain profile along the link length (at mid-width) is shown in Figure 5.53. Again, the findings of test MC-1B correlate nicely with the findings of test MC-1A. Strains peaked at the middle of the link near the dogbone detail, where the cross-section was smallest. Under elastic deformations the strain profile is approximately linear, but after excessive yielding (around 3\% drift) strain readings varied more along the link length.

Figure 5.54 shows the strain profile across the link flange width at the dogbone location where strains were highest and yielding was most concentrated. Strain was uniform across the flange width up to $0.02 \mathrm{rad}$ drift, then tended to increase on one side of the flange more than the other. Strains on the top flange tended to be sightly higher than on the bottom flange. This strain profile is for positive bending, where the top flange is in tension. Although flaking was observed at the dogbone location under $0.0075 \mathrm{rad}$ drift, uniform yielding of the flange did not occur until 


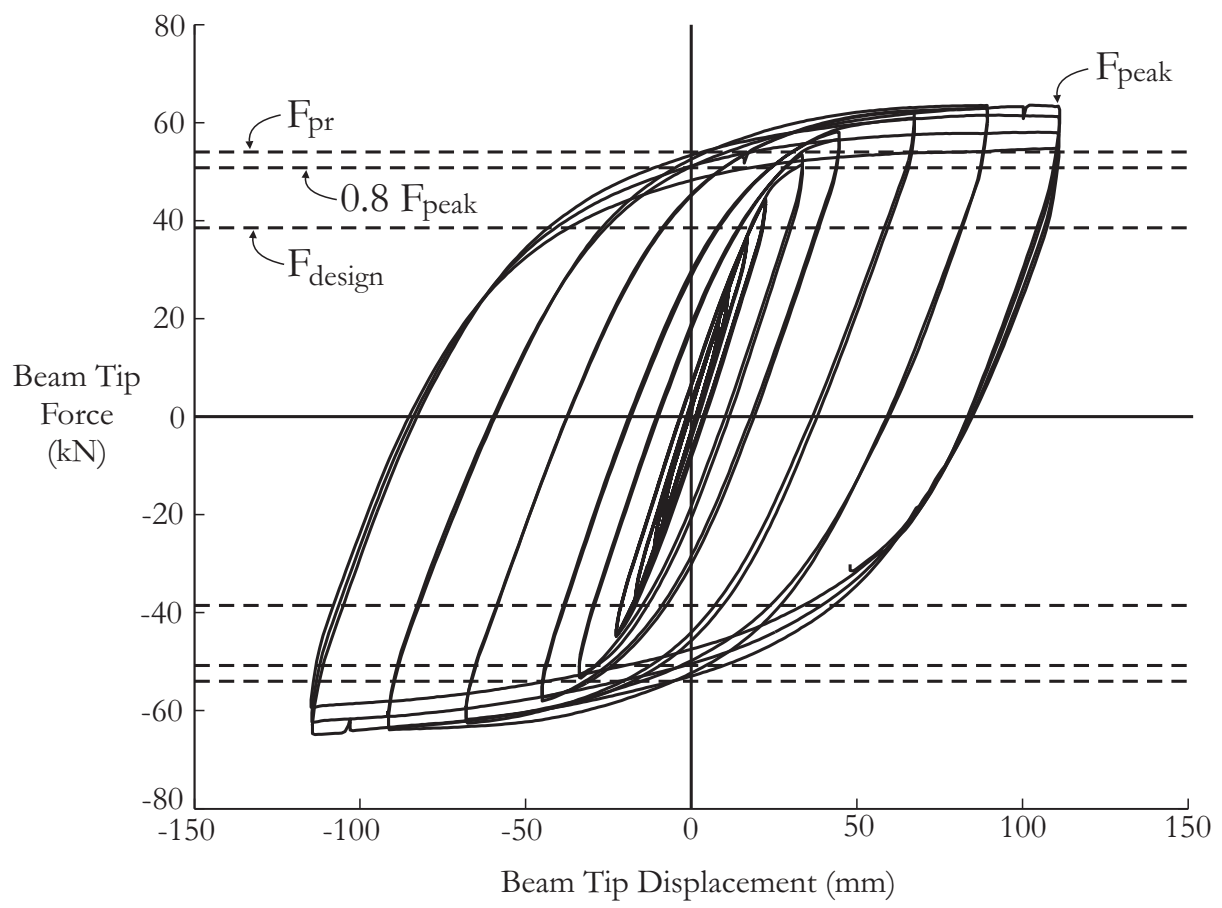

Figure 5.50: Force vs. Beam Tip Displacement Response for Test MC-1B

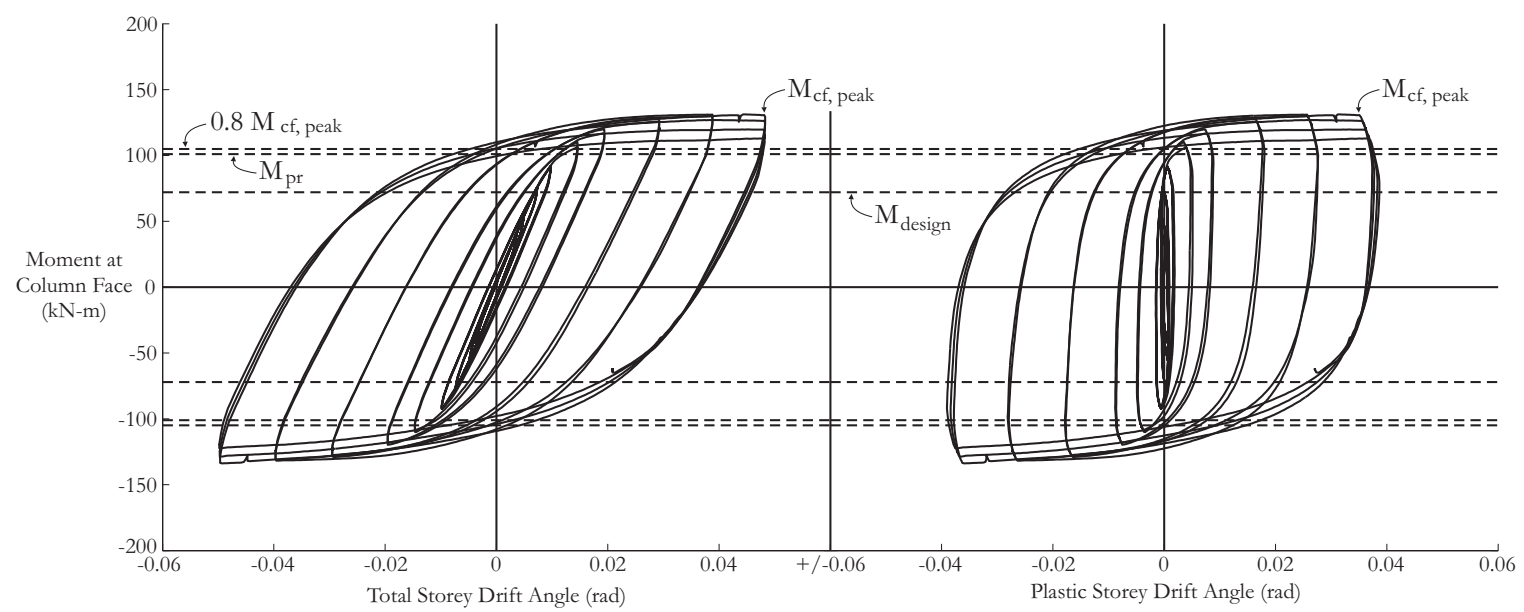

Figure 5.51: Moment vs. Rotation Responses for Test MC-1B 


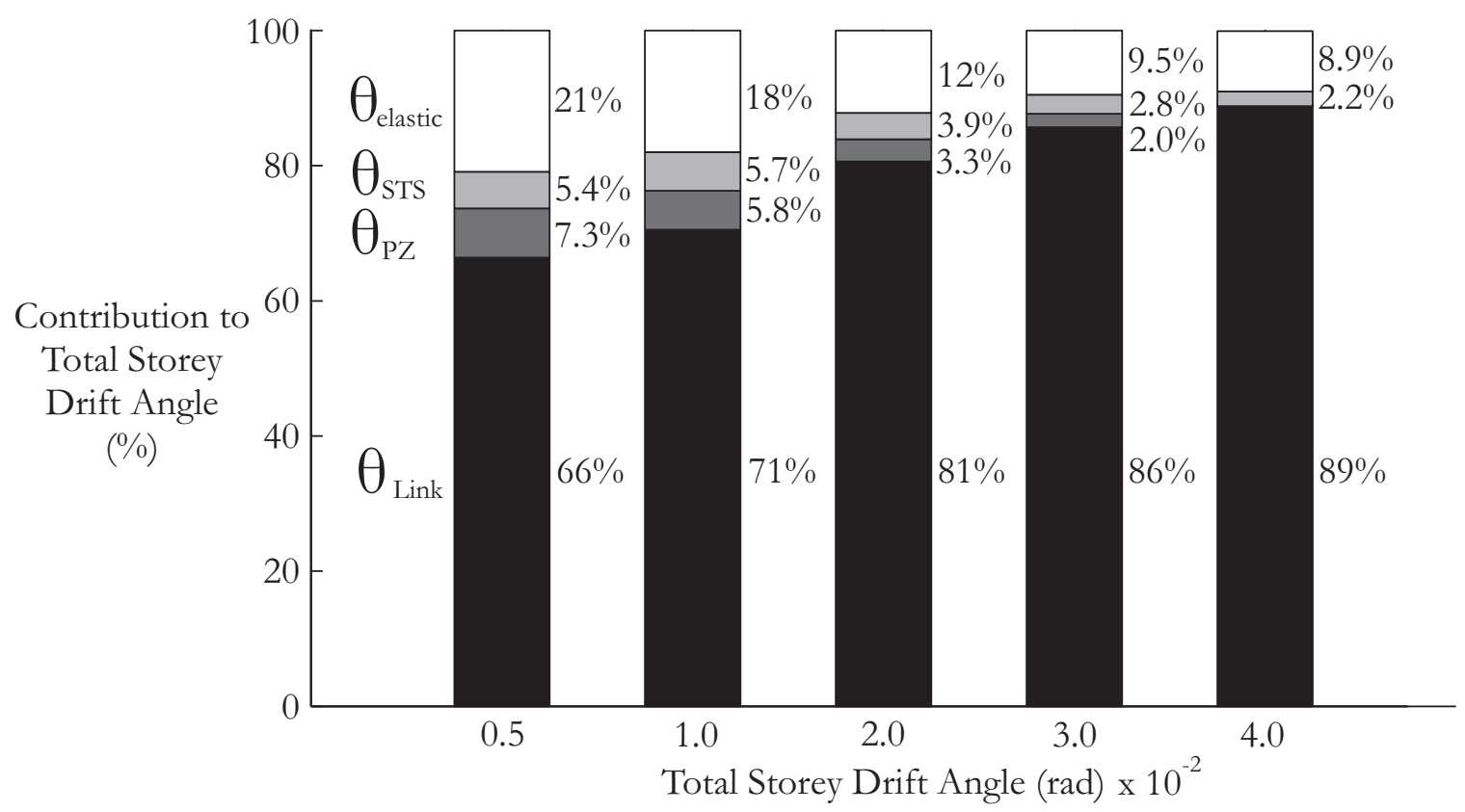

Figure 5.52: Total Storey Drift Decomposition for Test MC-1B

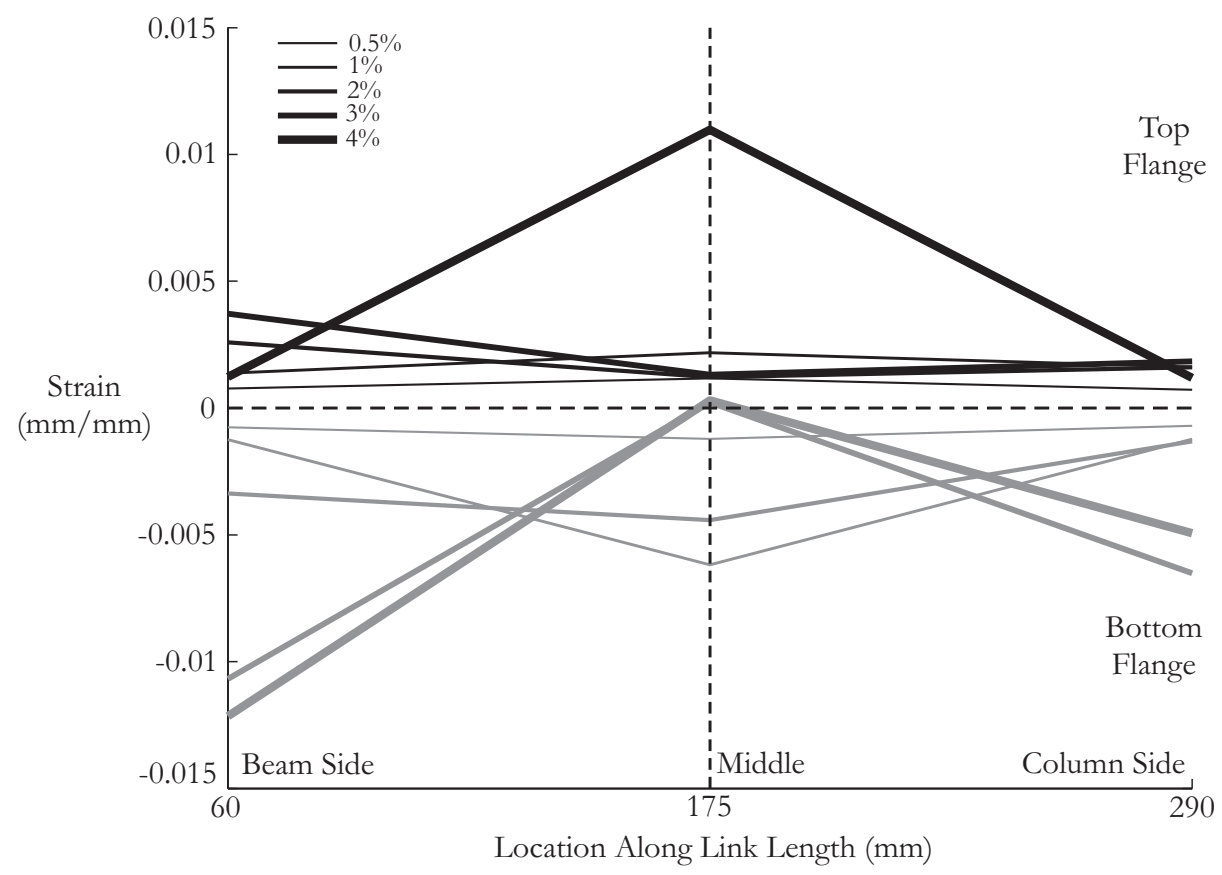

Figure 5.53: Strain Profile Along Link Length for Test MC-1B

Positive Bending at Mid-width of Flange 
approximately $0.03 \mathrm{rad}$ drift.

The strain profiles through the link depth at the column side presented in Figure 5.55 were approximately linear throughout the test, and strains were close to zero at mid-depth of the link, as expected. Strains tended to be higher at the bottom of the link web, indicating that yielding started at the bottom and propagated upwards, which is consistent with the experimental observations.

\subsubsection{MC-2B}

\subsubsection{Failure Sequence}

The fourth test used a steel link made identical to that of test MC-2A (no dogbone detail), and the beam connection type used ZD-plates, while the column STS connections remained the same as in the previous three tests. A summary of the test observations can be seen in Figure 5.56. Failure sequence and failure mode were similar to those of test MC-2A.

Figures 5.57, 5.58, and 5.59 show a summary of the yield propagation through the link at critical points in the test. The connection remained elastic during all cycles up to $0.0075 \mathrm{rad}$ storey drift, at which point initiation of yielding was observed near the flange-to-end-plate welds at both sides of the link. During the first cycle at $0.01 \mathrm{rad}$ drift, yielding at the link ends became more excessive and slight flaking of the white-wash was observed on the flange weld metal, as shown in Figure 5.60. Once the $0.015 \mathrm{rad}$ storey drift angle was reached, yielding (primarily at column side) began propagating into the weld access holes and into the link web (shown in Figure 5.61 at $0.02 \mathrm{rad}$ drift). At $0.02 \mathrm{rad}$ drift, yielding propagated into the middle of the flanges, and a slight gap opened in the end-plate at the column side of the link. By the end of the first cycle at $0.03 \mathrm{rad}$ drift, yielding was nearly uniform over the entire link flange. At $0.04 \mathrm{rad}$ drift yielding propagated into the middle of the link web (Figure 5.62). A small crack developed in the link web beginning at the web-to-end-plate weld during the second cycle at $0.04 \mathrm{rad}$ drift (Figure 5.63). Local flange buckling was observed during the first cycle at $0.05 \mathrm{rad}$ drift (Figure 5.64), followed by propagation of the web crack (Figure 5.65). During the negative portion of the first 


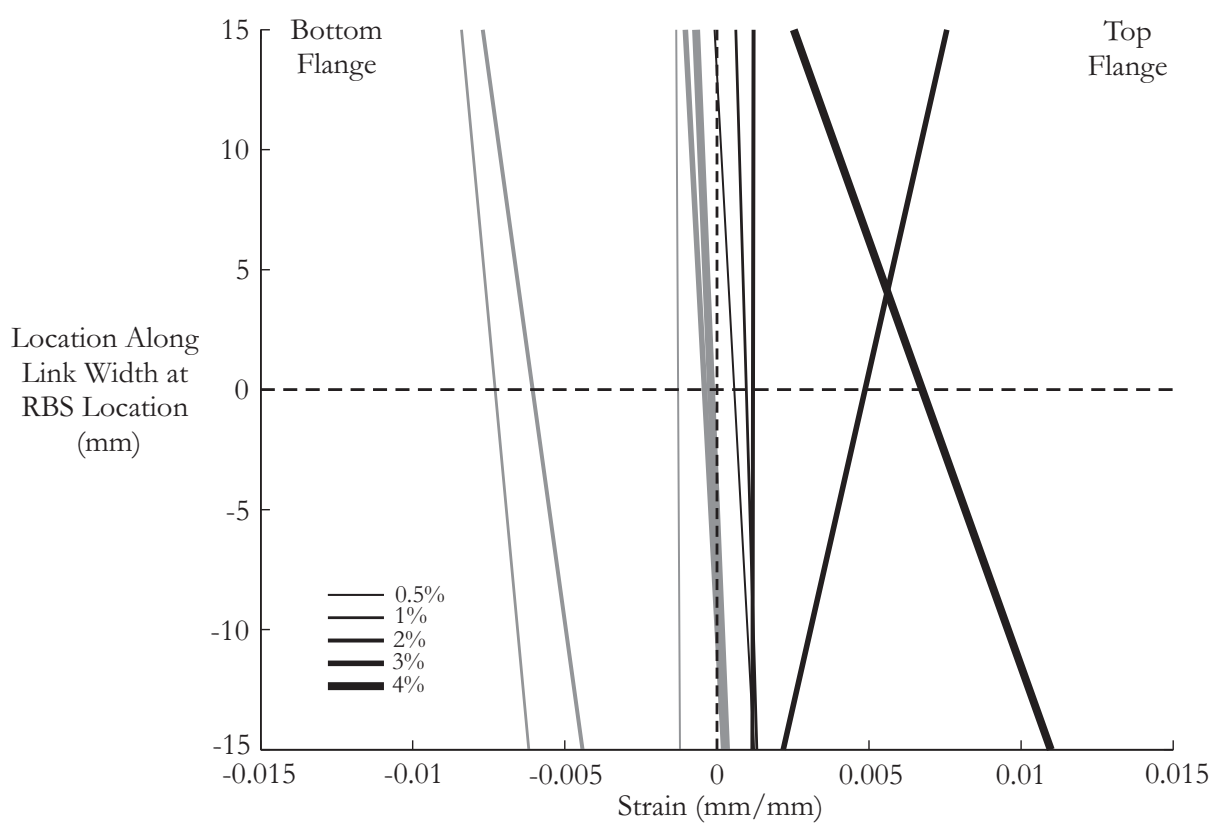

Figure 5.54: Strain Profile Across Link Width for Test MC-1B Positive Bending at Middle of Link

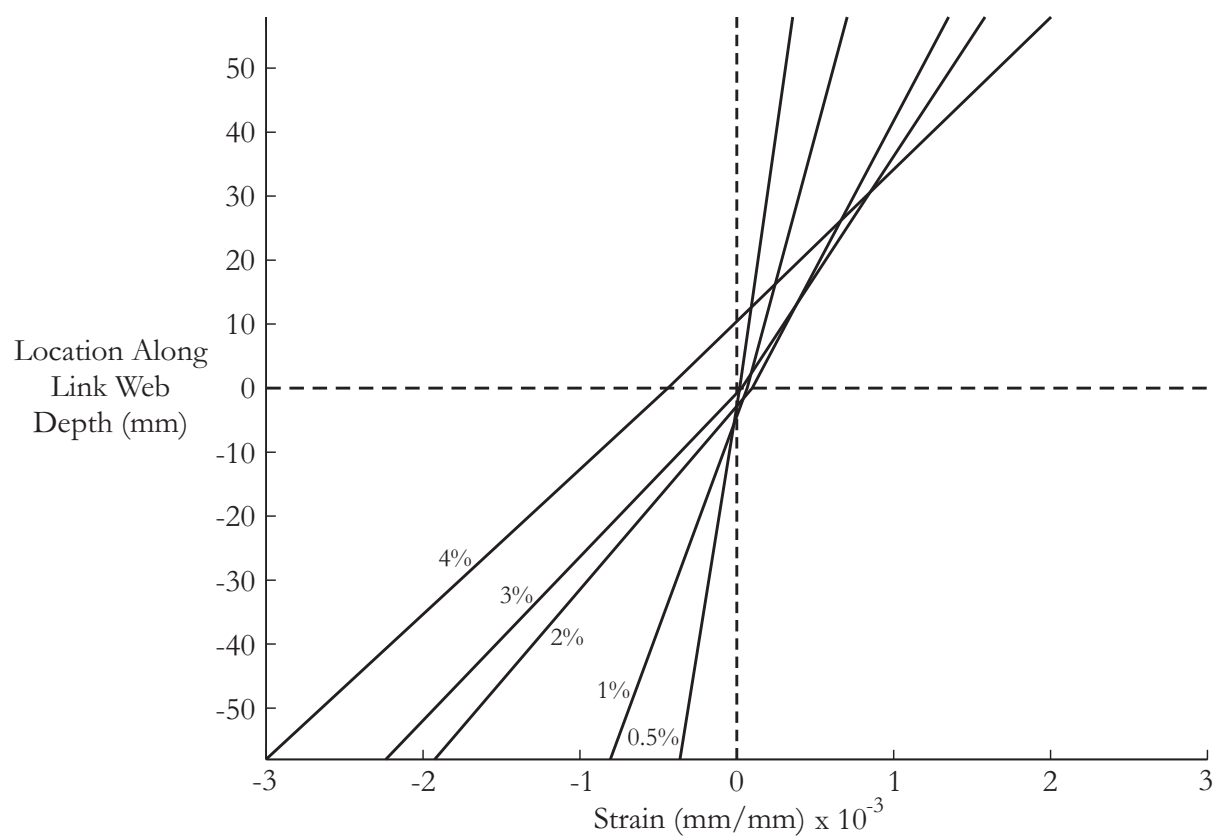

Figure 5.55: Strain Profile Through Link Depth for Test MC-1B (Positive Bending) 


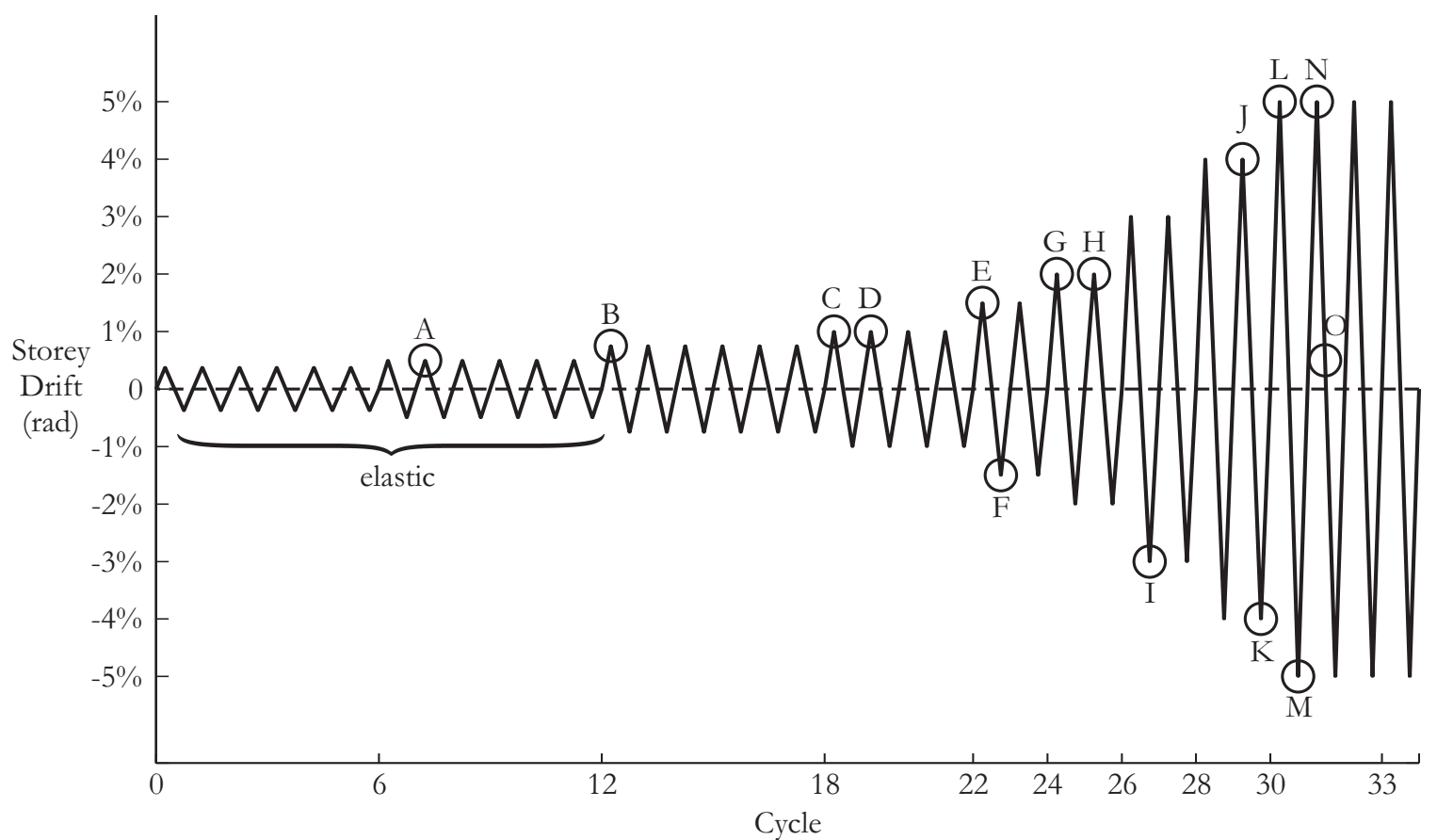

A - Slight creaking noise at steel-timber interfaces (ZD connection and bearing plate locations)

B - Signs of yielding on each end if bottom link flange near end-plate welds

C - Significant flange yielding near end-plate welds, slight flaking on flange-to-end-plate weld metal

$\mathrm{D}^{-}$Loud creaking noise at ZD-plate location

E - Yield propagation at CS of bottom link flange continues

$\mathrm{F}$ - Yielding around weld access holes (CS), slight yield propagation into web near weld (CS)

$\mathrm{G}^{-}$Flange yielding propagates towards centre of link length, small end-plate gap opening

$\mathrm{H}^{-}$Yielding propagates more into web (CS) and around access holes,

yielding uniform across flange width

I - Yielding uniform along flange length, yielding propagates into link web at mid-length

$\mathrm{J}$ - Small fracture at web-to-end-plate weld (CS)

$\mathrm{K}$ - Local buckling of link flange at CS

$\mathrm{L}$ - Local buckling of both flanges, large crack at web-to-end-plate weld (CS)

M- Large fracture in bottom flange-to-end-plate weld and web fracture propagates more into web

$\mathrm{N}$ - Top flange fractured nearly across entire width

O- Complete fracture of entire link cross-section at CS near end-plate weld

Figure 5.56: Summary of Observations for Test MC-2B 
$0.05 \mathrm{rad}$ cycle, a large fracture developed in the bottom flange, followed by a large fracture across the entire width of the top flange during the subsequent positive cycle, shown in Figure 5.66. The test was stopped nearing the zero displacement level after 1.5 cycles at $0.05 \mathrm{rad}$ drift due to complete fracture of the entire link cross-section, shown in Figure 5.67.

Similar to test MC-2A, a plastic hinge was formed at the column side of the link, resulting in a ductile response, but ultimately leading to brittle web and flange fracture at $0.05 \mathrm{rad}$ storey drift angle. Although this brittle failure mode is not ideal, the detailing of the connection postponed failure and avoided strength degradation until acceptance criteria was met. Ideally the link could be sized in future studies to promote more excessive local flange buckling, which could further delay fracture of the link. End-plate bolts remained tight following specimen failure, indicating that no bolt elongation took place. There was no evidence that plastic deformations or brittle failure occurred in the timber elements, steel-to-timber connections, or the steel panel zone. There was a creaking noise present throughout this test as well (same as in the previous test) as a result of ZD-plate connection slippage, beginning at the second cycle at 0.005 rad drift, but it was not as loud as in the previous test.

\subsubsection{Hysteretic Behaviour and Drift Analysis}

The global force versus displacement response of the connection is shown in Figure 5.68. It should be noted that due to an error in test start-up, the frame was prematurely loaded to approximately $0.01 \mathrm{rad}$ storey drift angle prior to the start of the test. This resulted in slight yielding at each end of the bottom flange of the link. The specimen was returned to the point of zero displacement and the full loading protocol was applied. This did not affect connection behaviour since the performance of this test followed closely to that of test MC-2A. The peak

Ryan Gohlich, Department of Civil and Environmental Engineering, Carleton University 

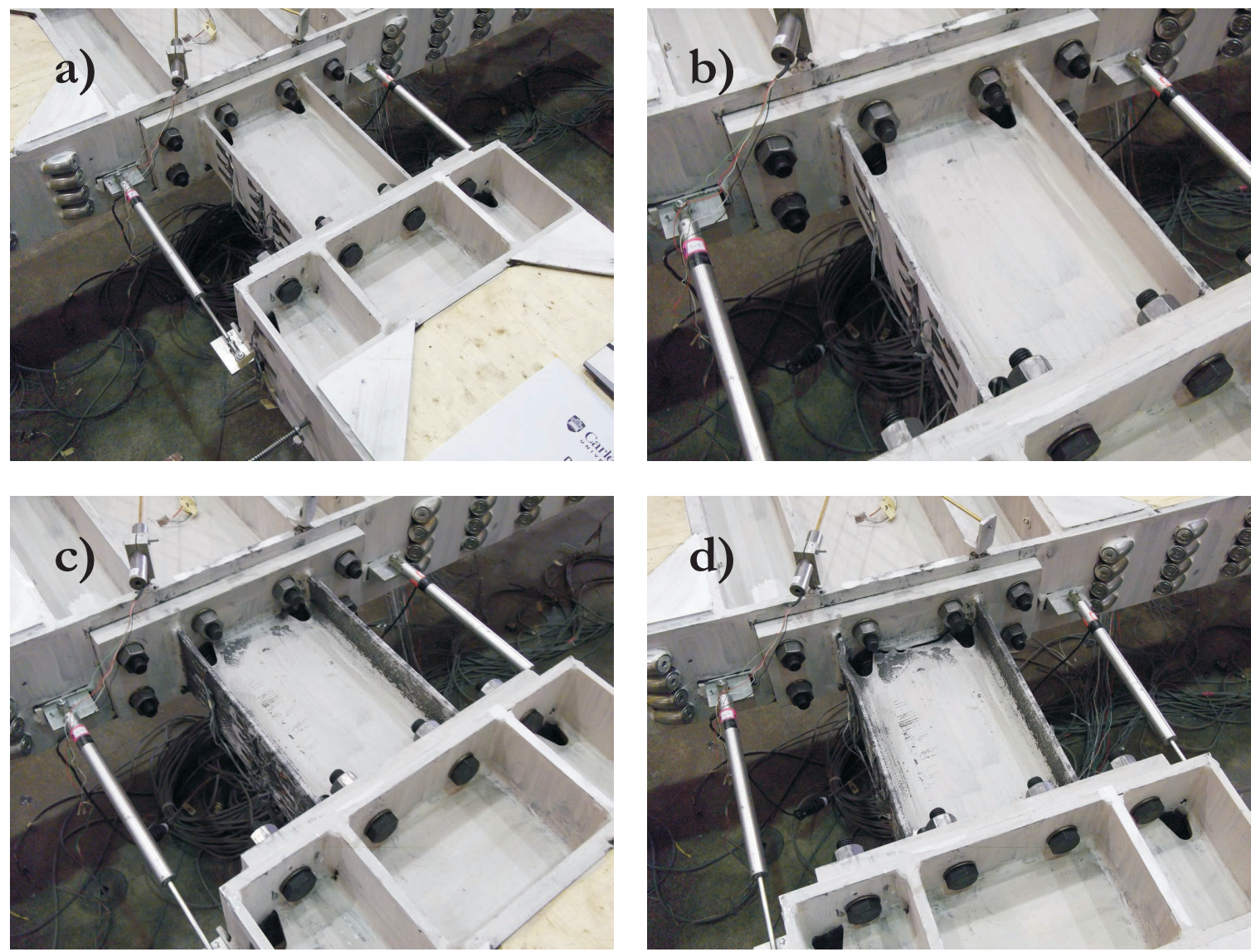

Figure 5.57: Yielding Propagation in Link for Test MC-2B

a) Initial b) $1 \%$ Drift c) $4 \%$ Drift d) Final 

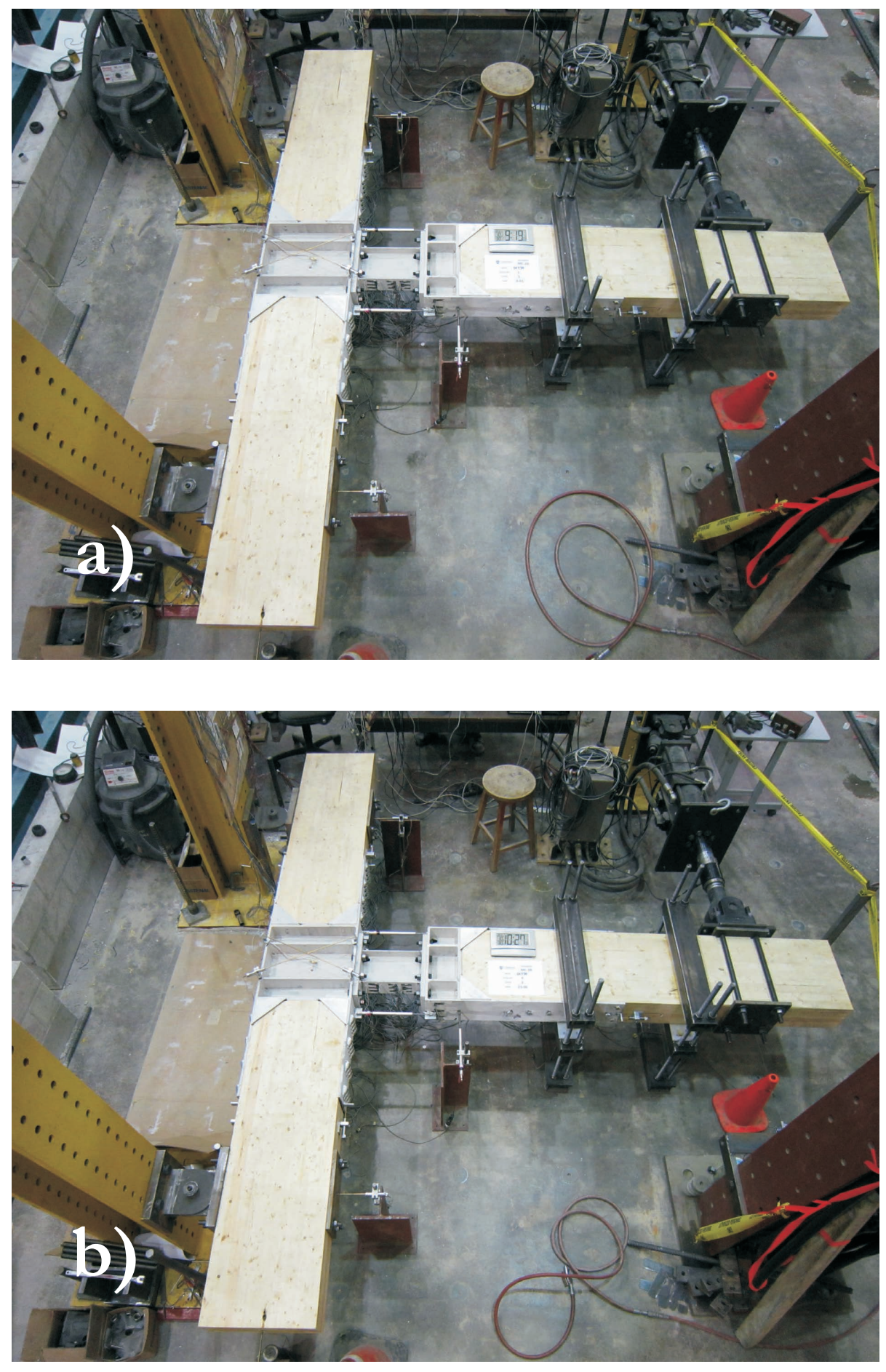

Figure 5.58: From Deformations Through Test MC-2B

a) Initial b) $1 \%$ Drift 

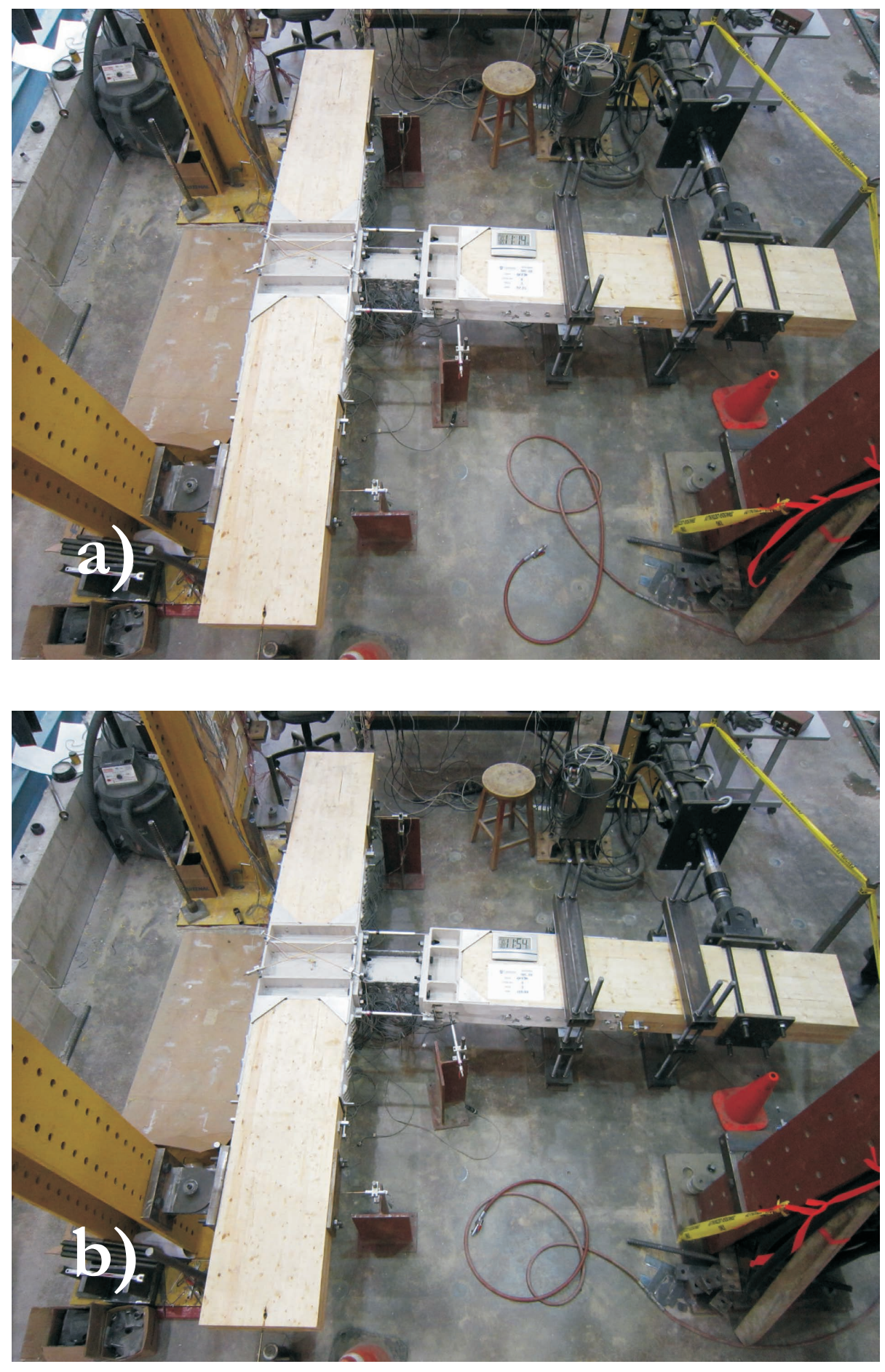

Figure 5.59: From Deformations Through Test MC-2B a) $4 \%$ Drift b) Final 

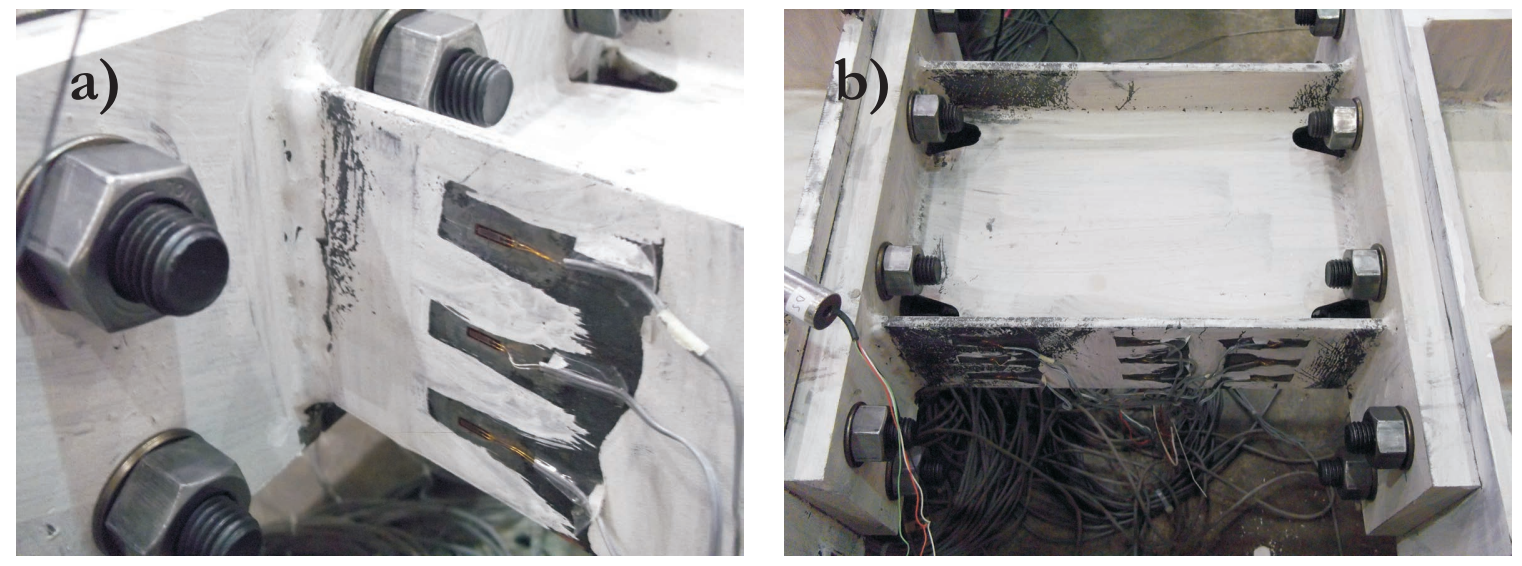

Figure 5.60: Flange Yielding for Test MC-2B

a) $1 \%$ Drift b) $2 \%$ Drift

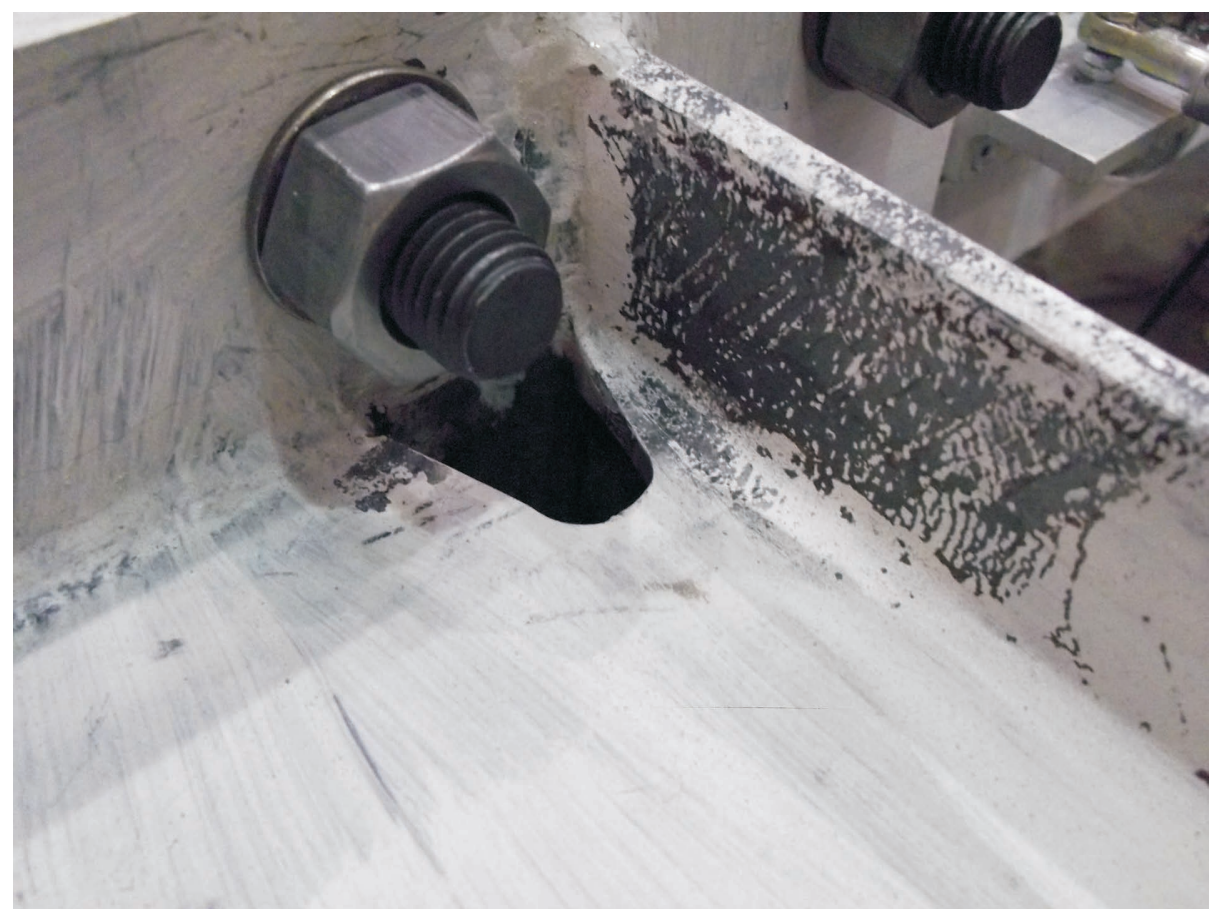

Figure 5.61: Yielding Around Weld Access Hole at 2\% Drift for Test MC-2B 


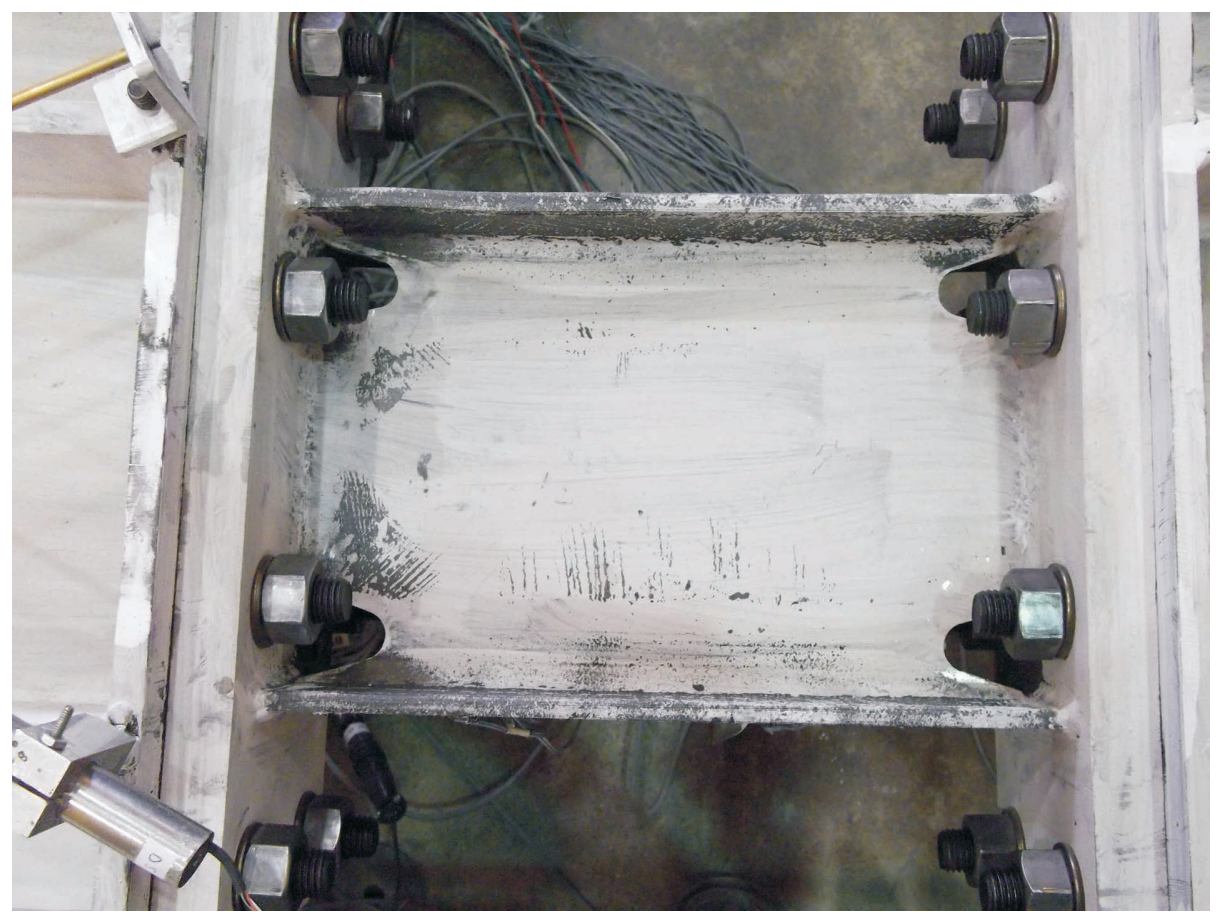

Figure 5.62: Web Yielding at 4\% Drift for Test MC-2B

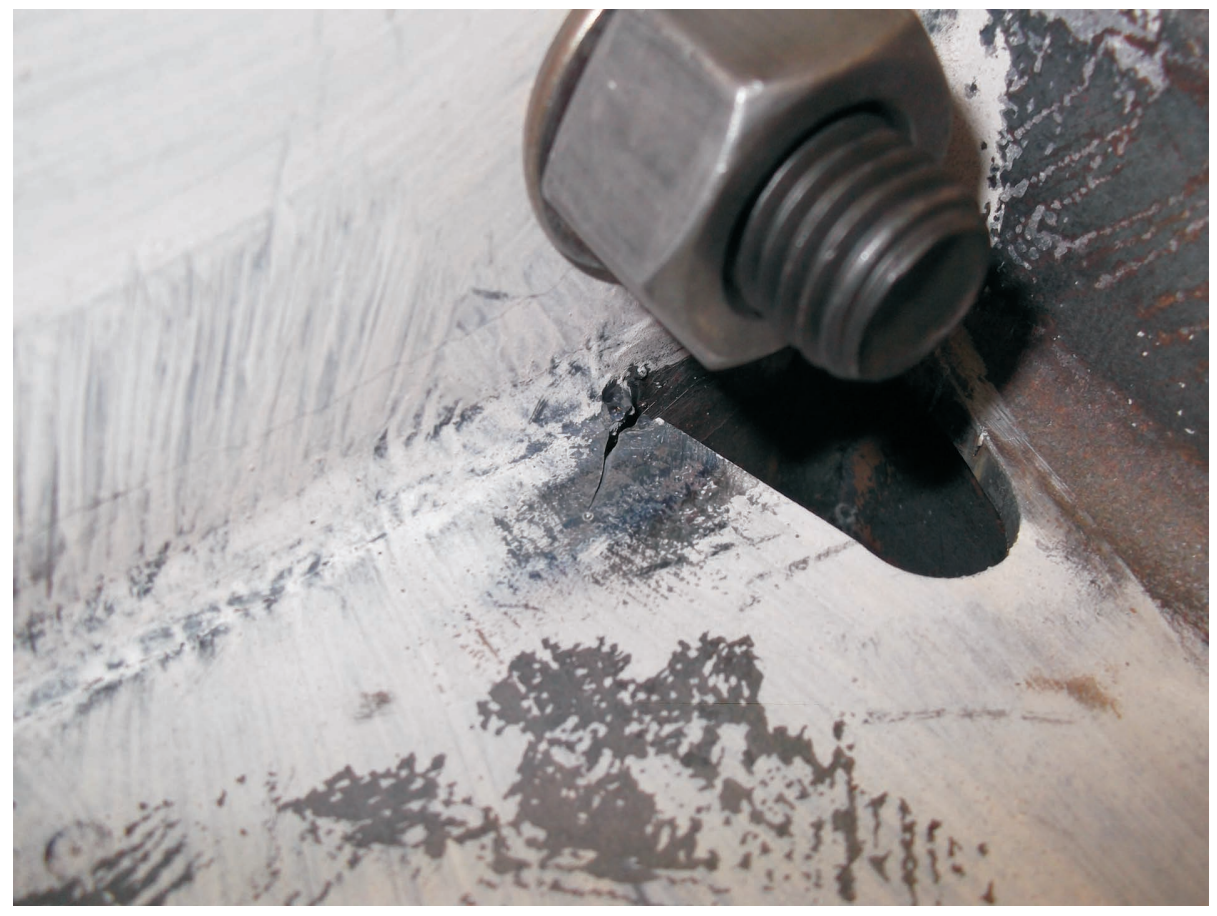

Figure 5.63: Initial Web Crack at 5\% Drift for Test MC-2B 

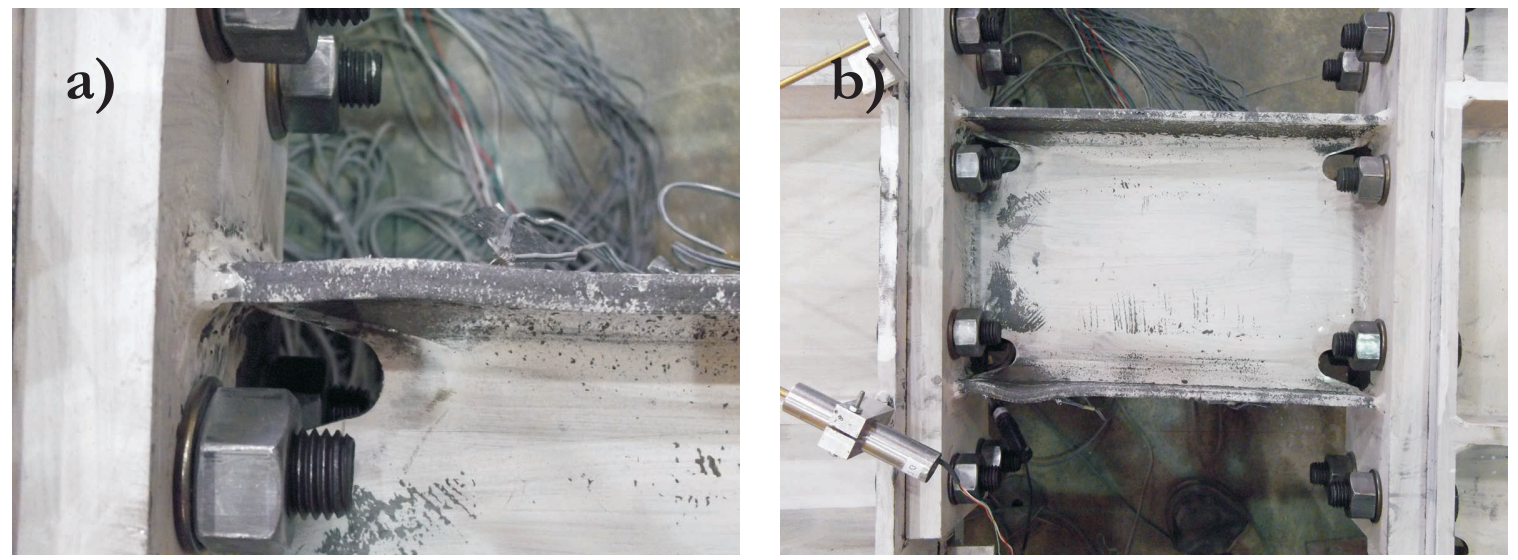

Figure 5.64: Local Buckling of Flange for Test MC-2B

a) $4 \%$ Drift b) $5 \%$ Drift

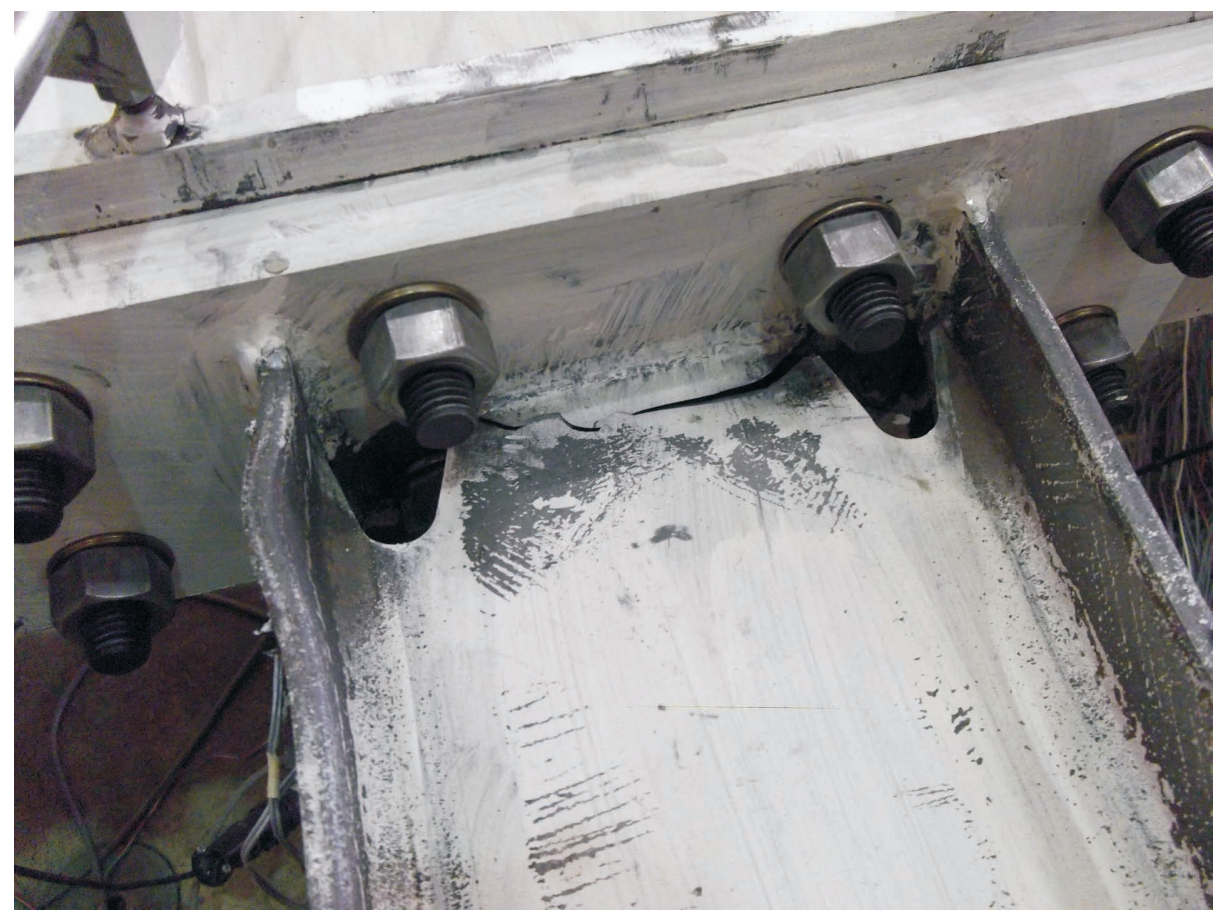

Figure 5.65: Propagation of Web Crack at 5\% Drift for Test MC-2B 


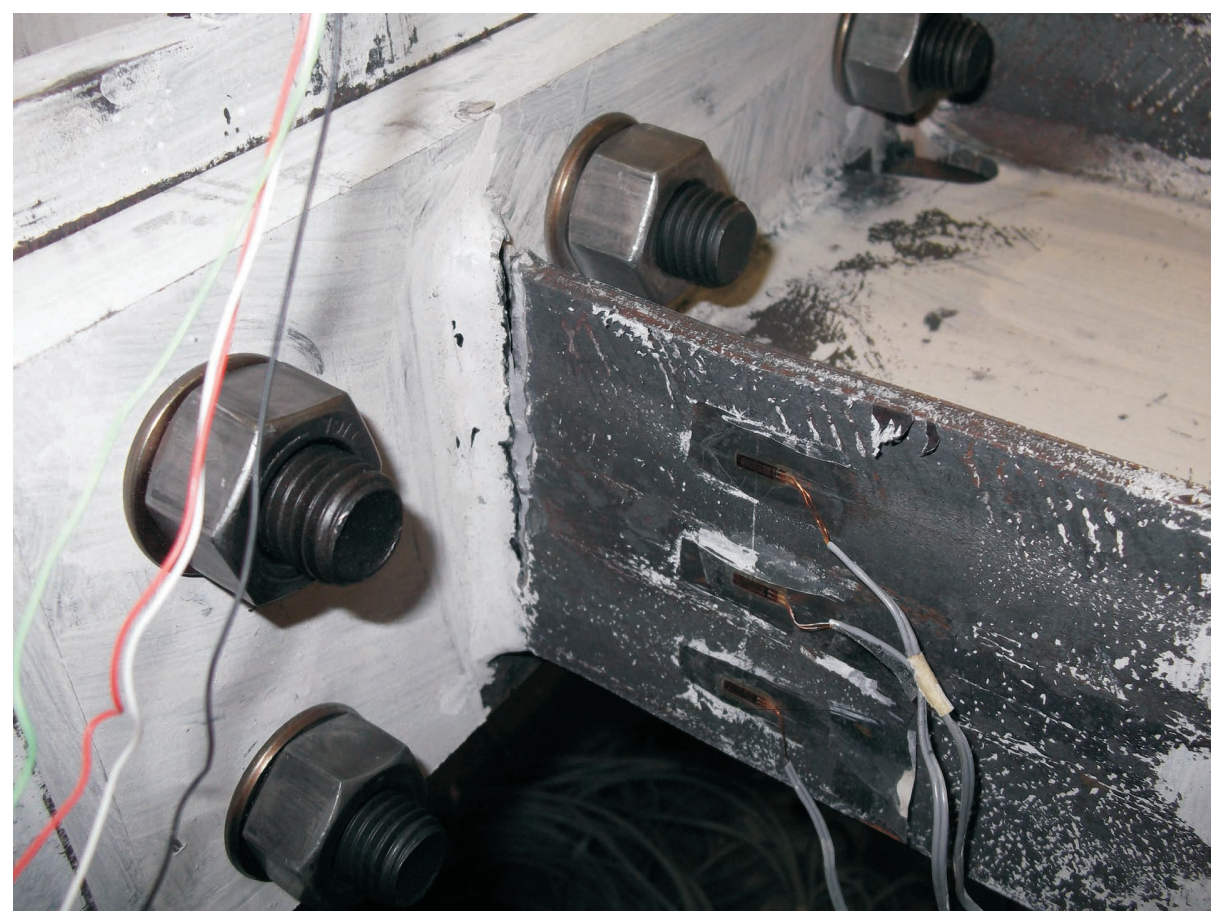

Figure 5.66: Fracture of Top Flange at 5\% Drift for Test MC-2B

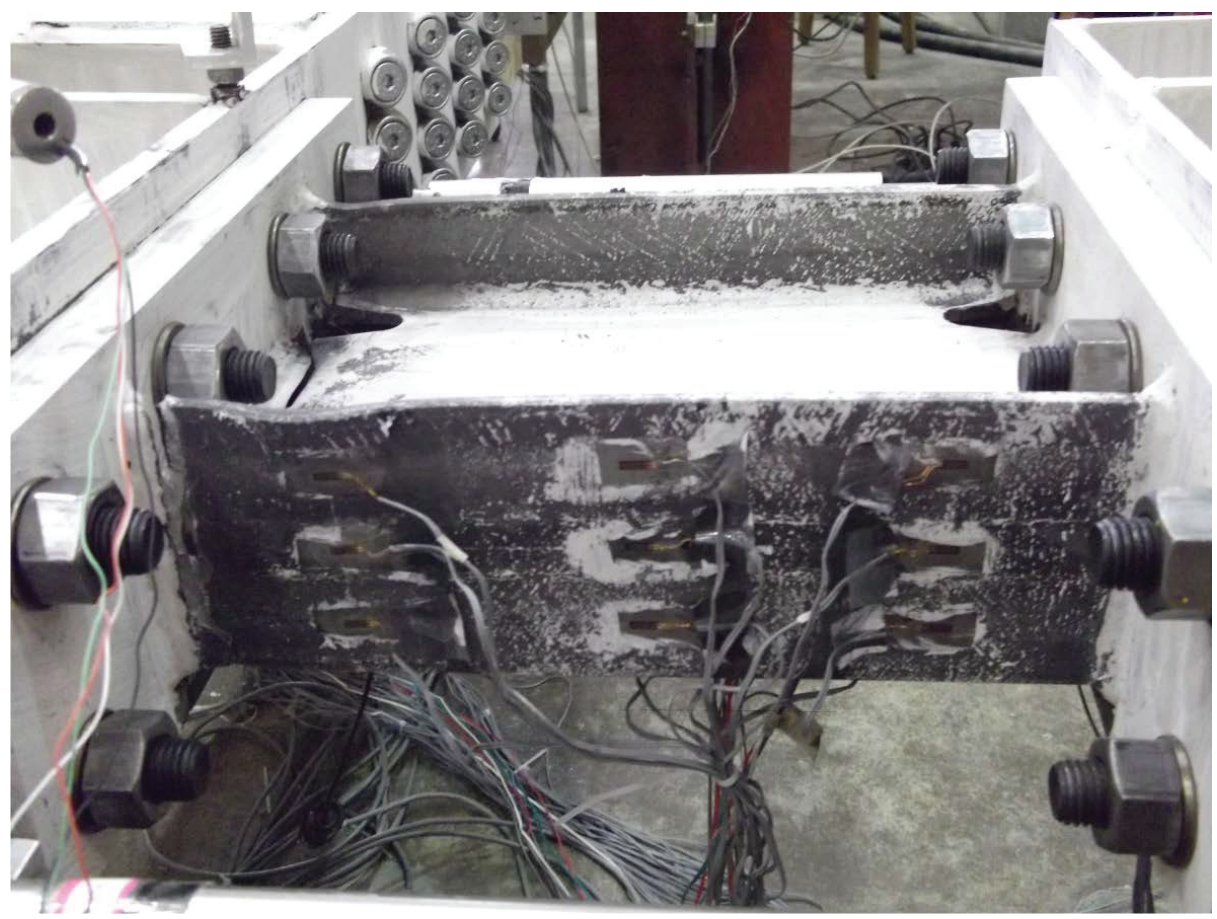

Figure 5.67: Complete Fracture of Link Cross-Section at 5\% Drift for Test MC-2B 
load sustained by the connection was $53 \mathrm{kN}$ under $0.05 \mathrm{rad}$ storey drift, nearly identical to that of test MC-2A. This connection showed no signs of strength degradation prior to brittle failure at $0.05 \mathrm{rad}$ storey drift angle. Because it sustained a complete cycle at $0.04 \mathrm{rad}$ drift without strength degradation below $42.4 \mathrm{kN}$ (80\% of peak load), this connection met acceptance criteria for prequalified connections. Initial web crack at $0.04 \mathrm{rad}$ drift did not result in a drop in strength. During the negative portion of the first cycle at $0.05 \mathrm{rad}$ storey drift, there was a significant strength drop as a result of fracture across the width of the bottom link flange. As the frame approached the maximum amplitude of the second cycle, the opposite flange fractured and there was a second associated strength drop. During the unloading portion of the second cycle, fracture of the remaining portion of the web occurred, and the test was ended. The connection remained elastic under the design level forces. Again, there were no signs of pinching behaviour, indicating the absence of any excessive deformations in the STS connections or bolt elongation.

Figure 5.69 shows the moment versus rotation response of the connection (for both total and plastic drift). The peak moment sustained by the connection was approximately $9 \%$ higher than the estimated moment capacity of the link under full plastic behaviour. The peak plastic storey drift sustained by the connection prior to fracture was $0.036 \mathrm{rad}, 72 \%$ of the total peak drift. This indicates high levels of energy dissipation were achieved. Like all previous tests, the global hysteretic response closely resembled that of a typical steel-only moment-resisting connection.

The contribution of each connection component to total storey drift angle is presented in Figure 5.70. Similar to the previous tests, link rotation contributed to a majority of the total storey drift, particularly for the larger drift cycles where high plastic deformations were present. Panel zone rotations were minimal, even after three previous tests. The contribution of the STS connections was lower during the intial cycles, and then increased during the $0.01 \mathrm{rad}$ cycles. The contribution to total storey drift of the STS connections was significantly lower than in the previous test. This could partly be a result of residual connection slip because the beam was reused, and was likely also due to the reduced stiffness of the link relative to the previous test 


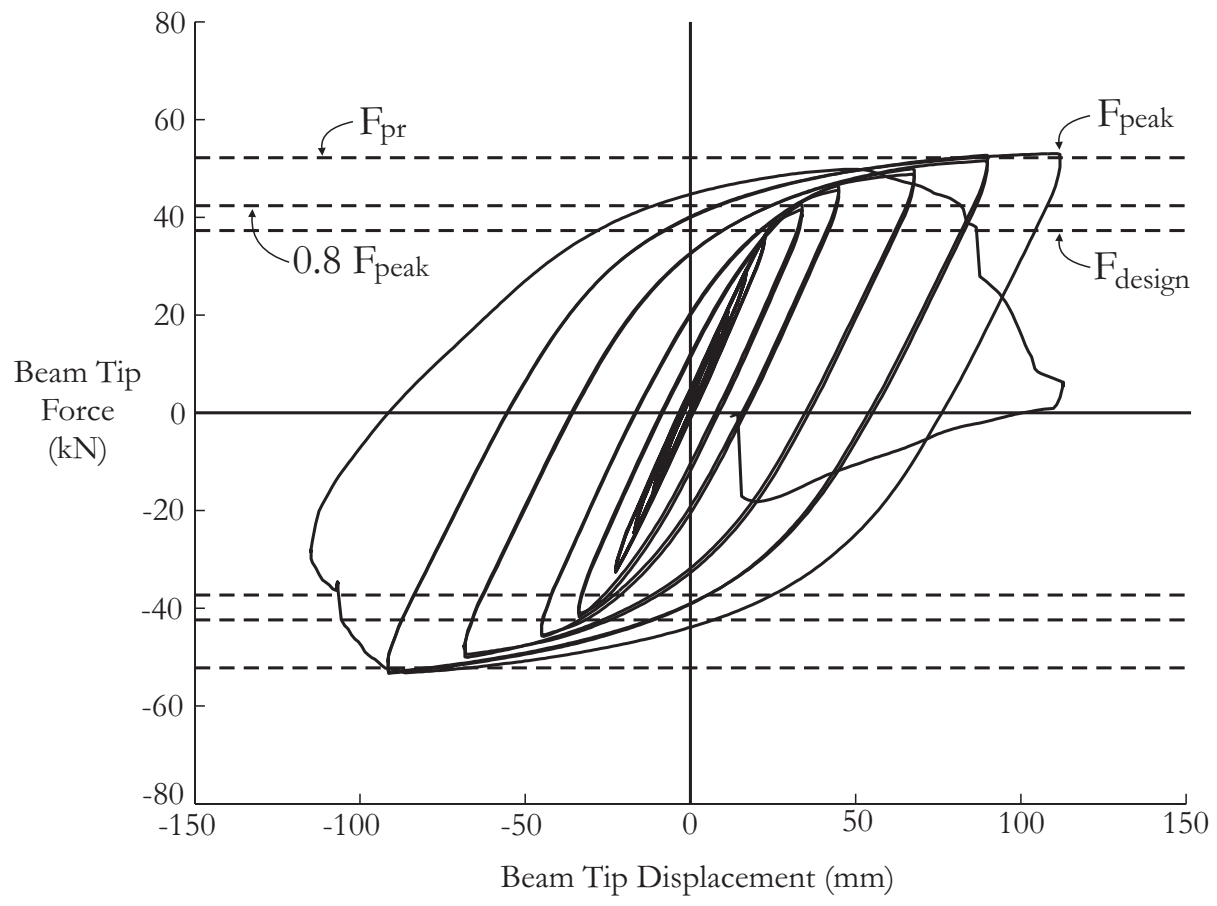

Figure 5.68: Force vs. Beam Tip Displacement Response for Test MC-2B

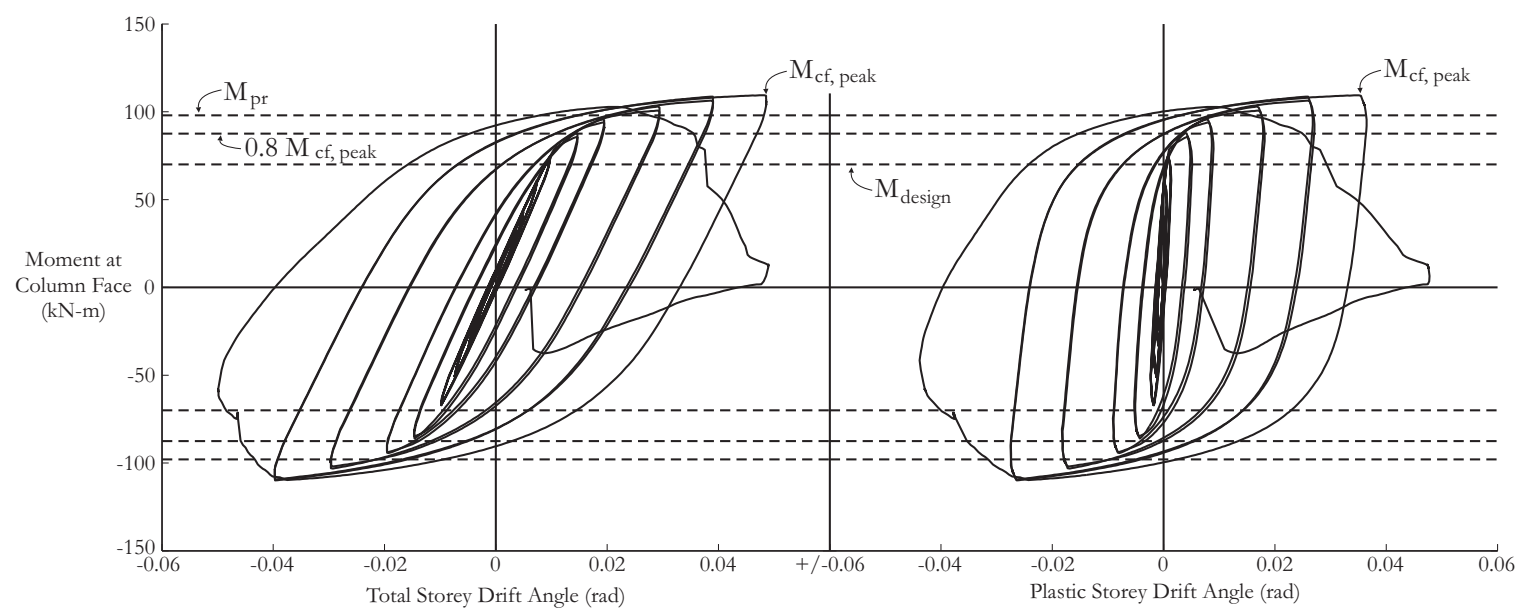

Figure 5.69: Moment vs. Rotation Responses for Test MC-2B 


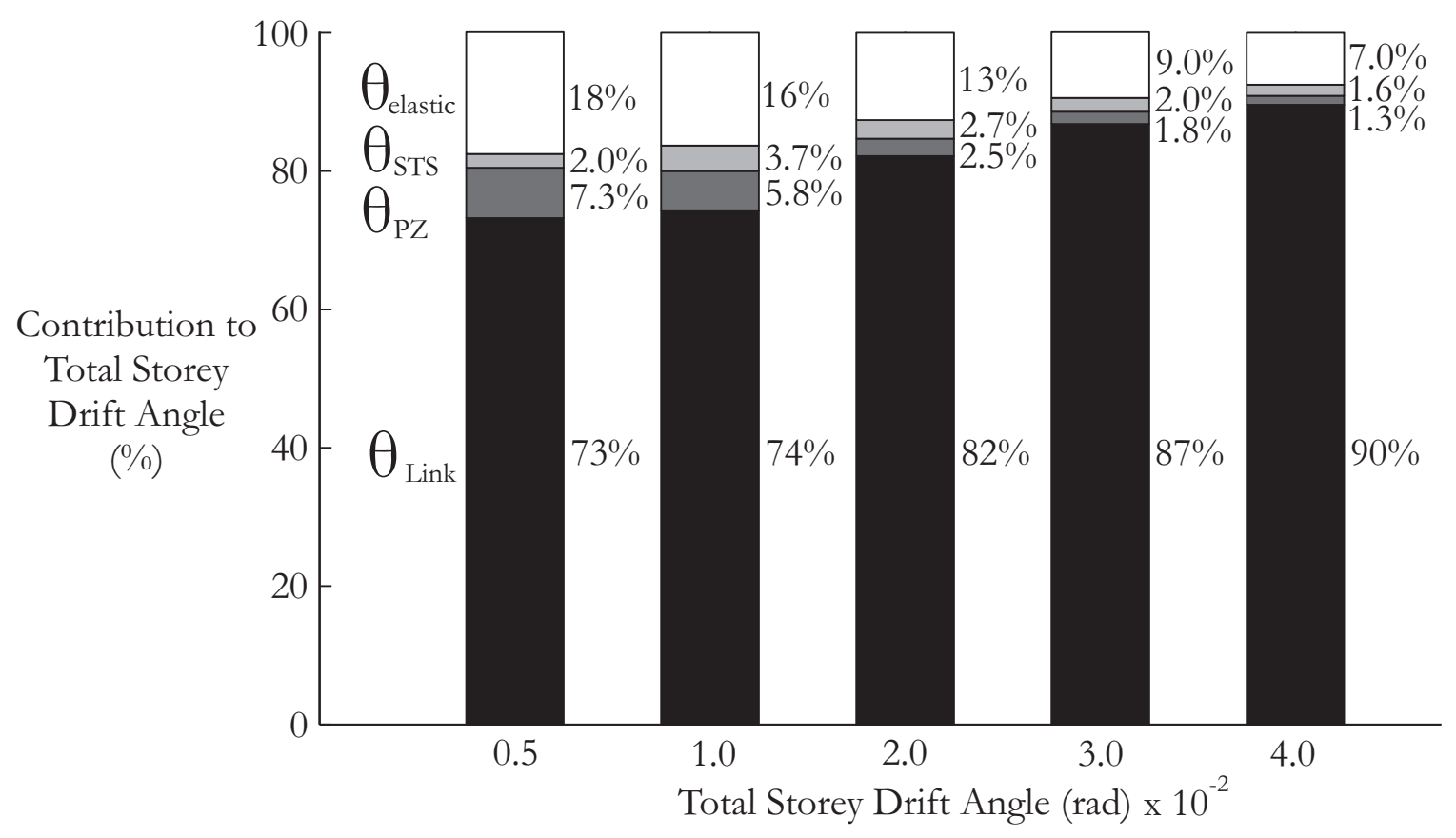

Figure 5.70: Total Storey Drift Decomposition for Test MC-2B

(link contribution to total drift was higher for MC-2B than for MC-1B).

\subsubsection{Strain Analysis}

Figure 5.71 shows the strain profile along the link flanges at mid-width. The profile remained linear and uniform during initial cycles prior to flange yielding. Strain peaked at the column side of the link where the applied moment was highest, which corresponds to the observed pattern of yield propagation during the test. For the most part, the strain in the beam side of the link remained relatively low, and somewhat uniform between the middle and beam side. During the high drift levels in the top flange, tensile strains increased in the middle, and the strain profile became nearly linear. Strain in the top and bottom flanges were less symmetrical than in test MC-2A.

Figure 5.72 shows the strain profile across the width of the link flanges at the column side of the link where strains were highest. They remained uniform and linear prior to yielding, and became less linear after yielding took place. Yielding presented in the plot corresponds with the test observations. Strain remained nearly uniform across the flange width; some locations that 


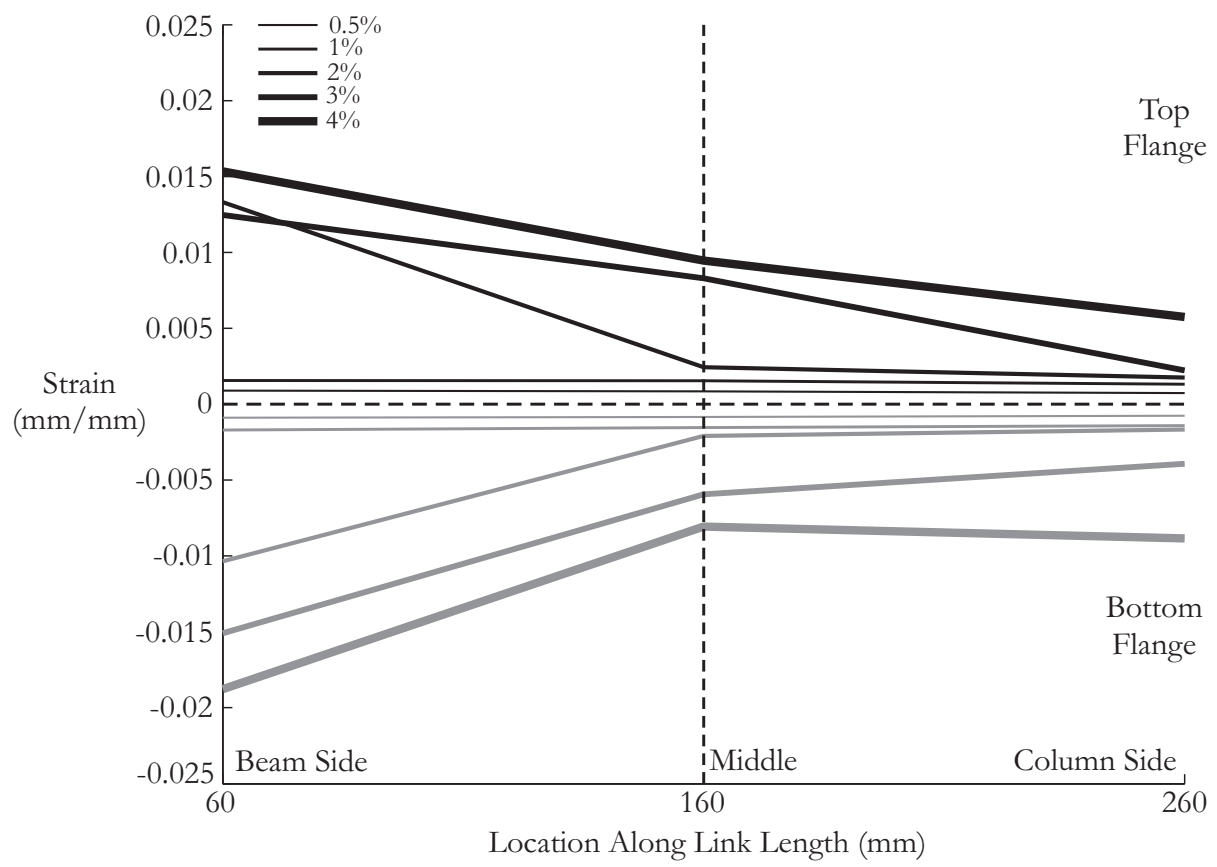

Figure 5.71: Strain Profile Along Link Length for Test MC-2B

Positive Bending at Mid-width of Flange

were not uniform were likely a result of local flange buckling.

Figure 5.73 shows the strain profile through the depth of the link web at the column side of the link. The strain profiles remained linear throughout the entire test, and were roughly symmetrical about the mid-depth of the link.

\subsection{STS Connection Performance}

Because the beam and column specimens remained essentially elastic during the experimental program, they will be reused for future studies, and were not disassembled to check for any potential damage sustained during testing. Nonetheless, performance of the STS connections was closely monitored, and there were no obvious signs of excessive deformations or damage in the STS connections throughout any of the four tests. 


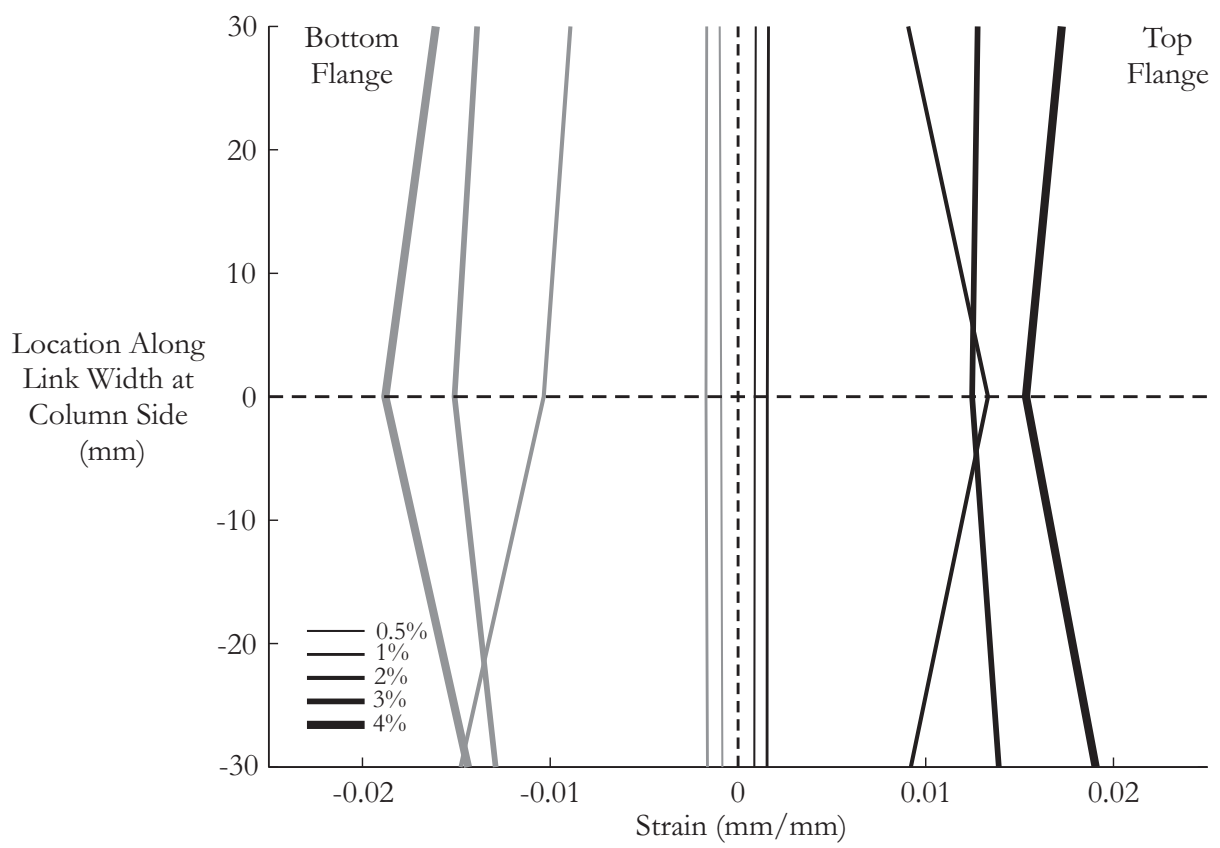

Figure 5.72: Strain Profile Across Link Width for Test MC-2B

Positive Bending at Column Side of Link

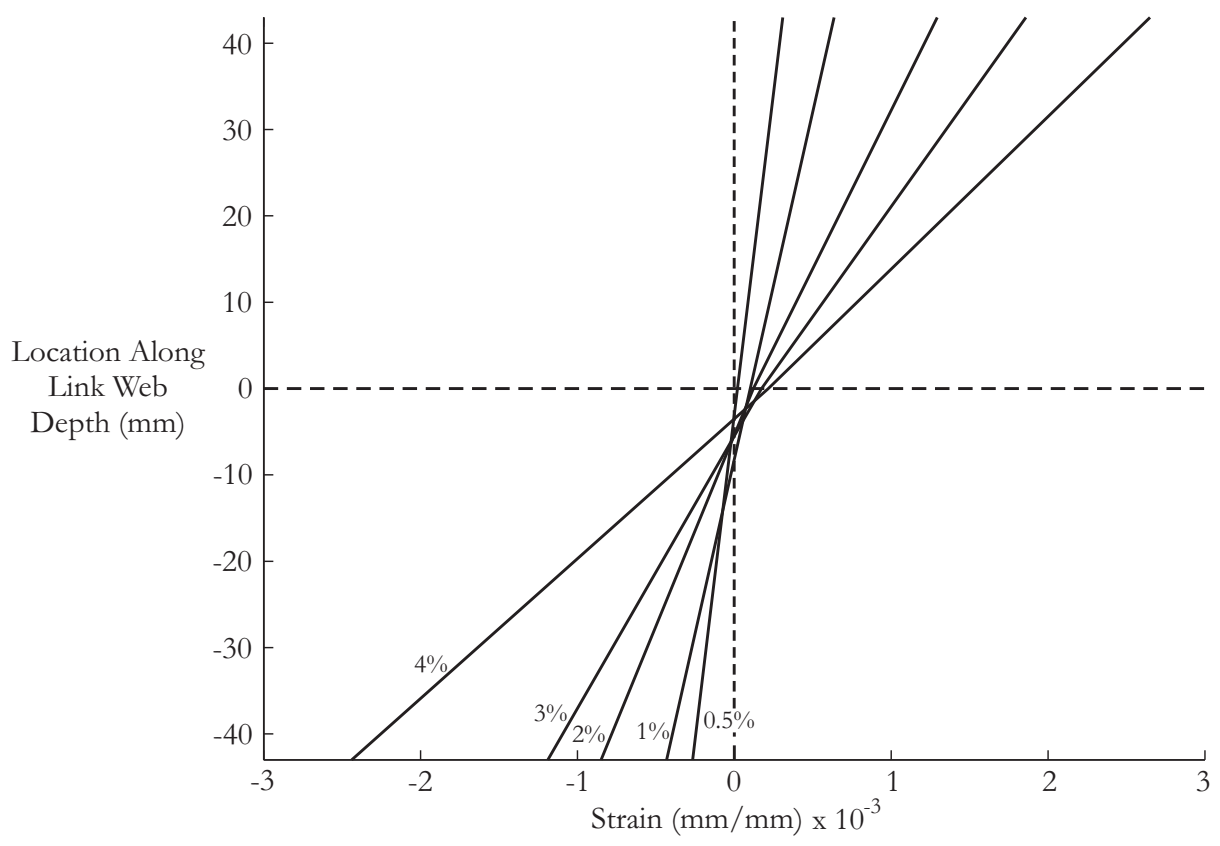

Figure 5.73: Strain Profile Through Link Depth for Test MC-2B (Positive Bending) 


\subsubsection{Observations}

Behaviour of the STS connections was monitored visually during testing. Figures 5.74 and 5.75 show photos of the 45 degree STS and ZD-plate connections following completion of all tests. Each beam connection was used for two tests, and the column connections were used for all four tests. Slip of the connection was monitored by placing a line on the timber section at the steel-timber interface (see Figure 5.74), and using LVDTs. No movement between the line and the steel plate was observed at any point during any test. Furthermore, no signs of yielding were found in the steel connection plates, and all screws and washers remained tightly fixed in place, indicating that there was no withdrawal failure of any of the 45 degree screws. The ZD-plates could not be visually inspected after testing due to the presence of the steel collar, however no loud cracking was heard to indicate that head tear-off failure occurred in the ZD-plate screws, and pullout and head tear-off failure was unlikely given the small levels of screw slip measured by the LVDTs.

Loud creaking noises were heard coming from the ZD-plate connection throughout the entire duration of tests $\mathrm{MC}-1 \mathrm{~B}$ and $\mathrm{MC}-2 \mathrm{~B}$. This was likely caused by friction between the top and bottom surfaces of the timber beam and the steel beam collar. No creaking noises were heard in tests MC-1A or MC-2A (which used 45 degree STS connections for the beam), which indicates that the ZD-plate connection slipped more and provided a greater contribution to total storey drift than the 45 degree STS connection. The ZD-plate connection could allow for more slip at the steel plate-to-ZD-plate bolted connection, where bolt holes were oversized by $2 \mathrm{~mm}$. If friction forces between the timber and steel were not high enough to withstand the applied load along the shear plane, the steel plate could potentially slip without any movement of the STS that secured the ZD-plate to the timber.

Figure 5.76 shows sample photos of the timber beam following test MC-2B. There were no signs of crack formation near the expected location of the failure planes (near the screw tip depth). This was true for all timber sections following all tests. No cracking noises were heard during testing that might indicate crack formation in the timber members, nor were there any sudden 

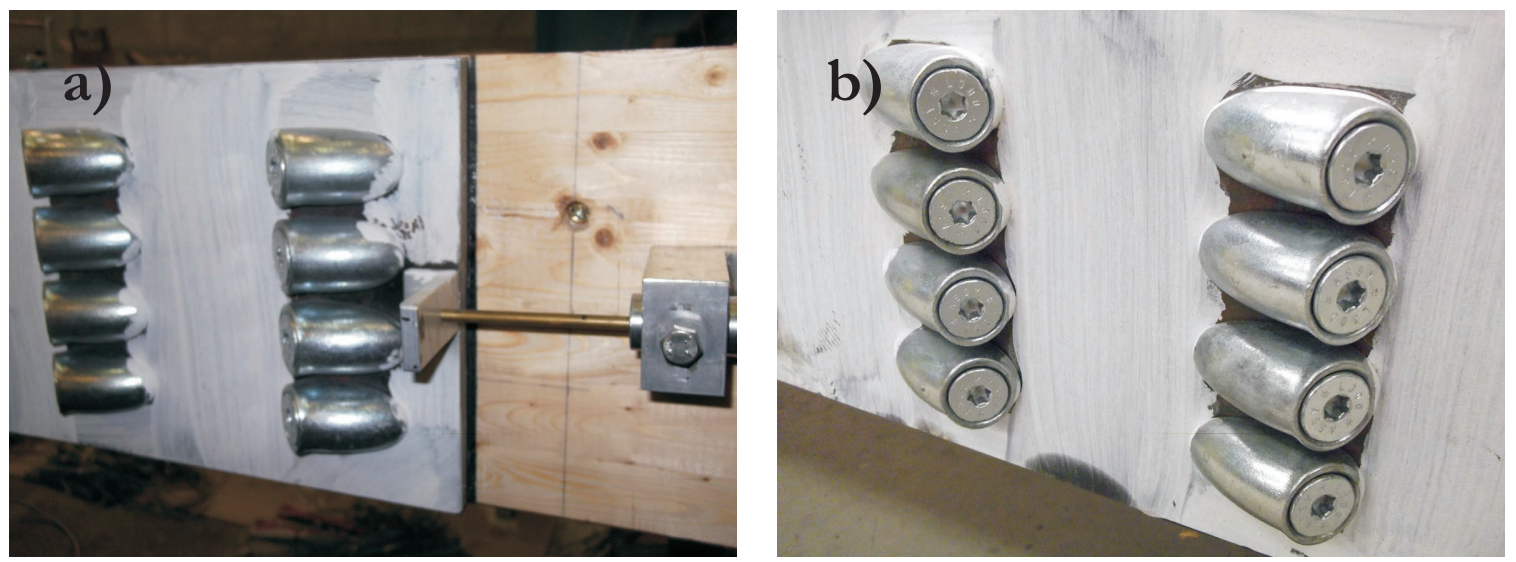

Figure 5.74: Beam STS Observations Following Tests MC-1A and MC-2A
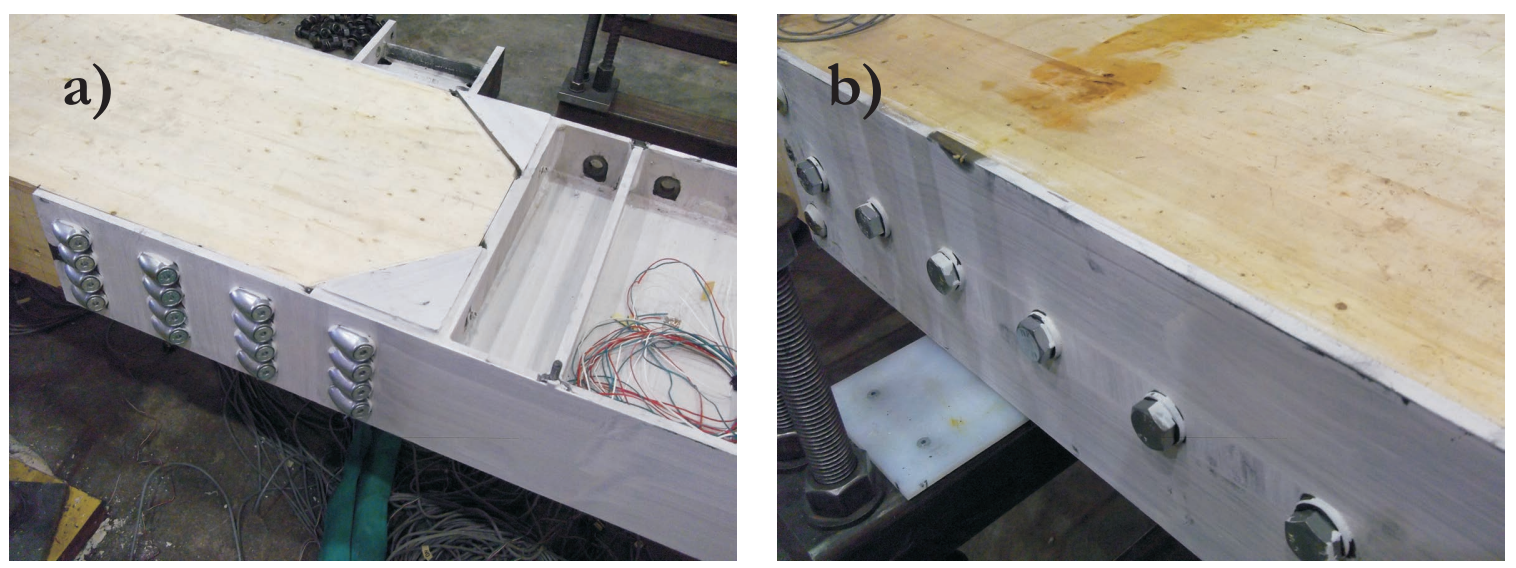

Figure 5.75: Post-test Inspection of Beam STS Connections

a) 45 Degree STS b) ZD-plate 
changes in the screw slip readings output by the LVDTs. This verifies the design methodology that the screws do not need to be crossed at mid-depth of the beam, provided that the beam is properly reinforced to withstand the applied tension perpendicular-to-grain and longitudinal shear forces applied by the force couple of the STS connection plates. Nonetheless, it is good practice to cross the screws and can sometimes make assembly of the connection more simple. For this research, the long perpendicular-to-grain reinforcing screws installed along the depth of the wood members for the 45 degree STS connections were successful in negating tension perpendicular-tograin failure in the wood members. Furthermore, these tests verified that beams with a sufficient shear plane area do not need additional reinforcement to withstand the longitudinal shear forces applied with this connection configuration. However, close attention must be paid during the design stages, and if insufficient longitudinal shear strength is provided by the timber member, it may be good practice to cross the screws at mid-depth by four screw diameters as previously suggested by Krenn and Schickhofer (2009).

\subsubsection{Connection Slip}

Connection slip was monitored throughout each test using LVDTs D10 to D15 (as shown in Figure 4.13. Screw slip was measured in millimeters, and converted into an effective rotation using equation (5.5) as mentioned previously. Using each effective STS connection rotation and the respective moment at mid-length of each STS connection, the moment versus rotation
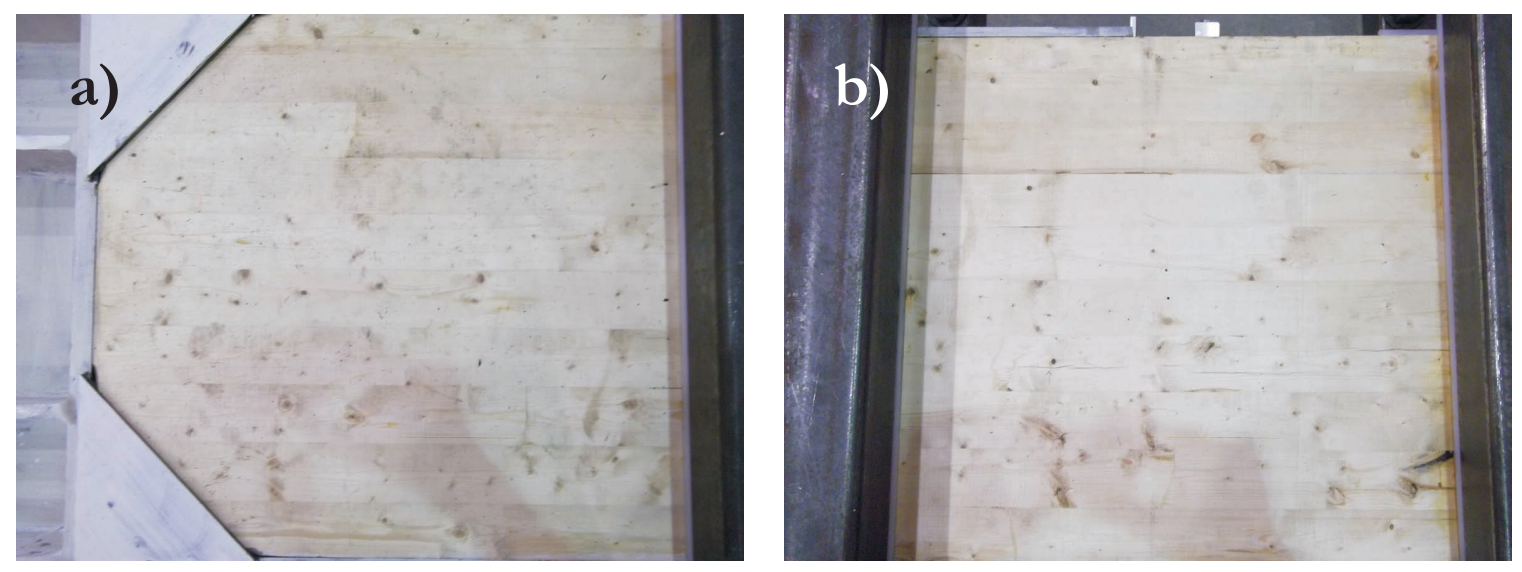

Figure 5.76: Sample Wood Member Inspection

Ryan Gohlich, Department of Civil and Environmental Engineering, Carleton University 
hysteretic response of each of the three connections was plotted. Figure 5.77 shows a sample hysteresis from one of the beam connections using 45 degree STS (MC-1A), as well as for one of the beams using ZD-plate connectors (MC-1B). Figure 5.78 shows samples of the hysteretic response of the upper and lower column STS connections (for MC-1B only). The general trend in hysteretic response of all STS connection was the same. Maximum rotation contributions were around $0.001 \mathrm{rad}$ for the beams, and $0.00045 \mathrm{rad}$ for the columns under a total frame storey drift angle of $0.05 \mathrm{rad}$.

Some energy dissipation was provided by the connections, although the total amount of energy dissipation from all connections was insignificant relative to the amount of energy dissipated by the link element. During initial loading of the STS connection, reasonably high stiffness was attained, followed by a reduction in stiffness which stayed constant throughout the loading cycle. Upon load reversal, stiffness returned to its initial value before lessening again for the duration of the cycle. This affect was more pronounced for the ZD-plate connection (MC-1B). The energy dissipation caused by this affect is likely a result of friction forces between the steel STS connecting plate and the surface of the timber members. This is due the pretensioning of the STS after installation, which cause a clamping force that provides additional connection resistance by means of friction. In some instances, for the 45 degree STS connections under high storey drift angles (see the lower-left portion of the curve in Figure 5.77 for test MC-1A, and the lower-left portion of either curve in Figure 5.78), there was a brief period where stiffness increased just prior the load reversal. This is likely due to the reduction in velocity of loading before load reversal, which increases the coefficient of friction. This effect is inherent in the hysteretic behaviour of friction interfaces (Christopoulos and Filiatrault, 2006).

Table 5.2 shows the maximum screw slip for each test specimen. It is clear when looking at the maximum slip in beam STS connections that multiple tests on a single specimen did not significantly affect the screw slip. Overall connection slip was minimal, and the reduction in slip between test MC-1A and MC-2A (for the 45 degree STS connection) and between tests MC-1B and MC-2B (for the ZD-plate connection) did not significantly affect performance.

Ryan Gohlich, Department of Civil and Environmental Engineering, Carleton University 


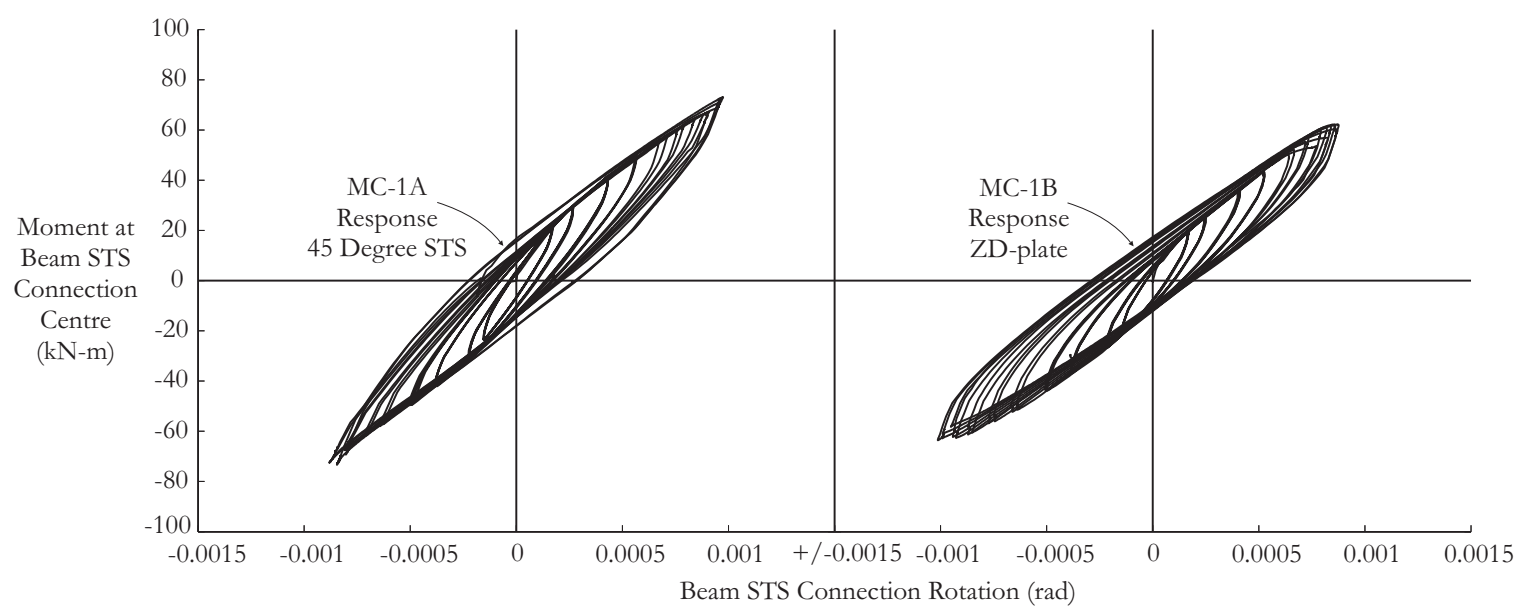

Figure 5.77: Sample Beam STS Hystereses

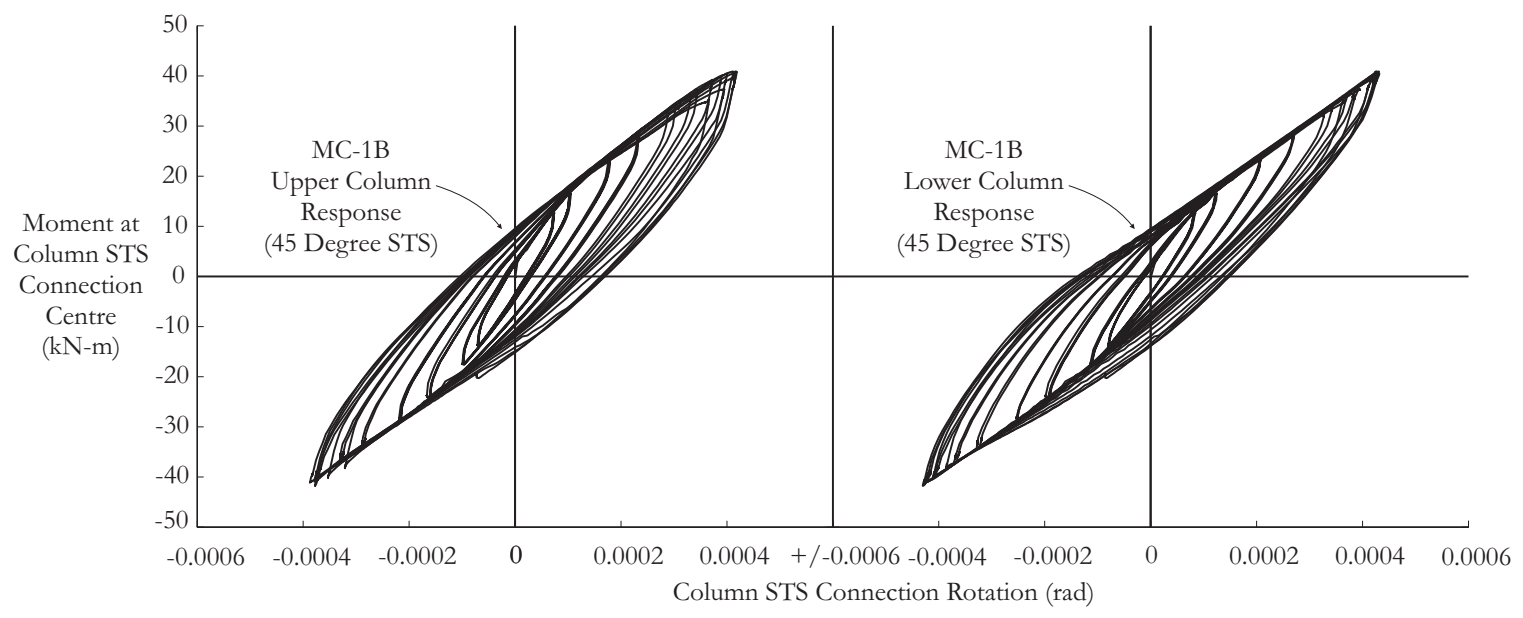

Figure 5.78: Sample Column STS Hystereses

Table 5.2: Maximum Screw Slip

\begin{tabular}{c|cccc}
\hline Specimen & Beam Type & Beam Slip $(\mathrm{mm})$ & Upper Col Slip $(\mathrm{mm})$ & Lower Col Slip $(\mathrm{mm})$ \\
\hline MC-1A & 45 Degree & 0.51 & 0.18 & 0.25 \\
MC-2A & 45 Degree & 0.45 & 0.18 & 0.18 \\
MC-1B & ZD-plate & 0.69 & 0.18 & 0.22 \\
MC-2B & ZD-plate & 0.51 & 0.16 & 0.20 \\
\hline
\end{tabular}


Overall, the STS connections performed as expected, with little deformation and no signs of damage. This shows that these connections perform well as a primary load transfer mechanism between steel yielding hinges and timber members. Since it is likely that these connections were over-designed, future studies should be done to determine the true capacity of these connections by stiffening the yielding hinge component and applying load until failure of the STS connection. Furthermore, studies should be done to determine the overall frame performance using STS connections designed with a lower factor of safety to optimize performance with cost.

\subsection{Ductility and Energy Dissipation}

The cumulative energy dissipation of the connection provides valuable insight into how a building designed using the proposed system will perform when subjected to severe ground motions. Figure 5.79 shows the cumulative energy dissipation for each test, which was determined by calculating the area enclosed by the force-displacement hystereses for each respective test. Cumulative energy dissipated at a given cycle is the sum of the energy dissipated during that and all previous cycles. Figure 5.79 shows that the energy dissipation sustained by specimens MC-1A and MC-1B (with dogbone detail) were considerably higher than that of MC-2A and MC-2B. The increase in energy dissipation shown by the dogbone connections during the lower level cycles is a result of the increased link capacity and stiffness over that of the regular links, which allowed for higher force development at given drift levels (subsequently resulting in a larger hysteretic area). The large jump in cumulative energy dissipation during the $0.05 \mathrm{rad}$ drift cycles is a result of the RBS link's ability to avoid brittle failure, and sustain additional cycles at that drift level. The peak energy dissipated by test MC-1B was $113.5 \mathrm{kN} \cdot \mathrm{m}$ under 3.5 cycles at $0.05 \mathrm{rad}$ drift. Since test MC-1A was ended after only 2.5 cycles, cummulative energy dissipation was slightly less $(108 \mathrm{kN} \cdot \mathrm{m})$, but was nearly identical the the energy dissipated by specimen MC-1B after two cycles $(107.5 \mathrm{kN} \cdot \mathrm{m})$. Peak cumulative energy dissipation of specimens MC-2A and MC-2B were 67.6 and $59.5 \mathrm{kN} \cdot \mathrm{m}$ respectively. Because of the absence of the brittle failure mode, the RBS link showed superior performance regarding cumulative energy dissipation.

The maximum ductility of each connection was found using equation (5.10). The target

Ryan Gohlich, Department of Civil and Environmental Engineering, Carleton University 


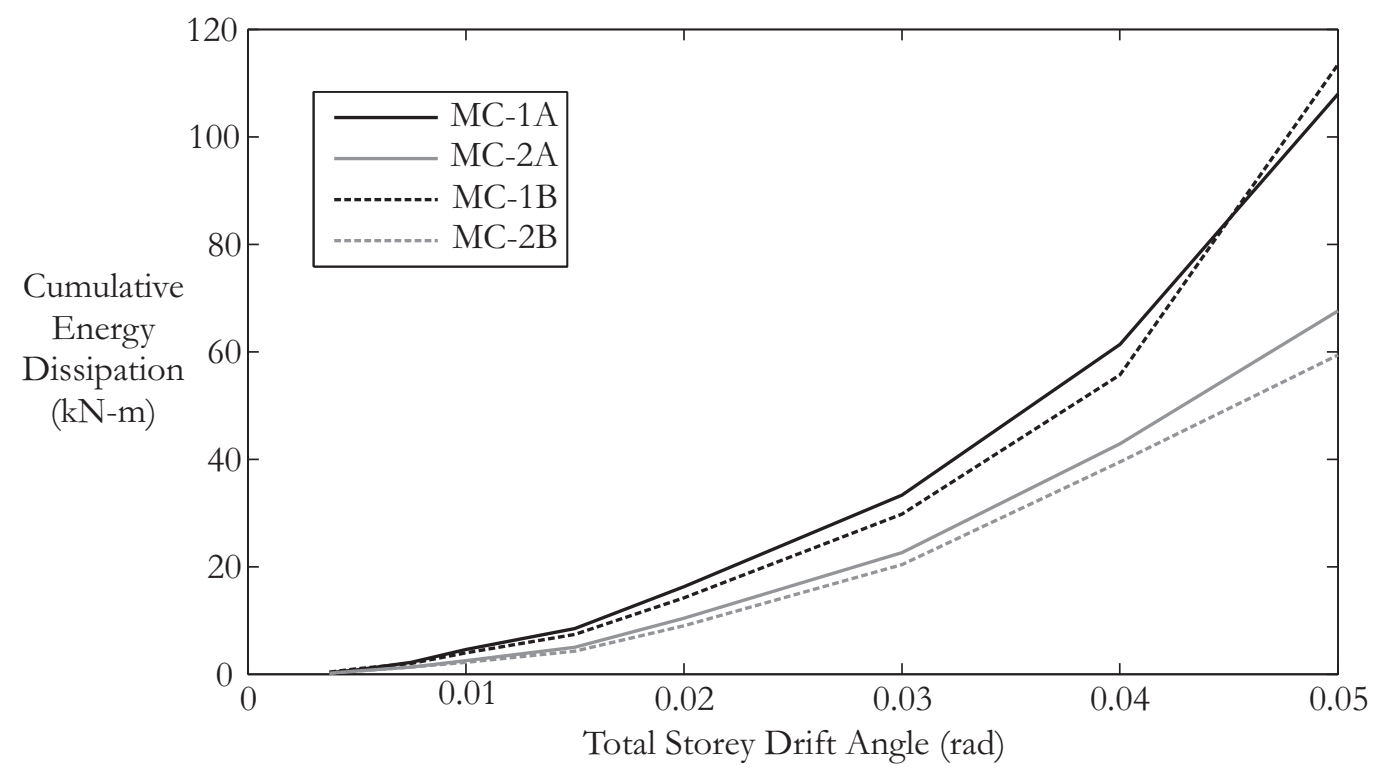

Figure 5.79: Cumulative Energy Dissipation

ductility used in the design of the connection was 5.0, based on the NBCC (2010) for steel ductile moment-resisting frames. The ductility of each connection is shown in Table 5.3.

$$
\mu=\frac{\delta_{\text {ultimate }}}{\delta_{\text {yield }}}
$$

where $\delta_{\text {ultimate }}$ is taken as the ultimate beam tip displacement before failure. The beam tip displacement at yield $\left(\delta_{\text {yield }}\right)$ was taken as the displacement at the intersection of a line drawn between the origin and first-yield of the force versus displacement response, and the line tangent to the force versus displacement response at ultimate displacement. The first onset of yielding was selected based on an inspection of the global hysteresis, and was found to occur at a storey drift angle of $0.0075 \mathrm{rad}$. Figure 5.80 shows the general method used to evaluate the ultimate and yield displacements of each specimen. The sensitivity of the ductility calculations to changes in yield deformation make it difficult to definitively quantify the ductility achieved, so future studies could give more attention to assessment of connection ductility.

The specimens with the RBS link achieved a higher maximum ductility than the specimens with the regular link because the elastic stiffness of the RBS link was higher. Although the 


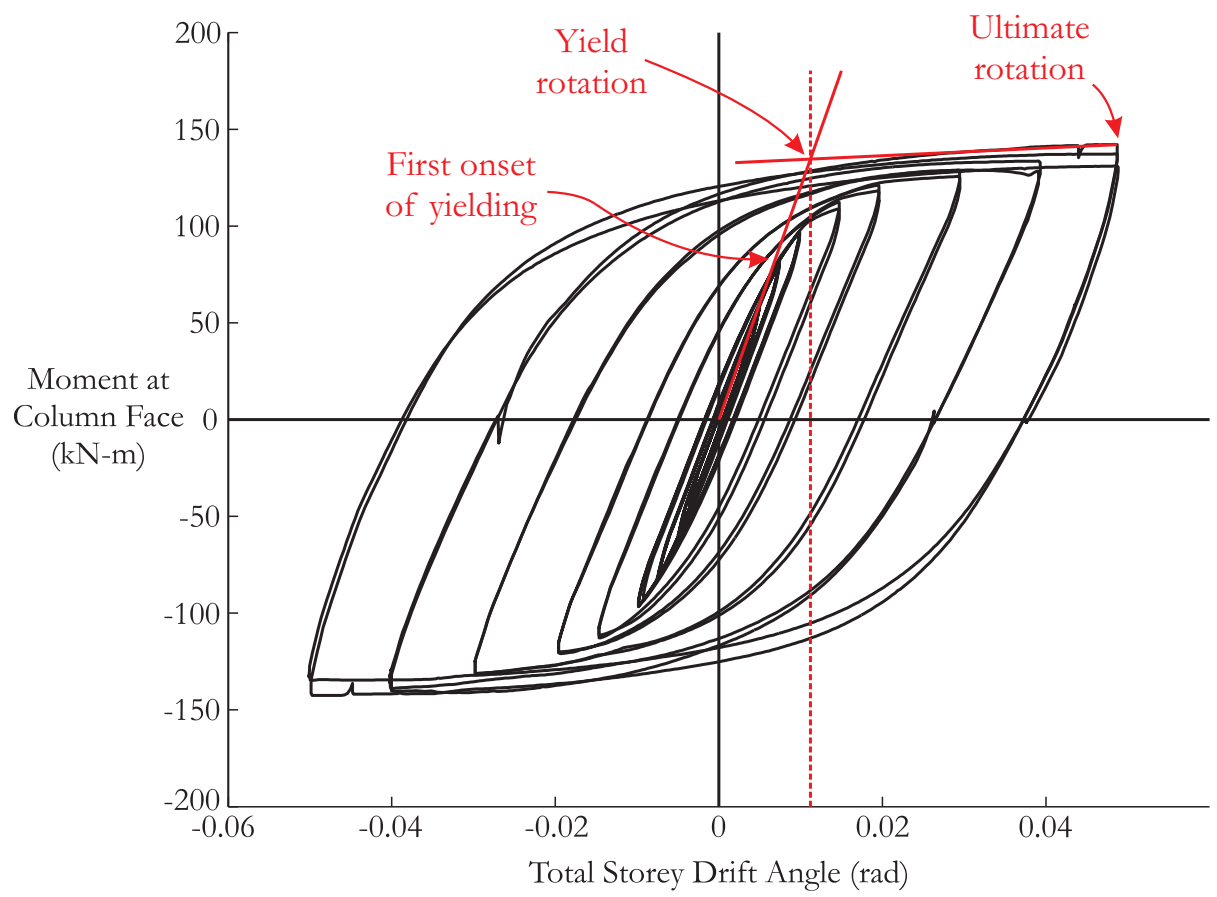

Figure 5.80: Method of Ductility Calculation

Table 5.3: Global Connection Ductility

\begin{tabular}{c|ccc}
\hline Specimen & $\delta_{\text {yield }}(\mathrm{mm})$ & $\delta_{\text {ultimate }}(\mathrm{mm})$ & $\mu$ \\
\hline MC-1A & 25.9 & 112 & 4.3 \\
MC-2A & 28.1 & 113 & 4.0 \\
MC-1B & 26.2 & 111 & 4.3 \\
MC-2B & 27.3 & 112 & 4.1 \\
\hline
\end{tabular}


ductility was high, it fell short of the target ductility of 5.0 for ductile steel moment resisting frames. If the imposed displacement of the frame was not limited to $0.05 \mathrm{rad}$ storey drift angle by the test setup, the connections could have sustained a higher ultimate displacement and achieved a maximum ductility closer to the target value. Furthermore, since the $2 / 3$ scale regular links used for the test specimens did not meet the target stiffness when scaled down (refer to table 3.5), yield rotations were higher than desired which lowered ductility. Tests at a larger scale with higher connection stiffness could further increase ductility, so the use of a higher ductility factor for seismic design may still be justifiable. These tests verify that a high ductility factor can be achieved with the proposed connection, however future tests should be performed to determine if a maximum ductility of 5.0 is achievable.

\subsection{Effect of Specimen Variation}

The overall setup for each test specimen was the same. The link type was varied between tests to examine the effects of the dogbone detail (MC-1A and MC-1B used a RBS link, whereas MC-2A and MC-2B used a regular link), and the beam STS connection type was varied between tests to compare the performance of the 45 degree STS connection configuration and the ZDplate connection. Tests MC-1A and MC-2A used the 45 degree STS connection, whereas MC-1B and MC-2B used the ZD-plate connection.

\subsubsection{Link Type}

Figure 5.81 shows a comparison of the hysteretic behaviour (force versus beam tip displacement) of tests MC-1A and MC-2A and Figure 5.82 shows a comparison the hysteretic behaviour of tests MC-1B and MC-2B. As expected, due to the reduced depth and weight of the regular link section and associated reduction in moment of inertia compared to the RBS link, the regular link had a considerably lower elastic stiffness. The elastic stiffness of each test specimen is presented in Table 5.4.

Ryan Gohlich, Department of Civil and Environmental Engineering, Carleton University 


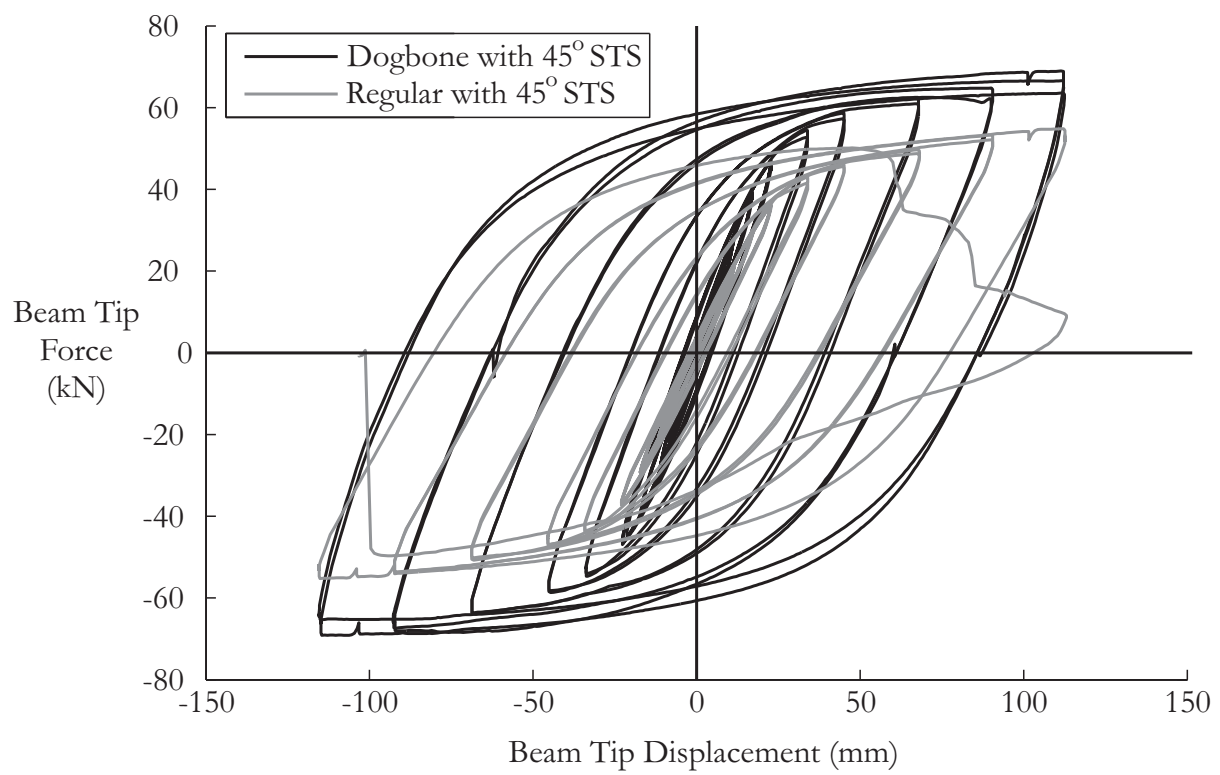

Figure 5.81: Comparison of Hysteretic Behaviour for Specimens MC-1A and MC-2A

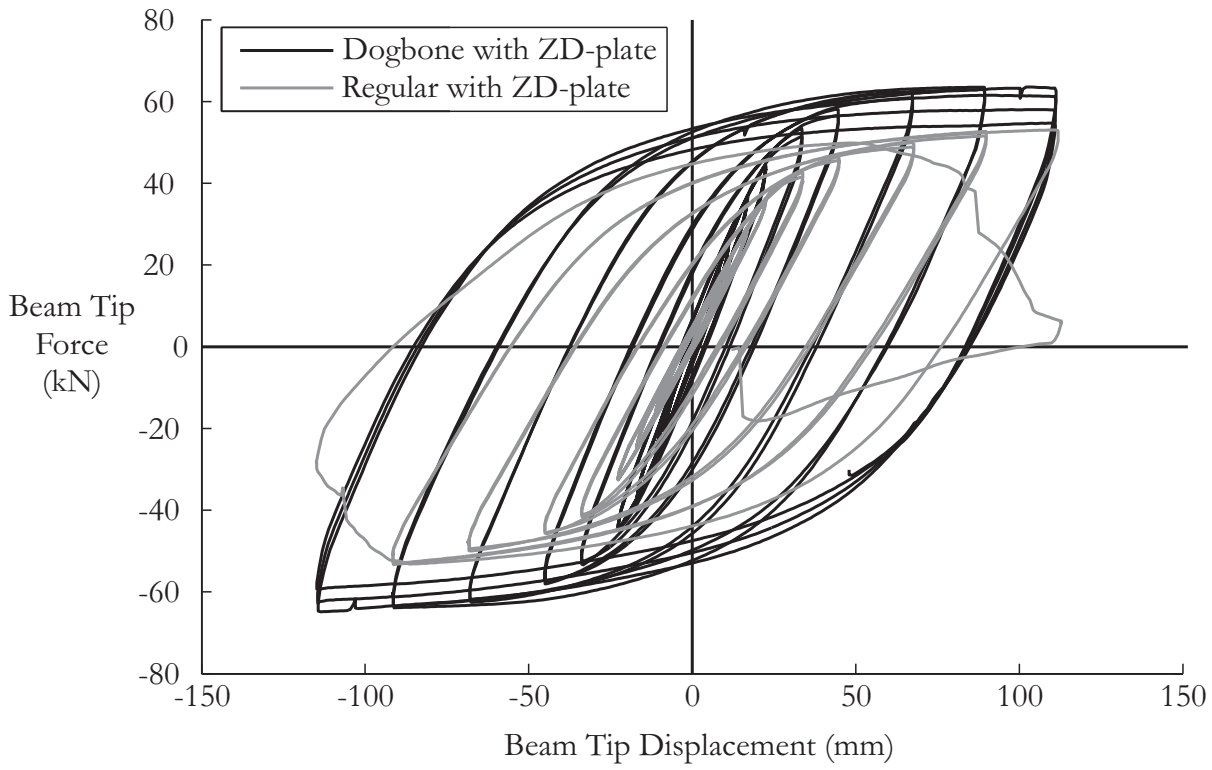

Figure 5.82: Comparison of Hysteretic Behaviour for Specimens MC-1B and MC-2B 
Table 5.4: Elastic Stiffness of Test Frames

\begin{tabular}{c|c}
\hline Specimen & Elastic Stiffness $(\mathrm{kN} / \mathrm{mm})$ \\
\hline MC-1A & 2.42 \\
MC-2A & 1.77 \\
MC-1B & 2.10 \\
MC-2B & 1.75 \\
\hline
\end{tabular}

Figure 5.81 shows that the peak load sustained by the RBS link (for test MC-1A) is approximately $25 \%$ higher than that of the regular link (for MC-2A), although both links were designed to sustain the same applied force. Similar findings are shown when comparing test MC-1B and MC-2B (Figure 5.82). This is a result of the length of plastic hinge formation in the RBS link. Since the link was designed based on the strength at the centre (smallest width), but plastic deformation was spread to areas of greater width, the strength achieved during testing was greater than the estimated design strength. This has both positive and negative implications in design. The increased force leads to higher energy dissipation, but also increases capacity-design forces applied to adjacent connection components. If the factor of safety for these components is not high enough during the design process, this could potentially lead to premature failure. The absence of the dogbone detail in the regular link led to a more predictable peak load.

Although the maximum storey drift reached by each connection was the same, based on the observed failure mode of the connections, it is likely that the RBS link has a higher rotation capacity than the regular link. The regular link failed at the link-to-end-plate welds in a brittle manner during the second cycle at 0.05 rad storey drift angle, whereas the RBS link sustained more cycles, and likely could have sustained higher drift levels before failure. The RBS link was successful in localizing plastic deformations to the centre of the link, away from brittle weld metal, whereas the plastic hinge formed near the column face of the regular link, which is a much less desirable location.

The lower stiffness, peak load, and rotation capacity of the regular link, along with the location of the plastic hinge, led to an overall reduction in cumulative energy dissipation, as previously shown in Figure 5.79. The lower strength and stiffness of the regular link resulted in a 
lower energy dissipation during the initial loading cycles, and brittle failure during the final cycles reduced the final cumulative energy dissipation of the regular link (relative to the RBS link).

Figures 5.18 and 5.36 show that the contribution of the link to total storey drift angle was greater for the regular link during the initial cycles due to the lower elastic stiffness. The link contribution became more balanced with that of the RBS link during the later cycles, which relied more heavily on plastic deformations.

The RBS link exhibited more preferable performance since it successfully localized plastic hinging to the centre of the link. If the connection is designed using the regular link, link size should be chosen to withstand the applied moment at the column face of the connection.

\subsubsection{Beam Connection Type}

Figure 5.83 shows a comparison of the hysteretic behaviour (force versus beam tip displacement) of tests MC-1A and MC-1B, and Figure 5.84 shows a similar comparison for tests MC-2A and MC-2B. Specimens MC-1A and MC-2A used a 45 degree STS connection, while MC-1B and MC-2B used a ZD-plate connection. Similar trends were seen in both comparisons. Overall performance was quite similar in terms of achievable ductility, energy dissipation, and capacity. Specimen MC-1B had a slightly lower peak force, which is likely due to slight variations in material strength and fabrication dimensions of the link itself. The failure mode of each connection was identical. As previously discussed, the contribution of each connection to total storey drift was nearly the same. As shown previously in Table 5.2, the maximum connection slip was greater for the ZD-plate than for the 45 degree STS.

In terms of performance, the two connection types were similar. During testing, the ZDplate connection was considerably louder, which could potentially lead to serviceability-related issues, but it is unlikely that these connections would undergo significant enough drift levels under regular service conditions to cause the creaking noises observed during testing. In general, the ZD-plates were easier to install, albeit placement tolerances are more stringent since they must align with pre-drilled holes in steel plates. Screws were smaller, making installation easier, and no reinforcing screws were necessary to accommodate tension perpendicular-to-grain stresses. The 


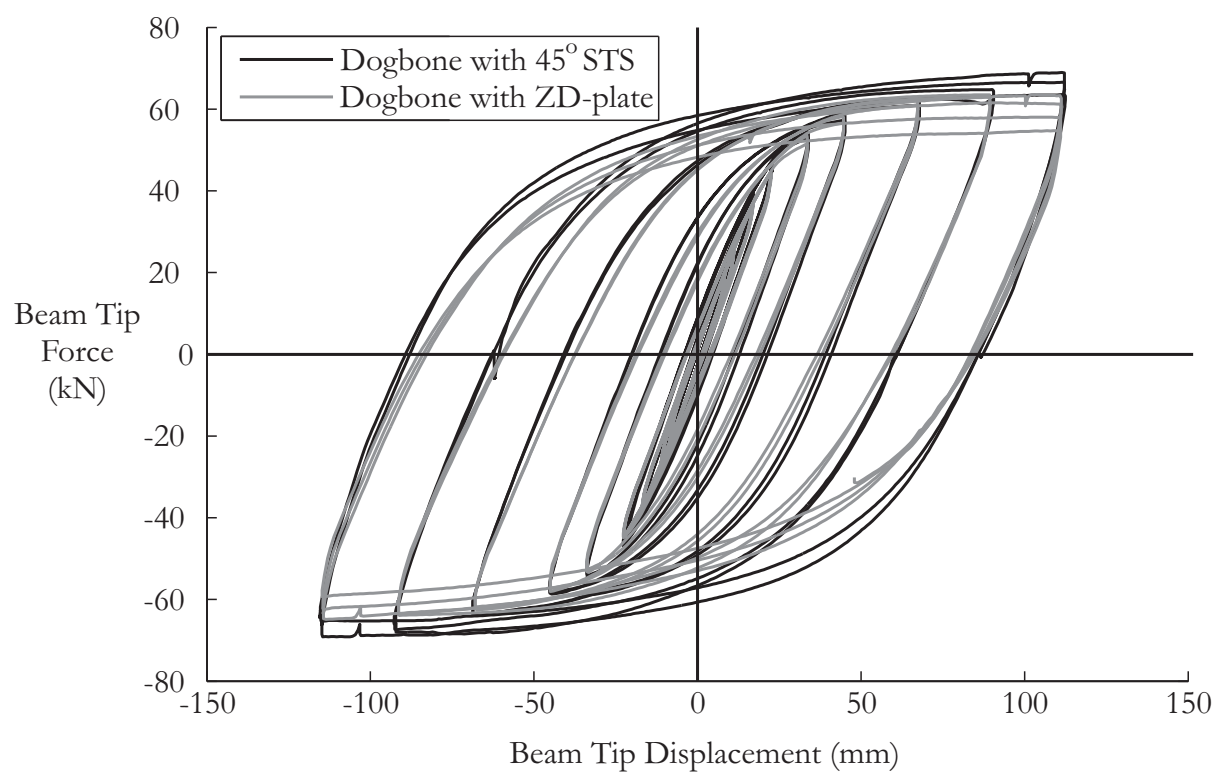

Figure 5.83: Comparison of Hysteretic Behaviour for STS Connectiona MC-1A and MC-1B

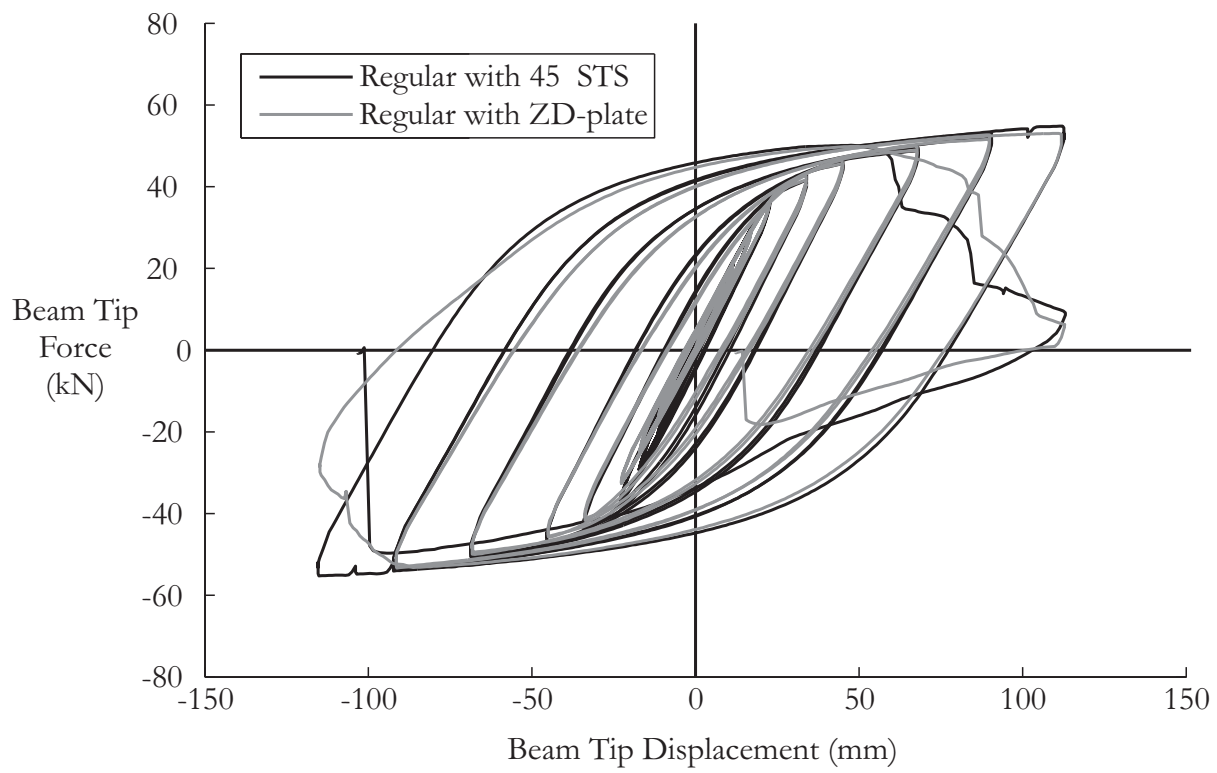

Figure 5.84: Comparison of Hysteretic Behaviour for STS Connectiona MC-2A and MC-2B 
overall appearance is less bulky for the ZD-plates, and can more easily be taken apart because of the bolt-on assembly. Overall, the cost of the ZD-plates is higher.

\subsection{Effect of Scaling}

No prior research exists on the performance of nonlinear replaceable links at a small scale. Research presented by Shen (2009) used a significantly larger link size (W460 x 128) than that used in this research (W250 × 28 for the RBS link and W200 × 22 for the regular link), since seismic design forces were lower for the proposed hybrid connection, and a $2 / 3$ scale specimen was tested. The link sizes used in this research still fell within the allowable size specified in the Moment Connections for Seismic Applications guidelines (CISC, 2008). The RBS link used in this research had low out of plane stiffness which led to local buckling of the link web as the primary failure mode (after flange yielding), followed by local flange buckling. In the study performed by Shen (2009), the link (no dogbone detail was present) failed by means of flange local buckling, followed by local web buckling at high drift levels. For the regular link in this research, local flange buckling occurred near the weld access hole, which is likely a result of the low flange thickness relative to a full-scale connection. If a larger link was used, local flange buckling likely would have occurred at mid-length of the link. Strength degradation of the connection used in this research occurred at higher drift levels than in the research presented by Shen (2009). In the study performed by Shen (2009), strength degradation began during the second cycle at $4 \%$ drift, whereas in this study, strength degradation began during the second cycle at $5 \%$ drift, and reduced strength less between cycles than in the study by Shen (2009). This is likely a result of the delay in flange local buckling in this study relative to the study done by Shen (2009), which could be an effect of link scaling. Overall, similar performance was seen between the small-scale connection presented in this research and that presented by Shen (2009) for a full-scale steel-only nonlinear replaceable link connection. Future studies should be performed on the proposed connection at full scale.

Ryan Gohlich, Department of Civil and Environmental Engineering, Carleton University 


\subsection{Link Replaceability}

Figure 5.85 shows the stages of link replacement after testing and the link has undergone significant plastic deformation. These tests are not an accurate representation of the level of difficulty that link replacement may pose in the field since in the tests the beam is cantilevered and can move freely after the bolts are released. Furthermore, it is low to the ground in the horizontal position so it is easier to handle.

When the test was complete, the beam was brought back to the point of zero load, and was still at a small drift level when the link was removed. The link had been axially shortened by a small amount, so removal of the deformed link was not difficult after bolts were removed. Shoring of the beam was not necessary since it was held in place by the lateral restraint systems. The replacement link was slightly shorter than the original link, so there was a gap between the beam-side link end and the end of the beam. Since there was no noticeable plastic deformation at the column face or end of the beam collar, aligning the new end-plate with the existing bolt holes was simple. Pretensioning of the bolts in the field could be done with a long wrench or an air powered impact gun. The replaced link was slightly misaligned compared the the original link, as shown in Figure 5.86; this had no noticeable effect on connection performance.

In the field, the beam would have to be shored in place while the link is replaced. If significant residual drift is present, the members would have to be jacked as close as possible to the original position before replacement. It may sometimes be necessary to have custom replacement links fabricated to fit in-situ geometry where there is significant residual displacement.

After four complete tests, there was no obvious signs of damage to any of the connection members (beams or column) that were design to remain elastic. Figure 5.87 shows a photo of the column panel zone after four tests, and Figure 5.88 shows photos of each beam collar (following two tests each). No flaking of the white-wash was seen around any of the bolt holes, and no plastic deformation was visible. This indicates that these areas remained entirely elastic, and it is unlikely that they would pose problems during link replacement.

Ryan Gohlich, Department of Civil and Environmental Engineering, Carleton University 

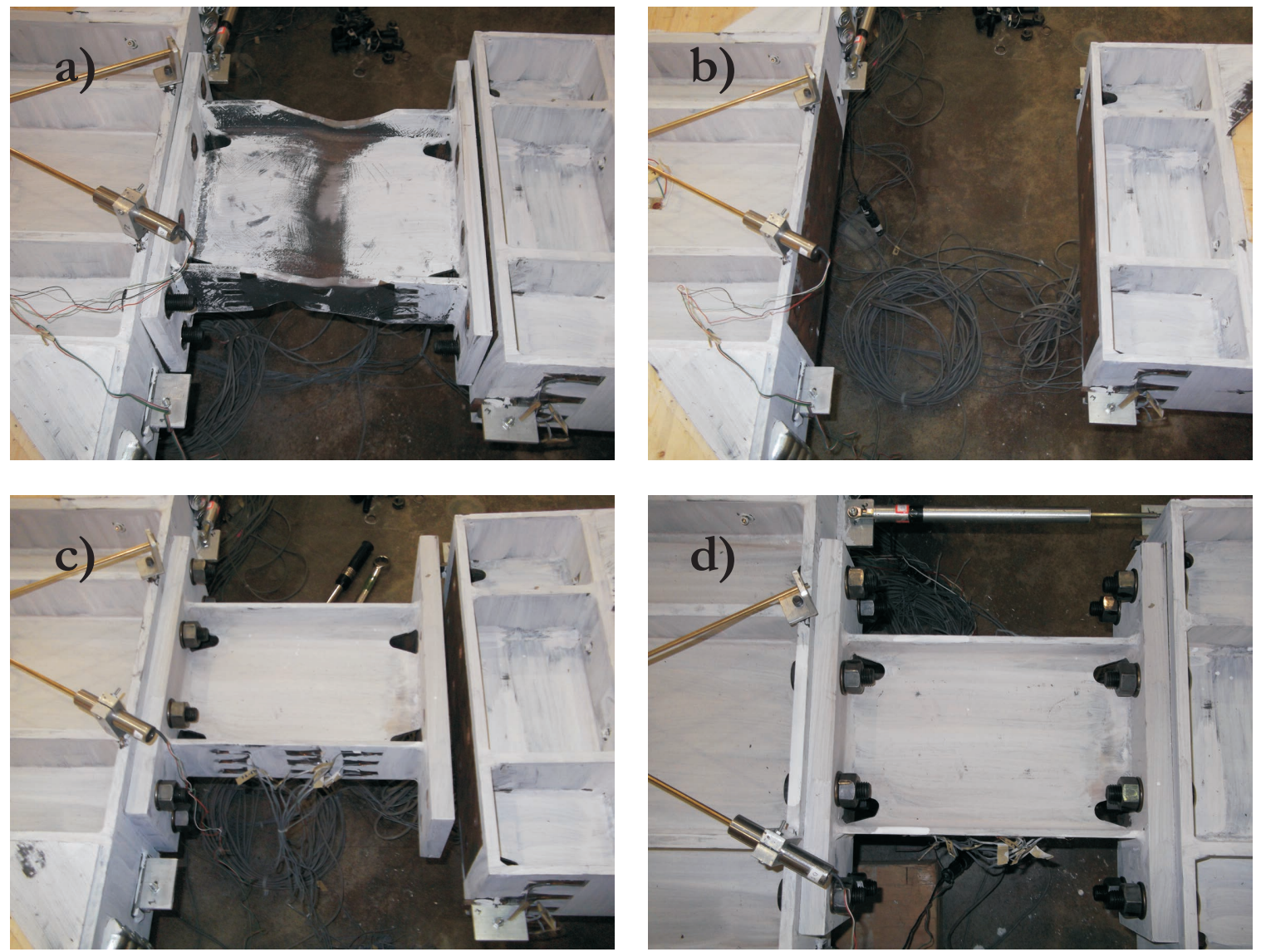

Figure 5.85: Link Replacement a) Bolt Removal b) Link Removal c) Link Installation d) Bolt Tightening 


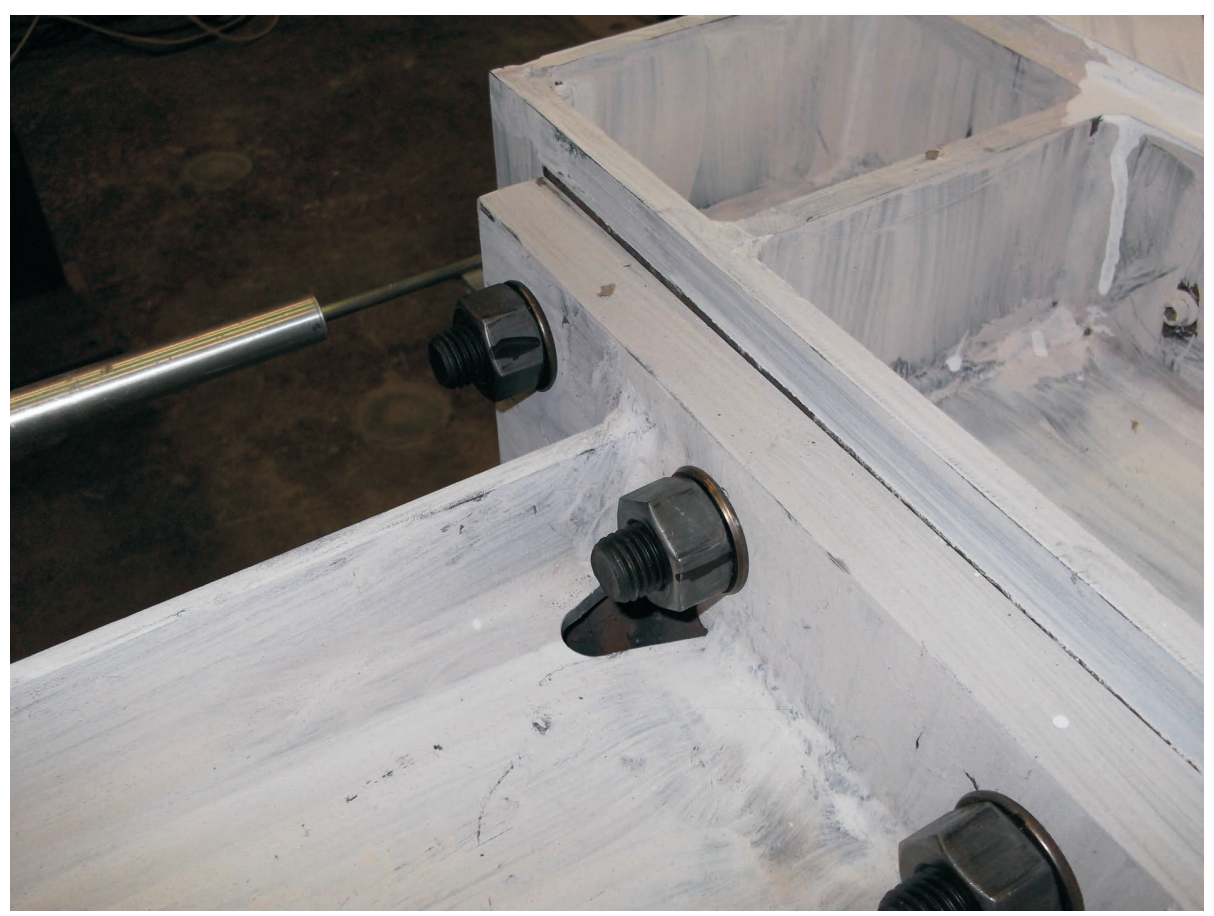

Figure 5.86: Misalignment of Replaced Link

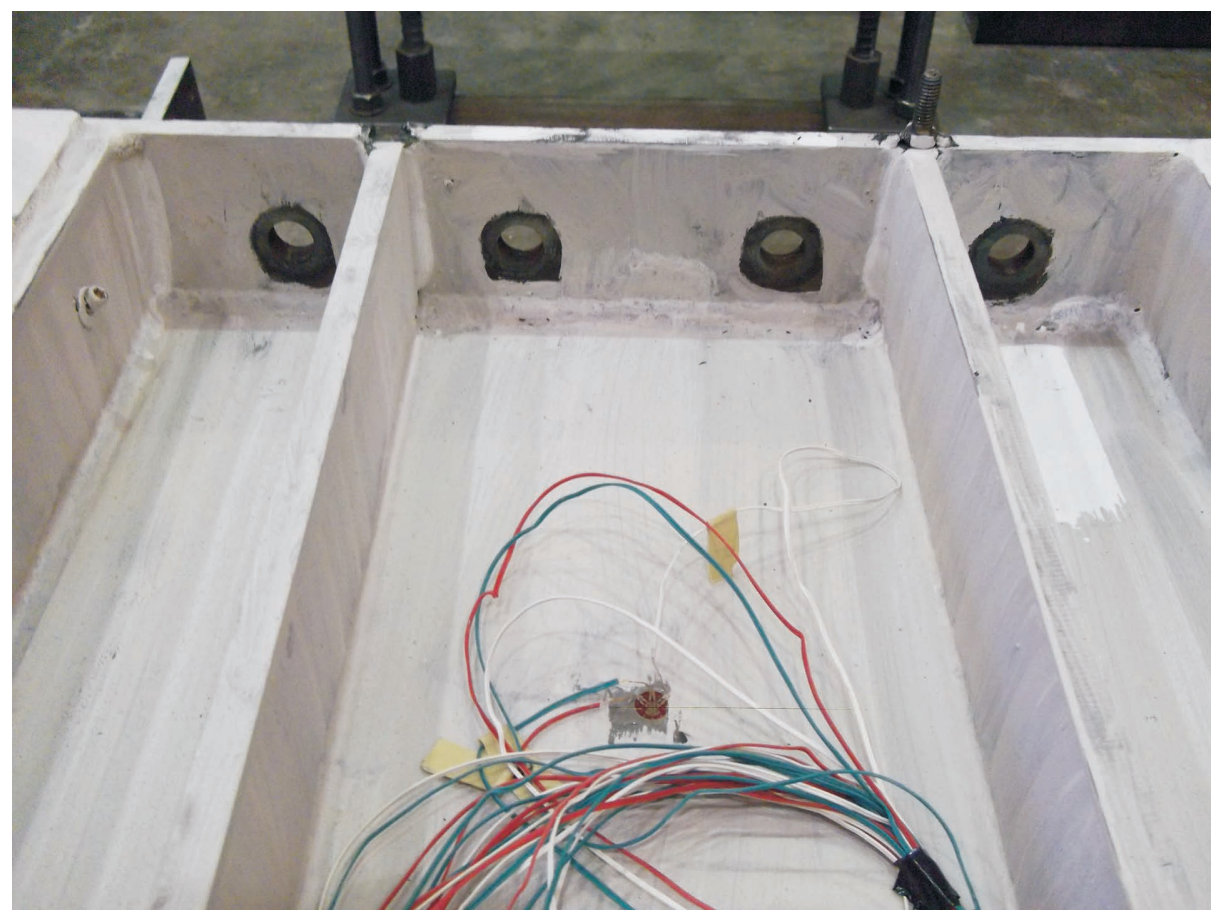

Figure 5.87: Post-test Inspection of Panel Zone 

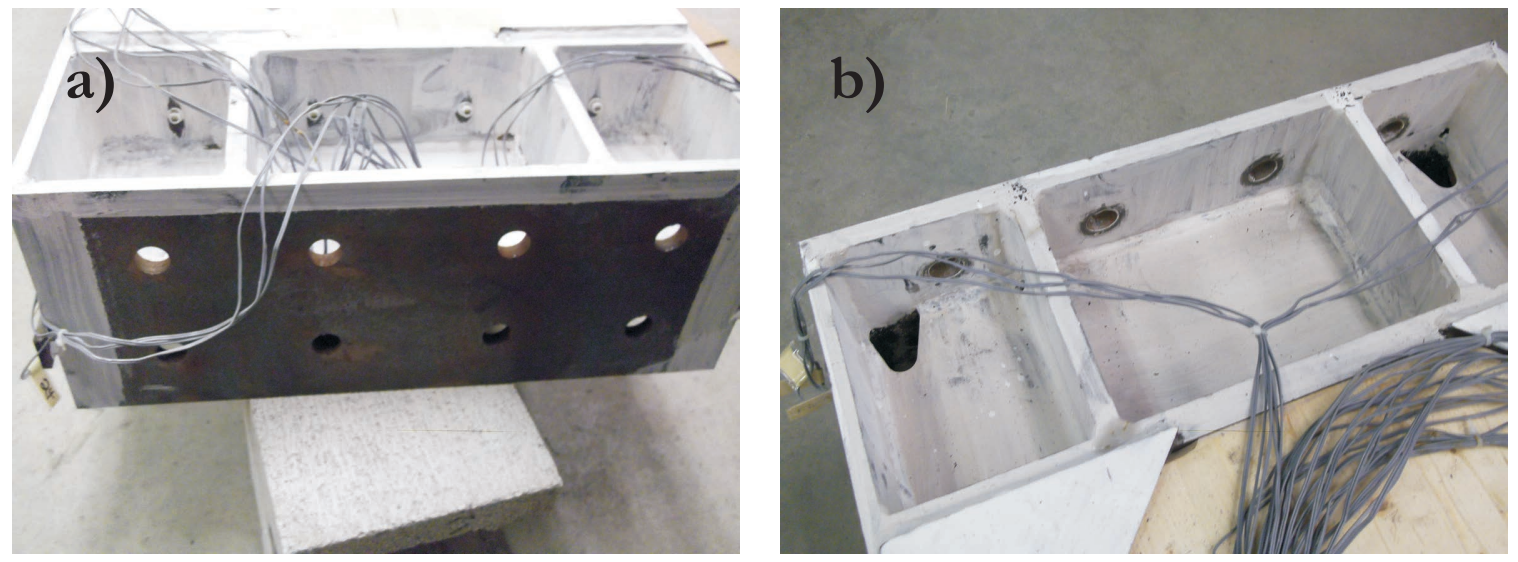

Figure 5.88: Post-test Inspection of Beam Collars

a) 45 Degree STS b) ZD-plate

\subsection{Summary of Results}

This chapter presented and discussed the findings of the experimental testing of four hybrid timber-steel connection specimens. Global and local connection performance was evaluated and compared between test variables. Validity of design concepts and procedures was discussed, and some conclusions were drawn.

Each of the four tests conducted performed as expected when designed according to current Canadian standards. Slight changes in the expected failure sequence were observed, which can be attributed to scaling effects and link size. All test specimens were able to withstand multiple cycles at a total storey drift angle of up to $0.04 \mathrm{rad}$ without signs of significant strength degradation. Since the AISC Seismic Provisions for Structural Steel Buildings (2010) only requires the connection to withstand a single cycle at 0.04 rad storey drift, based on this experimental program, it can concluded that the proposed connections meet the acceptance criteria for prequalified connections. Table 5.5 below shows a summary of the key test results. As expected, the failure mode of test MC-1A and MC-1B were identical and the failure mode of test MC-2A and MC-2B were identical. Overall connection strength was close to the predicted value.

Examination of the global hysteretic response and behaviour of the STS connections showed that the strength of the hybrid connection is similar to that of a modern steel-only 
Table 5.5: Summary of Test Results

\begin{tabular}{c|ccccc}
\hline Specimen & Failure Mode & $\theta$ & $\theta_{P}$ & $\mathrm{M}_{\mathrm{cf}, \max }(\mathrm{kN} \cdot \mathrm{m})$ & $\mu$ \\
\hline MC-1A & Out of Plane & 0.05 & 0.037 & 142 & 4.34 \\
MC-2A & Flange Fracture & 0.05 & 0.037 & 114 & 4.01 \\
MC-1B & Out of Plane & 0.05 & 0.035 & 134 & 4.25 \\
MC-2B & Flange Fracture & 0.05 & 0.036 & 110 & 4.10 \\
\hline
\end{tabular}

moment-resisting connection. High ductility was achieved. It was slightly lower than the target ductility factor of 5.0; however, it is likely that higher ductility could have been achieved for the RBS link if a larger displacement had been applied to the beam tip during testing. The STS connections showed little connection rotation. No decrease in overall connection stiffness or pinching was seen in the global connection response. STS connection slip was observed to be on the order of one tenth of a millimeter.

The dogbone detail was successful in localizing plastic deformations to the centre of the link, resulting in high ductility and energy dissipation capacity, with little strength degradation, even at 0.05 rad storey drift. The regular link specimens formed a plastic hinge near the columnside of the link, leading to brittle failure of the end-plate welds at 0.05 rad drift. A majority of the total drift was accommodated solely by the link rotation throughout all tests.

Little difference in overall performance was seen between the 45 degree STS connection configuration and the ZD-plate connection, although connection slip was slightly higher in the ZD-plate connection. Members designed to remain elastic showed no signs of plastic behaviour, verifying the use of the capacity-design method. No crack formation was observed in the timber elements. The reinforcing screws were successful in avoiding tension perpendicular-to-grain failure of the timber. Overall, the RBS link exhibited higher performance in terms of ductility and energy dissipation capacity, failure mode, and rotation capacity than the regular link detail. 


\section{Chapter 6: Numerical Modelling}

\subsection{Objectives}

The following chapter presents the methodology and findings of the numerical modelling of a frame incorporating the hybrid timber-steel moment-resisting connection developed in this study. The goal of this study was to determine if high R-factor design is justifiable for hybrid timber-steel systems. Two full-scale two-dimensional moment-resisting frames (MRFs) were modelled using OpenSees (McKenna et al. 2000), an open source nonlinear structural analysis software. One frame was designed using the newly developed hybrid system with predominantly wood members, and the other was an equivalent steel-only frame designed using typical steel connection detailing. Each frame was designed with the same geometry for ease of comparison. Nonlinear dynamic time-history analysis of each MRF was conducted, and the seismic performance was evaluated and compared. To calibrate the stiffness and nonlinear behaviour of the connection models, the test specimen described in Chapter 4 was modelled and compared to experimental findings. Seismic performance of each frame was evaluated on both the component and global level and compared to code-based design criteria. Recommendations for the seismic design of these systems will be presented based on the findings of these analyses in an attempt to limit excessive storey drifts and accelerations, as well as to avoid inelastic behaviour in the timber members. 


\subsection{Prototype Structure}

For this study, two full three-dimensional, six storey prototype structures were designed in order to determine appropriate member sizes for the numerical modelling of the MRFs. One building was primarily timber and incorporated the newly developed hybrid timber-steel beamcolumn joint, while the other building was steel and used typical connection detailing for steel buildings based on the Moment Connections for Seismic Applications guidelines (CISC, 2008). A graphical representations of each building is shown in Figure 6.1. Each building was designed using a moment-resisting frame in the east-west direction, and a buckling-restrained braced frame $(\mathrm{BRBF})$ in the north-south direction. Figure 6.2 shows a plan view of each prototype building depicting the layout of structural members. The hybrid building used a one-way cross-laminated timber floor slab system in the east-west direction, allowing for a reduced number of beams for the gravity frame. The steel building used a two-way concrete composite deck, typical of steel structures.

For this study, primary focus was placed on the seismic design of the MRF. The design of the BRBFs was part of a parallel companion study, so only a preliminary design was completed for this analysis. Each prototype building was designed using ETABS (Computers \& Structures Inc., 2013), an advanced computer-aided structural analysis software used for the design of buildings. Although hysteretic behaviour can be defined in this software to better capture the nonlinear performance of elements that are expected to yield under dynamic loading conditions, strictly a linear analysis was performed for this design, and adequacy was verified using the OpenSees models. First, a preliminary design of each structure was completed by manually analyzing twodimensional gravity frames (one in each direction), lateral load resisting systems, and floor slabs (based on tributary area). Once initial estimates of required member sizes were made, the seismic weight of each structure was determined, and the equivalent static method of seismic analysis was used to estimate lateral forces imposed on each BRBF and MRF. Design of the two-dimensional frames was then updated, and each structure was modelled in three-dimensions in the ETABS software (Computers \& Structures Inc., 2013).

Ryan Gohlich, Department of Civil and Environmental Engineering, Carleton University 

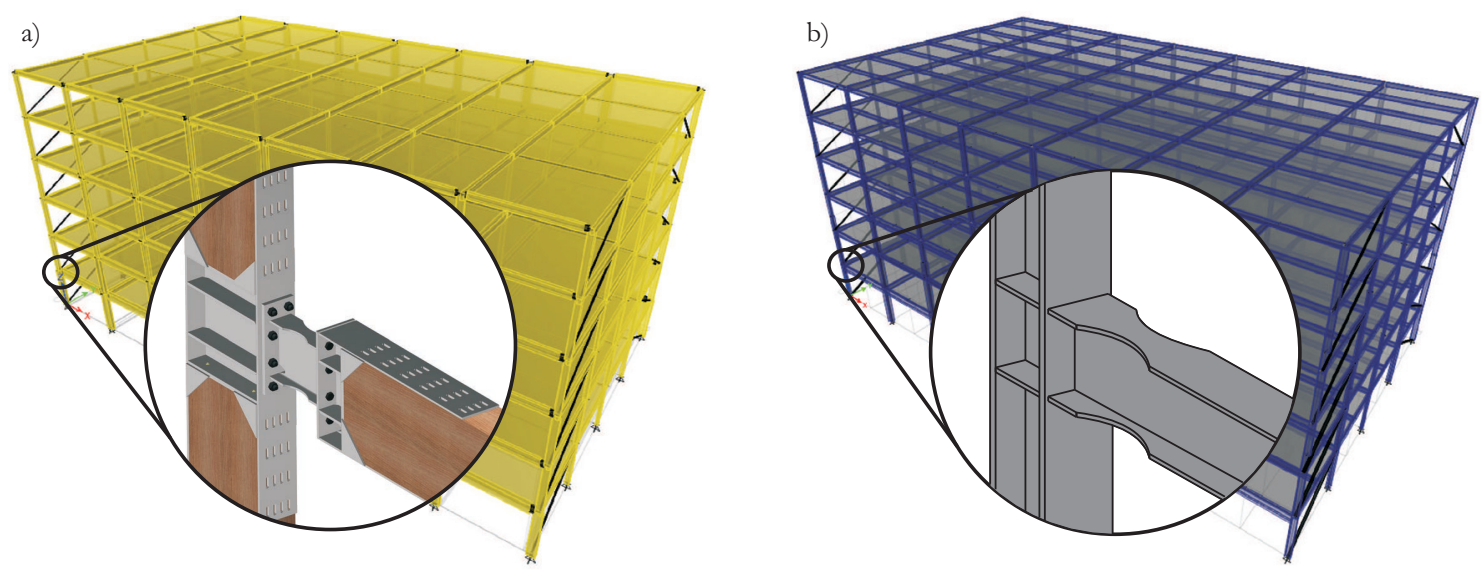

Figure 6.1: Prototype Buildings

a) Hybrid Timber-Steel b) Steel-Only

All structural members were designed according to applicable Canadian standards. All gravity and seismic loading was calculated acording to the NBCC (2010). The timber beams and columns were designed according to CSA O86-09 (2010), and the CLT floor slabs were sized using the CLT Slab Selection Tables provided by Nordic Wood Structures Technical Note S23 (2013). All steel members and detailing was designed in accordance with Limit States Design of Steel Structures (CSA S16-09, 2010) and the Moment Connections for Seismic Applications guidelines (CISC, 2008).

The initial model of the hybrid structure used timber-only beam-column joints, assuming that no loss of stiffness occurred due to the addition of the steel nonlinear replaceable links. Once initial seismic forces were estimated at the beam-column joints, the links were designed and explicitly implemented into the ETABS model. The steel-only building used RBS details at each beam-column joint. These details were not explicitly modelled, but instead the total output storey drift was increased by $9 \%$ to account for loss in frame stiffness (CISC, 2010). The design of each building was iteratively updated using response spectrum analysis in order to take advantage of the high period of the structure in reducing imposed lateral forces (as compared to equivalent static method). Details on the complete seismic design of the prototype structures can be found in Appendix B.

It should be noted that design of the MRF was often governed by drift requirements and 


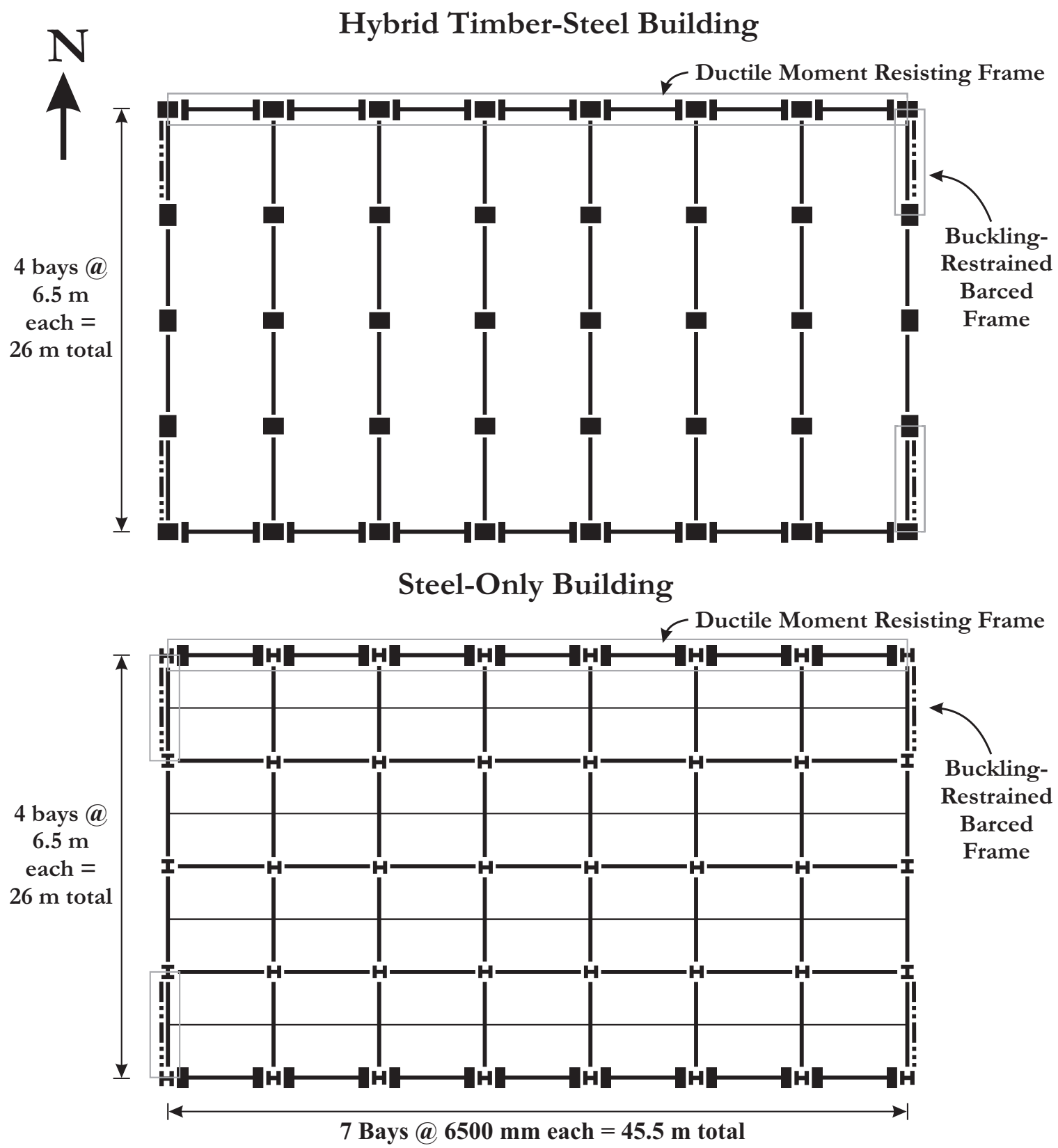

Figure 6.2: Structural Layout of Prototype Buildings 
not member strength. For this structure, the NBCC (2010) limits allowable storey drift to $2.5 \%$ of storey height. Due to the flexible nature of timber, deep beams and columns were required in the lower few storeys of the hybrid structure to accommodate drift. In this system, the existence of the nonlinear replaceable link uncoupled strength and drift design, allowing beam and column sizes to be increased to accommodate drift requirements without increasing the capacity of the beam-column joint (because the nonlinear replaceable link remains the same size). In the steelonly system a typical reduced beam section (RBS) detail was used, so when beam sizes were increased to accommodate drift, strength of the yielding hinge also increased. Consequently, higher capacity-design forces in the structural members had to be accommodated by increased member size, thus the steel-only frame was necessarily significantly over-designed in terms of strength at the lower storeys. Designs were iterated using the ETABS model until both strength and deflection criteria was met for all members, and interstorey frame drifts did not exceed allowable limits.

\subsection{OpenSees Modelling}

Once the three-dimensional design of each building was complete, two-dimensional models of the hybrid and steel-only MRFs were created in OpenSees (McKenna et al. 2000) and subjected to earthquakes at the maximum credible earthquake (MCE) and design basis earthquake

(DBE) hazard levels. The goal of this numerical study was to determine if hybrid timber-steel systems can achieve a level of seismic performance similar to that of existing, well-understood steel-only systems. Figure 6.3 shows an elevation view of the structural layout used for both two-dimensional frame modells.

\subsubsection{Modelling of Test Specimen}

Prior to modelling the full buildings, a model representing the test specimen previously discussed in chapters 4 and 5 was created in order to calibrate the behaviour of each material and element in the model. This ensured that the behaviour of the full building model was a realistic 


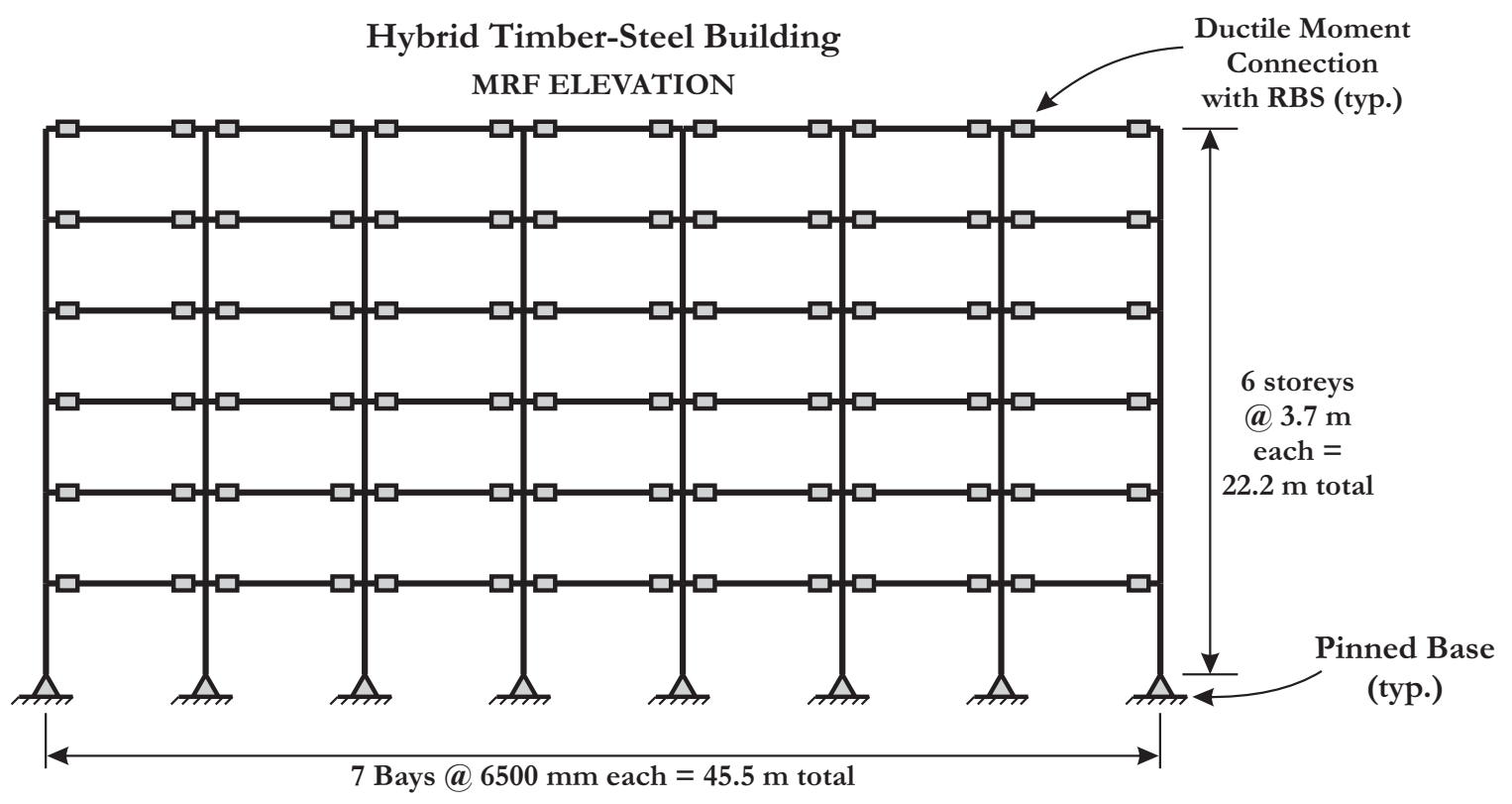

Figure 6.3: Structural Layout of 2-D Frames

simulation of the real connection behaviour. Figure 6.4 shows the configuration of the various nodes and elements used to model the test specimen. Figure 6.5 shows the elements types used to model each component surrounding a typical beam-column joint (for both the test specimen and the full building model). Figure 6.5 shows a typical interior beam-column joint (double-sided) as applied to the full building model that will be discussed later. For the test specimen model, the beam and link elements were only present on one side of the panel zone.

The beam-column joint of the test specimen model incorporated four main components: wood beams/columns, steel panel zone, gross steel link sections, and reduced steel link sections. The self-tapping screwed connections were not explicitly modelled since the tests found that the contribution of the screw connection to total rotation was small. This is a valid assumption providing that an adequate overcapacity factor is assigned to each STS connection during the design phase. Future research should further assess the validity of this assumption if attempts are made to optimize the design by reducing the overcapacity factor. Because the dogbone link showed better performance during the experimental program, this numerical modelling study focused on simulating a link with a dogbone detail; the regular link has not been modelled, 


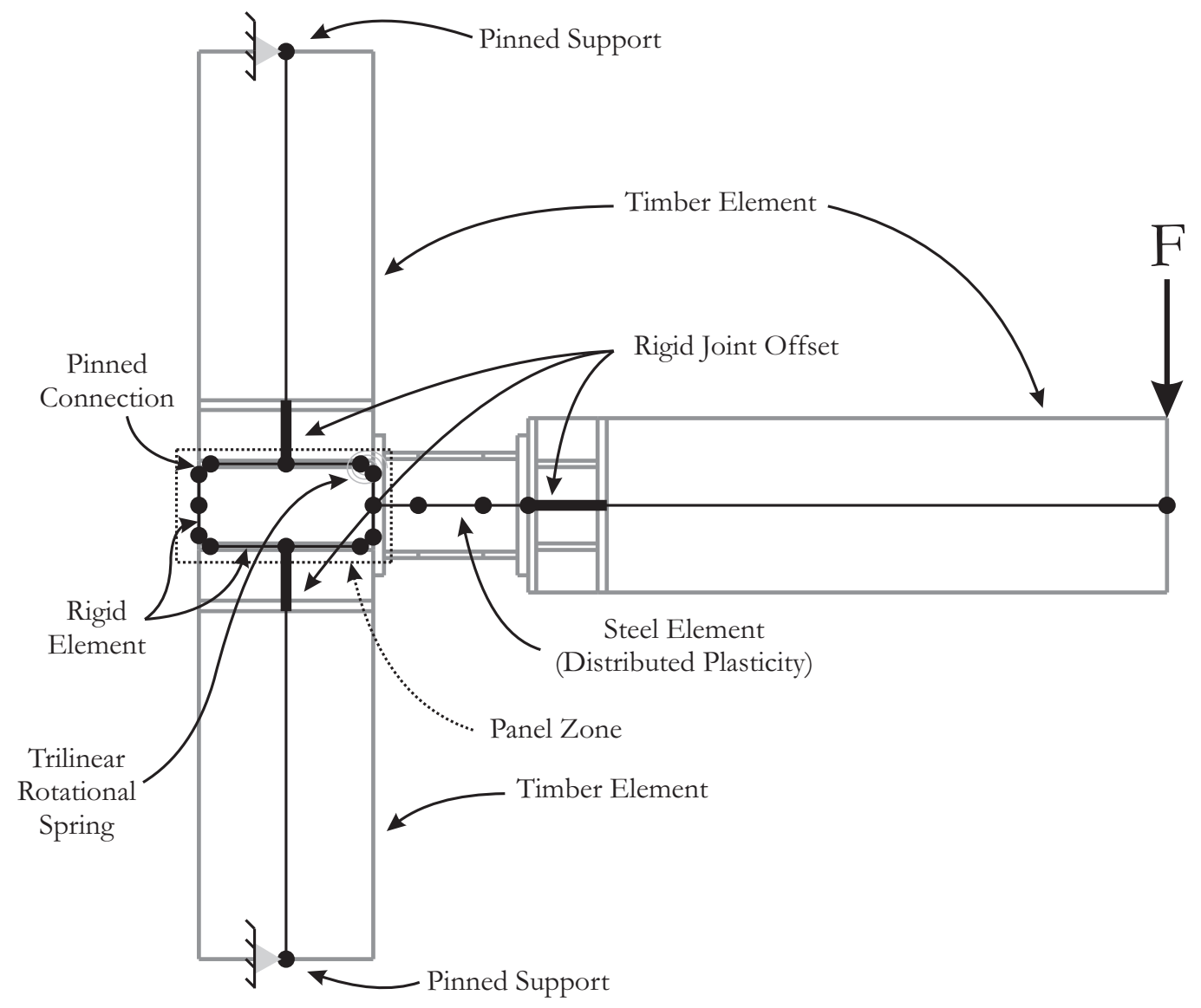

Figure 6.4: Model Configuration for Test Specimen

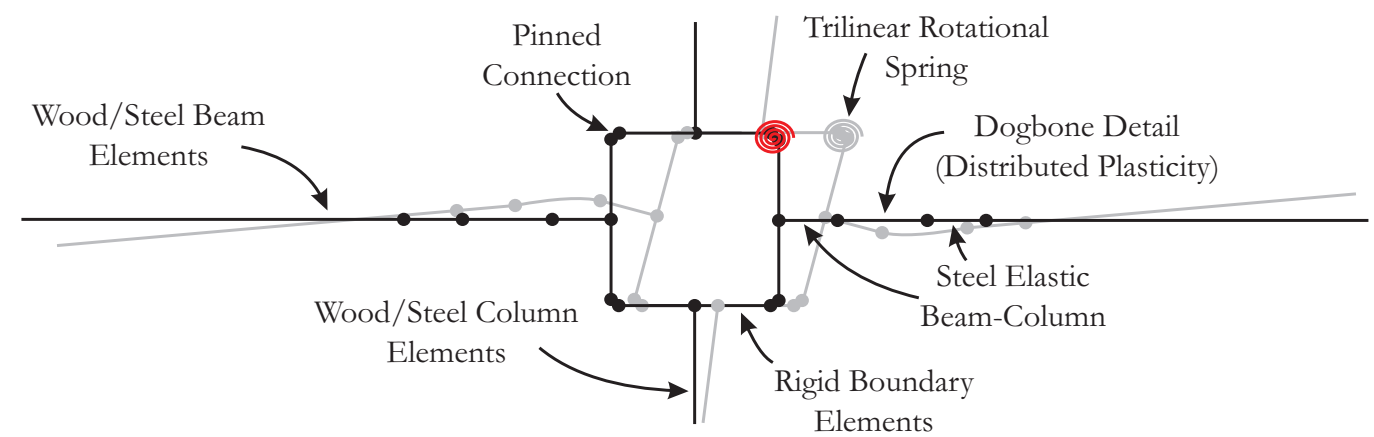

Figure 6.5: Model Element Types 
but similar methods could be used to model it. Since true pinned connections were fabricated and used to support the column ends, the model allowed free rotation of the column ends (but fixed all translation). All other nodes were free to rotate or translate in any direction on the two-dimensional plane. All elements were assigned linear geometric transformations; nonlinear geometric effects were not significant since there was no axial force on the beam in the test.

The wood beam and column members were modelled using elastic beam column elements with cross-sectional area and stiffness properties assigned based on the manufacturer specified values used for design (refer back to Table 3.7). Since the frame was capacity-designed such that the wood sections remained elastic, no strength or nonlinear modelling was necessary for the wood elements. In practice, high overcapacity factors will be assigned to timber member ensuring that they remain elastic, and the overcapacity will further increased by designing timber sections at the design (code-based) level. Ensuring linear behaviour in the wood elements inhibits the need for them to be modelled as orthotropic materials. Experimental data confirmed that the wood members remained entirely elastic. Wood members used a manufacturer specified modulus of elasticity of $12400 \mathrm{MPa}$, consistent with the type of wood used for the experimental test. The wood beam was assigned a rigid joint offset at the fixed-end to account for the high stiffness of the steel beam collar that connected the wood beam to the link. Similarly, the lower portion of the upper column and the upper portion of the lower column were assigned rigid joint offsets to simulate the portion of steel that extends beyond the top and bottom of the panel zone (the panel zone was considered to be the portion of steel between the stiffeners as shown in Figure 6.4). The location of the rigid joint offsets can be seen in Figure 6.4.

The link was modelled using three different elements. An elastic beam column element was located at each end of the link with a cross-section identical to the gross section dimensions of the W250 x 28 steel section used for the link in the experimental test. Since the tests showed that the plastic hinge was formed at the middle of the link, the end elements were not assigned plastic behaviour. In future studies, these portions of the link could be modelled using the same methods as discussed for the dogbone portion to account for the formation of a secondary plastic hinge, but this likely would not significantly alter overall model performance. The middle portion of the link was assigned a flange width equal to that of the narrowest portion of the dogbone 
detail from the test specimen (51 mm compared to the gross width of $102 \mathrm{~mm}$ ). The web and flange thickness of the middle portion of the link remained the same as the gross sizes of the end elements. The length of the reduced section was the total length of the dogbone detail $(170 \mathrm{~mm})$. This is a conservative approach because strength and stiffness of the dogbone section would increase towards the link ends; however, the tests showed that most yielding was localized to the middle of the link. An alternate approach would be to model the dogbone portion of the link as multiple sections of increasing flange width towards the link ends, but this would greatly increase program run times.

The middle dogbone portion of the link was assigned nonlinear behaviour using a distrubuted plasticity model with a force-based beam column element. The appropriate element configuration used five integration points along the length of the link. A fibre section was used in the element at each integration point with 10 fibres across the depth of the web and 3 fibres through the thickness of the flange. The appropriate number of fibres and integration points were determined through a sensitivity analysis. The uniaxial Giuffre-Menegotto Pinto material in OpenSees was used to represent the material behaviour of the link section. This material was chosen because it best captured the Bauschinger Effect and cyclic hardening of the link when transitioning into the plastic range. All link materials were assigned an elastic modulus of $200000 \mathrm{MPa}$. Other material properties were calibrated basd on the test specimen results.

The panel zone was modelled using a series of rigid boundary elements, and localizing the plastic behaviour into a single rotational spring, as suggested by Gupta and Krawinkler (1999) and shown in Figure 6.5. The panel zone extended from the link end at the column face to the back side of the column depth in the horizontal direction, and between panel zone stiffeners in the vertical direction (refer to Figure 6.4). The boundary elements were modelled using eight elastic beam column elements, assigned with high area and moment of inertia properties to negate any bending or axial deformations. The corner joints of the rigid elements were simulated as pins by restraining translation of one node to the other, but allowing free rotation between the two nodes so that all stiffness in the panel zone was provided by the rotational spring at one corner. The panel zone material behaviour was defined using the trilinear response shown in Figure 6.6. Strength and stiffness properties of the spring were calculated based on the cross-sectional 
dimensions of the panel zone, as suggested by Gupta and Krawinkler (1999).

\subsubsection{Model Verification}

The model of the experimental setup was initially constructed using estimated material parameters, assuming an elastic perfectly-plastic steel behaviour. Once the initial model reasonably approximated the response of the experimental test, material properties were calibrated to match the test behaviour of specimen MC-1A as closely as possible. In order to compare to the test data, a displacement-based loading history was applied to the beam tip in the model. The loading protocol input to the model was the beam tip displacement data from test specimen MC-1A that was output during testing. This ensured that the model was calibrated to the test data using an identical loading protocol (since the actual magnitude of the beam tip displacement of the specimen was slightly different than the code-specified loading protocol). Figure 6.7 shows the force versus beam tip displacement response of the model. The hysteresis was stable and represents the nonlinear behaviour of a steel moment connection well.

Figures 6.8 and 6.9 show a direct comparison of the model and the MC-1A experimental response hystereses. It is shown that the initial and post-yield stiffness, Bauschinger Effect, and ultimate capacity of the model correlate well with the experimental test after calibration. During the 0.02 and $0.03 \mathrm{rad}$ cycles it appears as though the force applied to the frame was slightly underestimated. The post-yield stiffness of the steel material was set to $0.3 \%$, which seemed to be adequate, especially during the final cycles. As expected, for the calibrated model to match the overstrength of the test specimen, it was necessary to increase the yield strength of the steel material applied to the section fibres of the link to $400 \mathrm{MPa}$ (from $350 \mathrm{MPa}$ ), since the actual link was found to be significantly stronger than the design value. This is a typical characteristic of steel, but the material strength should not be increased for design since variability in overstrength can be high; the increase applied to the test model was for calibration purposes only.

Figure 6.10 shows the model frame hysteresis without the increased steel yield strength. Compared to the response of Figure 6.7, this model is closer to the design forces, which shows that this model can adequately be used to performance a structural analysis of the proposed 


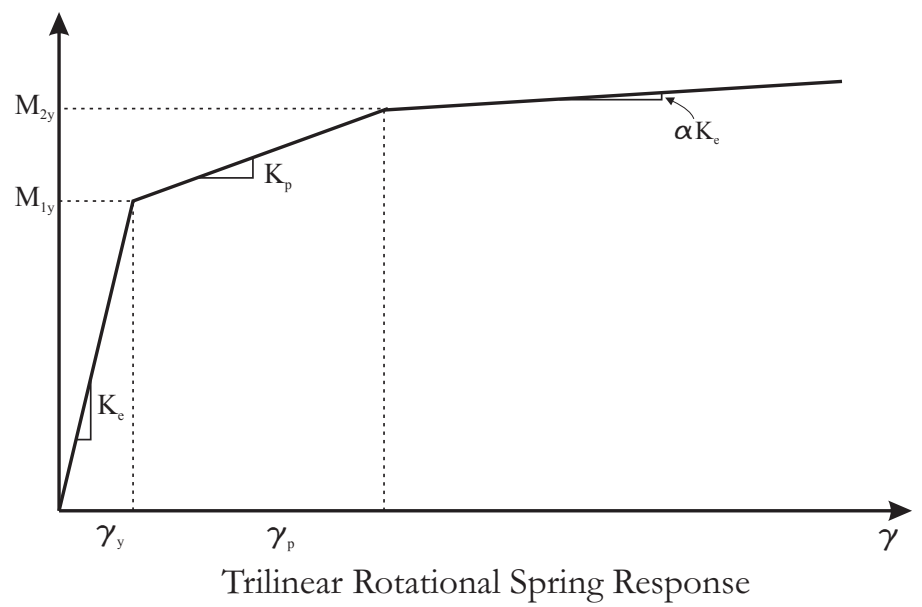

Figure 6.6: Trilinear Panel Zone Response (after Gupta and Krawinkler, 1999)

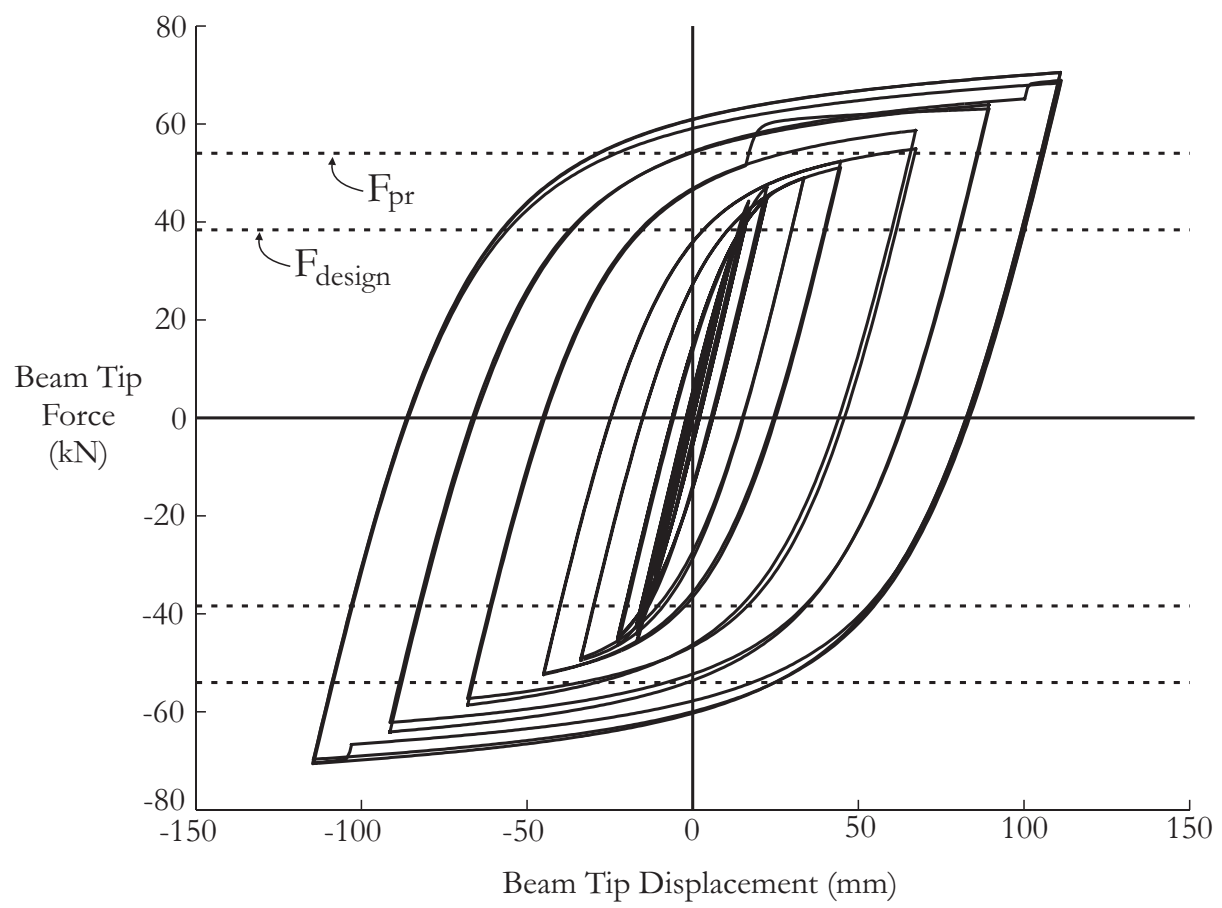

Figure 6.7: Force vs. Displacement Response of Model Frame 
connection for design. The material model for the steel link that was applied within the full building model used a yield strength of $350 \mathrm{MPa}$.

Table 6.1 shows the variables assigned to the uniaxial Giuffre-Menegotto Pinto material. Material parameters were iteratively updated to determine the combination of parameters that provided the most adequate response. The parameters controlling the material strength $\left(\mathrm{F}_{\mathrm{y}}\right)$, elastic stiffness (E), and strain hardening (b) were easily defined by initially selecting low values and iteratively increasing them (one at a time) until they matched the target response. The parameters controlling the cyclic hardening of the material (a1, a2, a3, and a4) and the shape of the Bauschinger Effect (RO, R1, and R2) were initially set to the values recommended (on the OpenSees website (McKenna et al. 2000)) for typical steel material behaviour, and increased or decreased iteratively (one at a time) until the modelling response matched that of the experimental specimen.

To verify the calibration of the model, the local performance of the dogbone portion of the link element was examined as well. The link moment versus rotation response can be seen in Figure 6.11, and is compared to the experimental link response. The experimental response shown was determined based on direct link rotation measurements. The link rotations from the model were taken as the rotation of the node at the dogbone-to-beam-side link end element. The node at the column side of the dogbone section showed negligible rotation, which indicates that nearly all connection rotation took place on the beam side of the link, adequately capturing the location of plastic hinging that was seen during testing. Overall, the link response was a good match with the test data, although the strength during some cycles was underestimated.

The contribution of each connection component (link, panel zone, and elastic components) to total storey drift was analyzed and compared to that of test specimen MC-1A to determine the effect of omitting the STS connection from the model. Figure 6.12 shows the decomposition of total drift between components, and Table 6.2 shows a comparison to the drift decomposition from test specimen MC-1A. The total link contribution was well matched to the 


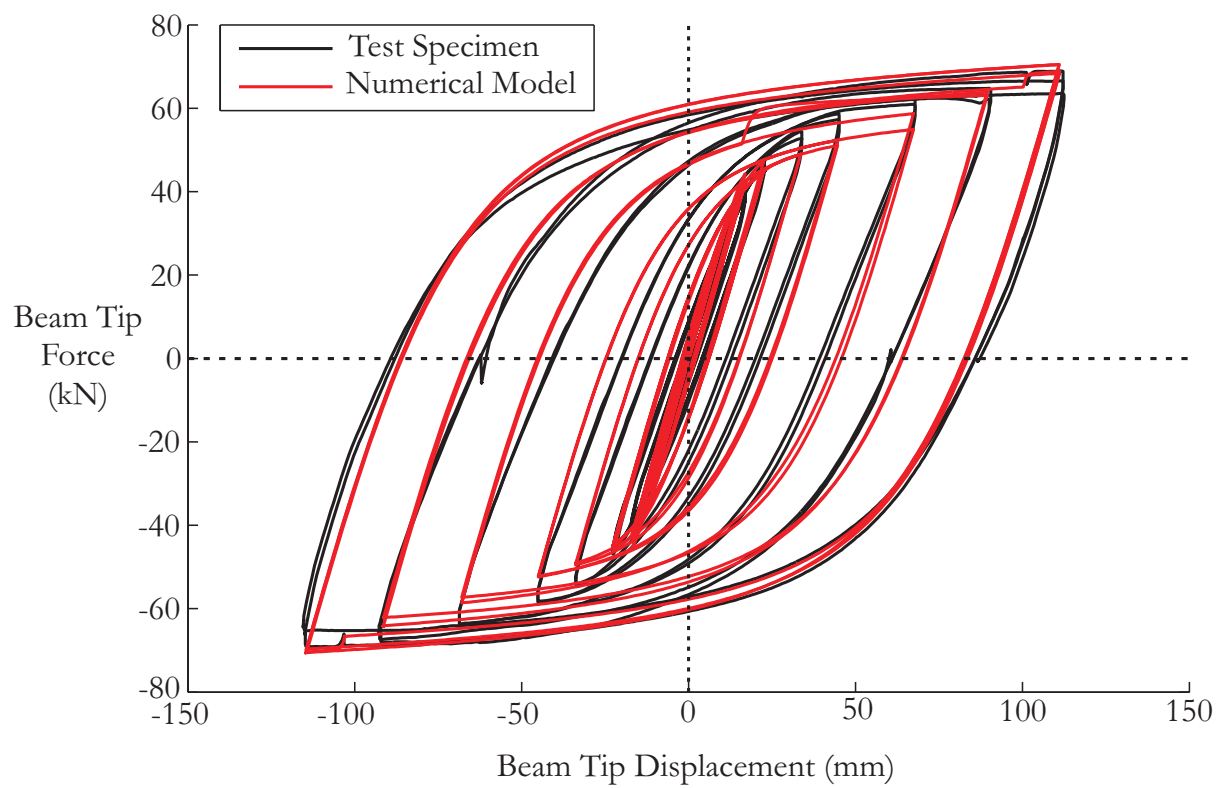

Figure 6.8: Force vs. Displacement Response Comparison

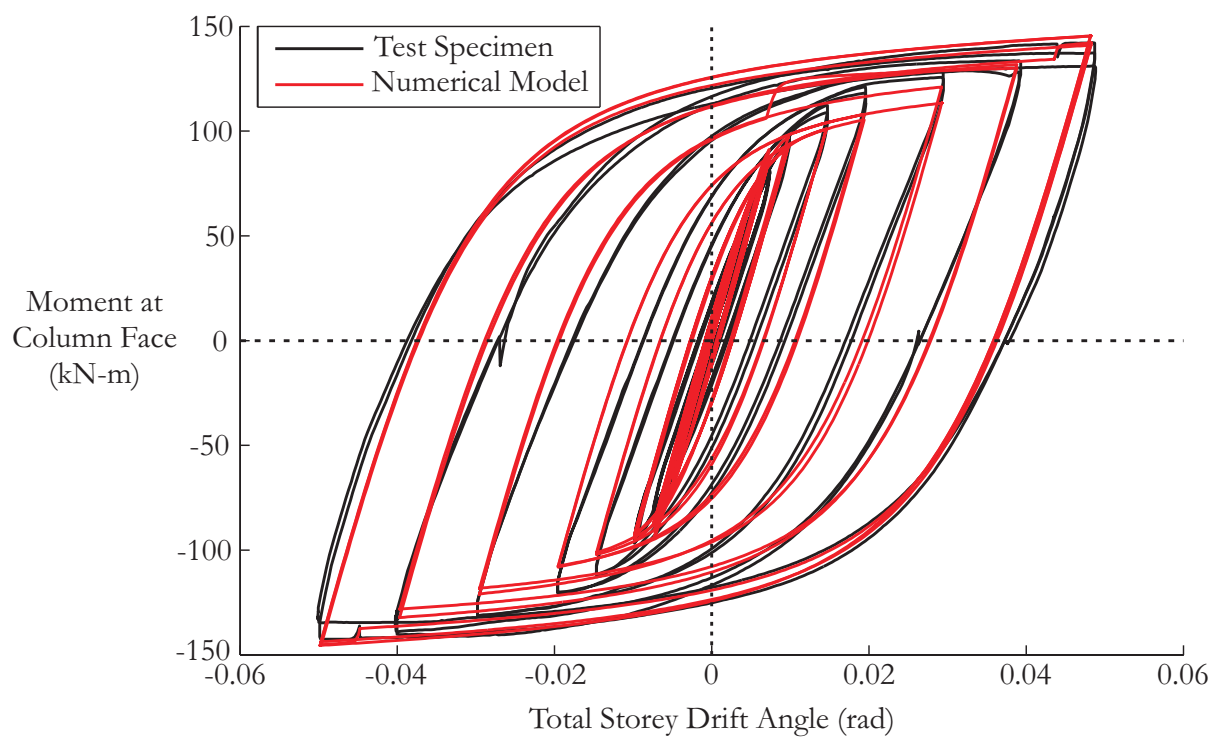

Figure 6.9: Moment vs. Rotation Response Comparison 


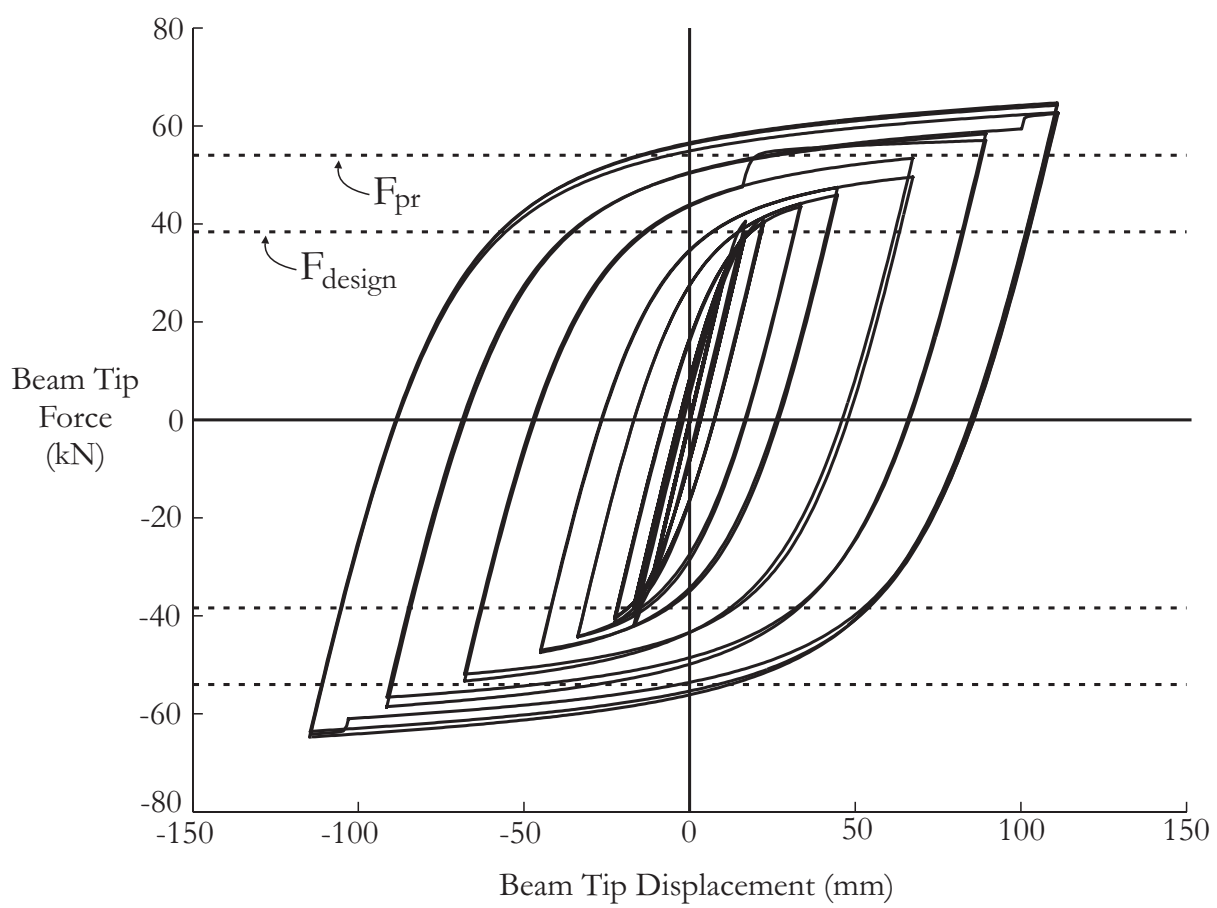

Figure 6.10: Force vs. Displacement Response with Design Link Strength

Table 6.1: Parameters for Uniaxial Giuffre-Menegotto Pinto Material

\begin{tabular}{c|c}
\hline Variable & Value \\
\hline $\mathrm{F}_{\mathrm{y}}$ & $400 \mathrm{MPa}$ \\
$\mathrm{E}$ & $200000 \mathrm{MPa}$ \\
$\mathrm{b}$ & 0.003 \\
$\mathrm{R} 0$ & 18 \\
$\mathrm{R} 1$ & 0.925 \\
$\mathrm{R} 2$ & 0.15 \\
$\mathrm{a} 1$ & 0.05 \\
$\mathrm{a} 2$ & 1.0 \\
$\mathrm{a} 3$ & 0.05 \\
$\mathrm{a} 4$ & 1.0 \\
\hline
\end{tabular}




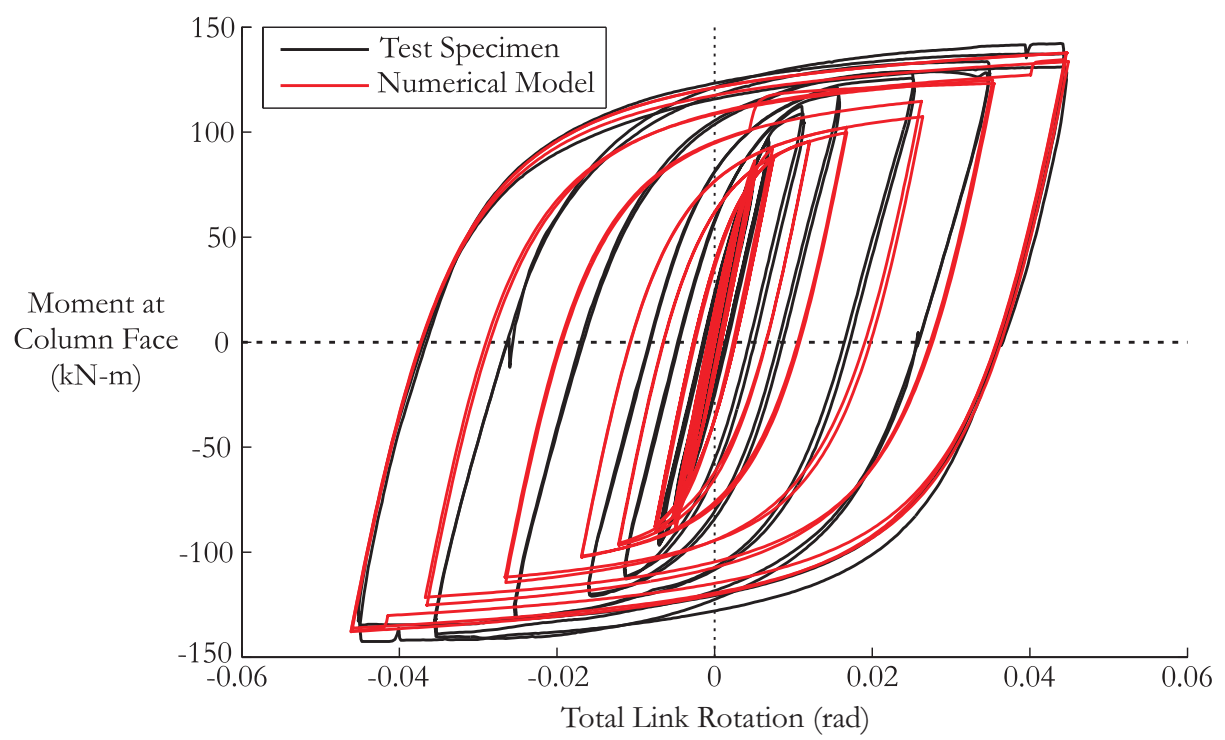

Figure 6.11: Link Response Comparison

experimental findings. It appears as though the total beam and panel zone rotations were higher for the model during the intial cycles, and balanced out during the larger cycles. Analysis of the modelling output showed that the panel zone remained entirely elastic during loading (hence the response is not shown) and the elastic stiffness was slightly less than that of the test response, which could in part account for the increased drift contribution of the panel zone in the model. This could also be amplified by the absence of the STS connection in the model, which in reality slightly lowers the stiffness at the beam-to-link joint. Overall, the modelling response is quite similar to the test response, especially during the later, more critical cycles, so modelling the STS connections is likely not worth the computational expense.

The cumulative energy dissipation of the model connection was determined and compared to that of the test specimen in Figure 6.13. As expected from examining the closely matched hysteretic responses, the cumulative energy dissipation of the model was almost identical to that of the test specimen. The largest difference was seen in the elastic cycles. While the initial cycles of the test specimen showed some energy dissipation, in the model, energy dissipation prior to $0.0075 \mathrm{rad}$ drift was nearly zero. The initial cycles on the modelled connection behaved in a nearly perfectly elastic manner. This is likely because of slight shifts in the test specimen during initial 


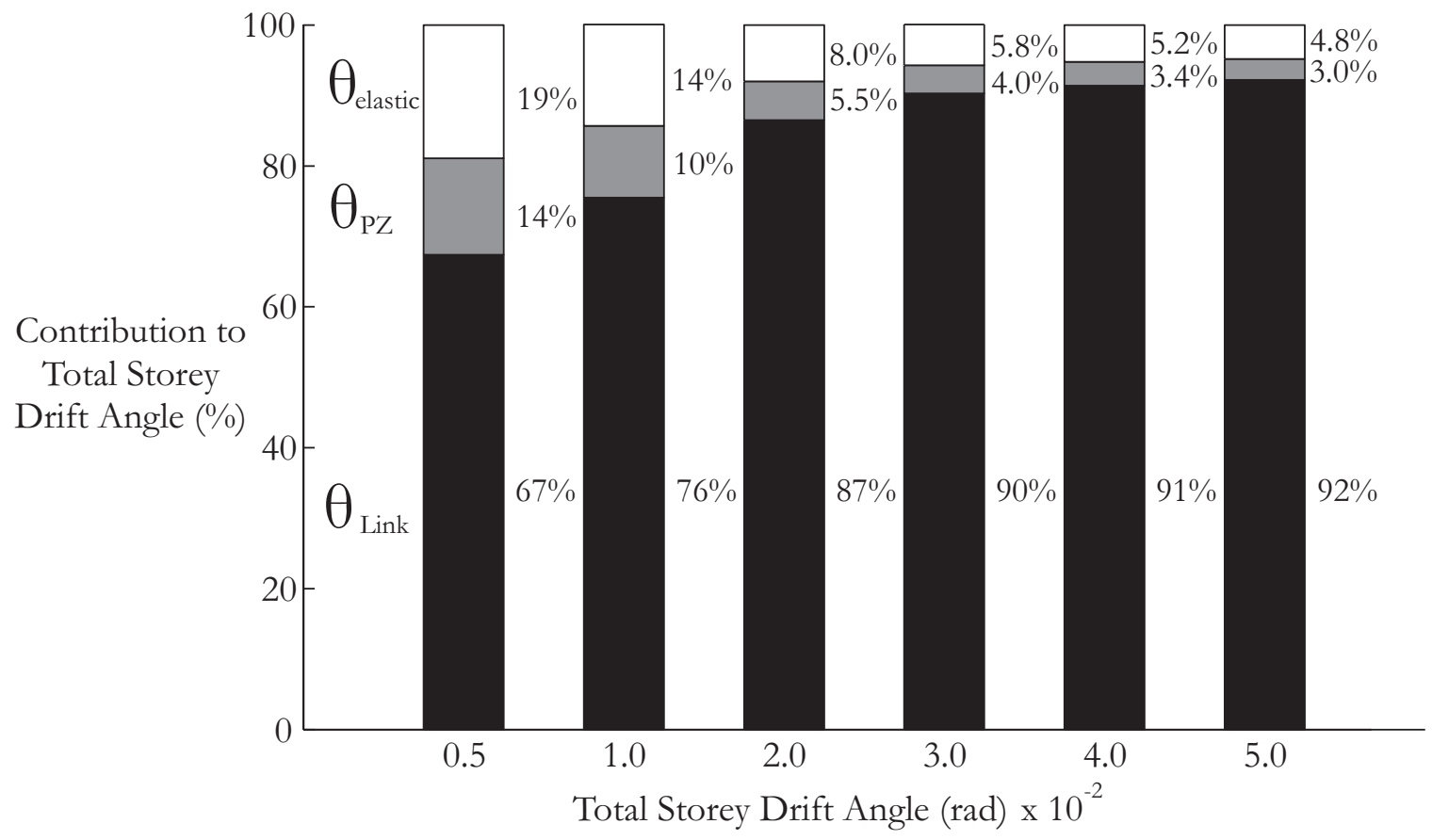

Figure 6.12: Drift Decomposition of Model

Table 6.2: Comparison of Drift Contribution Between Test and Model

\begin{tabular}{c|ccccc}
\hline Drift $(\mathrm{rad})$ & 0.005 & 0.01 & 0.02 & 0.03 & 0.04 \\
\hline Link $_{\text {test }}$ & $66 \%$ & $70 \%$ & $81 \%$ & $86 \%$ & $89 \%$ \\
Panel Zone $_{\text {test }}$ & $8.2 \%$ & $4.6 \%$ & $2.3 \%$ & $1.5 \%$ & $1.2 \%$ \\
Beam $_{\text {test }}$ & $20 \%$ & $19 \%$ & $13 \%$ & $9.6 \%$ & $7.7 \%$ \\
\hline Link $_{\text {model }}$ & $67 \%$ & $76 \%$ & $87 \%$ & $90 \%$ & $91 \%$ \\
Panel Zone $_{\text {model }}$ & $14 \%$ & $10 \%$ & $5.5 \%$ & $4.0 \%$ & $3.4 \%$ \\
Beam $_{\text {model }}$ & $19 \%$ & $14 \%$ & $8.0 \%$ & $5.8 \%$ & $5.2 \%$ \\
\hline
\end{tabular}


force application, which are not present in the model.

Overall, the model of the test frame was successfully calibrated to match the test response. Future studies could be conducted to account for STS slip and address issues related to panel zone stiffness, however these components had little effect on overall model performance, so the methods presented above were deemed adequate for modelling of the proposed connection in the context of a full building model.

\subsubsection{Full Moment-Resisting Frame Model}

After the material behaviour was adequately calibrated to match the test response, the model of the proposed connection was applied to full six-storey, seven-bay two-dimensional building models of both the proposed hybrid timber-steel MRF and an equivalent steel-only MRF. The general layout of the model elements and methods is shown in Figure 6.14, and was identical for both the hybrid and steel-only frames.

Nonlinear dynamic time-history analysis was conducted on each frame to compare their seismic performance when subjected to multiple earthquake records at both the MCE and DBE hazard levels. The modelling methods used for the experimental setup explained above were applied to the full frame, and the element configuration of each joint was nearly identical. The exception being that for the steel-only frame, the elastic beam column element used to model the beam side link end (gross section) was removed, since the beam and link were continuous for this building. This also meant that the column side link end (gross section) had the same crosssection as the steel beam element. Furthermore, the beam and column main members were given steel material properties based on the w-section cross-sections designed using response spectrum analysis (see Appendix B), but still modelled using elastic beam column elements. For both models, although the experimental tests showed that the yield strength of the link element was approximately $400 \mathrm{MPa}$, for modelling and design purposes, this parameter was set to the design value of $350 \mathrm{MPa}$. All columns were assigned p-delta geometric transformations to account for the p-delta effects caused by large lateral displacements.

Ryan Gohlich, Department of Civil and Environmental Engineering, Carleton University 


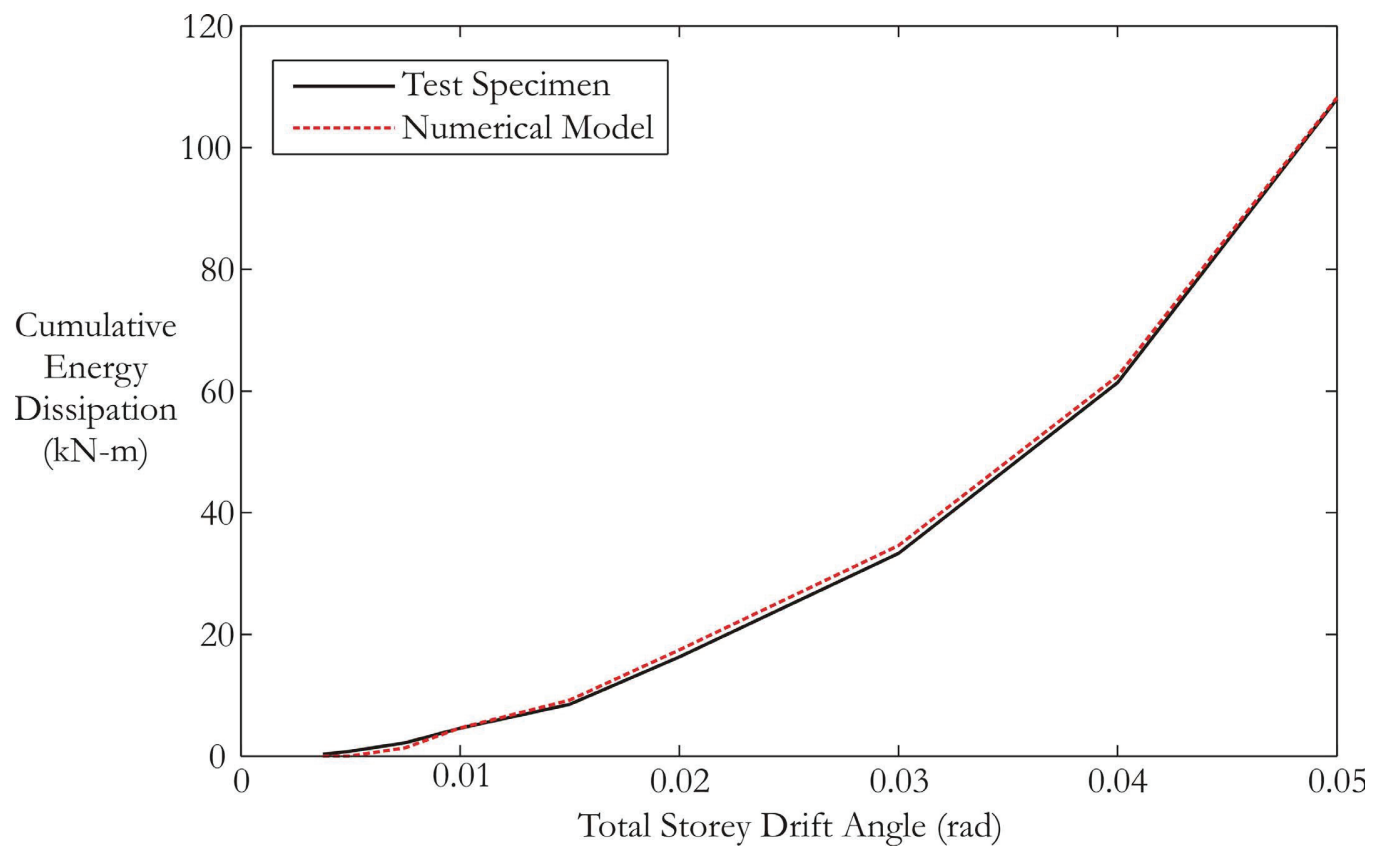

Figure 6.13: Cumulative Energy Dissipation of Model

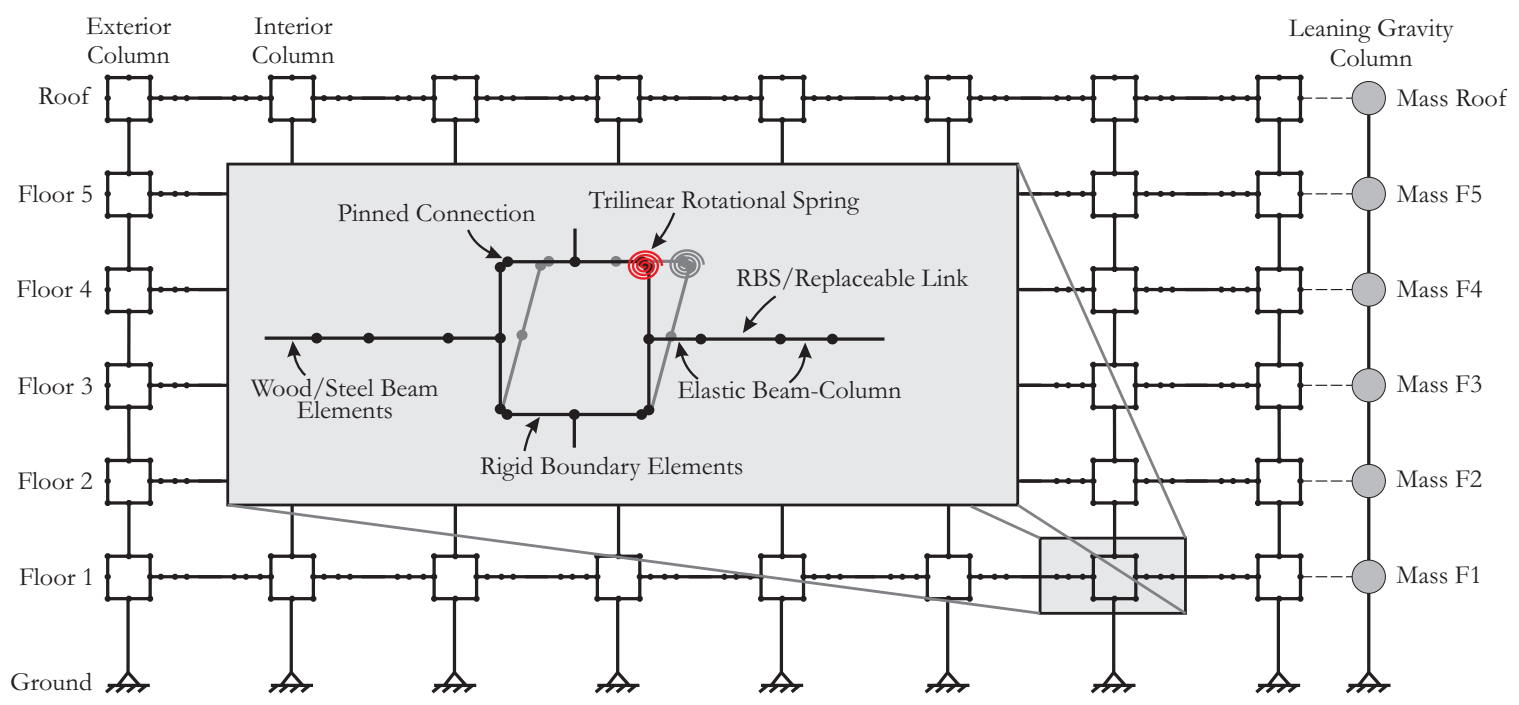

Figure 6.14: Full Building Model Components 
Expanding the model of the experimental setup to represent the entire building frame required the addition of several dynamic analysis parameters, members, and restraints. The leaning gravity column shown in Figure 6.14 was assigned lumped masses equivalent the the mass of half of the adjacent storey. When dynamic ground motions were applied, this allowed the model to account for inertial loads and p-delta effects. The leaning columns were modelled using stiff elastic beam column elements with p-delta geometric transformations and pinned connections between floors so that they did not add lateral stiffness to the building.

The CLT floor slab (hybrid building) and the concrete composite floor slab (steel-only building) were both modelled as a rigid diaphragm by restraining the lateral displacements of all nodes of a single storey to the corresponding node on the leaning column. Due to the high in-plane stiffness of CLT, a study by Ashtari et al. (2012) showed that these systems are capable of behaving as rigid diaphragms. The study also showed that behaviour is also dependent on the flexibility of the vertical lateral load resisting system; CLT panels connected to more flexible systems tend to transfer loads as a rigid diaphragm (Ashtari et al., 2012). Since MRF systems tend to be quite flexible compared to shear walls, it is likely that the load transferred between the CLT slab and the MRFs is based on the relative stiffness of the MRFs adjacent to the slab (as for rigid diaphragms) rather than based on tributary area (as for flexible diapgragms).

The gravity loads directly tributary to the MRF were lumped at each adjacent column location, while the remaining gravity loads present on the gravity frame (for one half of the building) were lumped at the leaning column node of the relevant storey.

\subsection{Dynamic Time-History Analysis}

Dynamic time-history analysis of each structural model was conducted by applying each of the 44 far-field (greater than 10 kilometers away from the epicentre) earthquake records from the FEMA P695 (Federal Emergency Management Agency, 2009) record set as an acceleration timehistory to the base of the model. The FEMA P695 (Federal Emergency Management Agency, 2009) record set includes 22 earthquake records, providing acceleration in two perpendicular directions for each earthquake, giving a total of 44 earthquake acceleration time-histories. Table 
6.3 shows the location and peak ground acceleration (PGA) of each earthquake record to gain an understanding of the relative magnitude of each applied ground motion (FEMA P695, 2009). The PGA values denoted in Table 6.3 are the unscaled normalized magnitudes, which were later scaled to match the buildings design location.

Each earthquake record was scaled using the ATC scaling method presented by Michaud and Leger (2014). The obtained records were previously normalized based on the median peak ground velocity (PGV) by scaling the record such that the PGV was equal to the average PGV of the whole record set. This eliminated any effects of magnitude, distance, and site specific characteristics (Michaud and Leger, 2014). The magnitude of each ground motion in the record set was then scaled to match the NBCC (2010) design spectrum for Victoria, British Columbia (see Appendix B). To do this, a single scaling factor was determined for each building that matched the median spectral acceleration of the record set $\left(S a_{\text {setmedian }}\left(T_{1}\right)\right)$ at the buildings first mode fundamental period of vibration with the spectral acceleration of the design spectrum $\left(\operatorname{Sa}_{\operatorname{design}}\left(T_{1}\right)\right)$ at the buildings first mode period. This calculation is shown in equation (6.1) (Michaud and Leger, 2014).

$$
F A=\frac{S a_{\text {set,median }}\left(T_{1}\right)}{S a_{\text {design }}\left(T_{1}\right)}
$$

Because the period for each building type was different, separate scaling factors were applied to the record set subjected to each building. These scaled record sets represent the maximum credible earthquake (MCE) hazard level earthquake. In order to examine the response of each building under the design basis earthquake (DBE) level ground motions, the records sets were each further scaled by a factor of $2 / 3$; thus each building type was subjected to two separate ground motion record sets. These scaling factors are presented in Table 6.4.

Rayleigh Damping of 3\% in modes 1 and 6 was applied, which is typical for the modelling of steel-only structures, and conservative for wood (Welch et al., 2014). Table 6.5 shows design period used for response spectrum analysis (as discussed in Appendix B) as well as the period of the first mode of vibration output from both the ETABS linear structural model and the 
Table 6.3: Earthquake Locations and PGAs (After FEMA P695, 2009)

\begin{tabular}{|c|c|c|c|}
\hline EQ ID & Station & Location & PGA $(\mathrm{g})$ \\
\hline 1 & Northridge 1994 & Beverly Hills & 0.34 \\
\hline 2 & Northridge 1994 & Canyon Country & 0.40 \\
\hline 3 & Duzce 1999 & Bolu & 0.52 \\
\hline 4 & Hector Mine 1999 & Hector & 0.37 \\
\hline 5 & Imperial Valley 1979 & Delta & 0.46 \\
\hline 6 & Imperial Valley 1979 & El Centro & 0.39 \\
\hline 7 & Kobe 1995 & Nishi-Akashi & 0.53 \\
\hline 8 & Kobe 1995 & Shin-Osaka & 0.26 \\
\hline 9 & Kocaeli 1999 & Duzce & 0.25 \\
\hline 10 & Kocaeli 1999 & Arcelik & 0.30 \\
\hline 11 & Landers 1992 & Yermo & 0.24 \\
\hline 12 & Landers 1992 & Coolwater & 0.48 \\
\hline 13 & Loma Prieta 1989 & Capitola & 0.58 \\
\hline 14 & Loma Prieta 1989 & Gilroy & 0.49 \\
\hline 15 & Manjil 1990 & Abbar & 0.40 \\
\hline 16 & Superstition Hills 1987 & El Centro & 0.31 \\
\hline 17 & Superstition Hills 1987 & Poe Road & 0.53 \\
\hline 18 & Cape Mendocino 1992 & Rio Dell & 0.45 \\
\hline 19 & Chi-Chi 1999 & CHY101 & 0.18 \\
\hline 20 & Chi-Chi 1999 & TCU045 & 0.49 \\
\hline 21 & San Fernando 1971 & LA-Hollywood & 0.44 \\
\hline 22 & Friuli 1976 & Tolmezzo & 0.50 \\
\hline
\end{tabular}

Table 6.4: Earthquake Scaling Factors

\begin{tabular}{c|c}
\hline Record Set & Scaling Factor \\
\hline Wood Building MCE & 1.464 \\
Wood Building DBE & 0.976 \\
Steel Building MCE & 1.411 \\
Steel Building DBE & 0.941 \\
\hline
\end{tabular}


OpenSees nonlinear numerical study. The periods output by the linear and nonlinear models were a close match, which helps to verify the accuracy of the OpenSees model. The full period of the frames in the numerical model were used to determine the seismic loads imparted on the frame. No maximum limit is applied to the period when a dynamic time-history analysis is performed. For design of the structure, the code-based limitations on the building period, especially for wood buildings, lead to higher design forces when relying on the equivalent static method of seismic analysis. The numerical study shows that the period of the buildings is much higher than specified by the empirical equation in the NBCC (2010). By taking advantage of the higher true building periods, response spectrum analysis or nonlinear dynamic time-history analysis can be used to reduce imparted base shears and seismic design forces on the frame. It should also be noted that although the seismic weight of the hybrid building is considerably lower than that of the steel-only building (which increases the period), the lower relative stiffness of the timber members results in comparable periods for both buildings.

\subsection{Results}

The nonlinear dynamic time-history analysis results were analyzed to compare the seismic performance of the two frame types at both the component level, and the global level. This analysis provides insight into the feasibility of incorporating the proposed connection into full mid-rise hybrid structures, and allows further design suggestions to be developed.

Table 6.5: Design and Model Building Periods

\begin{tabular}{c|ccc}
\hline Building & $\begin{array}{c}\text { Design Period } \\
\mathrm{T}(\mathrm{sec})\end{array}$ & $\begin{array}{c}\text { ETABS Period } \\
\mathrm{T}_{1}(\mathrm{sec})\end{array}$ & $\begin{array}{c}\text { Model Period } \\
\mathrm{T}_{1}(\mathrm{sec})\end{array}$ \\
\hline Wood Building & 0.90 & 2.691 & 2.63 \\
Steel Building & 1.30 & 2.423 & 2.51 \\
\hline
\end{tabular}




\subsubsection{Member Performance}

Since the main beam and column members were capacity-designed to remain elastic and modelled as elastic beam column elements, it was necessary to check the maximum shear force and moment in each member, and compare it to the design resistance to ensure that each member remained elastic under the average response of all ground motions. To accomplish this, the maximum shear force and moment in each member was determined for each ground motion. The average and mean plus one standard deviation of the force from all ground motions was then calculated. The average force in each member from all earthquakes was taken as the baseline for design, however the mean plus one standard deviation force was also calculated to better estimate the variation in response from the applied earthquake record set. All beam and column members remained entirely elastic under the average loads at the MCE level. Most lower storey elements were considerably overdesigned for strength, which was expected since they were designed to accommodate drift. All beam elements and most column elements remained elastic under the mean plus one standard deviation response as well. The moment applied to some interior column sections on the upper floors of the hybrid building exceeded the factored moment capacity of the member under the mean plus one standard deviation loads at the MCE hazard level. These sections were designed using the capacity-design procedure outlined in Appendix B, which distributes the moment at the column centre (due to plastic hinging of the link) between storeys based on relative upper and lower column stiffness. In the future, more attention should be given to the capacity-design procedure in these locations, and section sizes could be increased slightly to avoid failure under mean plus one standard deviation loading.

Figure 6.15 shows a comparison of the hysteretic response of the hybrid and steel-only dogbone link elements. The sample link shown is from a fifth storey interior joint when subjected to the 1994 Northridge earthquake. The general behaviour of each element was the same since both buildings were modelled with identical methods, and material properties defining the nonlinear behaviour of the link steel were the same. The elastic stiffness of the hybrid link was slightly less than the steel-only link, which is to be expected since the steel w-section was considerably lighter, but the peak and residual drift of each link was similar, which suggests that the overall 
performance of the link is similar. The peak and residual drift experienced by the link in the hybrid frame were $0.0128 \mathrm{rad}$ and $0.00725 \mathrm{rad}$ respectively, and the peak and residual drift experienced by the link in the steel-only frame were $0.0132 \mathrm{rad}$ and $0.00654 \mathrm{rad}$ respectively. Figure 6.15 shows that the force demand on the hybrid connection link is nearly $50 \%$ lower than the strength demand on the steel-only connection link. This is a direct result of the lower seismic forces imparted on the frame due to the reduced weight of the hybrid building. This shows that the nonlinear performance of hybrid joints can be comparable to equivalent steel-only joints if the wood-to-steel connection is adequately designed and detailed.

The panel zones were all explicitly modelled using the methods previously discussed. Analyzing the shear force versus shear deformation response of each panel zone when subjected to sample ground motions showed that all panel zones in both the hybrid and steel-only buildings remained elastic, verifying the design procedure for panel zone shear strength from Limit States Design of Steel Structures (CSA S16-09, 2010). The incorporation of the panel zone models greatly increased model run times.

The STS connections were not modelled in this study. Since the experimental program showed that the STS connections had little contribution to connection rotation, and no plastic behaviour, including STS behaviour would likely have little effect on overall frame performance, yet would be very computationally expensive. The performance of the test speciment also showed that the STS connections exhibited fairly stable hysteretic behaviour, so if needed, future studies could incorporate additional rotational strings at the beam collar-to-wood beam joint and each panel zone-to-wood column joint, calibrated to match the STS rotation response from the test in order to capture the slight contribution to total storey drift provided by the STS connections.

\subsubsection{Frame Performance}

The global response of each frame was analyzed and compared in terms of the base shear and foundation forces, peak and residual interstorey drift, and storey accelerations. Each response presents two sets of data; the mean response of all 44 earthquakes in the record set, and the 


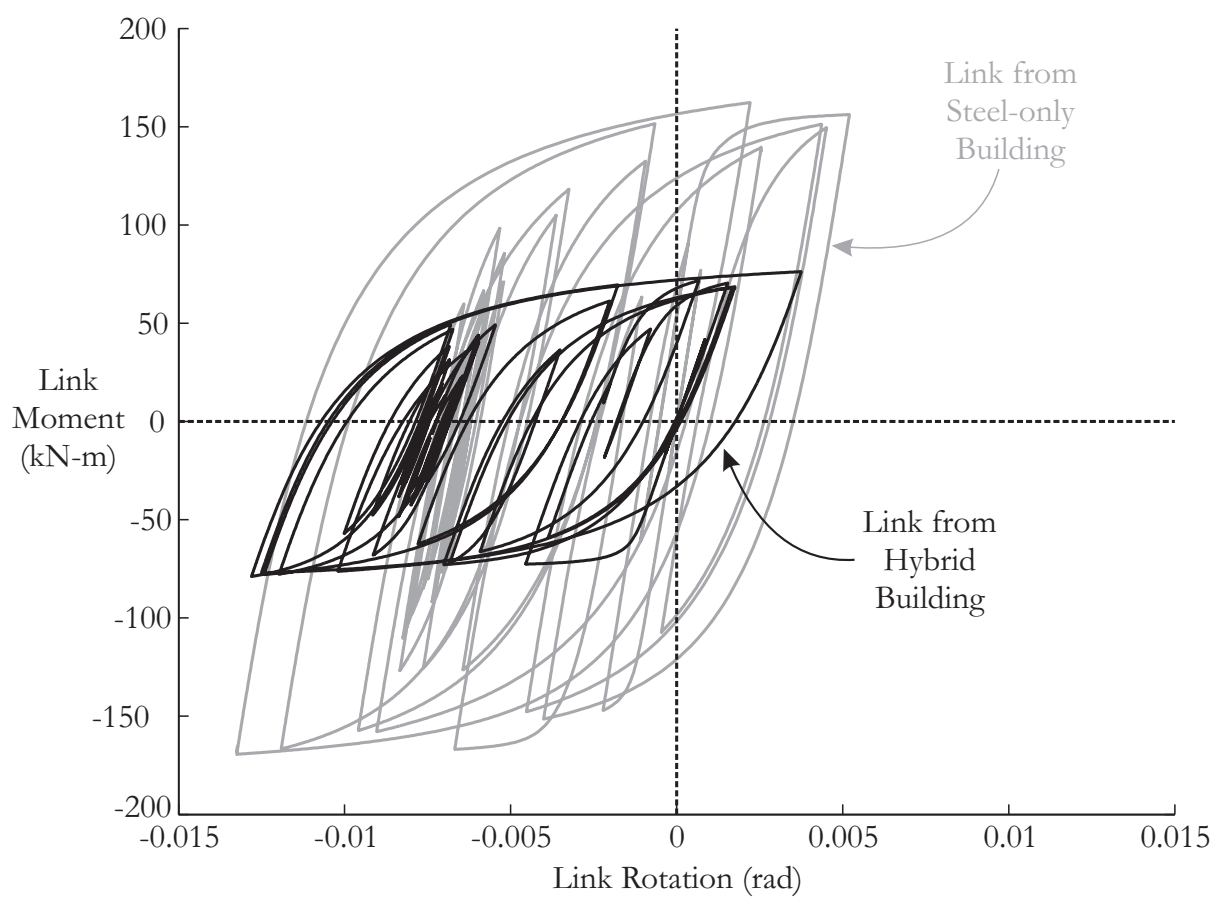

Figure 6.15: Link Behaviour Comparison for Fifth Storey Interior Joint Northridge Record Beverly Hills Station

mean plus one standard deviation response of all 44 earthquakes in the record set. The mean response at the MCE hazard level has been taken as the baseline of comparison to determine if the buildings show adequate seismic performance. Data has been presented for both MCE and DBE level ground motions. The NEHRP Recommended Provisions for Seismic Regulations for New Buildings and Other Structures (FEMA 450, 2003) requires that member forces and drift responses be taken as the maximum response of all earthquakes when the building is subjected to fewer than seven ground motions, or the average response of all earthquakes when the building is subjected to seven or more ground motions. The mean plus one standard deviation response is included to gain an understanding of the overall spread of the data, but is not required for design. The NBCC (2010) requires only three ground motions for design using nonlinear time-history analysis, but recommends at least seven. 


\subsubsection{Base Shear and Foundation Forces}

Table 6.6 gives the seismic weight of each building and the associated base shear at the MCE and DBE hazard levels. The seismic weight of the hybrid structure was approximately $60 \%$ of the seismic weight of the steel-only building because of the incorporation of the light CLT floor slab system. This significantly lowered the lateral forces imparted on the frame, resulting in a reduction in base shear of $48 \%$ relative to the steel-only frame. This has considerable implications from a design perspective, since the strength demand on individual connection components is much less, hence member sizes are smaller. This could potentially offset the higher cost of timber and the STS connections and make the overal construction cost of the hybrid frame more comparable to the steel-only alternative.

This reduction in lateral load comes with an inherent reduction in vertical foundation force, since the axial load in each column would be much lower than in the equivalent steel-only frame. Figure 6.16 shows the vertical forces applied to the foundations based on the axial load in the first floor columns for each building at the MCE and DBE hazard levels. This shows that the vertical foundation forces of the hybrid frame are 30 to $40 \%$ lower than that of the steel-only frame. This directly effects the foundation design and can further increase the feasibility of the hybrid systems.

\subsubsection{Interstorey and Residual Drift}

Figure 6.17 shows the peak interstorey drift of each building at each hazard level under both the mean and mean plus one standard deviation response. Since the design of the MRF was based primarily on interstorey drift, the peak and residual drift performance of the frames is

Table 6.6: Seismic Weight and Base Shear

\begin{tabular}{c|ccc}
\hline Building Type & $\begin{array}{c}\text { Seismic Weight } \\
\mathrm{W}(\mathrm{kN})\end{array}$ & $\begin{array}{c}\text { Mean Base Shear } \\
\mathrm{V}_{\mathrm{b}, \mathrm{MCE}}(\mathrm{kN})\end{array}$ & $\begin{array}{c}\text { Mean Base Shear } \\
\mathrm{V}_{\mathrm{b}, \text { DBE }}(\mathrm{kN})\end{array}$ \\
\hline Wood Building & 18700 & 910 & 770 \\
Steel Building & 31100 & 1740 & 1510 \\
\hline
\end{tabular}

Ryan Gohlich, Department of Civil and Environmental Engineering, Carleton University 


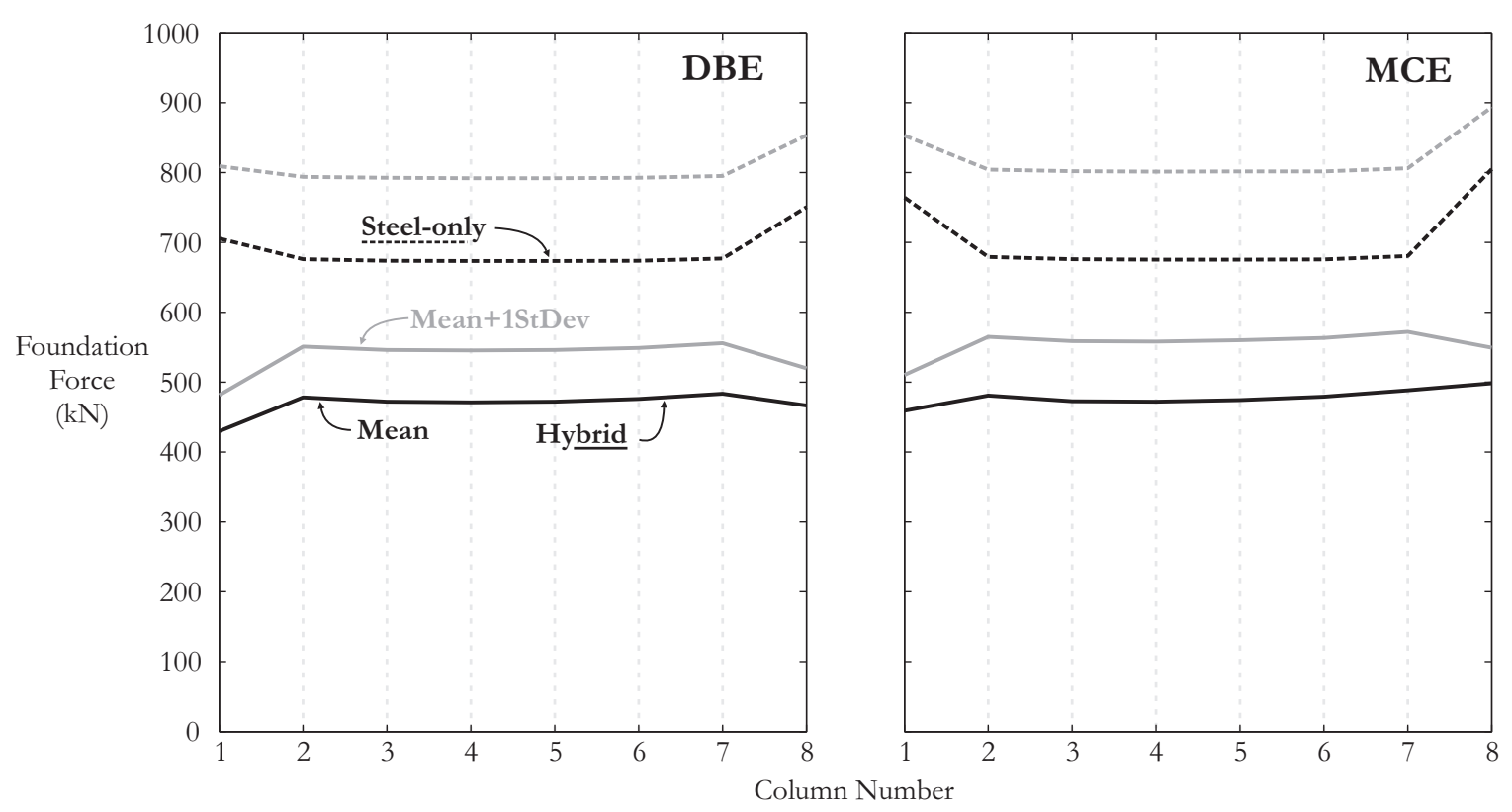

Figure 6.16: Peak Foundation Forces for Hybrid and Steel-only Buildings

imperative in determining whether or not use of these hybrid systems is feasible. All average peak interstorey drift levels remained below the NBCC specified drift limit of $2.5 \%$ of storey height for both frames at the MCE hazard level. The drift limit of $2.5 \%$ is based on the mean drift response at the MCE level, which is appropriate since the data was analyzed as the mean response from all 44 ground motions (FEMA 450, 2003). The drift levels present in the hybrid frame correspond well with the drift levels seen in the linear structural model. The overall performance of the hybrid and steel-only frames were comparable at the mean level, albeit higher drifts were present in the hybrid system at the MCE mean plus one standard deviation level. The maximum of the peak mean interstorey drifts at the MCE hazard level was $2.49 \%$ and $2.42 \%$ for the hybrid and steel-only frames respectively. The mean plus one standard deviation interstorey drift of the lower storeys of the hybrid frame at the MCE hazard level were quite high, indicating that some ground motions resulted in peak interstorey drifts that exceeded the NBCC (2010) limitations. The first storey of the hybrid frame exhibited a peak interstorey drift at the mean plus one standard deviation level of $4.73 \%$. By examining the effects of each individual earthquake on the peak drift of the lowest storey it was observed that some of earthquakes caused peak drifts with a magnitude significantly higher than average, which likely skewed the data and caused a large 
variation in mean plus one standard deviation response. Five out of fourty-four earthquakes resulted in a peak interstorey drift level that exceeded 5\%. When these five ground motions were excluded from the data set, the mean and mean plus one standard deviation peak interstorey drifts at the first floor were reduced to $2.07 \%$ and $3.58 \%$ respectively. The DBE level responses were much more closely grouped, and the mean and mean plus one standard deviation peak drift of both building types remained below the NBCC (2010) drift limits. The maximum of the mean peak interstorey drifts at the DBE hazard level were $1.77 \%$ and $1.72 \%$ for the hybrid and steel-only frames respectively. Overall, the drifts were fairly consistent at each storey; the steel building tended to exhibit slightly higher drifts at the lower storeys.

Figure 6.18 shows the peak residual drift of each building at each hazard level under both the mean and mean plus one standard deviation response. The same general trend was seen in the mean and mean plus one standard deviation peak residual drift performance of each frame. Although the NBCC (2010) does not limit the allowable residual drift, this data is important for assessing the post-disaster performance of the structures. A study by McCormick et al. (2008) on the serviceability of structures subject to large residual drifts showed that residual drift exceeding $0.5 \%$ was noticeable by occupants and residual drift of one percent can cause occupants to become ill. The mean residual drift at the MCE hazard level was found to be above this suggested limit for the hybrid frame, but the residual drift of the steel-only frame was nearly kept within these limits. The maximum of the peak mean residual drifts at the MCE hazard level was $1.31 \%$ and $0.59 \%$ for the hybrid and steel-only frames respectively. Residual drifts of the hybrid frame were significantly higher at the lower storeys than the upper storeys, while residual drifts of the steel-only frame were approximately uniform. The peak residual drift of the lower storeys of the hybrid frame under the mean plus one standard deviation level were significantly higher than mean response (3.65\% at the first storey). Five of the fourty-four ground motions resulted in residual drifts that exceeded $5 \%$ for the hybrid frame. When these ground motions were excluded from the data set, the mean and mean plus one standard deviation residual drift was reduced to $0.563 \%$ and $1.54 \%$ respectively. Mean and mean plus one standard deviation peak residual drifts were much more controlled at the DBE hazard level. The maximum of the DBE mean peak 


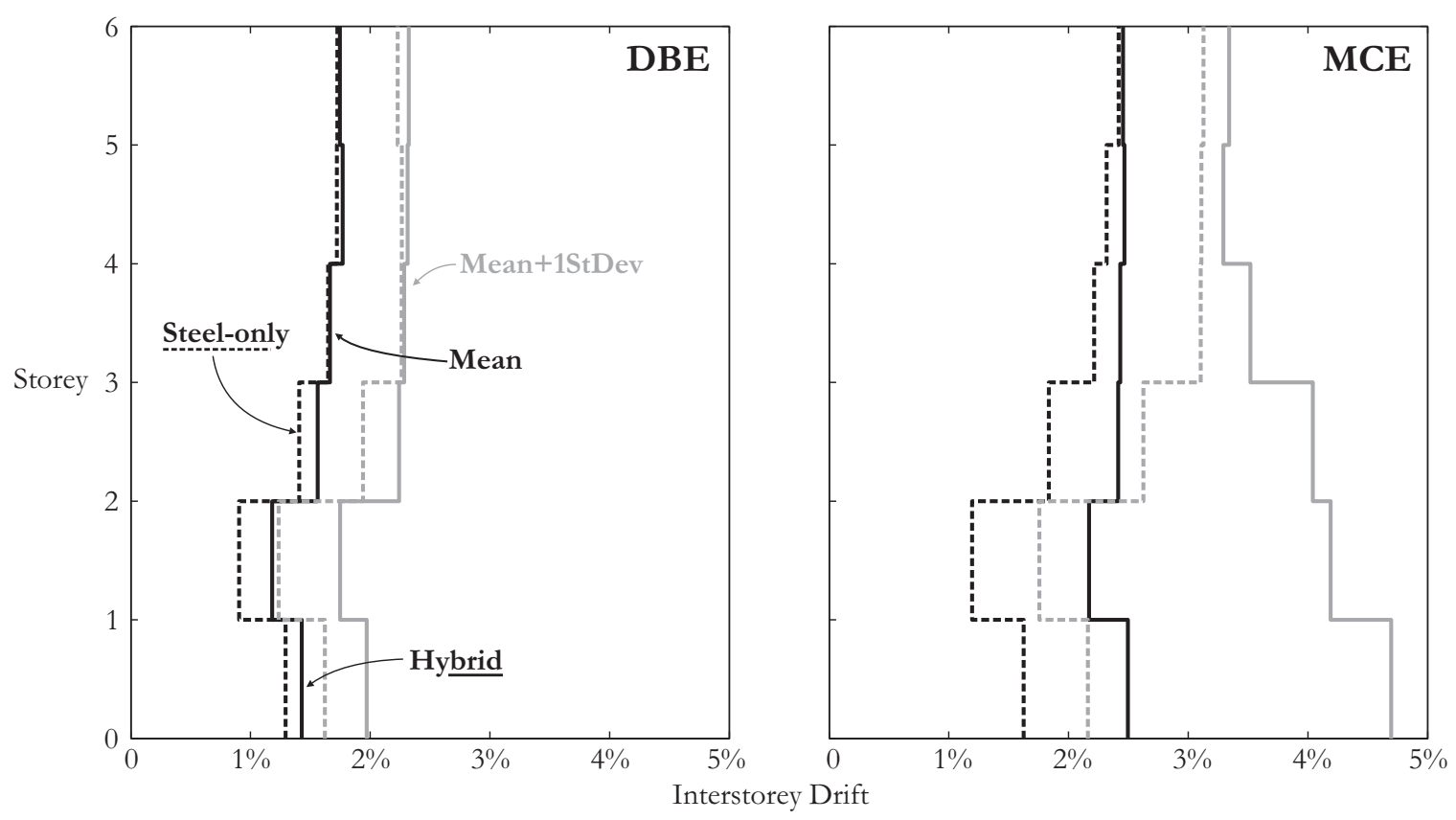

Figure 6.17: Peak Interstorey Drifts for Hybrid and Steel-only Buildings

residual drift was $0.47 \%$ and $0.35 \%$ for the hybrid and steel-only frames respectively; both below the suggested $0.5 \%$ limit, and residual drifts for both frames were approximately uniform for each storey.

\subsubsection{Storey Acceleration}

Figure 6.19 shows the peak storey acceleration for each frame at the MCE and DBE hazard levels. The trend in the response at each hazard level was similar, and there was little variation between storey accelerations of the hybrid and steel-only fames. The accelerations were well controlled, with little variation in acceleration between adjacent storeys. All MCE level storey accelerations were lower than the corresponding scaled PGA. Because the ground motion record set applied to each building was scaled based on the period of that building, the PGA of each building was slightly different. The maximum of the peak mean storey acceleration at the MCE hazard level was 0.398g (for a PGA of 0.492g) and 0.446g (for a PGA of 0.474g) for the hybrid and steel-only frames respectively. The maximum of the peak mean storey acceleration at the DBE hazard level was $0.335 \mathrm{~g}$ (for a PGA of $0.328 \mathrm{~g}$ ) and $0.365 \mathrm{~g}$ (for a PGA of $0.316 \mathrm{~g}$ ) for the hybrid and 


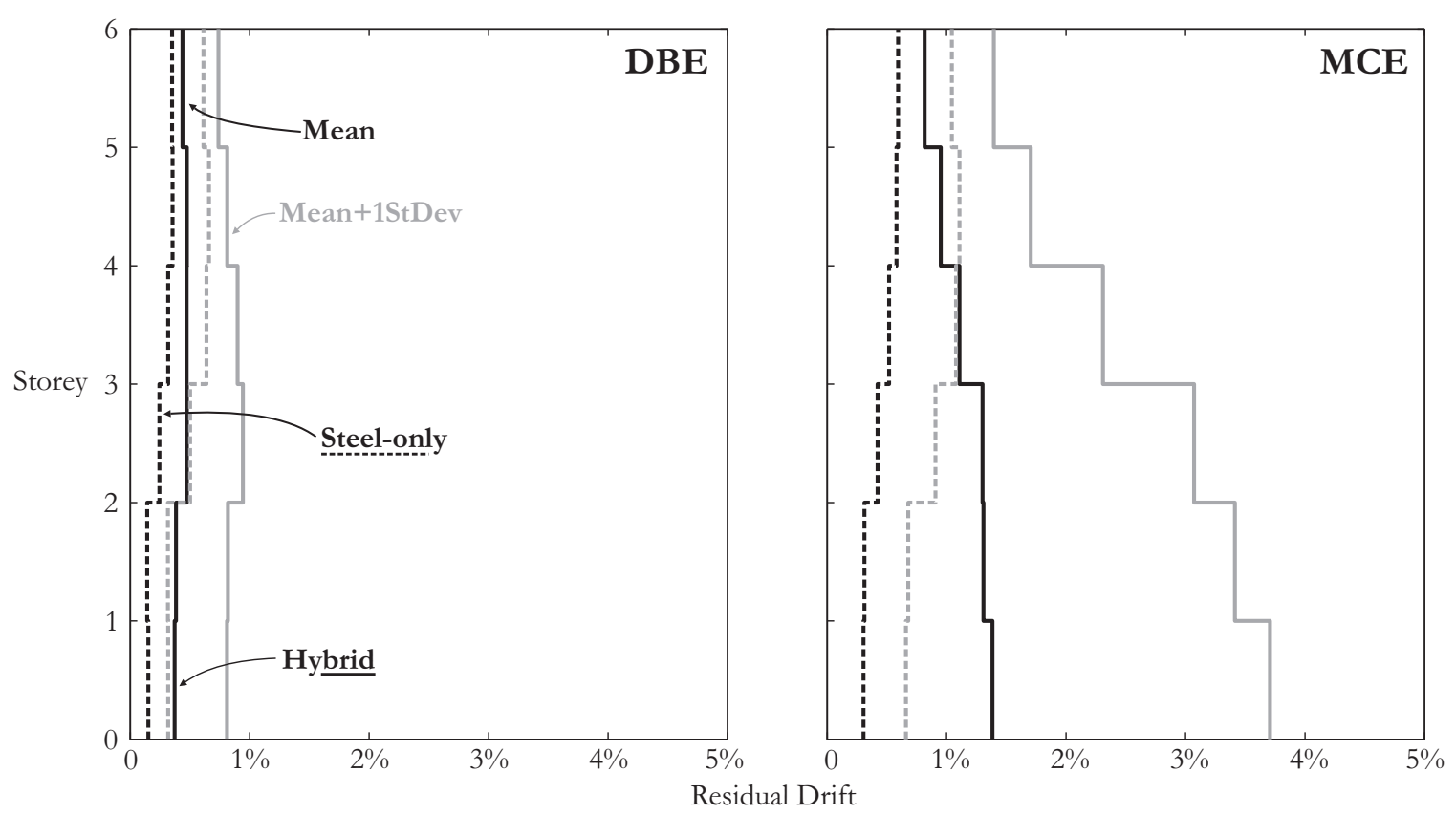

Figure 6.18: Peak Residual Drifts for Hybrid and Steel-only Buildings

steel-only frames respectively. The mean plus one standard deviation acceleration of both frame types remained below $0.6 \mathrm{~g}$ and $0.5 \mathrm{~g}$ at the MCE and DBE hazard levels respectively. Given the lower storey accelerations experienced by these frames, it is unlikely that any significant physical danger due to acceleration would be posed to building occupants during an MCE level ground motion, although some discomfort may occur.

\subsubsection{Simplified Model}

It is possible to adequately capture the performance of these frames using simplified methods that could be more easily modelled and decrease program run times. Similar models to the ones previously presented were constructed using identical main members and panel zones, however a simple elastic perfectly-plastic steel material parameter was specified for the dogbone element, which ignored the Bauschinger Effect and cyclic hardening. The Bauschinger Effect was somewhat captured because the material was analyzed over 5 integration points along the length of the link element, however the absence of the cyclic hardening parameters lowered the overall full plastic strength of the connection. Figure 6.20 shows a comparison between the simplified 


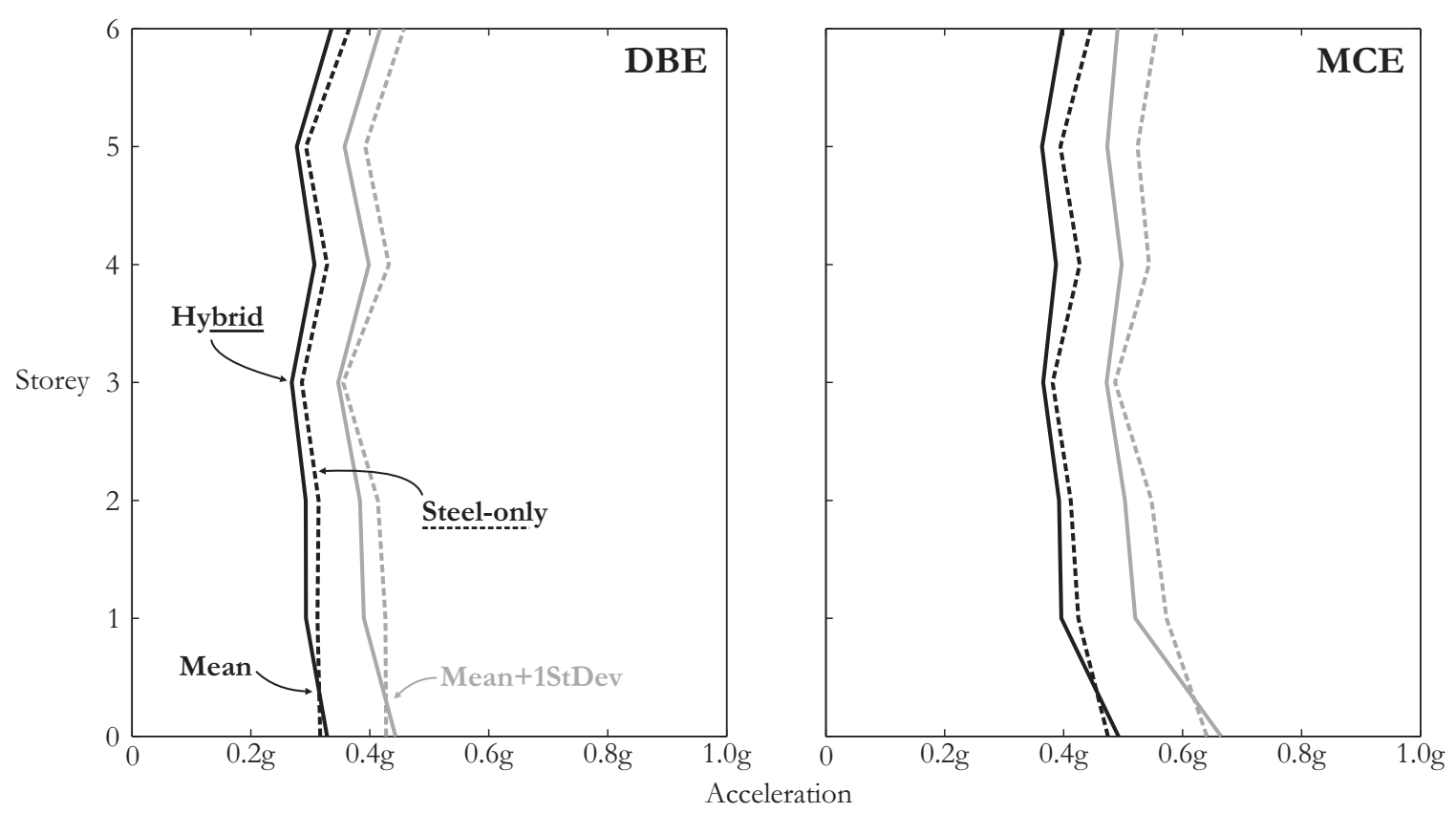

Figure 6.19: Peak Storey Accelerations for Hybrid and Steel-only Buildings

model connection response and the experimental response. It should be noted that for calibration to the experimental test response, in the absence of cyclic hardening, the yield strength of the link material was increased to better match the full connection strength; however, this was not incorporated in the full frame model. This shows the potential for the simplified model to match the overall ductility, energy dissipation, and rotation capacity of the experimental test specimen with reasonable accuracy.

Figure 6.21 shows the mean peak interstorey drift, residual drift, and storey acceleration responses at the MCE hazard level for the hybrid and steel-only buildings when modelled using the simplified elastic perfectly-plastic steel material. All responses were nearly identical to that of the previously described frame model, with the exception of the mean plus one standard deviation interstorey and residual drift responses of the lower storeys, which were slightly higher. Some slight increase in drift at the lower storeys was seen for the more complex method (even under the mean response), which could be a result of the Bauschinger Effect, which causes the material to lose strength and stiffness earlier than the simplified model. Overall, the drift decreased slightly when using the more complex model, which is likely an effect of the increase in connection 


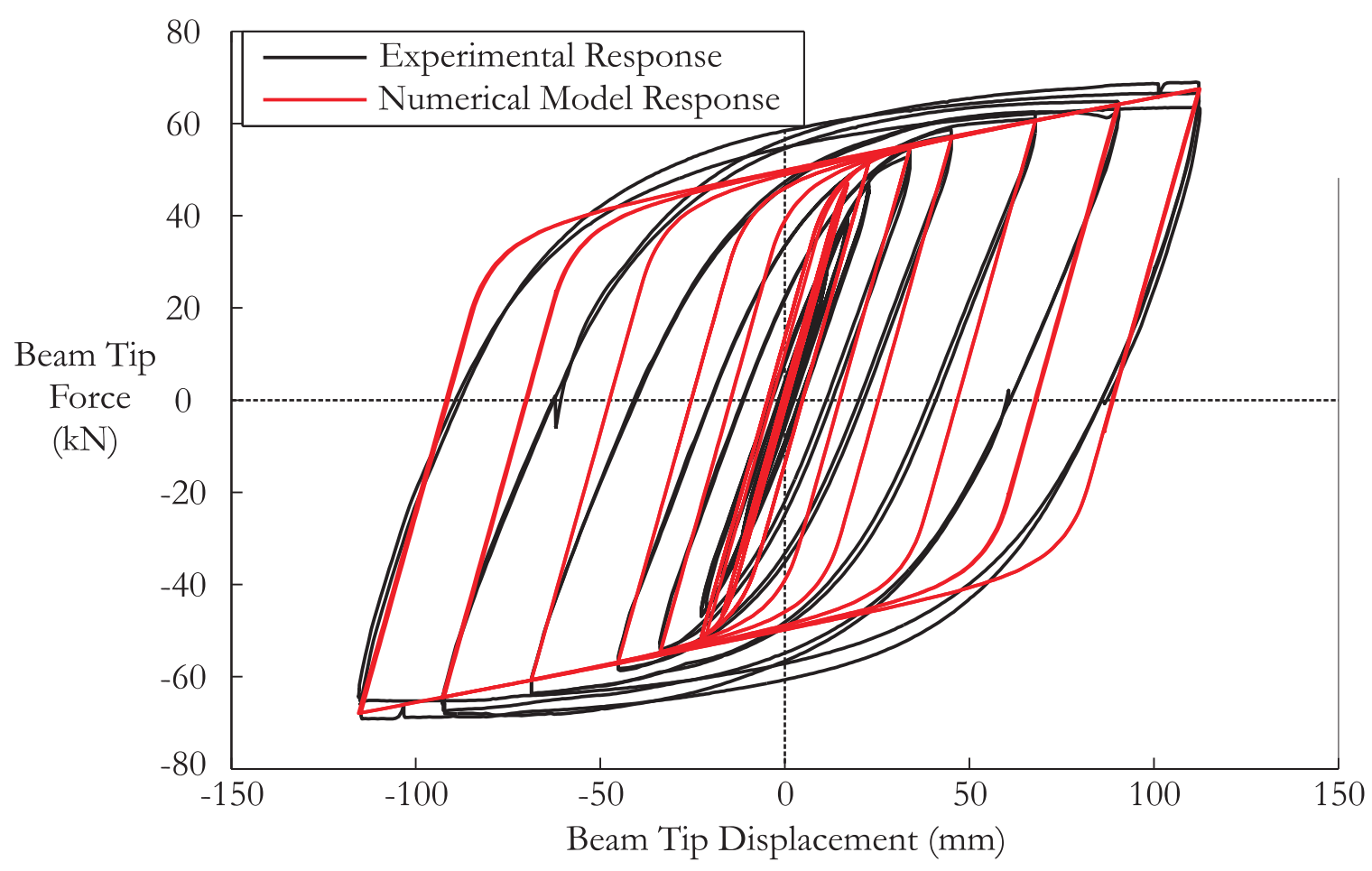

Figure 6.20: Comparison of Link Response for Test MC-1A and Simplified Model

strength due to cyclic hardening. The storey accelerations remained nearly identical for the two modelling methods.

\subsubsection{Effect of Link Size}

The absence of a trivial method for estimating residual drift can potentially lead to a completed building design that still exhibits residual drift beyond desirable levels. Although the interstorey drift of both prototype buildings remained within allowable code-based limits, results of the nonlinear dynamic analysis of the hybrid building indicated that excessive residual drifts may hinder the structures post-earthquake performance, and make replacement of the yielding links difficult. For this reason, the design of the hybrid structure could be updated in future studies based on initial OpenSees results by increasing the size of the link in hopes of reducing interstorey and residual drifts. This likely would not effect the adjacent members that were capacity-designed, since beam and column sizes were increased after capacity-design loads were 
a) MCE Interstorey Drift

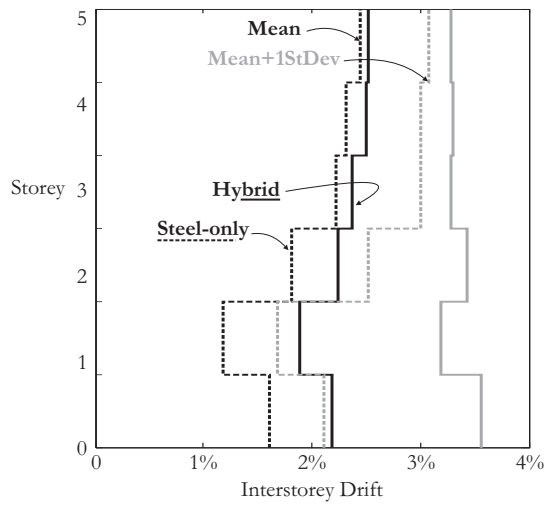

b) MCE Residual Drift

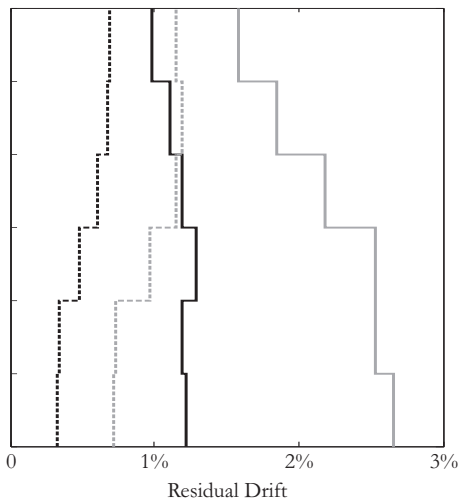

c) MCE Storey Acceleration

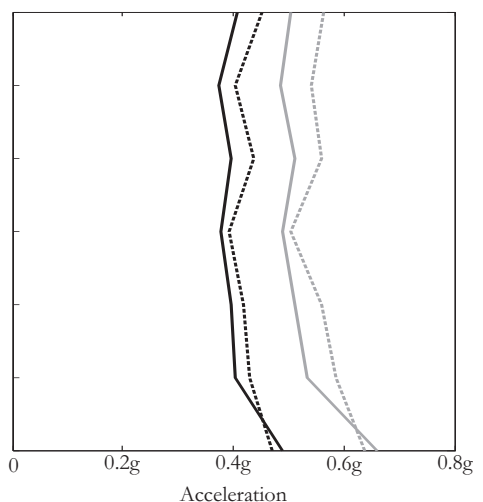

Figure 6.21: Response Plots of Simplified Model for Hybrid and Steel-only Buildings

applied to accommodate the excessive drifts. This means that the adjacent members are overdesigned for strength, so link sizes can be increased without altering other member sizes. Since most structures designed in accordance with the NBCC (2010) do not require analysis into the nonlinear range, detrimental effects relating to residual drift are not often captured. Further studies should be done in the future in an attempt to estimate and limit residual drift in the earlier stages of design of these hybrid frames. Results of a numerical study done by Erochko et al. (2011) suggest that it may be possible to estimate residual drifts as a function of the peak interstorey drift. Findings indicate that the maximum possible residual drift is approximately determined by subtracting the recoverable elastic drift from the peak storey drift; residual drifts can potentially approach (but never exceed) the level of maximum interstorey drift. This method could be used in future studies to optimize the design of the hybrid MRF system prior to the nonlinear analysis.

\subsection{Summary of Numerical Study Findings}

Two six-storey buildings were designed to compare the seismic response of a hybrid timbersteel MRF incorporating the proposed connection, to an equivalent steel MRF. Modelling methods have been presented that adequately capture the response of the proposed hybrid timber-steel connection. Simplified modelling methods have also been proposed which can reduce program run times and still match the test specimen response with reasonable accuracy. The following suggestions may be applied to future models to better capture the connection response or reduce 
analysis times:

- Secondary plastic hinge at column face

- Additional rotational springs to simulate STS connections

- Panel zone omitted if well-designed to reduce model run times

Nonlinear dynamic time-history analysis of the full hybrid timber-steel and steel-only frame models showed that well-detailed hybrid systems can perform comparably to equivalent steel-only structures in terms of global drift and storey acceleration, as well as ductility and energy dissipation. The behaviour of nonlinear elements can be similar if the wood-to-steel joints are properly designed and detailed. The low seismic weight and stiffness relative to the steelonly frame resulted in similar first mode periods for the two building types; the higher building periods obtained form nonlinear dynamic time-history analysis lowered seismic design forces imparted on the frames. The lower strength demands on connection components, main members, and foundations relative to steel-only structures increase the feasibility of using advanced hybrid timber-steel systems. Residual drifts were higher than expected, but can potentially be limited in future designs by iteratively increasing the link strength since adjacent beams and columns have designs governed by stiffness, not strength. This numerical study provides valuable insight into the dynamic performance of hybrid systems, and suggest that it is possible to design these systems using high R-values equivalent to that of ductile steel MRFs.

Ryan Gohlich, Department of Civil and Environmental Engineering, Carleton University 


\section{Chapter 7: Concluding Remarks}

\subsection{Summary of Findings}

This research has provided insight into the validity of the design methods and assumptions used to develop this hybrid timber-steel moment-resisting connection. Furthermore, methods and models used to evaluate the nonlinear behaviour of frames incorporating such systems have been presented. Several conclusions have been drawn which led to design recommendations that can optimize the performance of these connections.

\subsubsection{Design Process}

The connection was developed and designed using pre-existing steel and timber design methodology. Steel detailing was done according to CSA S16-09 (2011) and the Moment Connections for Seismic Applications guidelines (CISC 2010). A linear structural analysis was completed on a full-scale building designed using response spectrum analysis according to NBCC (2010), and finally, nonlinear dynamic time-history analysis was performed to verify the adequacy of the design procedure.

Overall, the success of the study in localizing plastic deformations to a single well-detailed ductile steel component suggest that the existing methods of steel construction are adequate for use in the newly developed hybrid connection. Fabrication methods for the steel components are identical to existing methods for steel buildings, and no special or advanced methods are required for adequate fabrication. The high strength and stiffness of the self-tapping screw (STS) connections designed according to the recently released Canadian approval for the design of STS using SWG ASSY VG Plus and SWG ASSY 3.0 Self-Tapping Wood Screws (National Research 
Council of Canada, 2013) allow transfer of high forces between steel and wood elements with little detrimental effect on overall connection performance. The use of ZD-plates over STS with 45 degree washers has little consequence regarding overall connection performance, and should be chosen based on preference of the fabricator and cost analysis.

\subsubsection{Experimental Findings}

The results of the experimental program show that connections incorporating nonlinear replaceable links with or without dogbone details are capable of achieving stable hysteretic behaviour comparable to typical steel-only moment-resisting connections. The overall ductility of the connections nearly met the target ductility for ductile steel MRFs. Both ductility and cumulative energy dissipation were higher for the system incorporating the dogbone link. Most of the total rotation undergone by the link elements was in the plastic range, and the link contributed to a majority of the total connection rotation in all cases.

All connections met the acceptance criteria for prequalified moment-resisting connections set forth by the Seismic Provisions for Structural Steel Buildings (AISC 342, 2010). Little strength degradation was seen prior to $0.04 \mathrm{rad}$ drift (acceptance level), and all connections were able to withstand at least one cycle at $0.05 \mathrm{rad}$ drift. The dogbone links began to show signs of strength degradation after the first cycle at $0.05 \mathrm{rad}$ drift, and tests were ended early due to excessive out of plane deformations. The regular links showed little signs of strength degradation and began to fracture near the link-to-end-plate weld after a single cycle at 0.05 rad drift. The failure mode was similar to that of pre-Northridge steel moment-resisting connections, albeit at much higher drift levels. The dogbone links showed better overall performance, and would be preferred in design.

No connection components that were capacity-designed to remain elastic under forces associated with yielding of the plastic hinge showed signs of plastic behaviour. Each wood beam and steel beam collar assembly withstood two separate loading sequences, and the column and panel zone assembly withstood four separate loading sequences without any signs of plastic behaviour. This verifies the ability of the capacity-design procedure to localize plastic deformations to a single replaceable element.

Installation of all STS connections were completed in-house. Pre-drilling was necessary

Ryan Gohlich, Department of Civil and Environmental Engineering, Carleton University 
to avoid torsional failure of the screws during installation. The steel-to-wood STS connections showed no sign of plastic behaviour during testing. Some slight connection slip was present, but overall contribution to connection rotation was negligible. No wood members showed signs of crack formation at the expected failure plane. The reinforcing screws used in the 45 degree STS connection were successful in negating tension perpendicular-to-grain failure in the wood members, and no reinforcing screws were necessary for the ZD-plate connection.

\subsubsection{Numerical Modelling}

Results from the numerical study show that hybrid MRFs designed using high seismic force reduction factors can behave similarly to typical steel-only structures of equivalent geometry. The response of the numerical model was easily calibrated to match that of the experimental specimens. Interstorey drifts remained below the NBCC (2010) specified drift limit of $2.5 \%$, and matched well with the drift response from the linear analysis. Residual drifts of the hybrid frame were higher than that of the steel-only frame. Designers could consider increasing link sizes to reduce residual drift. Since the interstorey drifts of the nonlinear numerical model matched well with those of the linear model, attempts should be made to approximate the level of residual drift experienced by the hybrid MRF during the linear analysis in order to choose appropriate link size at the optimal design stage. Storey accelerations of the hybrid frame remained below the magnitude of the associated PGA.

Omission of the STS connection from the numerical model had little effect on the total contribution of each component to total storey drift, especially when high plastic deformations are expected. All panel zones remained entirely elastic, and can likely be omitted from the model as well to reduce run times.

\subsection{Future Research}

A number of suggestions for future research can be made based on the findings of the experimental and numerical study:

- Updated design procedure to limit residual drift in hybrid frame.

Ryan Gohlich, Department of Civil and Environmental Engineering, Carleton University 
- Experimental investigation into the performance of full scale connections.

- Effect of varying link length on failure mode and ductility.

- Additional test using stiff link to determine the ultimate capacity of the STS connection.

- Comprehensive study on optimal size of STS connection to maintain elastic behaviour without excessive overcapacity.

- Use of lumped plasticity with the Ibarra Medina Krawinkler model to capture strength degradation of links under high drift levels.

- Comprehensive numerical study to determine the optimal structural layout of the hybrid MRF.

- Comprehensive numerical study to examine the performance of hybrid frames with a varying number of storeys.

- Feasibility study on the economic cost of full scale hybrid connections could provide insight into the practicality of using such systems.

The findings of the experimental and numerical study provide an important first step in the development of large-scale high-ductility hybrid timber-steel moment-resisting connections, and future studies should focus on optimization of these systems to determine appropriate overcapacity factors to assign to the elastic components of the connection.

Ryan Gohlich, Department of Civil and Environmental Engineering, Carleton University 


\section{References}

American Institute of Steel Construction [AISC] (2010). Seismic Provisions for Structural Steel Buildings, ANSI/AISC 341-10. Chicago: American Institute of Steel Construction.

Andreolli, M., Piazza, M., Tomasi, R., \& Zandonini, R. (2011). Ductile Moment-resistant Steeltimber Connections. Structures and Buildings. 164(SB2), 64-78.

Angst, V., \& Malo, K. (2012). Effect of Self-Tapping Screws on Moisture Induced Stresses in Glulam. Engineering Structures. 45, 299-306.

Ashtari, S. (2009). In-plane Stiffness of Cross-Laminated Timber Floors. Vancouver: University of British Columbia, B.C.

Batchelar, M. (2006). Timber Frame Moment Joints with Glued-In Steel Rods - A Designer's Perspective. NZ Timber Design Journal. 15(2).

Bejtka, I., \& Blaß, H. (2002). Joints with Inclined Screws. International Council for Research ad Innovation in Building and Construction. Universität Karlsruhe, Germany.

Blaß, H., \& Bejtka, I. (2004). Reinforcements Perpendicular to the Grain Using Self-Tapping Screws. Karlsruhe: University of Karlsruhe, Germany.

Blaß, H., \& Schädle, P. (2011). Ductility Aspects of Reinforced and Non-reinforced Timber Joints. Engineering Structures. 33, 3018-3026.

Blaß, H., Schmid, M., Harald, L., \& Barbara, W. (n.d.). Nail Plate Reinforced Joints with Dowel-type Fasteners. Karlsruhe: University of Karlsruhe, Germany.

Bouchair, A., Racher, P., \& Bocquet, J. (2007). Analysis of Dowelled Timber Moment-Resisting Joints. Materials and Structures. 40, 1127-1141.

Bruneau, M., Uang, C., \& Whittaker, A. (1998). Ductile Design of Steel Structures. McGraw-Hill. 
Buchanan, A., \& Fairweather, R. (1993). Seismic Design of Glulam Structures. Bulleton of the New Zealand National Society for Earthquake Engineering. 26(4), 415-436.

Canadian Institute of Steel Construction [CISC] (2008). Moment Connections for Seismic Applications, Markham: Canadian Institute of Steel Construction.

Canadian Standards Association [CSA](2010). Limit States Design of Steel Structures, CAN/CSA S16-09. Mississauga, ON. Canadian Standards Association.

Canadian Standards Association [CSA](2010). Engineering Design in Wood, CSA O86-09. Mississauga, ON. Canadian Standards Association.

Chasten, C., Lu, L., \& Driscoll, G. (1992). Prying and Shear in End-Plate Connection Design. Journal of Structural Engineering. 118, 1295-1311.

Chi, B., \& Uang, C. (2002). Cyclic Response and Design Recommendations of Reduced Beam Section Moment Connections with Deep Columns. Journal of Structural Engineering. 128, 464473.

Choi, H., Erochko, J., Christopoulos, C., \& Tremblay, R. (2008). Comparison of the Seismic Response of Steel Buildings Incorporating Self-Centering Energy-Dissipative Braces, Buckling Restrained Braces and Moment-Resisting Frames. (Report No. 05-2008). Toronto: Dept. of Civ. Eng. University of Toronto, ON.

Christopoulos, C., \& Filiatrault, A. (2006). Principles of Passive and Supplemental Damping and Seismic Isolation. Pavia, Italy: Multimedia Cardano.

Closen, M. Pre-drilling Instructions for SWG ASSY Screws, Surrey, B.C. MyTiCon Timber Connectors.

Closen, M. (2012). Self-Tapping Screw Assemblies Under Monotonic and Reverse Cyclic Load. Vancouver: University of British Columbia, B.C.

Ryan Gohlich, Department of Civil and Environmental Engineering, Carleton University 
CSI Computers \& Structures Inc. (2013). ETABS [Computer Software]. Berkeley, CA.

Deylami, A., \& Tabar, A. (2004). Effect of Column Panel Zone Characteristics on Instability of Beams with RBS Moment Resisting Connections. 13th World Conference on Earthquake Engineering. (Paper No. 31). Vancouver, B.C.

Dietsch, P., \& Brandner, R. (2015). Self-Tapping Screws and Threaded Rods as Reinforcement for Structural Timber Elements - A State-of-the-art Report. Construction and Building Materials. 97, 78-89.

Ellingsbo, P., \& Malo, K. (2012). Withdrawal Capacity of Long Self-Tapping Screws Parallel to Grain Direction. World Conference on Timber Engineering. Auckland, New Zealand.

Erochko, J., Christopoulos, C., Tremblay, R., \& Choi, H. (2011). Residual Drift Response of SMRFs and BRB Frames in Steel Buildings Designed According to ASCE 7-05. Journal of Structural Engineering. 137(5), 589-599.

European Organization for Technical Approvals [EOTA](2012). European Technical Approval ETA-11/0470, Copenhagen, Denmark. European Organization for Technical Approvals.

Federal Emergency Management Agency [FEMA] (2000). Recommended Seismic Design Criteria for New Steel Moment-Frame Buildings, FEMA-350. Washington DC: Federal Emergency Management Agency.

Federal Emergency Management Agency [FEMA] (2003). NEHRP Recommended Provisions for Seismic Regulations or New Buildings and Other Structures, FEMA-450. Washington DC: Federal Emergency Management Agency.

Federal Emergency Management Agency [FEMA] (2009). Quantification of Building Seismic Performance Factors, FEMA-P695. Washington DC: Federal Emergency Management Agency.

Filiatrault, A., Tremblay, R., Christopoulos, C., Folz, B., \& Pettinga, D. (2013). Elements of Earthquake Engineering and Structural Dynamics. Presses Internationales Polytechnique. 
Gehloff, M. (2011). Pull-out Resistance of Self-Tapping Wood Screws with Continuous Thread. Vancouver: University of British Columbia, B.C.

Gupta, A., \& Krawinkler, H. (1999).Seismic Demands for Performance Evaluation of Steel Moment Resisting Frame Structures.(Report No. 132). Stanford: Dept. of Civ. and Env. Eng. The John A. Blume Earthquake Engineering Center, Stanford University, CA.

Humbert, J., Lee, S., Park, J., \& Park, M. (2014). Moment Resistance of Post-and-Beam Joints with Concealed Metallic Connectors. World Conference on Timber Engineering. Quebec City, Canada.

Johansen, K. (1949). Theory of Timber Connections. Zurich: Ein Dienst der ETH-Bibliothek Ramistrasse, Switzerland.

Jones, S., Fry, G., \& Engelhardt, M. (2002). Experimental Evaluation of Cyclically Loaded Reduced Beam Section Moment Connections. Journal of Structural Engineering. 128, 441-451.

Jorissen, A. (1999). Double Shear Timber Connections with Dowel Type Fasteners. HERON. 44(3), 163-186.

Jorissen, A., \& Fragiacomo, M. (2011) General Notes on Ductility in Timber Structures. Engineering Structures. 33, 2987-2997.

Kevarinmäki, A. (2002). Joints with Inclined Screws. International Council for Research ad Innovation in Building and Construction. VTT Building and Transport, Finland.

Komatsu, K., Mori, T., Kitamori, A., \& Araki, Y. (2014). Evaluation on Dynamic Performance of Glulam Frame Structure Composed of Slotted Bolted Connection System. World Conference on Timber Engineering. Quebec City, Canada.

Krenn, H., \& Schickhofer, G. (2009). Joints with Inclined Screws and Steel Plates as Outer Members. International Council for Research ad Innovation in Building and Construction. Graz University of Technology, Austria.

Ryan Gohlich, Department of Civil and Environmental Engineering, Carleton University 
Lam, F., Gehloff, M., \& Closen, M. (2010). Moment-Resisting Bolted Timber Connections. Structures and Buildings. 163(SB4), 267-274.

Lam, F., Wrede, M., Yao, C., \& Gu, J. Moment Resistance of Bolted Timber Connections with Perpendicular to Grain Reinforcements. Vancouver: University of British Columbia, B.C.

Lee, C., Jeon, S., Kim, J., Kim, J., \& Uang, C. (2004). Seismic Performance of Reduced Beam Section Steel Moment Connections: Effects of Panel Zone Strength and Beam Web Connection Method. 13th World Conference on Earthquake Engineering. (Paper No. 3449). Vancouver, B.C.

Mahlknecht, U., Brandner, R., Ringhofer, A., \& Schickhofer, G. (2014). Resistance and Failure Modes of Axially Loaded Groups of Screws. Materials and Joints in Timber Structures. RILEM Bookseries 9, 289-300.

McCormick, J., Aburano, H., Ikenaga, M., \& Nakashima, M. (2008). Permissible Residual Drift Deformation Levels for Building Structures Considering Both Safety and Human Elements. 14th World Conference on Earthquake Engineering. (Paper No. 05-06-0071). Beijing, China.

McKenna, F., Fenves, G., Scott, H., \& Jeremic, B. (2000). Open System for Earthquake Engineering Simulation (OpenSees) [Computer Software]. Pacific Earthquake Engineering Research Center, University of California, Berkeley, CA. Available from http://opensees.berkeley.edu/

Michaud, D., \& Leger, P. (2012). Ground Motions Selection and Scaling for Nonlinear Dynamic Analysis of Structures Located in Eastern North America. Canadian Journal of Civil Engineering. 41, 232-244.

Ministry of Municipal Affairs and Housing. (2015). 2012 Ontario Building Code Compendium. Ministry of Municipal Affairs and Housing, Toronto, ON.

Nakatani, M., Mori, T., \& Komatsu, K. (2012). Development of Cross Embedded Joint Using Lagscrewbolt. World Conference on Timber Engineering. Auckland, New Zealand.

National Research Council of Canada [NRC](2013). Evaluation Report CCMC 13677-R, SWG 
ASSY VG Plus and SWG ASSY 3.0 Self-Tapping Wood Screwes, Ottawa, ON. National Research Council of Canada.

National Research Council of Canada [NRC](2010). National Building Code of Canada. Ottawa, ON. National Research Council of Canada.

Nordic Engineered Wood. (2013). Nordic X-Lam Slabs. Nordic Wood Structures Technical Note S23. Nordic Structures.

Nordic Engineered Wood. (2013). Design Properties, Nordic Lam. Nordic Wood Structures Technical Note S01. Nordic Structures.

Pachoumis, D., Galoussis, E., Kalfas, C., \& Christitsas, A. (2009). Reduced Beam Section Moment Connections Subjected to Cyclic Loading: Experimental analysis and FEM Simulation. Engineering Structures. 31, 216-223.

Palma, P., Frangi, A., Hugi, E., Cachim, P., \& Cruz, H. (2013). Fire Resistance Tests on Steel-toTimber Dowelled Connections Reinforced with Self Drilling Screws. 2nd CILASCI-Ibero-LatinAmerican Congress on Fire Safety Engineering Coimbra. Portugal.

Pedersen, M. (2002). Dowel Type Timber Connections. (Dissertation). Kongens Lyngby: Department of Structural Engineering and Materials. Denmarks Tekniske Universitet, Denmark.

Persson, M., \& Wogelberg, S. (2011). Analytical Models of Pre-stressed and Reinforced Glulam Beams. (Master's Thesis 2011:52). Goteborg: Dept. of Civ. and Env. Eng. Chalmers University of Technology, Sweden.

Popov, E., Yang, T., \& Chang, S. (1998). Design of Steel MRF Connections Before and After 1994 Northridge Earthquake. Engineering Structures. 20(12), 1030-1038.

Popovski, M., \& Karacabeyli, E. (2004). Seismic Performance of Riveted Connections in Heavy Timber Construction. 13th World Conference on Earthquake Engineering. (Paper No. 3356). Vancouver, B.C.

Ryan Gohlich, Department of Civil and Environmental Engineering, Carleton University 
Ricles, J., Zhang, X., Fisher, J., \& Lu, L. (2004). Seismic Performance of Deep Column-to-Beam Welded Reduced Beam Section Moment Connections. Connections in Steel Structures V. 211-222.

Ringhofer, A., \& Schickhofer, G. (2014). Influencing Parameters on the Experimental Determination of the Withdrawal Capacity of Self-Tapping Screws. World Conference on Timber Engineering. Quebec City, Quebec.

Shen, Y. (2009). Seismic Performance of Steel Moment-Resisting Frames with Nonlinear Replaceable Links. Toronto: Dept. of Civ. Eng. University of Toronto, ON.

Shen, Y., Christopoulos, C., Mansour, N., \& Tremblay, R. (2011). Seismic Design and Performance of Steel Moment-Resisting Frames with Nonlinear Replaceable Links. Journal of Structural Engineering. 137, 1107-1117.

Shi, G., Shi, Y., \& Wang, Y. (2007). Behaviour of End-Plate Moment Connections Under Earthquake Loading. Engineering Structures. 29, 703-716.

Sofias, C., Kalfas, C., \& Pachoumis, D. (2014). Experimental and FEM Analysis of Reduced Beam Section Moment End-plate Connections Under Cyclic Loading. Engineering Structures. 59, 320329.

Sumner, A. (2003). Unified Design of Extended End-Plate Moment Connections Subject to Cyclic Loading. (Dissertation). Blackburg: Virginia Polytechnic Institute and State University, Virginia.

Sumner, E., \& Murray, T. (2002). Behaviour of Extended End-Plate Moment Connections Subject to Cyclic Loading. Journal of Structural Engineering. 128, 501-508.

Tlustochowicz, G., \& Serrano, E. (2011). State-of-the-art Review on Timber Connections with Glued-in Steel Rods. Materials and Structures. 44, 997-1020. 
Tomasi, R., Crosatti, A., \& Piazza, M. (2010). Theoretical and Experimental Analysis of Timberto-Timber Joints Connected with Inclined Screws. Construction and Building Materials. 24, $1560-$ 1571.

Tsai, K., \& Popov, E. (1990). Cyclic Behaviour of End-Plate Moment Connections. Journal of Structural Engineering. 116, 2917-2930.

Uang, C., \& Fan, C. (2001). Cyclic Stability Criteria for Steel Moment Connections with Reduced Beam Section. Journal of Structural Engineering. 127, 1021-1027.

Welch, D., Sullivan, T., \& Filiatrault, A. (2014). Equivalent Structural Damping of Drift-Sensitive Nonstructural Building Components. 10th U.S. National Conference on Earthquake Engineering. Anchorage, Alaska.

Zarnani, P., \& Quenneville, P. (2014). Design Method for Coupled-Splice Timber Moment Connections. World Conference on Timber Engineering. Quebec City, Canada.

Zarnani, P., \& Quenneville, P. (2014). Strength of Timber Connections Under Potential Failure Modes: An Improved Design Procedure. Construction and Building Materials. 60, 81-90.

Zhang, X., \& Ricles, M. (2006). Seismic Behavior of Reduced Beam Section Moment Connections to Deep Columns. Journal of Structural Engineering. 132, 358-367.

Ryan Gohlich, Department of Civil and Environmental Engineering, Carleton University 


\section{Appendix A: Fabrication Drawings}

This chapter presents the parts and assembly drawings used to fabricate all steel and timber

elements. Weld details are shown which adhere to the requirements of Limit States Design of Steel Structures (CSA S16-09, 2010) and the Moment Connections for Seismic Applications guidelines (CISC, 2008). 


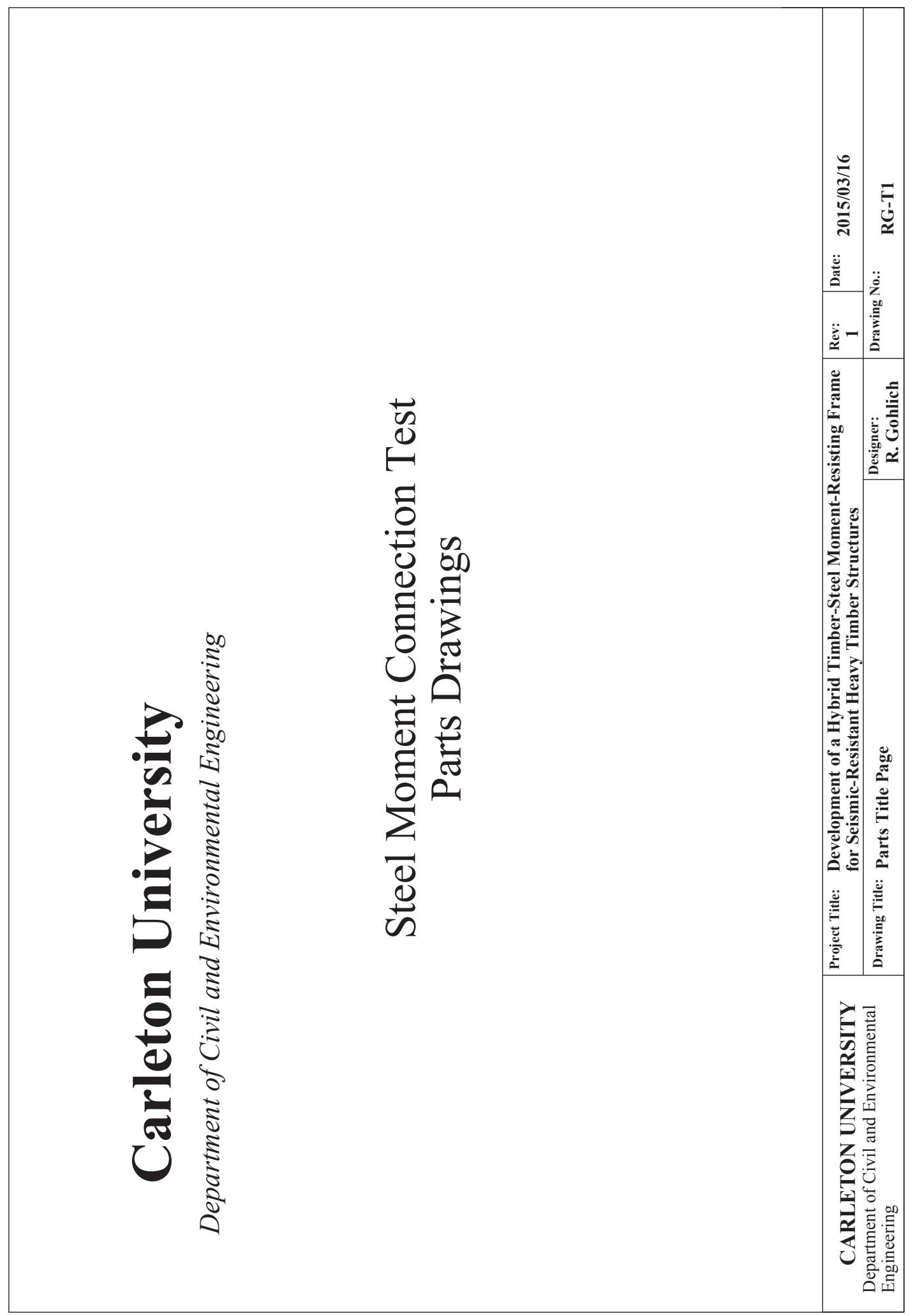

Ryan Gohlich, Department of Civil and Environmental Engineering, Carleton University 


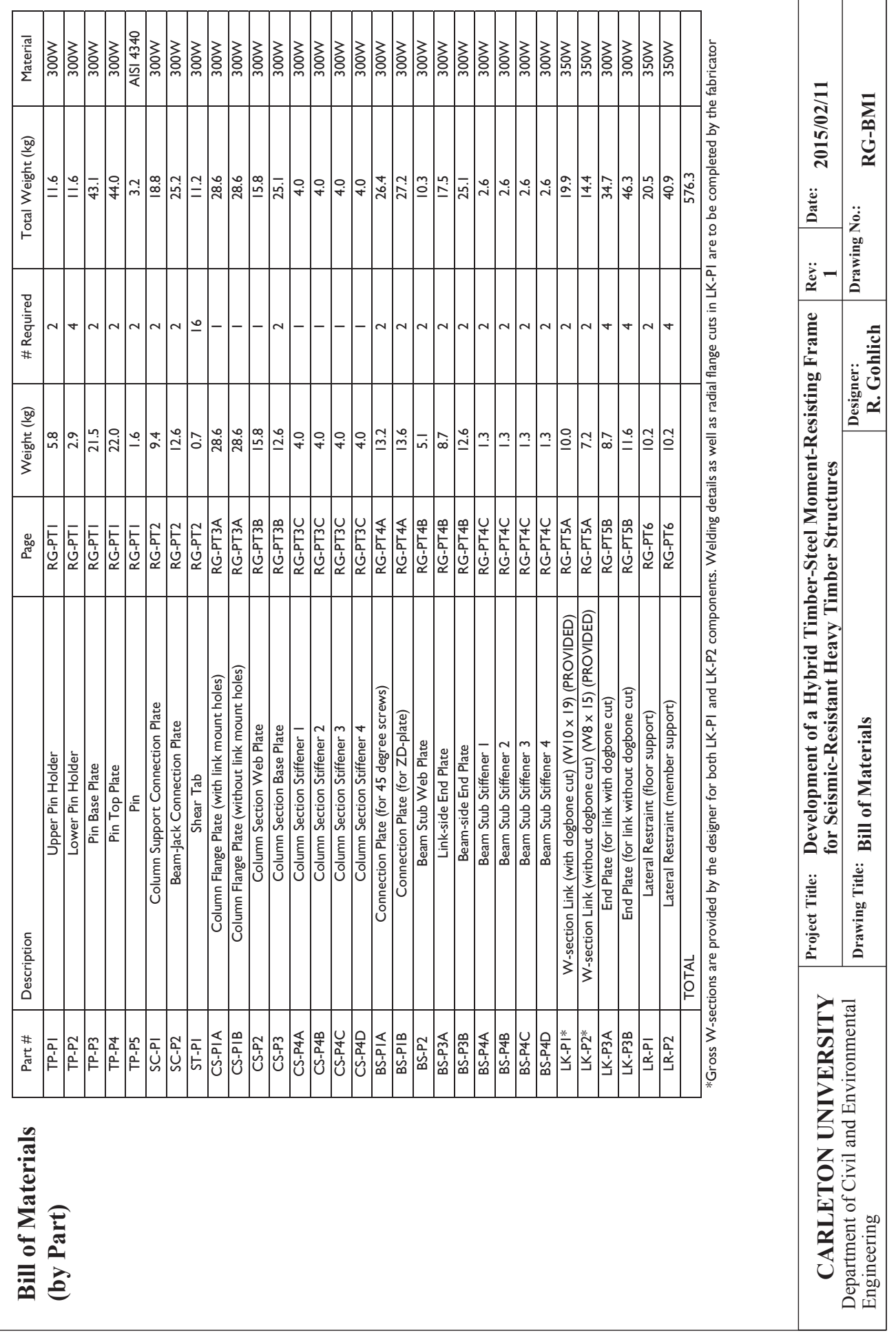




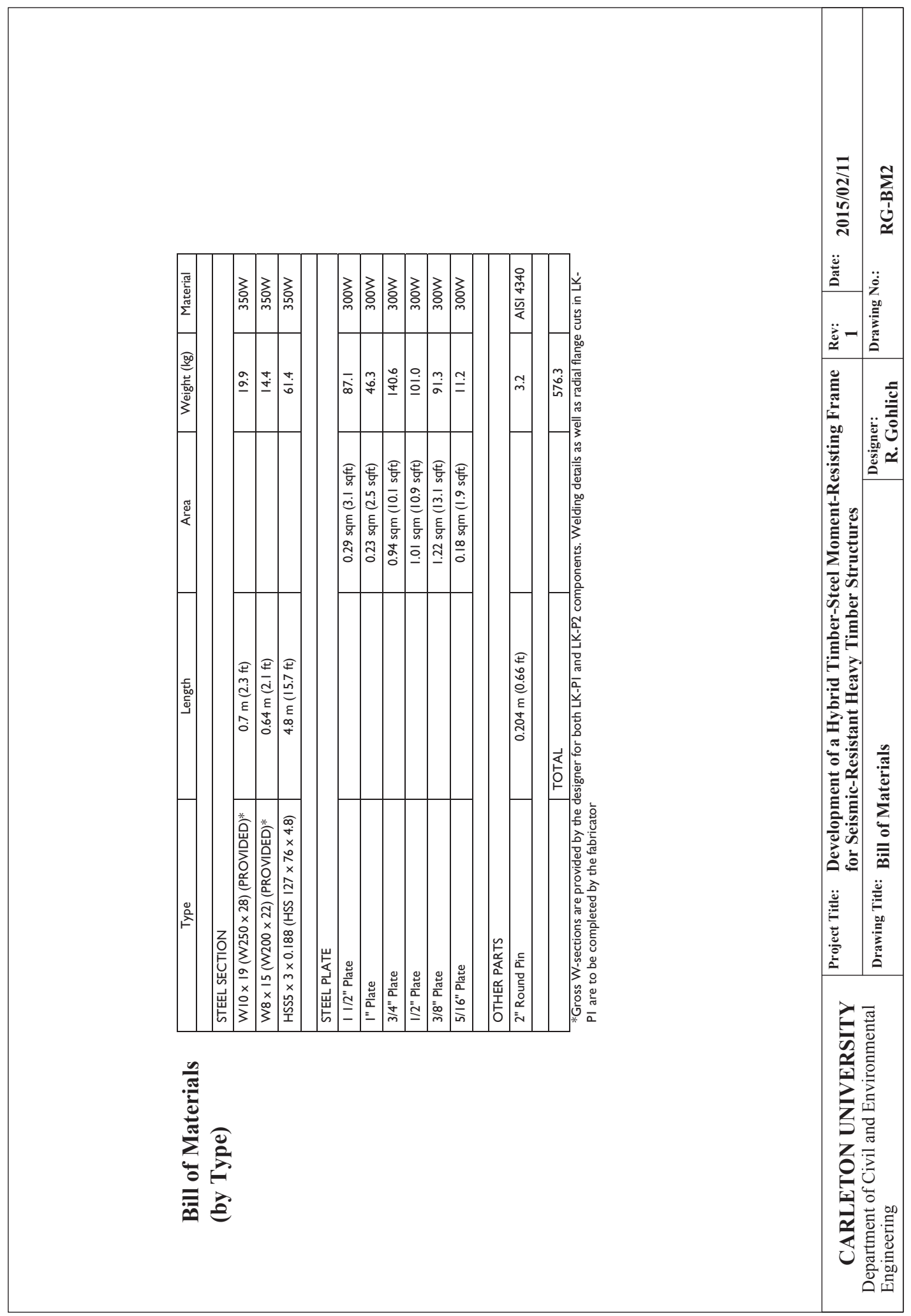

Ryan Gohlich, Department of Civil and Environmental Engineering, Carleton University 


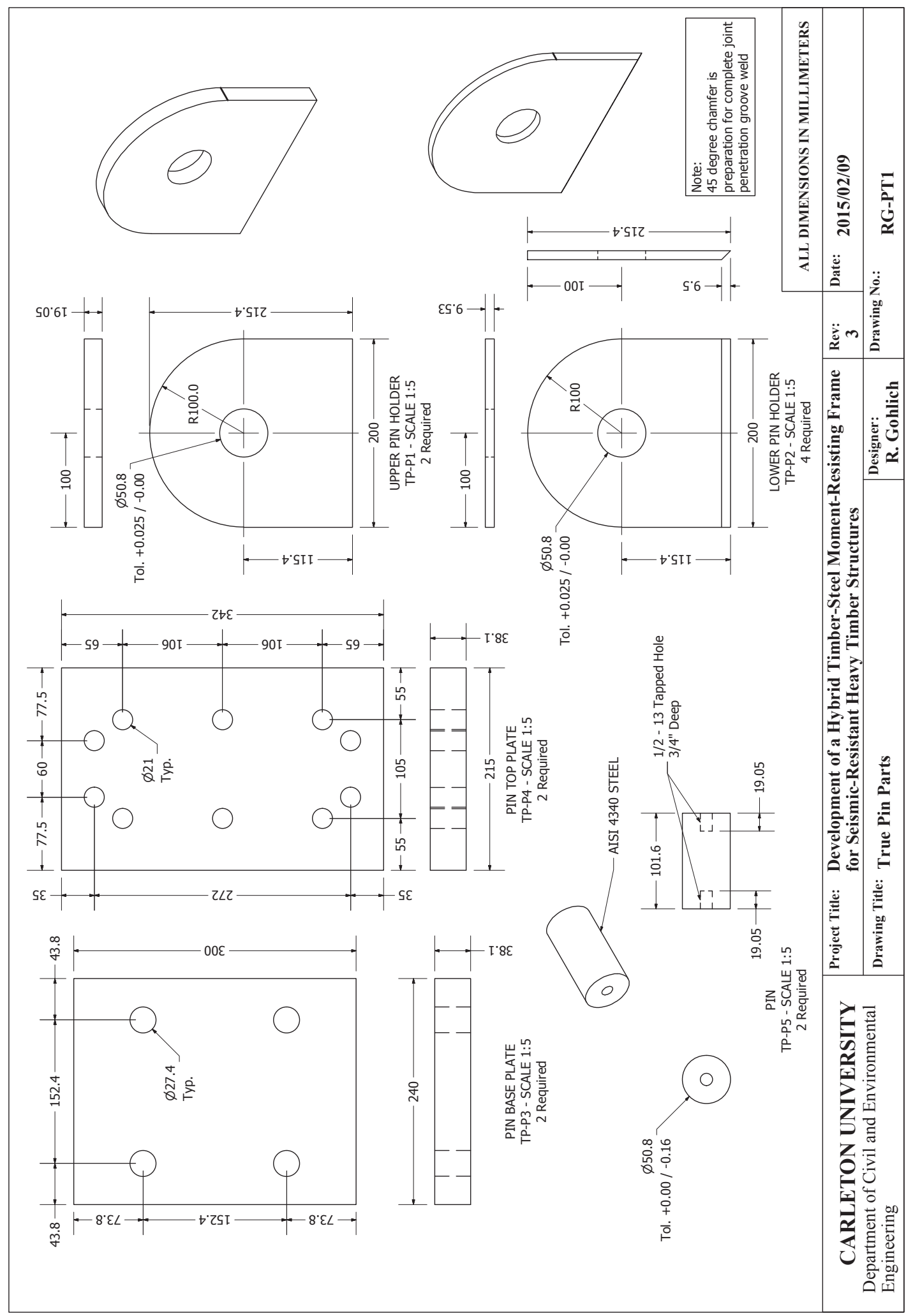

Ryan Gohlich, Department of Civil and Environmental Engineering, Carleton University 


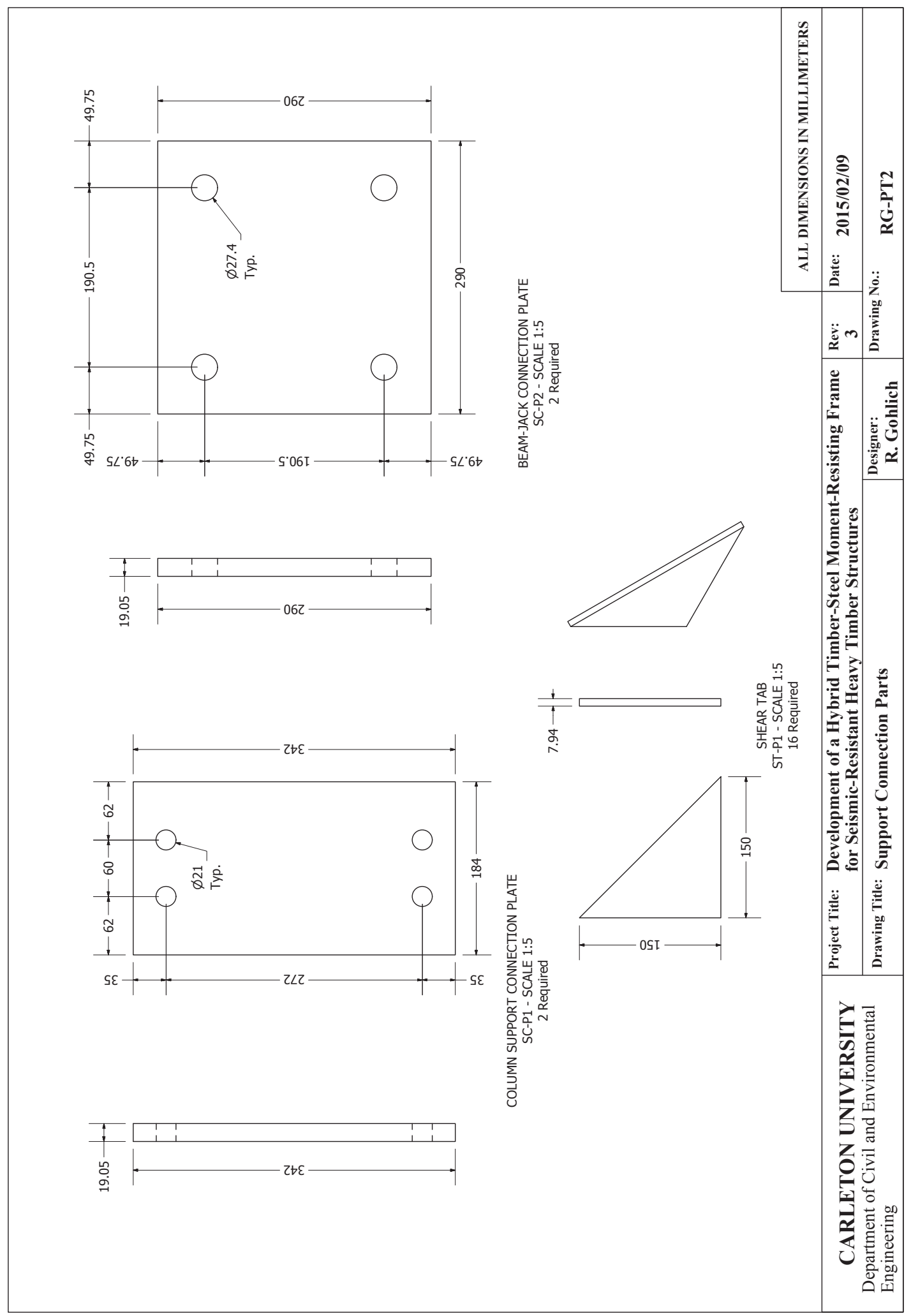

Ryan Gohlich, Department of Civil and Environmental Engineering, Carleton University 


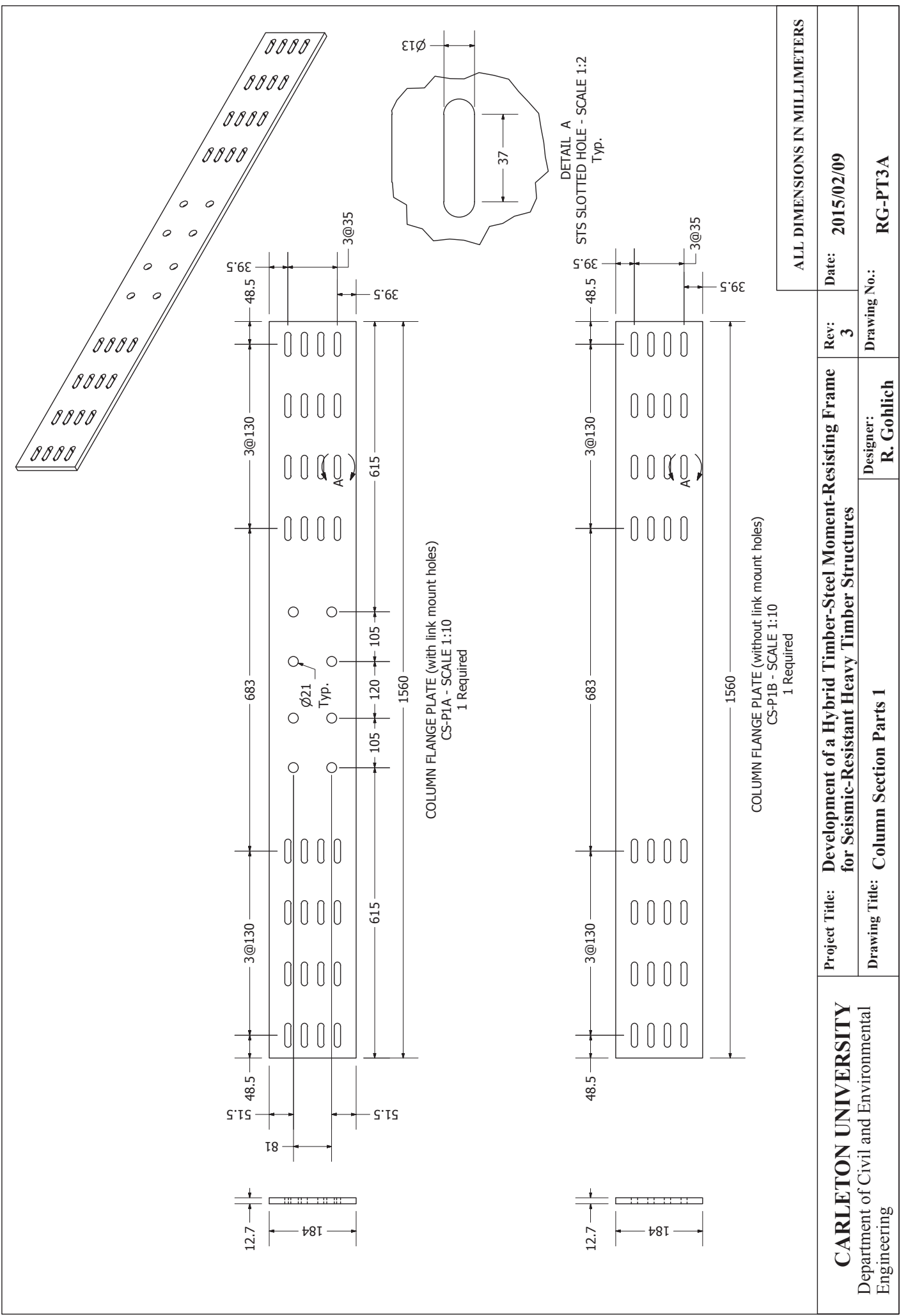

Ryan Gohlich, Department of Civil and Environmental Engineering, Carleton University 


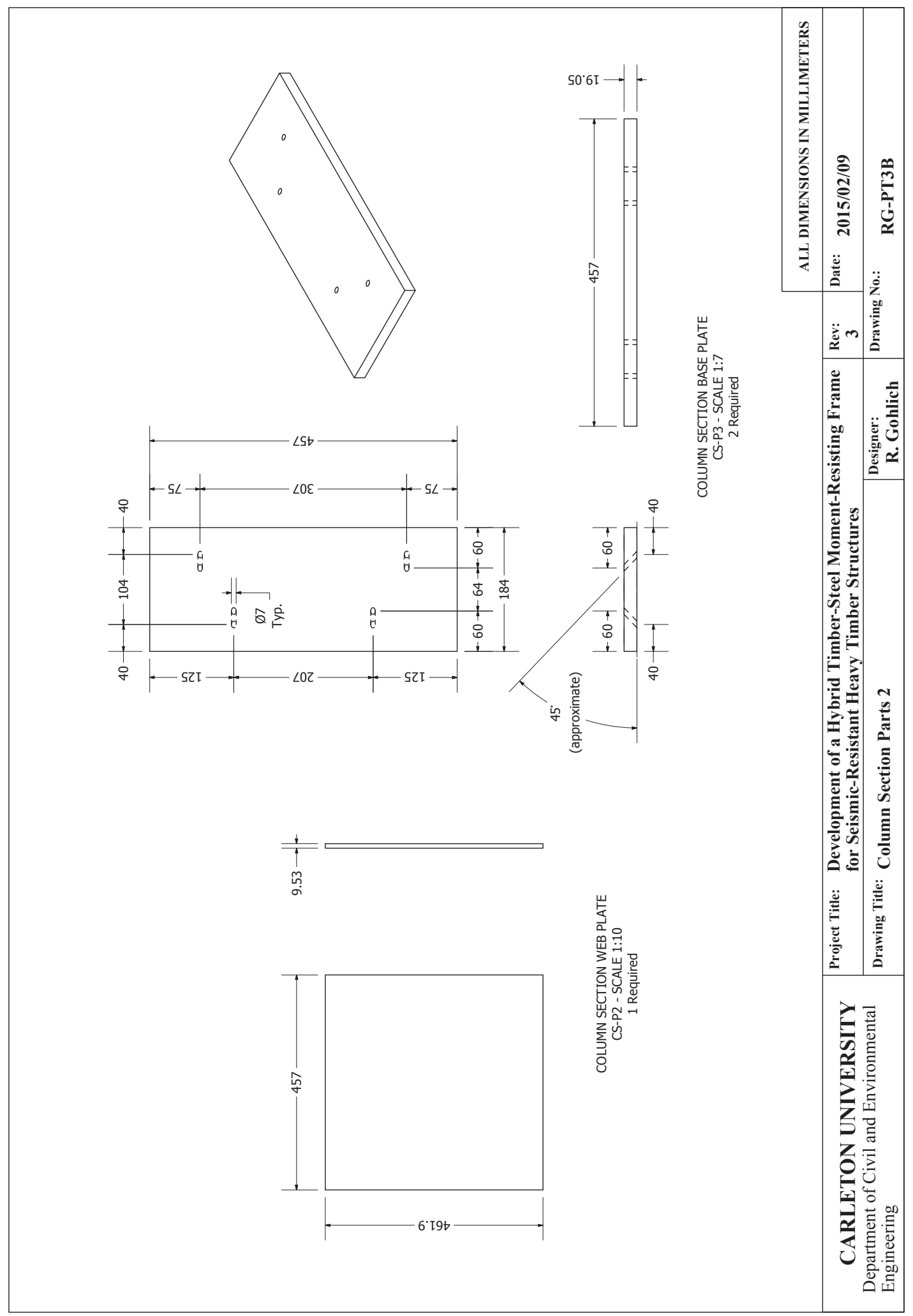

Ryan Gohlich, Department of Civil and Environmental Engineering, Carleton University 


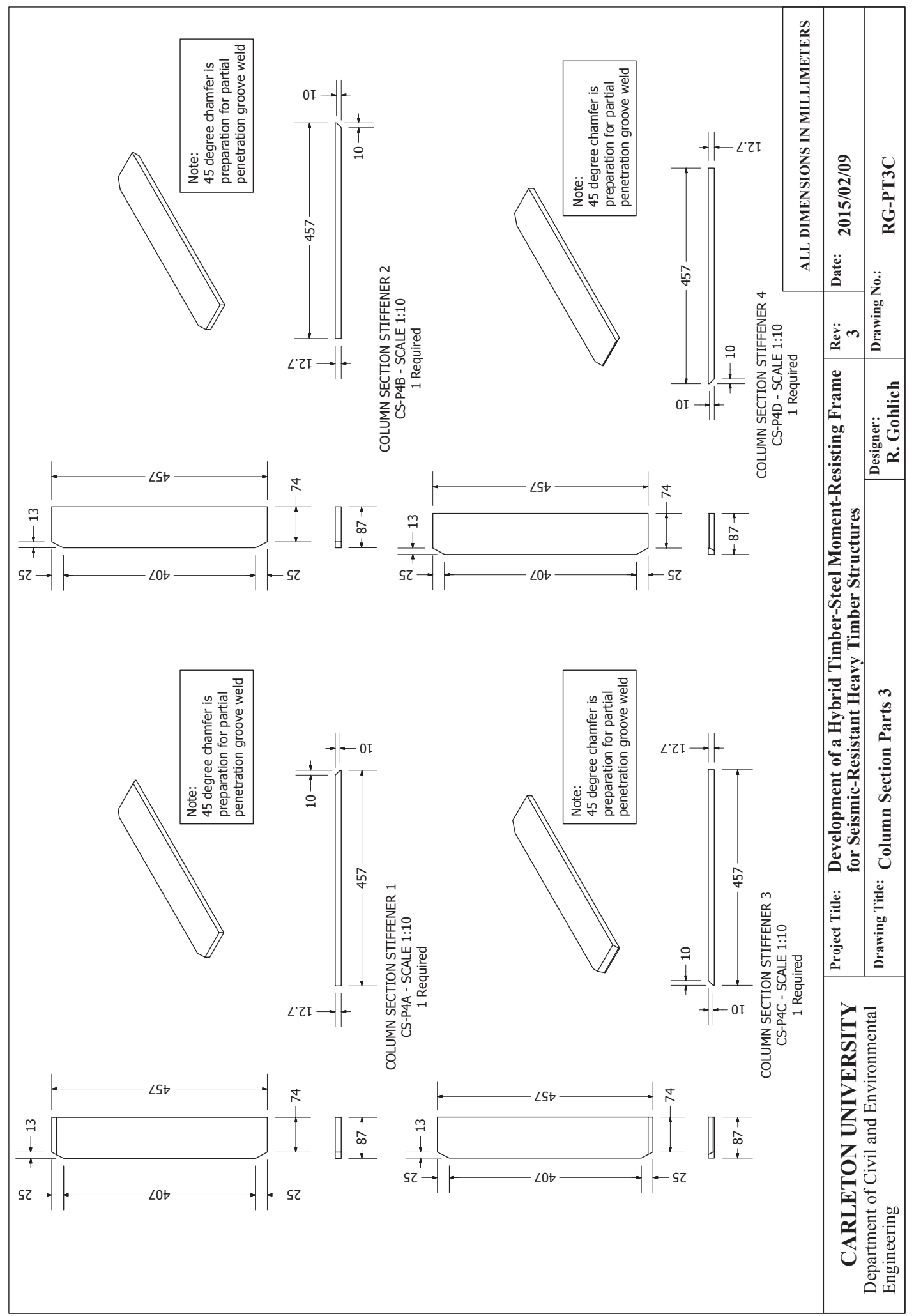




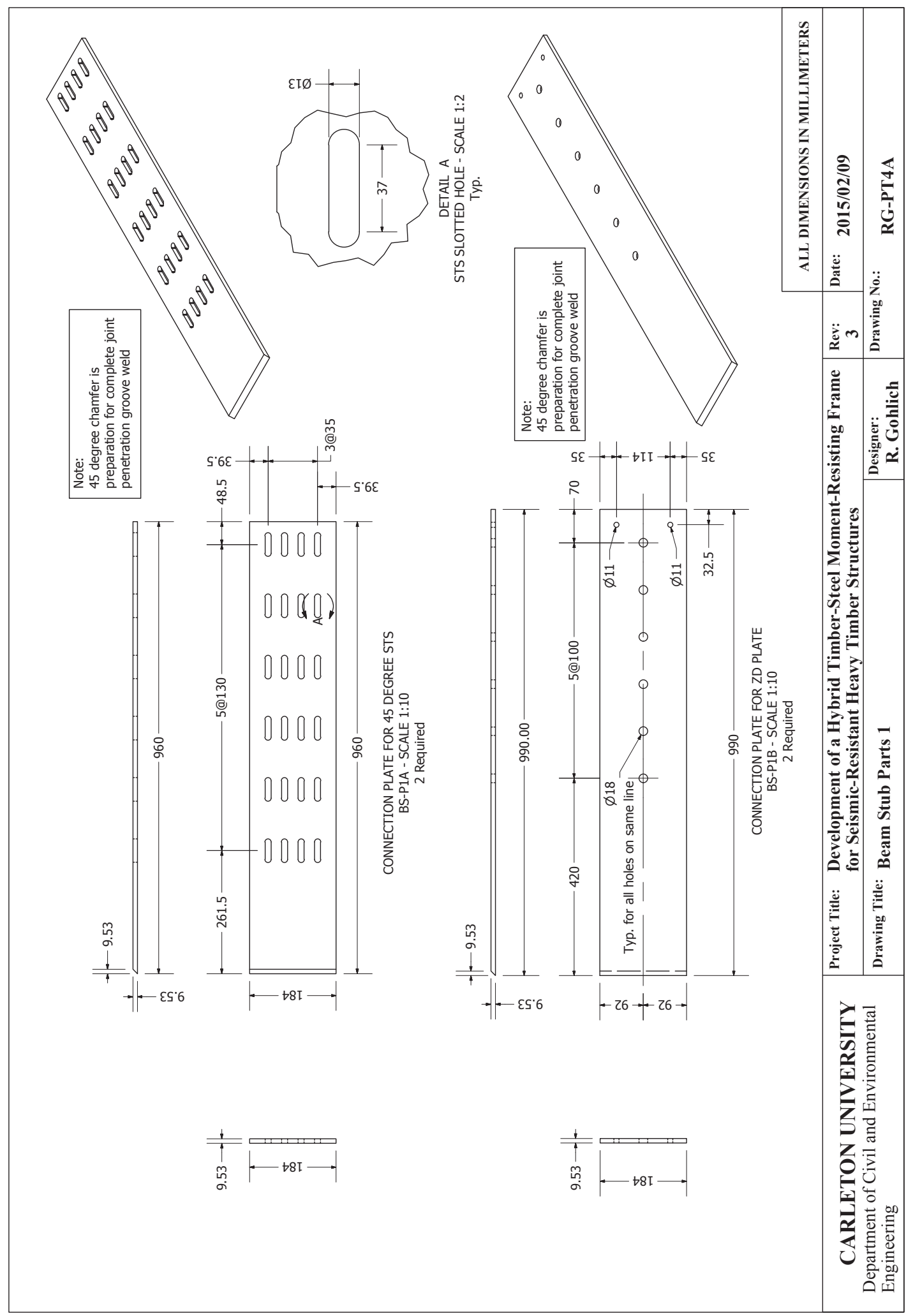

Ryan Gohlich, Department of Civil and Environmental Engineering, Carleton University 


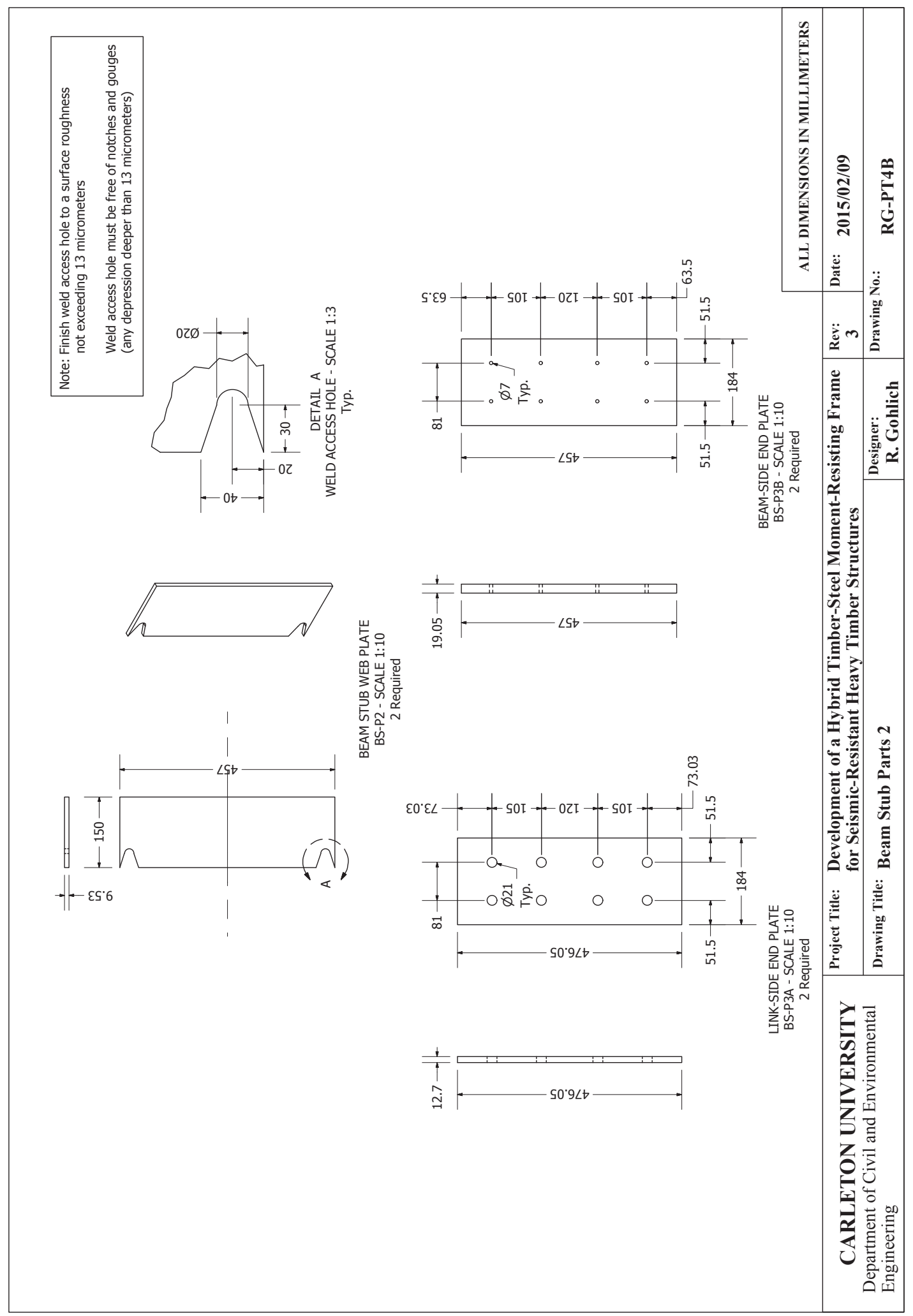

Ryan Gohlich, Department of Civil and Environmental Engineering, Carleton University 


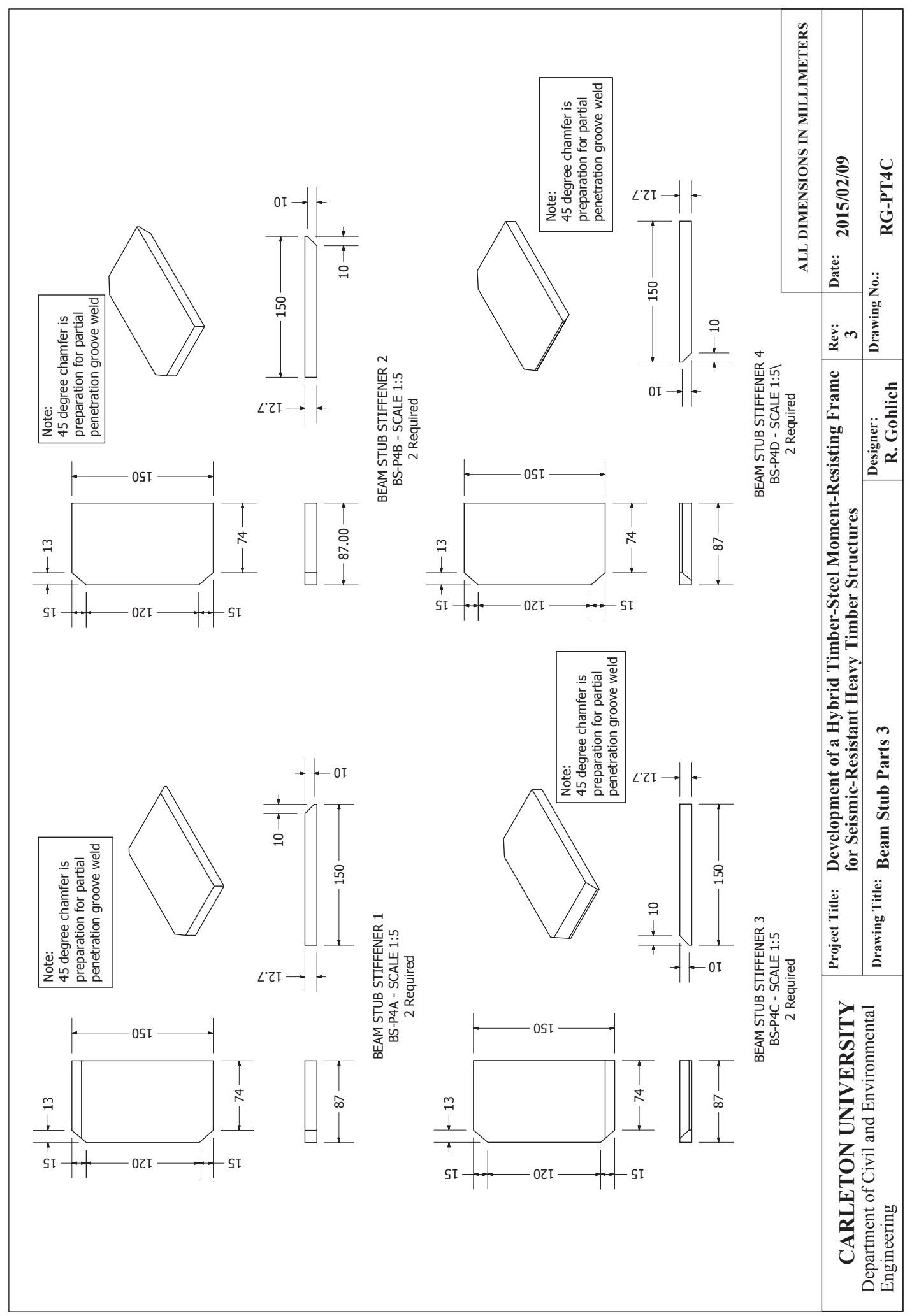

Ryan Gohlich, Department of Civil and Environmental Engineering, Carleton University 


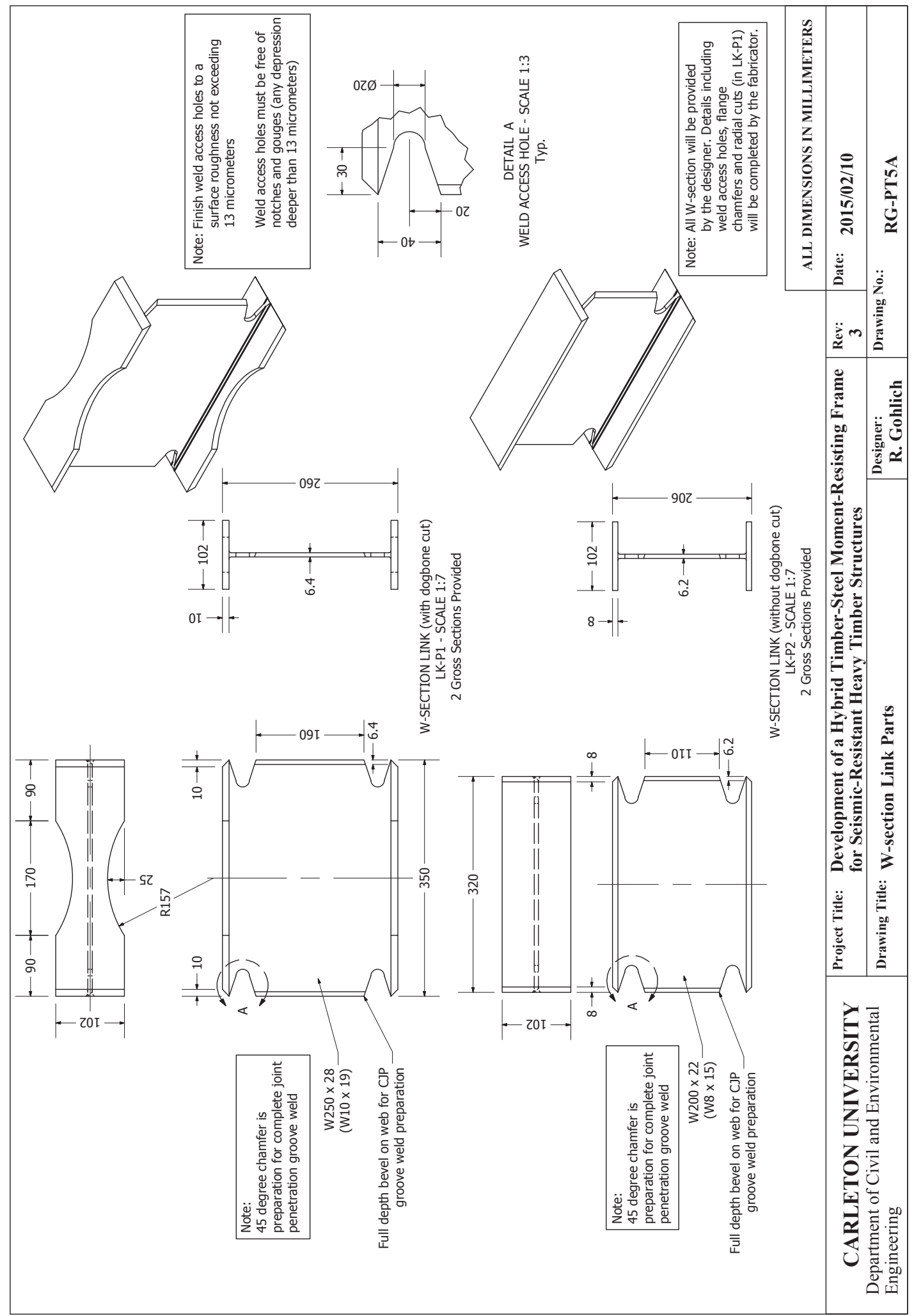

Ryan Gohlich, Department of Civil and Environmental Engineering, Carleton University 


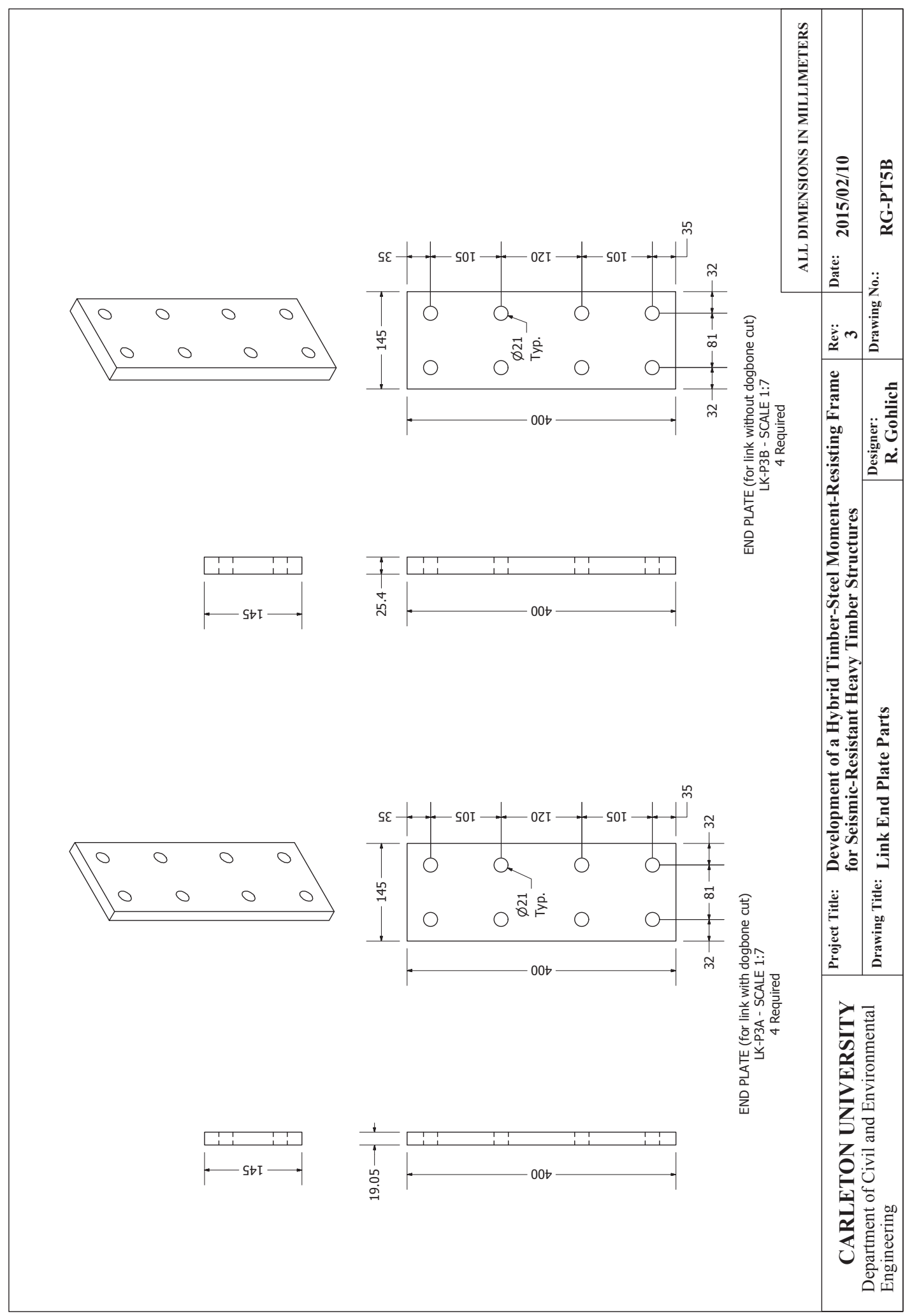

Ryan Gohlich, Department of Civil and Environmental Engineering, Carleton University 


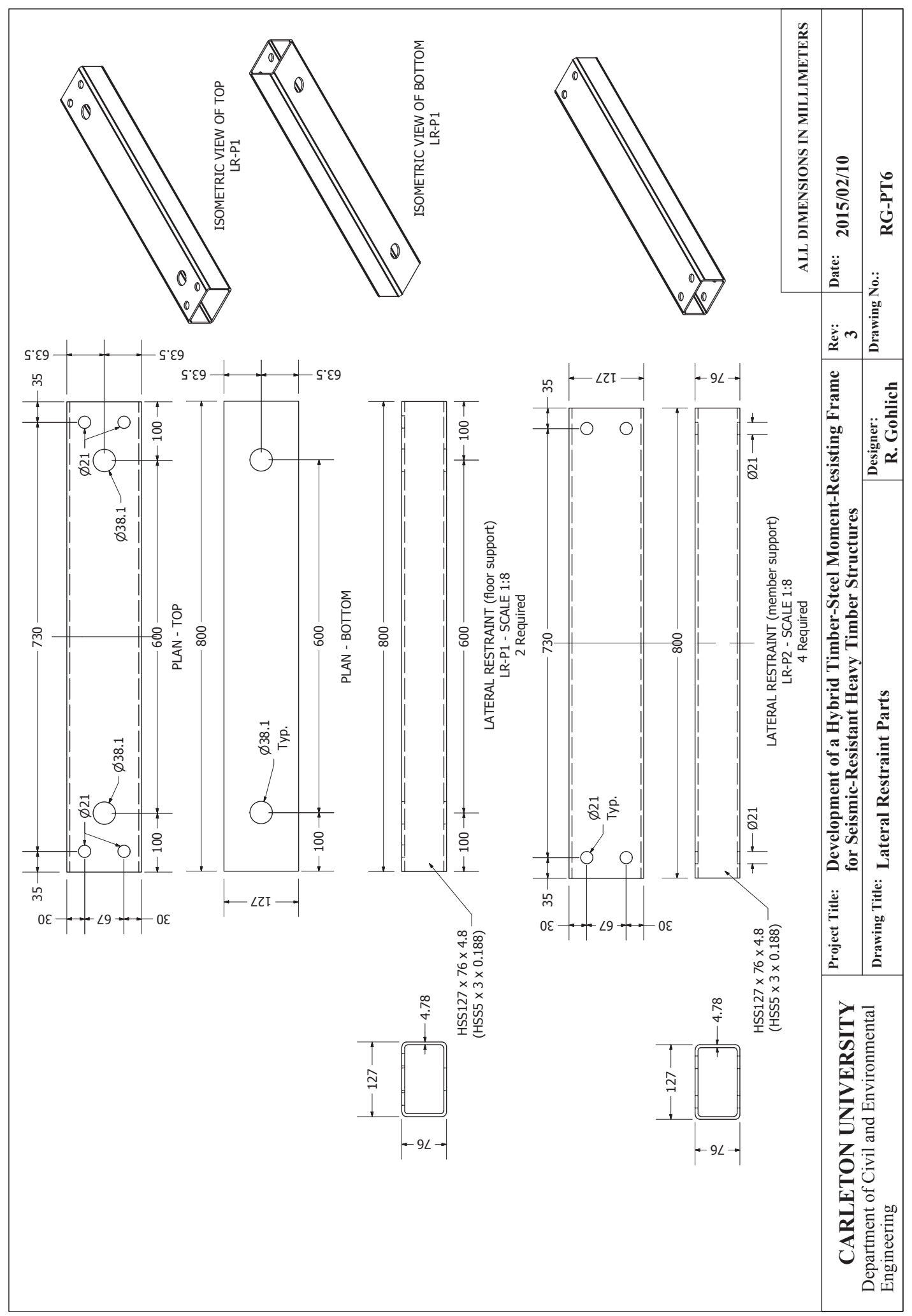

Ryan Gohlich, Department of Civil and Environmental Engineering, Carleton University 


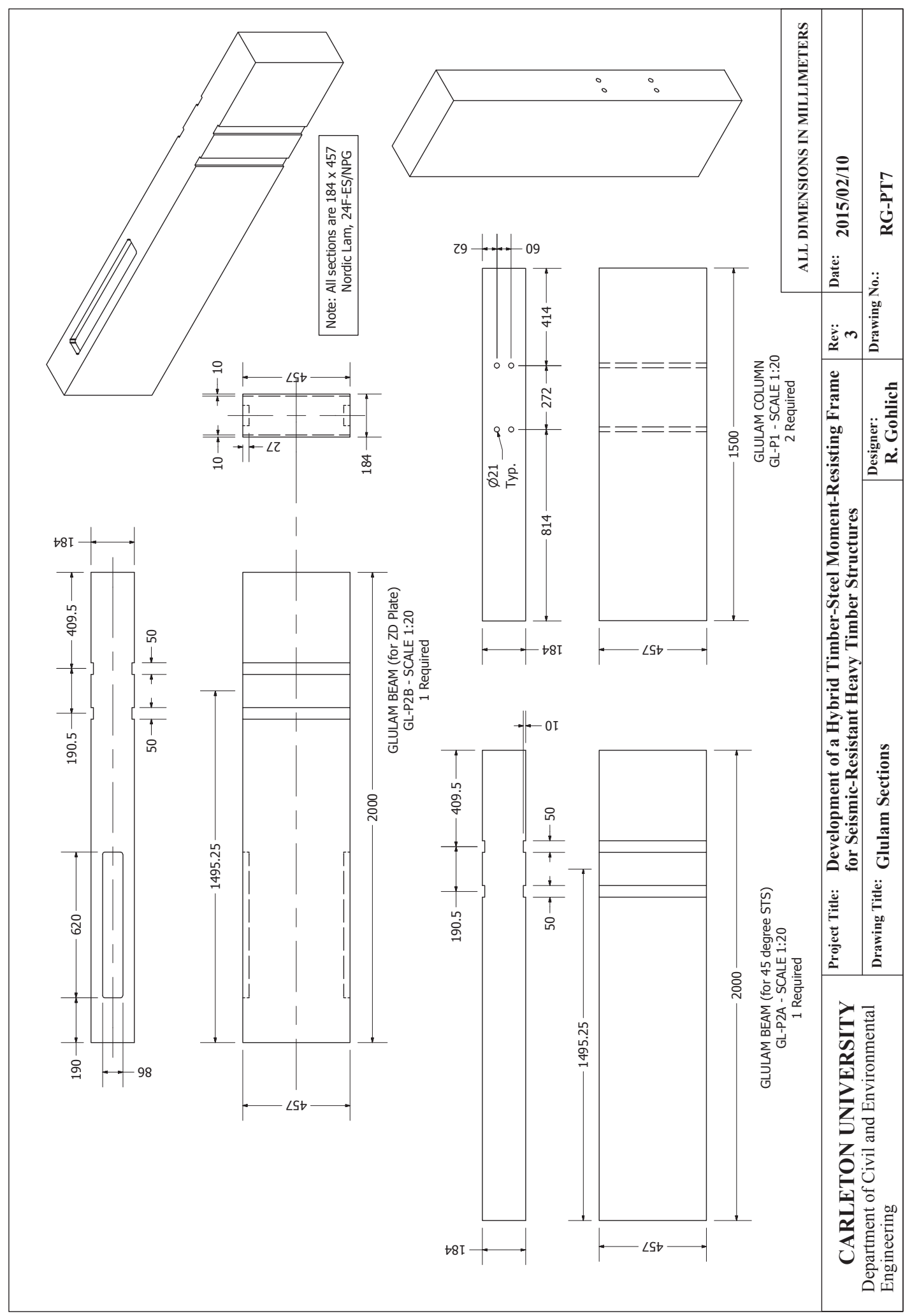

Ryan Gohlich, Department of Civil and Environmental Engineering, Carleton University 


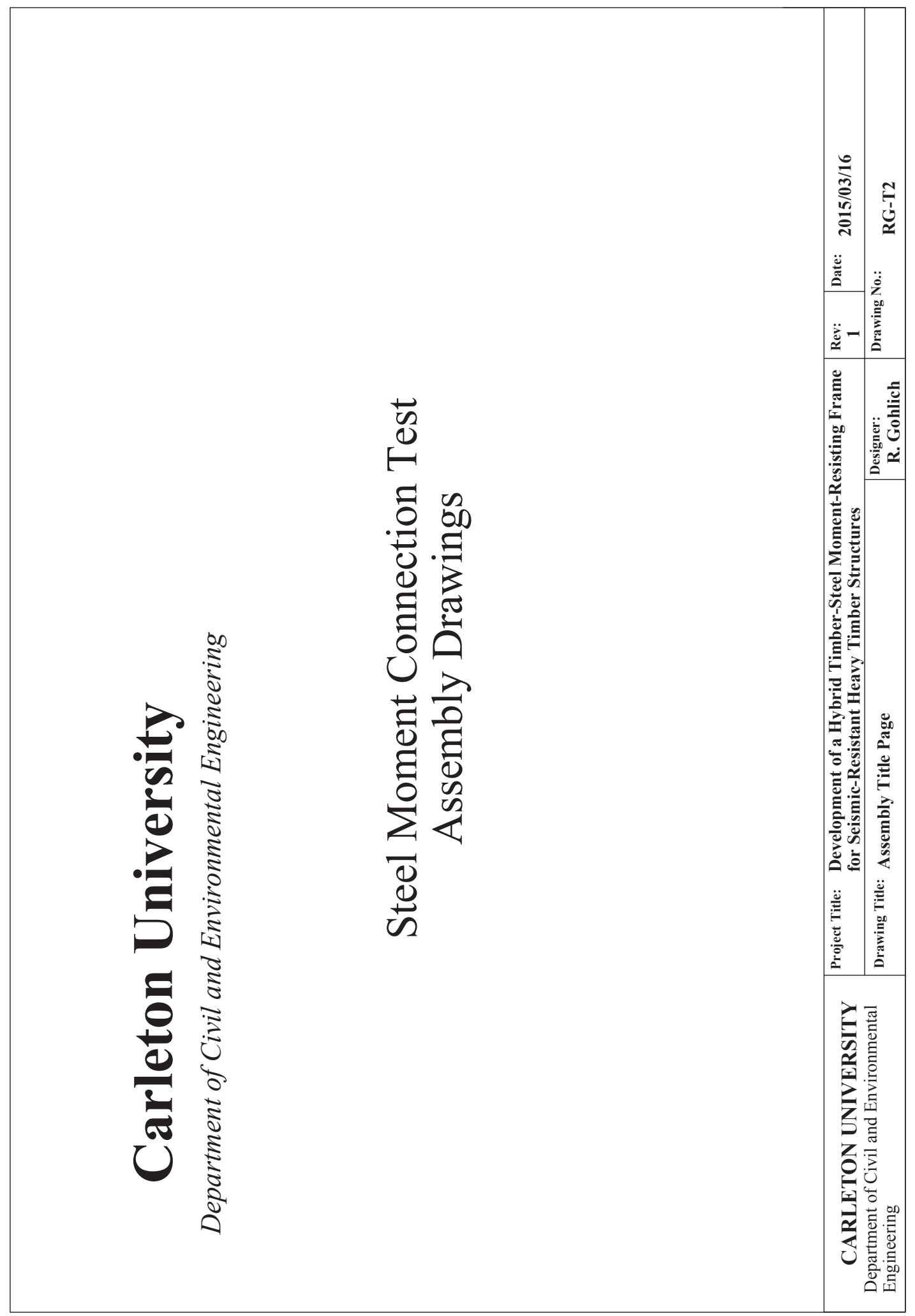

Ryan Gohlich, Department of Civil and Environmental Engineering, Carleton University 


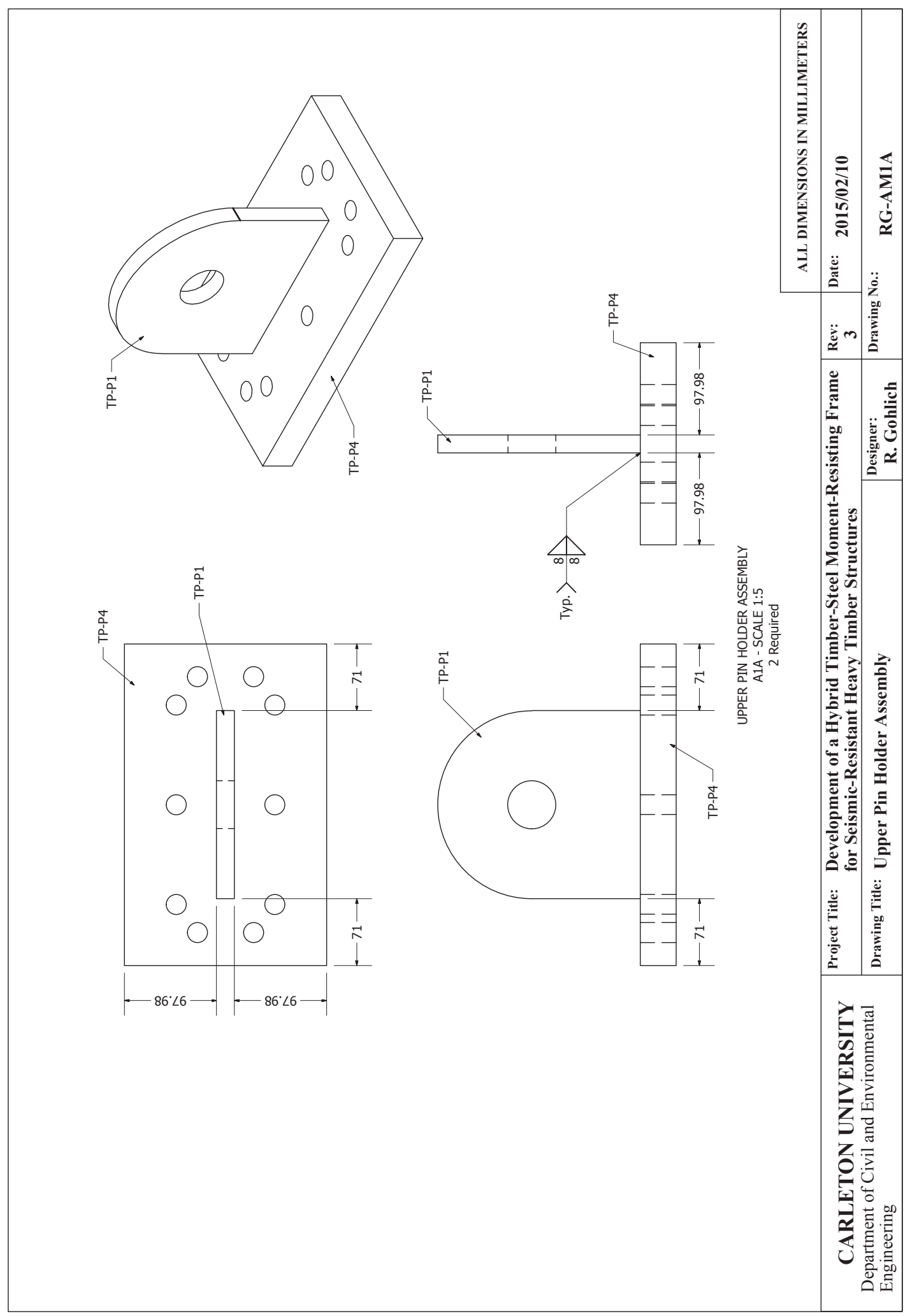

Ryan Gohlich, Department of Civil and Environmental Engineering, Carleton University 


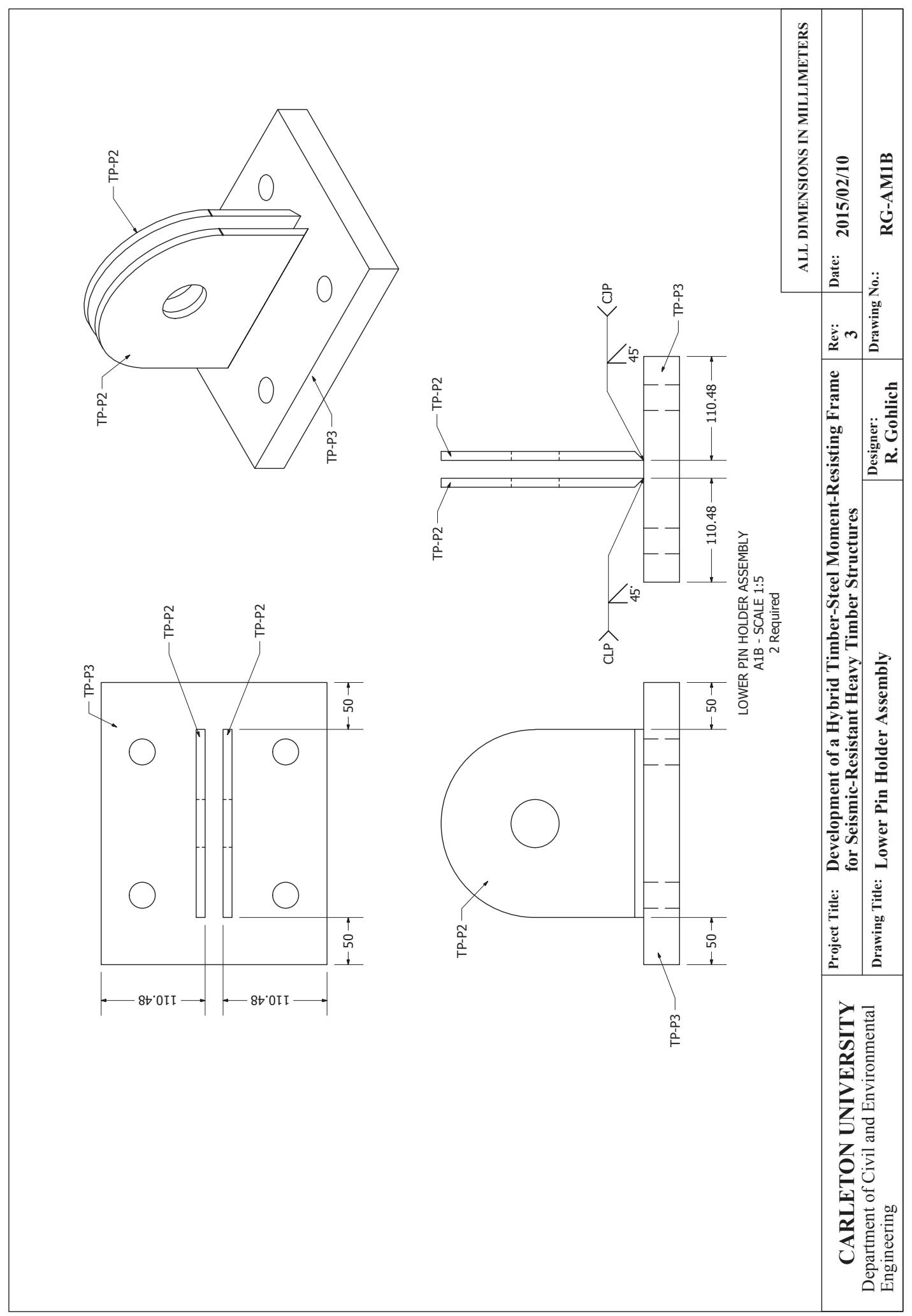

Ryan Gohlich, Department of Civil and Environmental Engineering, Carleton University 


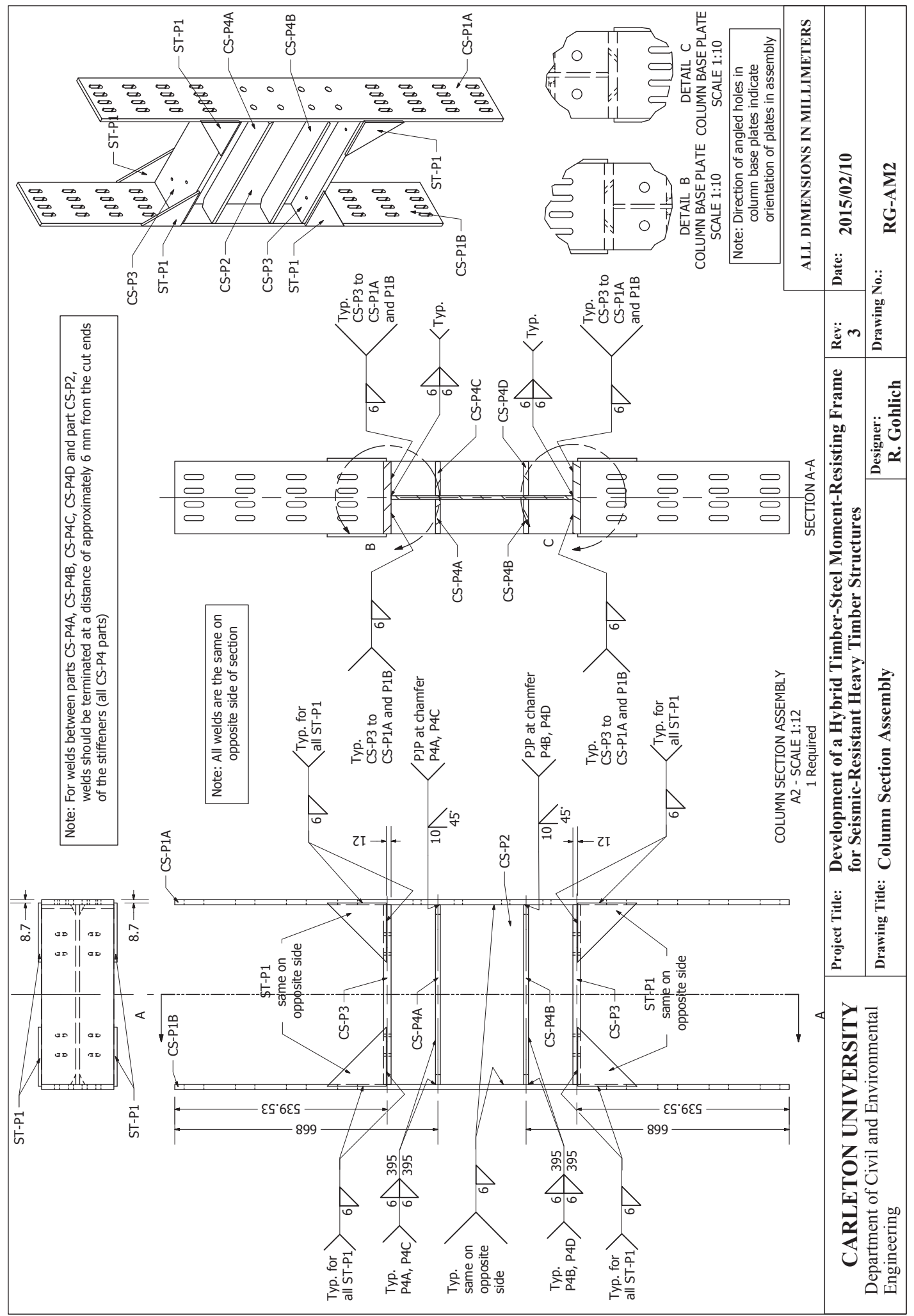




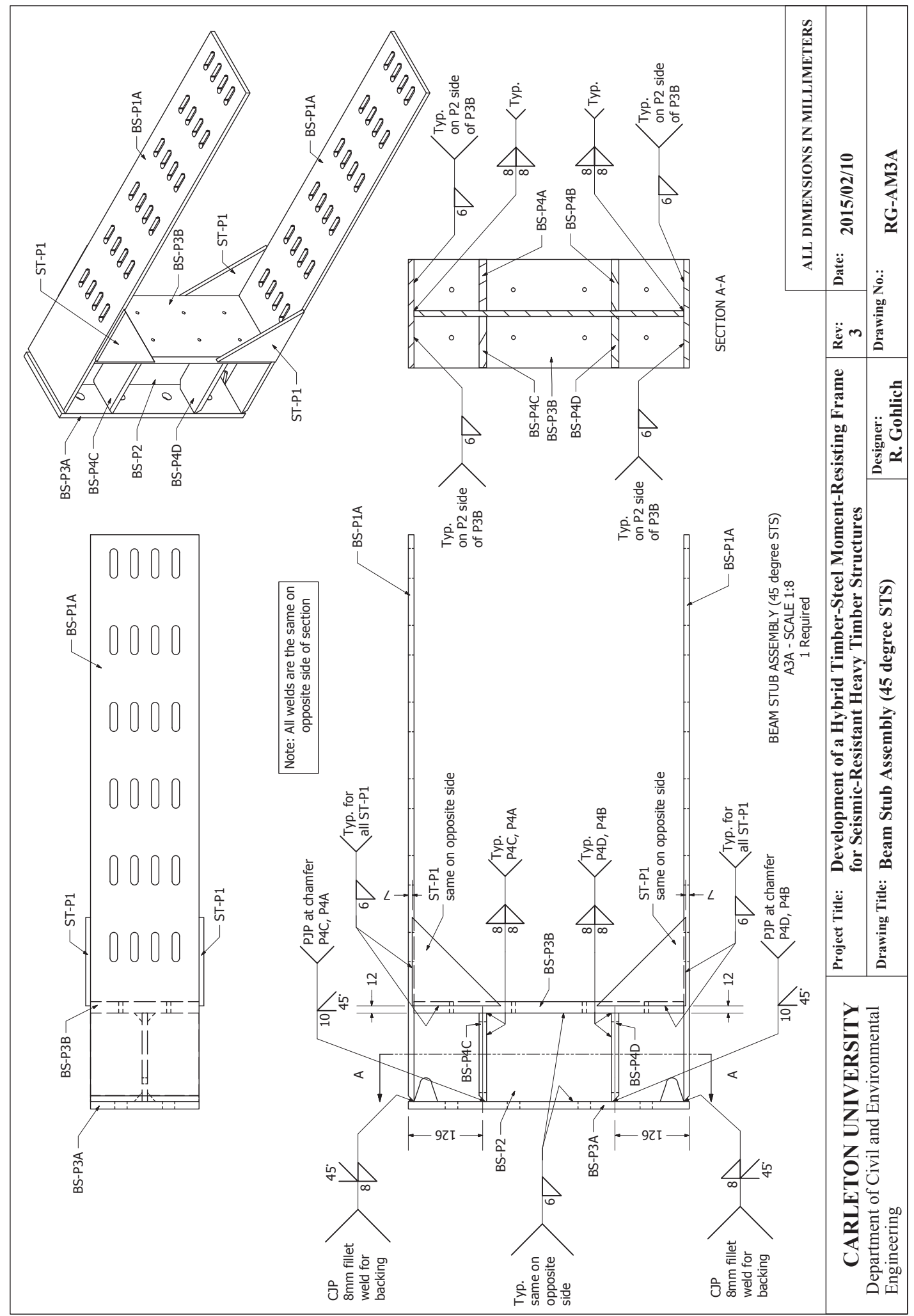

Ryan Gohlich, Department of Civil and Environmental Engineering, Carleton University 


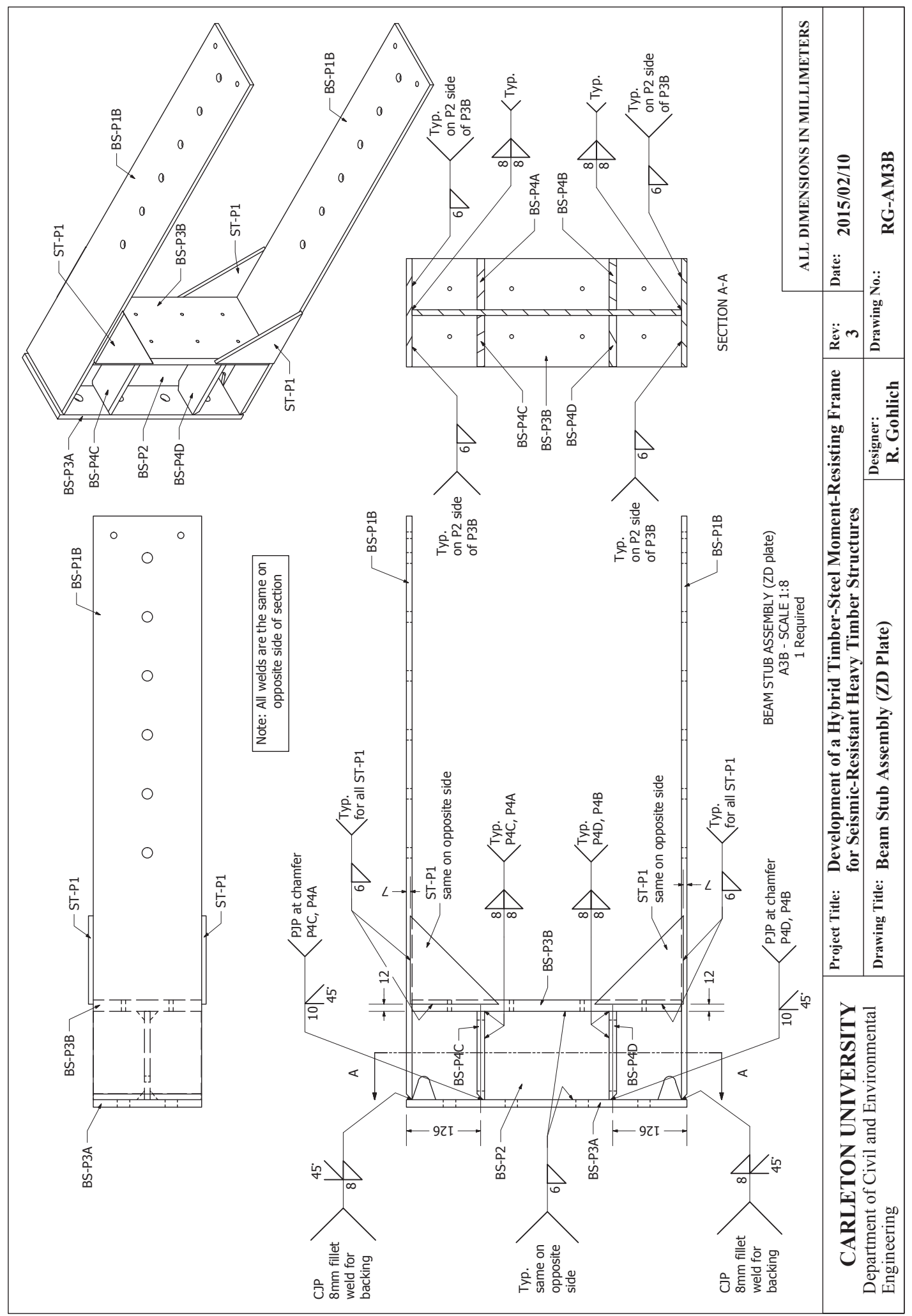

Ryan Gohlich, Department of Civil and Environmental Engineering, Carleton University 


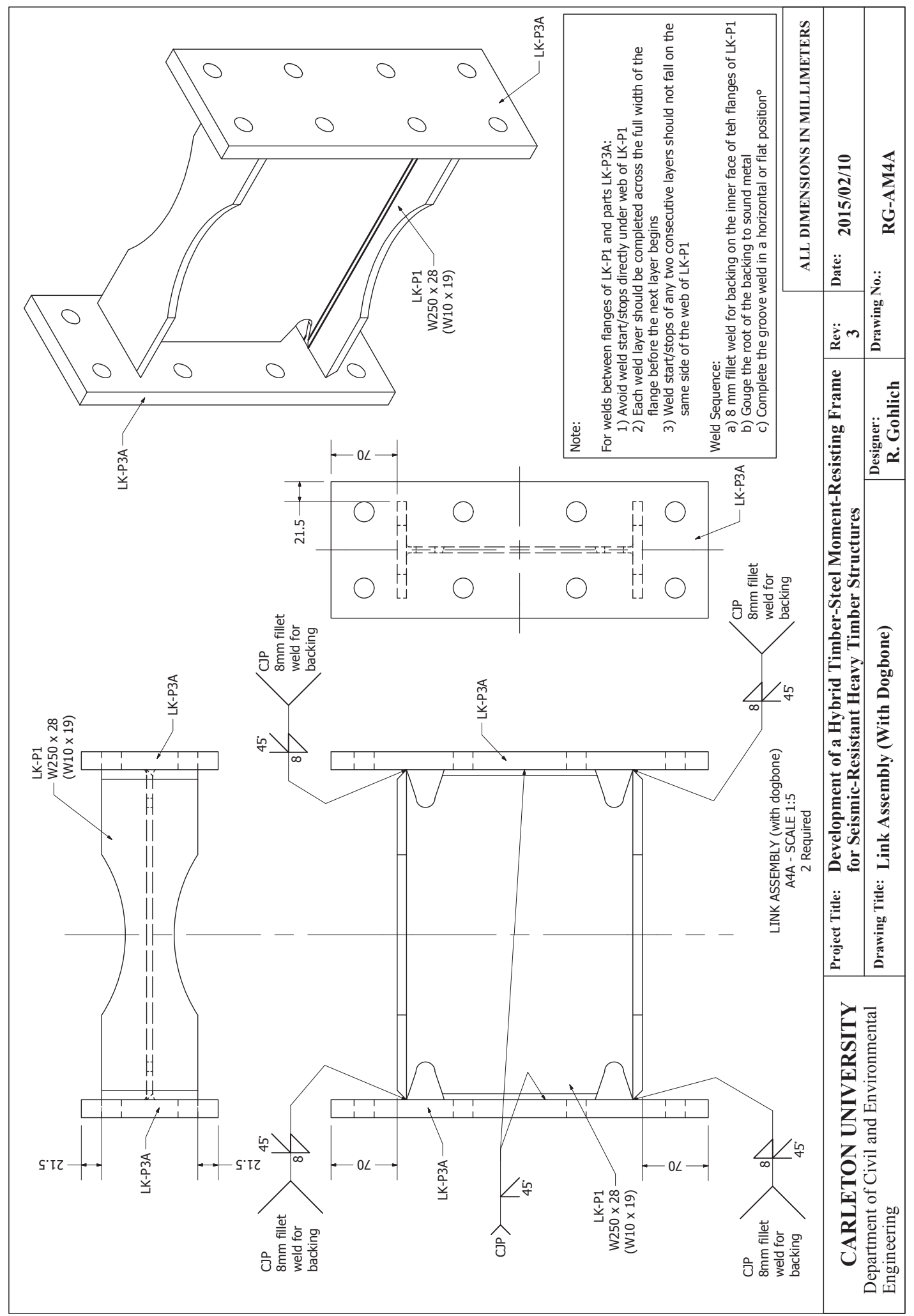

Ryan Gohlich, Department of Civil and Environmental Engineering, Carleton University 


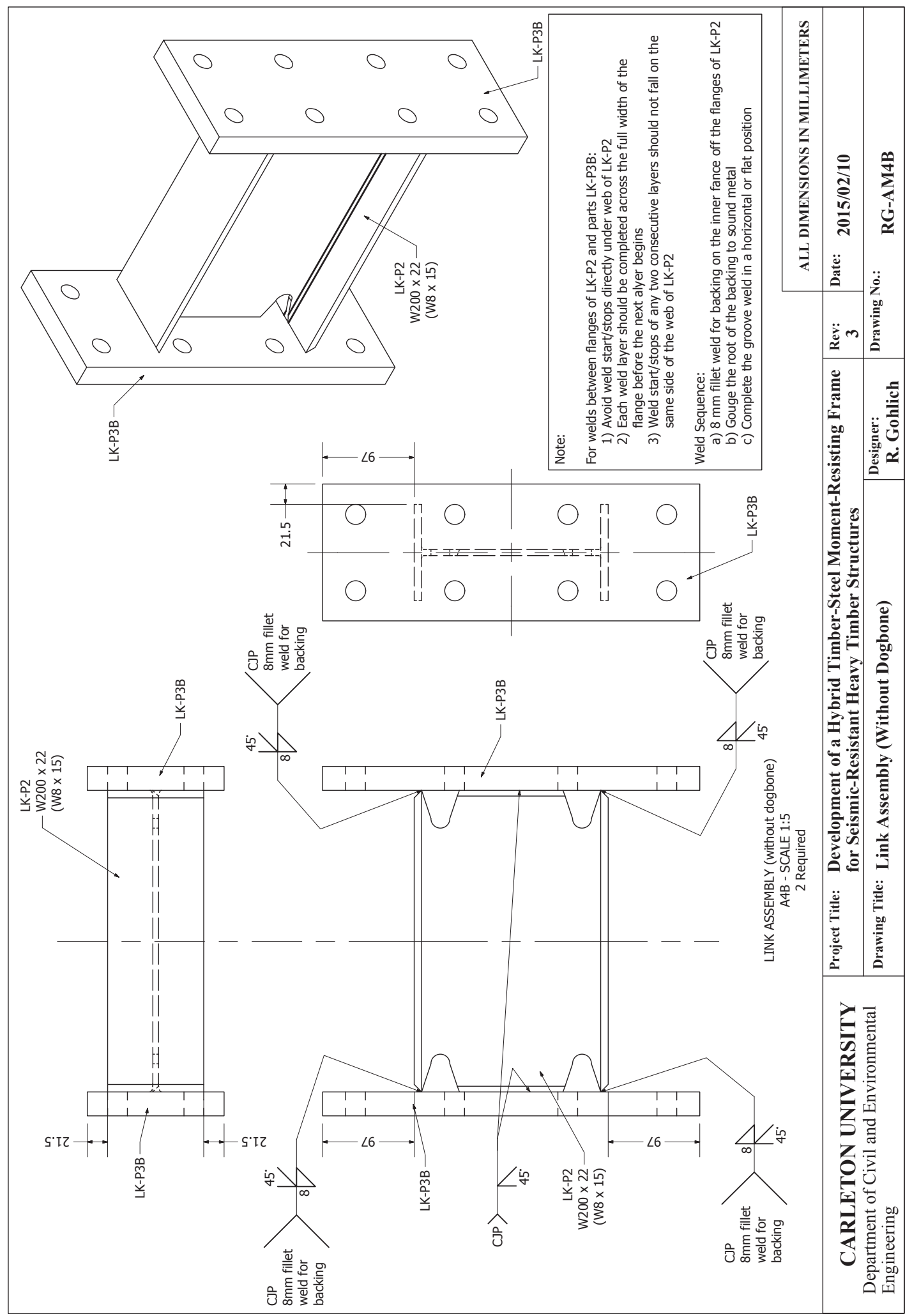

Ryan Gohlich, Department of Civil and Environmental Engineering, Carleton University 


\section{Appendix B: Seismic Design of Prototype Structures}

\section{B.1 Prototype Structure}

The sample calculations and procedures outlined in this Appendix show the methods and assumptions used in the seismic design of a hybrid timber-steel moment-resisting frame (MRF) and an equivalent steel-only MRF. The objective of the designs was to determine if an MRF incorporating the hybrid timber-steel connection could achieve levels of seismic performance comparable to a typical steel-only MRF. To ensure the adequacy of estimated seismic design forces and drifts, each structure was analyzed as a three-dimensional model using ETABS software (Computers \& Structures Inc., 2013). The structures were designed in accordance with relevant Canadian codes. Seismic design criteria was followed as specified in the National Building Code of Canada (NBCC, 2010), main structural members for the steel-only building, links for the hybrid building, and seismic design of steel panel zones was completed with reference to Limit States Design of Steel Structures (CSA S16-09, 2010), main timber members in the hybrid structure were designed according to Engineering Design in Wood (CSA O86-09, 2010), and all moment connections were detailed using prequalified connections found in the Moment Connections for Seismic Applications guidelines (CISC, 2010).

Each prototype structure was six-storeys tall and designed to be located in Victoria, British Columbia. Lateral load resisting systems consisted of a buckling-restrained braced frames (BRBF) in the north-south direction and MRFs in the east-west direction. A full design of the BRB frame was completed for a separate parallel study, so only a preliminary design of the BRBFs is presented 
in this appendix. The performance of the BRBFs have only a minor impact on the design of the MRF members. The structural layout of each building varied slightly, as seen in Figure B.1. The hybrid building used a one-way cross-laminated timber (CLT) floor slab system and hence required less beams in the east-west direction than the steel-only building, which utilized a two-way composite concrete floor slab. The selected storey height was $3.7 \mathrm{~m}$ and identical for each floor. The MRFs and BRBFs consisted of seven bays and four bays respectively, each bay spanning $6.5 \mathrm{~m}$. The bay width was selected to limit the clear-span of the timber beams and reduce required member depth, as well as to limit deflections and vibrations of the CLT slabs. Longer spans could be used for the steel-only structure but identical bay-size was used to facilitate comparison of seismic performance between the two structures. Pinned column bases were used for both the BRBFs and the MRFs.

\section{B.2 ETABS Modelling Assumptions}

Mechanical properties of the wood material were based on those provided in Table 6.3 of Engineering Design in Wood (CSA O86-09, 2010) for glulam members made using Douglas FirLarch with a stress rating of 24f-EX. This type of wood was selected based on its high strength and stiffness comparied to other species, and its availability in Western Canada (location of the prototype building). The mass was set to $470 \mathrm{~kg} / \mathrm{m}^{3}$, and the modulus of elasticity was 12 $800 \mathrm{MPa}$. The steel was modelled as an isotropic material using basic properties of plain carbon steel. To account for concrete casing around the BRBs, the self-weight of the steel for the bracing elements was increased using estimated areas of steel and concrete casing. The yield and ultimate strengths presented in Table B.1 are that of the steel nonlinear replaceable links.

\section{B.3 Seismic Analysis}

Seismic analysis of each prototype building was completed first manually using the equivalent static method (NBCC, 2010) and the portal method for frame analysis, refined using 


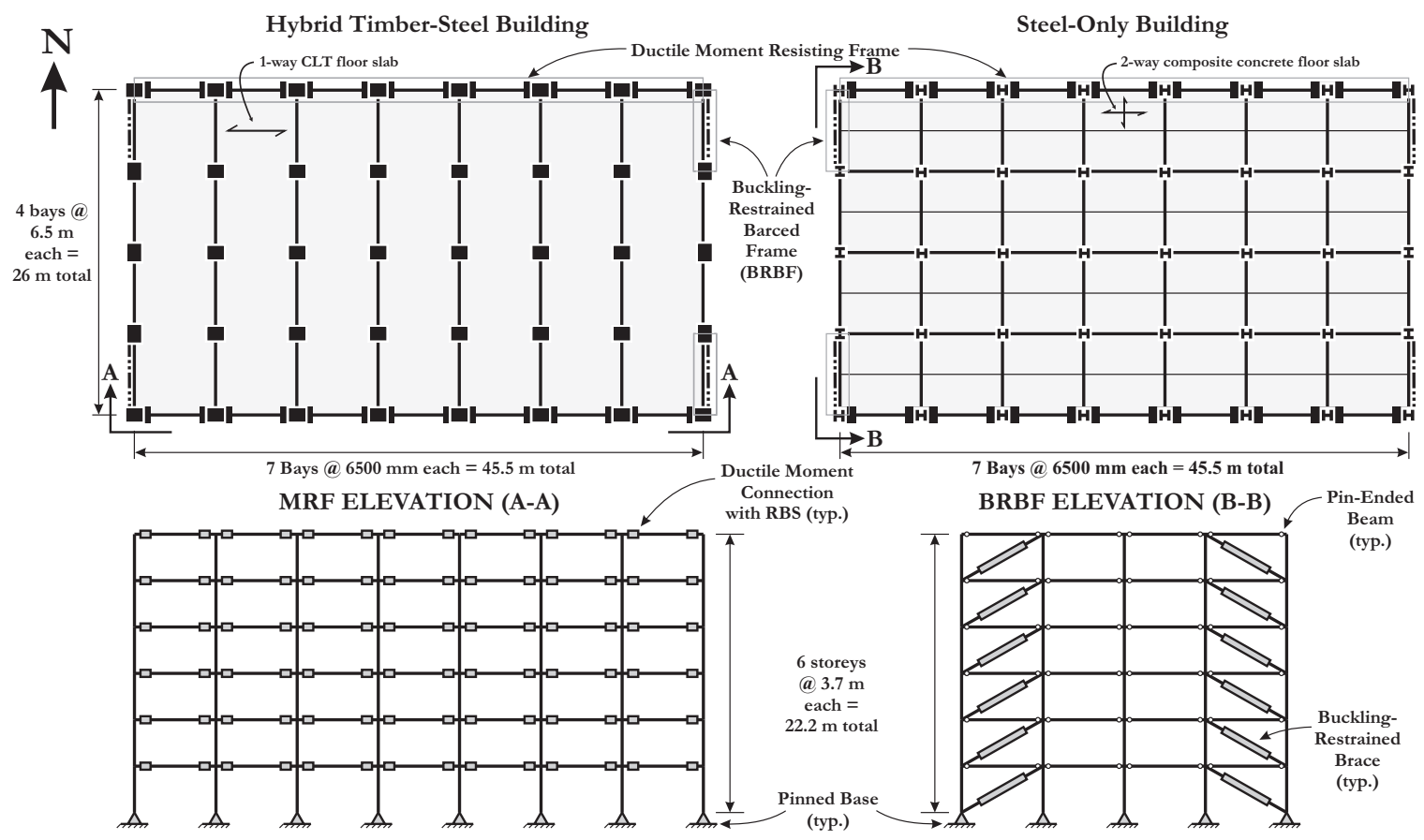

Figure B.1: Structural Layout of Prototype Buildings

Table B.1: Modelling Assumptions for Steel Materials

\begin{tabular}{c|c}
\hline Weight $\left(\mathrm{kN} / \mathrm{m}^{3}\right)$ & 76.8 \\
$\mathrm{E}(\mathrm{MPa})$ & 200000 \\
Poisson's Ratio & 0.3 \\
Shear Modulus $(\mathrm{MPa})$ & 76885 \\
Yield Stress $(\mathrm{MPa})$ & 350 \\
Ultimate Stress $(\mathrm{MPa})$ & 450 \\
\hline
\end{tabular}


ETABS models of two-dimensional frames, and finally by response spectrum analysis of the three-dimensional building models (as a combination of the two-dimensional frames). Nonlinear dynamic time-history analysis of the final two-dimensional hybrid and steel-only MRFs was performed in OpenSees to verify the accuracy of the design under severe seismic loading (results of which are presented in Chapter 6).

\section{B.3.1 Gravity Loads}

The gravity frame was manually designed using the estimated dead and live loads shown in Table B.2, including allowance for non-structural components, floor slabs, and main structural member self-weight estimates (updated during design iterations). Unless otherwise noted by subscripts, the values in the table apply to the design of both prototype buildings. The contribution of the CLT floor slab to the dead load presented in Table B.2 was estimated using design selection tables and accompanying technical documents provided by Nordic Engineered Wood. The thickness of the CLT panels was chosen to accommodate dead, live, and snow loads for the floors and roof of the hybrid building. The appropriate CLT slab was found to be a 131-5s (131 mm thick with 5 plies). The slab thickness and associated self-weight of the composite concrete deck for the steel-only building was chosen based on existing literature with a similar steel building design (Choi et al. 2008). A concrete slab thickness of $93 \mathrm{~mm}$ was applied to the structural model to account for this seismic weight.

The prototype buildings were designed assuming that they functioned as typical office buildings, with normal importance levels (importance factor of 1.0 for ultimate limit states design). These buildings were designed to withstand severe seismic events, but it was not necessary for them to be useable as post-disaster facilities. Live loads were as specified in the NBCC (2010) for standard office buildings.

The design snow load was also determined using the NBCC (2010) statistics for the Victoria, British Columbia region. The snow load profile is shown in Figure B.2, and was estimated assuming a parapet height of $0.5 \mathrm{~m}$ on all roof edges. For modelling simplicity, a snow load of $1.142 \mathrm{kPa}$ was assumed to be uniformly distributed over the entire roof area. The snow load was

Ryan Gohlich, Department of Civil and Environmental Engineering, Carleton University 
Table B.2: Gravity Loads on Prototype Buildings

\begin{tabular}{|c|c|c|c|}
\hline Roof & Load (kPa) & Floor & Load $(\mathrm{kPa})$ \\
\hline Roofing & 0.24 & Floor Finish & 0.1 \\
\hline Insulation & 0.1 & Partitions & 1.0 \\
\hline Fire Proofing & 0.1 & Fire Proofing & 0.1 \\
\hline Ceiling & 0.24 & Ceiling & 0.24 \\
\hline Mech/Elec & 0.48 & Mech/Elec & 0.48 \\
\hline CLT Slab ${ }_{\text {hybrid }}$ & 0.623 & CLT Slab ${ }_{\text {hybrid }}$ & 0.623 \\
\hline Composite Deck steel-only & 2.2 & Composite Deck steel-only & 2.2 \\
\hline Wood Framing & 0.30 & Wood Framing ${ }_{\text {hybrid }}$ & 0.30 \\
\hline Steel Framing ${ }_{\text {steel-only }}$ & 0.72 & Steel Framing ${ }_{\text {steel-only }}$ & 0.72 \\
\hline Total $_{\text {hybrid }}$ & 2.08 & Total $_{\text {hybrid }}$ & 2.84 \\
\hline Total $_{\text {steel-only }}$ & 4.08 & Total $_{\text {steel-only }}$ & 4.84 \\
\hline Live Load & 1.0 & Live Load & 2.4 \\
\hline
\end{tabular}

identical for both hybrid and steel-only buildings.

\section{B.3.2 Equivalent Static Method}

Seismic analysis for the design of the lateral load resisting systems was initially carried out using the equivalent static method as specified in the NBCC (2010) on two-dimensional MRFs and BRBFs. This was done manually using estimated member weights in the preliminary design phase. The general procedure for this method is presented below, and calculation details are shown in the following sections (NBCC, 2010).

1. The design spectrum is established based on building location. This is done by adjusting

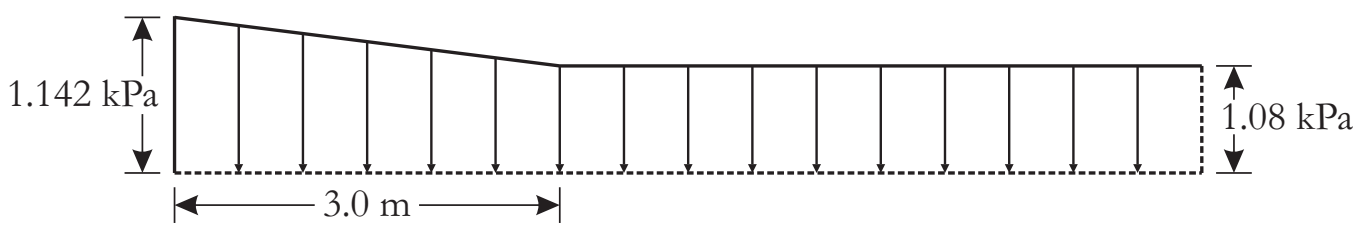

Figure B.2: Snow Load Profile for Victoria, British Columbia 
the predefined $5 \%$ damped spectral response to account for site class.

2. Seismic properties of the structure are selected based on building type, including importance factor, ductility and overstrength factors, and an estimate of the fundamental lateral period.

3. Seismic weight of the structure is approximated accounting for estimated superimposed dead loads, self-weight, and a portion of snow load.

4. Static base shear is calculated for each primary building axis, and distributed vertically to each floor.

5. Torsional sensitivity is determined in order to select the appropriate method of accounting for torsional effects.

6. Storey forces are amplified to account for accidental torsion, notional loads, and P-delta effects.

7. Final storey forces are distributed between the vertical lateral load resisting systems in the appropriate directions (parallel to the force).

8. Local seismic forces are calculated for each element. Structural members are re-sized, and the equivalent static seismic analysis is reiterated with updated seismic weight until the design converges.

Several iterations were applied using the equivalent static method until no significant changes were required. The final design was refined using response spectrum analysis.

\section{B.3.2.1 Design Spectrum}

Site class $\mathrm{C}$ was selected for the seismic design of the prototype buildings based on existing literature presenting a similar building design in the Victoria region (Shen, 2009). For site class C, Tables 4.1.8.4B and 4.1.8.4C of the NBCC (2010) specify modification factors of $1.0\left(F_{a}\right.$ and $\left.F_{v}\right)$, meaning that the design spectrum is identical to the $5 \%$ damped spectral response for Victoria provided by Appendix C of Division B (NBCC, 2010). Table B.3 and Figure B.3 show the design spectrum used for both the equivalent static procedure and response spectrum analysis.

Ryan Gohlich, Department of Civil and Environmental Engineering, Carleton University 
Table B.3: Design Spectrum for Victoria, British Columbia

\begin{tabular}{c|cc}
\hline$T(\mathrm{~s})$ & $S(T)$ & $S_{a}(T)$ \\
\hline 0.2 & $1.2 \mathrm{~g}$ & $1.2 \mathrm{~g}$ \\
0.5 & $0.82 \mathrm{~g}$ & $0.82 \mathrm{~g}$ \\
1.0 & $0.38 \mathrm{~g}$ & $0.38 \mathrm{~g}$ \\
2.0 & $0.18 \mathrm{~g}$ & $0.18 \mathrm{~g}$ \\
4.0 & N/A & 0.09 \\
\hline
\end{tabular}

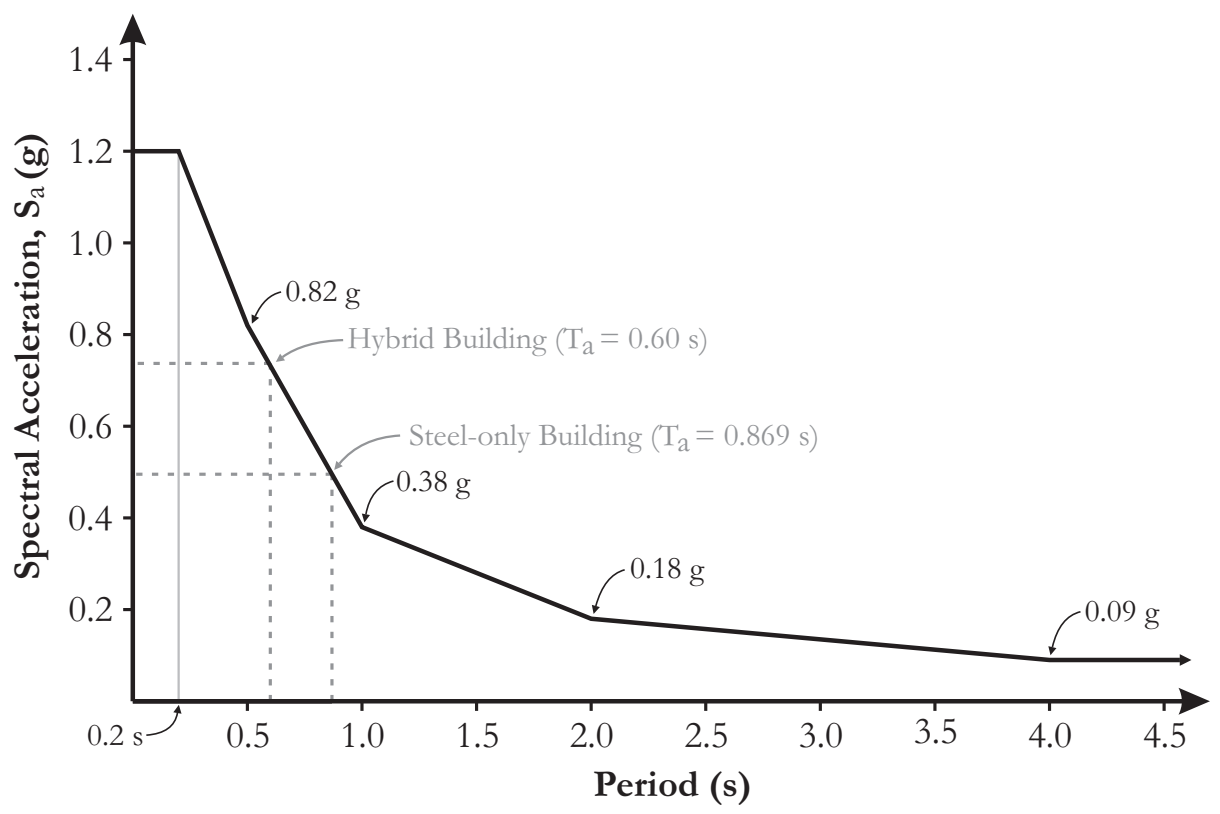

Figure B.3: Design Spectrum for Victoria, British Columbia 
An estimate of the fundamental lateral period $\left(T_{a}\right)$ of each building was made based on the empirical equations defined in section 4.1.8.11 (3) (a) (i) and (iii) of the NBCC (2010). The method for estimating the period for MRFs varies with building material according to equations (B.1) and (B.2) for steel and "other moment frames" respectively, hence $T_{a}$ of each prototype building was different. The hybrid moment frame fell into the latter category.

$$
\begin{gathered}
T_{a, \text { steel }}=0.085\left(h_{n}\right)^{3 / 4} \\
T_{a, h y b r i d}=0.1 \mathrm{~N}
\end{gathered}
$$

where $h_{n}$ and $N$ are the total building height and the total number of storeys respectively.

The steel and hybrid buildings had initial period estimates of 0.869 and 0.6 seconds respectively. It should be noted that this is likely a very conservative estimate for a timber building, since it is a flexible material, but in the absence of more applicable code-based estimates, this value was implemented in design. Because these empirical periods are often conservative and underestimated (to increase spectral acceleration), the upper limit specified in section 4.1.8.11 (3) (d) (i) for MRFs (limited to 1.5 times the aforementioned values) was applied, assuming that the response spectrum analysis would provide a dynamic period that is above that limit. This reduced the total number of design iterations required for convergence. This was done based on design methods suggested by Filiatrault et al. (2013), and resulted in final initial period estimates of 1.30 and 0.9 seconds for response spectrum analysis design of the steel and hybrid buildings respectively.

\section{B.3.2.2 Seismic Weight}

The seismic weight of each building was estimated based on self-weight of structural components, superimposed dead loads, and $25 \%$ of the total snow load, as specified int he NBCC (2010). Table B.4 shows the approximate seismic weight at each floor of both prototype buildings. A small amount was added to the total weight of the hybrid building to account for the steel connection components in the MRF beam-column joints. It is interesting to note that because 
of the low weight of CLT panels as compared to composite concrete decks, the seismic weight of the hybrid structure was significantly lower than the steel-only building; the effect of this is reflected in the total base shear imposed on the MRFs as shown in the following section.

\section{B.3.2.3 Design Base Shear}

The design static base shear can be estimated based on section 4.1.8.11 (2) of the NBCC (2010) using equation (B.3). This imposed minimum lateral earthquake force is also dependent on the design spectral acceleration of the structure $\left(S\left(T_{a}\right)\right)$ (determined according to Figure B.3) and the estimated ductility and overstrength of the lateral load resisting system. The estimated seismic design properties of each building for the static analysis can be found in Table B.5.

$$
V=S\left(T_{a}\right) M_{v} I_{E} W /\left(R_{d} R_{o}\right)
$$

The benefit of reduced seismic weight in the timber structure is not entirely captured in a static analysis since the code requires such a conservative estimate for the fundamental period of a wood building as compared to steel (raising the $S\left(T_{a}\right)$ ), but even so, the hybrid structure has a static base shear that is $24 \%$ lower than the equivalent steel building. This will be further decreased after completion of the response spectrum analysis, taking full advantage of the low seismic weight and reduced lateral period. The higher mode factor, $\mathrm{M}_{\mathrm{v}}$, is taken as unity for both structures according to Table 4.1.8.11 of the NBCC (2010). Since the goal of this study was to determine if high R-factor design could be applied to hybrid structures (verified by the experimental program), the ductility and overstrength factors for both the hybrid and steel-only buildings was selected using recommendations for steel ductile moment resisting frames. This corresponds to an R-factor of 7.5, while R-factors for timber MRFs are typically limited to 3.0. If it could be shown that similar performance is possible between hybrid and steel-only systems, then this increase in R-factor significantly reduces total base shear of the hybrid system. 
Table B.4: Seismic Weight of Prototype Buildings

\begin{tabular}{c|cccccc}
\hline & $\begin{array}{c}\text { Floor } \\
\text { Area } \\
\left(\mathrm{m}^{2}\right)\end{array}$ & $\begin{array}{c}\text { Snow } \\
\text { Load } \\
(\mathrm{kPa})\end{array}$ & $\begin{array}{c}\text { Dead } \\
\text { Load } \\
(\mathrm{kPa})\end{array}$ & $\begin{array}{c}\text { Total } \\
\text { Weight }_{\text {hybrid }} \\
(\mathrm{kN})\end{array}$ & $\begin{array}{c}\text { Dead } \\
\text { Load }_{\text {steel }} \\
(\mathrm{kPa})\end{array}$ & $\begin{array}{c}\text { Total } \\
\text { Weight }_{\text {steel }} \\
(\mathrm{kN})\end{array}$ \\
\hline Roof (6) & 1183 & 0.286 & 1.783 & 2600 & 3.36 & 4682 \\
5 & 1183 & - & 2.543 & 3208 & 4.12 & 5271 \\
4 & 1183 & - & 2.543 & 3224 & 4.12 & 5292 \\
3 & 1183 & - & 2.543 & 3235 & 4.12 & 5292 \\
2 & 1183 & - & 2.543 & 3257 & 4.12 & 5314 \\
1 & 1183 & - & 2.543 & 3307 & 4.12 & 5314 \\
\hline \multicolumn{7}{r}{}
\end{tabular}

Table B.5: Seismic Properties of Prototype Buildings

\begin{tabular}{c|cc}
\hline Seismic Property & $\mathrm{MRF}_{\text {hybrid }}$ & $\mathrm{MRF}_{\text {steel }}$ \\
\hline $\mathrm{S}\left(\mathrm{T}_{\mathrm{a}}\right)(\mathrm{g})$ & 0.40 & 0.319 \\
$\mathrm{M}_{\mathrm{v}}$ & 1.0 & 1.0 \\
$\mathrm{I}_{\mathrm{E}}$ & 1.0 & 1.0 \\
$\mathrm{R}_{\mathrm{d}}$ & 5.0 & 5.0 \\
$\mathrm{R}_{\mathrm{o}}$ & 1.5 & 1.5 \\
$\mathrm{~V}$ & 1009 & 1326 \\
\hline
\end{tabular}




\section{B.3.2.4 Vertical Lateral Force Distribution}

Equation (B.4) of the NBCC (2010) gives a method of distributing the total base shear along the height of the building, concentrated at floor locations (assuming all mass is lumped at

floors). It is also required that an additional force, $\mathrm{F}_{\mathrm{t}}$, be applied at the roof level according to equation (B.5). Initial storey shear distributions on the MRFs are shown in Tables B.6 and B.7 for the hybrid and steel-only buildings respectively.

$$
\begin{gathered}
F_{x}=\left(V-F_{t}\right) W_{x} h_{x} /\left(\sum_{i=1}^{n} W_{i} h_{i}\right) \\
F_{t}=0.07 T_{a} V \leq 0.25 \mathrm{~V}
\end{gathered}
$$

\section{B.3.2.5 Notional Loads}

The Notional Load Approach is used in the design of beam-columns according to CSA S1609 (2010) to account for initial out-of-plumb of the columns and "partial yielding at factored load levels" in an elastic analysis. This method estimates additional lateral loads that can be applied to the frame, taken as $0.5 \%$ of the total gravity loads acting on each floor according to the relevant load combination. The load combination used for this study was $1.0 \mathrm{D}+1.0 \mathrm{E}+0.5 \mathrm{~L}+0.25 \mathrm{~S}$. Tables B. 8 and B.9 show the estimated notional loads acting on each storey of the hybrid and

Table B.6: Initial Storey Shear for Hybrid Building

\begin{tabular}{c|cccc}
\hline Storey & $\mathrm{h}_{\mathrm{x}}(\mathrm{m})$ & $\mathrm{W}_{\mathrm{x}}(\mathrm{kN})$ & $\mathrm{W}_{\mathrm{x}} \mathrm{h}_{\mathrm{x}}(\mathrm{kN} \cdot \mathrm{m})$ & $\mathrm{F}_{\mathrm{x}}(\mathrm{kN})$ \\
\hline Roof $(6)$ & 22.2 & 2600 & 57719 & 294 \\
5 & 18.5 & 3208 & 59354 & 237 \\
4 & 14.8 & 3224 & 47714 & 190 \\
3 & 11.1 & 3235 & 35911 & 143 \\
2 & 7.4 & 3257 & 24101 & 96 \\
1 & 3.7 & 3307 & 12237 & 49 \\
\hline
\end{tabular}

Ryan Gohlich, Department of Civil and Environmental Engineering, Carleton University 
Table B.7: Initial Storey Shear for Steel-only Building

\begin{tabular}{c|cccc}
\hline Storey & $\mathrm{h}_{\mathrm{x}}(\mathrm{m})$ & $\mathrm{W}_{\mathrm{x}}(\mathrm{kN})$ & $\mathrm{W}_{\mathrm{x}} \mathrm{h}_{\mathrm{x}}(\mathrm{kN} \cdot \mathrm{m})$ & $\mathrm{F}_{\mathrm{x}}(\mathrm{kN})$ \\
\hline Roof $(6)$ & 22.2 & 4682 & 103932 & 436 \\
5 & 18.5 & 5271 & 97511 & 296 \\
4 & 14.8 & 5292 & 78316 & 237 \\
3 & 11.1 & 5292 & 58737 & 178 \\
2 & 7.4 & 5314 & 39324 & 119 \\
1 & 3.7 & 5314 & 19662 & 60 \\
\hline
\end{tabular}

steel buildings respectively as per CSA S16-09 (2010).

\section{B.3.2.6 P-Delta Effect}

The vertical loads acting on a laterally deformed frame produce secondary bending moments in MRF members. This phenomenon, known as the P-delta effect, is accounted for by amplifying the first order moments in the bending members, attained through an elastic analysis, by a factor $\left(\mathrm{U}_{2}\right)$ (Filiatrault et al. 2013). This factor is determined using estimated storey drifts based on previously studied frames in accordance with equation (B.6); for an MRF, total storey drift is estimated as $2.5 \%$ of the storey height (Filiatrault et al. 2013).

$$
U_{2}=\left(1+\theta_{x}\right)
$$

Table B.8: Notional Loads for Hybrid Building

\begin{tabular}{c|ccccc}
\hline Storey & $\begin{array}{c}\text { Dead Load } \\
(\mathrm{kN})\end{array}$ & $\begin{array}{c}\text { Live Load } \\
(\mathrm{kN})\end{array}$ & $\begin{array}{c}\text { Snow Load } \\
(\mathrm{kN})\end{array}$ & $\begin{array}{c}\text { Gravity Load } \\
(\mathrm{kN})\end{array}$ & $\begin{array}{c}\text { Notional Load } \\
(\mathrm{kN})\end{array}$ \\
\hline Roof $(6)$ & 2109 & 1183 & 1351 & 3039 & 15 \\
5 & 3008 & 2839 & - & 4428 & 22 \\
4 & 3008 & 2839 & - & 4428 & 22 \\
3 & 3008 & 2839 & - & 4428 & 22 \\
2 & 3008 & 2839 & - & 4428 & 22 \\
1 & 3008 & 2839 & - & 4428 & 22 \\
\hline
\end{tabular}


Table B.9: Notional Loads for Steel-only Building

\begin{tabular}{c|ccccc}
\hline Storey & $\begin{array}{c}\text { Dead Load } \\
(\mathrm{kN})\end{array}$ & $\begin{array}{c}\text { Live Load } \\
(\mathrm{kN})\end{array}$ & $\begin{array}{c}\text { Snow Load } \\
(\mathrm{kN})\end{array}$ & $\begin{array}{c}\text { Gravity Load } \\
(\mathrm{kN})\end{array}$ & $\begin{array}{c}\text { Notional Load } \\
(\mathrm{kN})\end{array}$ \\
\hline Roof $(6)$ & 4827 & 1183 & 1351 & 5756 & 29 \\
5 & 5726 & 2839 & - & 7145 & 36 \\
4 & 5726 & 2839 & - & 7145 & 36 \\
3 & 5726 & 2839 & - & 7145 & 36 \\
2 & 5726 & 2839 & - & 7145 & 36 \\
1 & 5726 & 2839 & - & 7145 & 36 \\
\hline
\end{tabular}

where the stability coefficient, $\theta_{x}$, is as given as follows:

$$
\theta_{x}=\frac{P_{x} \Delta_{x}}{R_{o} F_{x} h_{s x}}
$$

In equation (B.7), $P_{x}$ is the total gravity load at a given floor, $\Delta_{x}$ is the anticipated storey drift, $F_{x}$ is the design base shear of the MRF at the corresponding storey (as per Table B.7), and $h_{s x}$ is storey height. Tables B.10 and B.11 present the P-delta amplification factor for the hybrid and steel-only buildings respectively.

Table B.10: P-delta Amplification Factor for Hybrid Building

\begin{tabular}{c|ccc}
\hline Storey & $\mathrm{P}_{\mathrm{x}}(\mathrm{kN})$ & $\theta_{x}$ & $\mathrm{U}_{2}$ \\
\hline Roof $(6)$ & 3039 & 0.17 & 1.17 \\
5 & 7467 & 0.23 & 1.23 \\
4 & 11894 & 0.27 & 1.27 \\
3 & 16322 & 0.31 & 1.31 \\
2 & 20750 & 0.36 & 1.36 \\
1 & 25178 & 0.42 & 1.42 \\
\hline
\end{tabular}


Table B.11: P-delta Amplification Factor for Steel-only Building

\begin{tabular}{c|ccc}
\hline Storey & $\mathrm{P}_{\mathrm{x}}(\mathrm{kN})$ & $\theta_{x}$ & $\mathrm{U}_{2}$ \\
\hline Roof $(6)$ & 5756 & 0.22 & 1.22 \\
5 & 12901 & 0.29 & 1.29 \\
4 & 20047 & 0.34 & 1.34 \\
3 & 27192 & 0.39 & 1.39 \\
2 & 34337 & 0.45 & 1.45 \\
1 & 41482 & 0.52 & 1.52 \\
\hline
\end{tabular}

\section{B.3.2.7 Structural Irregularities}

Because the selected building geometry was rectangular and symmetrical, none of the structural irregularities exist that are outlined in Table 4.1.8.6 of the NBCC (2010). Stiffness and mass of adjacent storeys was checked using the three-dimensional ETABS models. Because two identical MRFs were used in the east-west direction and two identical BRBFs were used in the north-south direction, the structure was not sensitive to torsional effects. Torsional sensitivity was checked with equation (B.8) following section 4.1.8.11 (9) of the NBCC (2010).

$$
B_{x}=\delta_{\max } / \delta_{\text {ave }}
$$

where $\delta_{\text {max }}$ is "the maximum sotrey displacement induced by the equivalent static forces acting at a distance of $\pm 0.10 \mathrm{D}_{\mathrm{nx}}$ from the centre of mass of each floor," and $\delta$ ave is "the average displacements at the extreme points of the structure produced by the above-mentioned forces" (NBCC, 2010).

Since the sensitivity factor was below 1.7 at each storey of both buildings, the NBCC (2010) allows accidental torsion to be accounted for by applying a 10\% offset between the centre of mass and the centre of rigidity. For simplification of the equivalent static seismic analysis, storey forces were increased by $10 \%$ to account for accidental torsion. This estimate was used for the preliminary static design, and methods specified in section 4.1.8.12 of NBCC (2010) for response spectrum analysis were strictly followed for the final design in ETABS.

Ryan Gohlich, Department of Civil and Environmental Engineering, Carleton University 


\section{B.3.2.8 Final Static Seismic Forces}

Final design storey forces from the equivalent static seismic analysis of the MRFs can be seen in Tables B.12 and B.13 for the hybrid and steel-only buildings, respectively. These forces take into account the aforementioned notional loads, P-delta amplification, and torsional effects. Due to the symmetrical building geometry, the total storey force was distributed equally between the two MRFs on each floor. Total static base shears were found to be $1559 \mathrm{kN}$ and $2206 \mathrm{kN}$ for the hybrid and steel-only buildings respectively.

where:

$$
F_{x, \text { inal }}=\left(1.1 F_{x}+N_{x}\right) U_{2}
$$

using values of $N_{x}$ and $U_{2}$ as presented above.

\section{B.3.3 Response Spectrum Analysis}

Although the Equivalent Static Method would be adequate for the seismic analysis of the prototype structures as defined by the NBCC (2010), Response Spectrum Analysis was carried out in order to optimize the design and achieve a more accurate basis for comparison of the hybrid and steel-only prototype structures. The following general procedure was followed for the response spectrum analysis of each building (Filiatrault et al. 2013):

Table B.12: Final Equivalent Static Storey Forces for Hybrid MRF

\begin{tabular}{c|ccc}
\hline Storey & $1.1 \mathrm{~F}_{\mathrm{x}}(\mathrm{kN})$ & $\mathrm{F}_{\mathrm{x}, \text { final }}(\mathrm{kN})$ & $\mathrm{F}_{\mathrm{x}, \text { final }} / 2(\mathrm{kN})$ \\
\hline Roof $(6)$ & 323 & 397 & 198 \\
5 & 261 & 349 & 174 \\
4 & 209 & 295 & 148 \\
3 & 158 & 236 & 118 \\
2 & 106 & 174 & 87 \\
1 & 54 & 107 & 54 \\
\hline
\end{tabular}

Ryan Gohlich, Department of Civil and Environmental Engineering, Carleton University 
Table B.13: Final Equivalent Static Storey Forces for Steel-only MRF

\begin{tabular}{c|ccc}
\hline Storey & $1.1 \mathrm{~F}_{\mathrm{x}}(\mathrm{kN})$ & $\mathrm{F}_{\mathrm{x}, \text { final }}(\mathrm{kN})$ & $\mathrm{F}_{\mathrm{x}, \text { final }} / 2(\mathrm{kN})$ \\
\hline Roof $(6)$ & 480 & 620 & 310 \\
5 & 325 & 467 & 234 \\
4 & 261 & 399 & 200 \\
3 & 196 & 323 & 162 \\
2 & 131 & 242 & 121 \\
1 & 66 & 154 & 77 \\
\hline
\end{tabular}

1. The design response spectrum is determined according to the equivalent static method of the NBCC (2010).

2. A three-dimensional building model must be constructed using structural analysis software such as ETABS (Computers \& Structures Inc., 2013).

3. An additional three-dimensional model is constructed wherein the lateral displacements of the frame are restrained in the direction perpendicular to the direction of ground motion. The roof and floors must also be restrained against rotation.

4. If the structure is not sensitive to torsional effects, an eccentricity of $5 \%$ is applied in each direction to account for accidental torsion.

5. The seismic design parameters are obtained from the restrained model in the direction under consideration (elastic base shear $\left(V_{e}\right)$, seismic weight $(W)$, and fundamental natural period $\left.\left(T_{a}\right)\right)$. These periods are limited to 1.5 times the period determined from the empirical equation for the appropriate frame type specified in the NBCC (2010).

6. Using the fundamental natural period from the restrained model, the factor $2 S(0.2) / 3 S\left(T_{a}\right) \leq 1.0$ is calculated.

7. The design elastic base shear $\left(V_{e d}\right)$ is calculated by multiplying the factor from the previous step by $V_{e}$.

8. The minimum lateral earthquake force, $\mathrm{V}$, is determined form the equivalent static method (NBCC, 2010). For strength design, the period used to determine the static base shear shall be taken as the upper limit (1.5 for MRFs) of that specified in the NBCC (2010) based on 
the empirical equation. For drift design, the period shall be taken as $T_{a}$ from the restrained model, but must not exceed 2.0 for MRFs.

9. Calculate the design base shear, $V_{d}=V_{e d}\left(I_{E} / R_{d} R_{o}\right)$. This value shall not be taken less than $0.8 \mathrm{~V}$.

10. The factor $V_{d} / V_{e}$ is determined for both strength and drift design. All responses from the unrestrained three-dimensional model must be multiplied by this factor. Member forces should be multiplied by the corresponding factor for strength design, while drifts and deflections should be multiplied by the corresponding factor for drift design. Since the model is elastic and should not account for the ductility of the lateral load resisting system, drifts and deflections should also be multiplied by $R_{d} R_{o}$.

11. All building components should be designed considering both strength and storey drift limitations.

Response spectrum analysis is an iterative process, and the aforementioned steps should be repeated until no significant changes are necessary to accommodate member capacity and deflection.

\section{B.4 Seismic Design}

For the hybrid prototype structure, four iterations of response spectrum analysis were completed, at which point both strength and drift requirements were satisfied using the smallest possible section sizes. Focus was placed primarily on the design of the NRLs for strength at the beam-column interface, and drift requirements were satisfied by increasing the size of the timber beams. Capacity-design was later applied manually based on the probable moment capacity of the NRL, and final member dimensions were input and checked in the ETABS model.

For the steel-only prototype structure, three iterations of response spectrum analysis were necessary to attain an efficient design. The RBS portions of the beams were not explicitly modelled, but reduction in total frame stiffness due to this detail was accounted for by increasing storey drifts by $9 \%$; CISC (2010) indicates that the RBS detail can increase drift by $7-9 \%$. Because 
strength and drift designs are interlinked for the steel-only building, drifts were accommodated by increasing both beam and column sizes.

\section{B.4.1 Capacity-Design of MRFs}

Once the size of the nonlinear replaceable links (hybrid building) or RBS details (steelonly building) were determined, capacity-design forces could be calculated and used in the design of all other structural components. The beams were designed to withstand the probable moment capacity of the yielding hinge, and the columns were designed such that the combined resistance of the upper and lower column could withstand the moment applied at the centerline of the column panel zone (according to equation (B.9) (CSA S16-09, 2010)).

$$
\sum M_{r c}^{\prime} \geq \sum\left(1.1 R_{y} M_{p b}+V_{h}\left(x+\frac{d_{c}}{2}\right)\right)
$$

where $\sum M_{r c}^{\prime}$ is the sum of the combined factored moment resistance of the upper and lower columns, and $M_{p b}$ is the nominal plastic moment capacity of the column, and:

$$
M_{r c}^{\prime}=1.18 \phi M_{p c}\left(1-\frac{C_{f}}{\phi C_{y}}\right) \leq \phi M_{p c}
$$

The main structural members of the MRFs were designed using the methods presented in Chapter 3 for the design of the single exterior beam-column interface, however for the design of an entire frame, capacity-design procedures are slightly more complex and a greater number of iterations are usually necessary. Response spectrum analysis was used to determine the required capacity at the beam column interface. Subsequently, the link or RBS detail was designed, and based on the probable moment capacity and shear upon plastic hinging, capacity-design forces to be transferred to the beams and columns were manually calculated and appropriate member sizes chosen. Once the frames were designed based on strength requirements, the structural model was updated and the analysis was reiterated to determine if drift requirements were satisfied. If interstorey drifts exceeded the $2.5 \%$ limit specified in the NBCC (2010), member sizes were increased and the process was repeated. For the hybrid frame, floors 1 to 5 were governed by drift criteria and floor 6 was governed by strength criteria, while for the steel-only building, floor 
1 was governed by drift criteria and floors 2 to 6 were governed by strength criteria.

The NRLs of the hybrid frame incorporated RBS details in accordance with the Moment Connections for Seismic Applications guidelines (CISC, 2008). For the detailing of the RBS of both the hybrid and steel-only frames, a 50\% flange width reduction was used, which is the upper limit allowed by CISC (2010). The procedure used for the capacity-design of the hybrid and steel-only structures is presented below. This procedure is based on Limit States Design of Steel Structures (CSA S16-09, 2010) design requirements. Since the wood members in the hybrid frame were designed to remain elastic, similar methods were adopted for the capacity-design of the hybrid structure.

1. Determine the applied loads in the link element under lateral loading.

2. Select appropriate link size and dogbone details.

3. Determine the probable moment capacity of the link element.

4. Determine the moment at the column centre line and shear force in the link at plastic hinging of the link.

5. Select initial upper and lower column sizes.

6. Distribute the moment between upper and lower column based on relative stiffness.

7. Check the adequacy of the upper and lower column under the applied moments.

8. Check the axial and combined axial and moment capacity of each column.

9. Check column deflection.

This process should be performed at each beam-column joint in the MRF. It should be noted that since the upper column at one storey is the same as the lower column at the storey above it, the adequacy of this column must also be checked against capacity-design forces from the joint at the storey above.

Ryan Gohlich, Department of Civil and Environmental Engineering, Carleton University 


\section{B.5 Design Results}

\section{B.5.1 Dynamic Data}

The dynamic data used in the response spectrum analysis of each structure is presented in Table B.14. The lateral stiffness and the seismic weight of the hybrid building were both lower than that of the steel-only building, resulting in a similar period for both systems. The elastic base shear found using the ETABS model was used to determine scaling factors that were applied to the force and deflection of the structural members in the model. A lower limit of $80 \%$ of the static base shear was applied to the design base shear as specified by the NBCC (2010). The design forces output by the structural model were multiplied by the $V_{d, \text { strength }} / V_{e}$ scaling factor in order to account for the estimated ductility, because this factor incorporates the $R_{d} R_{o}$ of the system. The drift responses output by the model was multiplied by the $V_{d, d r i f t} / V_{e}$ scaling factor, as well as the assumed $R_{d} R_{o}$ of the system.

\section{B.5.2 Design Loads and Drift}

The design forces applied to the nonlinear replaceable links in the hybrid building and the RBS sections of the steel-only building are presented in Table B.15. Only link design forces are given since capacity-design forces applied to the columns were manually calculated using the capacity-design procedure explained above, and not determined from the structural model. The final interstorey drifts of the linear model are presented in Table B.16 for the hybrid and steelonly buildings. As previously mentioned, the design was iteratively updated until the drift at

Table B.14: Dynamic Data for Linear Structural Model

\begin{tabular}{c|cccccc}
\hline Frame Type & $\begin{array}{c}\text { Period } \\
(\mathrm{sec})\end{array}$ & $\begin{array}{c}\mathrm{V}_{\mathrm{e}} \\
(\mathrm{kN})\end{array}$ & $\begin{array}{c}\mathrm{V}_{\mathrm{d} \text {, strength }} \\
(\mathrm{kN})\end{array}$ & $\begin{array}{c}\mathrm{V}_{\mathrm{d} \text {, drift }} \\
(\mathrm{kN})\end{array}$ & $\mathrm{V}_{\mathrm{d} \text {, strength }} / \mathrm{V}_{\mathrm{e}}$ & $\mathrm{V}_{\mathrm{d} \text {, drift }} / \mathrm{V}_{\mathrm{e}}$ \\
\hline Hybrid & 2.69 & 2542 & 932 & 358 & 0.367 & 0.141 \\
Steel & 2.42 & 4709 & 1059 & 628 & 0.255 & 0.133 \\
\hline
\end{tabular}

Ryan Gohlich, Department of Civil and Environmental Engineering, Carleton University 
Table B.15: Link Design Forces

\begin{tabular}{c|cc}
\hline Storey & $\mathrm{M}_{\mathrm{f}}(\mathrm{kN} \cdot \mathrm{m})$ & $\mathrm{V}_{\mathrm{f}}(\mathrm{kN})$ \\
\hline \multicolumn{3}{l}{ HYBRID BUILDING } \\
Roof $(6)$ & 176 & 64 \\
5 & 95 & 34 \\
4 & 79 & 28 \\
3 & 69 & 25 \\
2 & 48 & 17 \\
1 & 27 & 10 \\
\hline \hline STEEL-ONLY BUILDING \\
Roof $(6)$ & 270 & 122 \\
5 & 153 & 80 \\
4 & 132 & 73 \\
3 & 132 & 73 \\
2 & 106 & 64 \\
1 & 71 & 47 \\
\hline
\end{tabular}


Table B.16: Storey Drifts

\begin{tabular}{c|c}
\hline Storey & Interstorey Drift (\%) \\
\hline \multicolumn{2}{c|}{ HYBRID BUILDING } \\
Roof (6) & 2.02 \\
5 & 2.40 \\
4 & 2.45 \\
3 & 2.32 \\
2 & 1.92 \\
1 & 2.20 \\
\hline \hline STEEL-ONLY BUILDING \\
Roof (6) & 1.87 \\
5 & 2.12 \\
4 & 2.03 \\
3 & 1.91 \\
2 & 1.45 \\
1 & 2.00 \\
\hline
\end{tabular}


each floor was below $2.5 \%$.

Figure B.4 shows the moments at the column centerline, $M_{c}$ (presented in $\mathrm{kN} \cdot \mathrm{m}$ ), upon plastic hinging in the yielding mechanism of the beam for the hybrid and steel-only buildings. Figure B.5 shows the shear in the yielding mechanisms upon plastic hinging, $V_{h}$ (presented in $\mathrm{kN}$ ), which was used to determine the axial force in the columns. Capacity-design moments and shear force at plastic hinging of the first storey were significantly higher than in the floors above. In order to accommodate the high interstorey drift present in the first storey due to the pinned column bases, larger members were necessary, which increased capacity-design forces on both the beams and the columns. This could be avoided in future studies by using fixed column bases in the seismic analysis.

\section{B.5.3 Final Member Selection}

Table B.17 shows a summary of the MRF beam, column, and link sizes used in the final design of the hybrid and steel-only buildings. These member dimensions were input into the numerical model to assess the nonlinear behaviour of the frames. The dogbone details are also presented for each frame; $a$ being the distance of the dogbone cut from the column face, $s$ being the length of the reduced section, and $c$ being the width of flange reduction (per side). All beams and links were identical for a single floor, all interior columns were identical for a single floor, and all exterior columns were identical for a single floor.

Ryan Gohlich, Department of Civil and Environmental Engineering, Carleton University 


\section{HYBRID MRF ELEVATION}

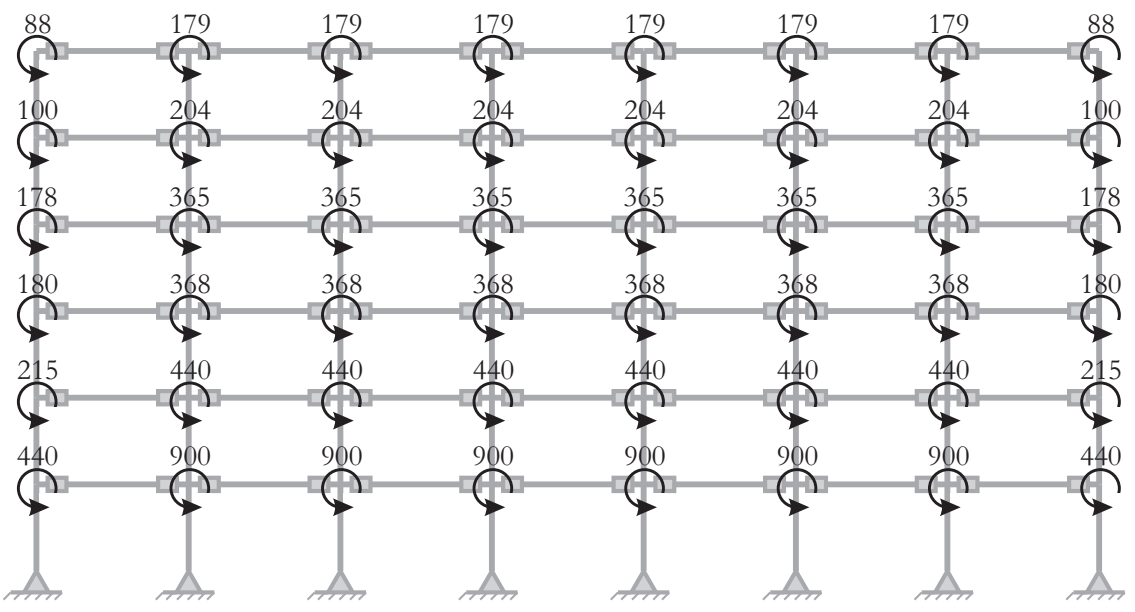

STEEL-ONLY MRF ELEVATION

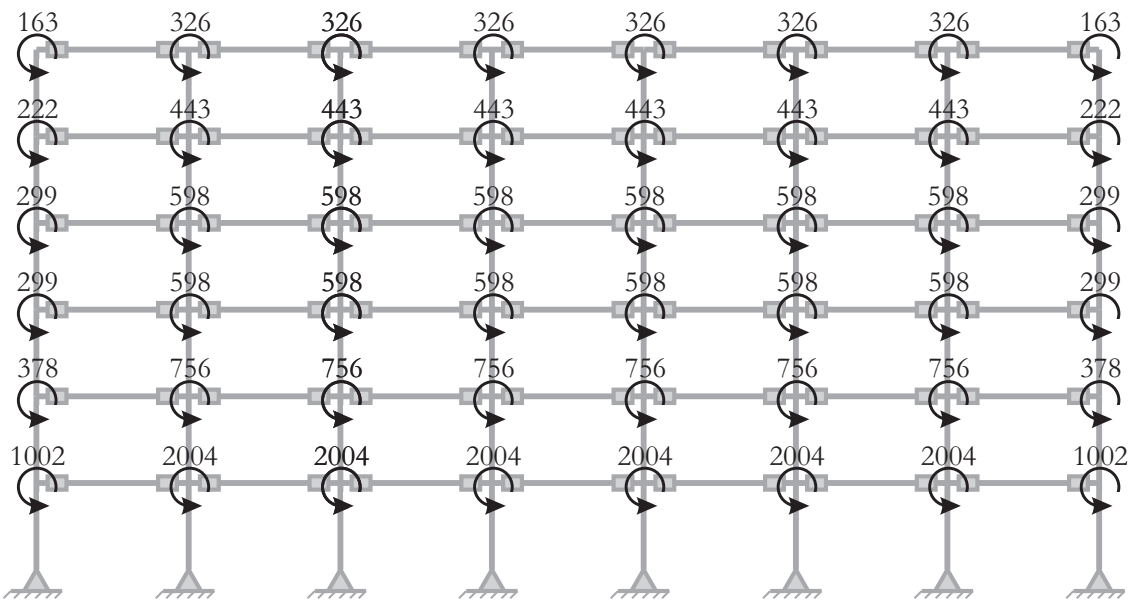

Figure B.4: Capacity-Design Force at Column Centre 
HYBRID MRF ELEVATION

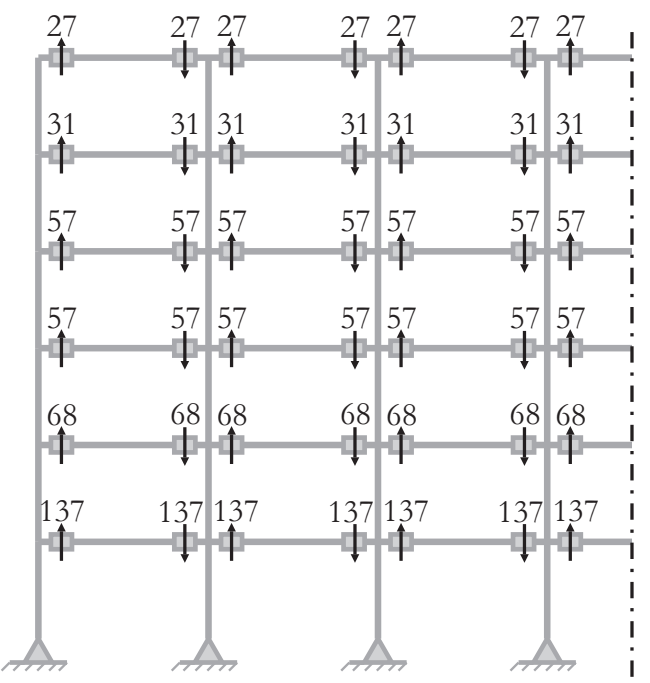

STEEL-ONLY MRF ELEVATION

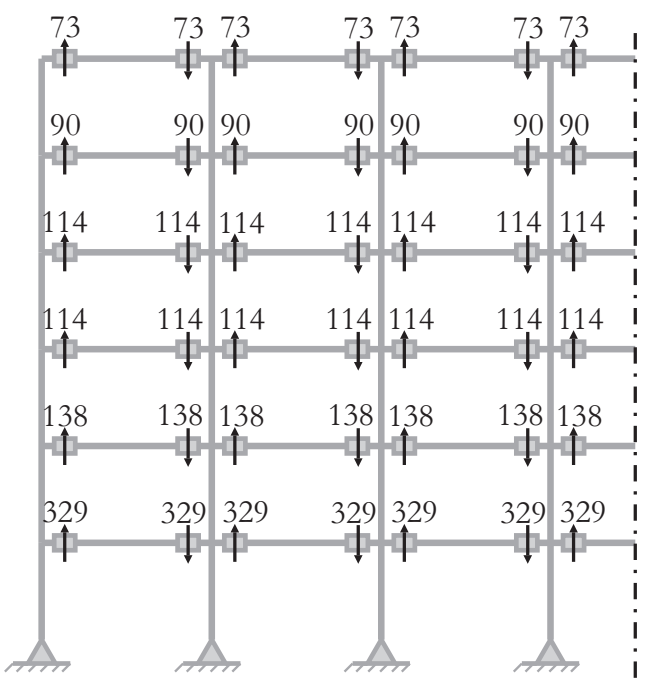

Figure B.5: Shear Force Upon Plastic Hinging

Table B.17: Summary of Member and Link Sizes

\begin{tabular}{|c|c|c|c|c|c|c|c|}
\hline Storey & Beam & $\begin{array}{l}\text { Exterior } \\
\text { Column }\end{array}$ & $\begin{array}{l}\text { Interior } \\
\text { Column }\end{array}$ & Link & $\begin{array}{c}\mathrm{a} \\
(\mathrm{mm})\end{array}$ & $\begin{array}{c}\mathrm{s} \\
(\mathrm{mm})\end{array}$ & $\begin{array}{c}\mathrm{c} \\
(\mathrm{mm})\end{array}$ \\
\hline \multicolumn{8}{|c|}{ HYBRID BUILDING } \\
\hline Roof (6) & $175 \times 380$ & & \multirow{2}{*}{$175 \times 456$} & W250 x 22 & \multirow{2}{*}{70} & \multirow{2}{*}{170} & \multirow{2}{*}{25} \\
\hline 5 & $175 \times 418$ & $175 \times 342$ & & W $250 \times 25$ & & & \\
\hline 4 & \multirow{2}{*}{$175 \times 494$} & & $175 \times 494$ & W $360 \times 33$ & \multirow{3}{*}{75} & \multirow{3}{*}{230} & \multirow{3}{*}{32} \\
\hline 3 & & $175 \times 418$ & $175 \times 532$ & & & & \\
\hline 2 & $175 \times 570$ & $215 \times 418$ & $265 \times 532$ & W360 × 39 & & & \\
\hline 1 & $265 \times 684$ & $265 \times 570$ & $265 \times 684$ & W $460 \times 60$ & 95 & 295 & 38 \\
\hline \multicolumn{8}{|c|}{ STEEL-ONLY BUILDING } \\
\hline Roof (6) & W $310 \times 33$ & \multirow{2}{*}{ W $360 \times 51$} & \multirow{2}{*}{ W $360 \times 72$} & N/A & 51 & 203 & 25 \\
\hline 5 & W360 x 39 & & & $\mathrm{~N} / \mathrm{A}$ & 64 & 230 & 32 \\
\hline $\begin{array}{l}4 \\
3\end{array}$ & W410 x 46 & W360 x 64 & W360 x 91 & $\begin{array}{l}\text { N/A } \\
\text { N/A }\end{array}$ & 70 & 262 & 35 \\
\hline 2 & W460 x 52 & \multirow{2}{*}{ W $360 \times 122$} & \multirow{2}{*}{ W $360 \times 216$} & N/A & 76 & 293 & 38 \\
\hline 1 & W610 x 101 & & & $\mathrm{~N} / \mathrm{A}$ & 114 & 392 & 57 \\
\hline
\end{tabular}

